\title{
EXPERIMENTAL STUDY ON THE FLEXURAL BEHAVIOR OF STRUCTURAL INSULATED SANDWICH TIMBER PANELS
}

\author{
BY \\ ALEEM SHAHZAD BUTT, B.Sc. \\ University of Engg. \& Tech., Pakistan, 1998
}

A Thesis

Presented to Ryerson University

In partial fulfillment of the

Requirement for the degree of

Master of Applied Science

In the program of

Civil Engineering

Toronto, Ontario, Canada, 2008

Aleem S. Butt 2008 우

PROPERTY OF

RYERSON UANERSTTY LIBRARY 


\section{AUTHOR'S DECLARATION}

I hereby declare that I am the sole author of this thesis.

I authorize Ryerson University to lend this document to other institutions or individuals for the purpose of scholarly research.

Aleem S. Butt

I further authorize the Ryerson University to reproduce the document by photocopying or by other means, in total or part, at the request of other institutions or individuals for the purpose of scholarly research.

Aleem S. Butt 


\section{BORROWERS}

Ryerson University requires the signature of all persons using or photocopying this thesis.

Please Sign below, and give address and date.

\begin{tabular}{|c|c|c|c|}
\hline Name & Signature & Address & Date \\
\hline DIHA BENASOVA & Benadour & Ro. & $15 / 00 / 2009$ \\
\hline & & & \\
\hline & & & \\
\hline & & & \\
\hline & & & \\
\hline & & & \\
\hline & & & \\
\hline & & & . \\
\hline & & & \\
\hline & & & \\
\hline & & & \\
\hline & & & \\
\hline & & & \\
\hline & & & \\
\hline & & & \\
\hline & & & \\
\hline & & & \\
\hline & & & \\
\hline & & & \\
\hline & & & \\
\hline & & & \\
\hline & & & \\
\hline & & & \\
\hline & & & \\
\hline & & & \\
\hline
\end{tabular}




\title{
EXPERIMENTAL STUDY ON THE FLEXURAL
}

\section{BEHAVIOR OF STRUCTURAL INSULATED SANDWICH}

\section{TIMBER PANELS}

\author{
By \\ Aleem S. Butt \\ Master of Applied Science in Civil Engineering \\ Department of Civil Engineering \\ Ryerson University, Toronto
}

2008

\begin{abstract}
A series of flexural test and creep tests were conducted on 53 OSB structural insulated sandwich timber panels to predict their behavior when subjected to gravity loading when used in residential and low rise nonresidential buildings. The experiments were designed and performed to test full-scale panels for roof and floor residential construction. The structural adequacy of the developed sandwich panel system is investigated with respect to the effectiveness of the foam core in providing composite action required to meet both strength and serviceability limit-state design requirements per Canadian Standards for timber design. Strength requirements included flexure and shear, while serviceability check included limiting deflection under operating conditions as well as creep performance under sustained loading. Results from experimental testing were used to draw conclusions with respect the structural qualifications for these SIPs to be "as good as" the structural capacity of conventional wood-frame buildings.
\end{abstract}




\section{ACKNOWLEDGEMENTS}

My sincere thanks and gratitude are due to His Almighty ALLAH, who helped me and blessed my work during the days of my study and research.

I wish to express my deep appreciation to my advisor, Dr. K. Sennah, for his continuous support and valuable supervision during the development of this research. Dr. K. Sennah devoted his time and effort to make this study a success. His most helpful guidance is greatly appreciated. I would like to acknowledge the financial support from Ryerson University in the form of graduate scholarship and research assistantship. The in-kind contribution from Thermapan Inc. of Fort Erie, Ontario, is greatly appreciated.

I am also very grateful to my parents, wife and daughter for their great support and encouragement during the course of study. 


\section{TABLE OF CONTENTS}

AUTHOR'S DECLARATIONS.................................................ii

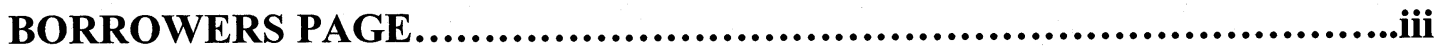

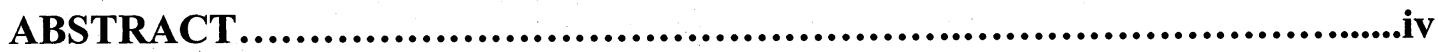

ACKNOWLEDGEMENTS...................................................v

TABLE OF CONTENTS......................................................vi

NOTATIONS....................................................................

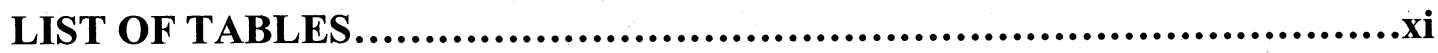

LIST OF FIGURES...........................................................xii

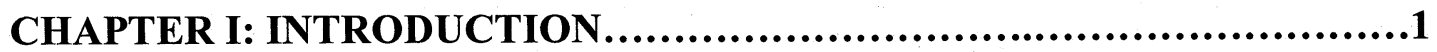

1.1 General...............................................................1

1.2 The problem..........................................................4

1.3 Objectives..............................................................4

1.4 Scope..................................................................5

1.5 Contents and Arrangement of this study.............................6

CHAPTER II: LITERATURE REVIEW ....................................7

2.1 General........................................................... 7

2.2 History of SIPs.................................................7

2.3 Types of Structural Insulated Panels.................................. 9

2.3.1 Light weight steel frame panels.......................................9

2.3.2 Fiber Cement faced Structural Insulated panels....................9

2.3.3 Concrete Sandwich Panels............................................10 
2.3.4 Plywood sandwich panels..........................................10

2.4 Structural Analysis \& Design of Sandwich Panels....................12

2.4.1 Historical Development of Sandwich Theory .........................14

2.4.1.1The General Method.................................................16

2.4.1.2 The Selective Method................................................17

2.4.1.3 Flexural Stresses in Sandwich panels..............................18

2.4.1.4 Flexural and Shear Stresses in Sandwich Panels...................20

2.4.1.5 Elastic Deflection Analysis of Sandwich panels....................21

CHAPTER III: EXPERIMENTAL STUDY

3.1 General.............................................................27

3.2 Descriptions of Panels,.............................................31

3.3 Material Properties ....................................................34

3.4 Test Method for SIP Panels in flexure................................35

3.4.1 Flexure Load Test Set up.............................................36

3.4.2 Instrumentation for Flexure Load test................................39

3.4.3 Flexure Load Test Procedure .........................................40

3.5 Creep Tests...........................................................41

CHAPTER IV: EXPERIMENTAL RESULTS

4.1 General.............................................................44

4.2 Code requirements for the structural qualification of the SIPs ........44

4.3 Group A.............................................................46

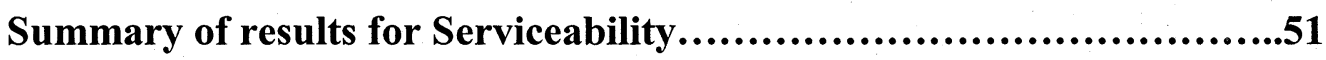

Summary of results for Strength.........................................52 


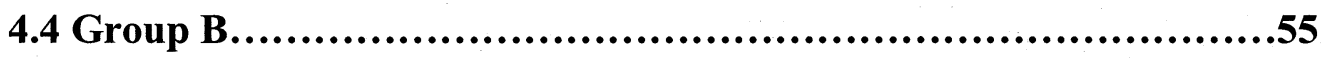

4.5 Group C...........................................................57

4.6 Group D.........................................................60

4.7 Group E.......................................................63

4.8 Group F..........................................................66

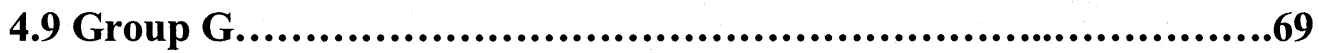

4.10 Group H..............................................................71

4.11 Group I.............................................................

4.12 Group J.......................................................74

4.13 Group K.......................................................75

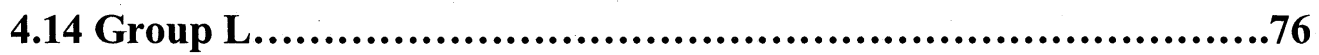

4.15 Group M.........................................................77

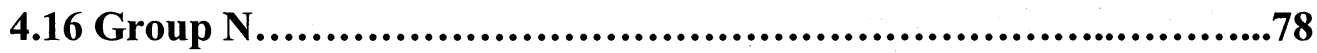

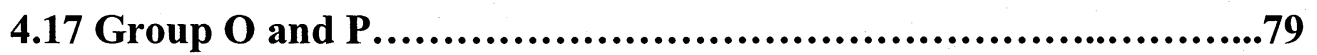

4.18 Flexure- Creep Test Results..........................................80

CHAPTER V: SUMMARY AND CONCLUSION

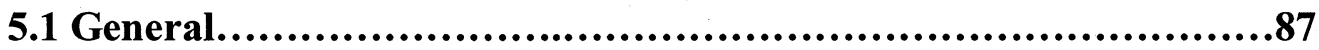

5.2 Conclusions..........................................................87

5.3 Recommendations for Future Research.............................899

REFERENCES...............................................................90

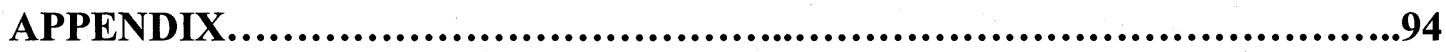

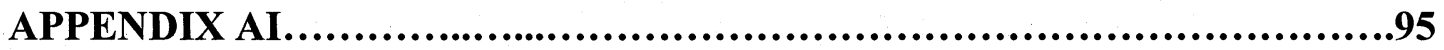




\section{NOTATIONS}
$\mathrm{x}, \mathrm{y}, \mathrm{z}$
Rectangular coordinates.
D
b
$\mathrm{t}$
1
L
$\mathrm{E}_{\mathrm{f}}, \mathrm{E}_{\mathrm{c}}$
c
$\Delta$
$\tau_{\mathrm{zx}}, \tau_{\mathrm{xy}}, \tau_{\mathrm{yz}}$
$\Delta_{\mathrm{B}}$
$\Delta_{\mathrm{S}}$
$\Delta_{\text {Total }}$
K
$\Delta_{\text {short term }}$
Flexural Rigidity
Width of Panel
Thickness of panel
Span length
Live load
Moduli of face and core along axis
core thickness
Deflection of panel
Shear Stress
Midspan sandwich deflection due to bending
Midspan sandwich deflection due to shear
Immediate deflection under dead load and long term portion of
live load
Constant to calibrate the long term effects of dead load and live loads
Deflections under short term portions of design load 


\section{LIST OF TABLES}

Table 3.1 Thermapan SIPs Properties............................................27

Table 3.2 Description of tested panels............................................32

Table 4.1 Summary of Results for Serviceability ................................51

Table 4.2 Summary of Results for Strength......................................5 


\section{LIST OF FIGURES}

Figure 1.1 Comparison between SIP \& I Beam....................................02

Figure 1.2 View of the Sandwich Panel.......................................02

Figure 1.3 View of residential building construction using SIPs..................03

Figure 1.4 Typical floor and wall panel layout for basement construction...........03

Figure 2.1 Dimension of Sandwich panel....................................14

Figure 2.2 Flexural stress and shear stress distribution across the depth of Sandwich

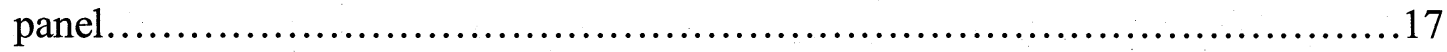

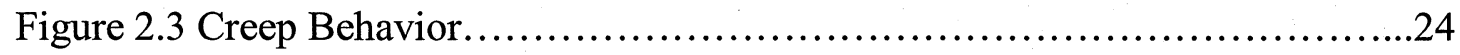

Figure 3.1 Sketch of structural insulated panel SIPs.............................28

Figure 3.2 Typical section at panel foam-spline connection before assembly........29

Figure 3.3 Typical section at panel foam-spline connection after assembly..........29

Figure 3.4 View of foam- spline connection for the tested panels..................30

Figure 3.5 Schematic diagram of solid lumber - spline connection between SIPs....30

Figure 3.6 Schematic view of test setup for Flexure testing .......................37

Figure 3.7 View of specimen S-1 before testing...............................38

Figure 3.8 Enlarged view of the roller support of the tested panels.................38

Figure 3.9 View of Dial Gauge and LVDTs under the panel.......................40

Figure 3.10 Schematic diagram for flexure-creep test setup......................42

Figure 3.11 Typical deflection- time history for creep test.......................43

Figure 4.1 View of specimen S-1 before testing .................................48

Figure 4.2 View of specimen S-1 after testing.................................49

Figure 4.3 Close up view of the failure pattern from one side of Specimen S-1.......49 


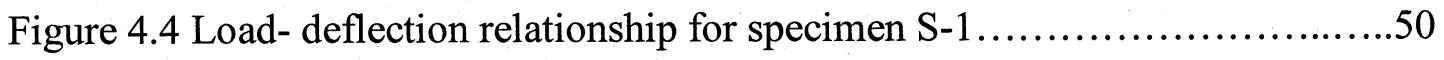

Figure 4.5 View of the combined horizontal and diagonal shear failure of panel

S-6

Figure 4.6 Close up view of the failure pattern from one side of Specimen S-7 ......60

Figure 4.7 Close up view of failure pattern in the spline stud from one side of

specimen $\mathrm{S}-7$

Figure 4.8 Close up view of failure pattern in the spline stud from one side of

specimen S-10. 63

Figure 4.9 View of the diagonal shear failure of specimen S-15 at the supports.....65

Figure 4.10 Load -strain relationship for specimen S-13.......................65

Figure 4.11 View of outward crushing of OSB fibers in one side of specimen S-19 at the interface of the loading beam and the top of the panel. .68

Figure 4.12 View of inward crushing of OSB fibers on the other free side of specimen S-19 at the interface of the loading beam and the top of the panel..................68

Figure 4.13 Load -strain relationship for specimen S-19.......................69

Figure 4.14 View of the flexural failure of specimen S-20......................71

Figure 4.15 Close up view of flexural failure on one free edge of specimen S-36...77

Figure 4.16 View of panel S-43 before start of Creep test.........................82

Figure 4.17 View of loaded panel S-43 during Creep test..........................82

Figure 4.18 Deflection- time history for panel S-43 ............................ 83

Figure 4.19 View of panel S-44 before start of Creep test........................83

Figure 4.20 View of loaded panel S-44 during Creep test.........................84

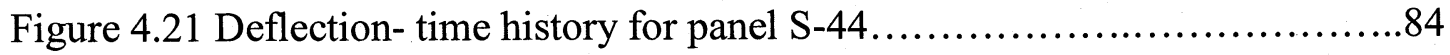


Figure 4.22 View of panel S-45 before start of Creep test........................85

Figure 4.23 View of loaded panel S-45 during Creep test.......................85

Figure 4.24 Deflection- time history for panel S-45 ...........................86 



\section{CHAPTER I}

\section{INTRODUCTION}

\subsection{General}

A structural insulated panel (SIP) is an engineered composite product composed of an insulating foam core sandwiched between two face materials. The core provides the insulation and rigidity, while the face materials provide durability and strength. Several materials such as oriented strand board (OSB), plywood, sheet rock, cement board, and sheet metal are used for face materials. SIPs can be built with a variety of structural skin materials, including oriented strand board, treated plywood, fiber-cement board, and metal. SIPs are available in a thickness ranging from 100 to $350 \mathrm{~mm}$, depending on climate conditions. Many manufacturers also offer curved SIPs for curved roof applications. The design capabilities, exceptional strength and energy saving insulation make SIPs a twenty-first century building material for high performance buildings. The increased popularity of SIPs is due to energy efficiency, ease and speed of construction, and cost effectiveness.

Structurally, a SIP can be compared to an I-beam as shown in Fig. 1.1; the foam core acts as the web, while the facings are analogous to the I-beam's flanges. In case of flexural loading, all of the elements of a SIP are stressed; the skins are in tension and compression, while the core resists shear and buckling. Under in-plane loading, the facings of a SIP act as slender columns, and the core stabilizes the facings and resists forces that may cause local bucking of the facings. Figure 1.2 shows view of the sandwich panel, while Fig. 1.3 shows 
how these panels are used in building a house or a small residential building. Figure 1.4 shows typical floor and wall panel layout in basement construction.

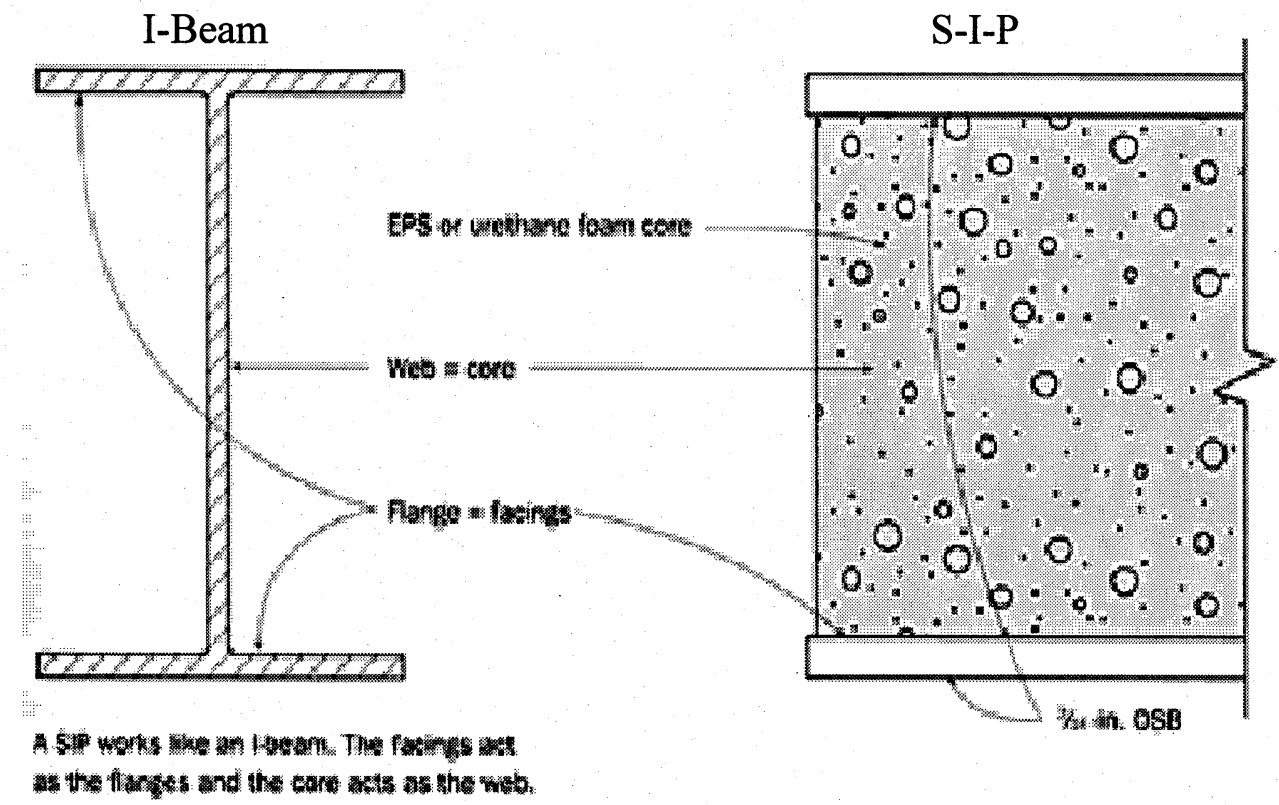

Fig. 1.1. Comparison between Structural Insulated Panel and I-Beam Cross-section

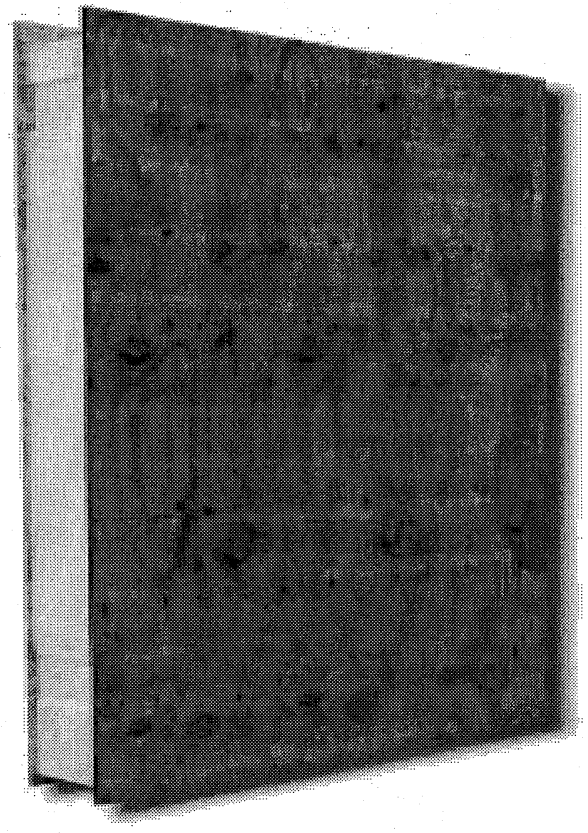

Fig. 1.2. View of the sandwich panel 


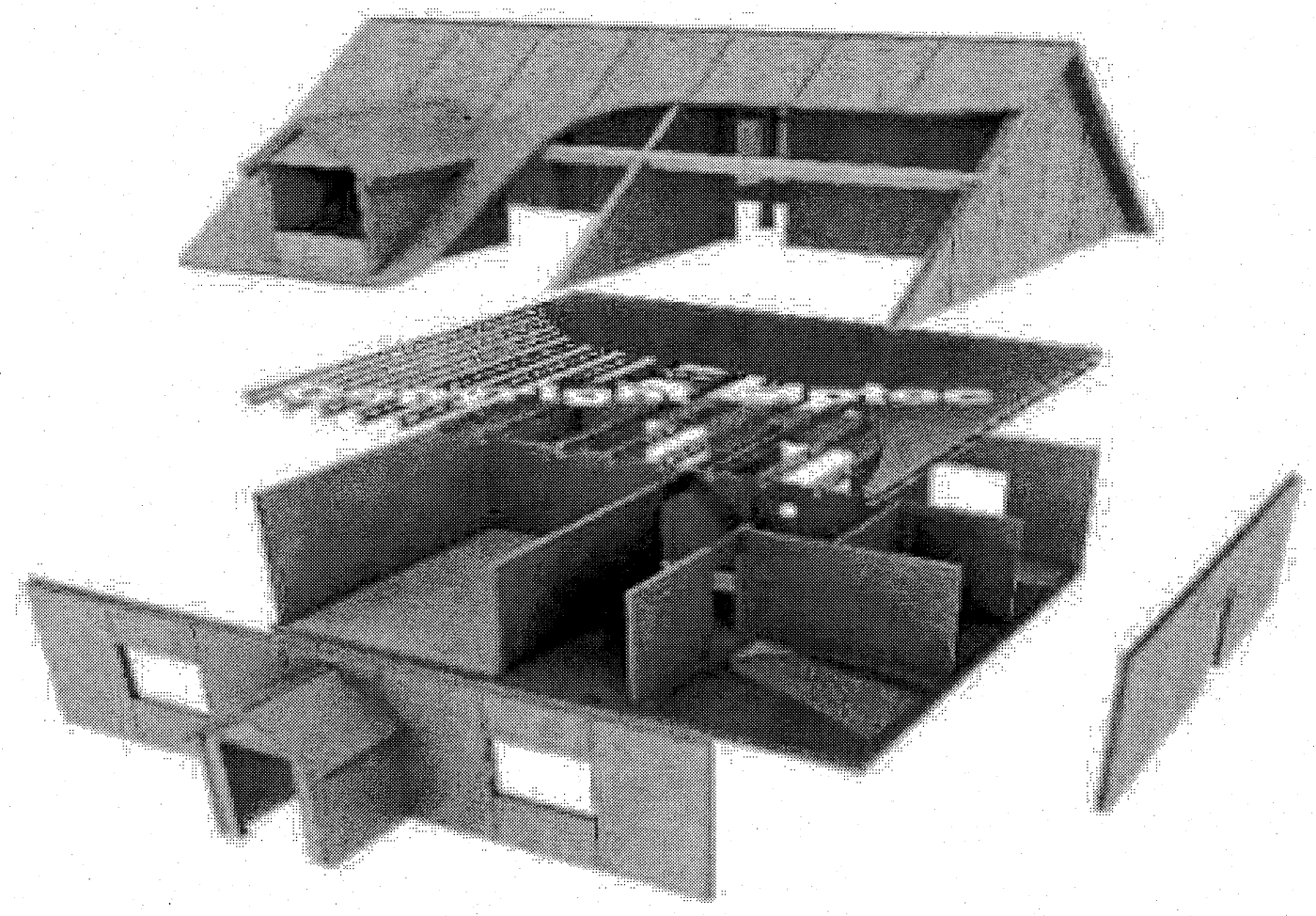

Fig. 1.3. View of residential building construction using SIPs

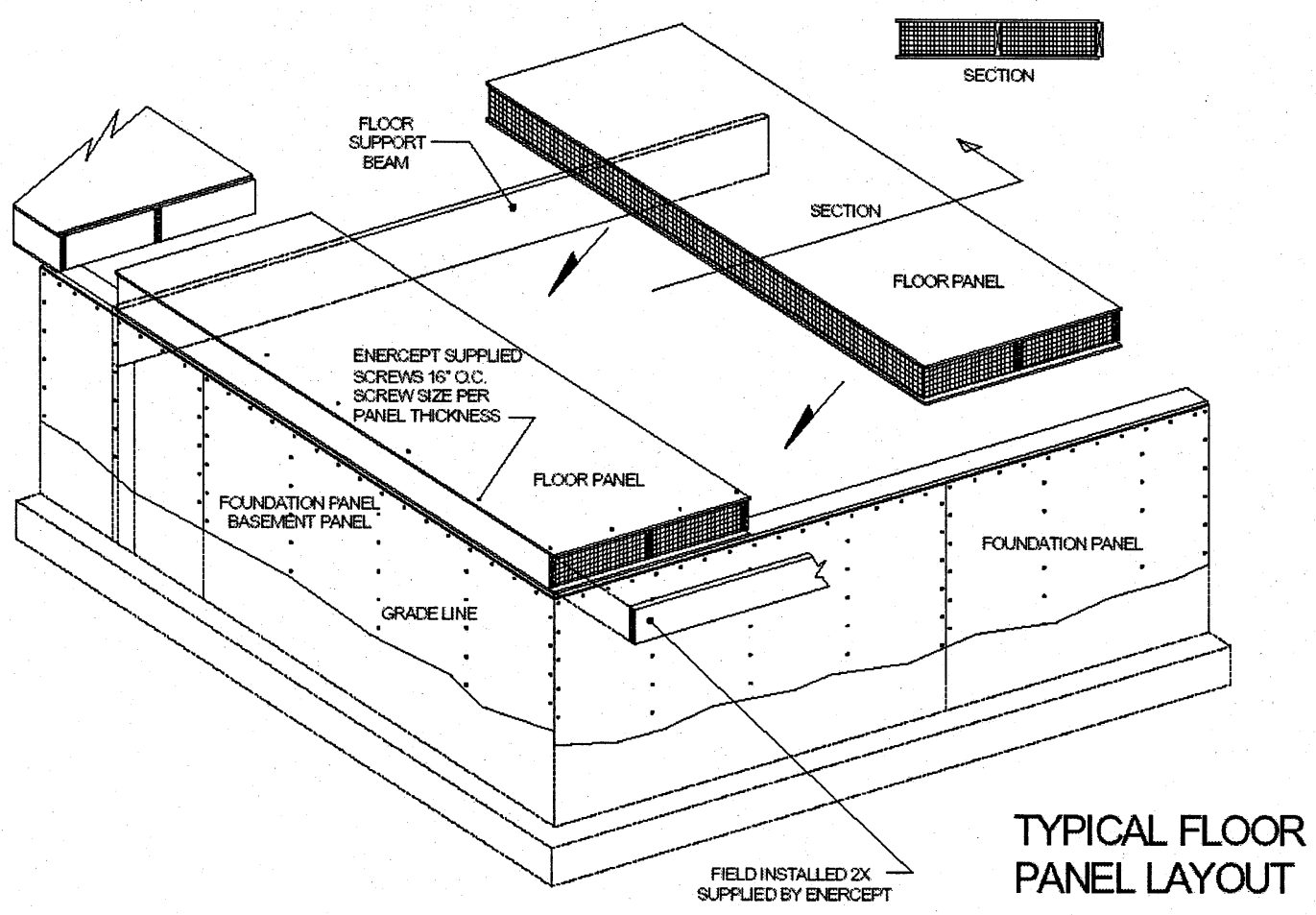

Fig. 1.4. Typical floor and wall panel layout for basement construction 


\subsection{The Problem}

A home constructed with Thermapan wall and foundation SIPs costs approximately 1-2\% more than a conventional concrete and $2 \mathrm{x}$ fiberglass home. On a 1,600 square foot bungalow home with 8' walls and 8' foundations, the material costs for SIP foundations and exterior walls would be approximately $\$ 4,000$ more than a conventionally constructed fiberglass home with concrete foundation and $2 \times 6$ walls. SIP home consumes $60 \%$ to $70 \%$ less energy to heat and cool - costing just $\$ 640$ a year compared to $\$ 1,600$ a year for a conventionally constructed fiberglass home. That's $\$ 960$ in savings per year.

Clause 8.6 of Canadian Standard for Engineering Design of Wood, CAN/CSA-O86-01 (2001) specifies the effective stiffness, bending resistance and shear resistance of stressed skin panels. These stressed skin panels have continuous or splice longitudinal web members and continuous or spliced panel flanges on one or both panel faces, with the flanges glued to the web members. However, the developed structural insulated sandwich timber panels comprise insulated foam glued between two OSB board. As such, it is felt necessary to conduct experimental testing to-collapse on these panels to determine the structural adequacy of the level of adhesion between the foam and the OSB Boards and the level of composite action between them. Moreover, testing would assist in examining the adequacy of the foam as the main shear carrying element near the supports. To address the need for testing of these developed panels, Canadian Construction Materials Commission (CCMC) and National Research Council Canada (NRC) developed technical guide for stressed skin panels (with lumber $1200 \mathrm{~mm}$ o.c. and EPS core) for walls and roof. This guide formed the basis for the experimental testing conducted in this thesis for flexure and creep, with the ultimate goal of providing enough technical data for 
strength and serviceability of such panel. With this database, Thermapan Inc. can certify these panels for use in the Canadian market.

\subsection{The Objectives}

The main objectives of this research work can be stated as follow:

1. To contribute to the efficient design of structural insulated sandwich timber panels by developing experimentally calibrated models capable of predicting accurately their response when subjected to flexural loading.

2. The developed panel system provides builders and homeowners with energy efficient, structurally superior, environmentally friendly and easy to install building system.

3. The proposed research fosters new industry-university interaction in the field of materials and manufacturing research and development that produces a specific benefit to the Canadian economy. 


\subsection{The Scope}

The scope of this study includes:

1. A literature review on previous research work and codes of practice related to the structural behavior of sandwich timber panels when subject to transverse loading.

2. Perform experiments up-to-collapse on 53 actual-size timber panels according to ASTM standards to determine their ultimate load carrying capacity, deflection at service load level and flexure-creep performance.

3. Correlate the experimental findings with code requirements at ultimate and serviceability limit states requirements for possible qualification for building construction.

4. Draw conclusion with respect to the structural adequacy of the tested sandwich panels for possible use in residential construction.

\subsection{The Contents and the Arrangement of the Thesis}

Chapter II of the thesis presents a literature review of previous research on all type of sandwich panels. While Chapter III discusses the experimental program conducted on selected panel sizes, including panel sizes and material properties, and the ASTM Standard test procedure for flexure and creep. Chapter 4 summarizes the experimental findings and their correlations with theoretical results. Chapter 5 presents the conclusion of this research work and recommendations for future research. While Appendix A summarizes the experimental results for each panel. 


\section{CHAPTER II}

\section{LITERATURE REVIEW}

\subsection{General}

In the past, a significant amount of research was conducted to predict the behavior of sandwich panels. However, only very few researchers have undertaken experimental studies to investigate the accuracy of design of timber sandwich panels. Building panels come in many configurations, known variously as foam-core panels, stressed-skin panels, nail-base panels, sandwich panels, and curtain-wall panels, among others. Many of these building panels are nonstructural, while some have no insulation. And the term "panelized construction" can also include prefabricated stud walls and other configurations associated with the modular industry.

The literature review conducted is presented in the following manner:

1. History of SIPs

2. Types of Structural insulated sandwich panels

3. Structural analysis and design of Sandwich panels

4. Experimental studies

\subsection{History of SIPs}

The concept of a structural insulated panel began in 1935 at the Forest Products Laboratory (FPL) in Madison, Wisconsin. FPL engineers speculated that plywood and hardboard sheathing could take a portion of the structural load in wall applications. Their prototype structural insulated panels (SIPs) were constructed using framing members within 
the panel combined with structural sheathing and insulation. The panels were used to construct test homes that were continually monitored for over thirty years, then disassembled and reexamined. During this time, FPL engineers continued to experiment with new designs and materials. Famed architect Frank Lloyd Wright used structural insulated panels in some of his affordable Usonian houses built throughout the 1930's and 1940's. SIPs took a major leap in technology when one of Wright's students, Alden B. Dow, son of the founder of Dow Chemical Company, created the first foam core SIP in 1952. By the 1960's rigid foam insulating products became readily available resulted in the production of structural insulated panels as we know them today. The Structural Insulated Panel Association (SIPA) in U.S.A. was founded in 1990 to provide support and visibility for those manufacturing and building with this emerging building technology. In the 1990's, forming the SIPs was positively affected by the development of advanced computer aided manufacturing (CAM) technology. Using these systems, computerized architectural drawings (CAD drawings) can be converted to the necessary code to allow automated cutting machines to fabricated SIPs to the specific design of a building. CAD/CAM technology has streamlined the SIP manufacturing process, bringing further labor savings to builders and produces SIPs with amazing accuracy to deliver flat, straight, and true walls. In response to the need for the industry to develop product documentation SIPA has cooperated with the American Society for testing Materials (ASTM) task group to define a standard test method to determine structural capacities of Insulated panels (ASTM, 2002). The ASTM standard defines a testing protocol to be followed by all manufacturers to document the strength and stiffness properties of their product to code agencies for product certification. The ASTM standard tests include test methods for the following load applications: (1) transverse Loads; (2) axial Loads; (3) 
racking and diaphragm Loads; (4) uplift Loads; (5) creep; (6) combined Loading; (7) impact loading; and (8) concentrated Loading.

\subsection{Types of Common Structural Insulated Sandwich panels}

\subsubsection{Light Weight Steel Frame Panels}

Mild steel panels tend to be of the open type. Locating insulation on the external side of the frame overcomes the risk of cold bridging. Protection against corrosion is provided by galvanizing.

\subsubsection{Fiber Cement Faced Structural Insulated Panels}

Cementitious SIPs are typically manufactured of cellulose reinforced cement boards, for inside and outside skins. The material can be taped and finished on the interior surface. The fire-resistive cement board eliminates the need for gypsum drywall. The exterior surface can be painted or coated with a vinyl or synthetic stucco permanent finish. If siding or brick veneer is to be used, oriented strand board (OSB) can be applied on the exterior to accept nailing of siding or brick wall ties. It is not necessary to have both OSB and fiber-cement board on one side for brick and stucco applications. OSB can be used instead of fiber-cement board for such an application. However, there may be some difficulty in finding a manufacturer that produces this type of SIPs. Cementitious SIPs can be used for below and above grade applications. They can be used to construct foundation or basement walls, floors spanning up to $4.90 \mathrm{~m}$ between supports, load-bearing walls up to four stories and roof panels up to $6.10 \mathrm{~m}$ spans. Cementitious SIPs are fastened together with power-driven screws through the inner and outer skins into either cement board or wood splines. Because of the strength of the panels, no headers are needed over standard size doors and windows. 
Connection details are similar to those of OSB-sheathed panels. Cementitious SIPs are light weight, and panels can be erected by as few as two workers, with minimal equipment. They are as energy efficient as OSB SIPs. Consumers often think that R-value is of primary importance, but effective air sealing is also significant. For the best energy performance, a continuous air barrier and uniform insulation coverage, with as few gaps as possible, are needed. Every air leak and every thermal bridge adds to heating and cooling bills. Cementitious SIP panels are air-tight and fully insulated. Buildings constructed with Cementitious SIPs typically last longer and require less maintenance than other types of SIPs panels. Fiber-Cement Board used as skins will not rot, burn, or corrode. It has a higher fire rating than OSB faced SIPs, and in most residential applications no drywall would be necessary. Cementitious boards will not support black mold growth, and they have a high resistance to moisture absorption. They are rot and vermin resistant, and are not significantly affected by water vapor. Fiber-cement panels can have different finished looks, such as a wood grain, stucco, or smooth. With the smooth finish, stucco, vinyl siding, brick or stone can be installed.

\subsubsection{Concrete Sandwich Panel}

Concrete panels have been in use for 50 years, and the science and engineering of durable concrete has made great progress since the precast concrete non-traditional housing of the 1960s and 1970s. Brick clad concrete panels should have a service life greater than 60 years. Concrete has an extensive role to play both in the construction and improvement of our civil engineering and infrastructure. Its great strength, its durability and versatility are properties that are utilized in the construction of roads, bridges, airports, railways, tunnels, ports and harbors and many other major infrastructure projects. Externally light weight 
insulating materials such as foamed concrete, plastic and glass provide good insulation, but they have low resistance to handling and service loads. A protective or load bearing structural concrete shell must be provided over one or both sides of these materials. These shells also provide a convenient means of imparting architectural treatment to the wall. Attractive surfaces may be obtained by many methods, such as exposed aggregate or patterns obtained from three dimensional forms. The face shells of sandwich panels must not only provide protection to the insulation and meet the immediate demands of handling and imposed loads, but must continue to give satisfactory performance under long time service. Exposure conditions cause temperature and moisture differentials is sandwich construction and these conditions may have a more pronounced effect on the satisfactory long time structural behavior than do the imposed loads. The light weight aggregate used in the concrete shells was expanded shale produced in a rotary kiln with the raw material pre- sized prior to burning. The particles are generally rounded and sealed. The structural concrete shells of the sandwich panels were reinforced with welded wire fabric confirming to ASTM A82-62T, "Cold Drawn Steel wire for concrete reinforcement." The insulating materials were commercially available rigid board stock or batting: one foamed polyurethane plastic, two foamed polystyrene plastics, one glass fiber, one foamed glass and one autoclaved cellular concrete.

\subsubsection{Plywood Sandwich Panels}

Plywood serves as an ideal material for the facings of sandwich panels. It is strong, light in weight, easily finished, dimensionally stable, and easily repaired if damaged. A variety of core materials may be used with plywood to complete the panel. Among these are polystyrene foams, and paper honey combs. Besides resistance to shearing forces, for 
some applications such as exterior wall panels and roof panels the core should posses high resistance to heat and vapor transmission. The designer should consider the stability of the core material to his application. Factors to consider include resistance to degradation by heat, age, and moisture; compatibility with glues; etc.

\subsection{Structural Analysis and Design of Sandwich Panels}

Sandwich construction is commonly used in structures where strength, stiffness, and weight efficiency are required. Sandwich Panel is composed of "weak" core material with "strong and stiff" faces bonded on the upper and lower side. The facings provide practically all of the over-all bending and in plane extensional rigidity to the sandwich. In principle, the basic concept of a sandwich panel is that the faceplates carry the bending stresses where as the core carries the shear stresses. The core plays a role which is analogous to that of the I-beam web while the sandwich facings perform a function very much like that of the I-beam flanges. The sandwich is an attractive structural design concept since, by the proper choice of materials and geometry, constructions having high ratios of stiffness to-weight can be achieved. Since rigidity is required to prevent structural instability, the sandwich is particularly well suited to applications where the loading conditions are conducive to buckling. The Sandwich Panel can be used in different

approaches as: (a) honeycomb material; (b) corrugated material; (c) wood; (d) expanded plastics (foam); and (e) mineral wool. Also, the faces can be made of different materials, such as: (a) thin metal plates; (b) profiled plates; (c) thick fiber reinforced composite materials like glass fiber, carbon fiber, and aramid fiber etc. The components of the sandwich material must also be bonded together, using either adhesives or mechanical fastenings, such that they can act as a composite load-bearing unit. 
Sandwich materials generally exhibit the following properties:

- High load bearing capacity at low'weight.

- Surface finished faceplates provide good resistance against aggressive environments.

- Excellent thermal insulation.

- Long life at low maintenance cost.

- Good water and vapor barrier.

- Excellent acoustic damping properties.

Naturally, the less favorable properties of sandwich materials can be identified as follows:

- Creep under sustained load with rigid foam cores

- Low thermal capacity

- Poor fire resistance with rigid plastic foam cores.

- Deformation when one side of faceplate is exposed to intense heat.

The correct design of the details of sandwich construction is at least as important as the analysis of deflections, stresses and backing loads. These details include nature of the edge members, splices and joints in the cores and faces, stiffeners and inserts to distributed concentrated load, type of adhesive, method of fabrication and so fourth. If the temperatures of the two faces differ, or if the moisture contents differ (as they may in asbestos cement or hardboard, for example) the differential expansion of the faces may lead to substantial transverse deflections. In building panels, especially problems arising concerning acoustic insulation, vapors transmission and fire resistance (but not usually heat insulation). All of the factors mentioned can be very important design considerations but they are beyond the scope of this topic. 


\subsubsection{Historical Development of Sandwich Theory}

Very few papers have been published which deal with the bending and buckling of sandwich panels with cores which are rigid enough to make a significant contribution to the bending stiffness of the panel, yet flexible enough to permit significant shear deformations.
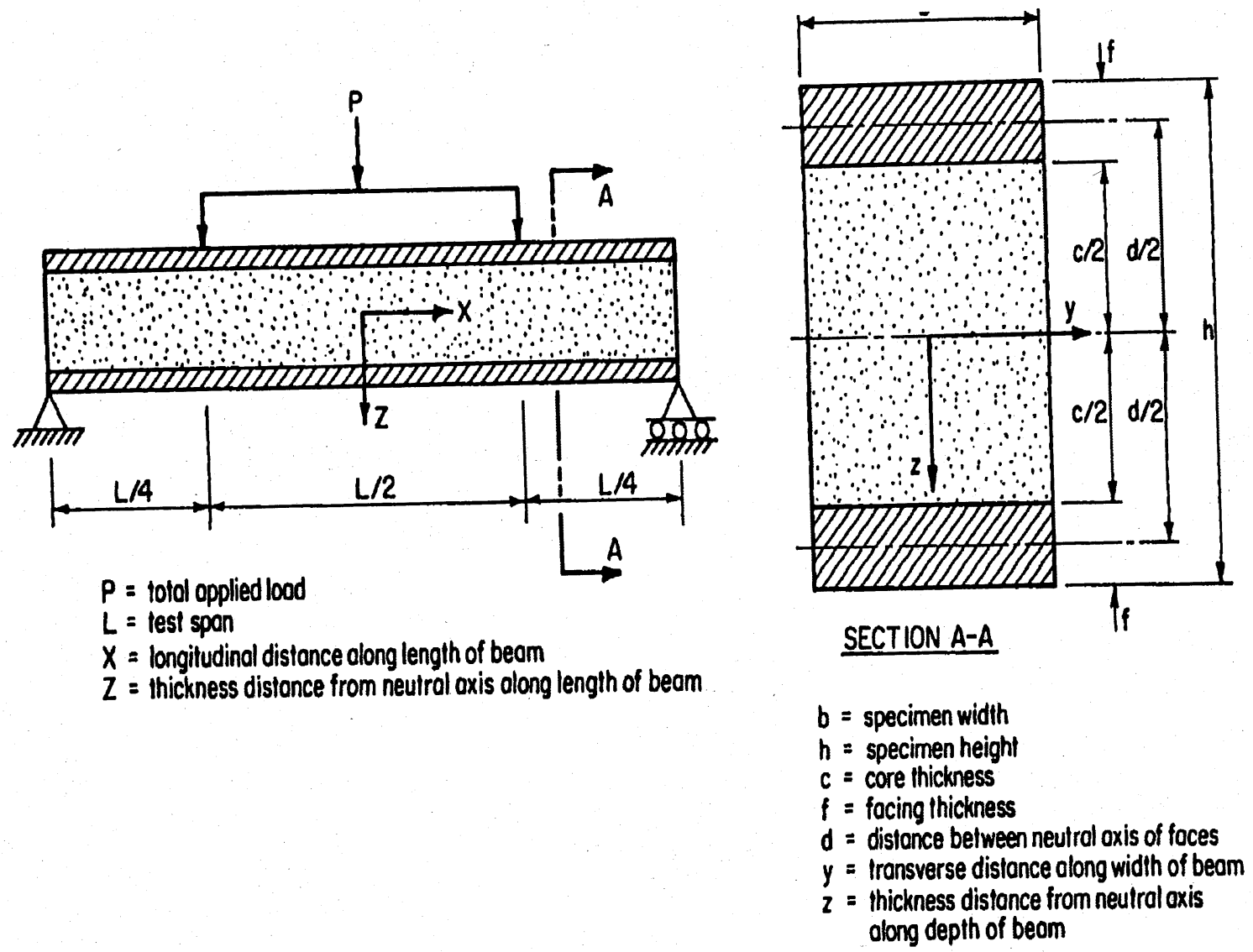

Fig. 2.1 Dimensions of Sandwich Panel

Figure 2.1 shows a typical longitudinal and cross-section in a sandwich beam made of a foam core and two facings (i.e. OSB boards). There remains the considerable problem of the sandwich panel with an anti-plane core, one which posses no stiffness in X-Y plane and in which the shear stresses $\tau_{\mathrm{zx}}, \tau_{\mathrm{yz}}$ are constant throughout the depth (i.e. they are independent of Z). Such panels differ from ordinary homogeneous plates in that the bending 
deformations may be enhanced by the existence of non-zero shear strains $\left(\varepsilon_{\mathrm{zx}}, \varepsilon_{\mathrm{yz}}\right)$ in the core and of direct strains $\varepsilon_{\mathrm{z}}$ in the core, perpendicular to the faces. The shear strain and the direct strain in the core are also directly associated with the possibility of short wavelength instability of the faces (wrinkling). This problem has been the subject of two main methods of analysis, which may be referred to for convenience as the general and the selective methods. In the general methods equations are setup to define the equilibrium of the separate faces and of the core and to prescribe the necessary continuity between the faces and the core. The result is a set of differential equations which may be solved in particular cases for the transverse deformation of the panel, the flattening of the core and other equations of interest. In the selective method, which has been the basis of this being named (again for convenience) as the bending problem and the wrinkling problem. In the bending problem, it is convenient to assume that the core is not only anti-plane, but also indefinitely stiff in the Zdirection. This excludes the flattening of the core and wrinkling instability, but it does permit the assessment of the effect of core shear deformation on the deflections and stresses in the panel. In the wrinkling problem the true elastic properties of the core are taken into account but the task is simplified by permitting the middle planes of the faces to deflect in the Zdirection only, not in their own planes.

\subsubsection{The general Method}

The general method was investigated by Reissner (1948) in relation to isotropic panels with very thin faces. Although his analysis is not simple, it is possible for Reissner to conclude that the effect of core flexibility in the Z- direction is after all less important than effect of core shear deformation in the transverse planes. Wrinkling instability as such is not 
discussed. It is only by neglecting the effect of direct transverse core strains that Reissner is able to derive a relatively simple differential equation for the transverse displacement, w. A much more recent analysis by Heath (1960) also includes a very similar equation, but for a sandwich with an orthotropic core. Heath's analysis work based on earlier work by Hemp (1948) and is apparently independent of the work of Reissner. Raville (1955) applies the general method to the simply-supported rectangular panel with the uniform transverse load and with thin faces. The three displacements of points in the orthotropic anti plane core are expresses as polynomials in $z$, but the complexity of the analysis again makes it necessary to revert to the simplifying assumption of infinite core stiffness in the $\mathrm{z}$ - direction. For practical purposes, the general method is the interact-table when applied to sandwich panels, but more success has been achieved in relation to sandwich struts and beams. The early works of Williams et al. (1941) and of Cox and Riddell (1945) fall into this category. The first of these deals with a sandwich struts with thick faces and an isotropic core (with an extension for an orthotropic cores) and the analysis used to form a link between the extreme cases of wrinkling instability (no longitudinal displacements of the faces during buckling) and of overall Euler- type instability, modified for shear deformations in the core (no direct core strains in the z- direction). A very thorough analysis of the behavior of the struts with isotropic faces and cores has been outlined by Goodier (1946) and completed by Goodier and Neou (1951). In the latter paper the works of Williams and of Cox are verified to a high degree of accuracy.

\subsubsection{The Selective Method}

Most of the published work on sandwich panels refers to the selective method and, in particular, to the bending problem, in which core strains in the z-direction is neglected. 


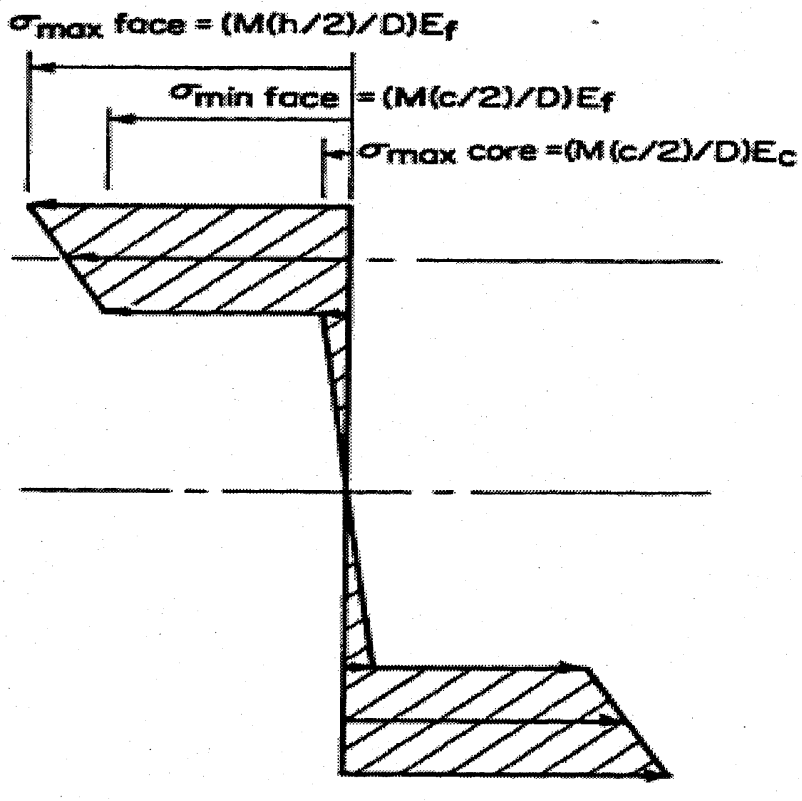

a. Normal Stress Profile

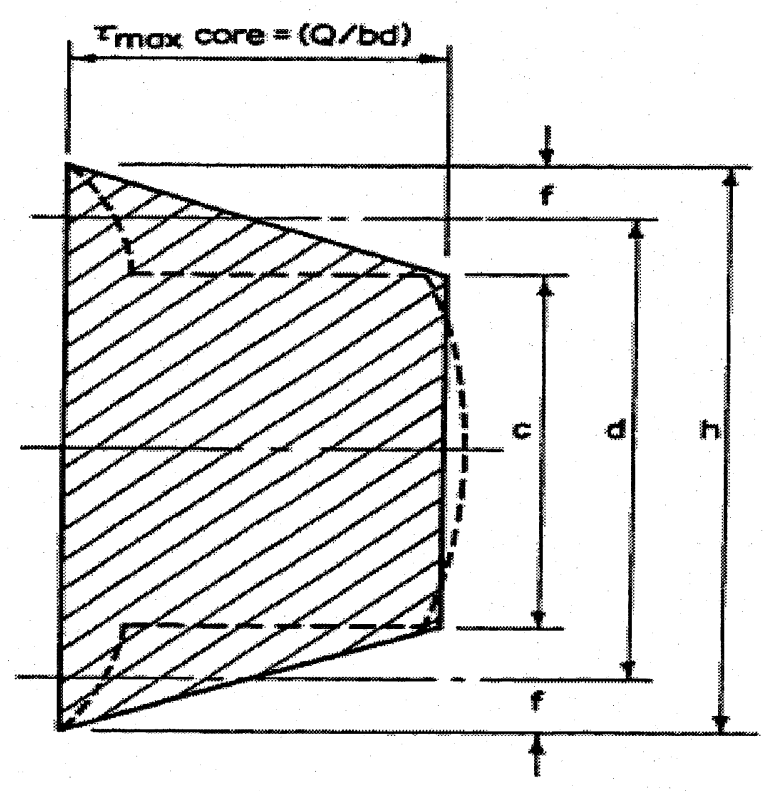

--- Dashed line - Theoretical Sheor Stress

Solid line - Approximated Shear Stress

Fig. 2.2. Flexural Stress and Shear Stress Distribution across the Depth of the

Sandwich Panel

The assumption that core is weak in the xy-plane leads in any case to the conclusions that the core makes no contribution to the flexural rigidity of the sandwich, that the core shear stresses $\tau_{\mathrm{zx}}$ and $\tau_{\mathrm{yz}}$ are independent of $\mathrm{z}$ and a straight line drawn in the unloaded core normal to the faces remains straight after deformation, but is no longer normal to the faces. These assumptions (core weak in $\mathrm{x}-\mathrm{y}$ plane, stiff in $\mathrm{z}$ - direction) allow the displacements of the panel to be expressed in terms of only three variables, one of which is the transverse displacement w. Figure 2.2 shows a summary of this method of analysis in case of flexural stresses as well as shear stresses. 


\subsubsection{Flexural Stresses in Sandwich Panels}

Ordinary bending theory is used to define the normal stresses in the faces and the core by adapting the composite nature of the cross section, defining the appropriate form of the flexural rigidity, $\mathrm{D}$, of the composite section. The stresses in the faces and the core, shown in Fig. 2.2, have been defined by Allen (1969) as follows:

$$
\begin{array}{ll}
\sigma_{f}=\frac{M z E_{f}}{D} & \text { for } \frac{c}{2} \leq z \geq \frac{h}{2} \\
\sigma_{c}=\frac{M z E_{c}}{D} & \text { for }-\frac{c}{2} \leq z \geq \frac{c}{2}
\end{array}
$$

Where: $\quad h=$ specimen height

$$
\begin{aligned}
& c=\text { core thickness } \\
& E_{f}=\text { modulus of elasticity of the facing material } \\
& E_{c}=\text { modulus of elasticity of the core material } \\
& D=\text { sandwich flexural rigidity (Equation 2.3) } \\
& \sigma_{c}=\text { normal core stress } \\
& \sigma_{f}=\text { normal facing stress } \\
& M=\text { bending moment } \\
& z=\text { distance from the neutral axis of the sandwich }
\end{aligned}
$$

The flexural rigidity is commonly referred to as D and can be defined as the sum of the flexural rigidities of the faces and the core measured about the neutral axis of the 
sandwich cross-section. Allen (1969) has defined the flexural rigidity for a narrow sandwich beam (transverse stresses in the y direction are assumed to be zero) as follows.

$$
D=E_{f} \frac{b f^{3}}{6}+E_{f} \frac{b f d^{2}}{2}+E_{c} \frac{b c^{3}}{12}
$$

Where: $\quad E_{f}=$ modulus of elasticity of the facing material

$$
\begin{aligned}
& E_{c}=\text { modulus of elasticity of core material } \\
& D=\text { sandwich flexural rigidity } \\
& b=\text { specimen width } \\
& c=\text { core thickness } \\
& f=\text { facing thickness } \\
& d \text { = distance between neutral axis of faces (c }+f \text { for equal facing thicknesses) }
\end{aligned}
$$

On the right hand side of the equation, the first term may be neglected in comparison with the second if:

$\mathrm{D} / \mathrm{f}>5.77$

If this condition is fulfilled, the local bending stiffness of the faces (bending about their own Separate centroidal axes) makes a negligible contribution of the flexural rigidity of the sandwich.

The third term may be neglected in comparison with the second if

$$
\frac{E_{f} f d^{2}}{E_{c} c^{2}} \succ 16.7
$$

If this condition is fulfilled, the bending stiffness of the core is negligible. 


\subsubsection{Flexural and Shear Stresses in Sandwich Panels}

The form of the shear stress $(\tau)$ for a point located at distance $\mathrm{z}$ from the neutral axis of a homogenous beam can be easily derived by ordinary bending theory and appears in many basics text books as follows.

$$
\tau=\frac{Q S}{I b}
$$

Where $\quad Q=$ shear force at the section

$$
\begin{aligned}
& \mathrm{I}=\text { second moment of area of the entire section about its centroid } \\
& \mathrm{b}=\text { width at given depth in section }\left(\mathrm{b}=\mathrm{z}_{1}\right) \\
& \mathrm{S}=\text { first moment of area of that part of the section where } \mathrm{z}>\mathrm{z}_{1}
\end{aligned}
$$

For a sandwich beam, the moduli of elasticity of the component parts are accounted for by representing the sum of the products of $\mathrm{S}$ and $\mathrm{E}$ in Equation (2.7); the profile of the shear stress through the depth is defined in Equation 2.8 (Allen, 1969).

$$
\begin{aligned}
& \tau=\frac{Q S}{D b} \sum(S E) \\
& \tau(z)=\frac{Q}{D}\left[E_{f} \frac{f d}{2}+\frac{E_{c}}{2}\left(\frac{c^{2}}{4}-z^{2}\right)\right]
\end{aligned}
$$

Allen (1969) shows that Equation 2.8 may be simplified if the sandwich has a relatively weak core and if the flexural rigidity of faces about axis of faces is small (Equation 2.4 satisfied). For sandwich cross-section with relatively stiff faces and weak core, it is common to assume the shear stress of the faces is negligible. Therefore, Equation 2.6, which defines the shear stress through the depth of the core, reduces to Equation 2.9

$$
\tau=\frac{Q}{b d}
$$


The normal and shear stress profiles of a sandwich beam are given in Fig. 2.2 where the maximum facing stress at the outer fiber is obtained by using $z=h / 2$ in Equation 2.1, the minimum facing stress at the interface of the core is obtained by using $\mathrm{z}=\mathrm{c} / 2$, and maximum shear stress in the core as given in Equation 2.9.

\subsubsection{Elastic Deflection Analysis of Sandwich Panels}

Equations defining the instantaneous elastic mid-span deflection of uniformly loaded simplysupported sandwich beams (with relatively thin, stiff faces and thick weak cores) are well known and widely cited. The plywood Design Specification Supplement, entitled "Design and Fabrication of plywood Sandwich Panels" (APA 1990) simplifies the total sandwich beam mid-span deflection $\left(\Delta_{\mathrm{T}}\right)$ to the sum of bending and shear deflection as follows:

$\Delta_{\mathrm{T}}=\Delta_{\mathrm{B}}+\Delta_{\mathrm{S}}$

Where: $\quad \Delta_{\mathrm{B}}=$ mid-span sandwich panel deflection due to bending

$\Delta_{\mathrm{S}}=$ mid-span sandwich panel deflection due to shear

The form of the elastic bending deflection for a simply-supported homogeneous beam of uniform cross-section in quarter-point loading, see Fig. 2.1, is easily derived by ordinary bending theory and appears in many basic text books as follow:

$\Delta_{B}=\frac{11 P L^{3}}{384 E I}$

Where: $\quad \mathrm{P}=$ total applied load

$\mathrm{L}=$ beam span

$\mathrm{E}=$ modulus of elasticity of the beam material 
$I=$ moment of inertia of the uniform cross-section

When defining the deflection of a sandwich beam, however, the flexural rigidity (EI) must be defined in terms of its component materials and their position in the cross-Section.

Allen (1969) also shows that for thin faces (local bending of faces is negligible), negligible core bending stiffness, constant shear stress throughout the core, and negligible shear stress in the skin material, the displacement $\left(\mathrm{w}_{2}\right)$ associated with the shear deformation of the core can be determined by integrating Equation 2.12.

$\int \frac{d w_{2}}{d x}=\frac{Q}{A G}$

Where $\quad A=b d^{2} / c$ and $A G$ is referred to as the shear stiffness

$\mathrm{Q}=$ shear force $=\mathrm{P} / 2$ for quarter-point loading

$\mathrm{G}=$ core shear modulus

$\mathrm{X}=$ distance from the reaction in shear zone of beam

$\mathrm{w}_{2}=$ displacement at $\mathrm{x}$

By applying the boundary conditions for the simply-supported quarter point load beam $\left(\mathrm{w}_{2}=\right.$ 0 at $\mathrm{x}=0$, the maximum shear deflection (at $\mathrm{x}=\mathrm{L} / 4$ ) associated with the shear deformation of the sandwich loaded at quarter points is defined by Equation 2.13. Thus the total sandwich beam deflection reflecting the bending and shear component is defined in Equation 2.14.

$$
\begin{aligned}
& \Delta_{s}=w_{2 \max }=\frac{P L}{8 A G} \\
& \Delta_{s}=\frac{11 P L^{3}}{384 D}+\frac{P L}{8 A G}
\end{aligned}
$$


In 1996, ASTM included creep loading as an official protocol addressing SIP performance. At this point engineers and designers need validated techniques to define SIP creep performance to consumers and code officials. The National Design Specification for Wood, NDS, (NFPA, 1991) provided convenient method (equation 2.15) for calculating total deflections for structural wood products subject to long term loading:

$\Delta_{\text {Total }}=\mathrm{K}\left(\Delta_{\text {long term }}\right)+\Delta_{\text {short term }}$

Where $\quad \Delta_{\text {long term }}=$ immediate deflection under dead load +long-term portion of live loads $\mathrm{K}=$ constant to calibrate the long-term effects of dead load and live load $\Delta_{\text {short term }}=$ deflections under short-term portions of design load The long-term deflection constant, $\mathrm{K}$, ranges in magnitude from 1.5 for seasoned lumber and glulum timbers to 2 for green lumber. There is a great need in the SIP industry to develop a similar relationship for long-term SIP behavior. This creep behavior can be defined by experimental testing. Figure 2.3 shows a schematic diagram of creep behavior of a typical material. The first region shows the instantaneous deflection-time relationship as the member reaches its immediate deflection. The next region defines primary creep where deflection increases at a decreasing rate. The secondary creep region shows the deflection increasing at a nearly constant rate and finally, the tertiary creep region ending in failure. Alternatively, if the structure is unloaded before the onset of the tertiary stage, the deflection is immediately reduced; the elastic deflection will be fully recovered for viscoelastic material and the structure continues to recover its creep deflection. 


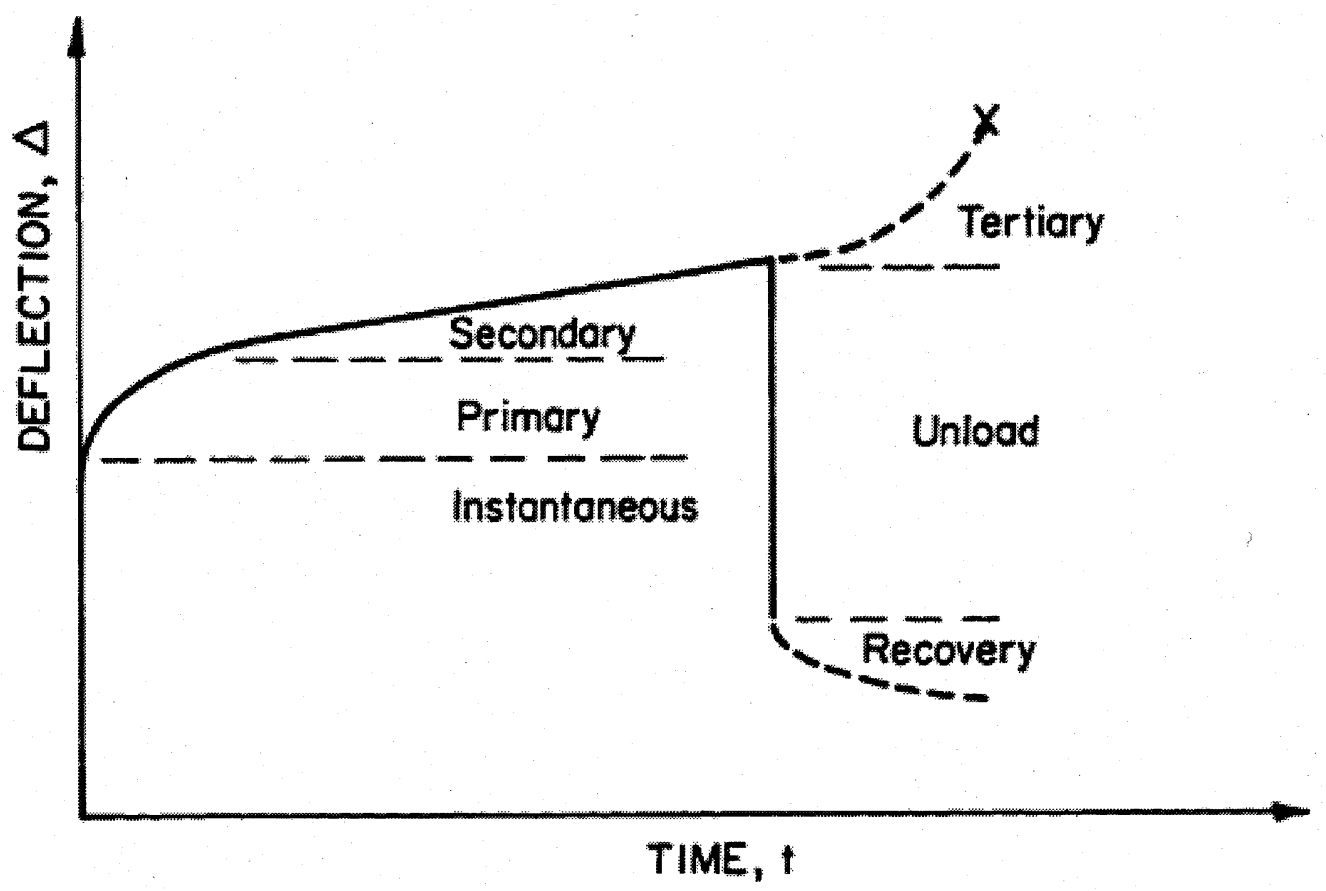

Figure 2.3 Creep Behavior

The creep behavior of wood on wood (OSB faced solid-sawn wood stud core) panels has been researched by Wong et al. (1988) for a three month load duration. Davis (1987) summarized research predicting the influence of creep on urethane and EPS core metal faced panels for ten year load duration. Huang and Gibson (1990) reported results on the creep of metal faced urethane core panels. Other work by Huang and Gibson (1991) defined creep parameters for polyurethane foam cores from shear creep tests as recommended by ASTMC273-61. Taylor (1996) conducted a series of creep testing on OSB/foam structural insulated panels to measure the three month mid-span creep deflections due to sustained loading at the quarter points. Four manufacturers were included in the experimental plan (two EPS core SIP manufacturers and two urethane core SIP manufacturers). The SPS designates the expanded polystyrene core type. The results suggested the use of a fractional deflection factor, $\mathrm{K}$, for 
the calibration of long-term deflection as 1.5 for EPS core and 2.0 for urethane core for cumulative deflection duration up to three months in the NDS long-term equation.

Few authors conducted research work on the structural behavior related to sandwich panels. Among them, Liu and Zhao (2007) studied the effect of soft honeycomb core on the flexural vibration of sandwich panel using low order and high order shear deformation models. Aviles and Carlsson (2006) conducted experimental study of the in-plane compressive failure of sandwich panels consisting of glass/epoxy face sheets over a range of PVC foam cores, and a balsa wood core containing one or two circular or square interfacial debonds. In most specimens, failure occurred by local buckling of the debonded face sheet followed by rapid debond growth towards the panel edges, perpendicular to the applied load. Meyer-Piening (2006) dealt with the linear static and buckling analysis of an asymmetric square sandwich plate with orthotropic stiffness properties in the face layers. Gupta and Woldesenbet (2005) and Gupta et al. (2002) studied experimentally and theoretically the behavior of sandwich-structured composites containing syntactic foam as core material under three-point bending loading conditions. They presented a method of analysis for syntactic foams and the sandwich structures containing syntactic foam as core material. Olsson (2002) suggested an engineering method to predict the impact response and damage of flat sandwich panels. The approach accounts for local core crushing, delamination and large face sheet deflections. Yoon el al. (2002) studied experimentally the non-linear behavior of sandwich panels made of thermoplastic foam core and carbon/epoxy fabric faces. The experimental data were compared with the predicted results from a proposed analytical method and the finite-element analysis. Tham et al. (1982) studied, using the finite-prism-strip modeling, the flexural and axial compressive behavior of the prefabricated architectural sandwich panels 
made of foam-in-place rigid urethane cores and light-gauge cold-formed metal facing. A similar study was recently conducted elsewhere but with plain concrete core (Hossain and Wright, 2004). 


\section{CHAPTER III}

\section{EXPERIMENTAL STUDY}

\subsection{General}

Thermapan Inc. is Canadian-based Company that developed Structural Insulated Timber Panels (SIPs). Thermapan SIPs are perfect for many different applications, such as interior and exterior walls, roofs, floors, foundations, timber frame, log homes, additions, and renovations. These panels are composed of thick layer of expanded polystyrene insulation (EPS) board laminated between two sheets of oriented strand board (OSB). Figure 3.1 shows structural insulated panel definition sketch. Thermapan SIPs are available in the following standard sizes of $1.2 \mathrm{~m}$ wide and lengths of $2.43,2.72,3.05,3.66,4.27$ and $4.90 \mathrm{~m}$. The used facing of these developed panels is made of $11 \mathrm{~mm}$ (7/16") Oriented Strand Board (OSB) on both sides of the foam core for floor and wall construction. Some panels developed for extra resistance to environmental conditions are made of $11 \mathrm{~mm}$ (7/16") Oriented Strand Board (OSB) on one facing and $28.6 \mathrm{~mm}\left(1-1 / 8^{\prime \prime}\right)$ thick timber sheathing on the outer facing. These SIPs provide exceptional resistance to fire and it meets building code for many commercial applications based on the R-Value shown in Table 3.1 (Thermapan, 2007).

Table 3.1 Thermapan SIPs Properties

\begin{tabular}{|l|l|l|l|l|l|}
\hline SIP Thickness (Timber) & $4.5^{\prime \prime}$ & $6.5^{\prime \prime}$ & $8.25^{\prime \prime}$ & $10.25^{\prime \prime}$ & $12.25^{\prime \prime}$ \\
\hline EPS Core Thickness & $3-5 / 8^{\prime \prime}$ & \multicolumn{1}{|c|}{$5-5 / 8^{\prime \prime}$} & $7-3 / 8^{\prime \prime}$ & $9-3 / 8^{\prime \prime}$ & $11-3 / 8^{\prime \prime}$ \\
\hline Dimensional Lumber & $2 \mathrm{x} 4$ & $2 \mathrm{x} 6$ & $2 \times 8$ & $2 \mathrm{x} 10$ & $2 \times 12$ \\
\hline Weight (lbs/sq.ft.) & 3.13 & 3.32 & 3.48 & 3.66 & 3.84 \\
\hline R-Value & 19.147 & 29.147 & 37.897 & 47.897 & 57.897 \\
\hline
\end{tabular}




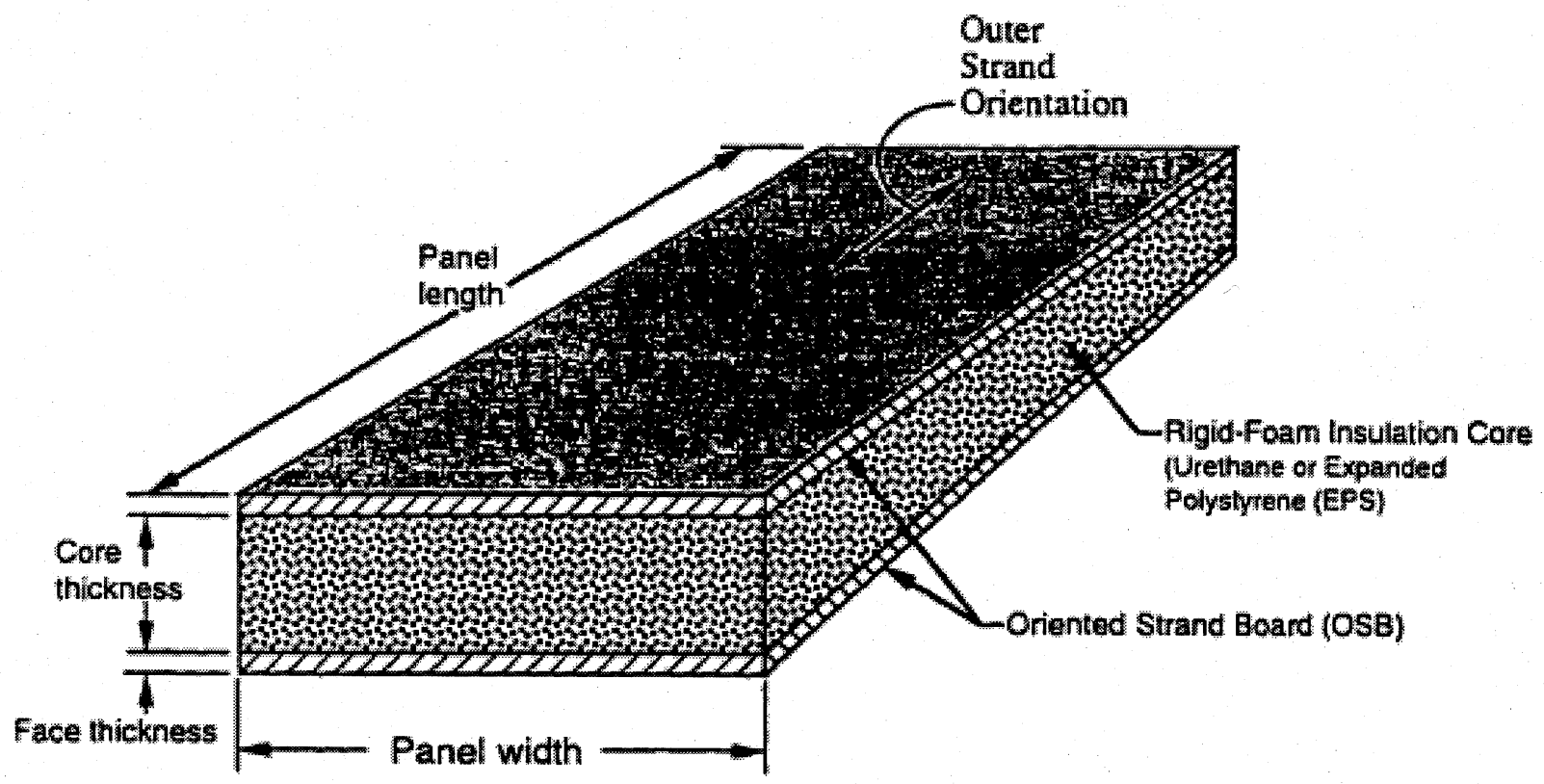

Figure 3.1 Sketch of Structural Insulated Panel, SIP

SIP floors and roofs are installed by placing the panels side by side as shown in Figs. 1.3 and 1.4. The connections between the panels in the span direction can be either foamspline or solid lumber spline. The foam-spline connection is preferred for roof construction to assist in energy efficiency, while the solid lumber spline connection is specified herein for floor construction. The foam-spline connection is constructed by providing a recess in the foam core at the long edges of the panels as shown in Fig. 3.2. A foam block with two OSB facings glued to it is inserted at the edge of one panel. Then, the adjacent panel is slide over spline. The block OSB facings are them nailed to the OSB of the connected panels to provide structural integrity of the floor/roof. Figure 3.3 shown typical section of foam-spline connection after assembly. While Fig. 3.4 shows view of the connection in a tested panel. Figure 3.5 shows a schematic diagram of the solid lumber-spline connection. A recess is formed in the foam core before gluing it to the OSB facings. The width of the insert is usually half the width of the solid sawn lumber. After placing a panel over the walls, as shown in Fig. 1.4, a sawn lumber is inserted in the recess along the panel length. Then, the 
adjacent panel slides over the sawn lumber, followed by nailing their OSB facings to the solid lumber.

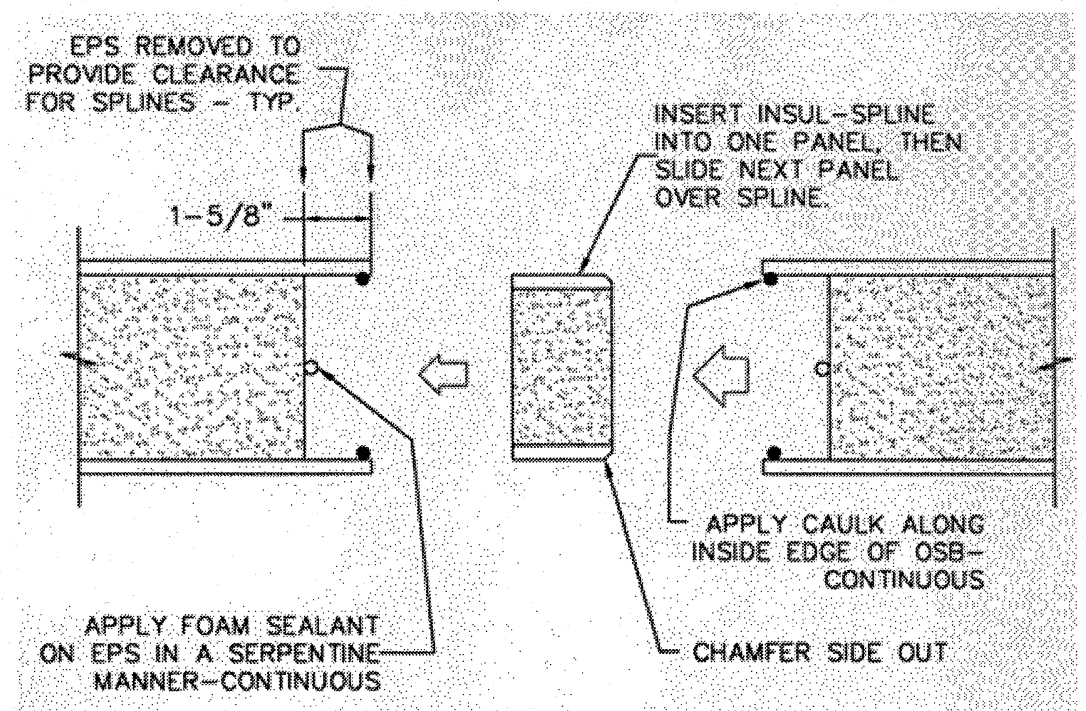

Fig. 3.2 Typical section at panel foam-spline connection before assembly

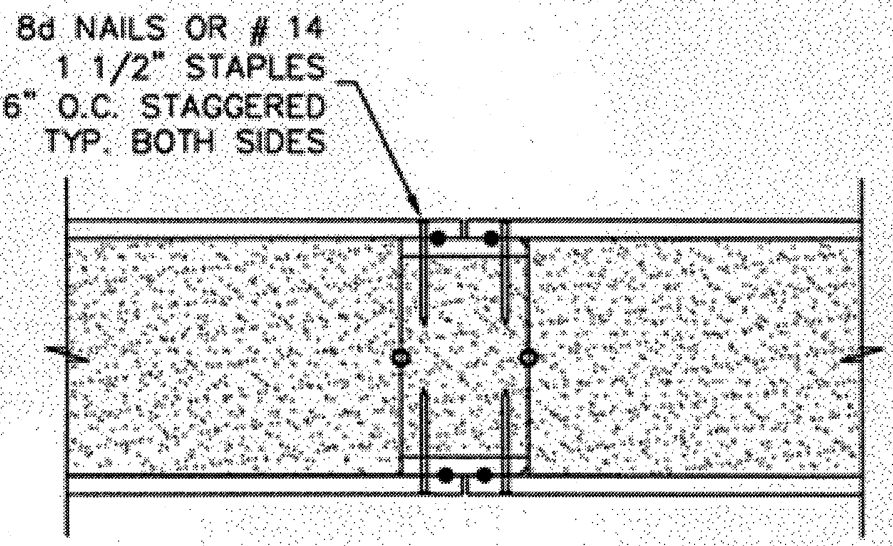

Fig. 3.3 Typical section at panel foam-spline connection after assembly 


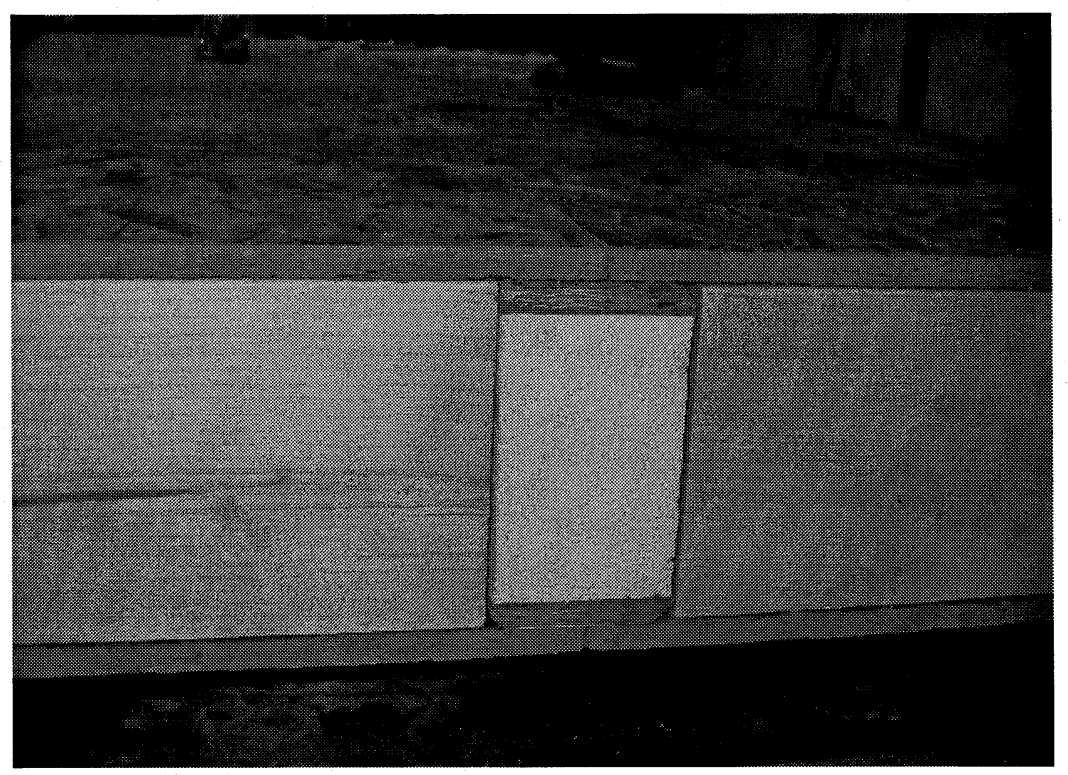

Fig. 3.4 View of the foam-spline connection for the tested panels

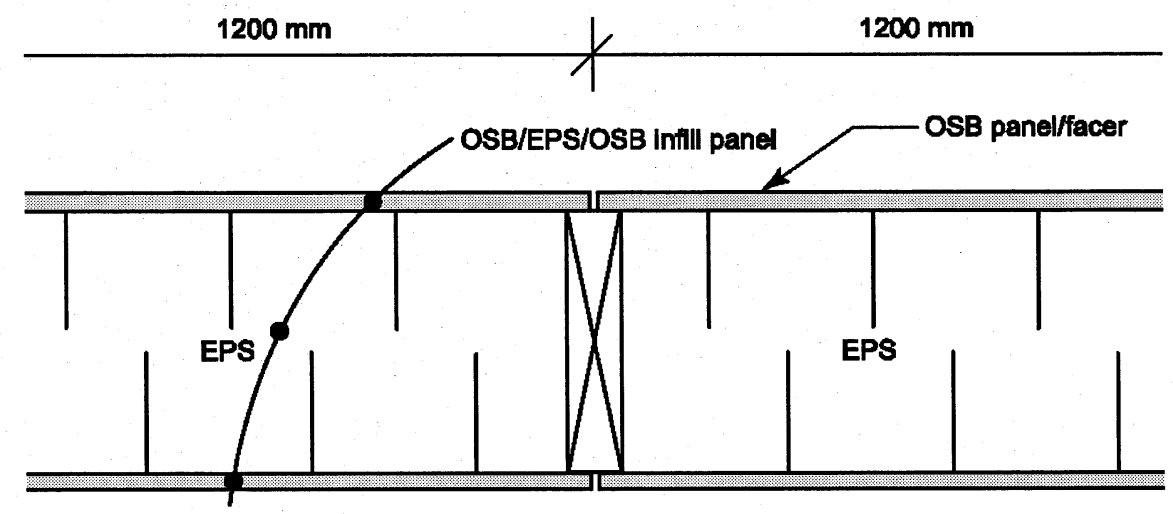

Fig. 3.5 Schematic diagram of solid lumber-spline connection between SIP panels

In order to develop a better understanding of the structural behavior of these timber sandwich panels at service and ultimate loading conditions, an experimental research program was performed at the structural laboratory of Ryerson University. 53 flexural tests as well as 3 flexural creep tests were performed on the panels to provide experimental data that was then evaluated for building code compliance. The experimental data was correlated 
to the predicted results obtained from available analytical method. This chapter summarizes the geometrical and material properties of the tested panels, the test setup for both flexural test and creep test, and the test procedure.

\subsection{Description of Panels:}

The experimental program originally included 44 panels for flexure testing under static fourpoint loading and 3 panels for flexure creep testing under uniform loading. However, 6 panels have been added to the tested panels after examining the results at each stage of testing. Table 3.2 summarizes the geometric characteristics of these panels. The tested panels were divided into 15 groups based on the size or the panel, the connection between adjacent panels in real structure (i.e. foam spline of lumber connection), and the thickness of the OSB. All panels from S-1 to S-45 were produced for roof and floor construction with $1.2 \mathrm{~m}$ wide and $11 \mathrm{~mm}$ thick OSB for the top and bottom facings, except group $\mathrm{O}$ that had $11 \mathrm{~mm}$ (7/16") Oriented Strand Board (OSB) on one facing and $28.6 \mathrm{~mm}$ (1-1/8") thick timber sheathing on the outer facing. Group A consisted of 3 panels of $2.43 \mathrm{~m}\left(8^{\prime}\right)$ length, $165 \mathrm{~mm}$ (6 1/2") total depth, and spline connection. It should be noted that the foam core depth is simply the difference between the total depth and the thickness of the two OSB facings. Group B is similar to Group A but with length of $3.05 \mathrm{~m}\left(10^{\prime}\right)$. It should be noted that Group B included a forth panel, S-6, with no connection details along its longer sides to examine the change in the deflection value and ultimate load carrying capacity with the presence of foam spline connection. This type of panel is defined as "regular panel" in the summary table and when referring to in the rest of the thesis. Group C consisted of 3 panels with lumber connection detail in the longitudinal direction, $3.66 \mathrm{~m}\left(12^{\prime}\right)$ length and $165 \mathrm{~mm}\left(6^{1 / 2}\right.$ ') $\left.^{\prime}\right)$ total 
depth. A forth "regular" panel, S-12 with added to this group to examine the gain in strength and deflection with the presence of sawn lumber every $1.2 \mathrm{~m}$ width. Group D is similar to group C but with foam spline connection. Group E is similar to Group B but with $3.05 \mathrm{~m}$ (10') length and $209.6 \mathrm{~mm}\left(8^{1 / 4}\right)$ total thickness. Group F is similar to Group E but with $3.66 \mathrm{~mm}\left(12^{\prime}\right)$ length. It can be observed that this group included additional panel, S-16-1, for repeat test S-16 since some results for the latter did not comply with code requirements. Regular panel S-19 was added to this group to examine the change in panel load carrying capacity with the presence of foam spline connection. Group $G$ is similar to Group F but with lumber connection. Group H is similar to Group F but with $4.27 \mathrm{~m}$ (14') length. Group I is similar to Group H but lumber connection. Groups J and K had spline connections and 260.4 $\mathrm{mm}\left(10^{1 / 4} \mathrm{4}^{\prime \prime}\right)$ total thickness. However, the former had $3.66 \mathrm{~m}\left(12^{\prime}\right)$ length while the latter had 4.27 m (14') length. Group L was similar to Group K but with lumber connection. Group M

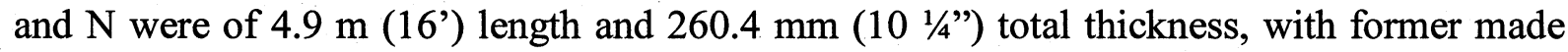
with foam spline connection and the latter made of lumber connection.

Table 3.2 Description of the tested panels

\begin{tabular}{|c|c|c|c|c|c|}
\hline Groups & $\begin{array}{l}\text { Test } \\
\text { No. }\end{array}$ & Test type & \begin{tabular}{l|} 
Panel size \\
Length $\times$ Width \\
Thick. Of pane
\end{tabular} & $\begin{array}{l}\text { Thickness of } \\
\text { sheathing } \\
\text { (OSB) }\end{array}$ & Comments \\
\hline \multirow[t]{3}{*}{$\mathbf{A}$} & 1 & Flexure & $4 \times 8 \times 6 \frac{1}{2} "$ & 7/16" & Foam spline \\
\hline & 2 & Flexure & $4 \times 8 \times 6 \frac{1}{2} "=$ & 7/16" & Foam spline \\
\hline & 3 & Flexure & $4 \times 8 \times 6 \frac{1}{2}, "$ & 7/16" & \begin{tabular}{|l|} 
Foam spline \\
\end{tabular} \\
\hline \multirow[t]{4}{*}{ B } & 4 & Flexure & $4 \times 10 \times 6 \frac{1 / 2 "}{}$ & $7 / 16 "$ & Foam spline \\
\hline & 5 & Flexure & $4 \times 10 \times 6 \frac{1 / 2 "}{}$ & $7 / 16 "$ & Foam spline \\
\hline & 6 & Flexure & $4 \times 10 \times 6 \frac{1 / 2 "}{}$ & 7/16" & Foam spline \\
\hline & 43 & Flexure-creep* & $4 \times 10 \times 6 \frac{1 / 2 "}{}$ & $7 / 16 "$ & Regular panel \\
\hline \multirow[t]{4}{*}{$\mathbf{C}$} & 7 & Flexure & $4 \times 12 \times 61 / 2 "$ & 7/16" & Lumber connection \\
\hline & 8 & Flexure & $4 \times 12 \times 61 / 2 "$ & 7/16" & Lumber connection \\
\hline & 9 & Flexure & $4 \times 12 \times 6 \quad 1 / 2 "$ & 7/16" & Lumber connection \\
\hline & 12 & Flexure & $4 \times 12 \times 61 / 2 "$ & 7/16" & Regular panel \\
\hline D & 10 & Flexure & $4 \times 12 \times 6 \frac{1}{1} 2^{\prime \prime}$ & $7 / 16^{\prime \prime}$ & Foam spline \\
\hline
\end{tabular}




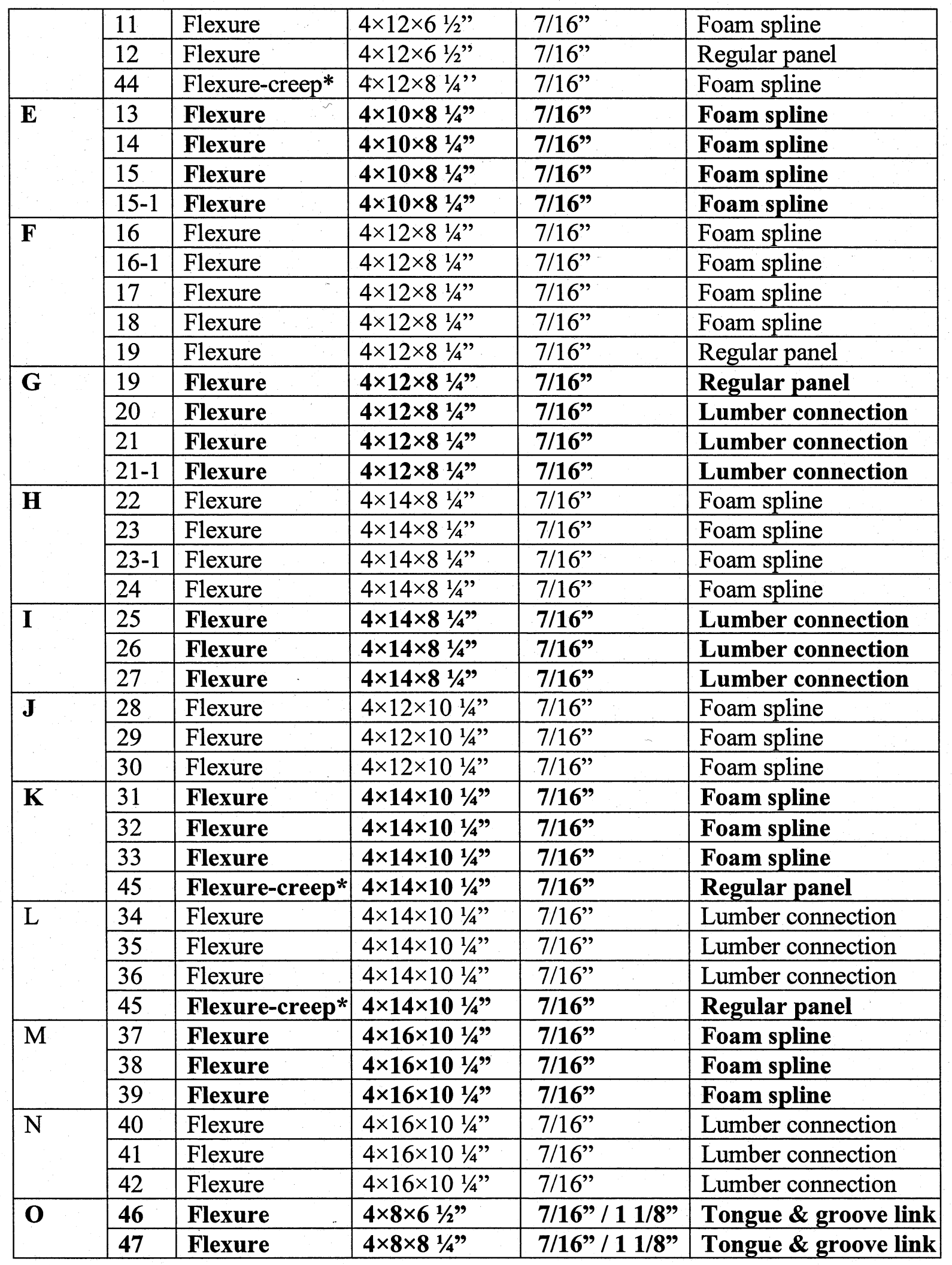




\subsection{Material Properties}

The Thermapan SIPs as manufactured by Thermapan Industries Inc. consists of three elements, factory crafted in a computer assisted lamination assembly line. The exterior faces are oriented strand board (OSB) manufactured and grade stamped as per APA (1990). The OSB board used to fabricate the panels had 1R24/EF16/W24 panel mark with $10.5 \mathrm{~mm}$ thickness construction sheathing. The minimum material properties for OBS boards, as supplied by the SIP manufacturer are specified as follows:

Modulus of rupture: $28.955 \mathrm{MPa}(4200 \mathrm{psi})$ in the span direction

12.409 MPa (1800 psi) in the direction normal to the span direction Modulus of elasticity: $5515 \mathrm{MPa}(800,000 \mathrm{psi})$ in the span direction

$1551 \mathrm{MPa}(225,000 \mathrm{psi})$ in the direction normal to the span direction However, material characteristics as specified in the OSB Design Manual (2004) for the 1R24/EF16/W24 panel are listed below.

Bending resistance, $M_{\mathrm{r}} \quad=228 \mathrm{~N} \cdot \mathrm{mm} / \mathrm{mm}$

Axial tensile resistance, $\mathrm{T}_{\mathrm{r}} \quad=57 \mathrm{~N} \cdot \mathrm{mm} / \mathrm{mm}$

Axial compressive resistance, $P_{\mathrm{r}} \quad=67 \mathrm{~N} \cdot \mathrm{mm} / \mathrm{mm}$

Shear through thickness resistance, $V_{r}=44 \mathrm{~N} / \mathrm{mm}$

Bending stiffness, EI $\quad=730,000 \mathrm{~N} \cdot \mathrm{mm}^{2} / \mathrm{mm}$

Axial stiffness, EA $\quad=38,000 \mathrm{~N} / \mathrm{mm}$

Shear through thickness rigidity, $\mathrm{G}=11,000 \mathrm{~N} / \mathrm{mm}$

$\mathrm{E}_{\text {wood }} \quad=6382.79 \mathrm{~N} / \mathrm{mm}^{2}$ 
Expanded Polystyrene is a polymer impregnated with a foaming agent with, when exposed to steam, creates a uniform closed cell structures highly resistant to heat flow and moisture penetration. This in-plant expansion process is fused into blocks which are cured for dimensional stability and cut into boards. The expanded polystyrene (EPS) core used to fabricate the panels was Type 1 . Thermapan Industries Inc. specifies a priority density that demonstrates a load failure of $25 \mathrm{psi}$ when tested as per ASTM C297. EPS core material must meet the minimum standard CAN/ULC-S701 and demonstrate the following minimum strength characteristics:

$\begin{array}{ll}\text { Nominal density } & 16 \mathrm{~kg} / \mathrm{m}^{3}\left(1.0 \mathrm{Ibs} / \mathrm{ft}^{3}\right) \\ \text { Shear strength: } & 83 \mathrm{kPa}(12 \mathrm{psi}) \\ \text { Shear modulus: } & 2758 \mathrm{kPa}(400 \mathrm{psi}) \\ \text { Flexural strength: } & 172 \mathrm{kPa}(25 \mathrm{psi}) \\ \text { Tensile strength: } & 103 \mathrm{kPa}(15 \mathrm{psi}) \\ \text { Compressive strength: } & 70 \mathrm{kPa}(10 \mathrm{psi}) \\ \text { E }_{\text {core }}: & 6.3086 \mathrm{~N} / \mathrm{mm}^{2}\end{array}$

The urethane adhesive must meet the following standards:

ASTM D-2294: 7 Day High Temperature Creep Test

ASTM D-905: Block Shear Test Using Plywood

ASTM C-297: Tension Test of Flat Sandwich Construction in a Flatwise Plane

ASTM D-1877: Resistance of Adhesive to Cyclic Laboratory Aging Conditions

ASTM D-1002: Strength Properties of Adhesive Bonds in Shear by Tension Loading 


\subsection{Test method for SIP Panels in Flexure}

In 2007, the National Research Council Canada (NRC) prepared a technical guide (IRC, 2007) that describe the technical requirements and performance criteria for the assessment of stressed skin panels (with lumber $1200 \mathrm{~mm}$ o.c. and EPS core) for walls and roofs for the purpose of obtaining a CCMC (Canadian Construction Materials Commission) evaluation report. The requirements and criteria referenced in this guide were developed to evaluate the performance of stressed skin panels for walls and roofs with respect to their performance as an alternative solution established with respect to Part 4, Structural Design, and Part 9, Housing and Small Buildings, of the National Building Code of Canada (NBCC, 2005). The Technical Guide focuses on the structural qualification of stressed skin composite panels as being "as good as" the structural capacity of the conventional wood-frame buildings. A successful evaluation conforming to this Technical Guide will result in a published CCMC Evaluation Report that is applicable only to products bearing the proper identification number of CCMC's evaluation number. This NRC/IRC/CCMC Technical Guide specifies test methods for SIPs similar to those specified in ASTM E72-02, Standard Test Methods for Conducting Strength Tests of Panels for Building Construction, (ASTM, 2002) as well as ICC AC04, Acceptance Criteria for Sandwich Panels, (2004). It should be noted that ICC AC04 acceptance criteria is based on ASTM E72 standard test methods. As such, bending qualification tests on the panels were conducted in accordance with the method described in the ASTM E72-02, Transverse Load Test. ASTM E72-02 specifies at least three identical specimens for each test. This condition is reflected in the tested panel groups shown in Table 3.1. 


\subsubsection{Flexure Load Test setup}

Figure 3.6 shows view of the test setup per ASTM E72-02. The panel was supported over two steel rollers of $25.4 \mathrm{~mm}$ diameter and $1200 \mathrm{~m}$ length, with a $1200 \times 150 \times 12 \mathrm{~mm}$ steel plate between each supporting roller and the specimens. Also, similar steel plates were inserted between the steel rollers and the supporting steel pedestal resting on the laboratory strong floor. The loading was applied at the quarter points from the jack using a 152 $\times 152 \times 9.5$ HSS beam of $2.6 \mathrm{~m}$ length. The spread beam was resting on a supporting assembly that rested over the panel at the quarter points. This supporting assemble consisted of a 25.4 $\mathrm{mm}$ steel roller, and a $150 \times 150 \times 12 \mathrm{~mm}$ steel base plate and a $152 \times 152 \times 9.5 \mathrm{HSS}$ of 1200 $\mathrm{mm}$ length. The weight of this loading system is $2.0 \mathrm{kN}$. Figure 3.7 shows view of the test setup for panel S-1, while Fig. 3.8 shows enlarged view of the roller support system used in this testing. 


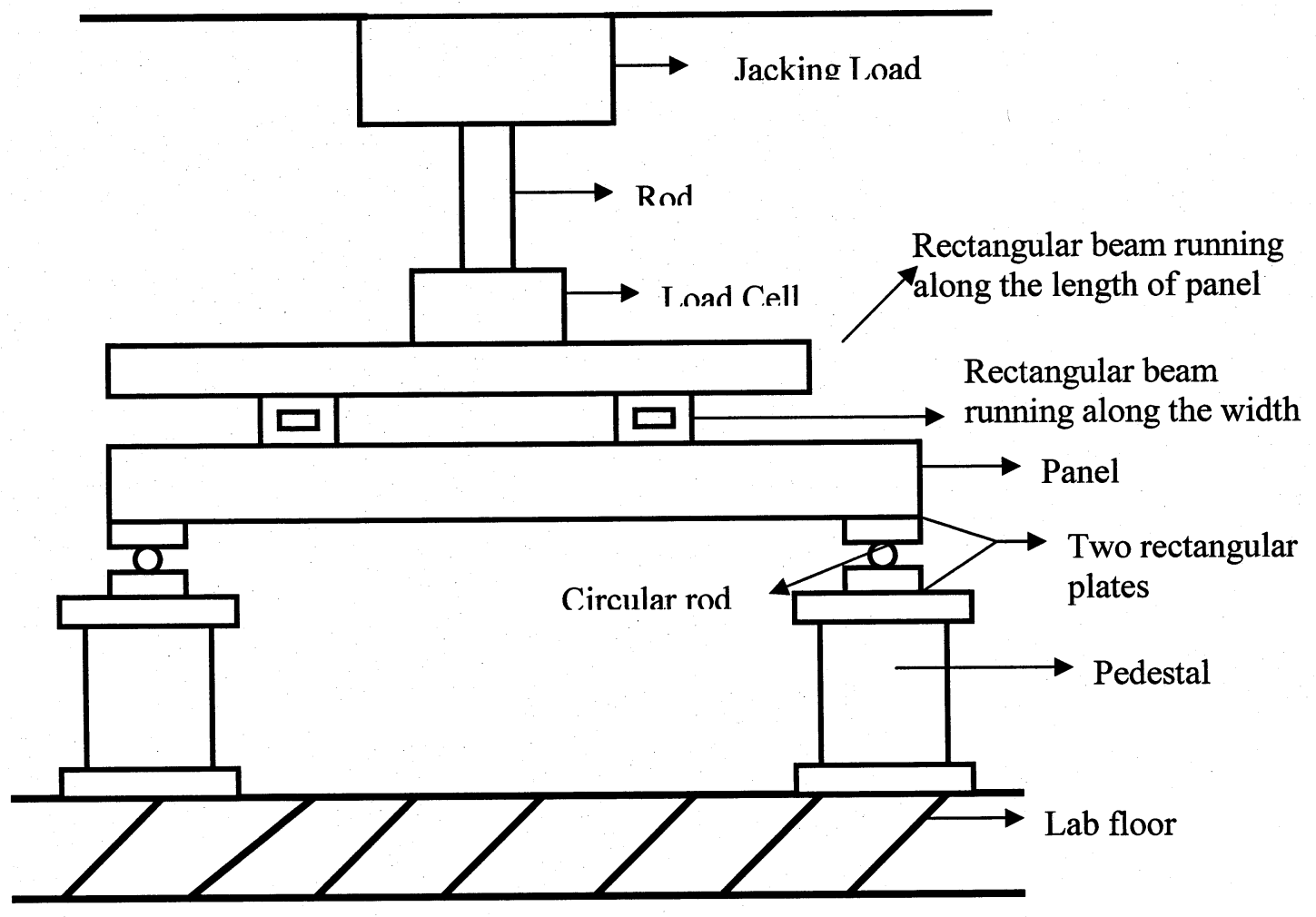

Figure 3.6 Schematic view of the test setup for flexure testing 


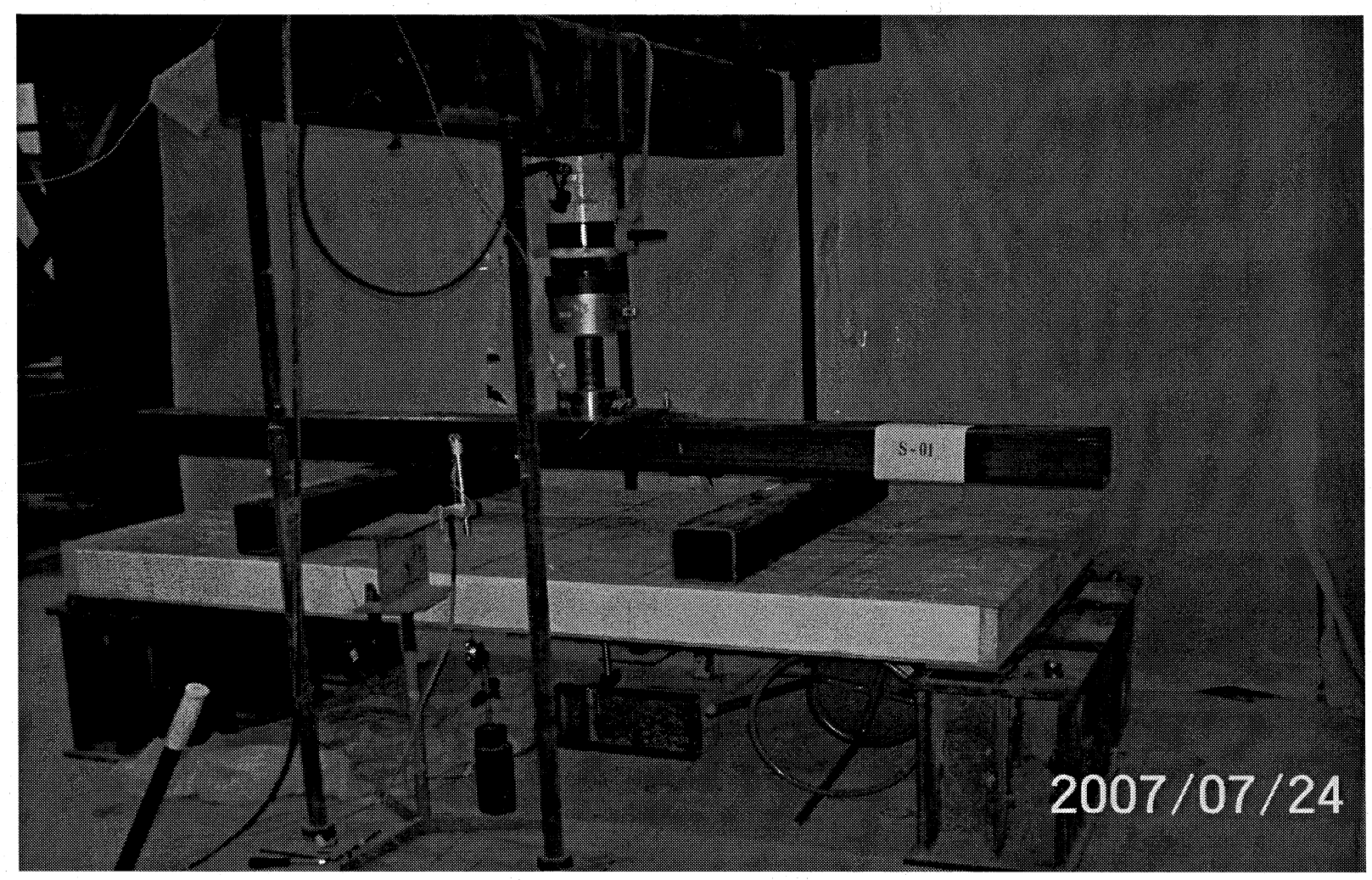

Figure 3.7 View of Specimen S-1 before testing

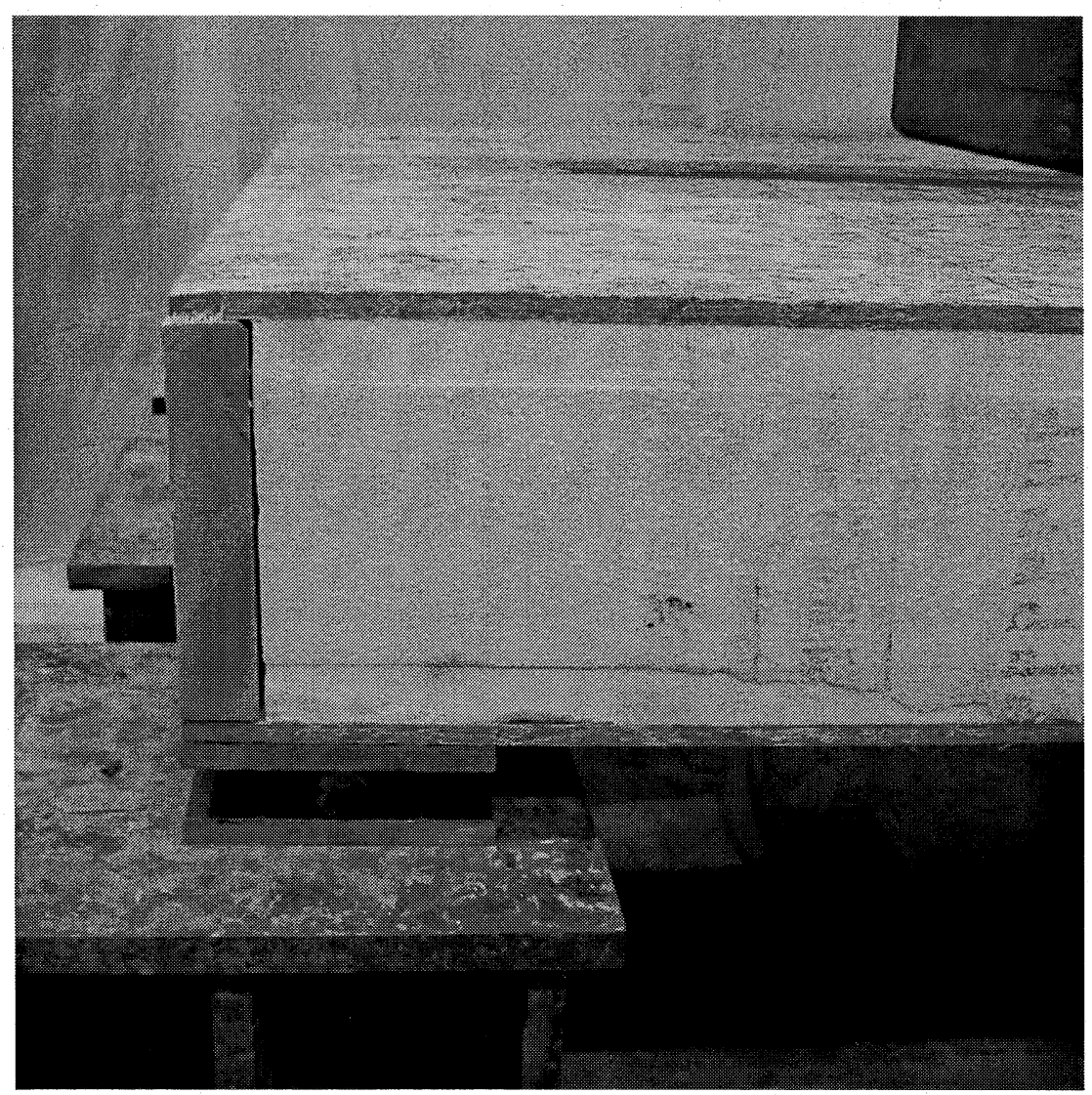


Fig. 3.8 Enlarged view of the roller support of the tested panels

\subsubsection{Instrumentation for Flexure Load Test}

To measure the longitudinal flexural strain on the top surface of the panel, two Pie gauges were used. The pie gauge had a length of $50 \mathrm{~mm}$, a resistance of $350 \mathrm{ohms}$ and a sensitivity of $2000 \times 10^{-6} \mathrm{strain} / \mathrm{mm}$. In some panels, electrical strain gauges were used in replacement of the Pie gauges but in both the tension and compression sides of the panel at the mid-span location. Generally, longitudinal flexural strains were recorded in on one specimen from each panel group at the two edges and central point of the mid-span location across the panel width. Linear Variable Displacement Transducers, (LVDT's) of $9.84 \mathrm{~mm}$ electrical stroke was used to measure deflection in all panels at the mid-span location, again at the two panel edges and central point across the panel width. Mechanical Dial gauges having travel sensitivity of $0.01 \mathrm{~mm}$ were used to measure the deflection at the panel edge of mid-span location for backup purpose. Dial gauge reading were manually taken at each increment of loading throughout the test up to certain load increment based on the level of deformation in the panel during testing. Figure 3.9 shows view of the dial gauge and LVDT's installed under the panel at mid-span location. A universal flat load cell of $222 \mathrm{KN}(50,000$ Ibs) capacity was used to measure the jacking loads applied on all the panels. During testing, the data from the LVDT's, strain sensors and load cell were captured by a test control software (TCS) using a SYSTEM 5000 data acquisition unit. The test control software, TCS, is a powerful tool developed specially for acquiring; reducing and analyzing the dynamic analog data captured using the SYSTEM 5000. It simplifies the process for collecting and converting data captured by strain gauges and LVDT's. The TCS was adjusted to sample the data at rate of one reading per second during the loading test. 


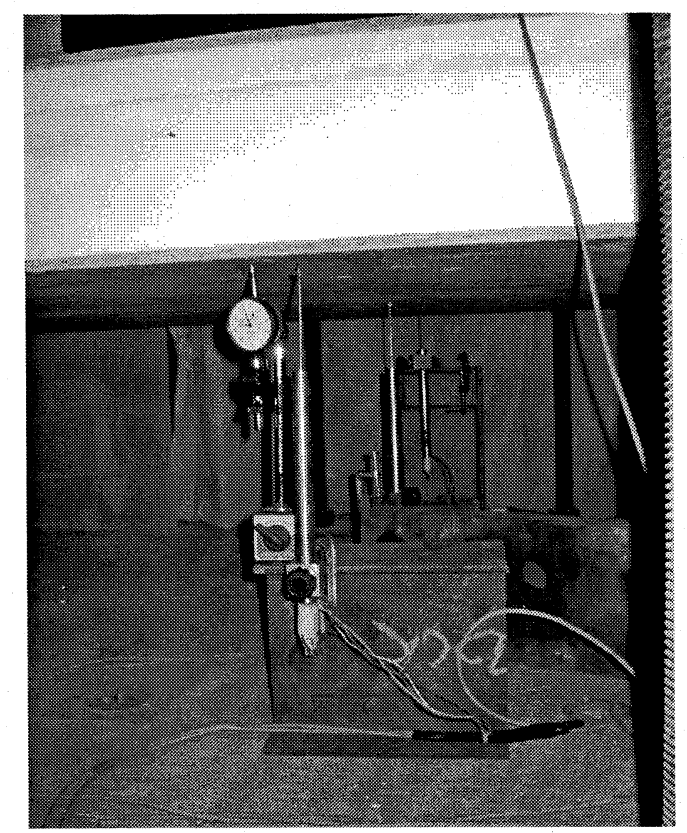

Fig. 3.9 View of dial gauge and LVDT's under the panel

\subsubsection{Flexure Load Test Procedure}

A test set-up was prepared for each test at the structural laboratory of Ryerson University. Both Linear Variable Displacement Transducers (LVDT's) and strain gauges were installed at predetermined locations in the panel to record deflection and normal strains. The available MTS system-5000 data-acquisition system was used to capture reading from sensors. For each panel, jacking load was applied in increments so that readings from dial gauge could be recorded. When significant panel deformation was noticed, the dial gauge was removed and the jacking load continued to be applied till failure. Visual inspection was conducted at each load increment during the test to record any change in structural integrity of the sandwich panel. The test was terminated after specimen failure, based on the type of testing. Test stopped when the jacking load was not increasing while panel deflection was increasing by continuous pressing of the pump handle. Test data were then used to draw the 
load-deflection and load-strain relationships for each panel. Mode of failure of each panel was also recorded.

\subsection{Creep Tests}

Flexure-creep is defined as deflection under constant load over period of time beyond the initial deformation due to the application of the load. ASTM C 480-62, Standard Test Methods of for Flexural Creep of Sandwich Construction, (1988) covers the determination of the creep rate of sandwich panels under constant flexural load. A typical setup for this test consists of a simply-supported panel loaded by concentrated line loads distributed uniformly across the panel width applied at the quarter points as shown in Fig. 3.10. Thus, the SIPs are subjected to one-dimensional flexure thereby minimizing the influence of transverse stiffness on the study results. Specified flexure-creep load is applied and mid-span instantaneous deflection is recorded using dial gauges. Dial gauges readings are then recorded at 10 minutes intervals for the first hour after loading, 30 minutes intervals up to 8 hours, one hour intervals up to 24 hours and then daily readings for the remaining period of testing. After removing the applied loading, mid-span deflection was recorded for 48 hours. The averaged measured mid-span deflection readings can then be used to develop the average deflectiontime history for each tested specimen. Figure 3.11 schematically defines the immediate deflection $\left(\Delta_{0}\right)$ as the deflection at time $\mathrm{t}=0$ immediately after the application of the load. The final deflection $\Delta_{\mathrm{f}}$ is defined as the deflection immediately before the removal of the load at the end of the test period. Figure 3.11 shows the definitions of critical points in deflection-time relationship for a typical creep curve as follows:

$\Delta_{0} \quad=$ immediate deflection after application of full load

$\Delta_{\mathrm{i}} \quad=$ Deflection at time $t_{\mathrm{i}}$ 
$\Delta_{\mathrm{f}} \quad=$ Final deflection before removal of the sustained load

$\Delta_{\mathrm{u}} \quad=$ Deflection immediately after removal of load (unload)

$\Delta_{\mathrm{u} 24}=$ Deflection 24hours after removal of load

$\Delta_{\mathrm{u} 48}=$ Deflection 48 hours after removal of load

In this thesis, flexure-creep tests were conducted on the three panels, namely S-43, S44 and S-45. Dimensions of these panels are listed in Table 3.2. The test apparatus consisted of simply-supported panel uniformly loaded cement pages.

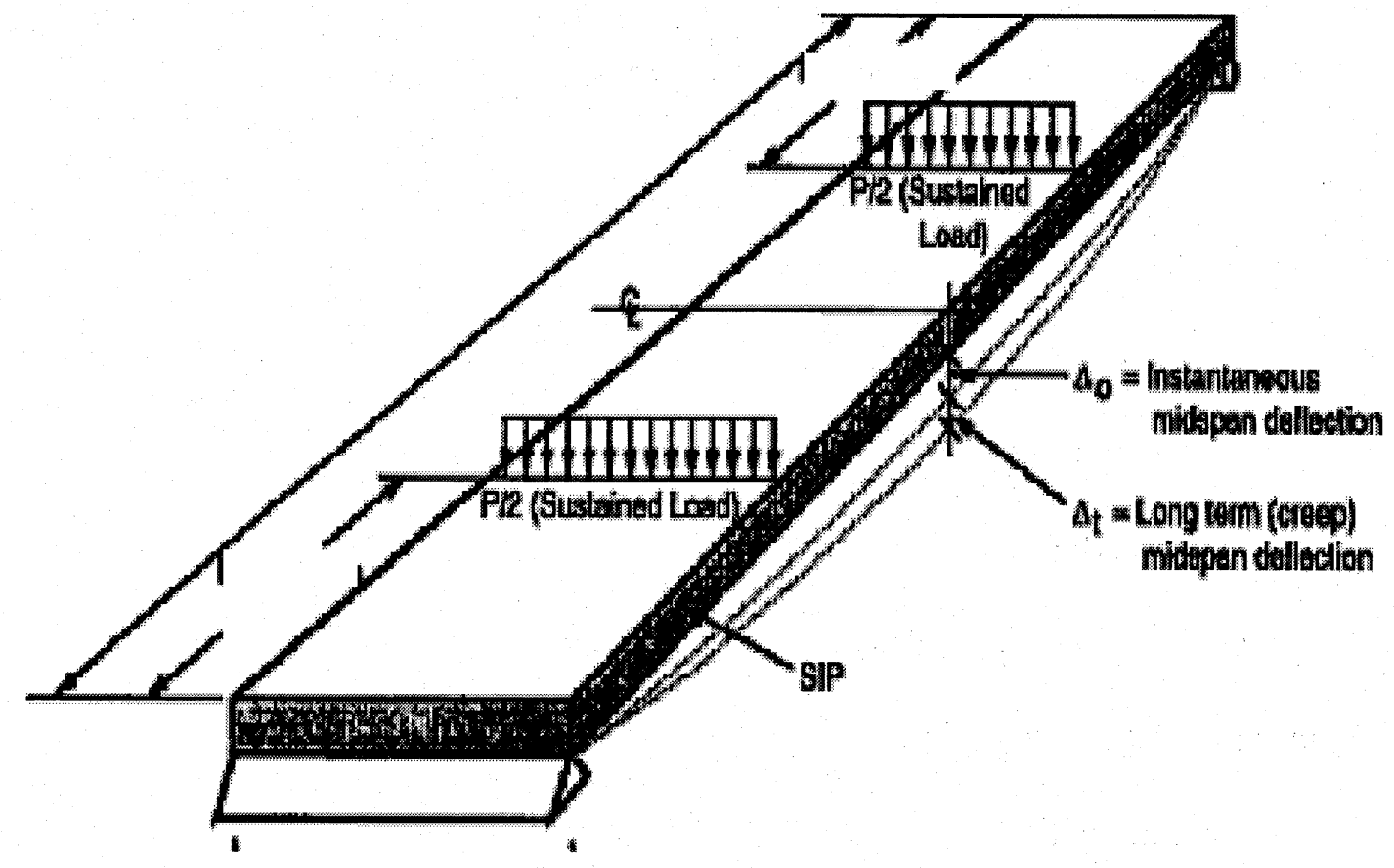

Fig. 3.10 Schematic Diagram for flexure-creep test setup 


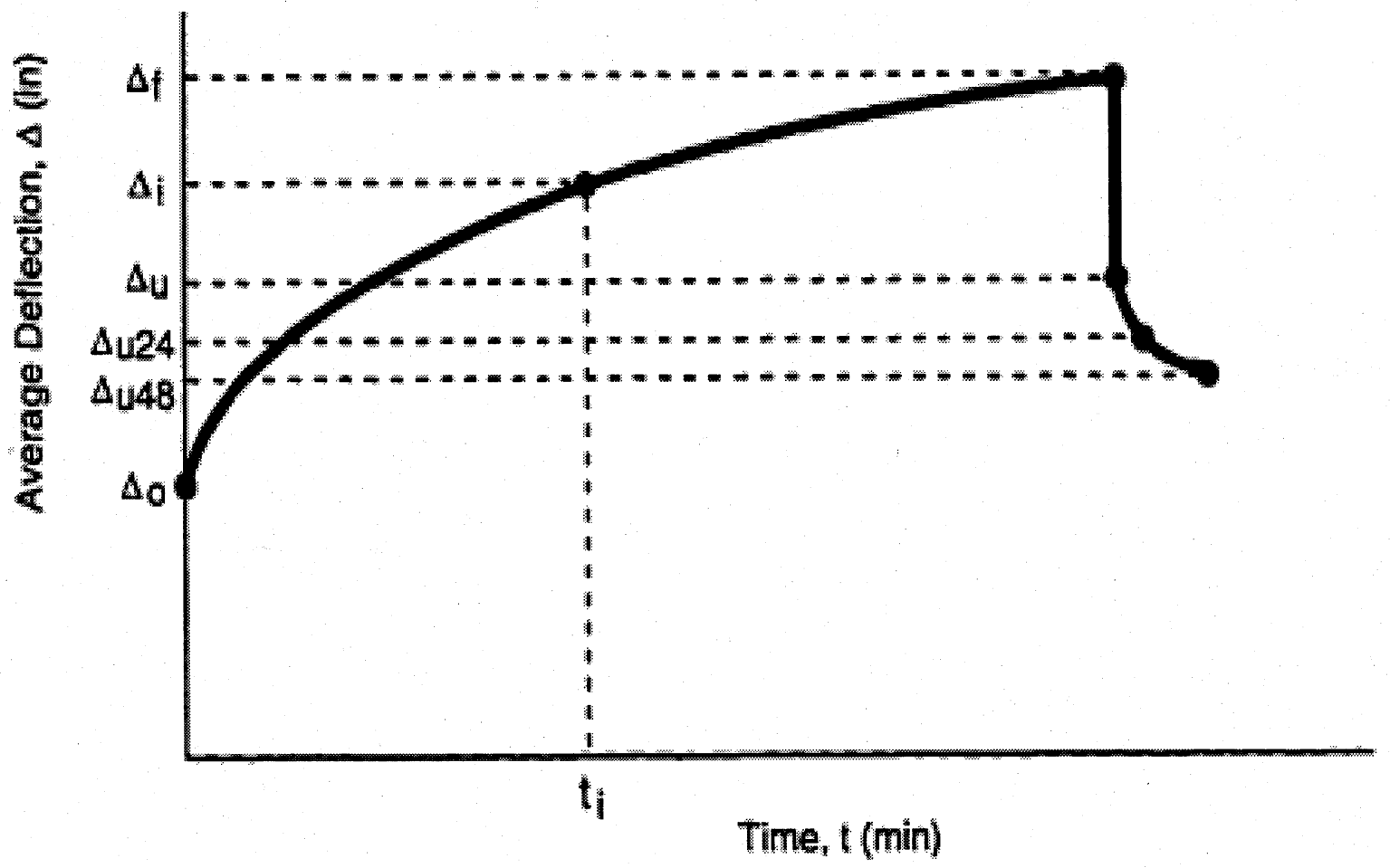

Fig. 3.11 Typical deflection-time history for creep test 


\section{CHAPTER IV \\ EXPERIMENTAL RESULTS}

\subsection{General}

Experimental testing to-collapse on 53 actual-size timber panels according to ASTM standards were performed to determine their structural behavior at service and ultimate load levels. Discussion of the experimental results with respect to the structural adequacy of the tested sandwich panels for possible use in residential construction was presented at the end of the chapter, with emphasis on code requirements for ultimate and serviceability limit states design of such panels. The experimental results for all panels are listed in sequence is Appendix A. However, selected results are included in this chapter for discussion regarding structural performance of each panel group.

\subsection{Code Requirements for the Structural Qualification of the SIPs}

The Structural qualifications of the SIPs as specified in NRC/CCMC Technical Guide focuses on them as being "as good as" the structural capacity of conventional wood-frame buildings. As such the general design principles provided in CSA Standard CAN/CSAO86.1, Engineering Design of Wood, are used to assess the structural adequacy of the panels. Based on CSA Standard CAN/CSA-S406-92, Construction of Preserved Wood Foundations, (1992) and the National Building Code of Canada (NBCC 2005), the following load and load factors are used to examine the structural adequacy of the panels as serviceability and ultimate limit states design.

Dead load for roofs $=0.5 \mathrm{kPa}$

Dead load for floors $=0.47 \mathrm{kPa}$ 
Live load for residential construction $=1.9 \mathrm{kPa}$

Snow load for residential construction $=1.9 \mathrm{kPa}$ (for simplification of comparison)

Dead load factor $\quad=1.25$

Live load factor $\quad=1.50$

Deflection limit for serviceability $=\operatorname{span} / 360$

The deflection limit of $\operatorname{span} / 360$ is intended to limit floor vibration and to avoid damage to structural elements or attached nonstructural elements. This condition may be waived in case of industrial buildings, with span/180 as live load deflection limit when no roof ceiling is provided and with span/240 when ceilings other than plaster or gypsum are used (NBCC Part 9, 2005).

The Acceptance criteria for SIPs set forth in ICC-ES AC04 (2004) includes testing three identical panels from each panel size. The average deflection and ultimate load carrying capacity of this panel size will be basically the average of those for the three panels. However, AC04 specifies that when the results of each tested panel vary more than $15 \%$ from the average of the three panels, either the lowest test value is used or the average result based on a minimum of five tests may be used regardless of the variations. The results from two tests may be used when the higher value does not exceed the lower value by more than $5 \%$ and the lower value is used with the required factors of safety.

Factor of safety for ultimate load carrying capacity of SIPs is dependant on the consistency of materials, the range of test results and the load deformation characteristics of the panel. AC04 generally applies a factor of safety of 3 to the ultimate load based on the 
average of three tests. However, AC04 provides the following factors of safety applicable to uniform transverse loads, when is the case of the tested panels in this research.

F.S. $\quad=2$ for ultimate load determined by bending (facing buckling) failure for allowable live loads up to $958 \mathrm{~Pa}$ (20 Psf).

F.S. $=2.5$ for ultimate load determined by bending (facing buckling) failure for allowable snow loads.

F.S. $=2.5$ for ultimate reaction at failure for all loading conditions

F.S. $=3.0$ for ultimate load at shear failure for all loading conditions.

\subsection{Group A}

In this group, three identical panels were tested to complete collapse. Each panel was of $165 \mathrm{~mm}$ thickness, $1.2 \mathrm{~mm}$ width and $2.43 \mathrm{~m}$ length, with foam-spline connection. Figure 4.1 shows view of panel S-1 before testing, while Fig. 4.2 shows view of the permanent deformed shape of the panel after failure. It was observed that the failure mode of the panel was due to horizontal shear failure between the top surface of the foam and the adhesive over a panel length between the support and the quarter-point line, causing delamination (debonding) between the top foam-OSB interface and the foam core over the support. Figure 4.3 shows close-up view of this type of failure. It should be noted that noise was heard when approaching failure load and the shear failure was abrupt causing a sudden drop in the applied jacking load as depicted in the load-deflection history shown in Figure 4.4. Similar failure mode was observed in panels S-2 and S-3.

Figure 4.4 depicts the jacking load-deflection history of panel S-1. The can be observed that the LVDT readings at the two edges and central point of the panel at mid-span 
location are very close and correlate well with the dial gauge readings. The design dead load, live load, the sum of dead and live load, and the factored dead and live load values are plotted in the figure to get the sense of the structural adequacy of the panel. It can be observed that linear elastic behavior was maintained at the live load level (i.e. serviceability limit state) and even at the design factored load level (i.e. ultimate limit state). Similar graphs were produced for panels S-2 and S-3 of the same group and presented in Table 4.1 below. Table 4.1 shows the deflection values for the three panels, S-1, S-2 and S-3, at the design live load level. These values were normalized to the span length and then averaged to be span/848 which is far below the deflection limit of $\operatorname{span} / 360$. It should be noted that the panel span length considered herein is the panel length of $2.43 \mathrm{~m}$ minus $76 \mathrm{~mm}$ (3") from each side of the support, which is typical in all panels. It can be observed herein that the deflection of each panel at the live load live is within $15 \%$ difference with the average deflection of the three panels.

Table 4.2 presents a summary of panel configurations along with the ultimate jacking load, failure mode and the average ratio of the ultimate jacking load to the factored design load $(1.25 \mathrm{D}+1.5 \mathrm{~L})$. It can be observed that the ultimate jacking load was $40.24,36.74$ and $34.47 \mathrm{kN}$ for panels $\mathrm{S}-1, \mathrm{~S}-2$ and $\mathrm{S}-3$, respectively. It can be observed that the average ratio of the ultimate jacking load to the design factored load is 3.83 for panel group A, which is more than the allowable factor of safety of 3 for shear failure. It should be noted that this ration was calculated using the jacking load rather without including the weight of the loading system of $2 \mathrm{kN}$. This makes the ratio 4.04 . This means that all actual factor of safety is more than the ratio provided in Table 4.2. It is worth mentioning that the ultimate jacking load for each panel is within $15 \%$ difference with the average jacking load of the three 
panels. Since the panel group A meets both the serviceability and ultimate limit states requirements, it can be considered qualified to be as good as the conventional frame building in Part 4 and Part 9 of NBCC of 2005.

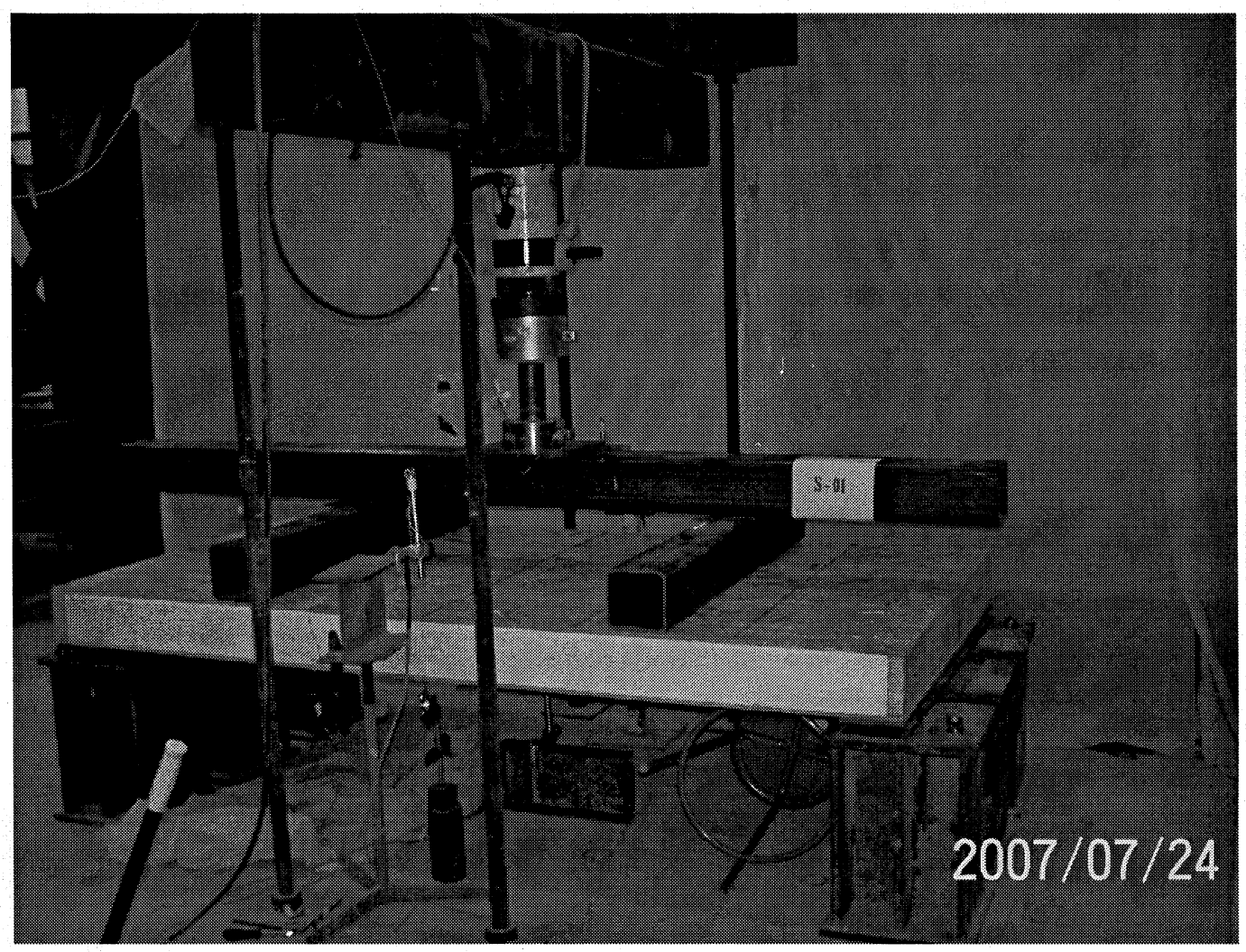

Figure 4.1 View of Specimen S-1 before testing 


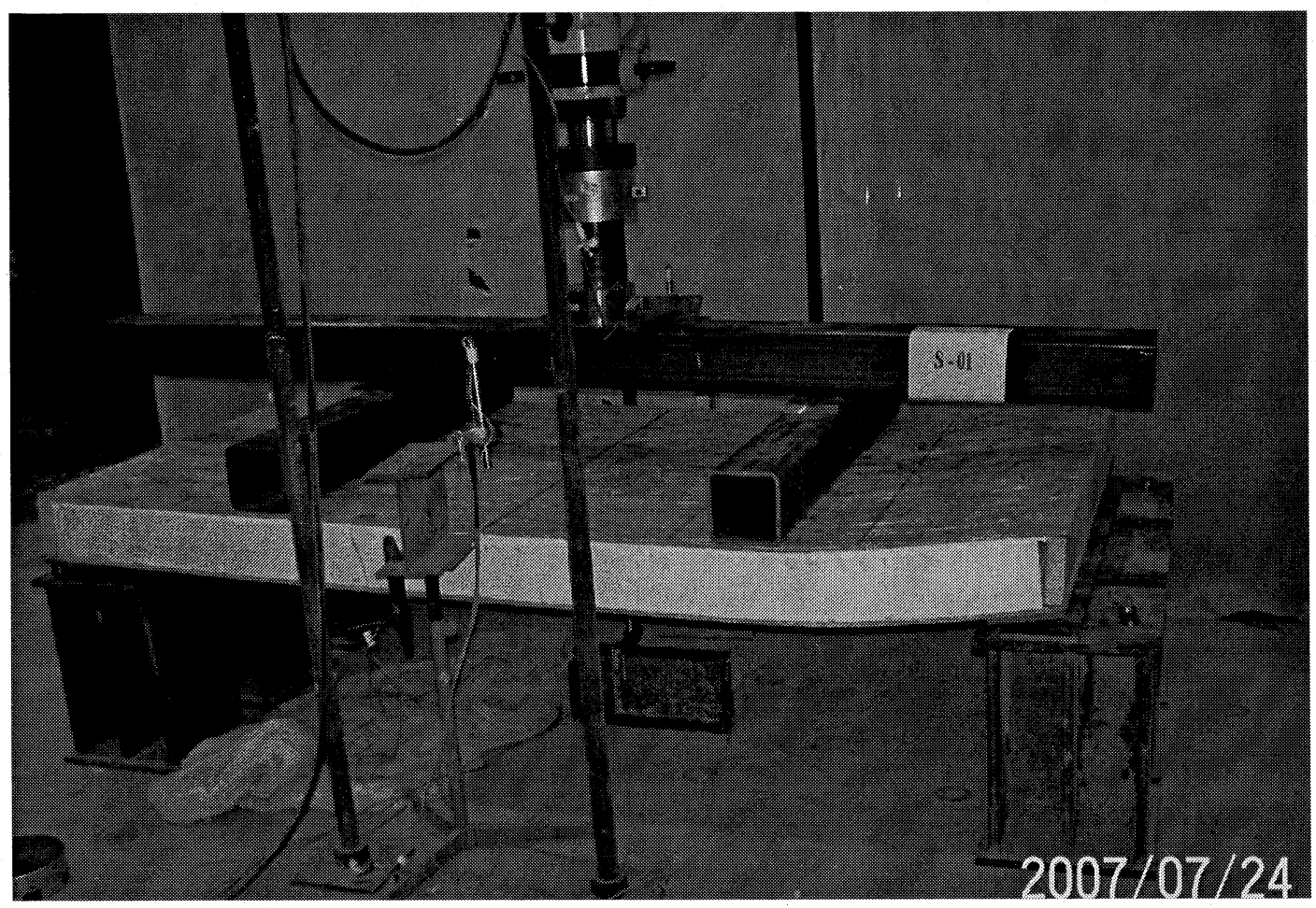

Figure 4.2 View of specimen S-1 after failure

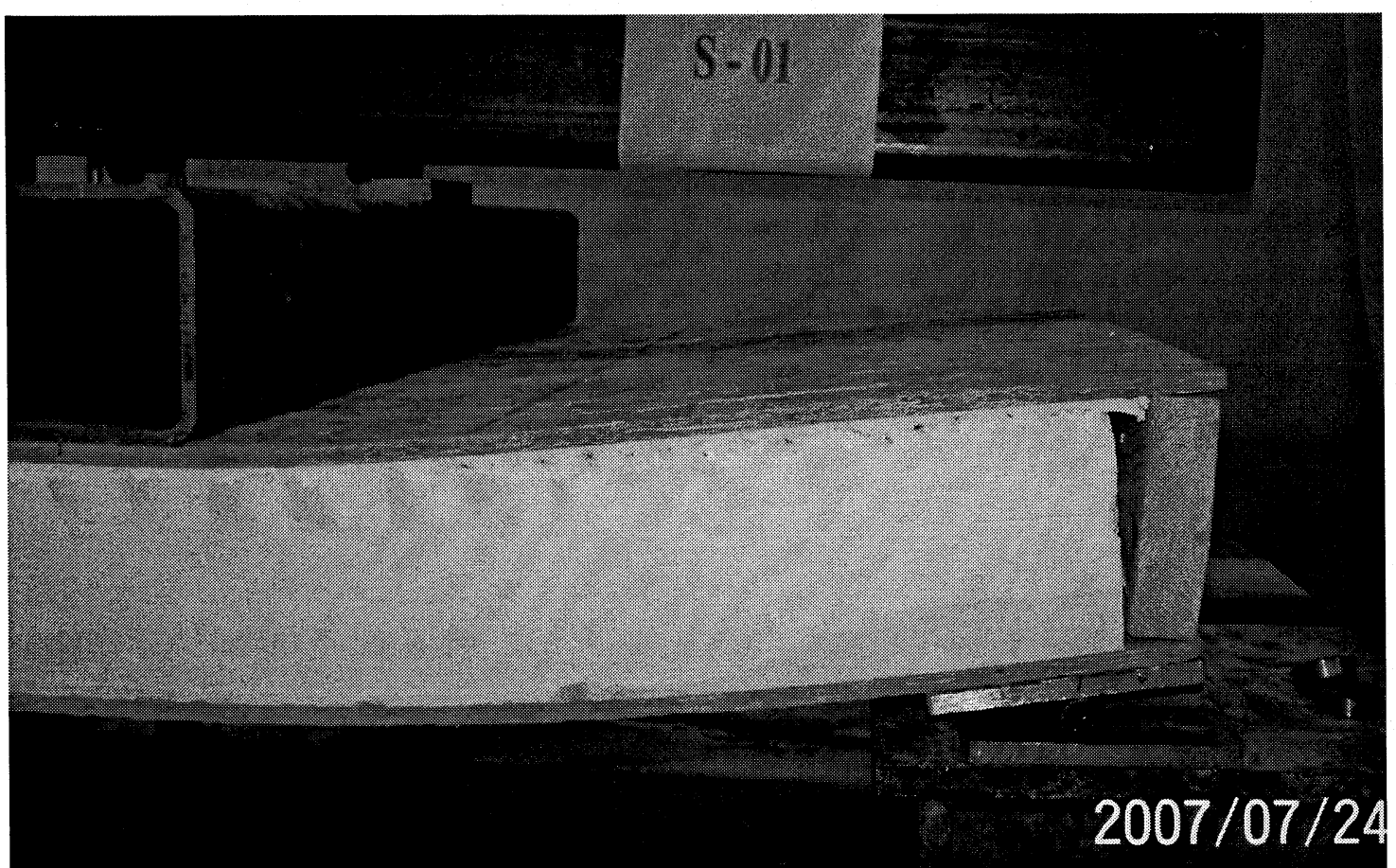

Figure 4.3 Close-up view of the failure pattern from one side of specimen S-1 


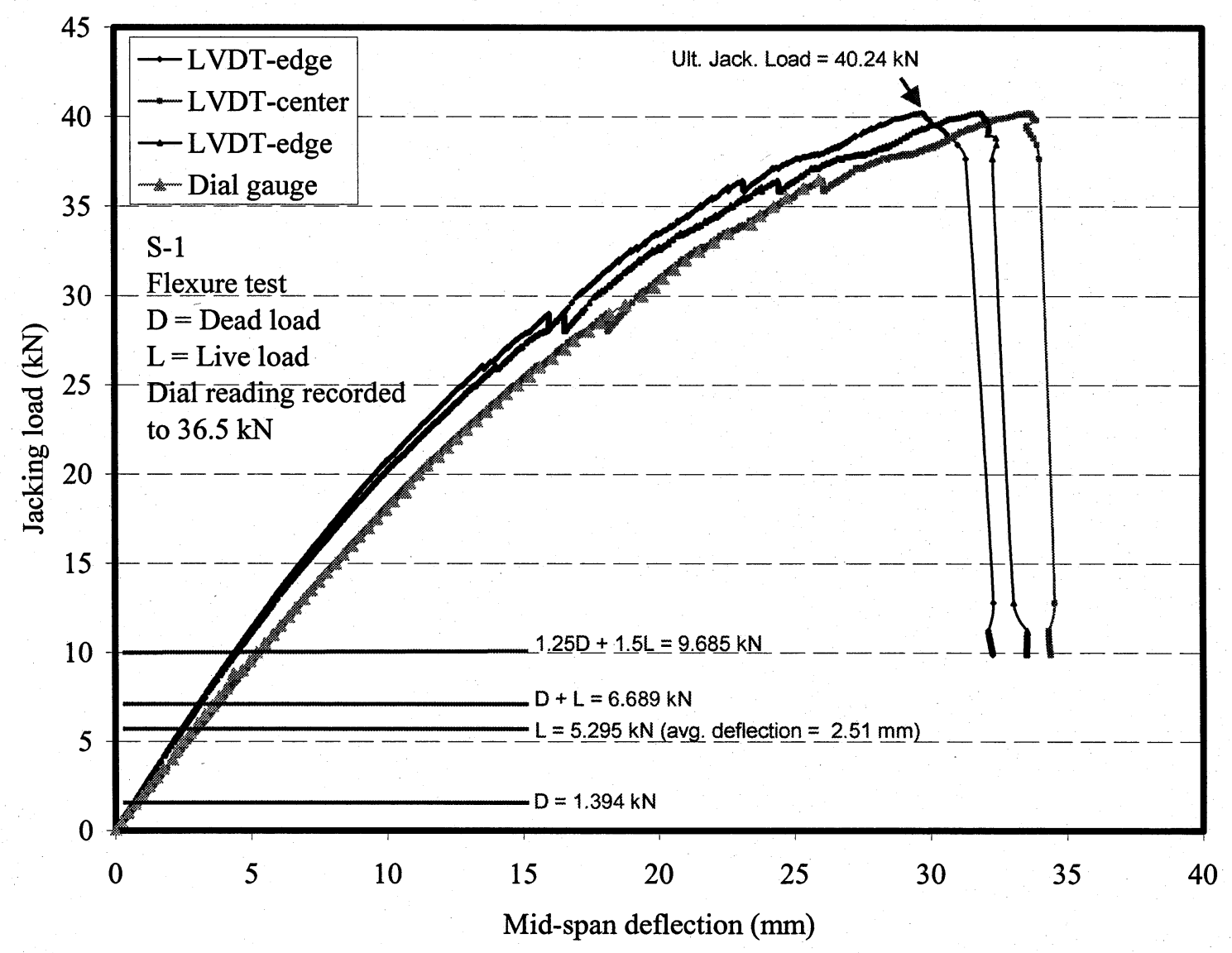

Figure 4.4 Load-deflection relationship for specimen S-1 
Table 4.1 Summary of results for Serviceability

\begin{tabular}{|c|c|c|c|c|c|c|c|}
\hline $\begin{array}{l}\text { Test } \\
\text { Symbol }\end{array}$ & $\begin{array}{l}\text { Panel size } \\
\mathrm{L} \times \mathrm{W} \times \mathrm{Th} . \\
(\mathrm{ft}, \mathrm{ft}, \text { inch) }\end{array}$ & $\begin{array}{l}\text { Panel } \\
\text { connection } \\
\text { detail }\end{array}$ & $\begin{array}{l}\text { Experime- } \\
\text { ntal live } \\
\text { load } \\
\text { deflection } \\
(\mathrm{mm})\end{array}$ & $\begin{array}{l}\text { Ratio of } \\
\text { exp. live } \\
\text { load } \\
\text { deflection } \\
\text { to panel } \\
\text { span }\end{array}$ & $\begin{array}{l}\text { Average } \\
\text { exp. live } \\
\text { load } \\
\text { deflection- } \\
\text { to-panel } \\
\text { span ratio } \\
\end{array}$ & $\begin{array}{l}\text { Live load } \\
\text { deflection } \\
\text { limit }\end{array}$ & Notes \\
\hline S-1 & $4 \times 8 \times 6 \frac{1 / 2 "}{}$ & Foam-spline & 2.51 & $1 / 911$ & \multirow[t]{3}{*}{$1 / 848$} & \multirow[t]{3}{*}{$1 / 360$} & \multirow{3}{*}{$\begin{array}{l}\text { Test } \\
\text { passed }\end{array}$} \\
\hline S-2 & $4 \times 8 \times 6 \frac{1 / 2 "}{}$ & Foam-spline & 2.88 & $1 / 794$ & & & \\
\hline S-3 & $4 \times 8 \times 6 \frac{1}{1 / 2}$ & Foam-spline & 2.70 & $1 / 847$ & & & \\
\hline S-4 & $4 \times 10 \times 61 / 2 "$ & Foam-spline & 4.90 & $1 / 591$ & \multirow[t]{4}{*}{$1 / 583$} & \multirow[t]{4}{*}{$1 / 360$} & \multirow{4}{*}{$\begin{array}{l}\text { Test } \\
\text { passed }\end{array}$} \\
\hline S-5 & $\left.4 \times 10 \times 6 \frac{1}{2}\right)^{\prime \prime}$ & Foam-spline & 4.70 & $1 / 616$ & & & \\
\hline S-6 & $4 \times 10 \times 61 / 2 "$ & Regular P. & 5.43 & $1 / 533$ & & & \\
\hline $\mathrm{S}-43$ & $4 \times 10 \times 6 \frac{1}{2} "$ & Foam-spline & 4.85 & $1 / 597$ & & & \\
\hline S-7 & $4 \times 12 \times 6 \frac{1}{2} "$ & Lumber-spline & 7.43 & $1 / 472$ & \multirow[t]{4}{*}{$1 / 472$} & \multirow[t]{4}{*}{$1 / 360$} & \multirow{4}{*}{$\begin{array}{l}\text { Test } \\
\text { passed }\end{array}$} \\
\hline S-8 & $4 \times 12 \times 61 / 2 "$ & Lumber-spline & 7.17 & $1 / 489$ & & & \\
\hline S-9 & $4 \times 12 \times 61 / 2 "$ & Lumber-spline & 7.65 & $1 / 458$ & & & \\
\hline S-12 & $4 \times 12 \times 61 / 2 "$ & Regular panel & 9.26 & $1 / 379$ & & & \\
\hline $\mathrm{S}-10$ & $4 \times 12 \times 61 / 2 "$ & Foam-spline & 9.52 & $1 / 368$ & \multirow[t]{4}{*}{$1 / 362$} & \multirow[t]{4}{*}{$1 / 360$} & \multirow{4}{*}{$\begin{array}{l}\text { Test } \\
\text { passed }\end{array}$} \\
\hline S-11 & $4 \times 12 \times 61 / 2 "$ & Foam-spline & 10.76 & $1 / 326$ & & & \\
\hline $\mathrm{S}-12$ & $4 \times 12 \times 61 / 2 "$ & Regular P. & 9.26 & $1 / 379$ & & & \\
\hline S-44 & $4 \times 12 \times 61 / 2 "$ & Foam-spline & 8.73 & $1 / 401$ & & & \\
\hline S-13 & $4 \times 10 \times 81 / 4 "$ & Foam-spline & 4.10 & $1 / 706$ & \multirow[t]{4}{*}{$1 / 739$} & \multirow[t]{4}{*}{$1 / 360$} & \multirow{4}{*}{$\begin{array}{l}\text { Test } \\
\text { passed }\end{array}$} \\
\hline S-14 & $4 \times 10 \times 81 / 4 "$ & Foam-spline & 3.75 & $1 / 772$ & & & \\
\hline S-15 & $4 \times 10 \times 8 \frac{1 / 4 "}{}$ & Foam-spline & 3.91 & $1 / 741$ & & & \\
\hline S-15-1 & $4 \times 10 \times 81 / 4 "$ & Foam-spline & 3.94 & $1 / 735$ & & & \\
\hline S-16 & $4 \times 12 \times 81 / 4 "$ & Foam-spline & 5.57 & $1 / 629$ & \multirow{5}{*}{$\begin{array}{l}1 / 582 \\
\text { (without } \\
\text { the } \\
\text { regular } \\
\text { panel) }\end{array}$} & \multirow[t]{5}{*}{$1 / 360$} & \multirow{5}{*}{$\begin{array}{l}\text { Test } \\
\text { passed }\end{array}$} \\
\hline S-16-1 & $4 \times 12 \times 81 / 4 "$ & Foam-spline & 6.94 & $1 / 505$ & & & \\
\hline S-17 & $4 \times 12 \times 81 / 4 "$ & Foam-spline & 5.97 & $1 / 587$ & & & \\
\hline S-18 & $4 \times 12 \times 81 / 4 "$ & Foam-spline & 6.54 & $1 / 536$ & & & \\
\hline S-19 & $4 \times 12 \times 81 / 4 "$ & Regular P. & 5.26 & $1 / 666$ & & & \\
\hline S-19 & $4 \times 12 \times 81 / 4 "$ & Regular P. & 5.26 & $1 / 666$ & \multirow{4}{*}{$\begin{array}{l}1 / 690 \\
\text { (without } \\
\text { regular } \\
\text { panel) }\end{array}$} & \multirow[t]{4}{*}{$1 / 360$} & \multirow{4}{*}{$\begin{array}{l}\text { Test } \\
\text { passed }\end{array}$} \\
\hline S-20 & $4 \times 12 \times 81 / 4^{\prime \prime}$ & Lumber-spline & 5.39 & $1 / 650$ & & & \\
\hline S-21 & $4 \times 12 \times 81 / 4 "$ & Lumber-spline & 5.31 & $1 / 660$ & & & \\
\hline S-21-1 & $4 \times 12 \times 81 / 4 "$ & Lumber-spline & 4.54 & $1 / 772$ & & & \\
\hline S-22 & $4 \times 14 \times 81 / 4^{\prime \prime}$ & Foam-spline & 12.03 & $1 / 345$ & \multirow[t]{3}{*}{$1 / 366$} & \multirow[t]{3}{*}{$1 / 360$} & \multirow{3}{*}{$\begin{array}{l}\text { Test } \\
\text { passed }\end{array}$} \\
\hline S-23 & $4 \times 14 \times 81 / 4^{\prime \prime}$ & Foam-spline & 11.11 & $1 / 370$ & & & \\
\hline S-24 & $4 \times 14 \times 81 / 4^{\prime \prime}$ & Foam-spline & 11.20 & $1 / 367$ & & & \\
\hline S-25 & $4 \times 14 \times 81 / 4^{\prime \prime}$ & Lumber-spline & 8.69 & $1 / 476$ & $1 / 464$ & $1 / 360$ & Test \\
\hline S-26 & $4 \times 14 \times 81 / 4$ & Lumber-spline & 8.23 & $1 / 500$ & & & passed \\
\hline S-27 & $4 \times 14 \times 81 / 4^{\prime \prime}$ & Lumber-spline & 9.70 & $1 / 424$ & & & \\
\hline S-28 & $4 \times 12 \times 10^{1 / 4^{\prime}}$ & Foam-spline & 4.65 & $1 / 754$ & $1 / 732$ & $1 / 360$ & Test \\
\hline S-29 & $4 \times 12 \times 10^{1 / 4}$ & Foam-spline & 5.04 & $1 / 695$ & & & passed \\
\hline $\mathrm{S}-30$ & $4 \times 12 \times 10^{1 / 4^{\prime}}$ & Foam-spline & 4.97 & $1 / 751$ & & & \\
\hline S-31 & $4 \times 14 \times 101 / 4 "$ & Foam-spline & 8.75 & $1 / 470$ & $1 / 491$ & $1 / 360$ & Test \\
\hline $\mathrm{S}-32$ & $4 \times 14 \times 10^{1 / 4 "}$ & Foam-spline & 8.25 & $1 / 499$ & (without & & passed \\
\hline $\mathrm{S}-33$ & $4 \times 14 \times 10^{1 / 4 "}$ & Foam-spline & 8.13 & $1 / 506$ & regular & & \\
\hline $\mathrm{S}-45$ & $4 \times 14 \times 10^{1 / 4 "}$ & Regular P. & 6.85 & $1 / 601$ & panel) & & \\
\hline
\end{tabular}




\begin{tabular}{|c|c|c|c|c|c|c|c|}
\hline S-34 & $4 \times 14 \times 101 / 4 "$ & Lumber-spline & 5.24 & $1 / 785$ & \multirow{4}{*}{$\begin{array}{l}1 / 753 \\
\text { (without } \\
\text { the plain } \\
\text { panel) }\end{array}$} & \multirow[t]{4}{*}{$1 / 360$} & \multirow{4}{*}{$\begin{array}{l}\text { Test } \\
\text { passed }\end{array}$} \\
\hline S-35 & $4 \times 14 \times 101 / 4 "$ & Lumber-spline & 5.51 & $1 / 747$ & & & \\
\hline S-36 & $4 \times 14 \times 101 / 4 "$ & Lumber-spline & 5.65 & $1 / 728$ & & & \\
\hline $\mathrm{S}-45$ & $4 \times 14 \times 101 / 4 "$ & Regular P. & 6.85 & $1 / 601$ & & & \\
\hline S-37 & $4 \times 16 \times 101 / 4 "$ & Foam-spline & 12.01 & $1 / 393$ & \multirow[t]{3}{*}{$1 / 422$} & \multirow[t]{3}{*}{$1 / 360$} & \multirow{3}{*}{$\begin{array}{l}\text { Test } \\
\text { passed }\end{array}$} \\
\hline S-38 & $4 \times 16 \times 101 / 4 "$ & Foam-spline & 10.97 & $1 / 431$ & & & \\
\hline S-39 & $4 \times 16 \times 101 / 4 "$ & Foam-spline & 10.56 & $1 / 447$ & & & \\
\hline $\mathrm{S}-40$ & $4 \times 16 \times 10^{1 / 4 "}$ & Lumber-spline & 8.29 & $1 / 570$ & \multirow[t]{3}{*}{$1 / 565$} & \multirow[t]{3}{*}{$1 / 360$} & \multirow{3}{*}{$\begin{array}{l}\text { Test } \\
\text { passed }\end{array}$} \\
\hline $\mathrm{S}-41$ & $4 \times 16 \times 10^{1 / 4 "}$ & Lumber-spline & 8.40 & $1 / 562$ & & & \\
\hline $\mathrm{S}-42$ & $4 \times 16 \times 101 / 4 "$ & Lumber-spline & 8.41 & $1 / 562$ & & & \\
\hline $\mathrm{S}-46$ & $4 \times 8 \times 6 \frac{1 / 2 "}{}$ & $\begin{array}{l}\text { Tongue and } \\
\text { groove link }\end{array}$ & 2.45 & $1 / 933$ & \multirow[b]{2}{*}{$1 / 962$} & \multirow[b]{2}{*}{$1 / 360$} & \multirow[t]{2}{*}{$\begin{array}{l}\text { Test } \\
\text { passed }\end{array}$} \\
\hline S-47 & $4 \times 8 \times 81 / 4 "$ & $\begin{array}{l}\text { Tongue and } \\
\text { groove link }\end{array}$ & 2.30 & $1 / 994$ & & & \\
\hline
\end{tabular}

Table 4.2 Summary of results for Strength

\begin{tabular}{|c|c|c|c|c|c|c|c|c|}
\hline Group & & $\begin{array}{l}\text { Panel size } \\
\mathrm{L} \times \mathrm{W} \times \text { th. }\end{array}$ & $\begin{array}{l}\text { Panel } \\
\text { connect- } \\
\text { ion } \\
\text { detail }\end{array}$ & $\begin{array}{l}\text { Ultimate } \\
\text { Jacking } \\
\text { load } \\
(\mathrm{kN})\end{array}$ & $\begin{array}{l}\text { Ratio of } \\
\text { ultimate } \\
\text { jacking } \\
\text { load to } \\
\text { factored } \\
\text { design } \\
\text { loads }\end{array}$ & $\begin{array}{l}\text { Average } \\
\text { ratio of } \\
\text { ult. Jack. } \\
\text { load to } \\
\text { factored } \\
\text { design } \\
\text { loads }\end{array}$ & Failure mode & Notes \\
\hline \multirow{3}{*}{ A } & S-1 & $4 \times 8 \times 6 \frac{1}{1 / 2 "}$ & $\begin{array}{l}\text { Foam- } \\
\text { spline }\end{array}$ & 40.24 & 4.15 & \multirow{3}{*}{3.83} & $\begin{array}{l}\text { Foam horizontal } \\
\text { shear }\end{array}$ & \multirow{3}{*}{$\begin{array}{l}\text { Test } \\
\text { passed }\end{array}$} \\
\hline & S-2 & $4 \times 8 \times 61 / 2 "$ & $\begin{array}{l}\text { Foam- } \\
\text { spline }\end{array}$ & 36.74 & 3.79 & & $\begin{array}{l}\text { Foam horizontal } \\
\text { shear }\end{array}$ & \\
\hline & S-3 & $4 \times 8 \times 6 \frac{1 / 2 "}{2}$ & $\begin{array}{l}\text { Foam- } \\
\text { spline }\end{array}$ & 34.47 & 3.56 & & $\begin{array}{l}\text { Foam horizontal } \\
\text { shear }\end{array}$ & \\
\hline \multirow{4}{*}{ B } & S-4 & $4 \times 10 \times 6 \frac{1}{1} 2 "$ & $\begin{array}{l}\text { Foam- } \\
\text { spline }\end{array}$ & 37.98 & 3.10 & \multirow{4}{*}{$\begin{array}{l}3.06 \\
\text { (without } \\
\text { regular } \\
\text { panel) }\end{array}$} & $\begin{array}{l}\text { Foam horizontal } \\
\text { shear }\end{array}$ & \multirow{4}{*}{$\begin{array}{l}\text { Test } \\
\text { passed }\end{array}$} \\
\hline & S-5 & $4 \times 10 \times 6 \frac{1}{1} 2^{\prime \prime}$ & $\begin{array}{l}\text { Foam- } \\
\text { spline }\end{array}$ & 39.48 & 3.20 & & $\begin{array}{l}\text { Foam horizontal } \\
\text { shear }\end{array}$ & \\
\hline & S-6 & $4 \times 10 \times 61 / 2 "$ & $\begin{array}{l}\text { Regular } \\
\text { panel }\end{array}$ & 40.92 & 3.34 & & $\begin{array}{l}\text { Foam horizontal } \\
\text { shear, combined } \\
\text { with diagonal shear } \\
\text { crack }\end{array}$ & \\
\hline & $\mathrm{S}-43$ & $4 \times 10 \times 6 \frac{1}{1} 2^{\prime \prime}$ & $\begin{array}{l}\text { Foam- } \\
\text { spline }\end{array}$ & 35.35 & 2.88 & & $\begin{array}{l}\text { Foam horizontal } \\
\text { shear }\end{array}$ & \\
\hline \multirow{4}{*}{$\mathrm{C}$} & S-7 & $4 \times 12 \times 6 \quad 1 / 2 "$ & $\begin{array}{l}\text { Lumber- } \\
\text { spline }\end{array}$ & 47.86 & 3.22 & \multirow{4}{*}{$\begin{array}{l}3.24 \\
\text { (without } \\
\text { regular } \\
\text { panel) }\end{array}$} & $\begin{array}{l}\text { Foam horizontal } \\
\text { shear, combined } \\
\text { with diagonal shear } \\
\text { crack }\end{array}$ & \multirow{4}{*}{$\begin{array}{l}\text { Test } \\
\text { passed }\end{array}$} \\
\hline & S-8 & $4 \times 12 \times 61 / 2 "$ & $\begin{array}{l}\text { Lumber- } \\
\text { spline }\end{array}$ & 52.66 & 3.55 & & $\begin{array}{l}\text { Foam horizontal } \\
\text { shear }\end{array}$ & \\
\hline & S-9 & $4 \times 12 \times 61 / 2 "$ & $\begin{array}{l}\text { Lumber- } \\
\text { spline }\end{array}$ & 43.72 & 2.94 & & $\begin{array}{l}\text { Foam horizontal } \\
\text { shear, combined } \\
\text { with diagonal shear } \\
\text { crack }\end{array}$ & \\
\hline & S-12 & $4 \times 12 \times 61 / 2 "$ & Regular & 35.07 & 2.35 & & Foam horizontal & \\
\hline
\end{tabular}




\begin{tabular}{|c|c|c|c|c|c|c|c|c|}
\hline & & & panel & & & & $\begin{array}{l}\text { shear, combined } \\
\text { with diagonal shear } \\
\text { crack }\end{array}$ & \\
\hline \multirow{4}{*}{$\mathrm{D}$} & S-10 & $4 \times 12 \times 6 \frac{1}{1} 2 "$ & $\begin{array}{l}\text { Foam- } \\
\text { spline }\end{array}$ & 34.88 & 2.35 & \multirow[t]{4}{*}{2.24} & $\begin{array}{l}\text { Foam horizontal } \\
\text { shear, combined } \\
\text { with diagonal shear } \\
\text { crack }\end{array}$ & \multirow[t]{4}{*}{$\begin{array}{l}\text { Test } \\
\text { did not } \\
\text { passed }\end{array}$} \\
\hline & S-11 & $4 \times 12 \times 6 \frac{1}{2} "$ & $\begin{array}{l}\text { Foam- } \\
\text { spline }\end{array}$ & 30.53 & 2.06 & & $\begin{array}{l}\text { Foam horizontal } \\
\text { shear }\end{array}$ & \\
\hline & S-12 & $4 \times 12 \times 61 / 2 "$ & $\begin{array}{l}\text { Regular } \\
\text { panel }\end{array}$ & 35.07 & 2.35 & & $\begin{array}{l}\text { Foam horizontal } \\
\text { shear, combined } \\
\text { with diagonal shear } \\
\text { crack }\end{array}$ & \\
\hline & S-44 & $4 \times 12 \times 61 / 2 "$ & $\begin{array}{l}\text { Foam- } \\
\text { spline }\end{array}$ & 34.27 & 2.31 & & $\begin{array}{l}\text { Unsymmetrical } \\
\text { (horizontal shear in } \\
\text { one free edge and } \\
\text { combined diagonal } \\
\text { and horizontal } \\
\text { shear at the other } \\
\text { free edge }\end{array}$ & \\
\hline \multirow{4}{*}{$\mathrm{E}$} & S-13 & $4 \times 10 \times 8 \frac{1 / 4}{4}$ & $\begin{array}{l}\text { Foam- } \\
\text { spline }\end{array}$ & 41.81 & 3.40 & \multirow[t]{4}{*}{3.26} & $\begin{array}{l}\text { Foam horizontal } \\
\text { shear }\end{array}$ & \multirow{4}{*}{$\begin{array}{l}\text { Differ } \\
\text { ence } \\
\text { to the } \\
\text { averag } \\
\text { e is } \\
23.5 \%\end{array}$} \\
\hline & S-14 & $4 \times 10 \times 81 / 4 "$ & $\begin{array}{l}\text { Foam- } \\
\text { spline }\end{array}$ & 43.96 & 3.58 & & $\begin{array}{l}\text { Foam horizontal } \\
\text { shear }\end{array}$ & \\
\hline & S-15 & $4 \times 10 \times 81 / 4 "$ & $\begin{array}{l}\text { Foam- } \\
\text { spline }\end{array}$ & 31.69 & 2.58 & & $\begin{array}{l}\text { Foam diagonal } \\
\text { shear crack over } \\
\text { the support }\end{array}$ & \\
\hline & $\begin{array}{l}\text { S- } \\
15-1\end{array}$ & $4 \times 10 \times 81 / 4 "$ & $\begin{array}{l}\text { Foam- } \\
\text { spline }\end{array}$ & 42.57 & 3.47 & & $\begin{array}{l}\text { Foam horizontal } \\
\text { shear }\end{array}$ & \\
\hline \multirow{5}{*}{$\mathrm{F}$} & S-16 & $4 \times 12 \times 81 / 4 "$ & $\begin{array}{l}\text { Foam- } \\
\text { spline }\end{array}$ & 47.89 & 3.22 & \multirow{5}{*}{$\begin{array}{l}2.71 \\
\text { (without } \\
\text { regular } \\
\text { panel) }\end{array}$} & $\begin{array}{l}\text { Foam horizontal } \\
\text { shear }\end{array}$ & \multirow{5}{*}{$\begin{array}{l}\text { Differ } \\
\text { ence } \\
\text { to the } \\
\text { averag } \\
\text { e is } \\
15.8 \%\end{array}$} \\
\hline & $\begin{array}{l}\text { S- } \\
16-1 \\
\end{array}$ & $4 \times 12 \times 81 / 4 "$ & $\begin{array}{l}\text { Foam- } \\
\text { spline }\end{array}$ & 36.72 & 2.47 & & $\begin{array}{l}\text { Foam horizontal } \\
\text { shear }\end{array}$ & \\
\hline & S-17 & $4 \times 12 \times 81 / 4 "$ & $\begin{array}{l}\text { Foam- } \\
\text { spline }\end{array}$ & 41.63 & 2.80 & & $\begin{array}{l}\text { Foam horizontal } \\
\text { shear }\end{array}$ & \\
\hline & S-18 & $\begin{array}{l}4 \times 12 \times 8 \\
1 / 4 " \\
\end{array}$ & $\begin{array}{l}\text { Foam- } \\
\text { spline }\end{array}$ & 34.96 & 2.35 & & $\begin{array}{l}\text { Foam horizontal } \\
\text { shear }\end{array}$ & \\
\hline & S-19 & $\begin{array}{l}4 \times 12 \times 8 \\
1 / 4 " \\
\end{array}$ & $\begin{array}{l}\text { Regular } \\
\text { Panel } \\
\end{array}$ & 52.29 & 3.52 & & $\begin{array}{l}\text { OSB crushing at } \\
\text { quarter-point line }\end{array}$ & \\
\hline \multirow{6}{*}{ G } & S-19 & $\begin{array}{l}4 \times 12 \times 8 \\
1 / 4 "\end{array}$ & $\begin{array}{l}\text { Regular } \\
\text { Panel } \\
\end{array}$ & 52.29 & 3.52 & \multirow{4}{*}{$\begin{array}{l}4.27 \\
\text { (without } \\
\text { the } \\
\text { regular } \\
\text { panel) }\end{array}$} & $\begin{array}{l}\text { OSB crushing at } \\
\text { quarter-point line }\end{array}$ & \multirow[t]{4}{*}{$\begin{array}{l}\text { Test } \\
\text { passed }\end{array}$} \\
\hline & S-20 & $4 \times 12 \times 81 / 4$ & $\begin{array}{l}\text { Lumber- } \\
\text { spline }\end{array}$ & 60.26 & 4.06 & & $\begin{array}{l}\text { Flexural failure } \\
\text { near mid-span with } \\
\text { tensile fracture in } \\
\text { both foam and } \\
\text { bottom OSB }\end{array}$ & \\
\hline & S-21 & $\begin{array}{l}4 \times 12 \times 81 / 4 \\
"\end{array}$ & $\begin{array}{l}\text { Lumber- } \\
\text { spline }\end{array}$ & 58.66 & 3.95 & & $\begin{array}{l}\text { horizontal shear } \\
\text { close to support }\end{array}$ & \\
\hline & $\begin{array}{l}\text { S- } \\
21-1 \\
\end{array}$ & $\begin{array}{l}4 \times 12 \times 81 / 4 \\
"\end{array}$ & $\begin{array}{l}\text { Lumber- } \\
\text { spline }\end{array}$ & 71.21 & 4.80 & & $\begin{array}{l}\text { Foam horizontal } \\
\text { shear }\end{array}$ & \\
\hline & S-22 & $\begin{array}{l}4 \times 14 \times 81 / 4 \\
"\end{array}$ & $\begin{array}{l}\text { Foam- } \\
\text { spline }\end{array}$ & 40.37 & 2.32 & \multirow[t]{2}{*}{2.15} & $\begin{array}{l}\text { Foam horizontal } \\
\text { shear }\end{array}$ & \multirow{2}{*}{$\begin{array}{l}\text { Differ } \\
\text { ence } \\
\text { to the } \\
\text { averag } \\
\text { e is } \\
28 \% \\
\end{array}$} \\
\hline & S-23 & $\begin{array}{l}4 \times 14 \times 81 / 4 \\
"\end{array}$ & $\begin{array}{l}\text { Foam- } \\
\text { spline }\end{array}$ & 29.30 & 1.68 & & $\begin{array}{l}\text { Un-symmetrical } \\
\text { diagonal shear } \\
\text { crack in the foam, }\end{array}$ & \\
\hline
\end{tabular}




\begin{tabular}{|c|c|c|c|c|c|c|c|c|}
\hline \multirow[t]{3}{*}{$\mathrm{H}$} & & & & & & & $\begin{array}{l}\text { continued with } \\
\text { delamination with } \\
\text { the bottom OSB }\end{array}$ & \\
\hline & $\begin{array}{l}\text { S- } \\
23-1\end{array}$ & $\begin{array}{l}4 \times 14 \times 81 / 4 \\
\text { " }\end{array}$ & $\begin{array}{l}\text { Foam- } \\
\text { spline }\end{array}$ & 37.00 & 2.12 & & $\begin{array}{l}\text { Foam horizontal } \\
\text { shear }\end{array}$ & \\
\hline & S-24 & $\begin{array}{l}4 \times 14 \times 81 / 4 \\
\text { " }\end{array}$ & $\begin{array}{l}\text { Foam- } \\
\text { spline }\end{array}$ & 42.59 & 2.44 & & $\begin{array}{l}\text { Foam horizontal } \\
\text { shear }\end{array}$ & \\
\hline \multirow{3}{*}{ I } & S-25 & $\begin{array}{l}4 \times 14 \times 81 / 4 \\
"\end{array}$ & \begin{tabular}{|l|}
$\begin{array}{l}\text { Lumber- } \\
\text { spline }\end{array}$ \\
\end{tabular} & 59.33 & 3.40 & \multirow[t]{3}{*}{3.20} & $\begin{array}{l}\text { Foam horizontal } \\
\text { shear }\end{array}$ & \multirow[t]{3}{*}{$\begin{array}{l}\text { Test } \\
\text { passed }\end{array}$} \\
\hline & S-26 & $\begin{array}{l}4 \times 14 \times 81 / 4 \\
"\end{array}$ & $\begin{array}{l}\text { Lumber- } \\
\text { spline }\end{array}$ & 56.68 & 3.25 & & $\begin{array}{l}\text { Foam horizontal } \\
\text { shear }\end{array}$ & \\
\hline & S-27 & $\begin{array}{l}4 \times 14 \times 81 / 4 \\
\text { " }\end{array}$ & $\begin{array}{l}\text { Lumber- } \\
\text { spline }\end{array}$ & 51.53 & 2.96 & & $\begin{array}{l}\text { Foam horizontal } \\
\text { shear }\end{array}$ & \\
\hline \multirow{3}{*}{$\mathbf{J}$} & S-28 & $4 \times 12 \times 10^{1 / 4^{\prime}}$ & $\begin{array}{l}\text { Foam- } \\
\text { spline }\end{array}$ & 40.57 & 2.73 & \multirow{3}{*}{$\begin{array}{l}2.87 \\
(3.004 \\
\text { with } \\
\text { system } \\
\text { weight })\end{array}$} & $\begin{array}{l}\text { Foam horizontal } \\
\text { shear }\end{array}$ & \multirow[t]{3}{*}{$\begin{array}{l}\text { Test } \\
\text { passed }\end{array}$} \\
\hline & S-29 & $4 \times 12 \times 10^{1 / 4}$ & $\begin{array}{l}\text { Foam- } \\
\text { spline }\end{array}$ & 42.04 & 2.83 & & $\begin{array}{l}\text { Foam horizontal } \\
\text { shear }\end{array}$ & \\
\hline & S-30 & $4 \times 12 \times 10^{1 / 4}$ & $\begin{array}{l}\text { Foam- } \\
\text { spline }\end{array}$ & 45.17 & 3.04 & & $\begin{array}{l}\text { Foam horizontal } \\
\text { shear }\end{array}$ & \\
\hline \multirow{4}{*}{$\mathrm{K}$} & S-31 & $\begin{array}{l}4 \times 14 \times 10 \\
1 / 4 "\end{array}$ & $\begin{array}{l}\text { Foam- } \\
\text { spline }\end{array}$ & 41.89 & 2.40 & \multirow{4}{*}{\begin{tabular}{|l}
2.40 \\
(without \\
the plain \\
panel)
\end{tabular}} & $\begin{array}{l}\text { Foam horizontal } \\
\text { shear }\end{array}$ & \multirow{4}{*}{$\begin{array}{l}\text { Test } \\
\text { did not } \\
\text { passed }\end{array}$} \\
\hline & S-32 & $\begin{array}{l}4 \times 14 \times 10 \\
1 / 4 "\end{array}$ & $\begin{array}{l}\text { Foam- } \\
\text { spline }\end{array}$ & 44.71 & 2.56 & & $\begin{array}{l}\text { Foam horizontal } \\
\text { shear }\end{array}$ & \\
\hline & S-33 & $\begin{array}{l}4 \times 14 \times 10 \\
1 / 4 "\end{array}$ & $\begin{array}{l}\text { Foam- } \\
\text { spline }\end{array}$ & 39.00 & 2.24 & & $\begin{array}{l}\text { Foam horizontal } \\
\text { shear }\end{array}$ & \\
\hline & S-45 & $\begin{array}{l}4 \times 14 \times 10 \\
1 / 4 " \\
\end{array}$ & $\begin{array}{l}\text { Regular } \\
\text { Panel }\end{array}$ & 51.27 & 2.94 & & $\begin{array}{l}\text { OSB crushing at } \\
\text { quarter-point line }\end{array}$ & \\
\hline \multirow{4}{*}{$\mathrm{L}$} & S-34 & $\begin{array}{l}4 \times 14 \times 10 \\
1 / 4 " \\
\end{array}$ & $\begin{array}{l}\text { Lumber- } \\
\text { spline }\end{array}$ & 77.85 & 4.47 & \multirow{4}{*}{$\begin{array}{l}4.44 \\
\text { (without } \\
\text { the plain } \\
\text { panel) }\end{array}$} & $\begin{array}{l}\text { Foam horizontal } \\
\text { shear }\end{array}$ & \multirow[t]{4}{*}{$\begin{array}{l}\text { Test } \\
\text { passed }\end{array}$} \\
\hline & S-35 & $\begin{array}{l}4 \times 14 \times 10 \\
1 / 4 "\end{array}$ & $\begin{array}{l}\text { Lumber- } \\
\text { spline }\end{array}$ & 72.62 & 4.17 & & $\begin{array}{l}\text { Foam horizontal } \\
\text { shear }\end{array}$ & \\
\hline & S-36 & $\begin{array}{l}4 \times 14 \times 10 \\
1 / 4 "\end{array}$ & $\begin{array}{l}\text { Lumber- } \\
\text { spline }\end{array}$ & 81.57 & 4.68 & & $\begin{array}{l}\text { Flexural failure } \\
\text { near mid-span with } \\
\text { tensile fracture in } \\
\text { both the foam and } \\
\text { bottom OSB }\end{array}$ & \\
\hline & S-45 & $\begin{array}{l}4 \times 14 \times 10 \\
1 / 4 "\end{array}$ & $\begin{array}{l}\text { Regular } \\
\text { Panel }\end{array}$ & 51.27 & 2.94 & & $\begin{array}{l}\text { OSB crushing in } \\
\text { compression at } \\
\text { quarter-point line }\end{array}$ & \\
\hline \multirow{3}{*}{$\mathbf{M}$} & S-37 & $\begin{array}{l}4 \times 16 \times 10 \\
1 / 4 "\end{array}$ & $\begin{array}{l}\text { Foam- } \\
\text { spline }\end{array}$ & 39.65 & 1.98 & \multirow[t]{3}{*}{2.09} & $\begin{array}{l}\text { Foam horizontal } \\
\text { shear }\end{array}$ & \multirow{3}{*}{$\begin{array}{l}\text { Test } \\
\text { did not } \\
\text { passed }\end{array}$} \\
\hline & S-38 & $\begin{array}{l}4 \times 16 \times 10 \\
1 / 4 "\end{array}$ & $\begin{array}{l}\text { Foam- } \\
\text { spline }\end{array}$ & 43.61 & 2.18 & & $\begin{array}{l}\text { Foam horizontal } \\
\text { shear }\end{array}$ & \\
\hline & S-39 & $\begin{array}{l}4 \times 16 \times 10 \\
1 / 4 "\end{array}$ & $\begin{array}{l}\text { Spline } \\
\text { connecti } \\
\text { on }\end{array}$ & 42.05 & 2.10 & & $\begin{array}{l}\text { Foam horizontal } \\
\text { shear }\end{array}$ & \\
\hline \multirow{3}{*}{$\mathrm{N}$} & S-40 & $\begin{array}{l}4 \times 16 \times 10 \\
1 / 4,\end{array}$ & $\begin{array}{l}\text { Lumber- } \\
\text { spline }\end{array}$ & 74.73 & 3.73 & \multirow[t]{3}{*}{3.49} & $\begin{array}{l}\text { Flexural failure at } \\
\text { mid-span with } \\
\text { tensile fracture in } \\
\text { both foam and } \\
\text { bottom OSB }\end{array}$ & \multirow[t]{3}{*}{$\begin{array}{l}\text { Test } \\
\text { passed }\end{array}$} \\
\hline & S-41 & $\begin{array}{l}4 \times 16 \times 10 \\
1 / 4 "\end{array}$ & $\begin{array}{l}\text { Lumber- } \\
\text { spline }\end{array}$ & 68.00 & 3.40 & & $\begin{array}{l}\text { Foam horizontal } \\
\text { shear }\end{array}$ & \\
\hline & S-42 & $\begin{array}{l}4 \times 16 \times 10 \\
1 / 4 "\end{array}$ & $\begin{array}{l}\text { Lumber- } \\
\text { spline }\end{array}$ & 67.37 & 3.37 & & $\begin{array}{l}\text { OSB crushing at } \\
\text { quarter-point line }\end{array}$ & \\
\hline
\end{tabular}




\begin{tabular}{|c|l|l|l|l|l|l|l|}
\hline $\mathrm{O}$ & S-46 & $4 \times 8 \times 6 \frac{1 / 2 "}{2}$ & $\begin{array}{l}\text { Tongue } \\
\text { and } \\
\text { groove } \\
\text { link }\end{array}$ & 52.01 & 5.37 & $\begin{array}{l}\text { Diagonal shear } \\
\text { crack in the foam, } \\
\text { continued with } \\
\text { delamination with } \\
\text { the top OSB }\end{array}$ & $\begin{array}{l}\text { Test } \\
\text { passed }\end{array}$ \\
\hline $\mathrm{P}$ & S-47 & $4 \times 8 \times 8 \frac{1 / 4}{\prime \prime}$ & $\begin{array}{l}\text { Tongue } \\
\text { and } \\
\text { groove } \\
\text { link }\end{array}$ & 59.68 & 6.16 & $\begin{array}{l}\text { OSB crushing at } \\
\text { quarter-point line }\end{array}$ & $\begin{array}{l}\text { Test } \\
\text { passed }\end{array}$ \\
\hline
\end{tabular}

\subsection{Group B}

In this group, three identical panels (S-4, S-5 and S-43) were tested to complete collapse. Each panel was of $165 \mathrm{~mm}$ thickness, $1.2 \mathrm{~mm}$ width and $3.05 \mathrm{~m}$ length, with foamspline connection. Additional regular panel, S-6, without foam-spline connection (i.e. foam core with OSB facings of $1.2 \mathrm{~m}$ width) was also tested to investigate the change in the reduction in the structural efficiency with the presence of foam-spline connections between panels. Figures AI-14 to AI-30 in Appendix A summarizes the experimental findings for this panel group.

It was observed that the failure mode of the panels with foams-spline connections failed due to horizontal shear between the top surface of the foam and the adhesive over a panel length between the support and the quarter-point line, causing delamination (debonding) between the top foam-OSB interface and the foam core over the support. It should be noted that noise was heard when approaching failure load and the shear failure was abrupt causing a sudden drop in the applied jacking load as depicted in the load-deflection history. One may observe that regular Panel, S-6, without foam-spline connection unexpectedly failed in diagonal shear failure in the foam close to the support line, combined with debonding between the OSB 
facings and the foam core between the ends of the diagonal shear crack and the support line s well as the quarter-point line as shown in Fig. 4.5.

The jacking load-deflection history for all the tested panels in this group showed linear elastic behavior at the live load level (i.e. serviceability limit state) and even at the design factored load level (i.e. ultimate limit state). Table 4.1 shows the deflection values for the three panels, S-4, S-5 and S-43, at the design live load level. These values were normalized to the span length and then averaged to be span/583 which is far below the deflection limit of span/360. It should be noted that the panel span length considered herein is the panel length of $3.05 \mathrm{~m}$ minus $76 \mathrm{~mm}$ (3") from each side of the support. It can be observed herein that the deflection of each panel at the live load live is within $15 \%$ difference with the average deflection of the three panels.

Table 4.2 presents a summary of panel configurations along with the ultimate jacking load, failure mode and the average ratio of the ultimate jacking load to the factored design load $(1.25 \mathrm{D}+1.5 \mathrm{~L})$. It can be observed that the ultimate jacking load was $37.98,39.48$ and $35.35 \mathrm{kN}$ for panels $\mathrm{S}-4, \mathrm{~S}-5$ and $\mathrm{S}-43$, respectively. It can be observed that the average ratio of the ultimate jacking load to the design factored load is 3.06 for panel group B, which is more than the allowable factor of safety of 3 for shear failure. This ratio would be 3.22 after adding the self-weight of the loading system. It is worth mentioning that the ultimate jacking load for each panel is within $15 \%$ difference with the average jacking load of the three panels. Since the panel group B meets both the serviceability and ultimate limit states requirements, it can be considered qualified to be as good as the conventional frame building in Part 4 and Part 9 of NBCC of 2005. 
One may observe in Table 4.1 that the regular panel S- 6 exhibited deflection value at the live load level very close to those for the identical panels with foam-spline connection. Also, Table 4.2 shows that the ultimate load carrying capacity of the regular panel S-6 is about $7 \%$ more than the average ultimate load carrying capacity of panels in group B. Thus, it may be concluded that the presence of foam-spline connections between panels may not significantly affected the serviceability and ultimate limit states design of such panels when assuming that the foam core and the OSB facings of $1200 \mathrm{~mm}$ width.

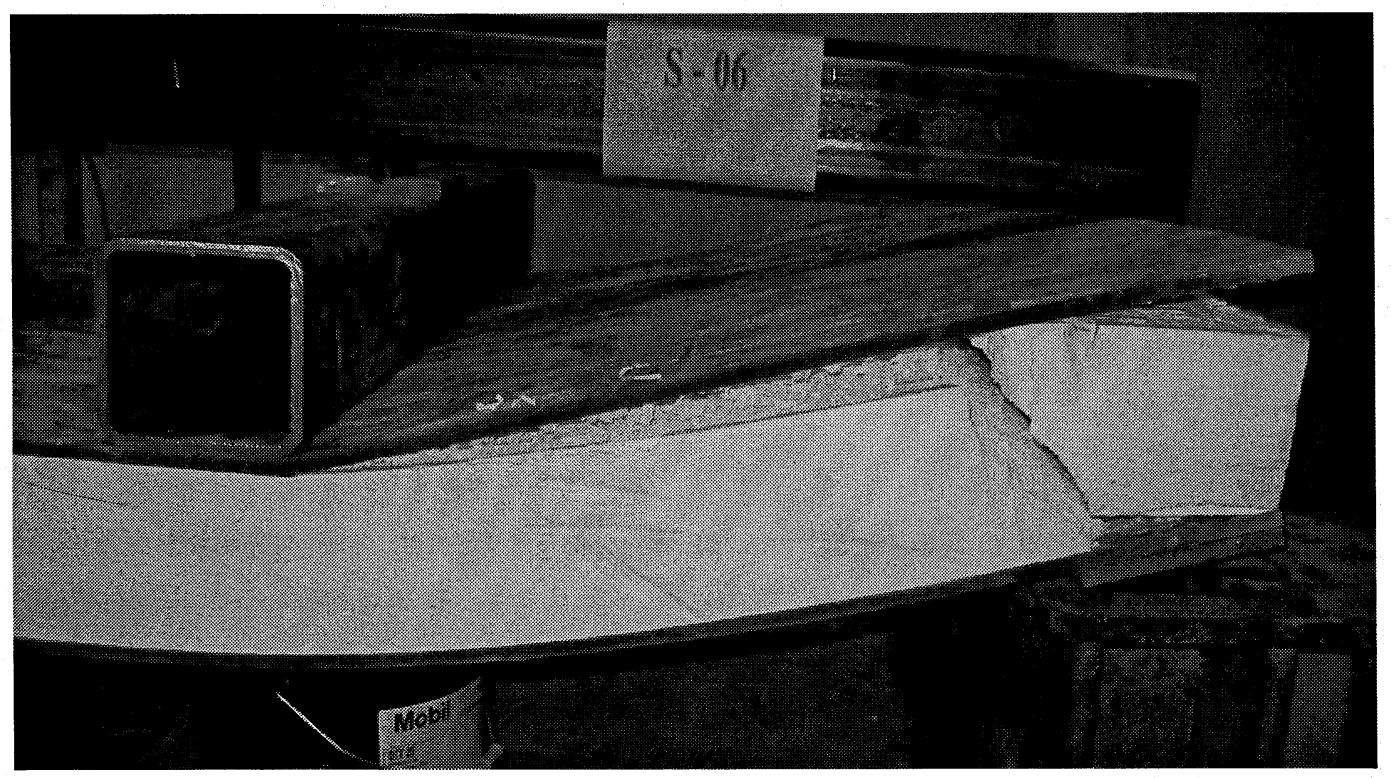

Figure 4.5 View of the combined horizontal and diagonal shear failure of panel S-6 


\subsection{Group C}

In this group, three identical panels (S-7, S-8 and S-9) were tested to complete collapse. Each panel was of $165 \mathrm{~mm}$ thickness, $1.2 \mathrm{~mm}$ width and $3.66 \mathrm{~m}$ length, with solid lumber-spline connection. Additional regular panel, S-12, without lumber-spline connection (i.e. foam core with OSB facings of $1.2 \mathrm{~m}$ width) was also tested to investigate the change in the reduction in the structural efficiency with the presence of lumber-spline connections between panels. Figures AI-31 to AI-48 in Appendix A summarizes the experimental findings for this panel group, while Figs AI-57 to AI-60 present experimental findings for S12. It was observed that the failure mode of S-7 and S-9 was due to diagonal shear crack in the foam core at about $660 \mathrm{~mm}$ from the support and extends as horizontal shear failure towards the quarter point from one side and towards the support from the other side. However, panel S-8 failed due to horizontal shear between the top surface of the foam and the adhesive over a panel length between the support and the quarter-point line, causing delamination (debonding) between the top foam-OSB interface and the foam core over the support. It should be noted that noise was heard when approaching failure load and the shear failure was sudden with loud sound, causing a sudden drop in the applied jacking load as depicted in the load-deflection history. One may observe that regular Panel, S-12, without lumber-spline connection failed in diagonal shear failure as for S-7 and S-9. Figure 4.6 shows view of the failure mode due to diagonal shear in the foam core for S-7. Also, Fig. 4.7 shows close-up view of the failure pattern in the lumber-spline stud from one side of specimen S-7 which means that the solid sawn lumber contributed to the strength of the panel.

The jacking load-deflection history for all the tested panels in this group showed linear elastic behavior at the live load level (i.e. serviceability limit state) and even at the 
design factored load level (i.e. ultimate limit state). Table 4.1 shows the deflection values for the three panels, S-7, S-8 and S-9, at the design live load level. These values were normalized to the span length and then averaged to be span/472 which is far below the deflection limit of span/360. Table 4.2 presents a summary of panel configurations along with the ultimate jacking load, failure mode and the average ratio of the ultimate jacking load to the factored design load $(1.25 \mathrm{D}+1.5 \mathrm{~L})$. It can be observed that the ultimate jacking load was 47.86 , 52.66 and $43.72 \mathrm{kN}$ for panels $\mathrm{S}-7, \mathrm{~S}-8$ and S-9, respectively. It can be observed that the average ratio of the ultimate jacking load to the design factored load is 3.24 for panel group $\mathrm{C}$, which is more than the allowable factor of safety of 3 for shear failure. This ratio would be 3.77 after adding the self-weight of the loading system. Since the panel group C meets both the serviceability and ultimate limit states requirements, it can be considered qualified to be as good as the conventional frame building in Part 4 and Part 9 of NBCC of 2005.

One may observe in Table 4.1 that the regular panel S-12 exhibited deflection value at the live load level of $9.26 \mathrm{~mm}$ compared to an average deflection of $7.41 \mathrm{~mm}$ for the panel group C with lumber-spline connection, and increase of deflection by $20 \%$. Also, Table 4.2 shows that the ultimate load carrying capacity of the regular panel S-12 is $35.07 \mathrm{kN}$ compared to an average ultimate load of $48.08 \mathrm{kN}$ for the panel group $\mathrm{C}$, an increase in ultimate jacking load by $37 \%$. Thus, it may be concluded that the presence of lumber-spline connections between panels significantly decreased the panel deflection by about $20 \%$ and increased the load carrying capacity by about $37 \%$ as compared to panels with or without foam-spline connection. 


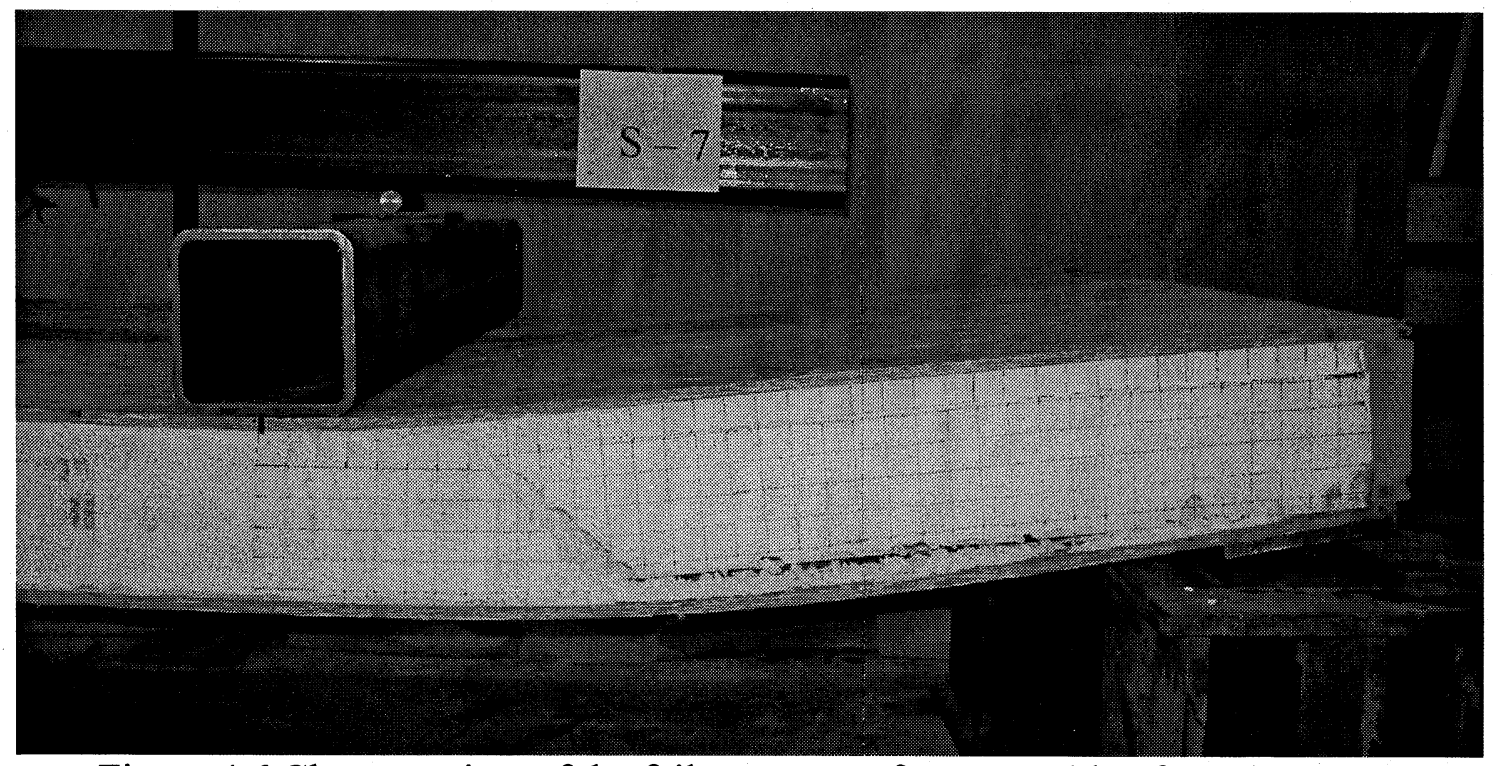

Figure 4.6 Close-up view of the failure pattern from one side of specimen S-7

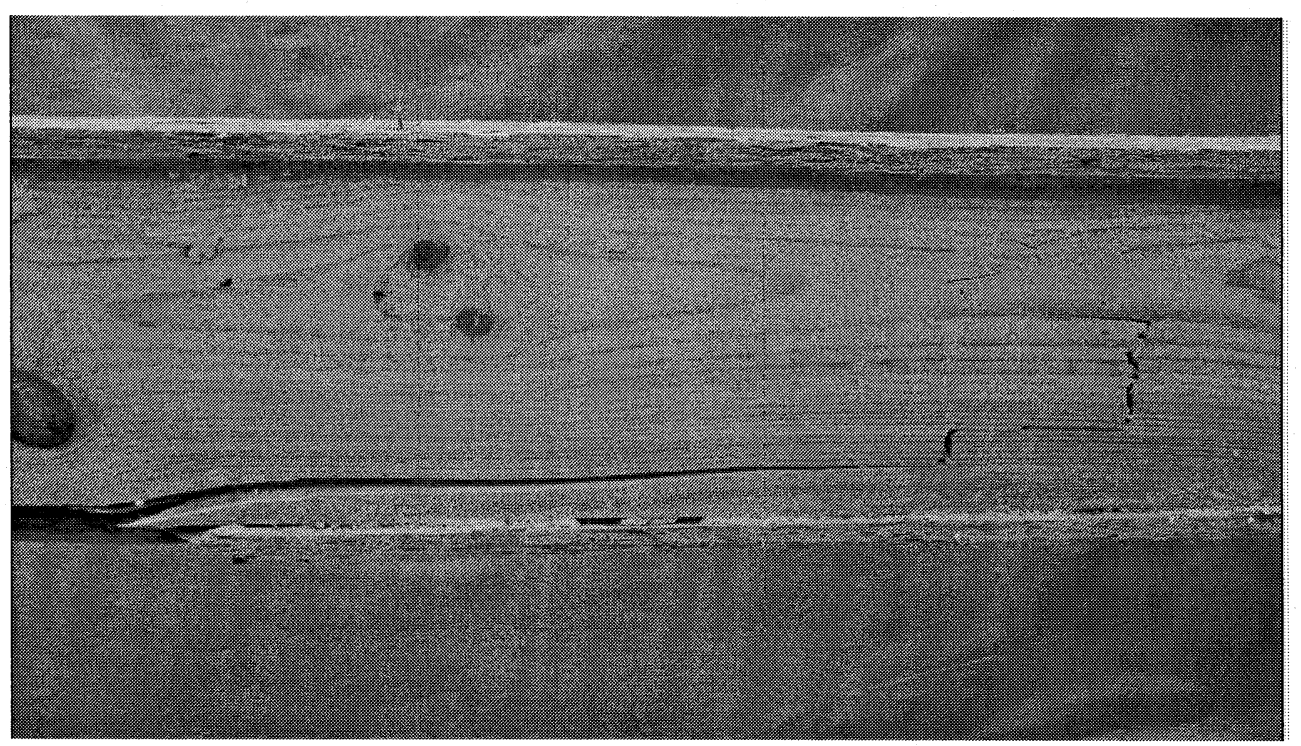

Figure 4.7 Close-up view of failure pattern in the spline stud from one side of specimen S-7 


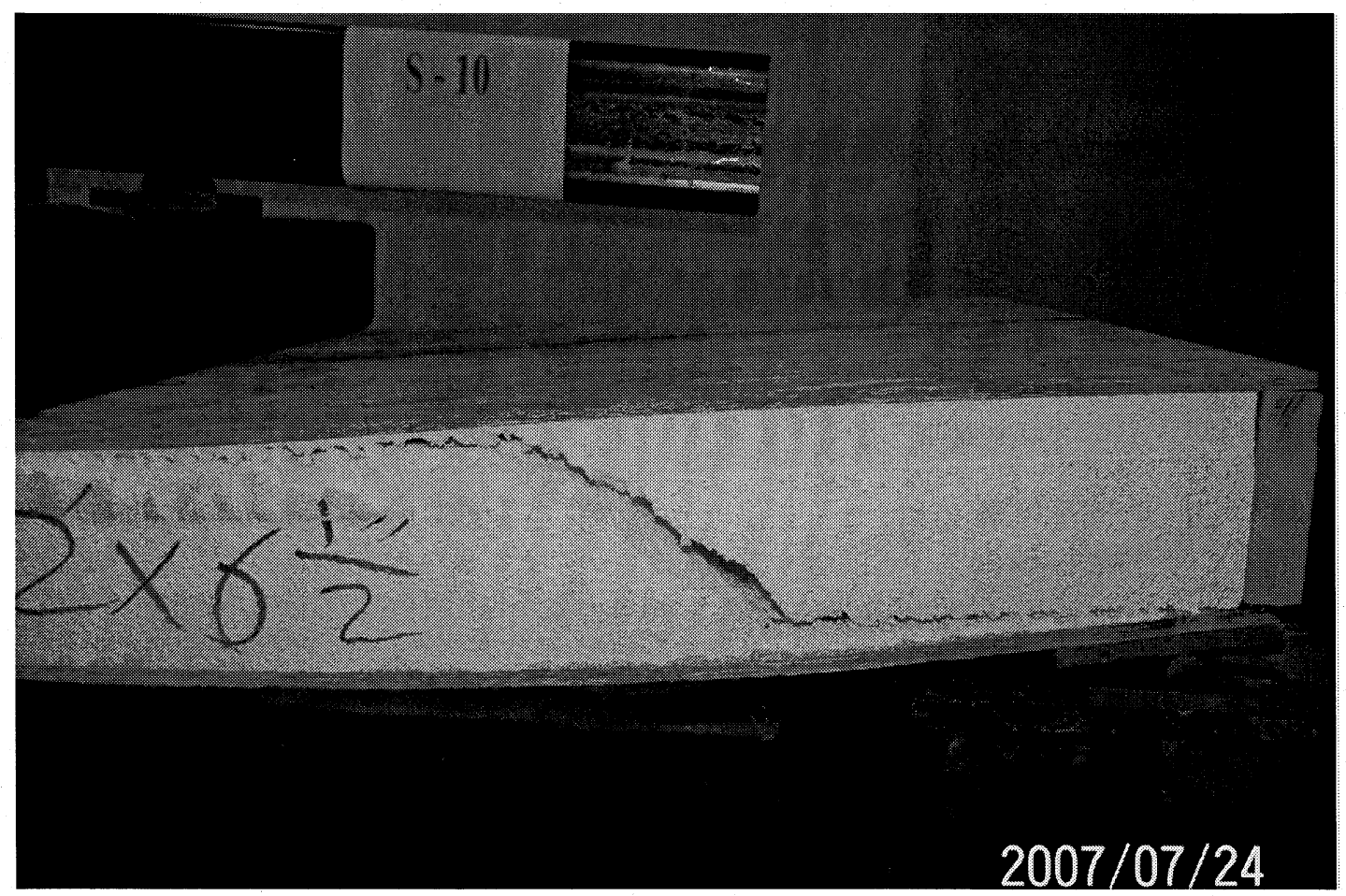

Figure 4.8 Close-up view of the failure pattern from one side of specimen S-10

\subsection{Group E}

In this group, three identical panels (S-13, S-14 and S-15) were tested to complete collapse. Each panel was of $210 \mathrm{~mm}$ thickness, $1.2 \mathrm{~mm}$ width and $3.05 \mathrm{~m}$ length, with foamspline connection. Figures AI-66 to AI-78 in Appendix A summarize the experimental findings for this panel group. It was observed panels S-13 and S-14 failed due to horizontal shear between the top surface of the foam and the adhesive over a panel length between the support and the quarter-point line, causing delamination (debonding) between the top foamOSB interface and the foam core over the support. However, panel S-15 failed due to diagonal shear at approximately $60^{\circ}$ at the end of foam over the support as shown in Fig. 4.9. Noise was heard when approaching failure load. Sudden, loud, sound was heard at failure. Table 4.2 summarizes the ultimate load carrying capacity of the tested panel on which it was observed that there was more that $15 \%$ difference in panel strength compared to the average 
strength of the three panels. As such, it was decided to test a fourth panel S-15-1. The experimental results of S-15-1 are listed in Figs. AI-75-1 to AI-78-1. The jacking loaddeflection history for all the tested panels in this group showed linear elastic behavior at the live load level (i.e. serviceability limit state) and even at the design factored load level (i.e. ultimate limit state). Table 4.1 shows the deflection values for the three panels, S-13, S-14, S15 and S-15-1, at the design live load level. These values were normalized to the span length and then averaged to be span/739 which is significantly below the deflection limit of span/360. Table 4.2 presents a summary of panel configurations along with the ultimate jacking load, failure mode and the average ratio of the ultimate jacking load to the factored design load $(1.25 \mathrm{D}+1.5 \mathrm{~L})$. It can be observed that the ultimate jacking load was 41.81 , 43.96, 31.69 and $42.57 \mathrm{kN}$ for panels $\mathrm{S}-13, \mathrm{~S}-14, \mathrm{~S}-15$ and $\mathrm{S}-15-1$, respectively. It can be observed that the average ratio of the ultimate jacking load to the design factored load is 3.26 for panel group E, with a factor of safety for ultimate strength of this panel more than the allowable factor of safety of 3 for shear failure. To qualify this panel group for ultimate limit state design, an additional panel is to be tested so that the average of the five panels can be used to determine the safety factor for strength. Figure 4.10 shows the jacking load- flexural strain relationship for panel S-13. It can be observed that behavior of the panel with respect to flexural stresses at mid-span location remained elastic till failure, confirming that the mode of failure was primarily pure shear. 


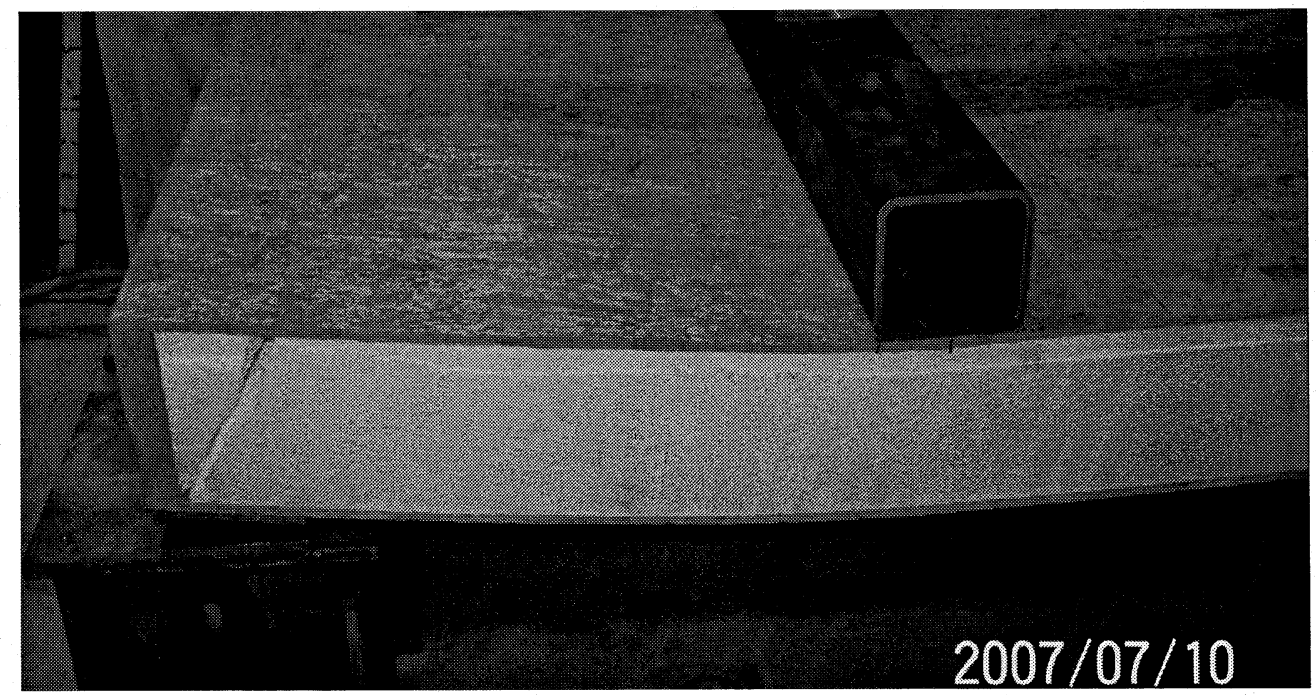

Figure 4.9 View of the diagonal shear failure of specimen S-15 at the support

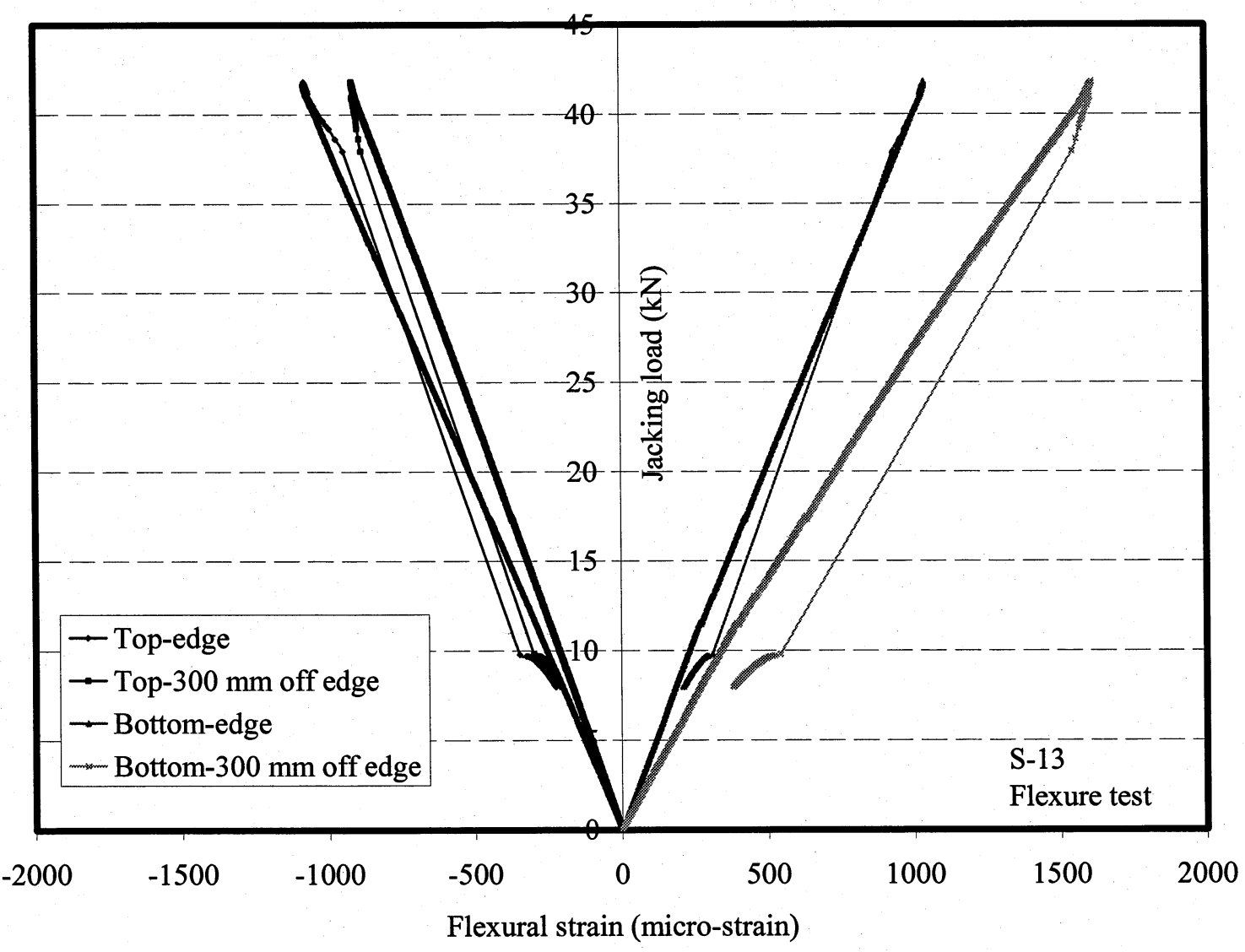

Figure 4.10 Load-strain relationship for specimen S-13 


\subsection{Group F}

In this group, three identical panels were tested to complete collapse, namely: S-16, $\mathrm{S}-17$, and S-18. Each panel was of $210 \mathrm{~mm}$ thickness, $1.2 \mathrm{~mm}$ width and $3.66 \mathrm{~m}$ length, with foam-spline connection. After testing these three panels, it was observed that more that $15 \%$ difference in the ultimate strength of panel S-18 existed as compared to the average experimental failure load. As such, it was decided to test a fourth panel, S-16-1. Figures AI79 to AI-91 summarizes the experimental findings for this panel group. It was observed that the failure mode of all panels was due to horizontal shear failure between the top surface of the foam and the adhesive over a panel length between the support and the quarter-point line, causing delamination (debonding) between the top foam-OSB interface and the foam core over the support. It should be noted that noise was heard when approaching failure load and the shear failure was sudden causing a sudden drop in the applied jacking load as depicted in the load-deflection history. From the load-deflection history for all panels, it can be observed that linear elastic behavior was maintained at the live load level (i.e. serviceability limit state) and even at the design factored load level (i.e. ultimate limit state). Table 4.1 shows the deflection values for the three panels, S-16, S-16-1, S-17 and S-18, at the design live load level. These values were normalized to the span length and then averaged to be span/582 which is far below the deflection limit of span/360. Table 4.2 presents a summary of panel configurations along with the ultimate jacking load, failure mode and the average ratio of the ultimate jacking load to the factored design load $(1.25 \mathrm{D}+1.5 \mathrm{~L})$. It can be observed that the ultimate jacking load was $47.89,36.72,41.63$ and $34.96 \mathrm{kN}$ for panels S-16, S-16-1, S-17 and S-18, respectively. It can be observed that the average ratio of the ultimate jacking load to the design factored load is 2.71 for panel group A ( 2.84 when adding the $2 \mathrm{kN}$ self-weight of the loading system) which is less than the allowable factor of safety of 3 for shear failure. 
To qualify panel group $\mathrm{F}$, a maximum live load of $1.68 \mathrm{kPa}$ to elevate the factor of safety for strength to 3 , or a fifth panel is to be tested to get the average strength of five panels and determine the corresponding factor of safety.

One may observe in Table 4.1 that a regular panel S-19 was tested to evaluate the change in strength and deflection with the presence of foam-spline connection between panels in floor construction. It can be observed that panel S-19 exhibited deflection value of $5.26 \mathrm{~mm}$ at the live load level compared to $6.53 \mathrm{~mm}$ average deflection for panel group $\mathrm{F}$ with foam-spline connection, with $19 \%$ difference. Also, Table 4.2 shows that the ultimate load carrying capacity of the regular panel S-19 is about $23 \%$ more than the average ultimate load carrying capacity of panels in group F. Thus, it may be concluded that the presence of foam-spline connections between panels have significant effect on the serviceability and ultimate limit states design of such panels when assuming that the foam core and the OSB facings of $1200 \mathrm{~mm}$ width, in contract to groups B and D of shallower panels. It is also interesting to mention that panel S-19 failed due to OSB crushing at the quarter point location. Figure 4.11 shows OSB crushing in compression outward on one side of the quarter point line, while Fig. 4.12 shows OSB crushing in compression in towards the foam core on the other side of the quarter point line. Figure 4.13 depicts the jacking load-flexural strain relationship at the mid-span location of the panel. It is interesting to mention that flexural strains at the mid-span location remained linear elastic which means that OSB crushing was sudden, causing panel failure. 


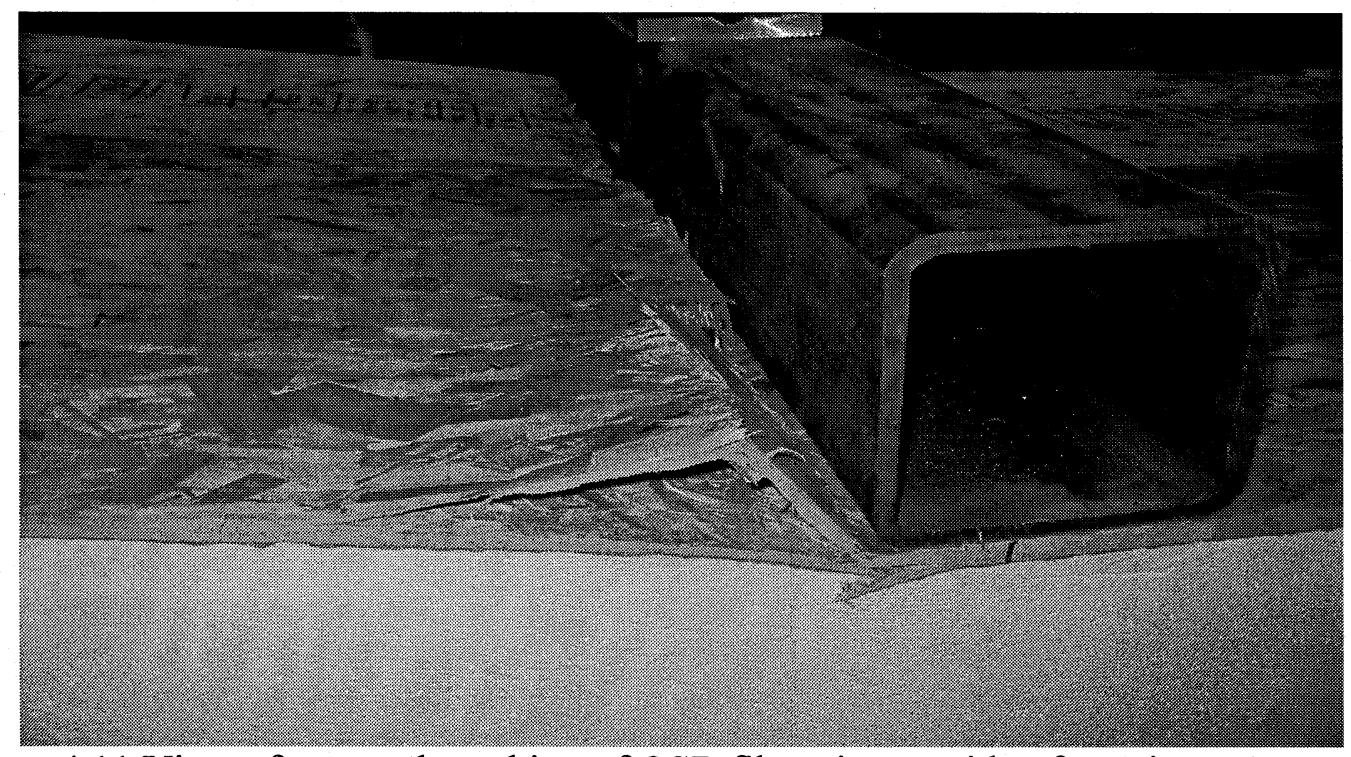

Figure 4.11 View of outward crushing of OSB fibers in one side of specimen S-19 at the interface of the loading beam and the top of the panel

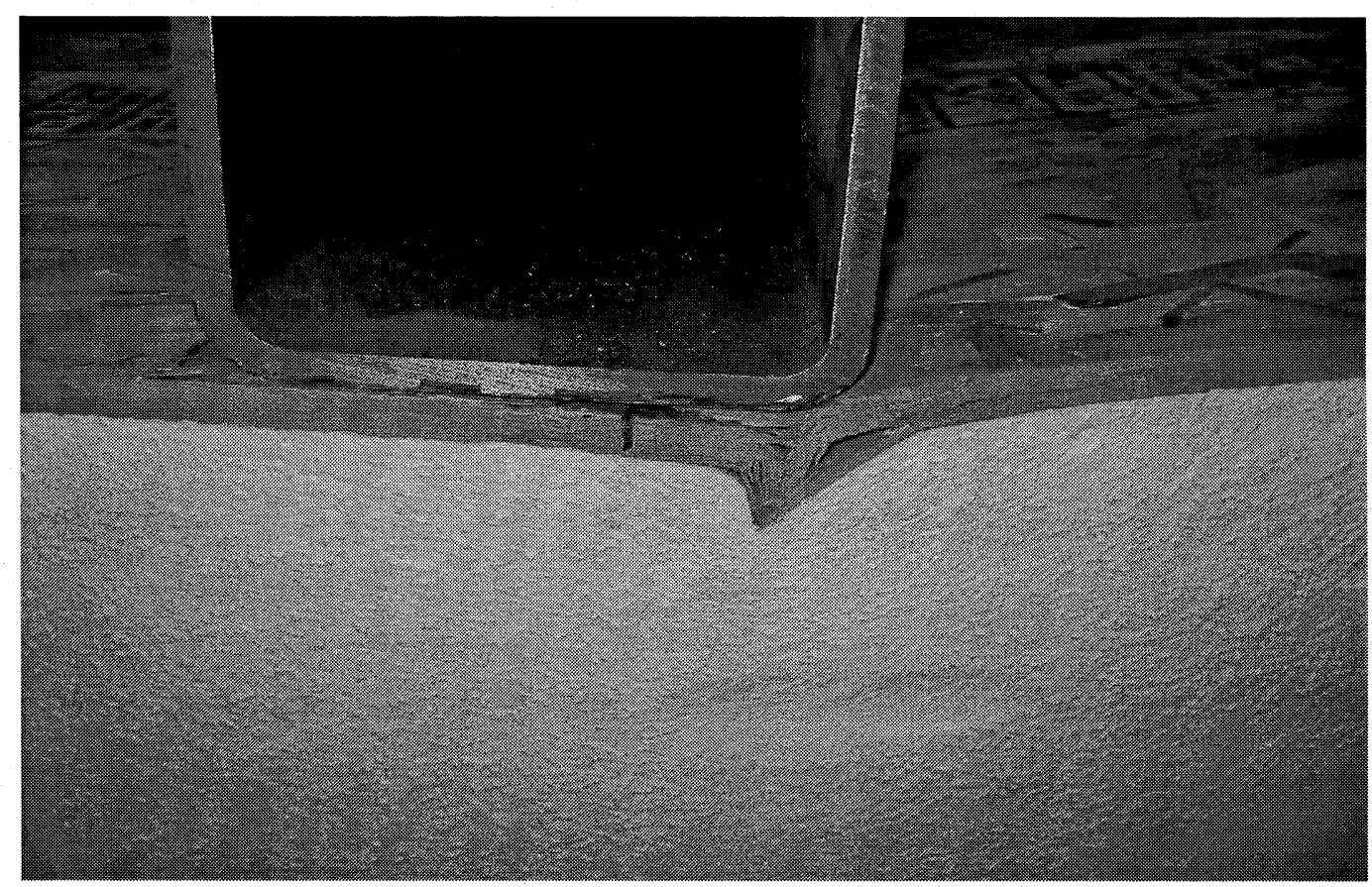

Figure 4.12 View of inward crushing of OSB fibers on the other free side of specimen S-19 at the interface of the loading beam and the top of the panel 


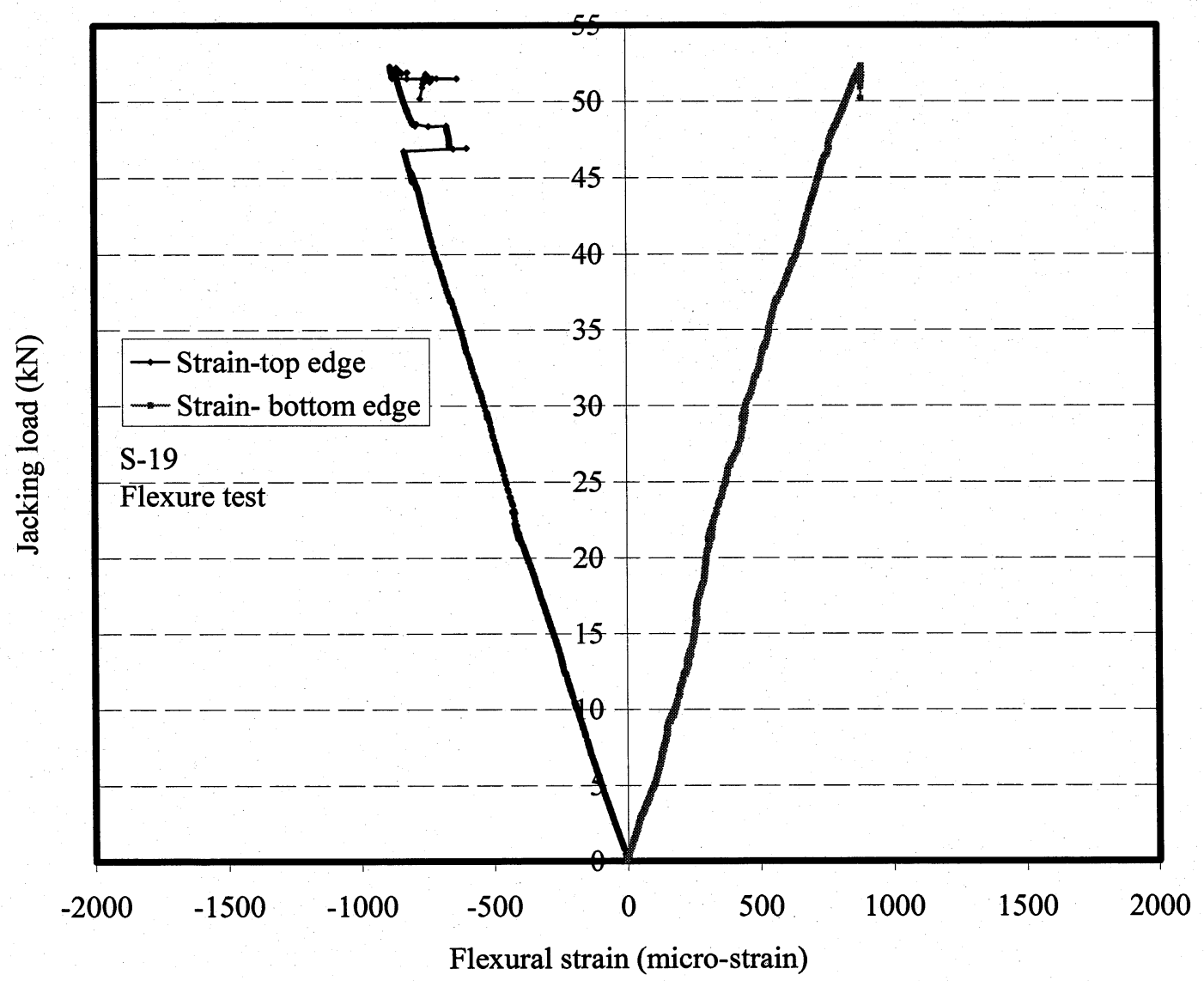

Figure 4.13 Load-strain relationship for specimen S-19

\subsection{Group G}

In this group, three identical panels were tested to complete collapse, namely: S-20, $\mathrm{S}-21$, and S-21-1. Each panel was of $210 \mathrm{~mm}$ thickness, $1.2 \mathrm{~mm}$ width and $3.66 \mathrm{~m}$ length, with solid lumber-spline connection. Figures AI-97 to AI-106-1 summarizes the experimental findings for this panel group. It was observed that for panels S-21 and S-21-1, the failure mode was due to horizontal shear failure between the top surface of the foam and the adhesive over a panel length between the support and the quarter-point line, causing delamination (debonding) between the top foam-OSB interface and the foam core over the support. However, panel S-20 failed due to flexure near the mid-span, with tensile fracture in both the bottom OSB board and the foam. Also, delamination between the top OSB board 
and the foam was noticed at failure as shown in Fig. 4.14. It should be noted that failure was sudden causing a sudden drop in the applied jacking load as depicted in the load-deflection history.

From the load-deflection history for all panels, it can be observed that linear elastic behavior was maintained at the live load level (i.e. serviceability limit state) and even at the design factored load level (i.e. ultimate limit state). Table 4.1 shows the deflection values for the three panels, S-20, S-21 and S-21-1 at the design live load level. These values were normalized to the span length and then averaged to be span/690 which is far below the deflection limit of span/360. It should be noted that this average deflection of span/690 is less than the live load deflection of span/582 for panel group F with foam-spline connection. Table 4.2 presents a summary of panel configurations along with the ultimate jacking load, failure mode and the average ratio of the ultimate jacking load to the factored design load $(1.25 \mathrm{D}+1.5 \mathrm{~L})$. It can be observed that the ultimate jacking load was $60.26,58.66$ and 71.21 $\mathrm{kN}$ for panels $\mathrm{S}-20, \mathrm{~S}-21$ and $\mathrm{S}-21-1$, respectively. It can be observed that the average ratio of the ultimate jacking load to the design factored load is 4.27 for panel group $G$ which is far more than the allowable factor of safety of 3 for shear failure in contract to the 2.71 safety factor obtained for panel group F with foams-spline connections. Since panel group G meets both the serviceability and ultimate limit states requirements, it can be considered qualified to be as good as the conventional frame building in Part 4 and Part 9 of NBCC of 2005.

One may observe in Table 4.1 that the regular panel S-19 exhibited deflection value of $5.26 \mathrm{~mm}$ at the live load level compared to $5.08 \mathrm{~mm}$ average deflection for panel group $\mathrm{G}$ with lumber-spline connection, with a $3.4 \%$ difference. Also, Table 4.2 shows that the 
ultimate load carrying capacity of the regular panel S-19 is about $21 \%$ less than the average ultimate load carrying capacity of panels in group G. Thus, it may be concluded that the presence of solid sawn lumber at the connections that contributed as a load carrying element.

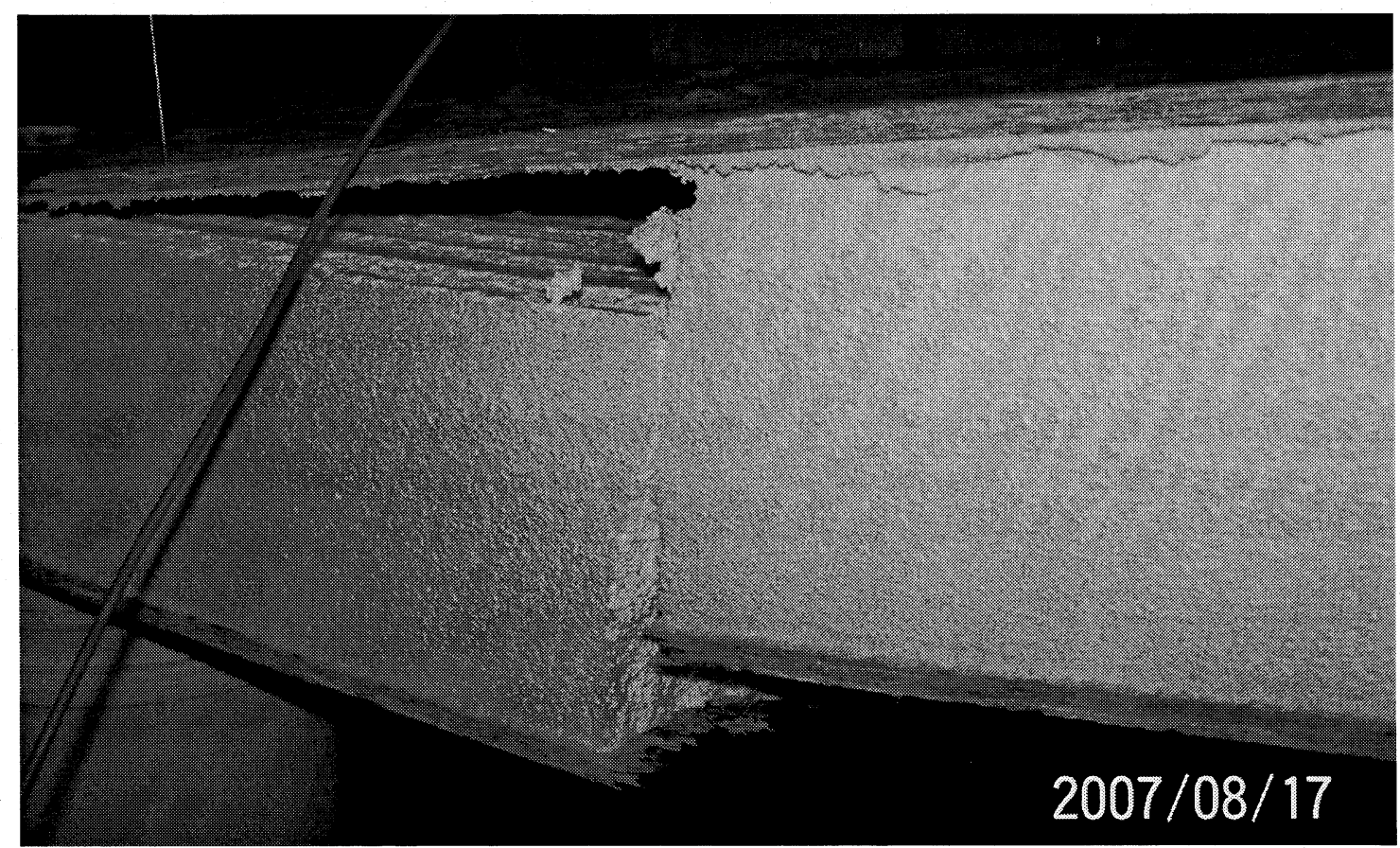

Figure 4.14 View of the flexural failure of specimen S-20

\subsection{Group H}

In this group, three identical panels were tested to complete collapse, namely: S-22, S-23, S-23-1 and S-24. Each panel was of $210 \mathrm{~mm}$ thickness, $1.2 \mathrm{~mm}$ width and $4.27 \mathrm{~m}$ length, with foam-spline connection. Figures AI-107 to AI-119 summarize the experimental findings for this panel group. It should be noted that panel S-23-1 was added to the group since it was found that there was a difference more that $15 \%$ between the ultimate load of panel S-23and the average strength of the three panels. It was observed that for panels S-22, S-23-1 and S-24, the failure mode was due to horizontal shear failure between the top surface 
of the foam and the adhesive over a panel length between the support and the quarter-point line, causing delamination (debonding) between the top foam-OSB interface and the foam core over the support. However, panel S-23 failed due to diagonal shear crack at approximately mid-length between the support and the quarter point, continued with delamination between OSB facings and the foam core towards support as well as the quarter point. Again, shear failure was sudden causing a sudden drop in the applied jacking load as depicted in the load-deflection history.

From the load-deflection history for all panels, it can be observed that linear elastic behavior was maintained at the live load level (i.e. serviceability limit state) and even at the design factored load level (i.e. ultimate limit state). Table 4.1 shows the deflection values for the three panels, S-22, S-23, S-23-1 and S-24 at the design live load level. These values were normalized to the span length and then averaged to be span/366 which is slightly less than the deflection limit of span/360. Table 4.2 presents a summary of panel configurations along with the ultimate jacking load, failure mode and the average ratio of the ultimate jacking load to the factored design load $(1.25 \mathrm{D}+1.5 \mathrm{~L})$. It can be observed that the ultimate jacking load was $40.37,29.30,37.00$ and $42.59 \mathrm{kN}$ for panels S-22, S-23, S-23-1 and S-24, respectively. It can be observed that the average ratio of the ultimate jacking load to the design factored load is 2.15 for panel group $\mathrm{H}$ ( 2.27 with $2 \mathrm{kN}$ self-weight of the loading system) which is far less than the allowable factor of safety of 3 for shear failure. To qualify panel group F, a maximum live load of $1.24 \mathrm{kPa}$ to elevate the factor of safety for strength to 3 , or a fifth panel is to be tested to get the average strength of five panels and determine the corresponding factor of safety. 


\subsection{Group I}

In this group, three identical panels were tested to complete collapse, namely: S-25, S-26 and S-27. Each panel was of $210 \mathrm{~mm}$ thickness, $1.2 \mathrm{~mm}$ width and $4.27 \mathrm{~m}$ length, with lumber-spline connection. Figures AI-120 to AI-135 summarizes the experimental findings for this panel group. It was observed that all panels failed due to horizontal shear failure between the top surface of the foam and the adhesive over a panel length between the support and the quarter-point line, causing delamination (debonding) between the top foam-OSB interface and the foam core over the support. Again, shear failure was sudden causing a sudden drop in the applied jacking load as depicted in the load-deflection history.

From the load-deflection history for all panels, it can be observed that linear elastic behavior was maintained at the live load level (i.e. serviceability limit state) and even at the design factored load level (i.e. ultimate limit state). Table 4.1 shows the deflection values for the three panels, S-25 S-26 and S-27 at the design live load level. These values were normalized to the span length and then averaged to be span/464 which is less than the deflection limit of span/360. Table 4.2 presents a summary of panel configurations along with the ultimate jacking load, failure mode and the average ratio of the ultimate jacking load to the factored design load $(1.25 \mathrm{D}+1.5 \mathrm{~L})$. It can be observed that the ultimate jacking load was $59.33,56.68$ and $51.53 \mathrm{kN}$ for panels $\mathrm{S}-25, \mathrm{~S}-26$ and S-27, respectively. It can be observed that the average ratio of the ultimate jacking load to the design factored load is 3.2 for panel group I (3.31 with $2 \mathrm{kN}$ self-weight of the loading system) which is more than the allowable factor of safety of 3 for shear failure. As such, panel group I meets both the 
serviceability and ultimate limit states requirements. Thus, it can be considered qualified to be as good as the conventional frame building in Part 4 and Part 9 of NBCC of 2005.

\subsection{Group J}

In this group, three identical panels were tested to complete collapse, namely: S-28, S-29 and S-230. Each panel was of $260 \mathrm{~mm}$ thickness, $1.2 \mathrm{~mm}$ width and $3.66 \mathrm{~m}$ length, with foam-spline connection. Figures AI-136 to AI-151 summarizes the experimental findings for this panel group. It was observed that all panels failed due to horizontal shear failure between the top surface of the foam and the adhesive over a panel length between the support and the quarter-point line, causing delamination (debonding) between the top foam-OSB interface and the foam core over the support. Again, shear failure was sudden causing a sudden drop in the applied jacking load as depicted in the load-deflection history. From the load-deflection history for all panels, it can be observed that linear elastic behavior was maintained at the live load level (i.e. serviceability limit state) and even at the design factored load level (i.e. ultimate limit state). Table 4.1 shows the deflection values for the three panels, S-28, S-29 and S-30 at the design live load level. These values were normalized to the span length and then averaged to be span/732 which is less than the deflection limit of span/360. Table 4.2 presents a summary of panel configurations along with the ultimate jacking load, failure mode and the average ratio of the ultimate jacking load to the factored design load (1.25D + 1.5L). It can be observed that the ultimate jacking load was $40.57,42.04$ and $45.17 \mathrm{kN}$ for panels S-28 S-29 and S-30, respectively. It can be observed that the average ratio of the ultimate jacking load to the design factored load is 2.87 for panel group J ( 3.00 with $2 \mathrm{kN}$ self-weight of the loading system) which is equal to the allowable factor of safety for shear 
failure. As such, panel group $\mathrm{J}$ meets both the serviceability and ultimate limit states requirements. Thus, it can be considered qualified to be as good as the conventional frame building in Part 4 and Part 9 of NBCC of 2005.

\subsection{Group K}

In this group, three identical panels were tested to complete collapse, namely: S-31, S-32 and S-33. Each panel was of $260 \mathrm{~mm}$ thickness, $1.2 \mathrm{~mm}$ width and $4.27 \mathrm{~m}$ length, with lumber-spline connection. Figures AI-152 to AI-171 summarizes the experimental findings for this panel group. It was observed that all panels failed due to horizontal shear failure between the top surface of the foam and the adhesive over a panel length between the support and the quarter-point line, causing delamination (debonding) between the top foam-OSB interface and the foam core over the support. Again, shear failure was sudden causing a sudden drop in the applied jacking load as depicted in the load-deflection history. From the load-deflection history for all panels, it can be observed that linear elastic behavior was maintained at the live load level (i.e. serviceability limit state) and even at the design factored load level (i.e. ultimate limit state). Table 4.1 shows the deflection values for the three panels, S-31 S-32 and S-33 at the design live load level. These values were normalized to the span length and then averaged to be span/491 which is less than the deflection limit of span/360. Table 4.2 presents a summary of panel configurations along with the ultimate jacking load, failure mode and the average ratio of the ultimate jacking load to the factored design load $(1.25 \mathrm{D}+1.5 \mathrm{~L})$. It can be observed that the ultimate jacking load was 41.89 , 44.71, and $39.00 \mathrm{kN}$ for panels S-31, S-32 and S-33, respectively. It can be observed that the average ratio of the ultimate jacking load to the design factored load is 2.40 for panel group $\mathrm{K}$ (2.51 with $2 \mathrm{kN}$ self-weight of the loading system) which is less than the allowable factor 
of safety of 3 for shear failure. To qualify panel group $\mathrm{K}$, a maximum live load of $1.44 \mathrm{kPa}$ to elevate the factor of safety for strength to 3 .

\subsection{Group L}

In this group, three identical panels were tested to complete collapse, namely: S-34, S-35 and S-36. Each panel was of $260 \mathrm{~mm}$ thickness, $1.2 \mathrm{~mm}$ width and $4.27 \mathrm{~m}$ length, with lumber-spline connection. Figures AI-172 to AI-187 summarizes the experimental findings for this panel group. It was observed that panels S-34 and S-35 failed due to horizontal shear failure between the top surface of the foam and the adhesive over a panel length between the support and the quarter-point line, causing delamination (debonding) between the top foamOSB interface and the foam core over the support. Shear failure was sudden causing a sudden drop in the applied jacking load as depicted in the load-deflection history. Panel S-36 failed in flexure at mid-length between the mid-span location and the quarter point location, with bottom OSB board fracture in tension and vertical crack in foam, as well as delamination of foam at its top interface with the top OSB board, as shown in Fig. 4.15. From the loaddeflection history for all panels, it can be observed that linear elastic behavior was maintained at the live load level (i.e. serviceability limit state) and even at the design factored load level (i.e. ultimate limit state). Table 4.1 shows the deflection values for the three panels, S-34, S-35 and S-36 at the design live load level. These values were normalized to the span length and then averaged to be span/753 which is far less than the deflection limit of span/360. Table 4.2 presents a summary of panel configurations along with the ultimate jacking load, failure mode and the average ratio of the ultimate jacking load to the factored design load $(1.25 \mathrm{D}+1.5 \mathrm{~L})$. It can be observed that the ultimate jacking load was 77.85 , 72.62 and $81.57 \mathrm{kN}$ for panels S-34 S-35 and S-36, respectively. It can be observed that the 
average ratio of the ultimate jacking load to the design factored load is 4.44 for panel group $\mathrm{L}$ which is more than the allowable factor of safety for shear failure. As such, panel group L meets both the serviceability and ultimate limit states requirements. Thus, it can be considered qualified to be as good as the conventional frame building in Part 4 and Part 9 of NBCC of 2005.

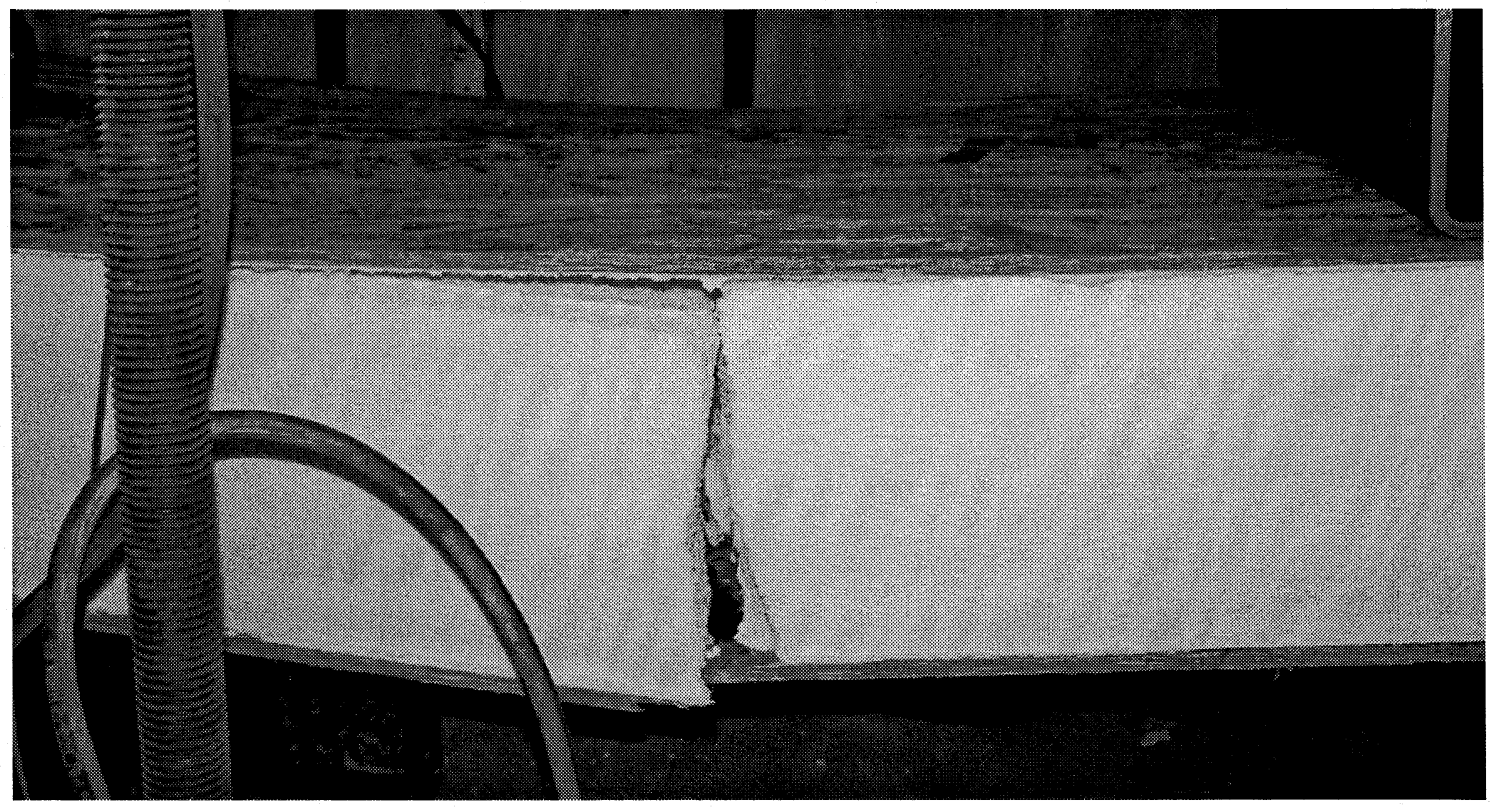

Figure 4.15 Close up of flexural failure on one free edge of specimen S-36

\subsection{Group M}

In this group, three identical panels were tested to complete collapse, namely: S-37, S-38 and S-39. Each panel was of $260 \mathrm{~mm}$ thickness, $1.2 \mathrm{~mm}$ width and $4.90 \mathrm{~m}$ length, with foam-spline connection. Figures AI-188 to AI-202 summarizes the experimental findings for this panel group. It was observed that all panels failed due to horizontal shear failure between the top surface of the foam and the adhesive over a panel length between the support and the quarter-point line, causing delamination (debonding) between the top foam-OSB interface and the foam core over the support. Again, shear failure was sudden causing a sudden drop in 
the applied jacking load as depicted in the load-deflection history. From the load-deflection history for all panels, it can be observed that linear elastic behavior was maintained at the live load level (i.e. serviceability limit state) and even at the design factored load level (i.e. ultimate limit state). Table 4.1 shows the deflection values for the three panels, S-37 S-38 and S-39 at the design live load level. These values were normalized to the span length and then averaged to be span/422 which is less than the deflection limit of span/360. Table 4.2 presents a summary of panel configurations along with the ultimate jacking load, failure mode and the average ratio of the ultimate jacking load to the factored design load (1.25D + 1.5L). It can be observed that the ultimate jacking load was $39.65,43.61$ and $42.05 \mathrm{kN}$ for panels S-37, S-38 and S-39, respectively. It can be observed that the average ratio of the ultimate jacking load to the design factored load is 2.09 for panel group M ( 2.19 with $2 \mathrm{kN}$ self-weight of the loading system) which is less than the allowable factor of safety of 3 for shear failure. To qualify panel group $\mathrm{M}$, a maximum live load of $1.19 \mathrm{kPa}$ to elevate the factor of safety for strength to 3 .

\subsection{Group N}

In this group, three identical panels were tested to complete collapse, namely: S-40,

S-41 and S-42. Each panel was of $260 \mathrm{~mm}$ thickness, $1.2 \mathrm{~mm}$ width and $4.90 \mathrm{~m}$ length, with lumber-spline connection. Figures AI-203 to AI-218 summarizes the experimental findings for this panel group. It was observed that panel S-40 failed due to flexure, with tensile fracture in both the foam core and the bottom OSB facing. While panel S-41 failed due to horizontal shear failure between the top surface of the foam and the adhesive over a panel length between the support and the quarter-point line, causing delamination (debonding) between the top foam-OSB interface and the foam core over the support. Panel S-42 failed 
due to OSB fracture in compression at the quarter point location. Table 4.1 shows the deflection values for the three panels, S-40, S-41 and S-42 at the design live load level. These values were normalized to the span length and then averaged to be span/565 which is far less than the deflection limit of span/360. Table 4.2 presents a summary of panel configurations along with the ultimate jacking load, failure mode and the average ratio of the ultimate jacking load to the factored design load $(1.25 \mathrm{D}+1.5 \mathrm{~L})$. It can be observed that the ultimate jacking load was $74.73,68.00$ and $67.37 \mathrm{kN}$ for panels S-40 S-41 and S-42, respectively. It can be observed that the average ratio of the ultimate jacking load to the design factored load is 3.49 for panel group $\mathrm{N}$ which is more than the allowable factor of safety for shear failure. As such, panel group L meets both the serviceability and ultimate limit states requirements. Thus, it can be considered qualified to be as good as the conventional frame building in Part 4 and Part 9 of NBCC of 2005.

\subsection{Groups $O$ and $P$}

In group $\mathrm{O}$, one panel was tested to complete collapse, namely: S-46, with $165 \mathrm{~mm}$ thickness, $1.2 \mathrm{~m}$ width and $2.43 \mathrm{~m}$ length, with tongue and groove link. A similar test was conducted in similar panel S-47 but with $210 \mathrm{~mm}$ thickness. Figures AI-219 to AI-230 summarizes the experimental findings for this panel group. It was observed that panel S-46 failed due to diagonal shear crack in the foam core at a location close to the support. While panel S-47 failed due to OSB crushing at the quarter point line. Both failure modes happened suddenly with noise. Panel S-36 failed in flexure at mid-length between the mid-span location and the quarter point location. From the load-deflection history for all panels, it can be observed that linear elastic behavior was maintained at the live load level (i.e. serviceability limit state) and even at the design factored load level (i.e. ultimate limit state). 
Table 4.1 shows the deflection values for the three panels, S-46 and S-47 at the design live load level. These values were normalized to the span length and then averaged to be span/933 and span/994 for S-46 and S-47, respectively, which is far less than the deflection limit of span/360. Table 4.2 presents a summary of panel configurations along with the ultimate jacking load, failure mode and the average ratio of the ultimate jacking load to the factored design load $(1.25 \mathrm{D}+1.5 \mathrm{~L})$. It can be observed that the ultimate jacking load was 52.01 and $59.68 \mathrm{kN}$ for panels S-46 and S-47, respectively. As such, the factor of safety for panel S-46 and S-47 were 5.37 and 6.16 , respectively, which is more than the allowable factor of safety for shear failure. It is recommended that at least one more panels to be tested in each group so that a reliable factor of safety can be recommended in design based on AC04 Acceptance Criteria.

\subsection{Flexure-Creep Test Results}

Flexure-creep tests were conducted on panels S-43, S-44 and S-45. All panels were loaded with the value of the dead load and live load at service loading conditions. (i.e. $\mathrm{D}+\mathrm{L}$ $=0.5+1.9=2.4 \mathrm{kPa})$. As such, panel S-43 was uniformly loaded using 24 cement bags $(40$ $\mathrm{kg}$ each) in two layers. This would make the sustained loading as $2.67 \mathrm{kPa}$ rather than the specified $2.4 \mathrm{kPa}$. Figures 4.15 and 4.16 show views of panel S-43 before and during creep testing. Similar arrangement was made for S-44 as shown in Figs. 4.18 and 4.19 using 28

cement bags. This made the sustained loading as $2.59 \mathrm{kPa}$. For S- 45,32 cement bags were used to load the panel in two layers during creep testing, making the applied creep loading as $2.46 \mathrm{kPa}$. Figures 4.21 and 4.22 show views of S- 45 before loading and during creep testing. 
Each panel was instrumented with three dial gauges at the mid-span location to measure edge and central deflections with time. After taking initial readings, each panel was loaded with the cement bags in two layers. Then, dial reading was recorded after 5 minutes of applying the loading. Then, deal readings were recorded every 30 minutes for six hours, followed by recording readings every day for 47 days. Then, each panel was unloaded. After unloading, dial gauge reading was recorded every 30 minutes for 6 hours. Figure 4.17 show the deflection-time history at the mid-span location of panel S-43. It was observed that immediate deflection after application of full dead and live load was $7.87 \mathrm{~mm}$, while it was $14.06 \mathrm{~mm}$ after 47 days and $5.82 \mathrm{~mm}$ after 6 hours of unloading. As such, the creep deflection was $79 \%$ of the original deflection. Figure 4.20 show the deflection-time history at the mid-span location of panel S-44. It was observed that immediate deflection after application of full dead and live load was $9.91 \mathrm{~mm}$, while it was $16.11 \mathrm{~mm}$ after 47 days and $14.78 \mathrm{~mm}$ after 6 hours of unloading. As such, the creep deflection was $63 \%$ of the original deflection. Figure 4.23 show the deflection-time history at the mid-span location of panel S45. It was observed that immediate deflection after application of full dead and live load was $11.00 \mathrm{~mm}$, while it was $17.81 \mathrm{~mm}$ after 47 days and $16.38 \mathrm{~mm}$ after 6 hours of unloading. As such, the creep deflection was $62 \%$ of the original deflection.

Based on the limited number of test specimens for flexure-creep testing, it is recommended to repeat creep tests over wide range of panel sizes and over a longer period of time to assist in developing a creep model for SIPs so that the long-term deflection can be determined as a fraction from the immediate deflection under sustained loading. 


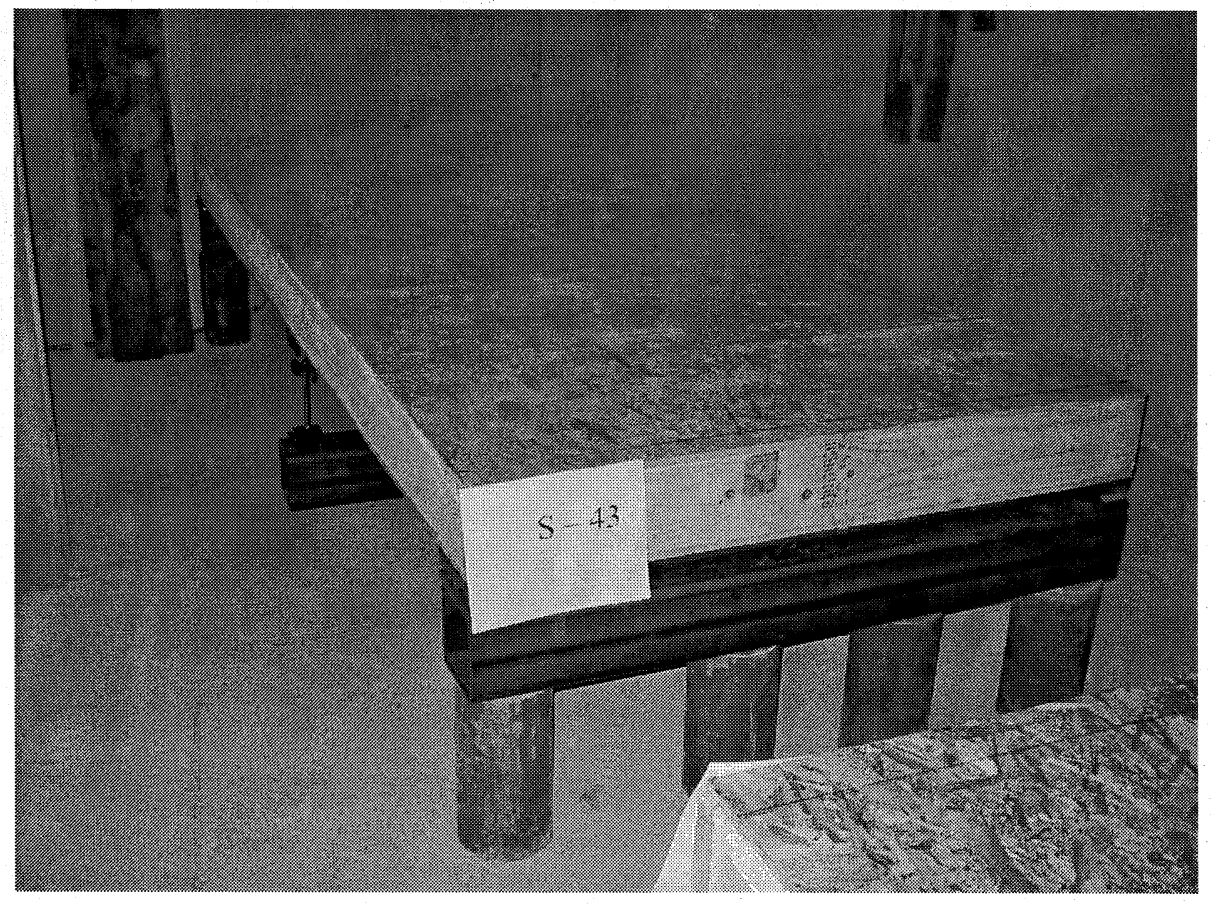

Figure 4.16 View of panel S-43 before start of creep test

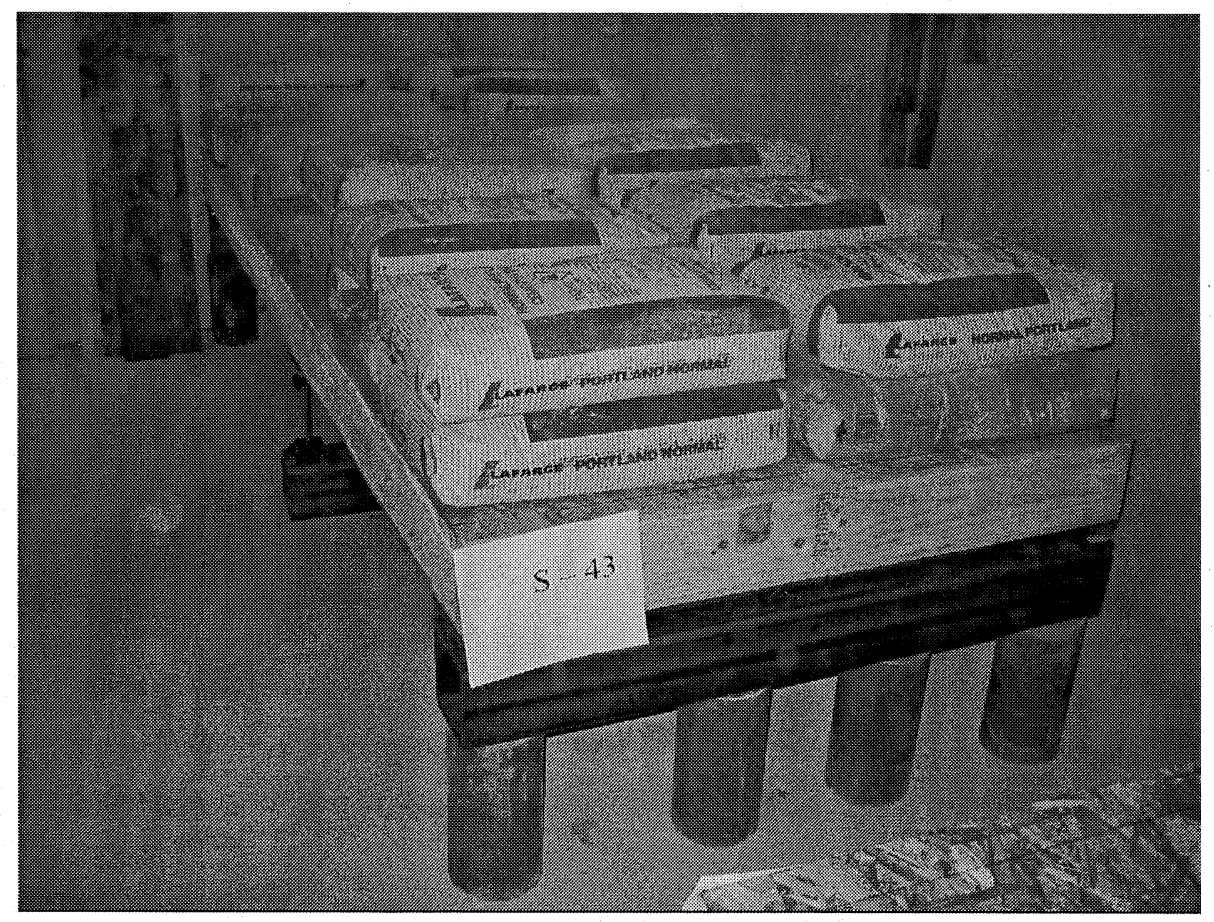

Figure 4.17 View of loaded panel S-43 before during creep test 


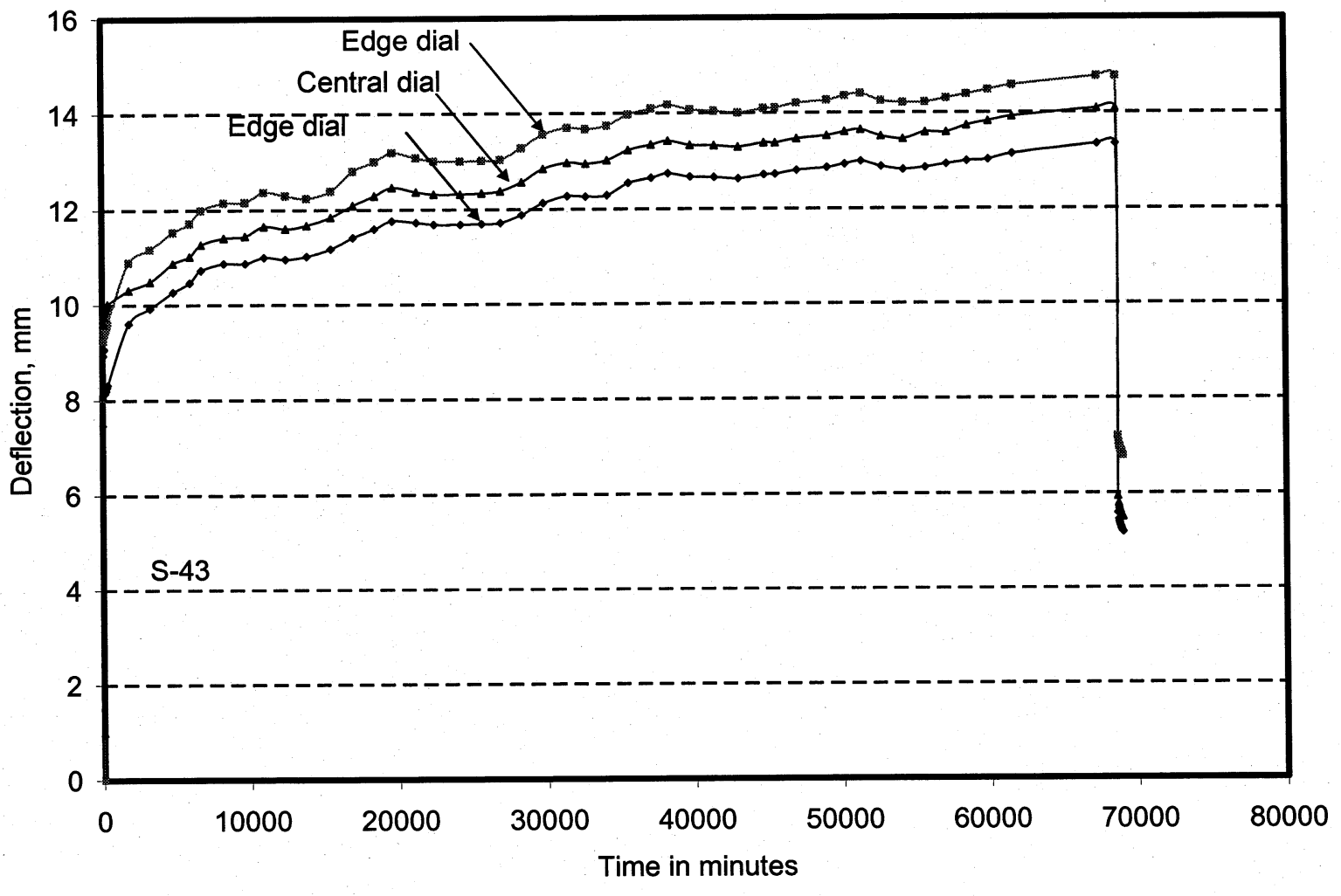

Figure 4.18 Deflection-time history for panel S-43

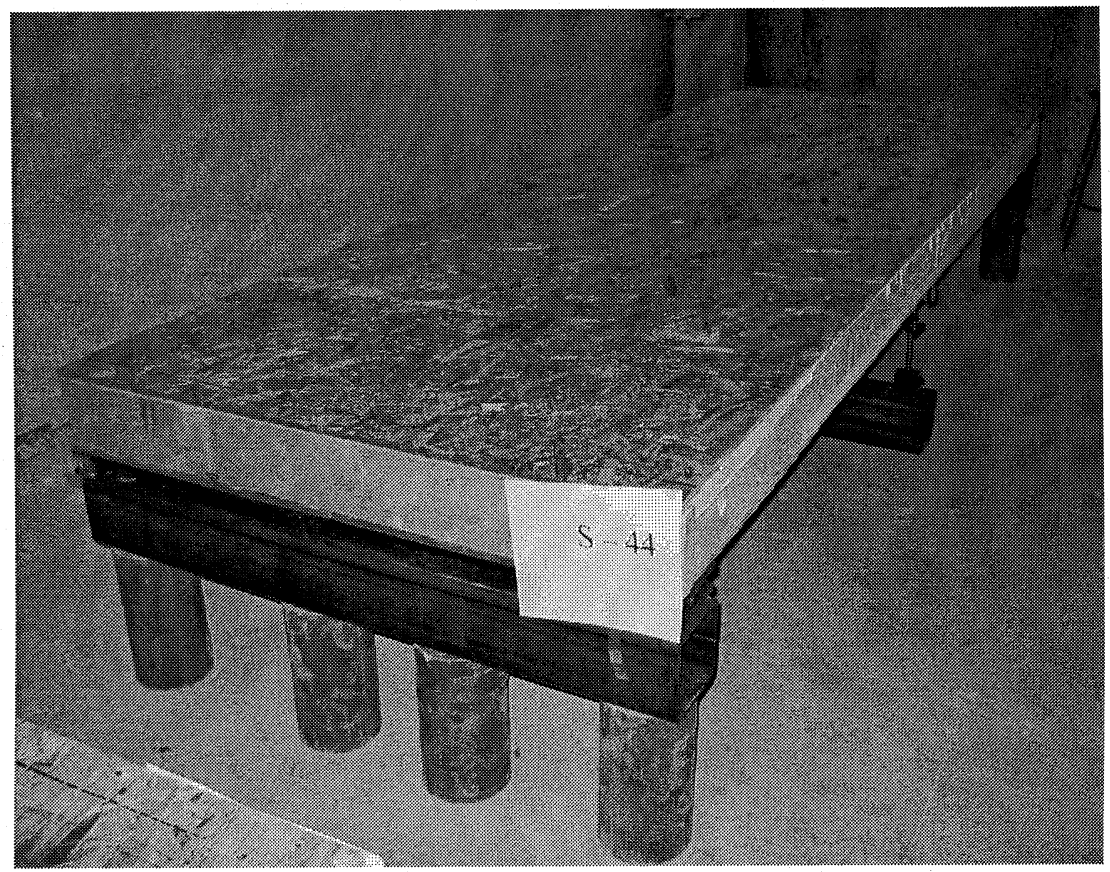

Figure 4.19 View of panel S-44 before start of creep test 


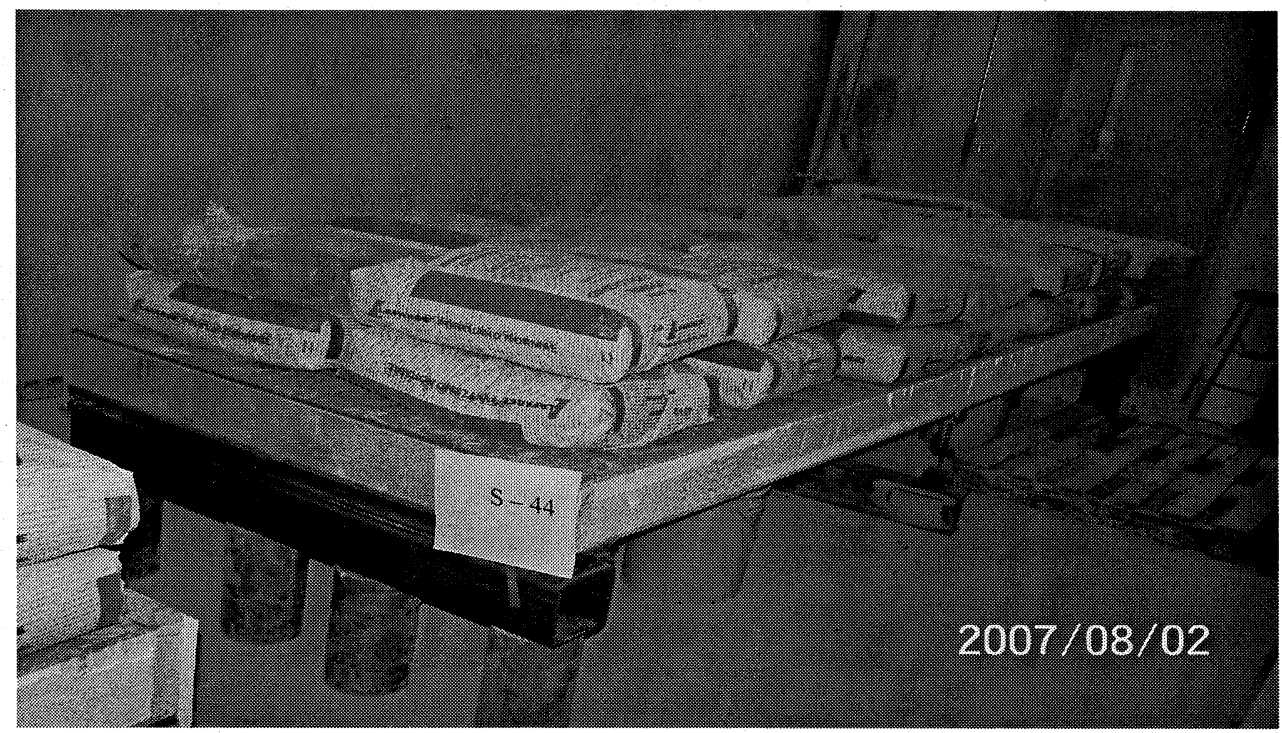

Figure 4.20 View of loaded panel S-44 before during creep test

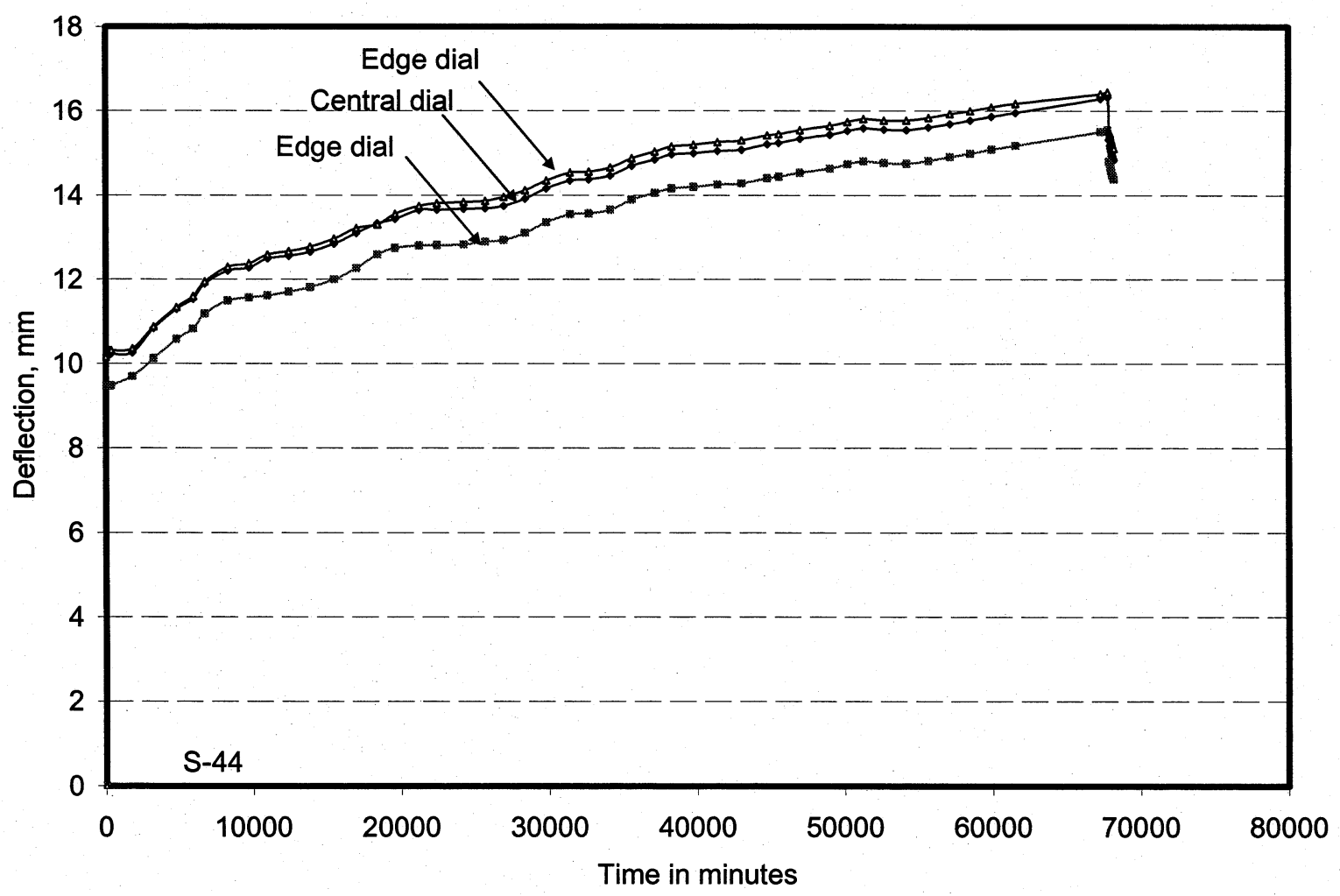

Figure 4.21 Deflection-time history for panel S-44 


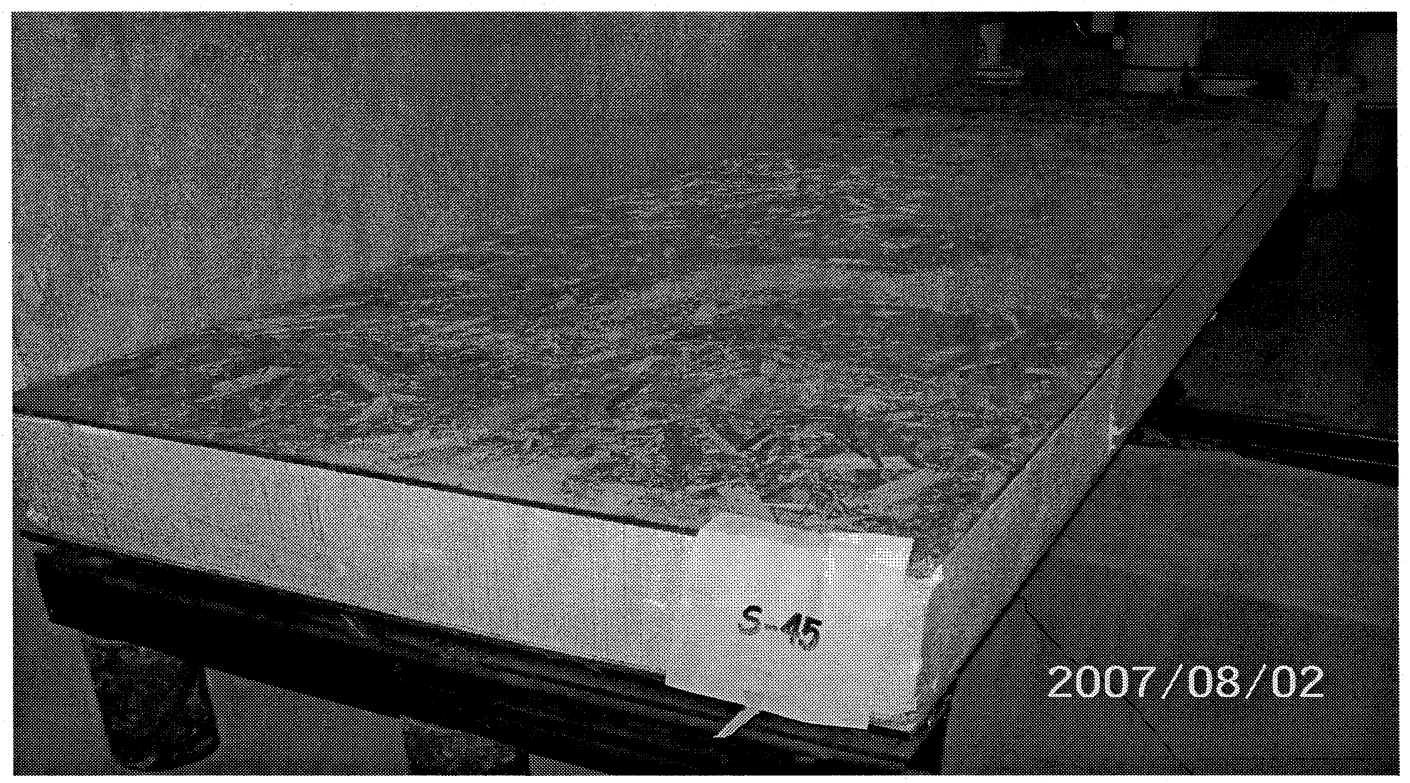

Figure 4.22 View of panel S-45 before start of creep test

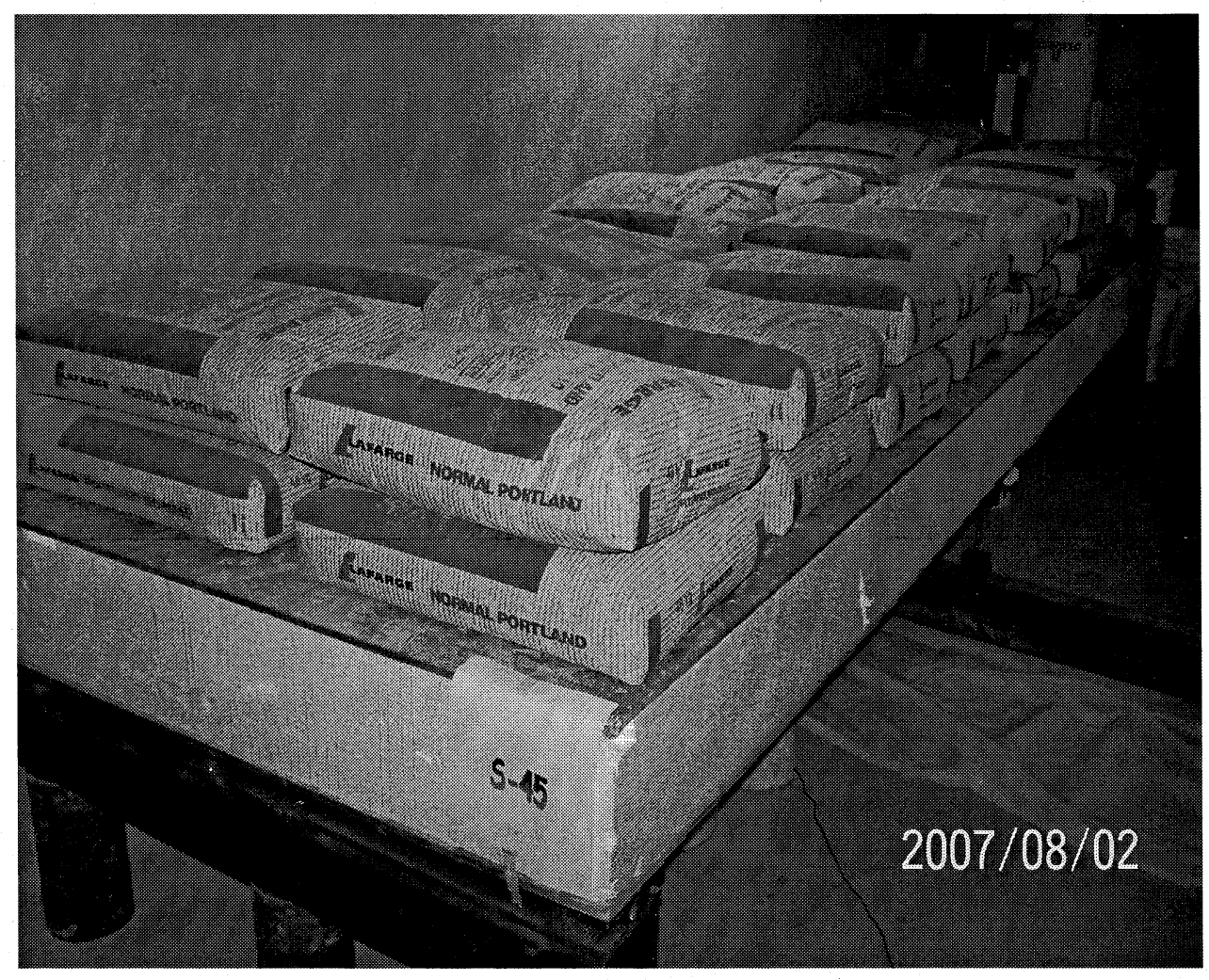

Figure 4.23 View of loaded panel S-45 before during creep test 


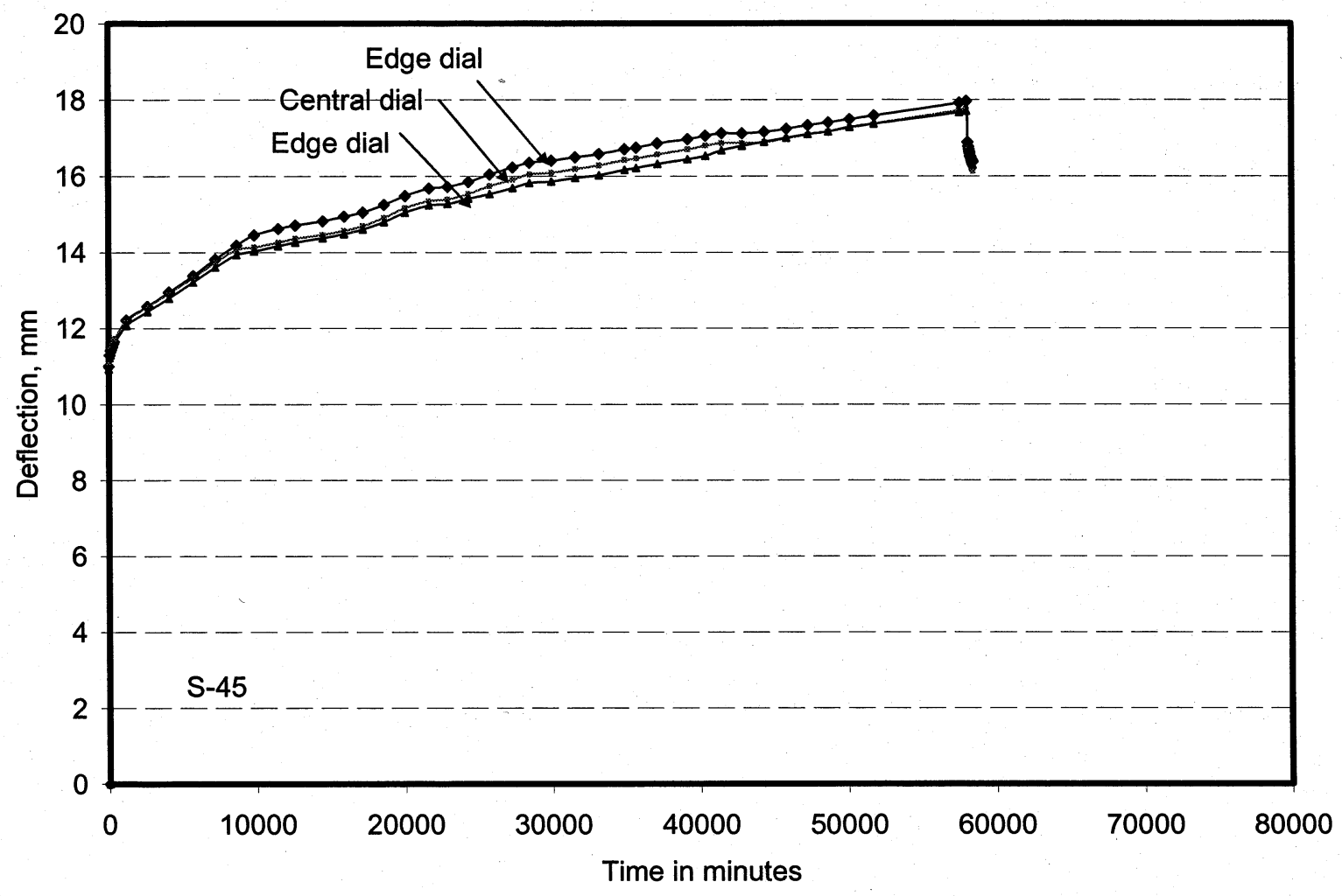

Figure 4.24 Deflection-time history for panel S-45 


\section{CHAPTER V}

\section{SUMMARY AND CONCLUSION}

\subsection{General}

An extensive experimental program was conducted to investigate the static structural behavior of structural insulated sandwich timber panels under flexural and creep loading. A literature review was conducted in order to establish the foundation of the study. The experimental program included testing to-collapse 53 actual-size timber panels according to ASTM standards. Discussion of the experimental results with respect to the structural adequacy of the tested sandwich panels for possible use in residential construction was presented, with emphasis on code requirements for ultimate and serviceability limit states design of such panels.

\subsection{CONCLUSIONS}

Based on the experimental finding, the following conclusions can be drawn:

1- The dominant failure mode in panels with foam-spline connection is due to horizontal shear between OSB facing and the foam core at location between the support and the quarter points.

2- All tested SIPs met the serviceability limit state design requirements irrespective of the type of the connection between panels in floor or roof systems, with a minimum factor of safety more than 3 .

3- All tested SIPs with solid lumber-spline connections met the ultimate limit state design requirements with a minimum factor of safety more than 3 . 
4- Some of the tested SIPs with foam-spline connections met the ultimate limit design requirements with a factor of safety equal or more than 3 . Other panels with foamsspline connections had factors of safety less than 3 and need to be qualified by assigning a maximum live load that would limit the factor of safety to 3 .

5- Few panels with foam-spline connections had more than $15 \%$ difference in flexural strength from the average of the three panels in a panel group. In spite the fact that one additional panel was tested, a fifth panel may be required to be tested so that the average of the five panels may qualify them to be as good as the conventional framing buildings per AC-04.

6- It may be concluded that the presence of foam-spline connections between shallow panels may not significantly affect the serviceability and ultimate limit states design of such panels when assuming that the foam core and the OSB facings of $1200 \mathrm{~mm}$ width. However, this effect increases with increase in panel thickness.

7- The live load deflection of panels with lumber-spline connection is less than that for panels with foam-spline connection. Also, the ultimate load carrying capacity in flexure for panels with lumber-spline connection is more than that for panels with foam-spline connections, as expected. 


\subsection{RECOMMENDATIONS FOR FUTURE RESEARCH}

1- Extend flexure-creep testing study to include more panel sizes and longer duration of the sustained loading (i.e. up to one year) so that a reliable equation for the long-term deflection can be developed.

2- Study the ultimate capacity and serviceability of SIPs under impact loading as well as under concentrated static load.

3- Conduct finite-element modeling of the tested panels to developed empirical expressions for the ultimate load carrying capacity for various SIP sizes. 


\section{REFERENCES}

Allen, H. G. (1969). Analysis and Design of Structural Sandwich Panels. Pergaman Press. APA. 1993. Design and Fabrication of Plywood Sandwich Panels. APA - The Engineering Wood Association, Tacoma, WA, USA.

ASTM. 2002. Standard Test Methods of Conducting Strength Tests of Panels for Building Construction, ASTM E72-02. American Society from Testing Materials, Philadelphia, PA, USA.

1988. Standard Test Methods of for Flexural Creep of Sandwich Construction. 5. ASTM C 480-62. American Society fro Testing Materials, Philadelphia, PA, USA.

Aviles, F. and Carlsson, L. (2006). Experimental Study of Debonded Sandwich Panels under Compressive loading. Journal of Sandwich Structures and Materials. 8: 7-31.

Canadian Standard Association. (1992). Construction of Preserved Wood Foundation, CAN/CSA-S406-92. Etobicoke, Ontario, Canada.

Canadian Standard Association (2001). Engineering Design of Wood. CAN/CSA-086-01 Etobicoke, Ontario, Canada.

Canadian Wood Council. (2005). Wood Design Manual 2005. Ottawa, Canada.

Gupta, N., Kishore, Woldesenbet, E. and Sankaran, S. (2001). Studies on Compressive Failure, Features in Syntactic foam Material, J. Mater. Sci., 36(18).

Gupta, N. and Woldesenbet, E. (2005).Characterization of Flexural Properties of Syntactic Foam Core Sandwich Composites and Effect of Density Variation. Journal of Composite Materials, 39: 2197-2212. 
Gupta, N., Woldesenbet, E., Hore, K. and Sankaran, S. (2002). Response of syntactic foam core sandwich structured composites to three point bending. Journal of Sandwich Structures and Materials, 4: 249-272.

Hossain, K. and Wright, H. (2004). Flexural and Shear Behavior of Profiled Double Skin Composite Elements. Journal of Steel and Composite Structures, 4(2): 1-20.

ICC AC04. (2004). Acceptance Criteria for Sandwich Panels. ICC Evaluation Service Inc., USA.

Institute for Research in Construction. 2005. National Building Code of Canada, NBCC2005. National Research Council, Ottawa, Ontario, Canada.

Institute for Research in Construction. 2007. Technical Guide for Stressed Skin Panels (with lumber $1200 \mathrm{~mm}$ o.c. and EPS Core) for Walls and Roofs. National Research Council, Ottawa, Ontario, Canada.

Liu, Q. and Zhao, Y. (2007). Effect of Soft Honeycomb Core on Flexural Vibration of Sandwich Panel using Low Order and High Order Shear Deformation Models. Journal of Sandwich Structures and Materials. 9: 95-108.

Meyer-Peining, H. (2006). Sandwich Plates: Stresses, Deflections, Buckling and Wrinkling Loads - A Case Study. Journal of Sandwich Structures and Materials. 8: 381-394.

Olsson, R. (2002). Engineering Method for Prediction of Impact Response and Damage in Sandwich panels. Journal of Sandwich Structures and Materials. 4: 3-29.

Structural Board Association. (2004). OSB Performance by Design Manual: Construction Sheathing and Design Rated Oriented Strand Board. Markham, Ontario, Canada.

Taylor, S. B. (1996). The Flexural Creep Behavior of Structural Insulated Panel (SIP) Sandwich Beam. Ph.D. Thesis. The Pennsylvania State University, University Park. 
Tham, L., Chong, K., and Cheung, Y. (1982). Flexural Bending and Axial Compression of Architectural Sandwich Panels by Combined Finite-Prim-Strip Method. Journal of Reinforced Plastics and Composites, 1: 16-28.

Thermapan Structural Insulated Panels Inc. 2007. www.thermapan.com.

Yoon, K., Kim, C. and Park, H. (2002).Nonlinear Flexural Deflection of Thermoplastic Foam Core Sandwich Beam. Journal of Composite Materials, 36: 1529-1539.

M.E. Raville Deflection and stresses in a uniformly loaded, simply supported, rectangular sandwich plate, FPL report1847, Dec. 1955.

W.S. Hemp, On a theory of Sandwich construction, A.R.C., R \& M 2672, Mar. 1948.

W.G. Heath, Sandwich construction. Correlation and extension of existing theory of flat panels subjected to lengthwise compression, Aircraft Engg. 32, 377 and 378, july and Aug. 1960, pp. 186-91 and 230-5.

D. Williams, D.M.A. Leggett and H.G. Hopkins, flat Sandwich panels under compressive End loads, A.R.C., R \& M 1987, 1947.

H.L. Cox and J.R.Riddell, Sandwich construction and core materials, part 3. Instability of sandwich struts and beams, A.R.C., R \& M 2125, 1945.

J. N. Goodier and I.M. Neou, The evaluation of theoretical critical compression in Sandwich plates, J. Aero. Sci. 18, 10, Oct. 1951, pp.. 649-57.

Davis J.M. 1987. Design criteria for structural sandwich panels. The structural engineer. Vol 65A No. 12. 435-441.

Haung and Gibson. 1991 Creep of polymer foams. Journal of Materials Science. Vol 26. No. 3 . 
APPENDIX 
APPENDIX-A1 


\section{GROUP A}

\section{Specimen \# S-1}

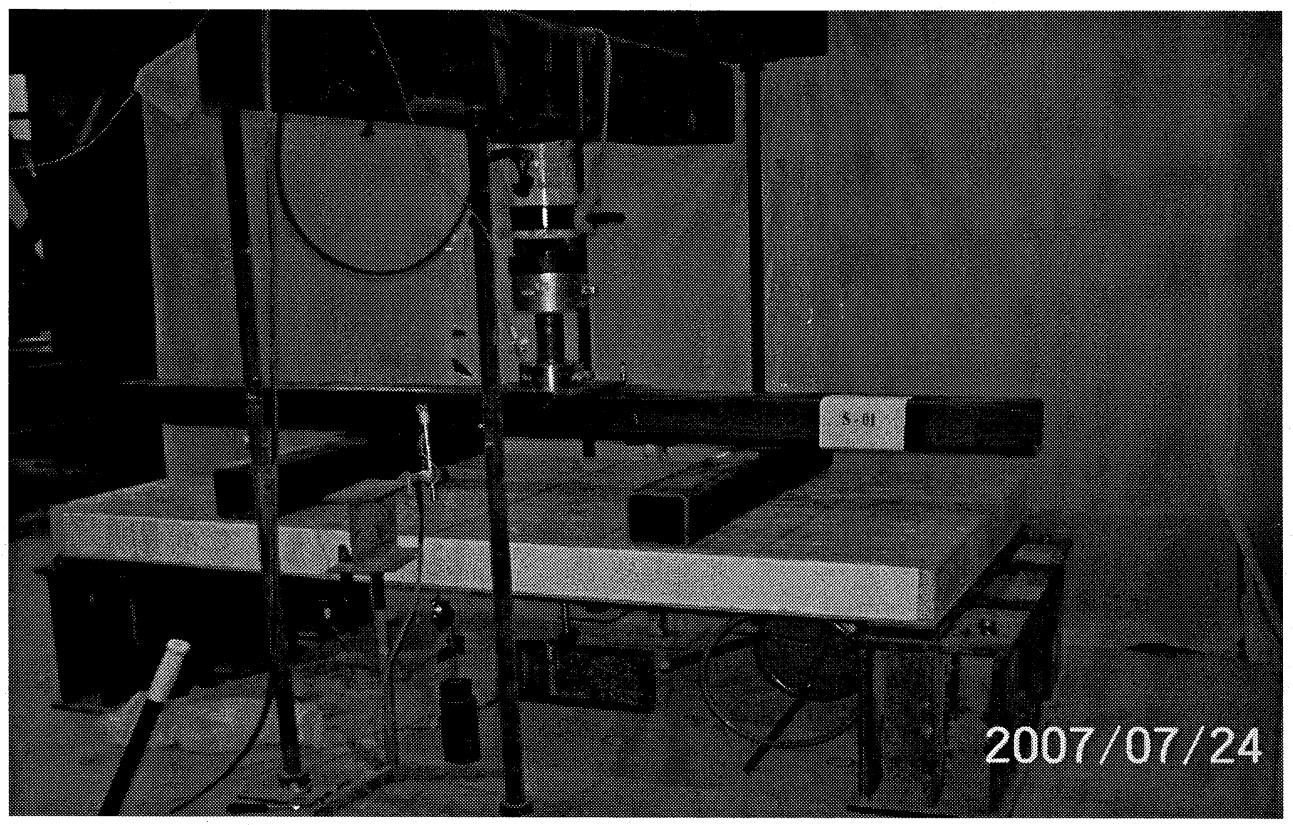

Figure AI-1. View of Specimen S-1 before testing

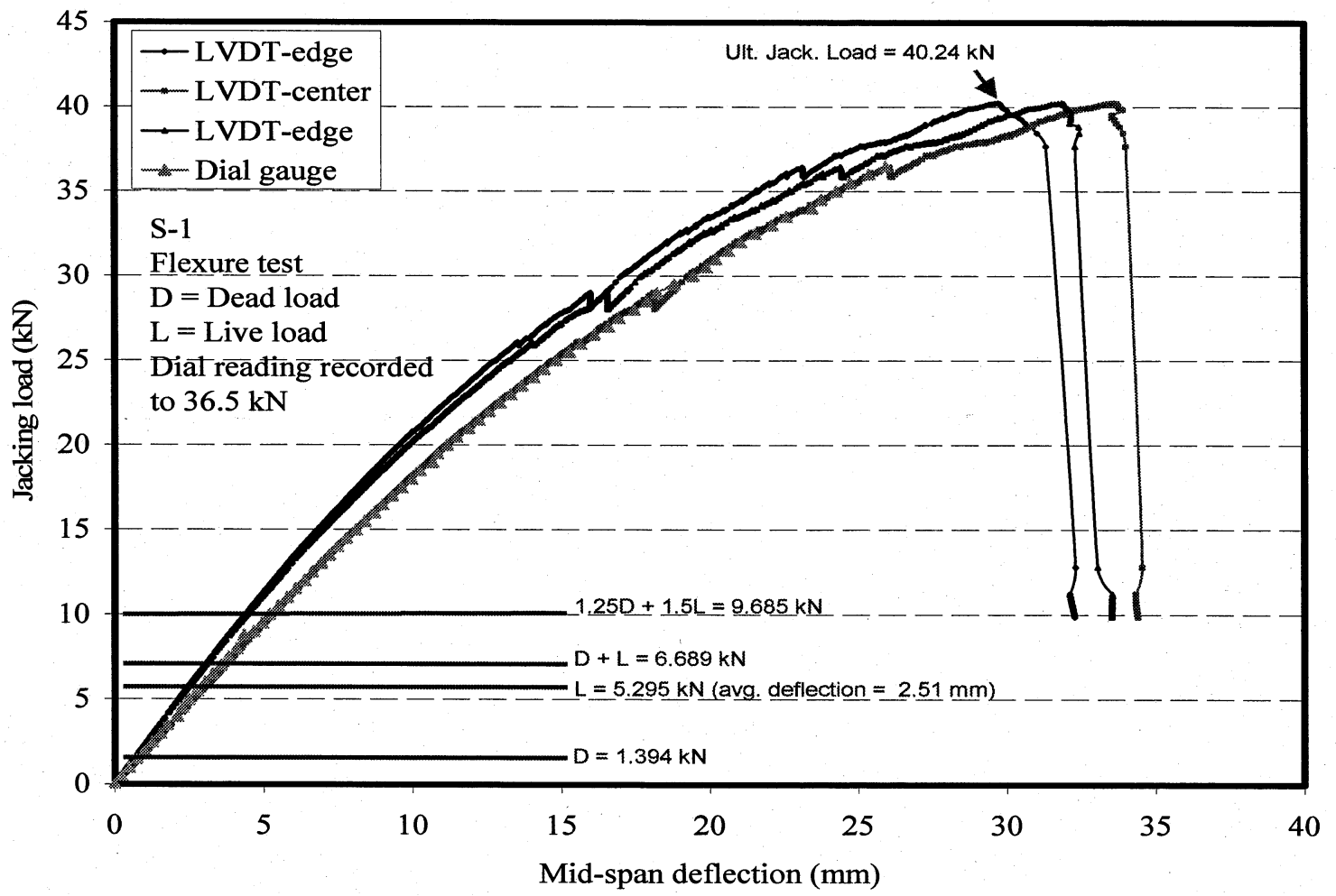

Figure AI-2. Load-deflection relationship for specimen S-1 


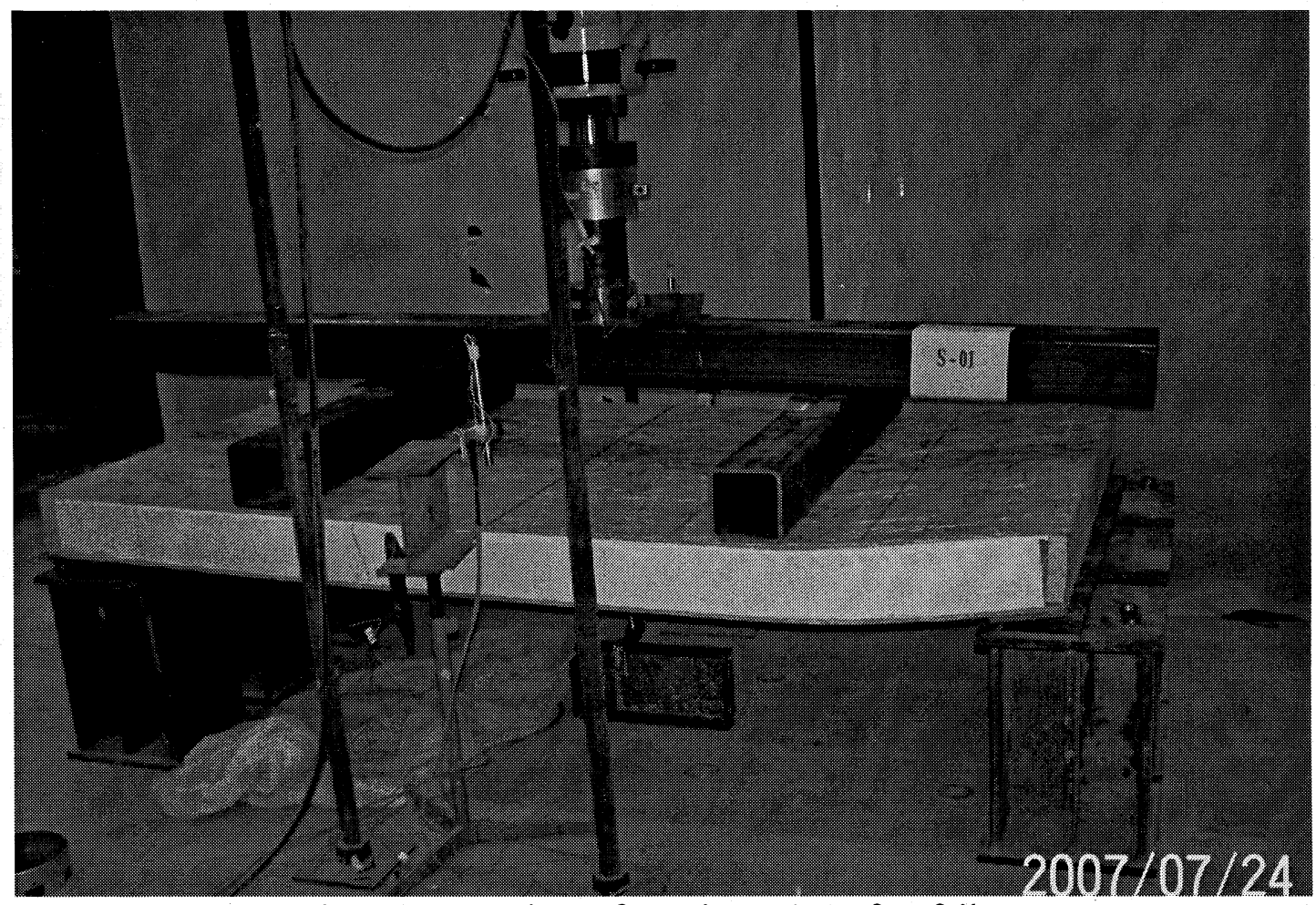

Figure AI-3. View of specimen S-1 after failure

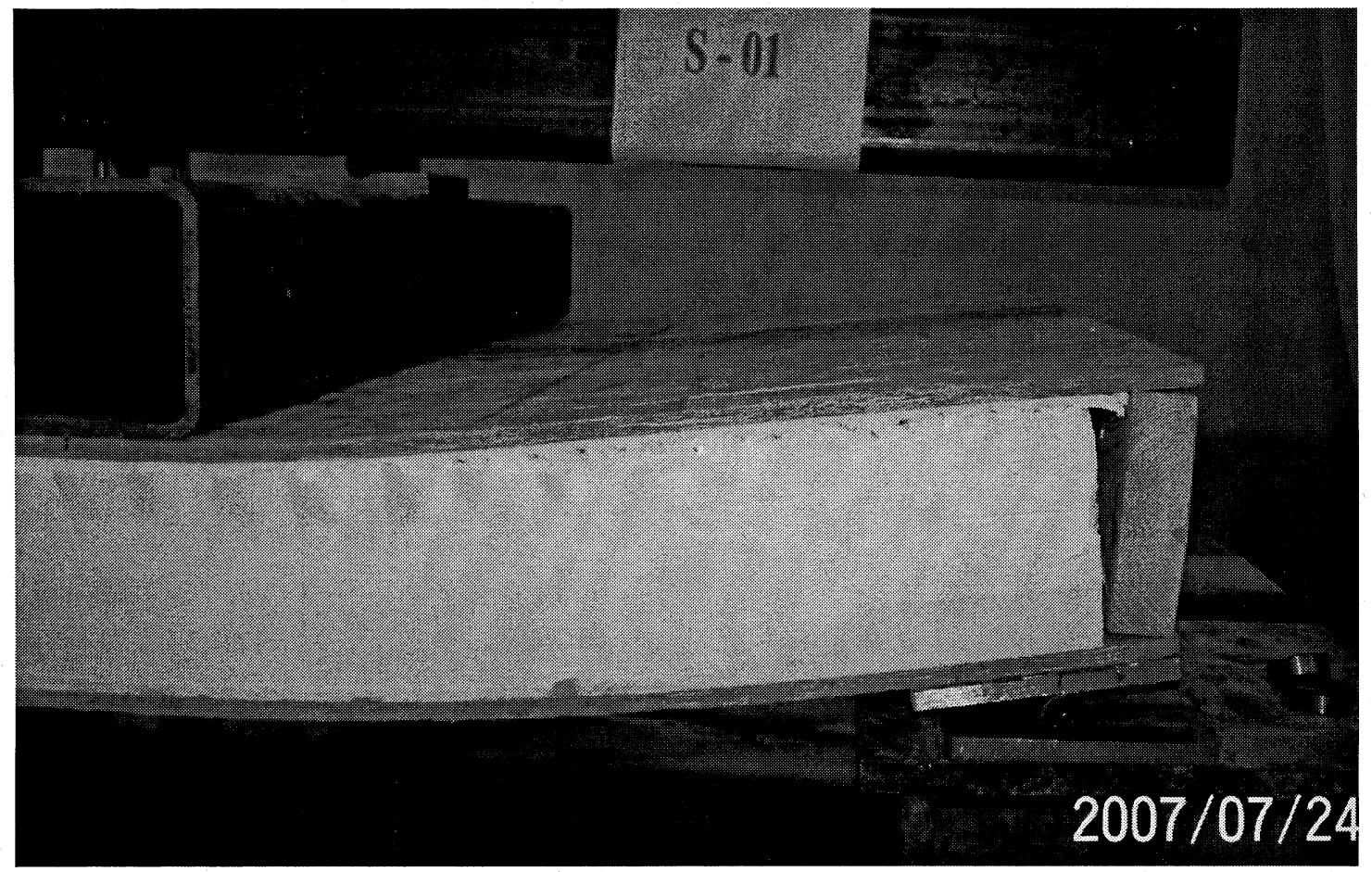

Figure AI-4. Close-up view of the failure pattern from one side of specimen S-1 


\section{Specimen \# S-2}

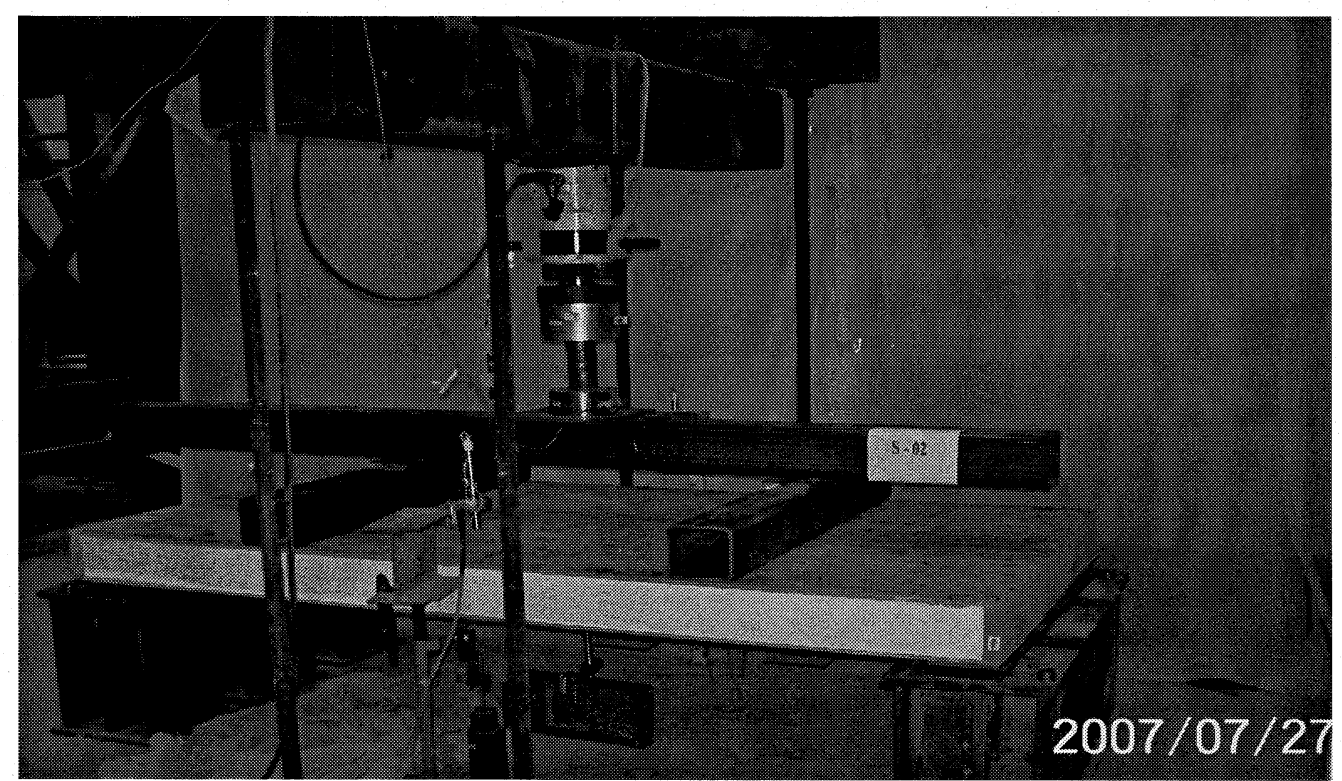

Figure AI-5. View of Specimen S-2 before testing

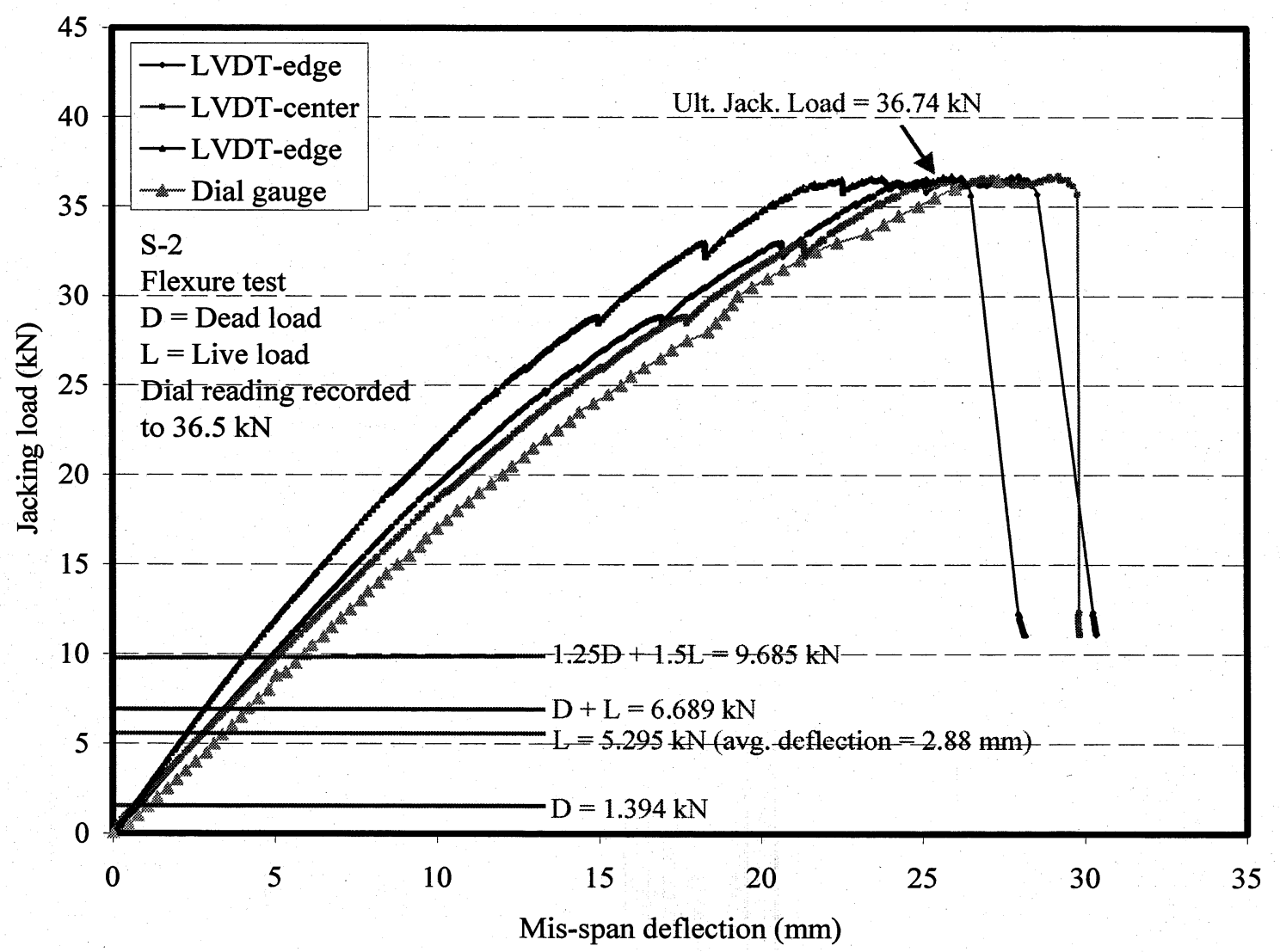

Figure AI-6. Load-deflection relationship for specimen S-2 


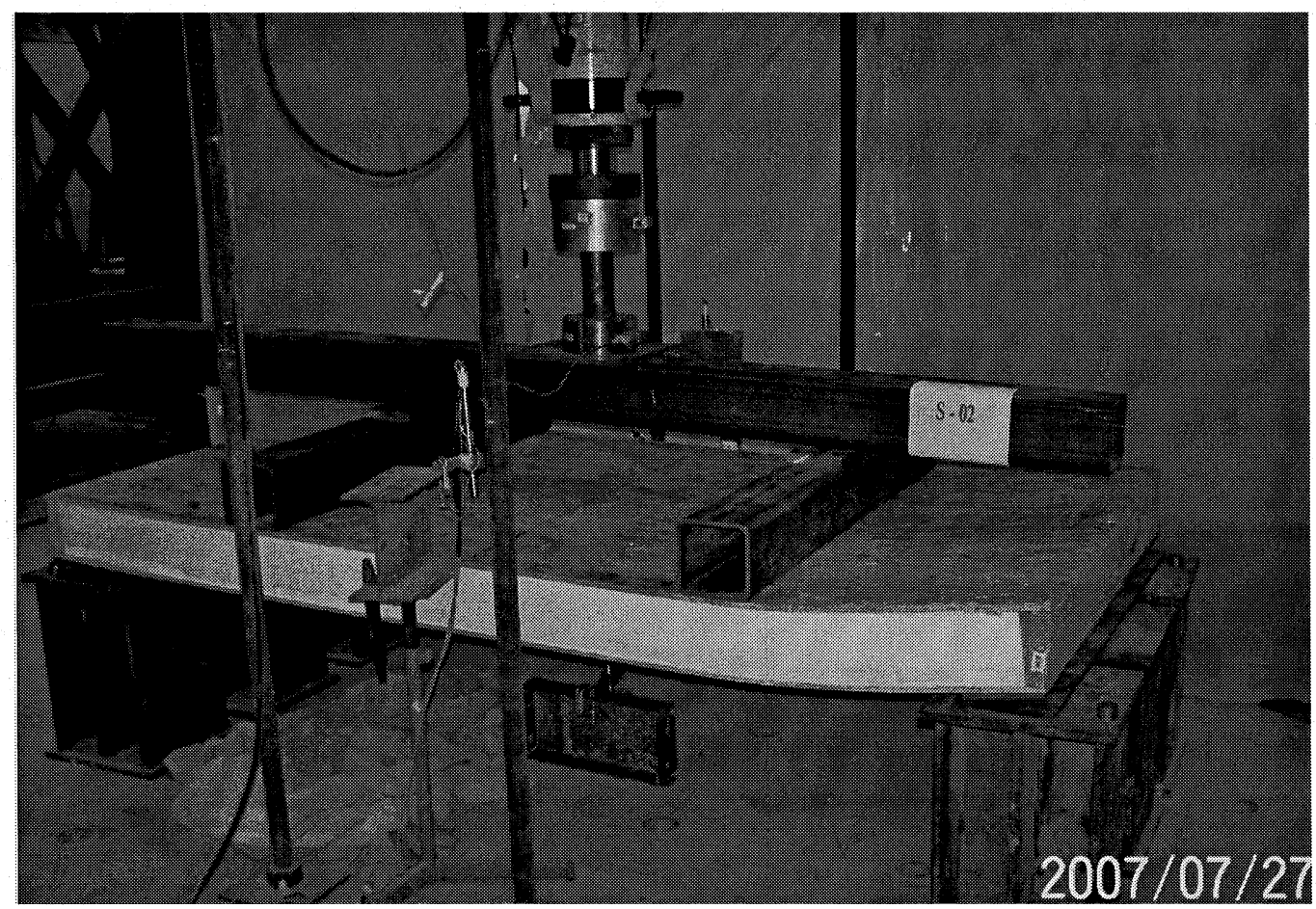

Figure AI-7. View of specimen S-2 after failure

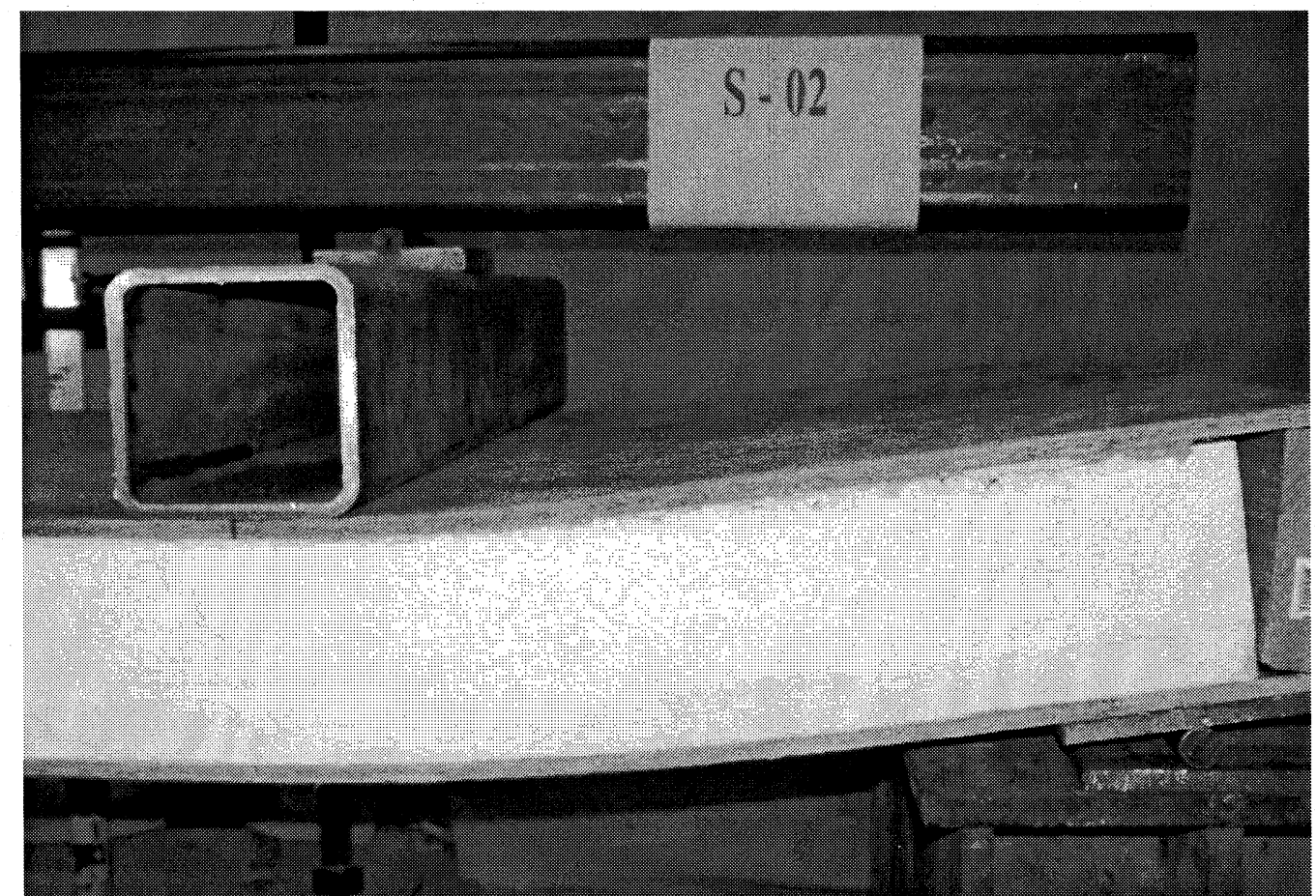

Figure AI-8. Close-up view of the failure pattern from one side of specimen S-2 


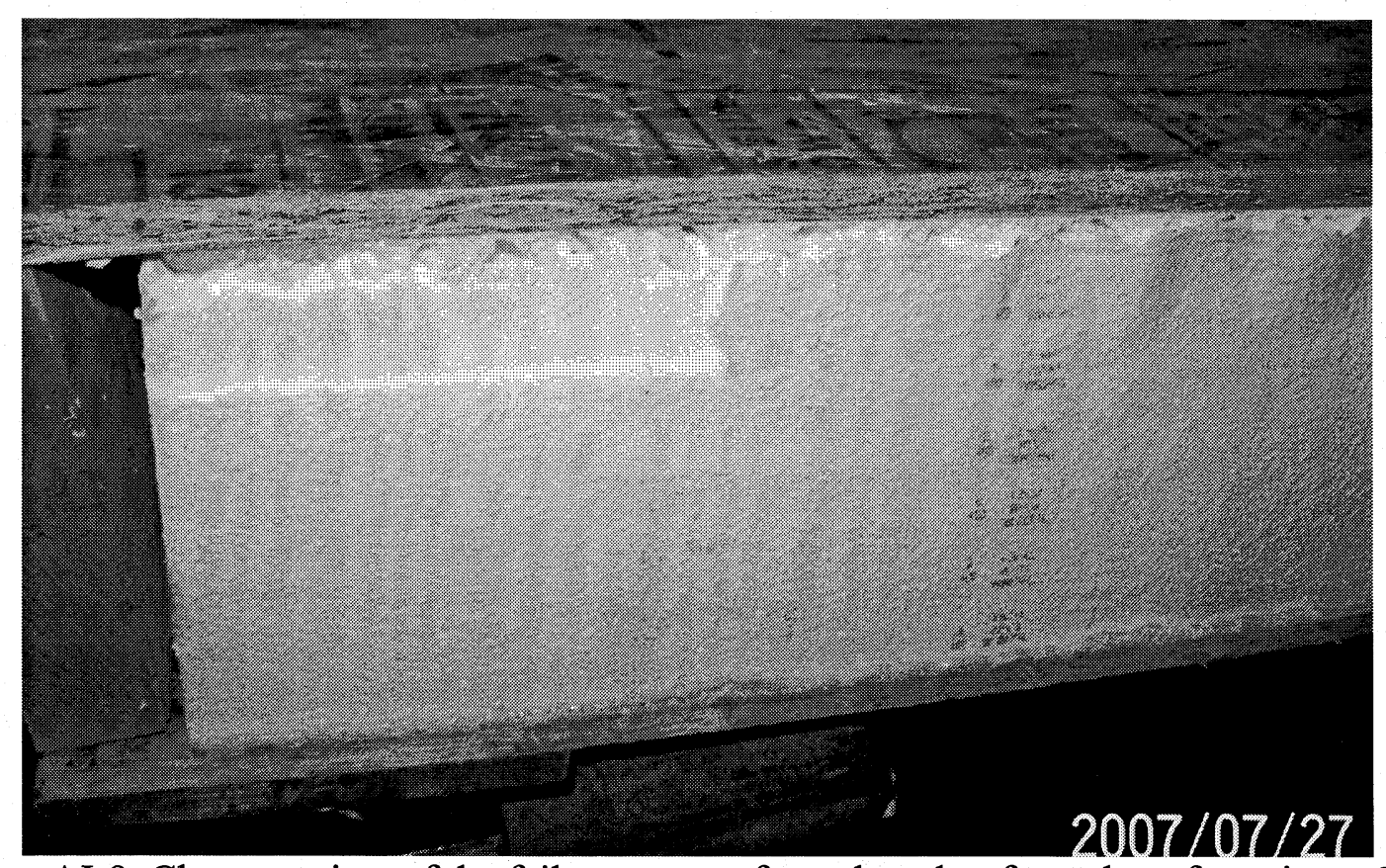

Figure AI-9. Close-up view of the failure pattern from the other free edge of specimen S-2 


\section{Specimen \# S-3}

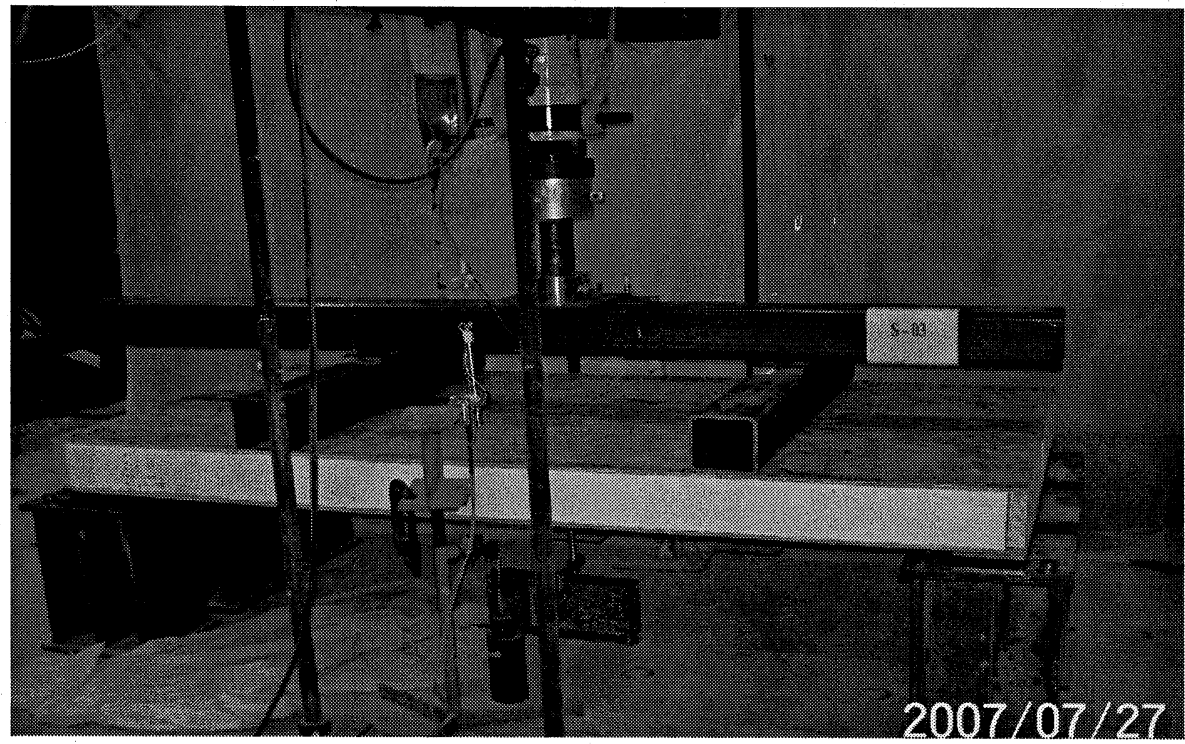

Figure AI-10. View of Specimen S-3 before testing

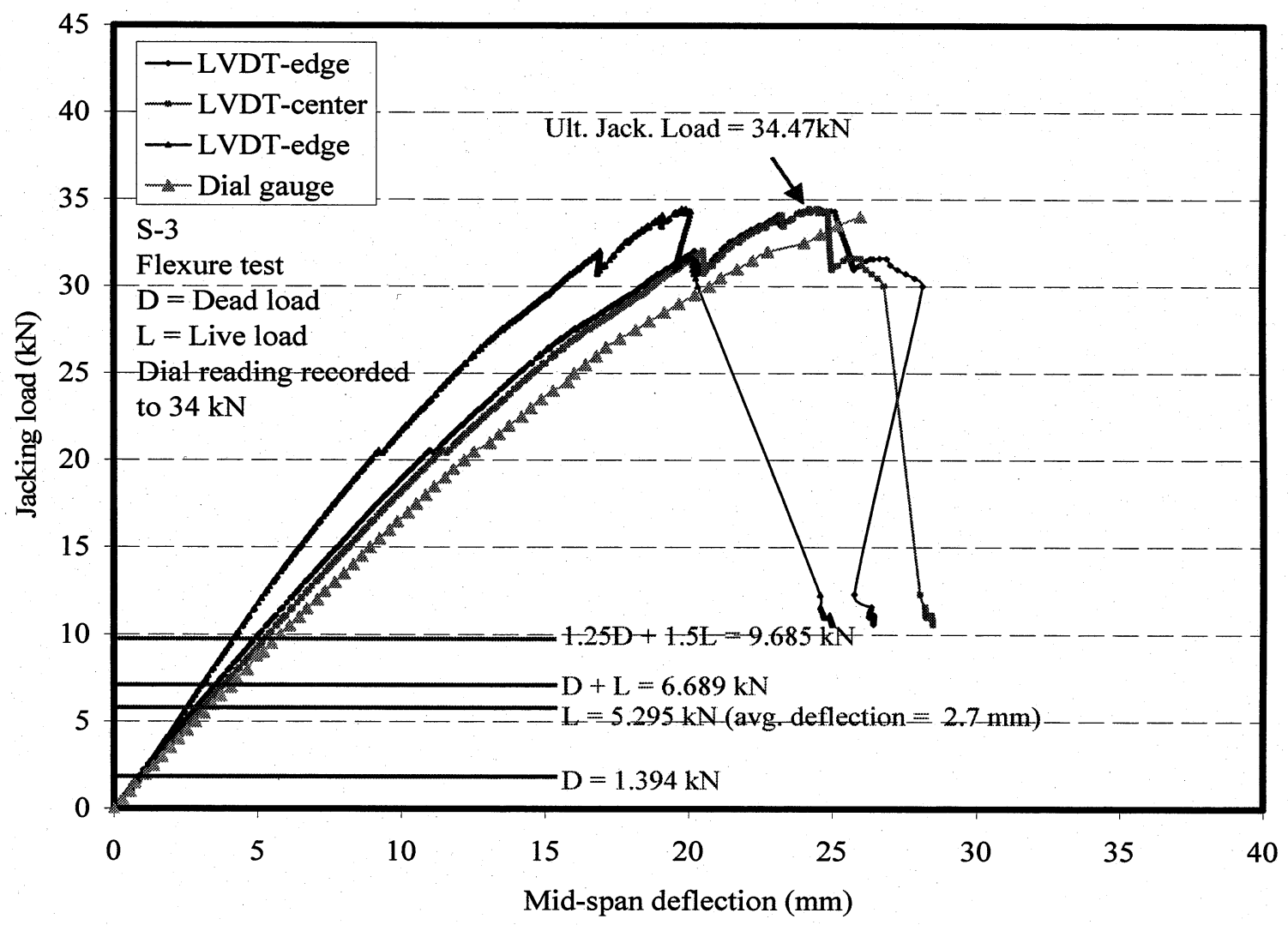

Figure AI-11. Load-deflection relationship for specimen S-3 


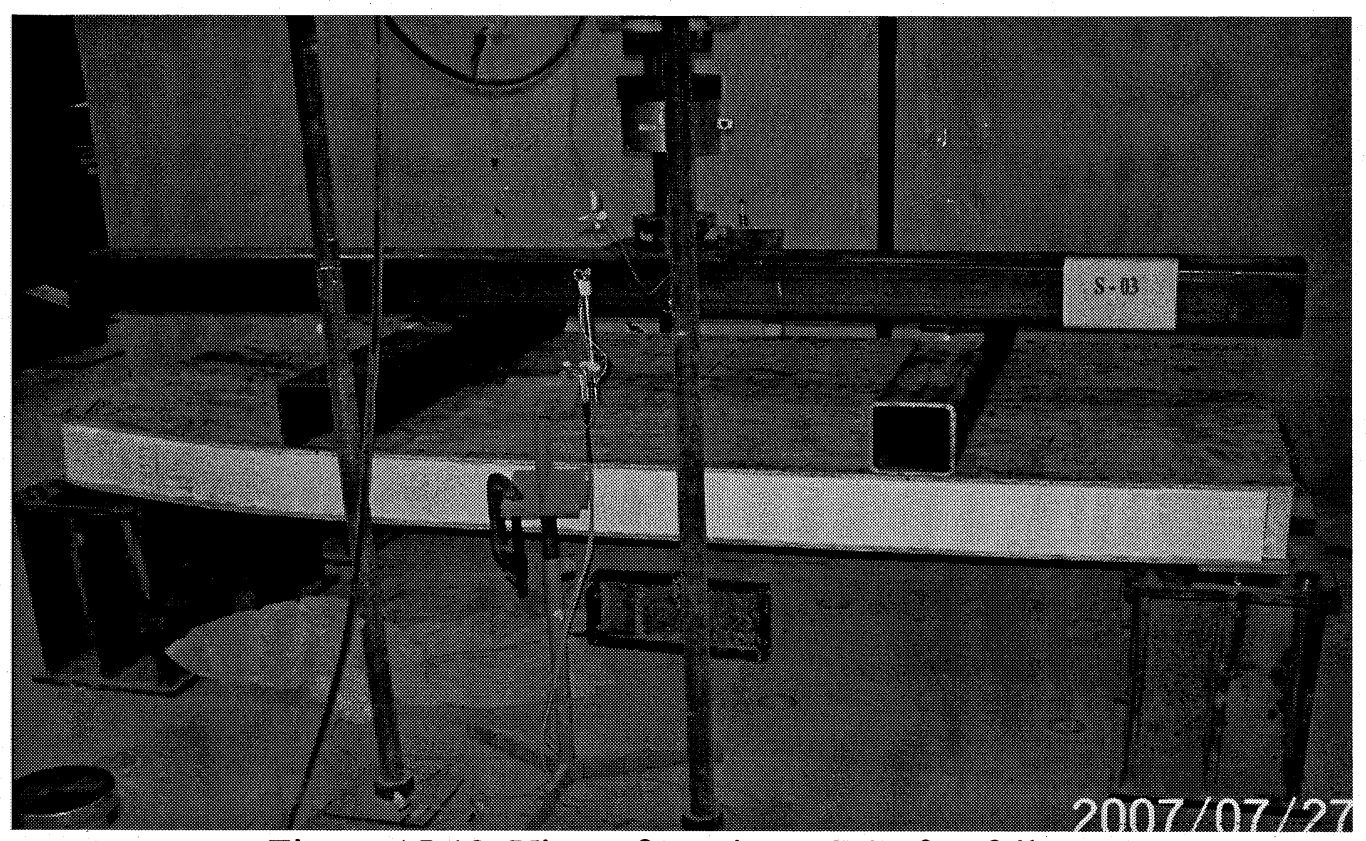

Figure AI-12. View of specimen S-3 after failure

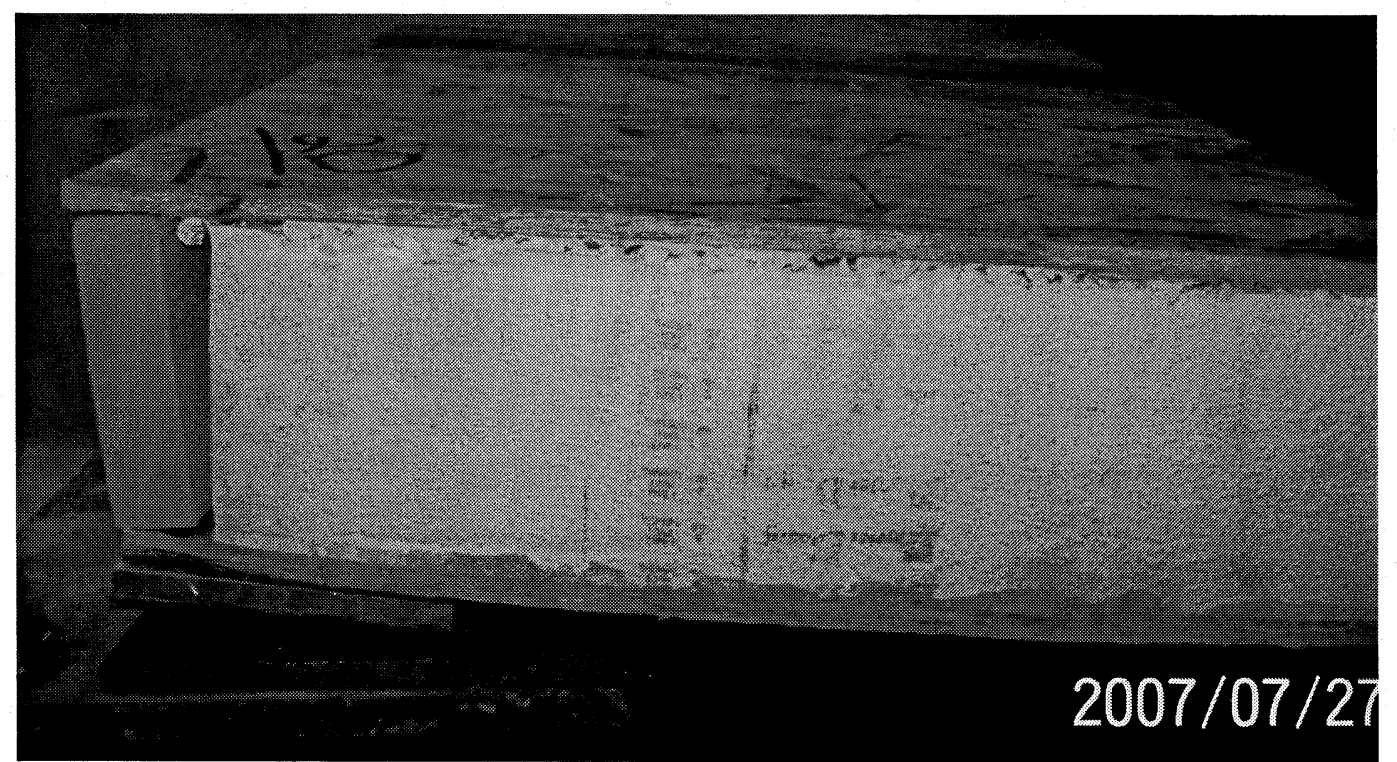

Figure AI-13. Close-up view of the failure pattern from one side of specimen S-3 


\section{GROUP B}

\section{Specimen \# S-4}

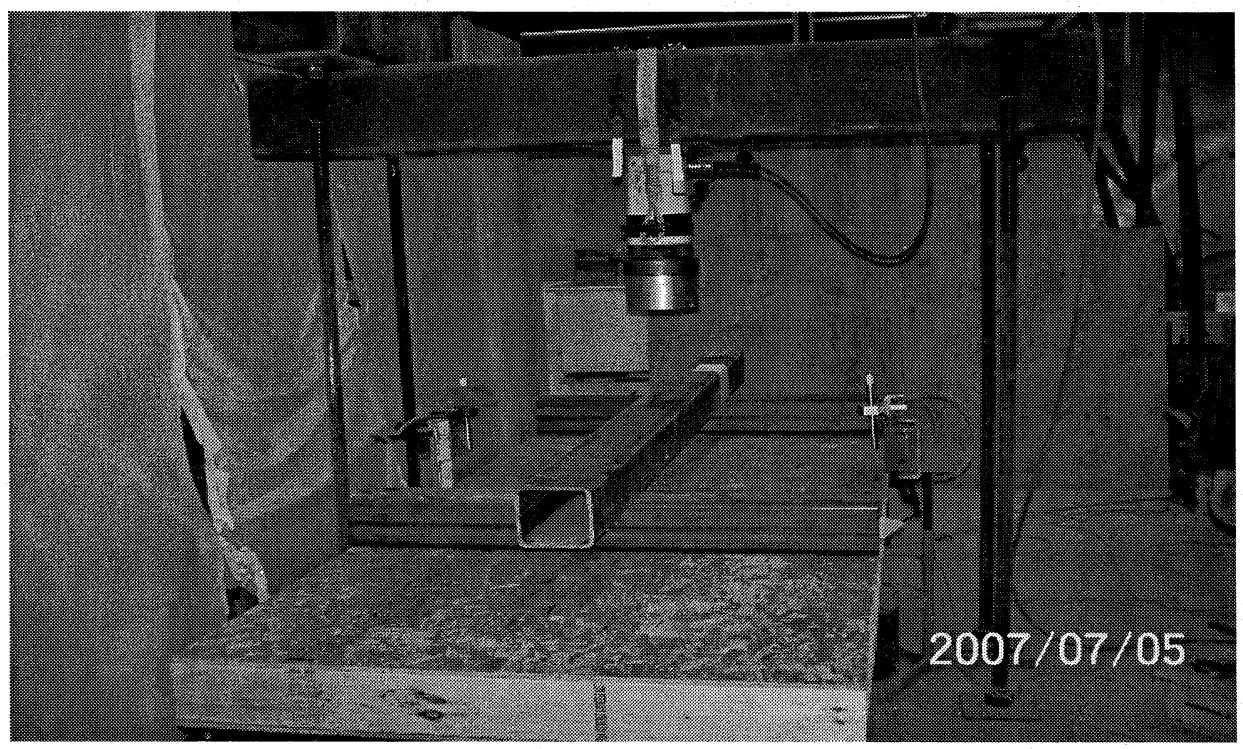

Figure AI-14. View of Specimen S-4 before testing

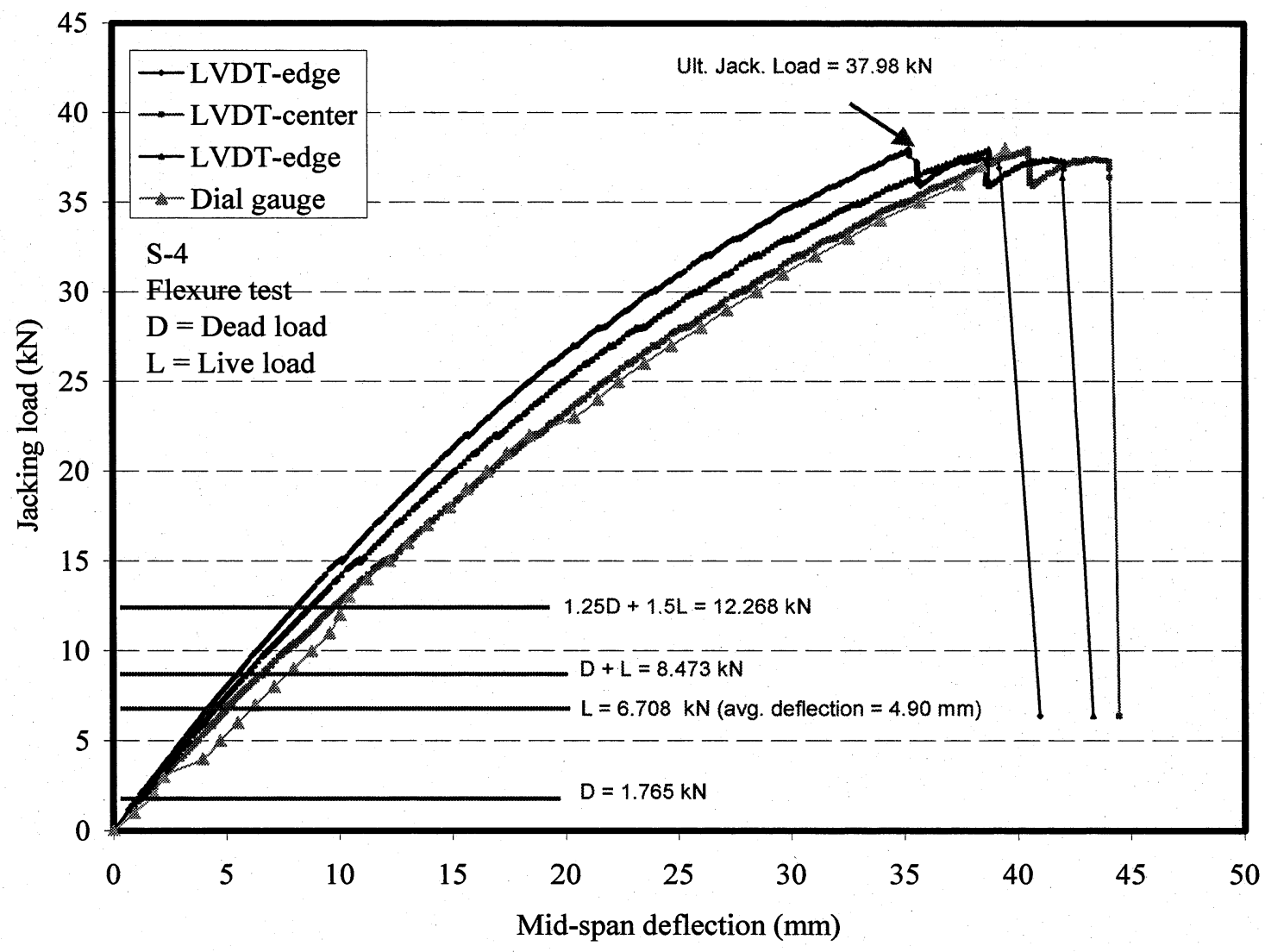

Figure AI-15. Load-deflection relationship for specimen S-4 


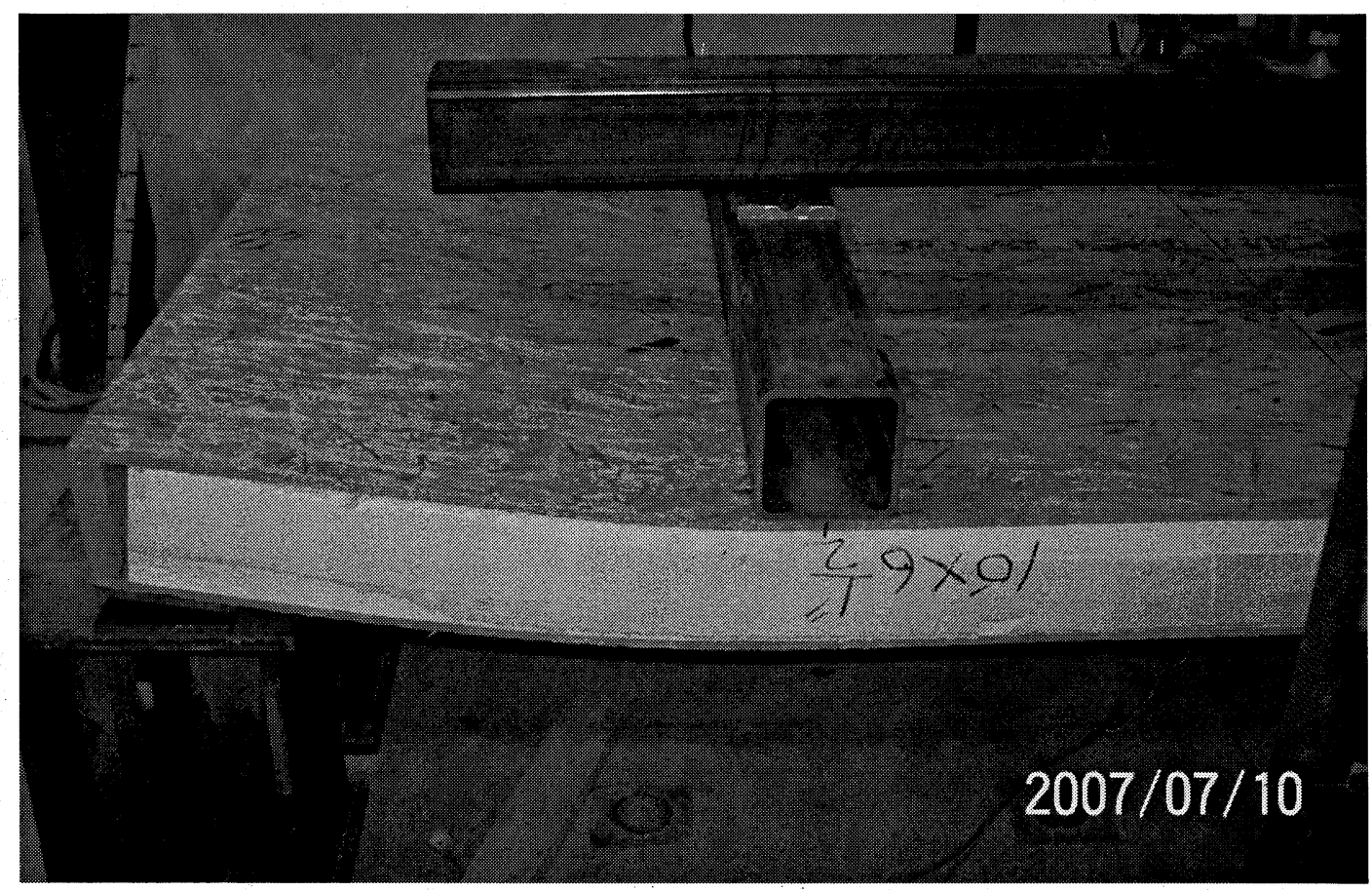

Figure AI-20. View of specimen S-5 after failure

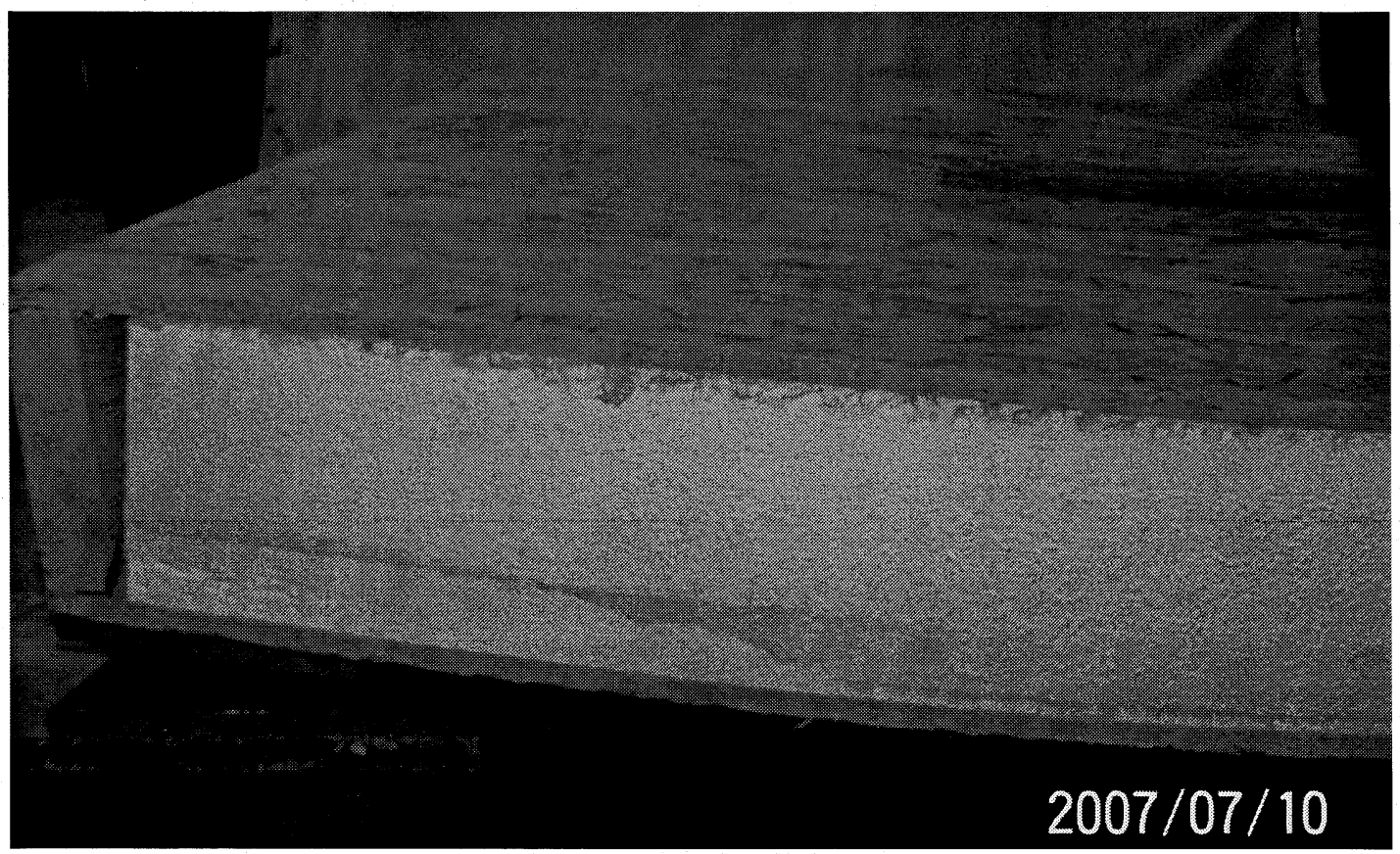

Figure AI-21. View of the horizontal shear failure of specimen S-5 at the interface of the foam and the top OSB board 


\section{Specimen \# S-6}

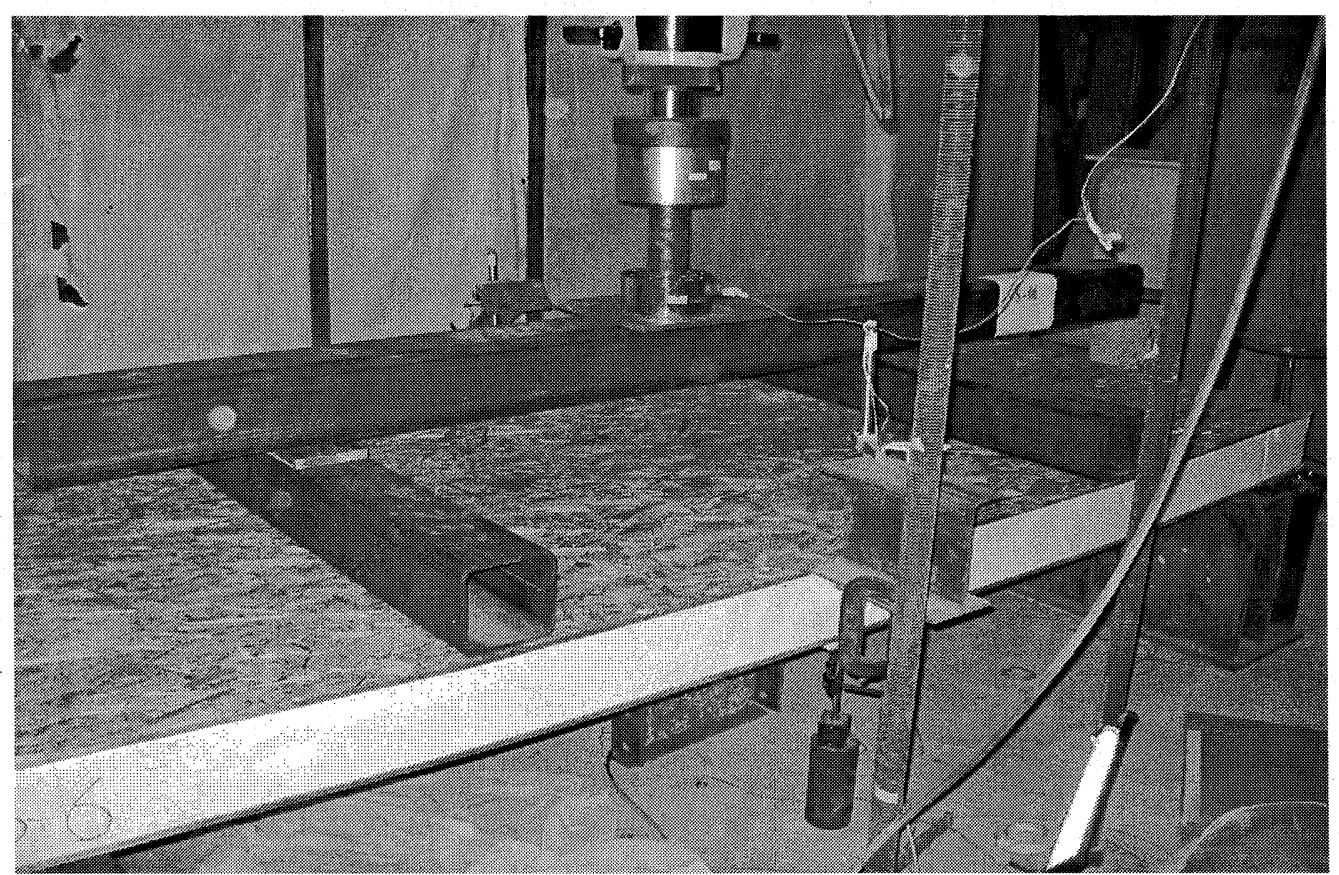

Figure AI-22. View of Specimen S-6 before testing

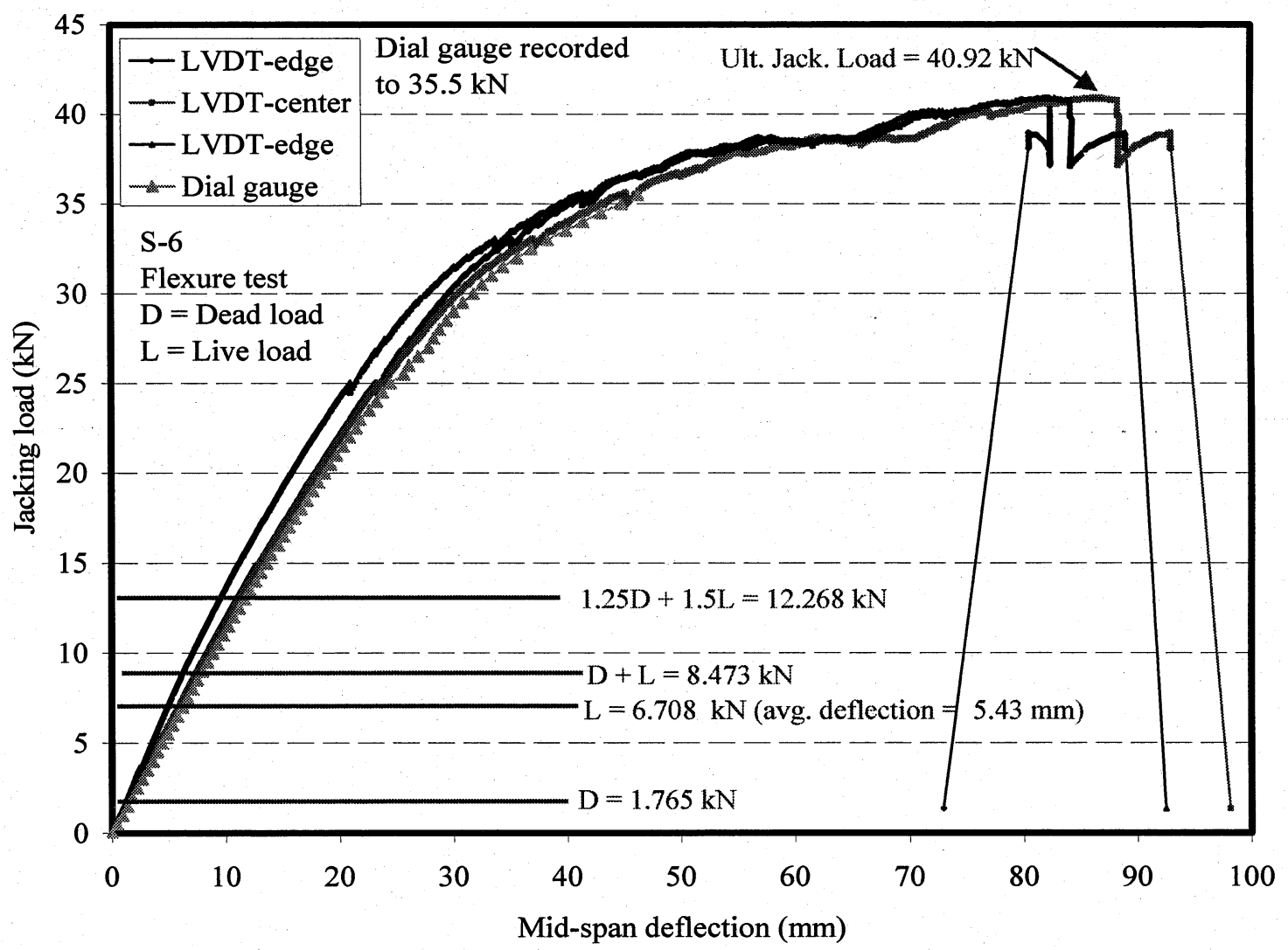

Figure AI-23. Load-deflection relationship for specimen S-6 


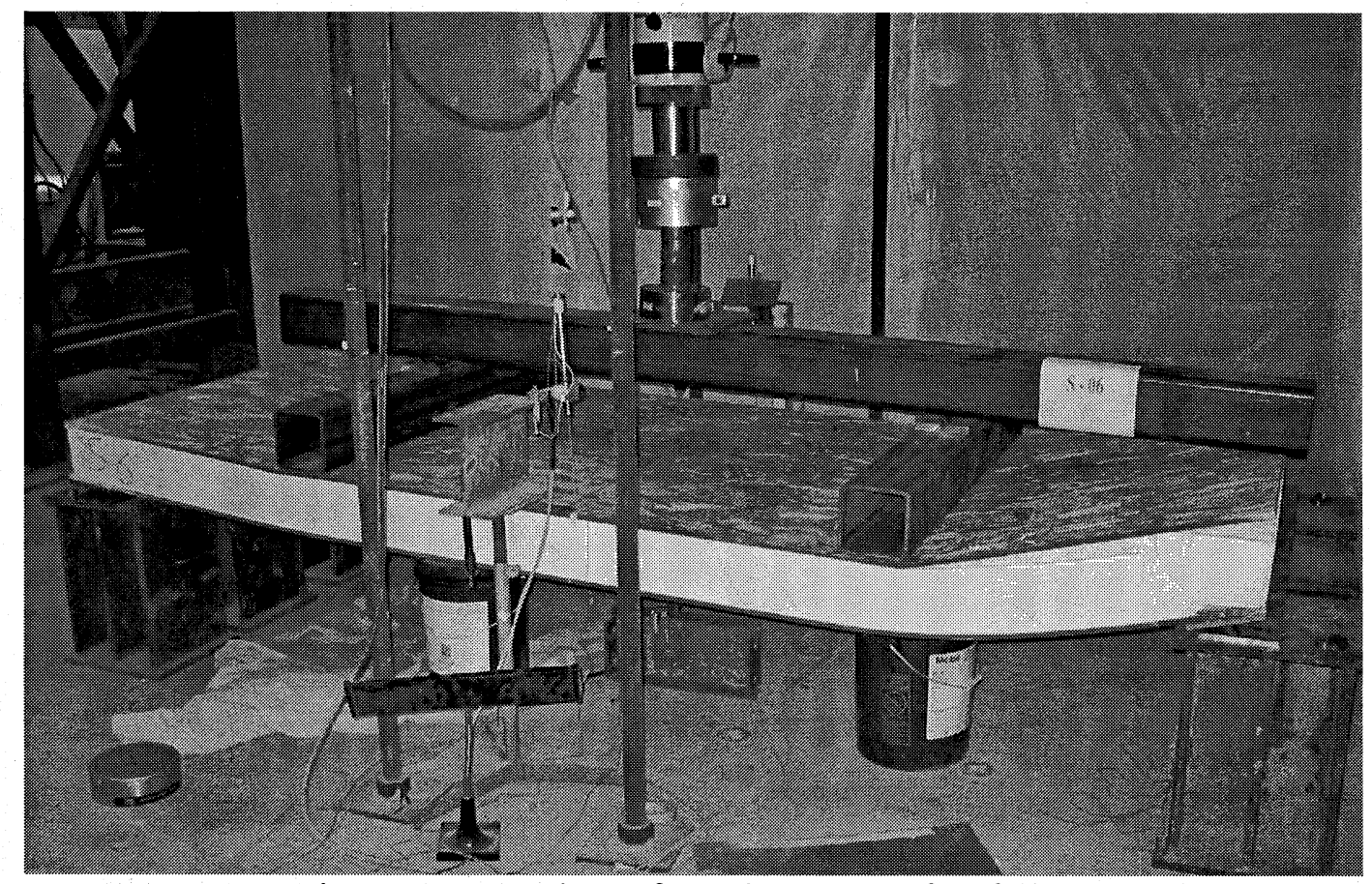

Figure AI-24. View of specimen S-6 after failure

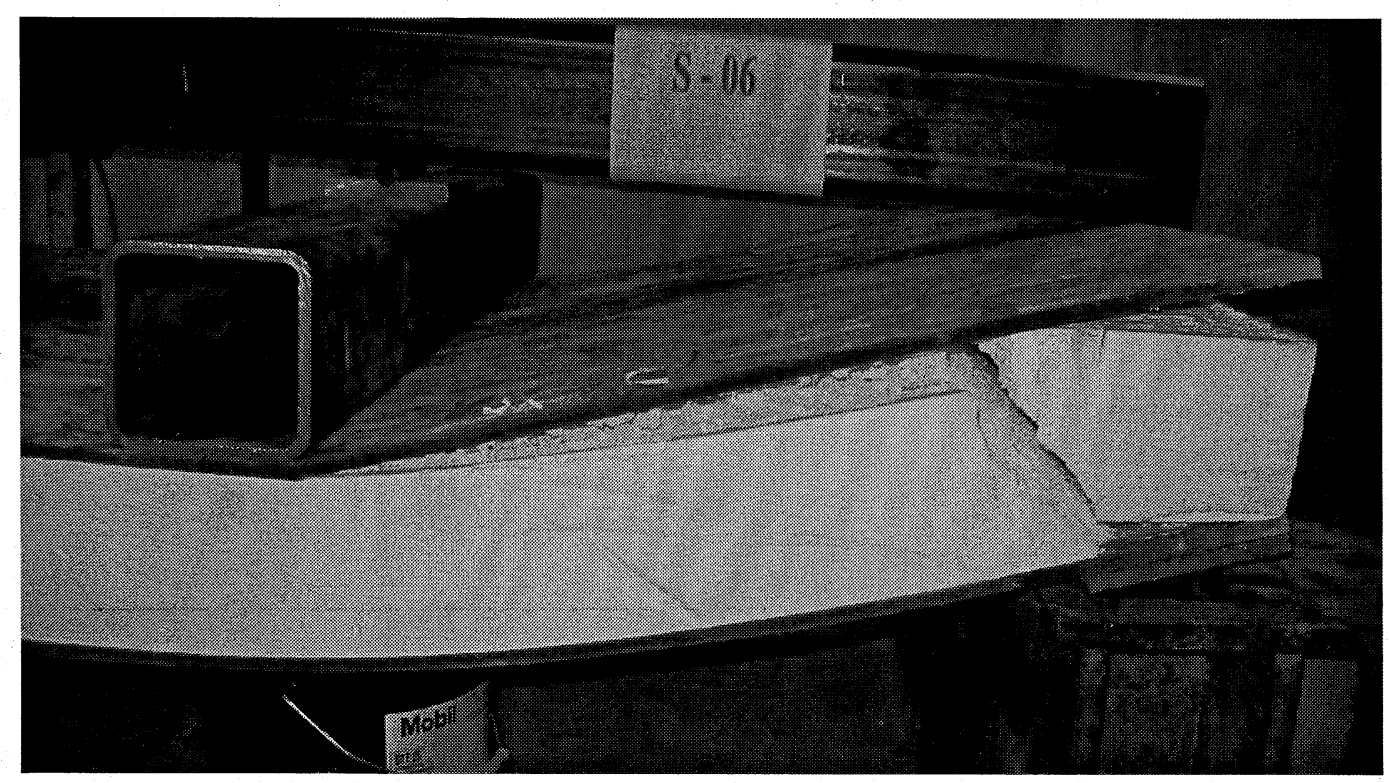

Figure AI-25. View of the combined horizontal and diagonal shear failure of specimen S-6 


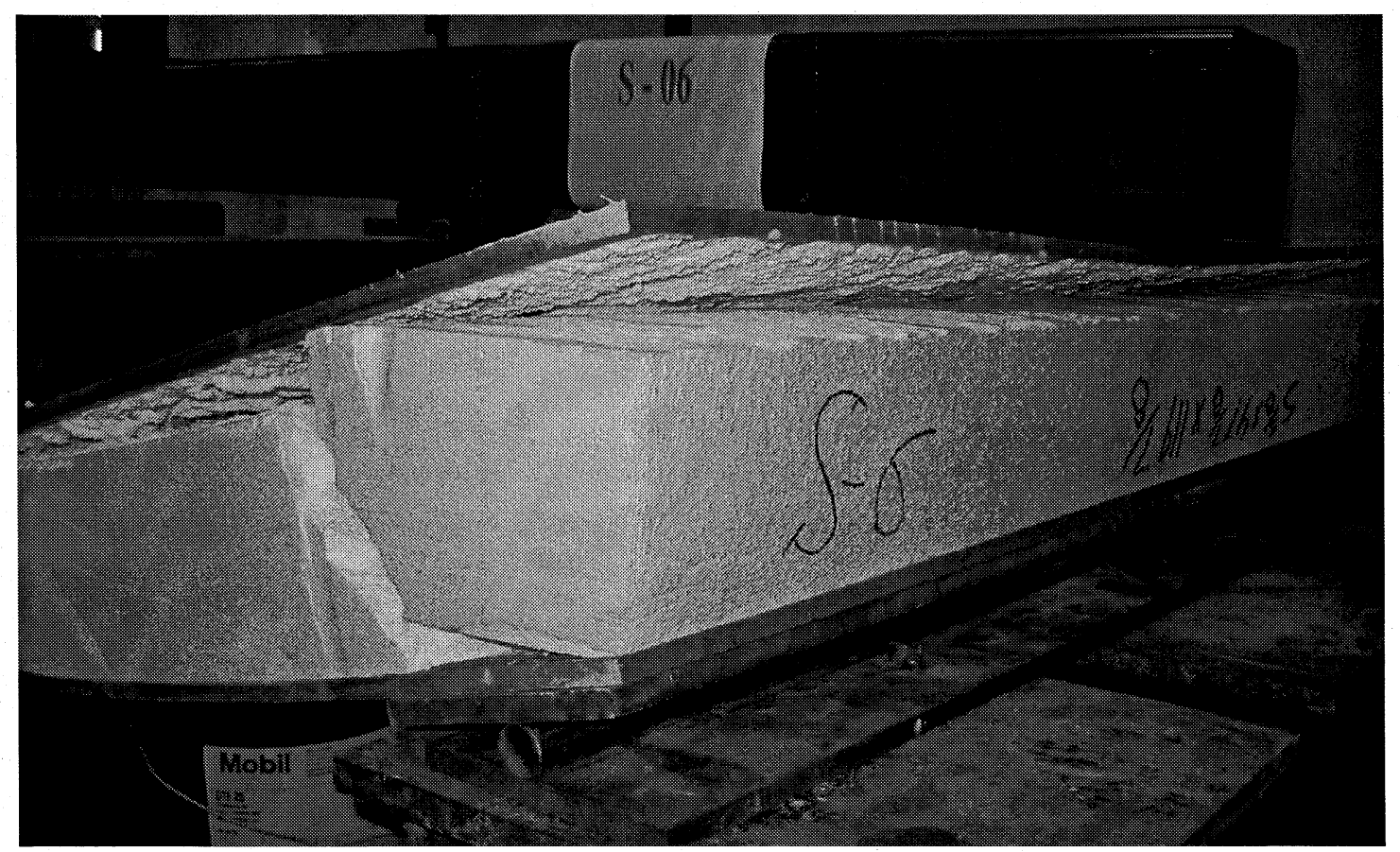

Figure AI-26. Other view of the combined horizontal and diagonal shear failure of specimen S-6 


\section{Specimen \# S-43}

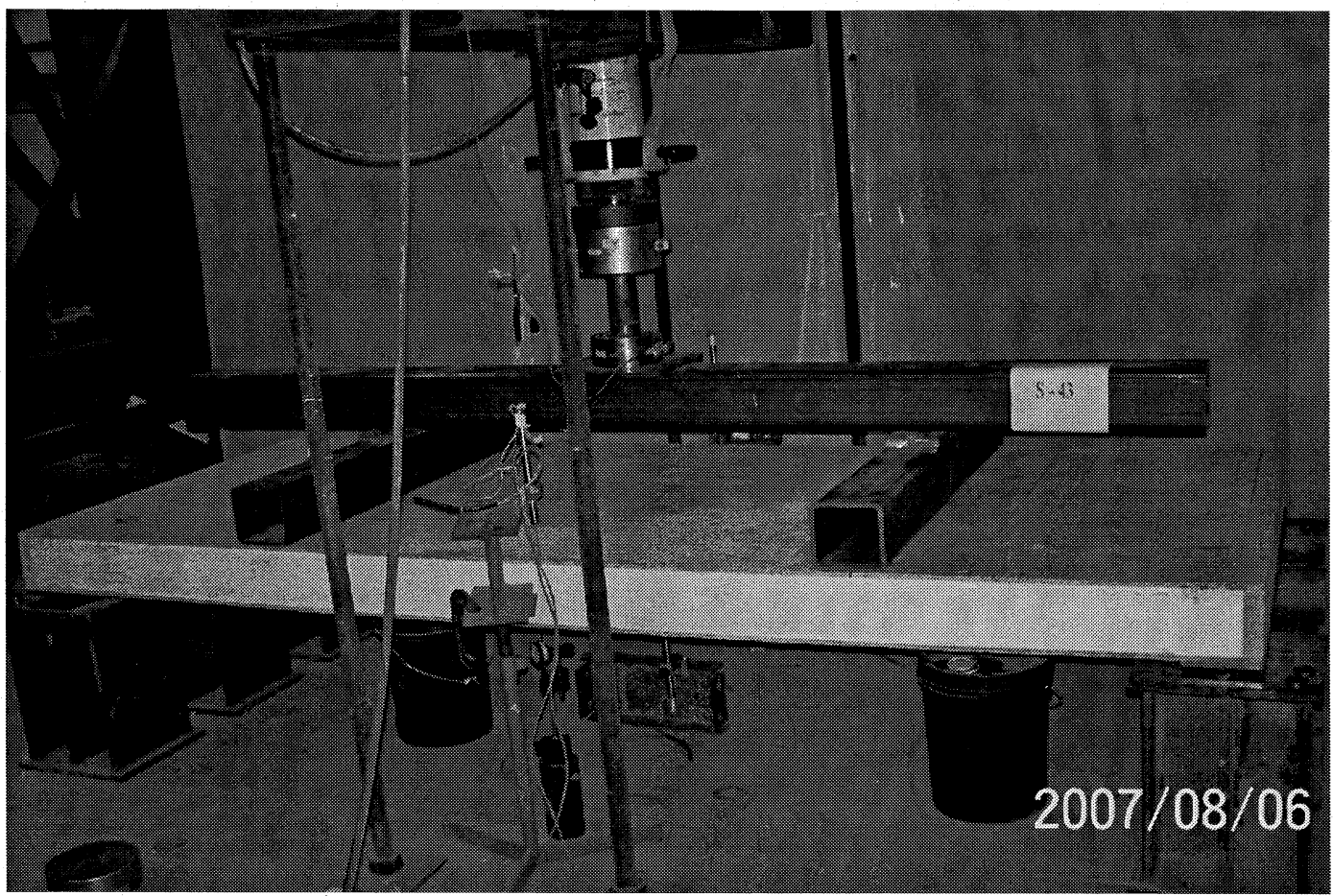

Figure AI-27. View of Specimen S-43 before testing

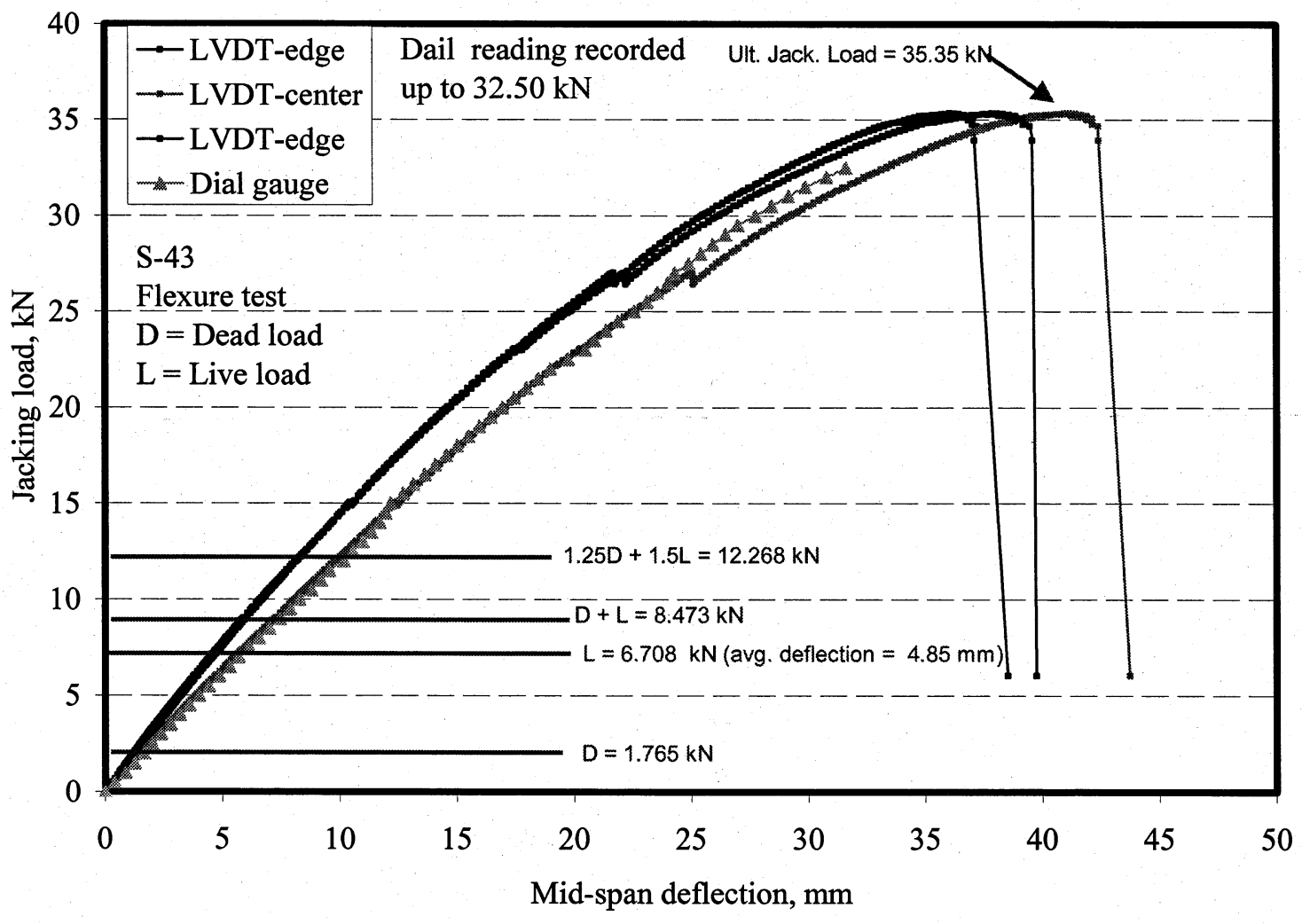

Figure AI-28. Load-deflection relationship for specimen S-43 


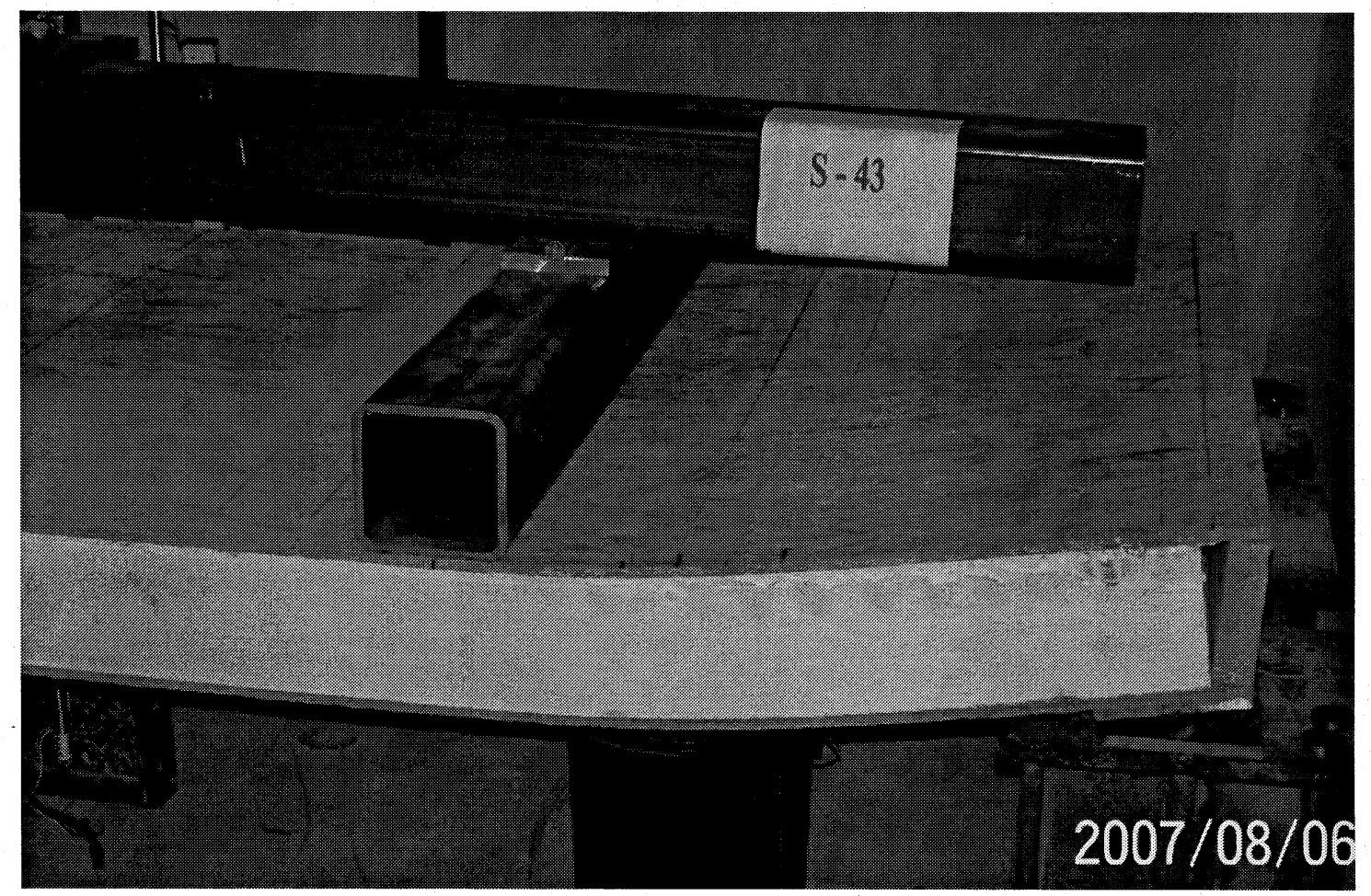

Figure AI-29. View of Specimen S-43 after failure

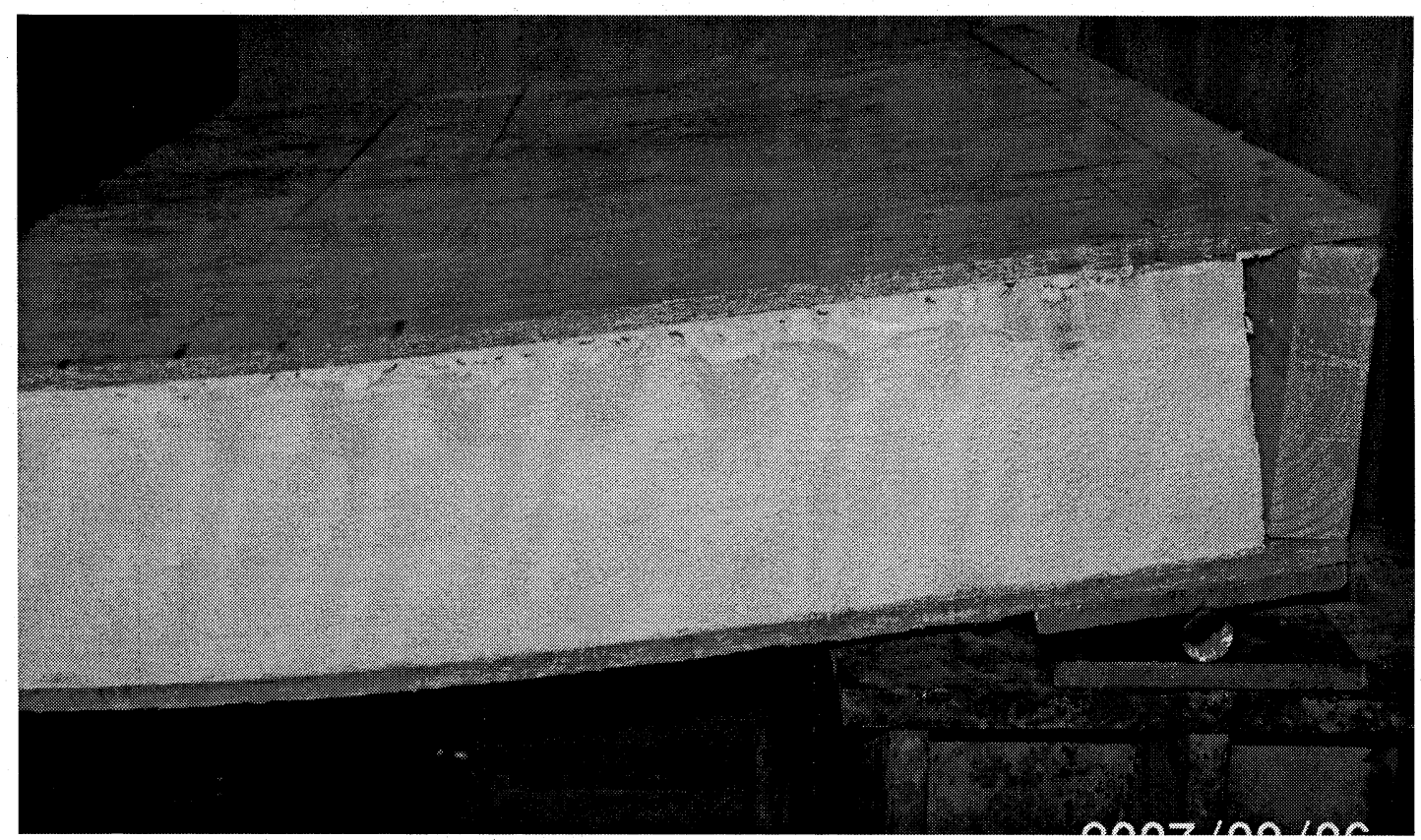

Figure AI-30. View of the horizontal shear failure of specimen S-43 at the interface of the foam and the top OSB board 


\section{GROUP C}

\section{Specimen \# S-7}

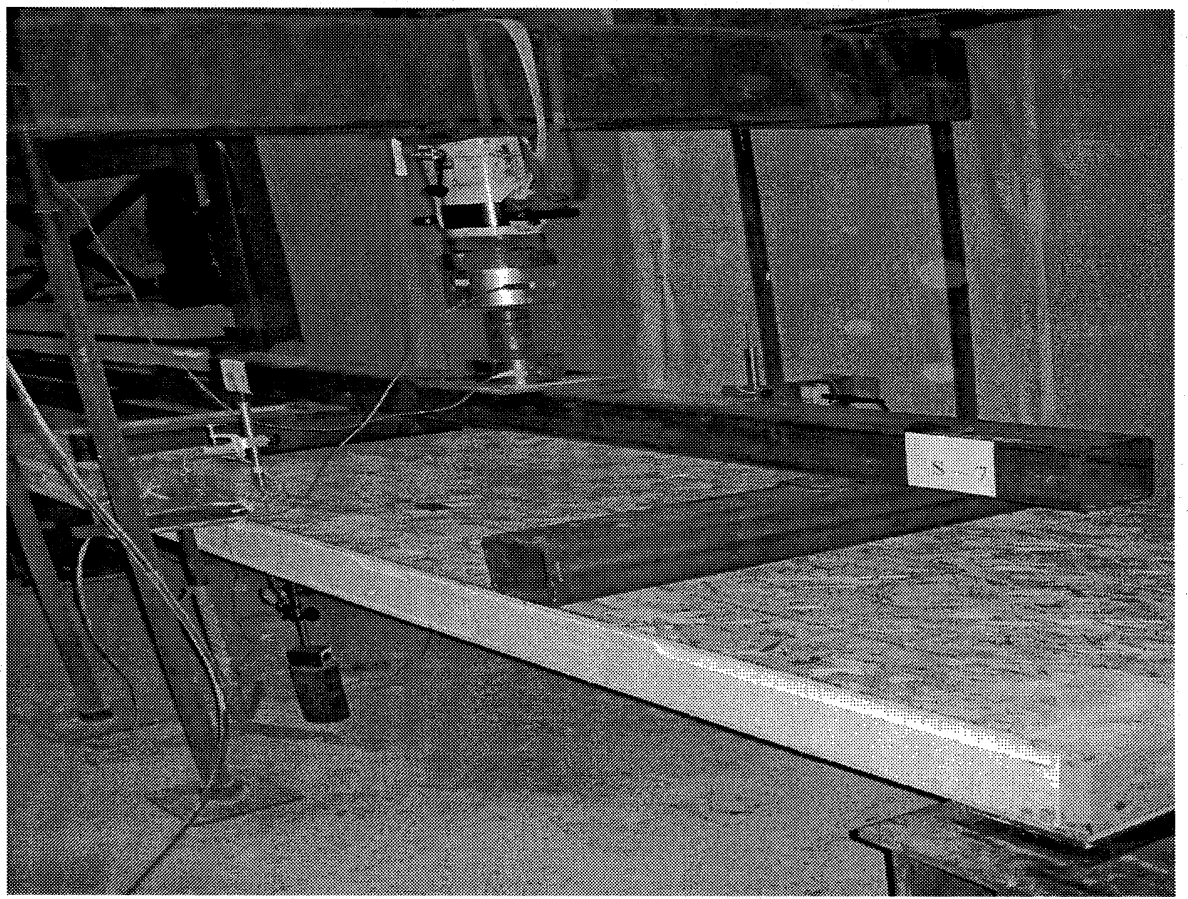

Figure AI-31. View of Specimen S-7 before testing

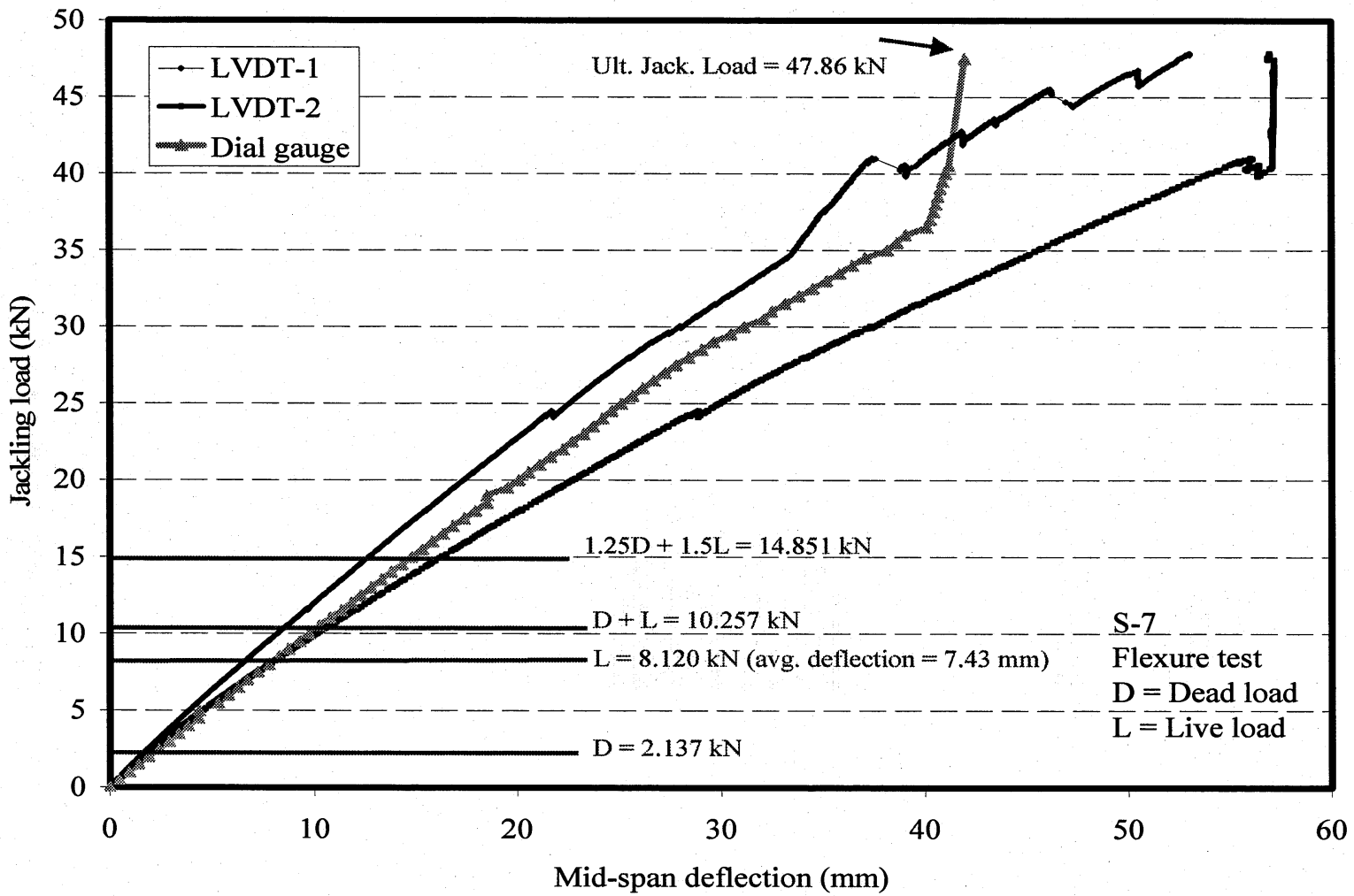

Figure AI-32. Load-deflection relationship for specimen S-7 


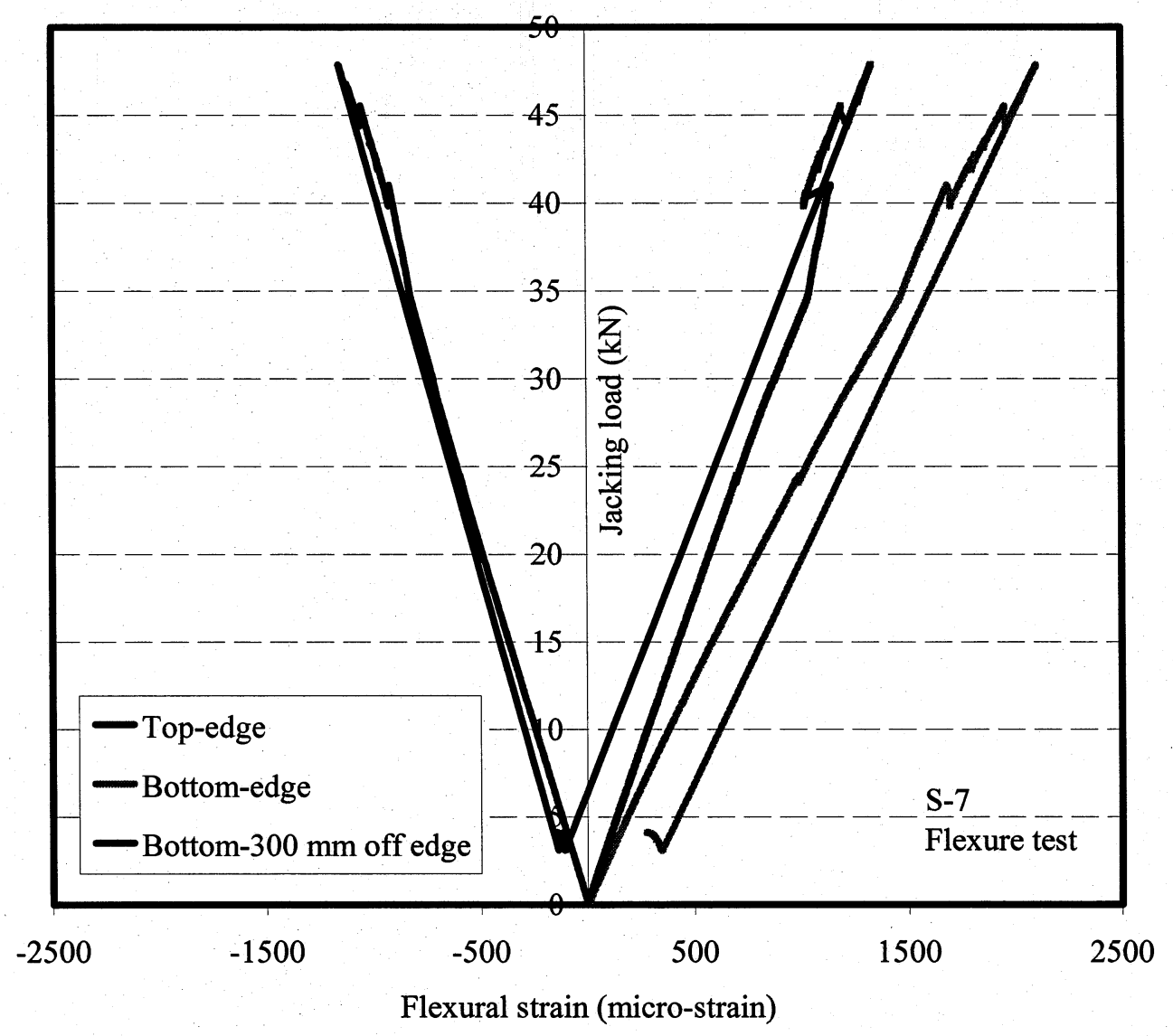

Figure AI-33. Load-strain relationship for specimen S-7

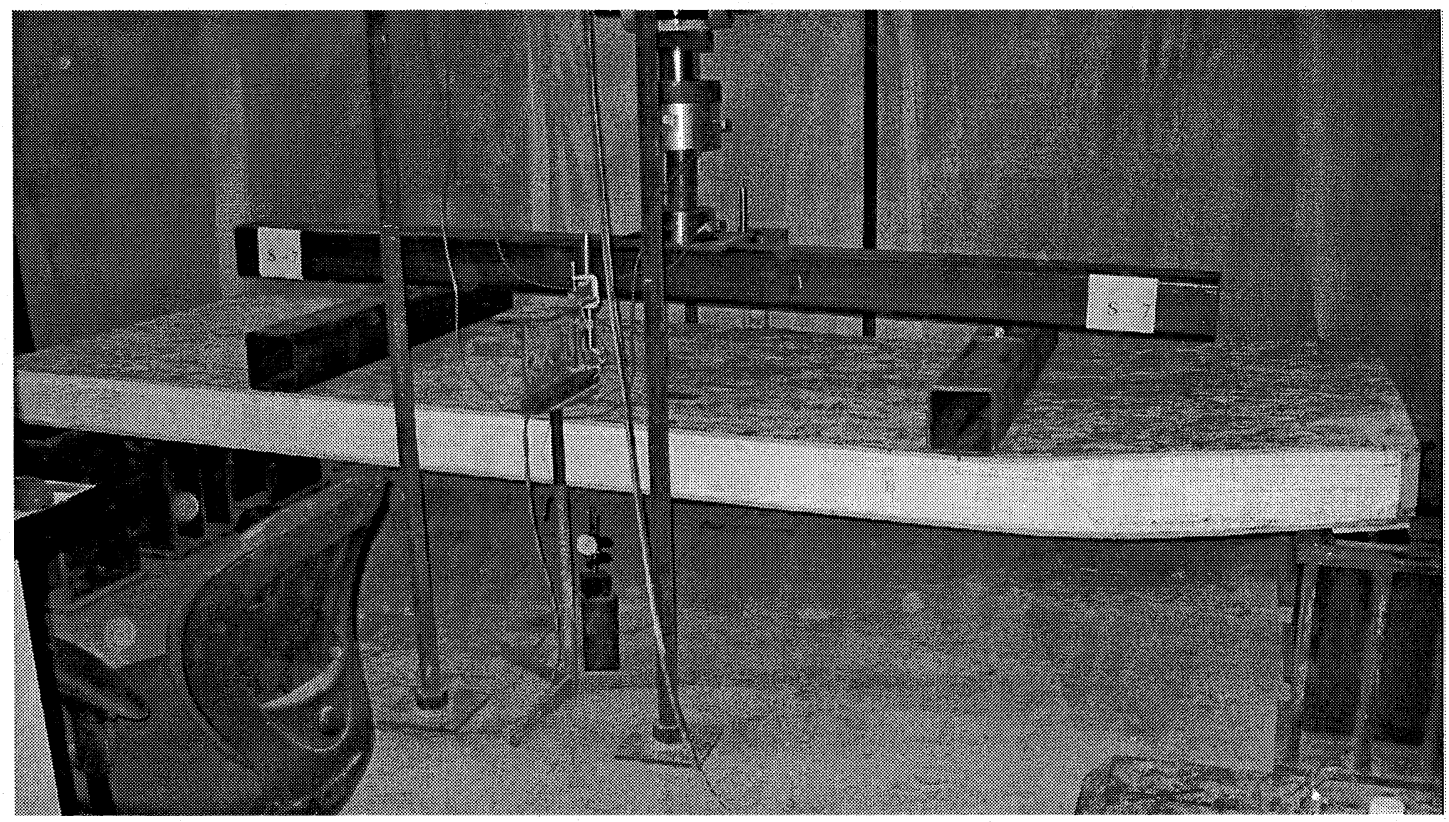

Figure AI-34. View of specimen S-7 after failure 


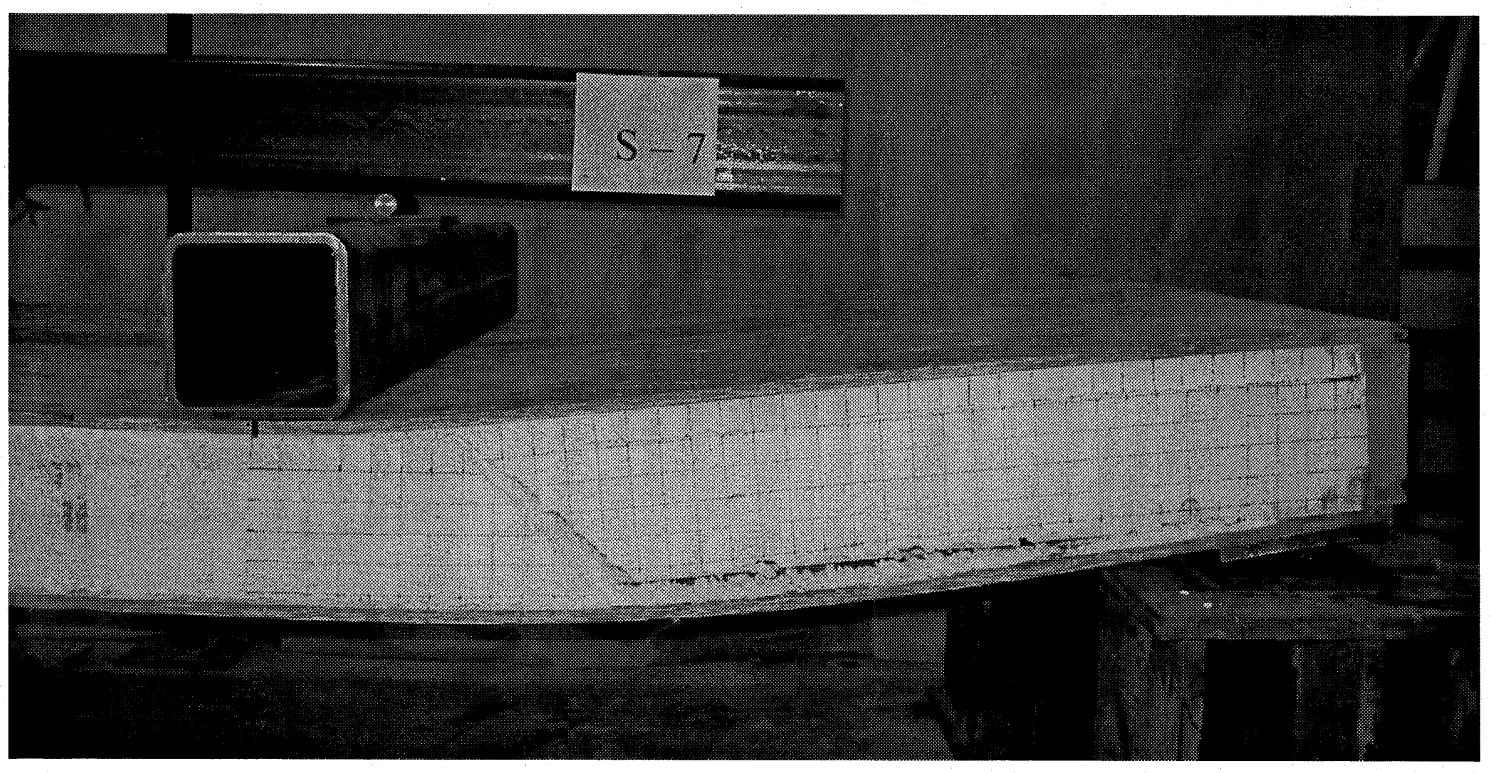

Figure AI-35. Close-up view of the failure pattern from one side of specimen S-7

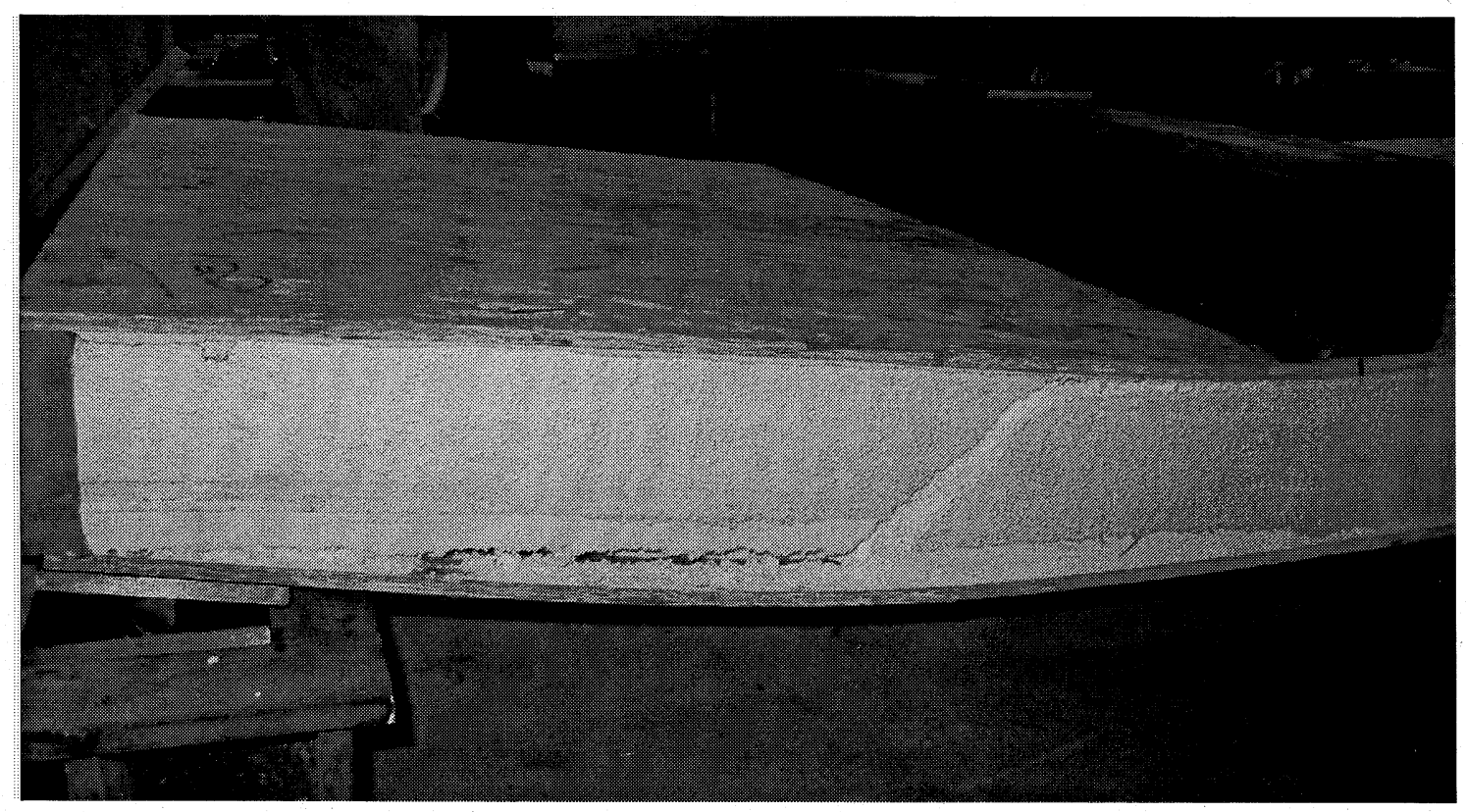

Figure AI-36. Close-up view of the failure pattern from the other free edge of specimen S-7 


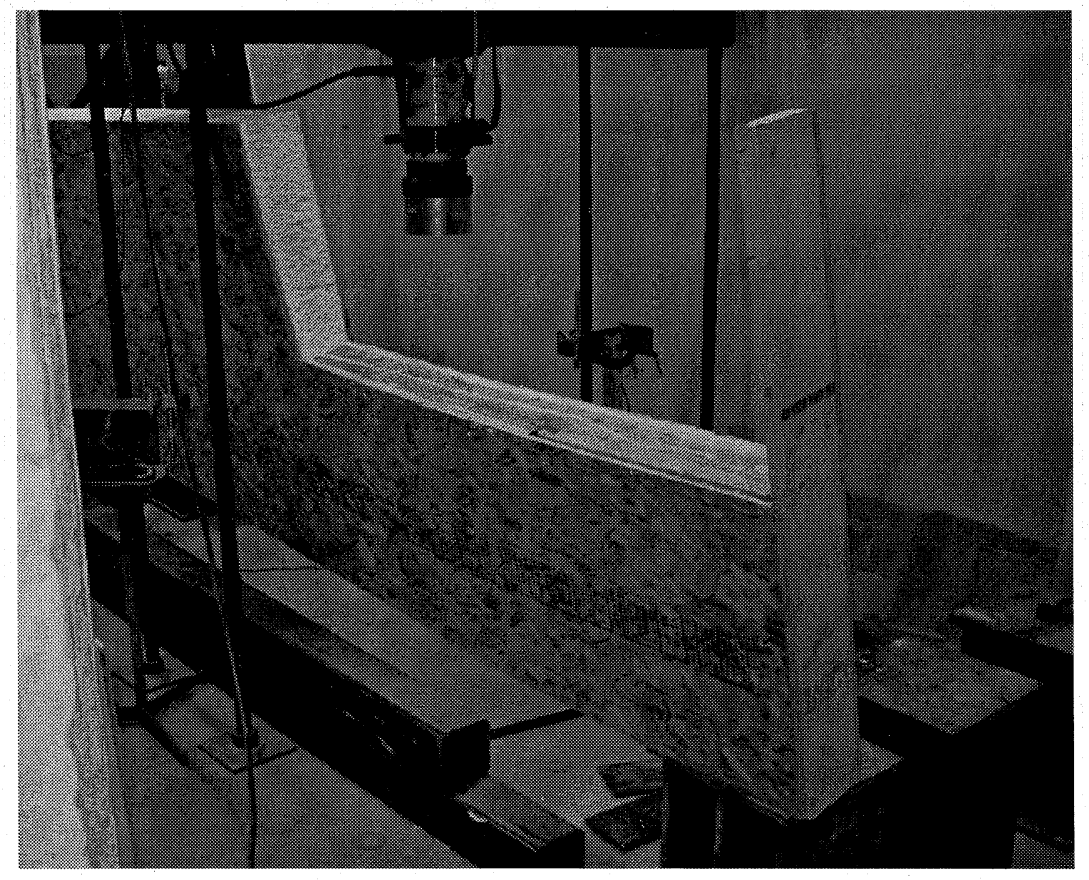

Figure AI-37. View of specimen S-7 after cutting part of the panel to observe failure in the spline stud

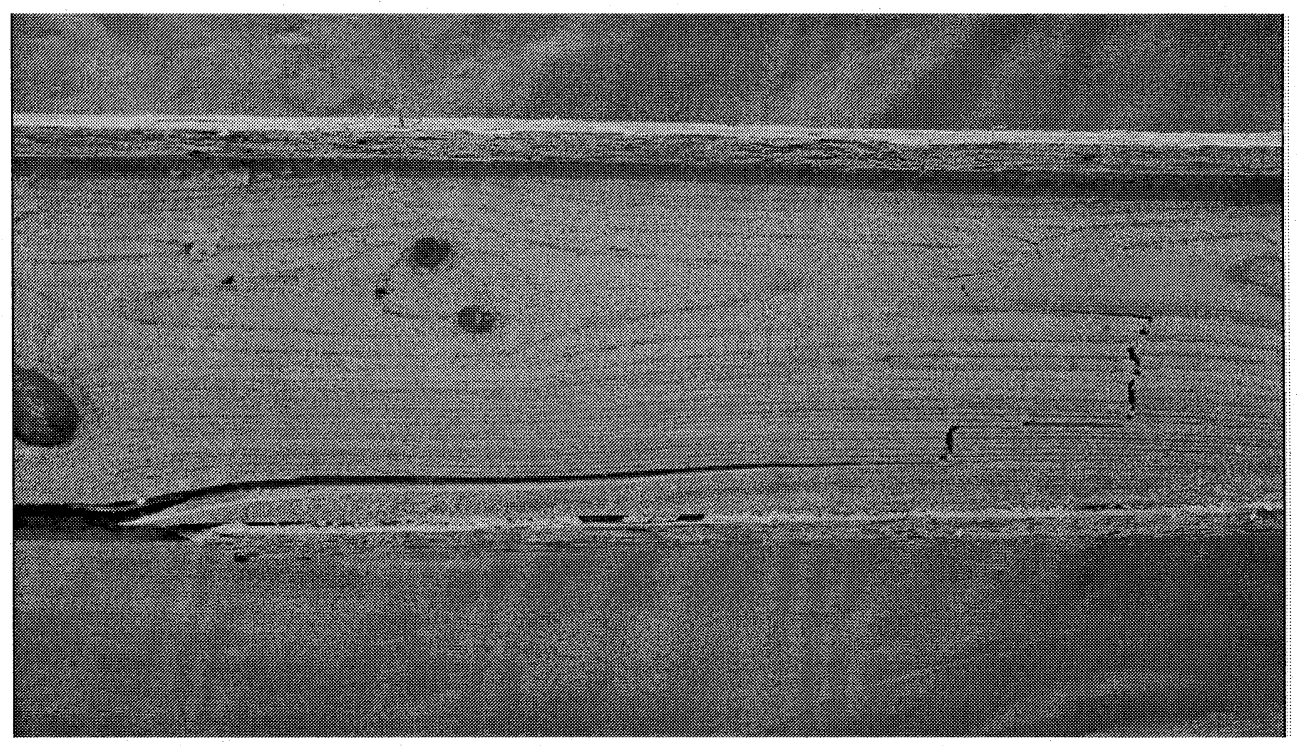

Figure AI-38. Close-up view of the failure pattern in the spline stud from one side of specimen S-7 


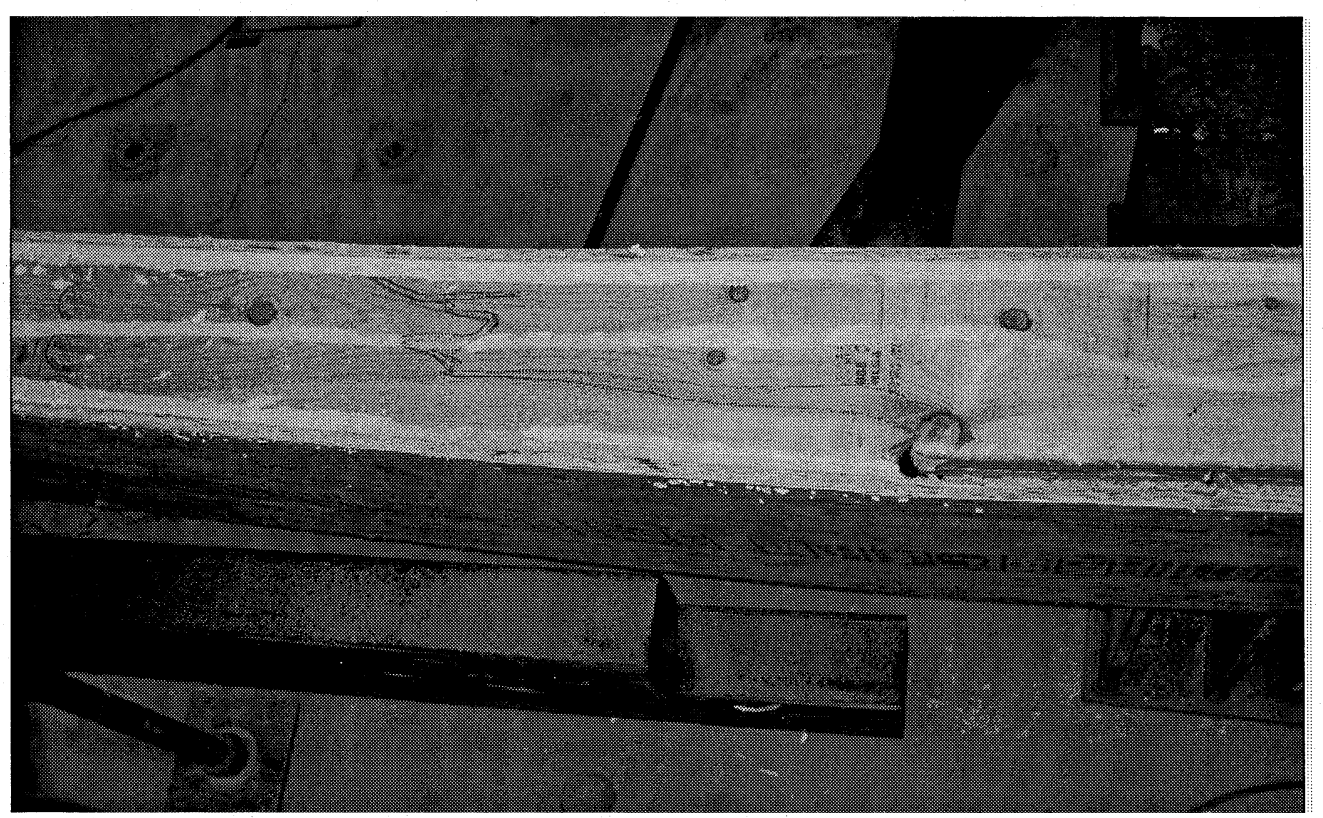

Figure AI-39. Close-up view of the failure pattern in the spline stud in the other free side of specimen $\mathrm{S}-7$ 


\section{Specimen \# S-8}

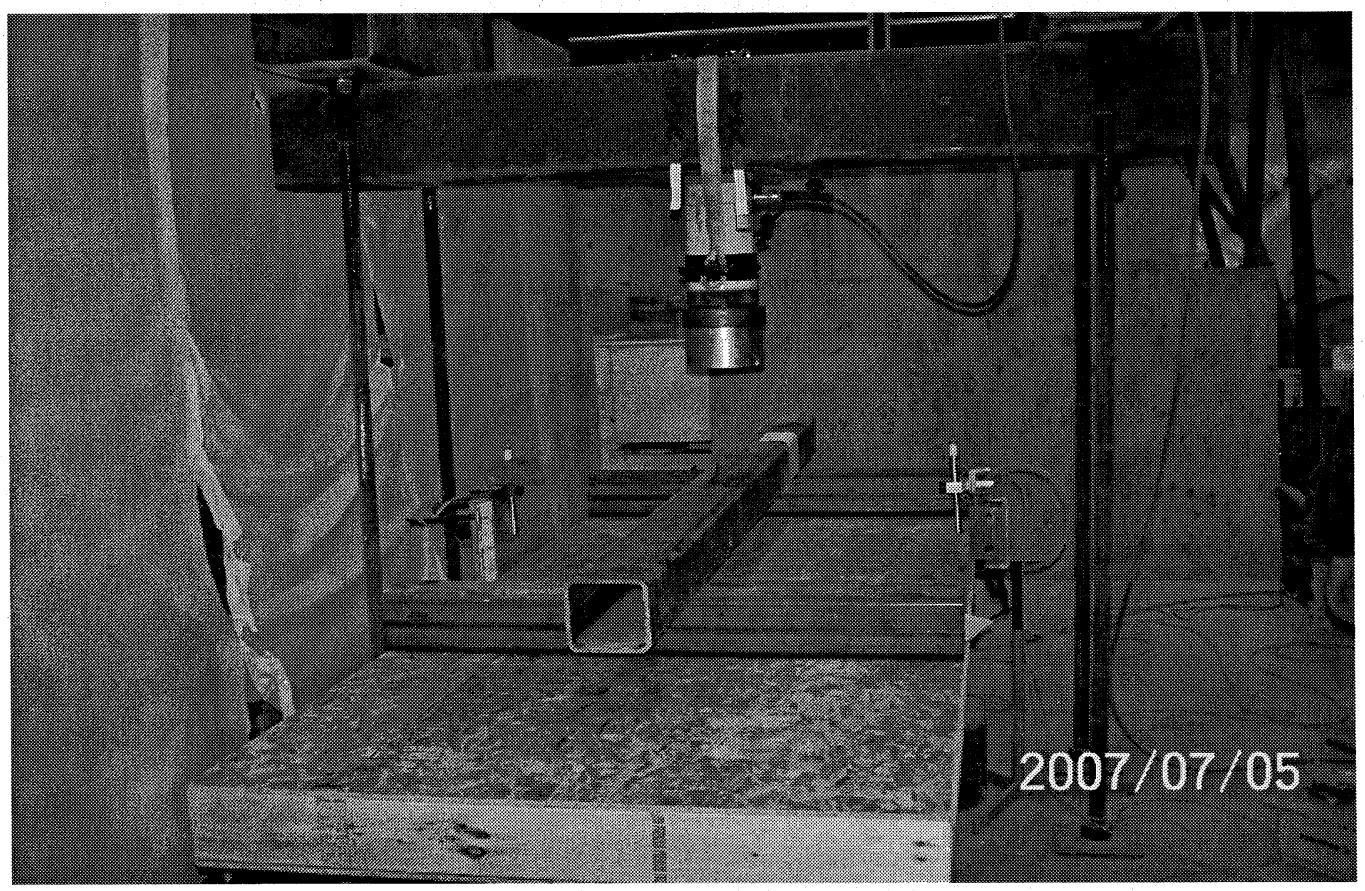

Figure AI-40. View of Specimen S-8 before testing

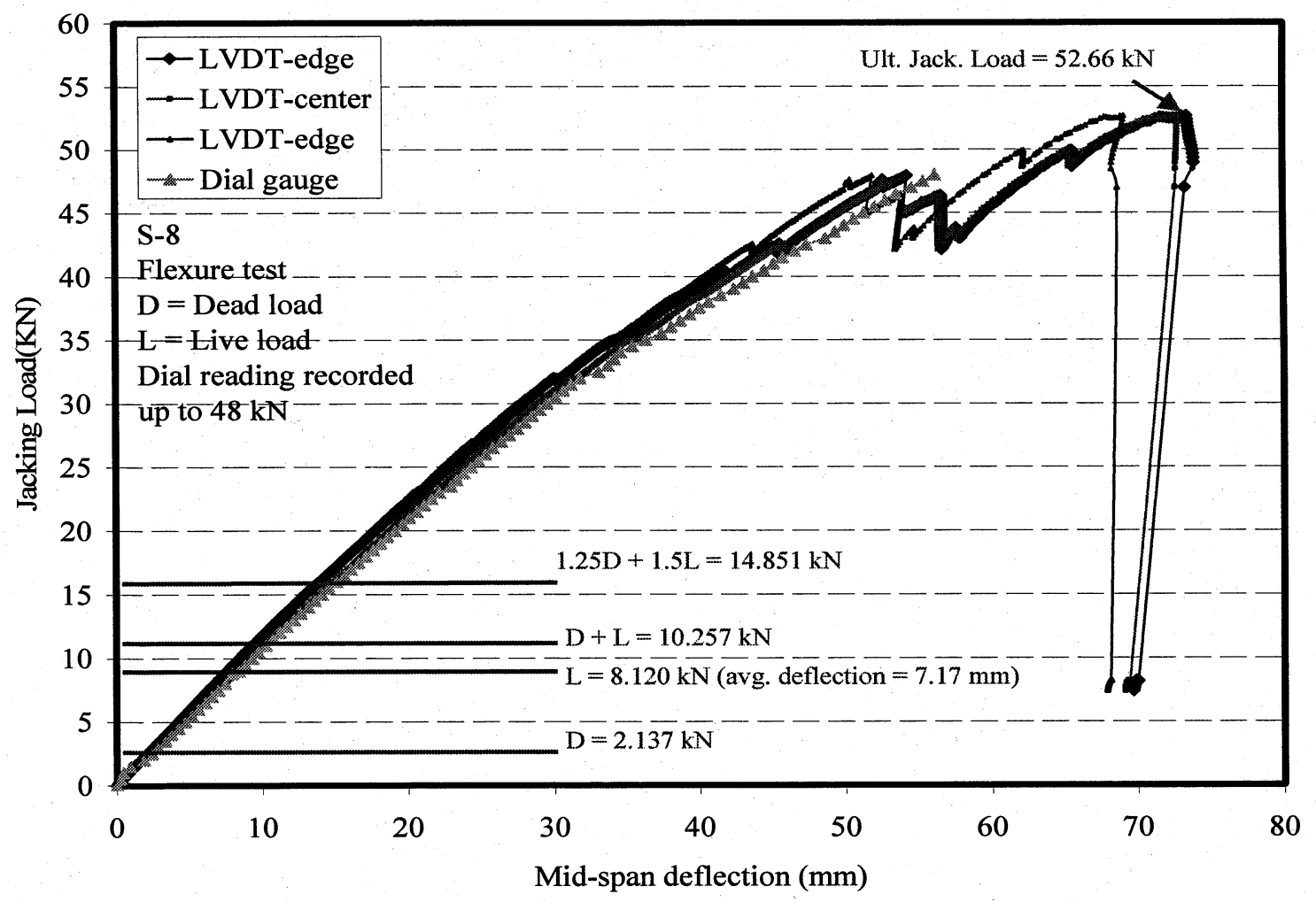

Figure AI-41. Load-deflection relationship for specimen S-8 


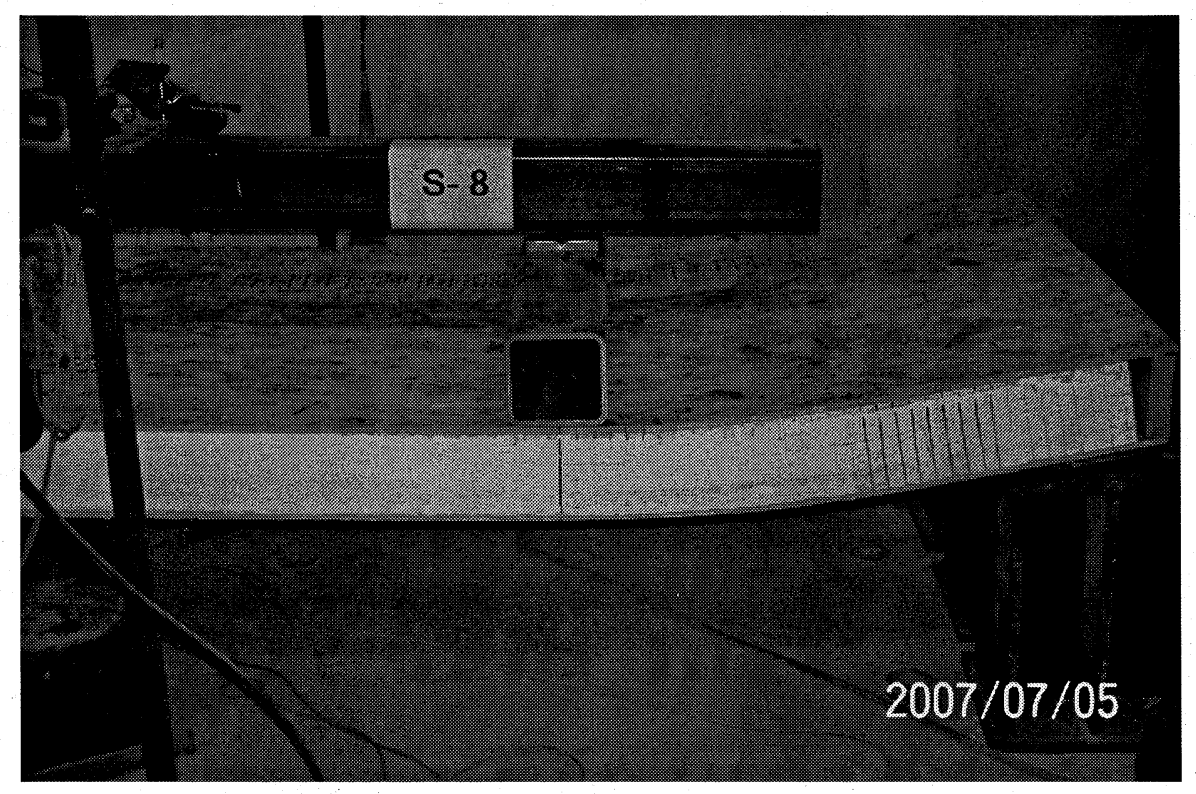

Figure AI-42. View of specimen S-8 after failure

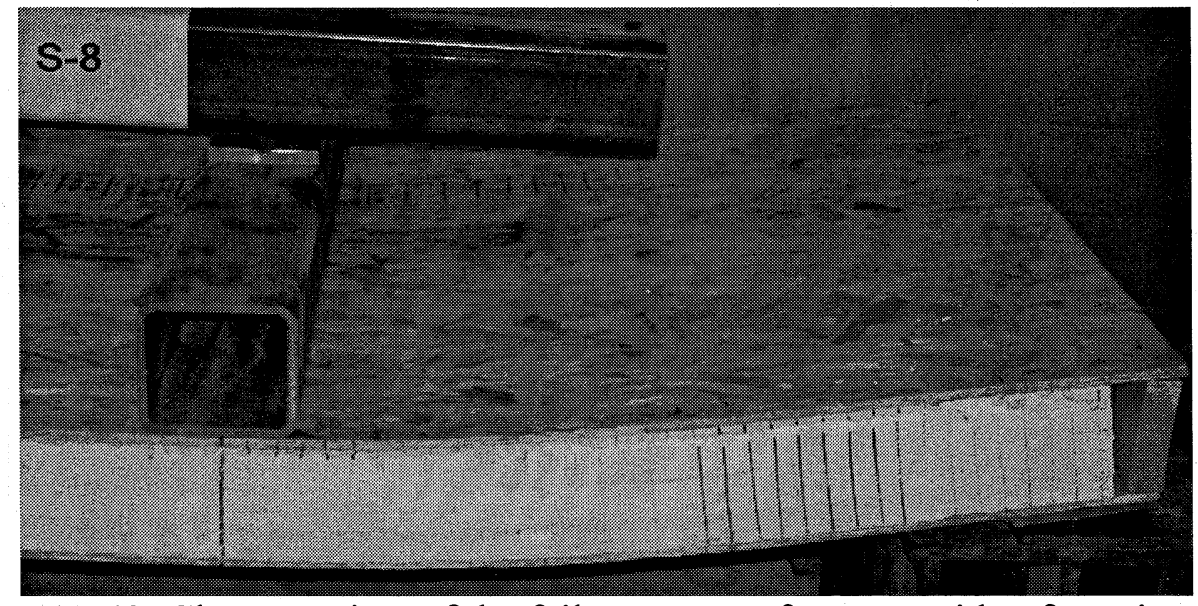

Figure AI-43. Close-up view of the failure pattern from one side of specimen S-8 


\section{Specimen \# S-9}

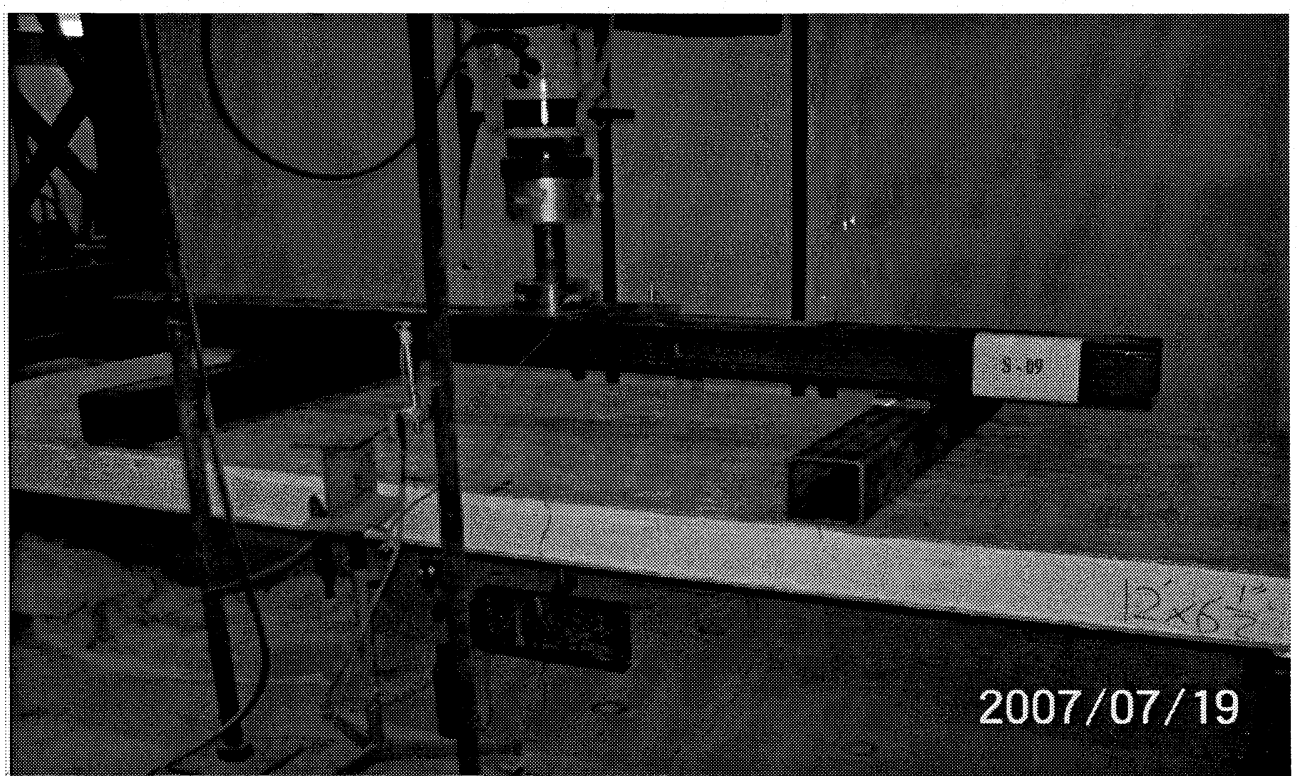

Figure AI-44. View of Specimen S-9 before testing

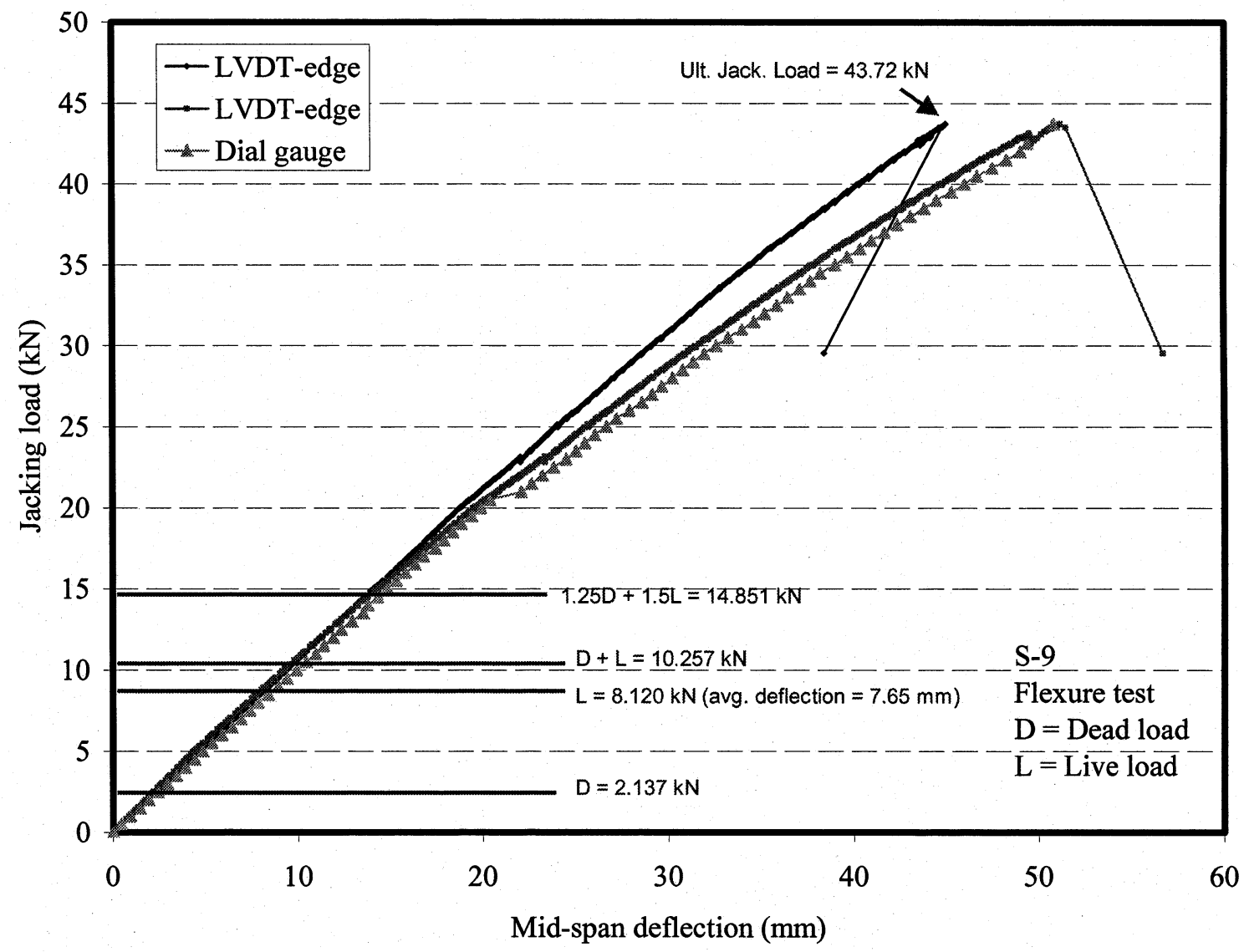

Figure AI-45. Load-deflection relationship for specimen S-9 


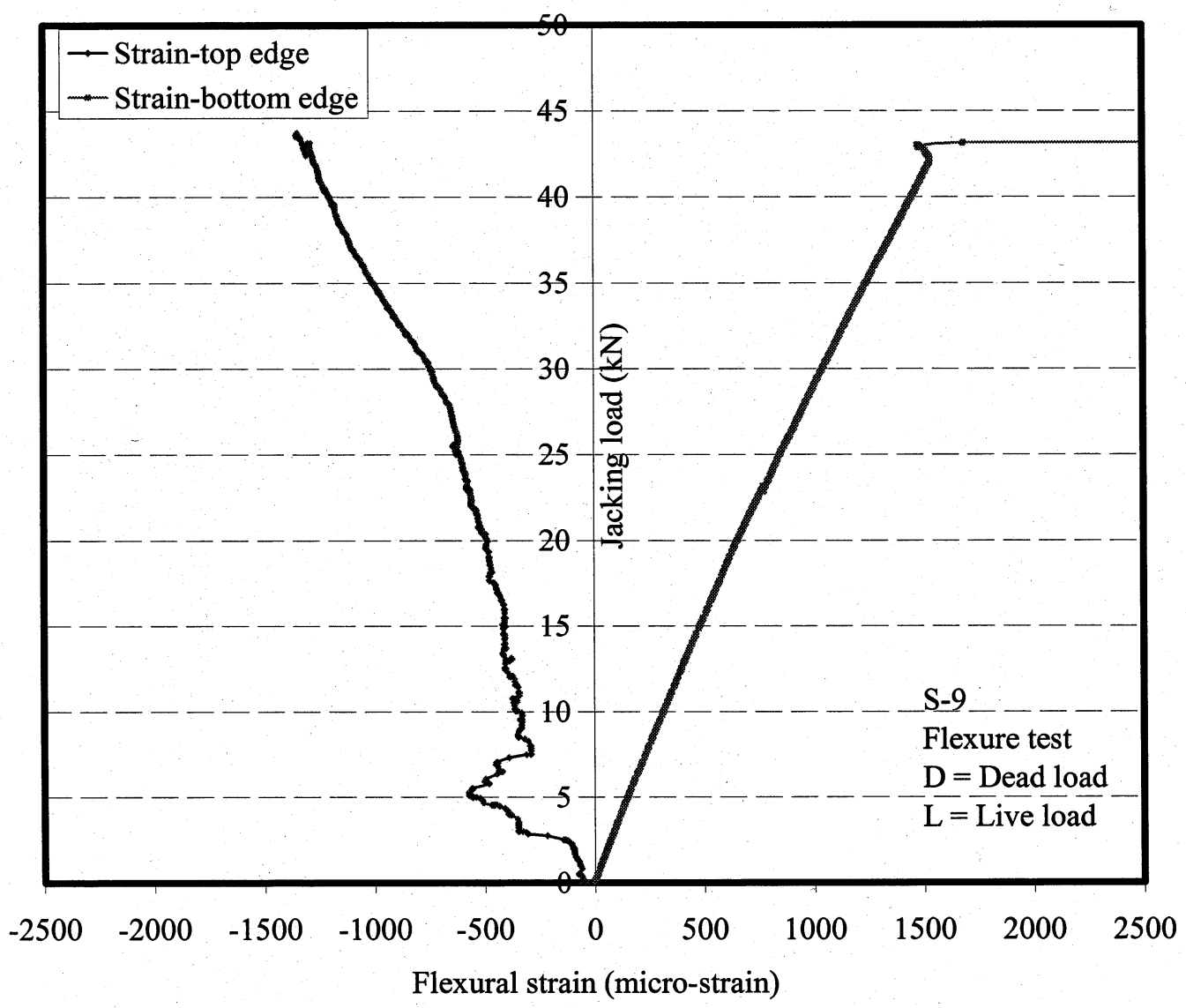

Figure AI-46. Load-strain relationship for specimen S-9

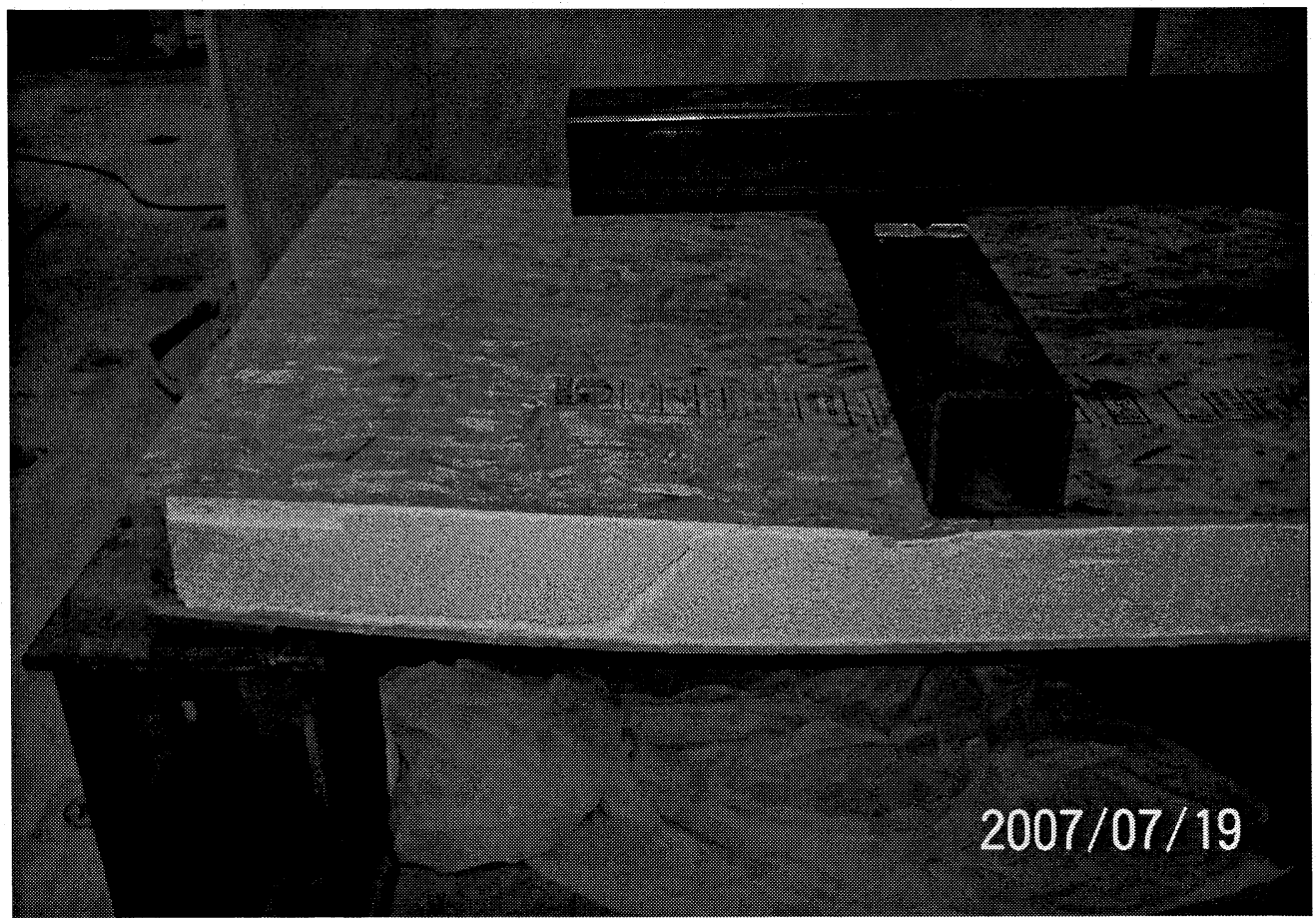

Figure AI-47. View of specimen S-9 after failure 


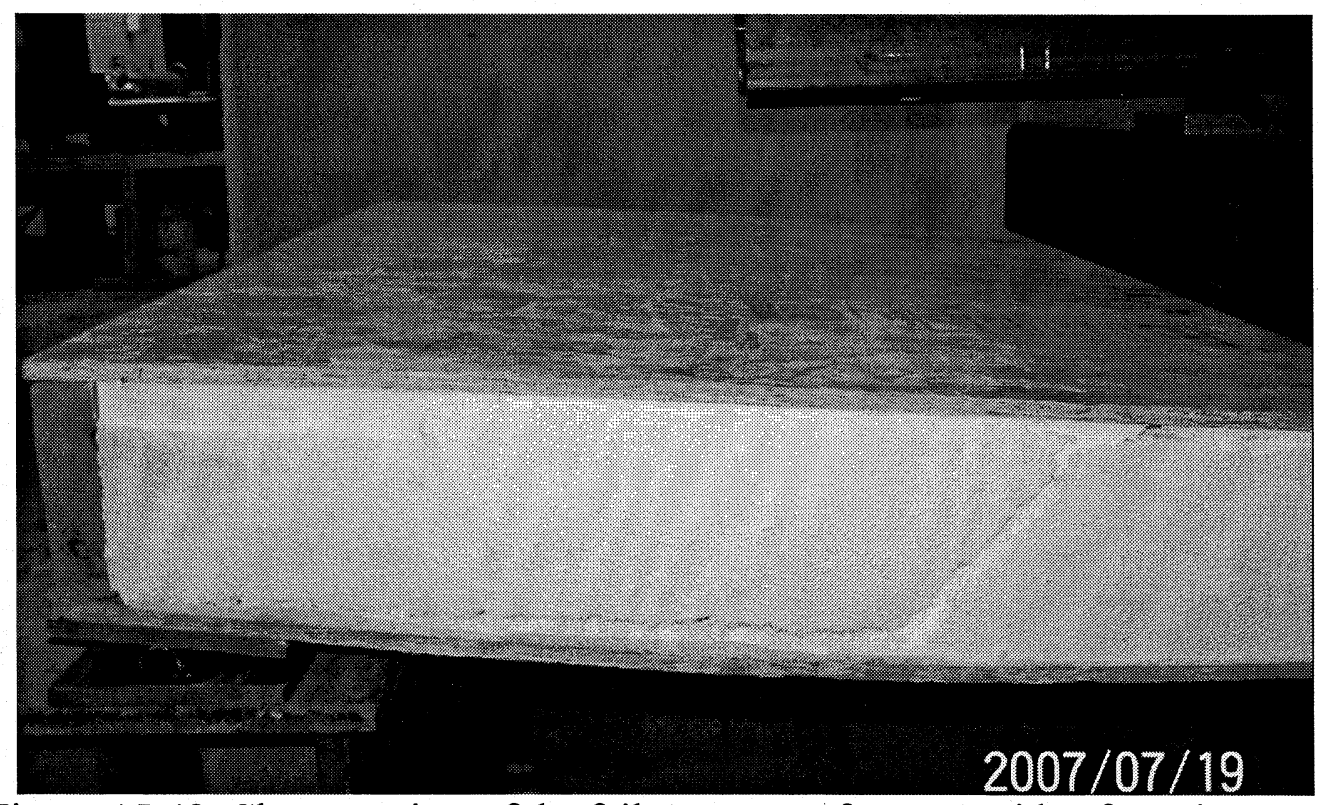

Figure AI-48. Close-up view of the failure pattern from one side of specimen S-9 


\section{GROUP D}

\section{Specimen \# S10}

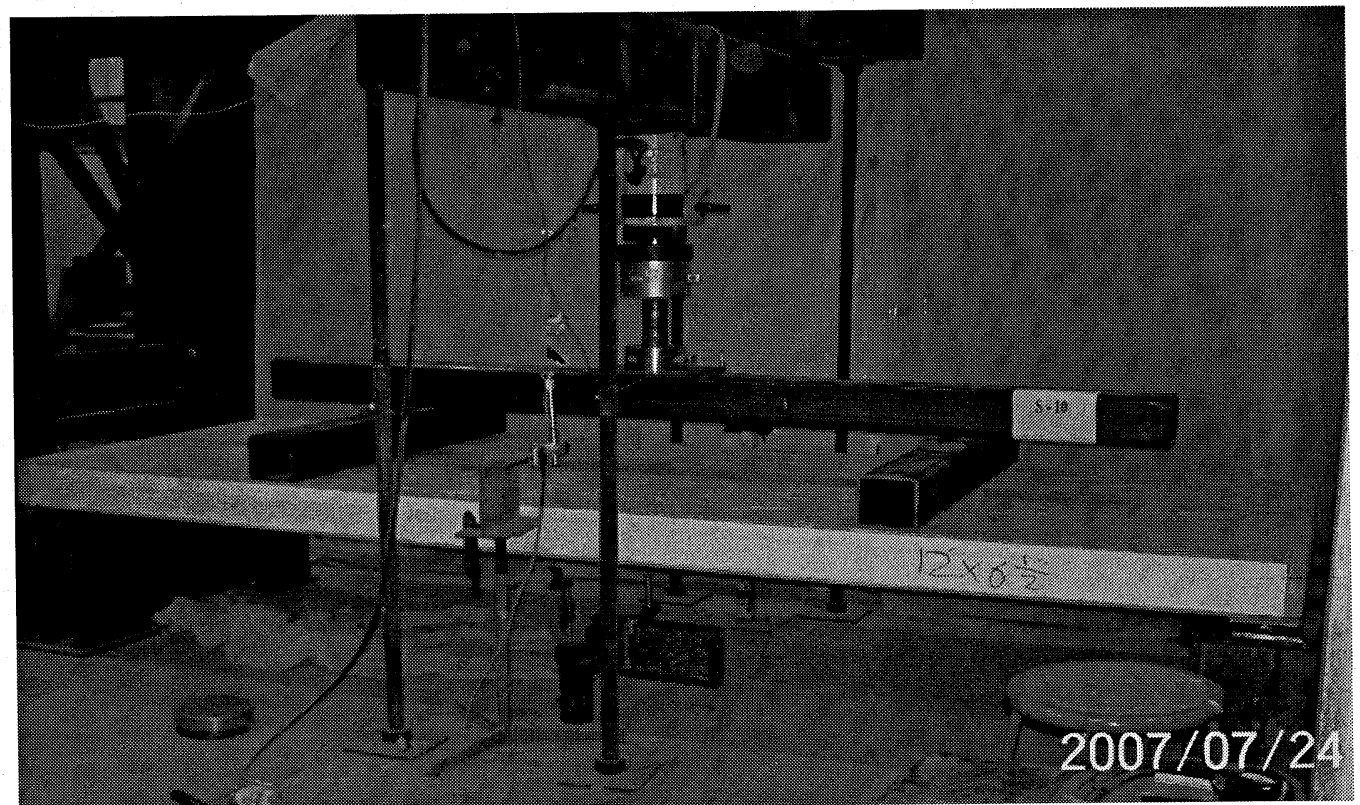

Figure AI-49. View of Specimen S-10 before testing

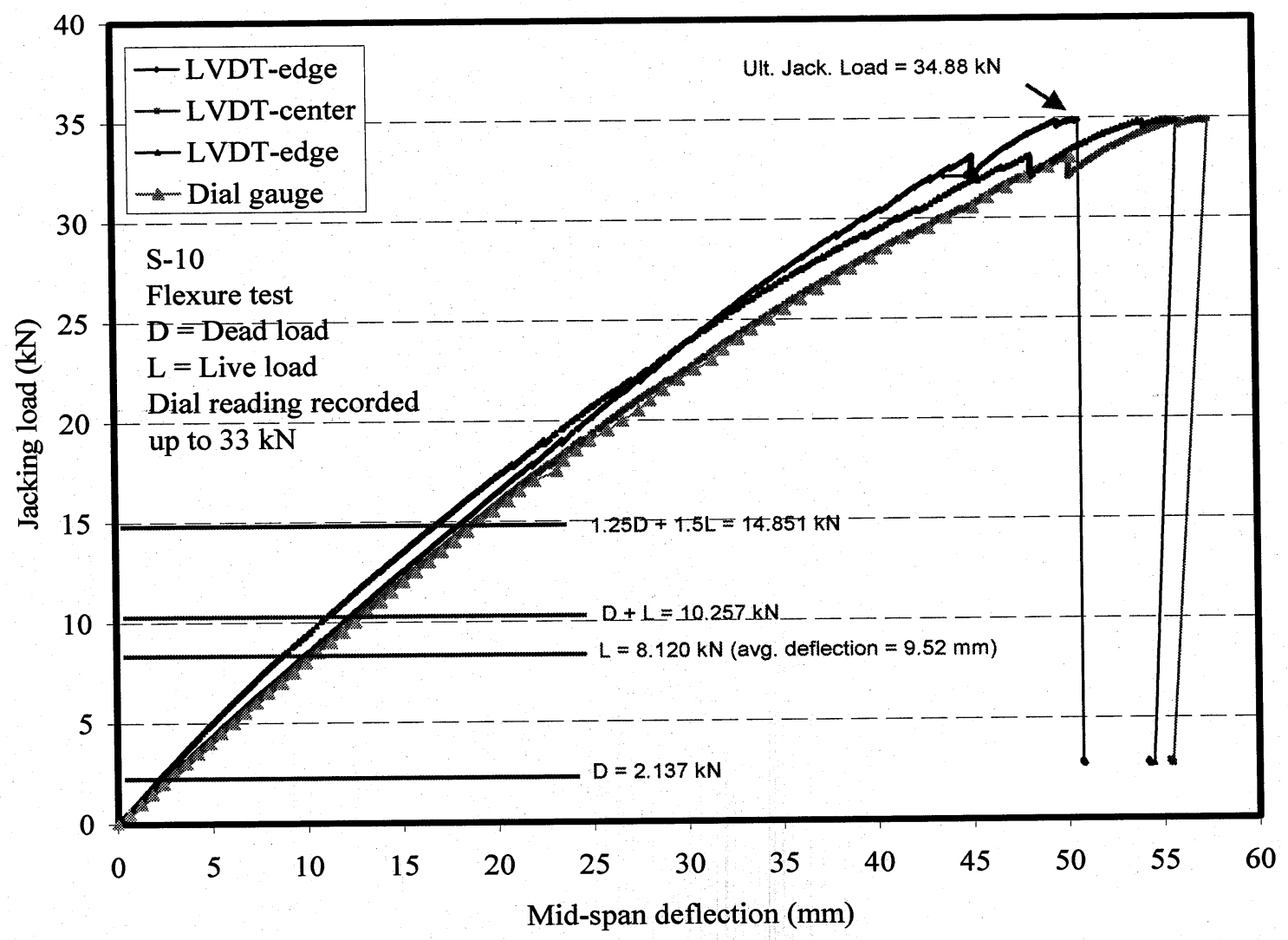

Figure AI-50. Load-deflection relationship for specimen S-10 


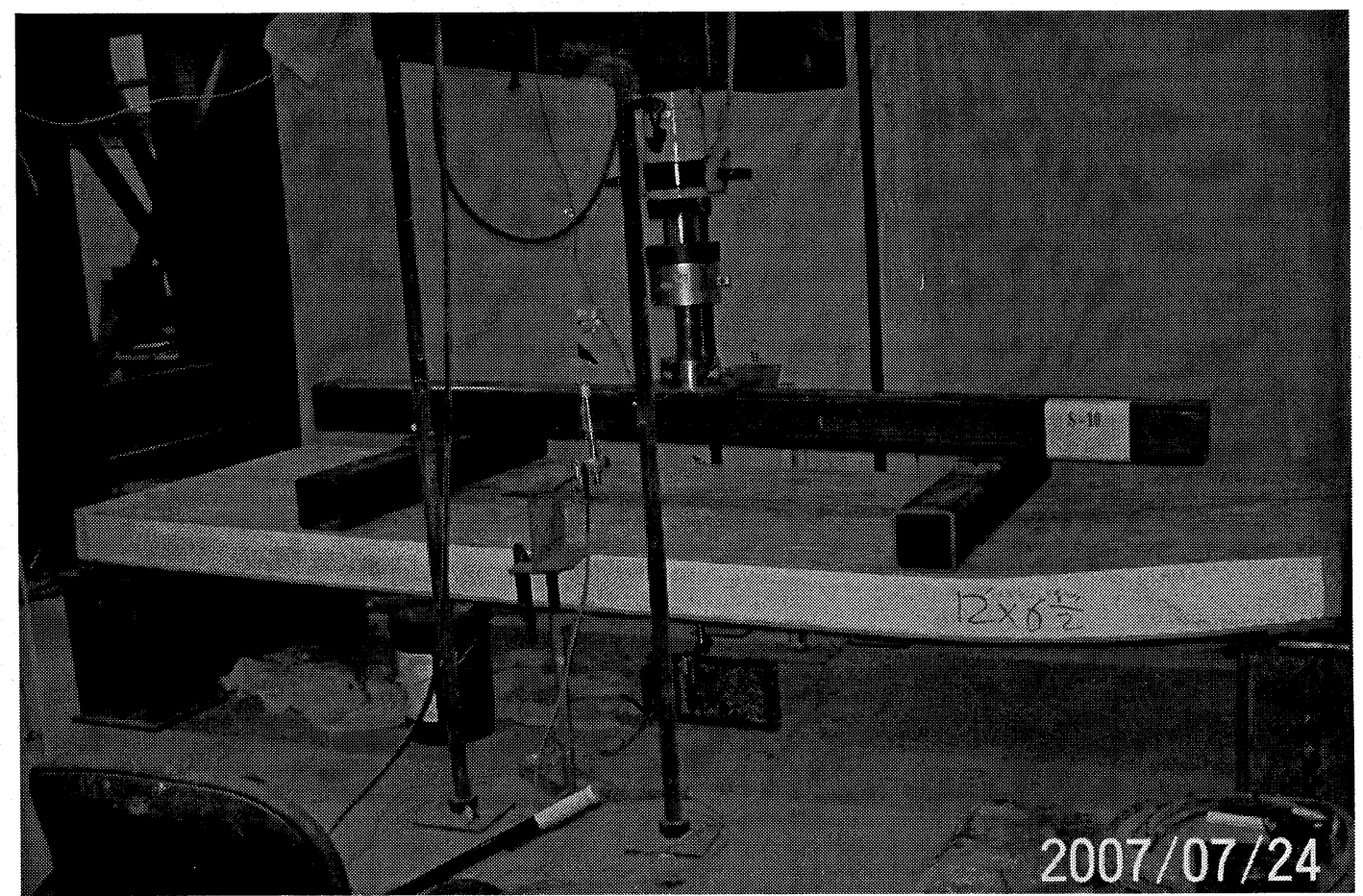

Figure AI-51. View of specimen S-10 after failure

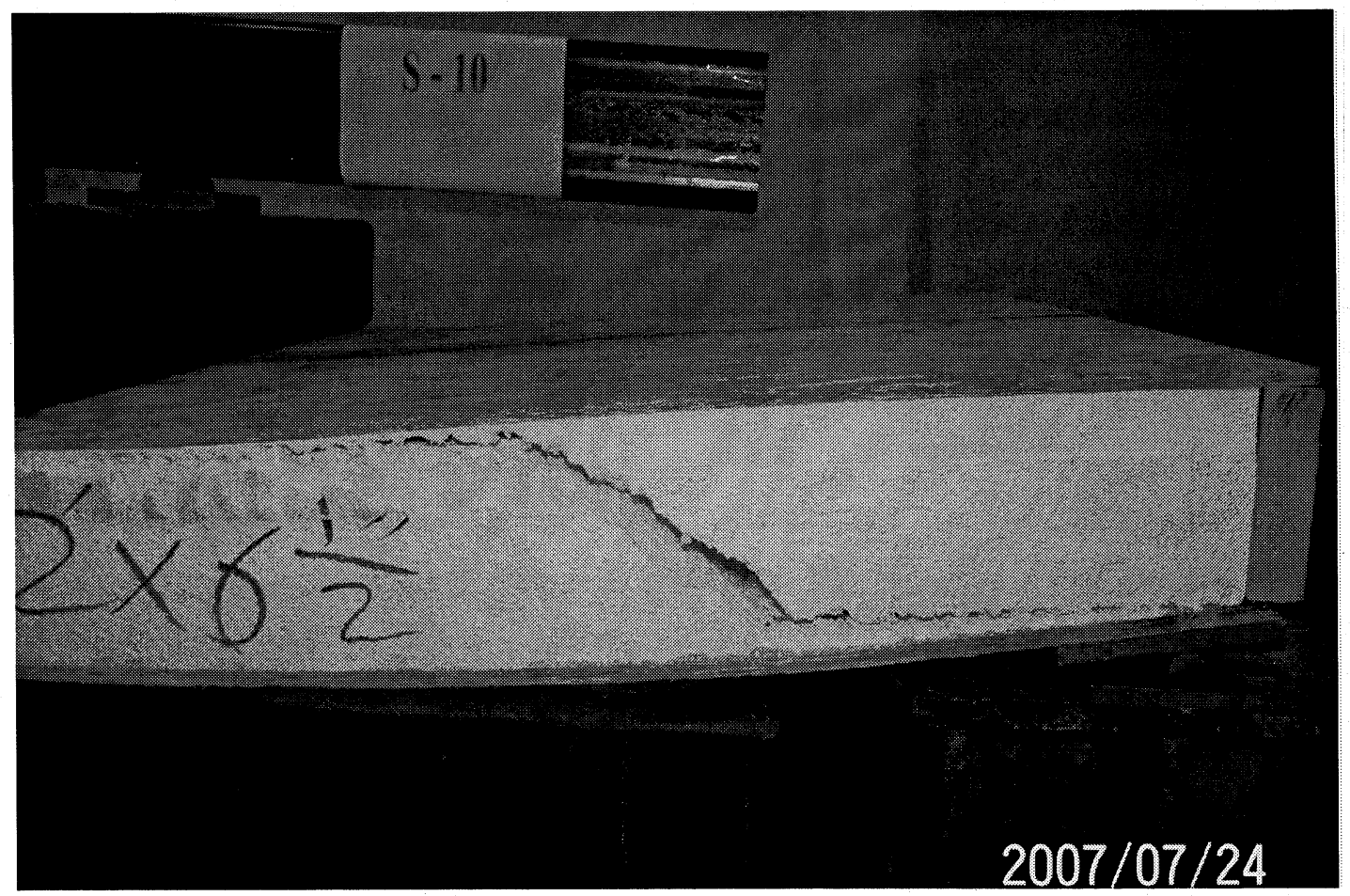

Figure AI-52. Close-up view of the failure pattern from one side of specimen S-10 


\section{Specimen \# S-11}

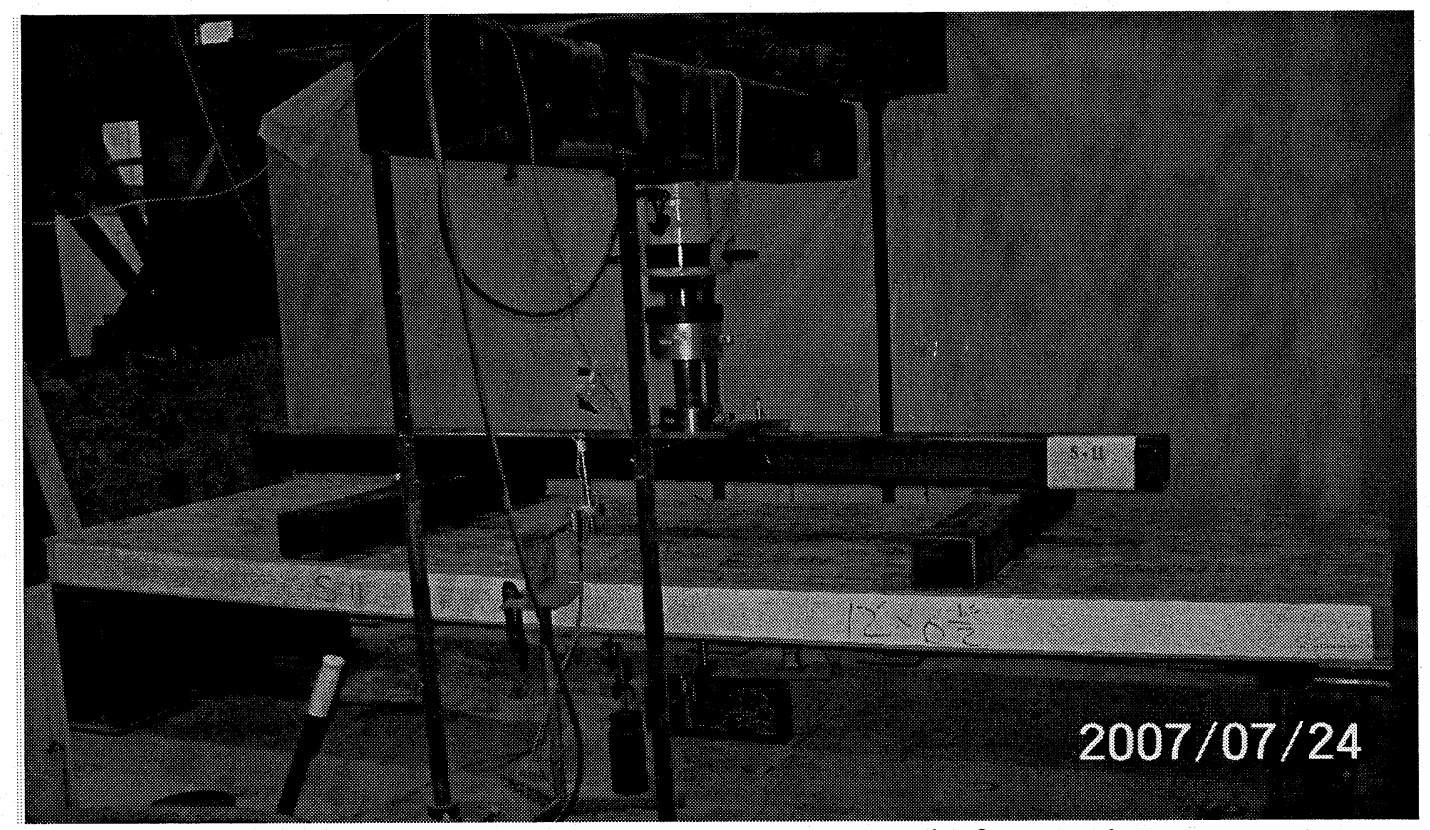

Figure AI-53. View of Specimen S-11 before testing

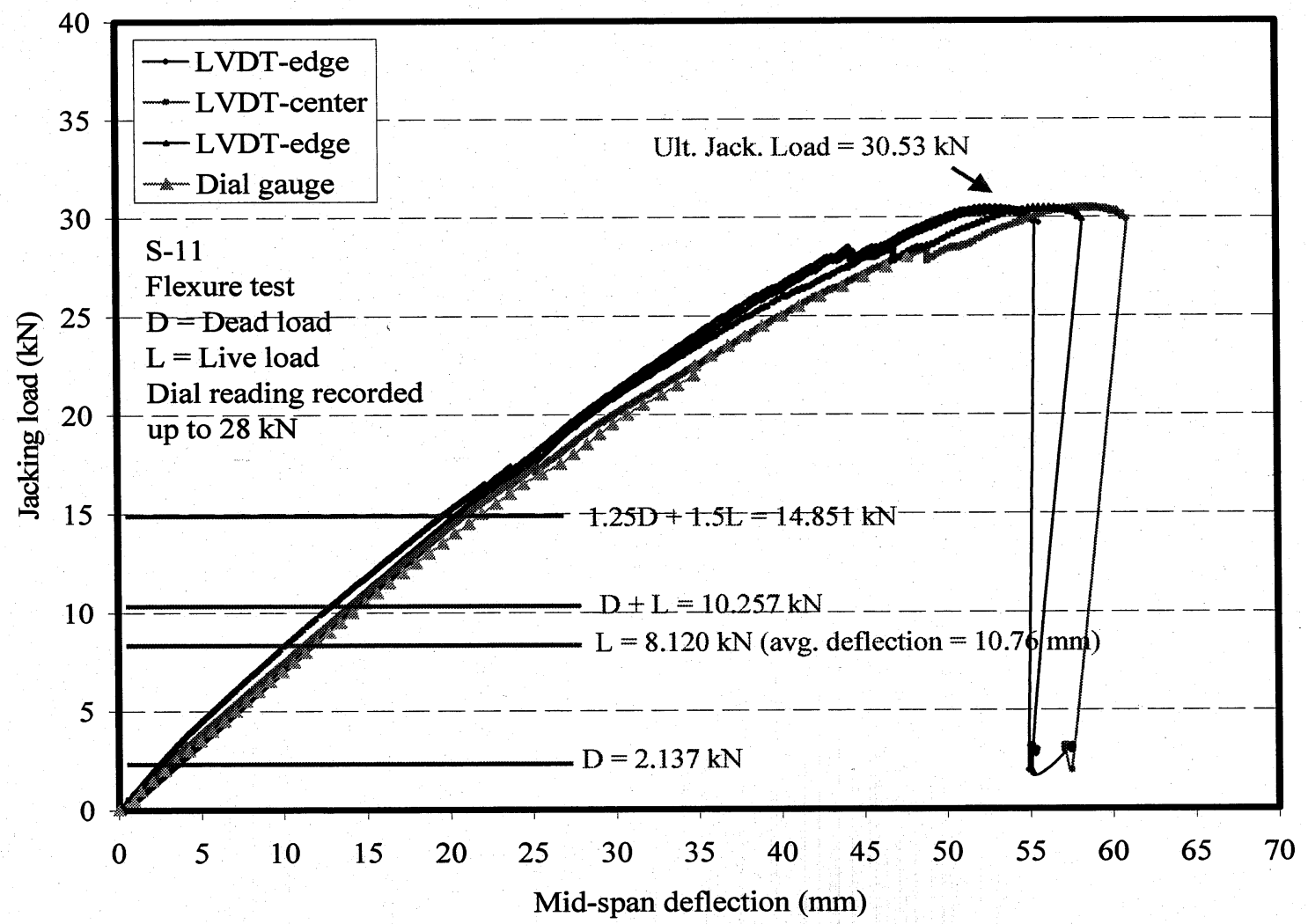

Figure AI-54. Load-deflection relationship for specimen S-11 


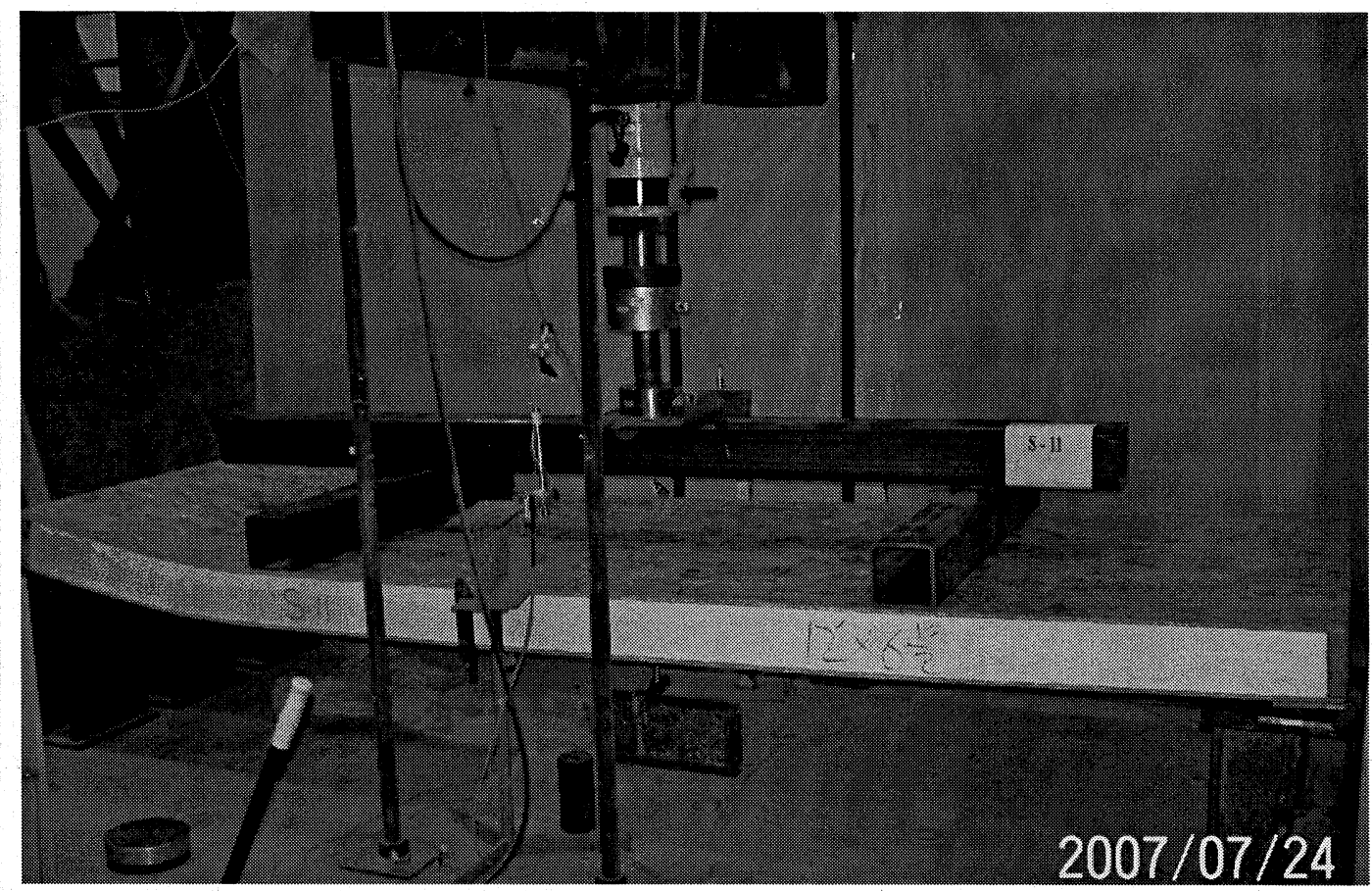

Figure AI-55. View of specimen S-11 after failure

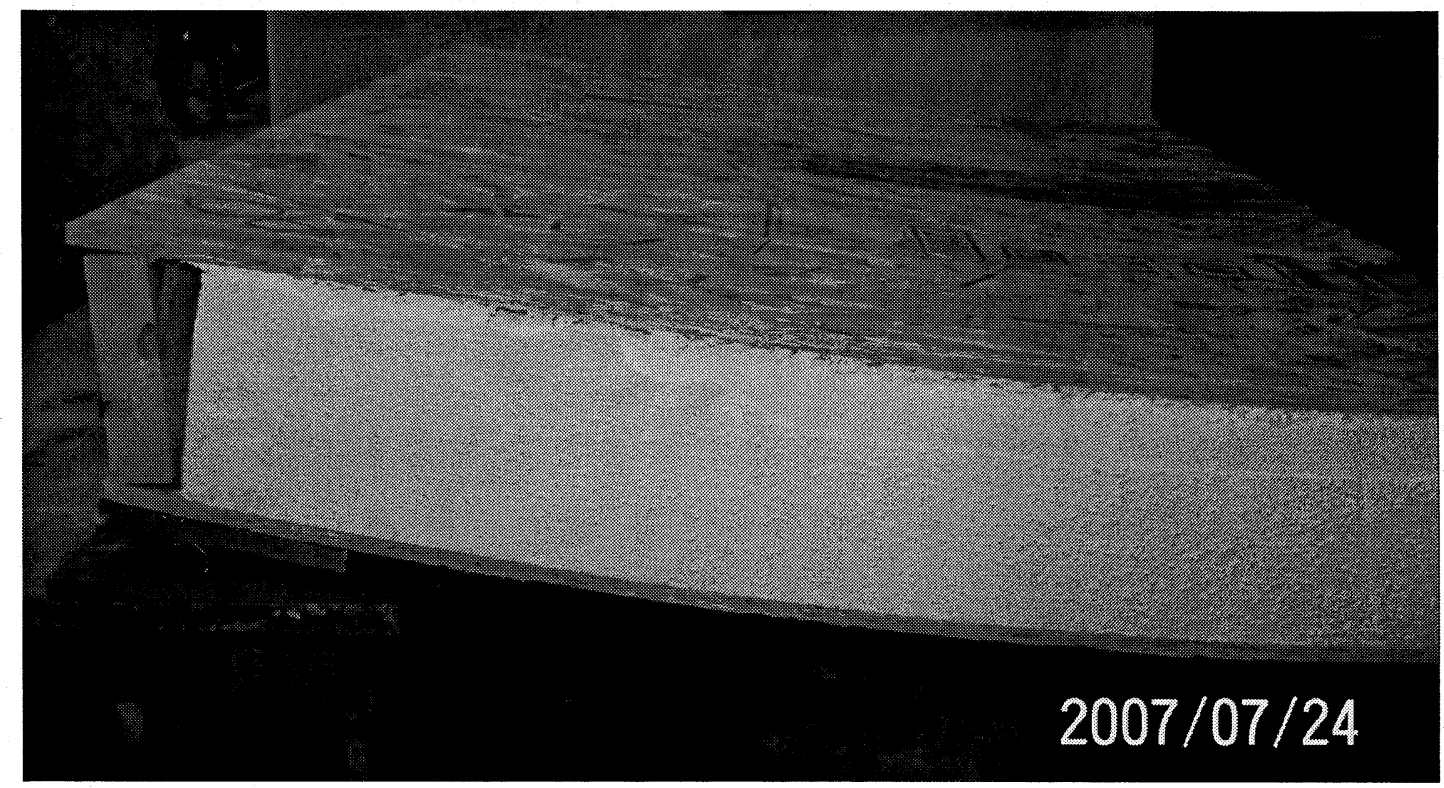

Figure AI-56. Close-up view of the failure pattern from one side of specimen S-11 


\section{Specimen \# S-12}

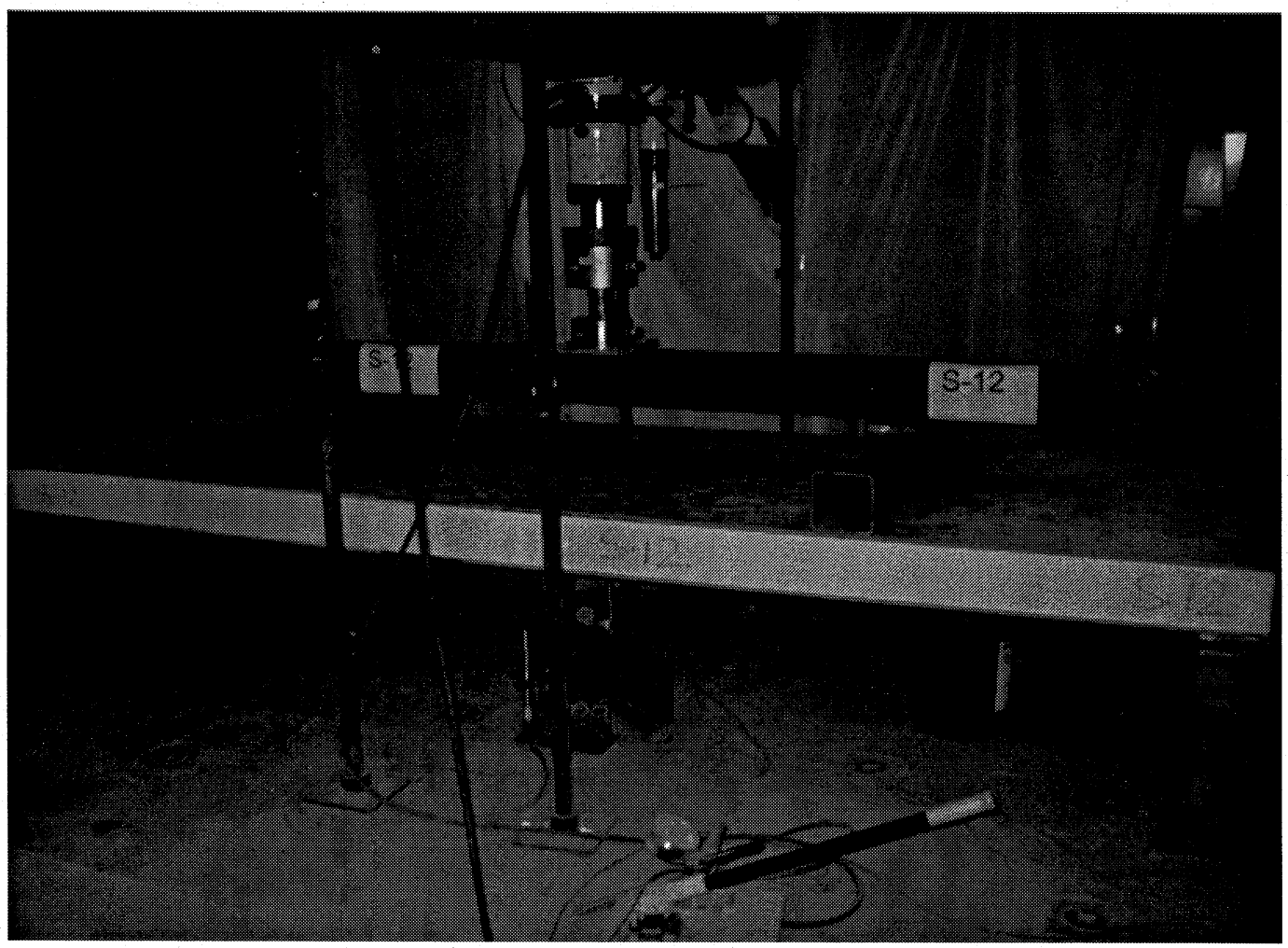

Figure AI-57. View of Specimen S-12 before testing

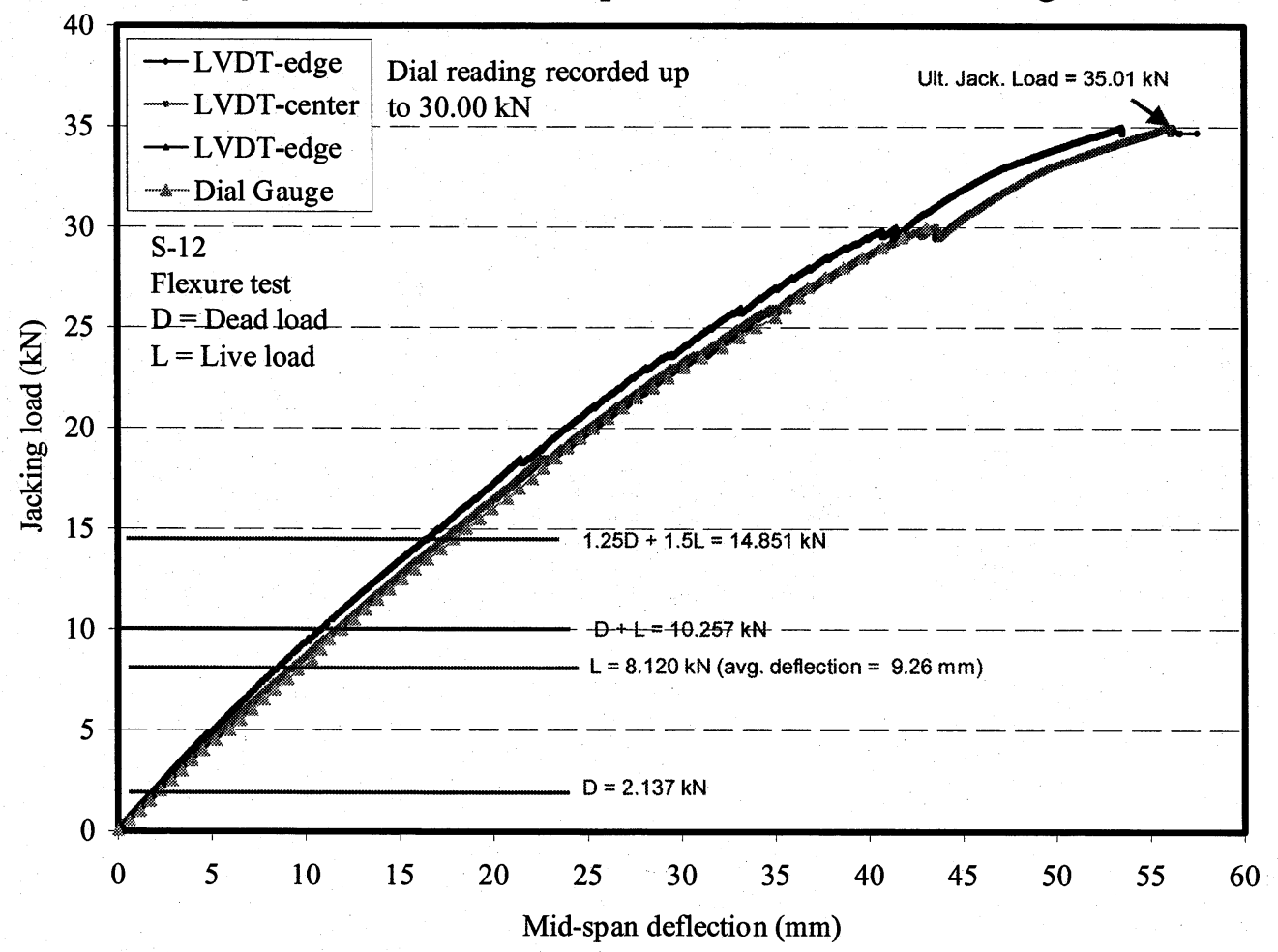

Figure AI-57. Load-deflection relationship for specimen S-12 


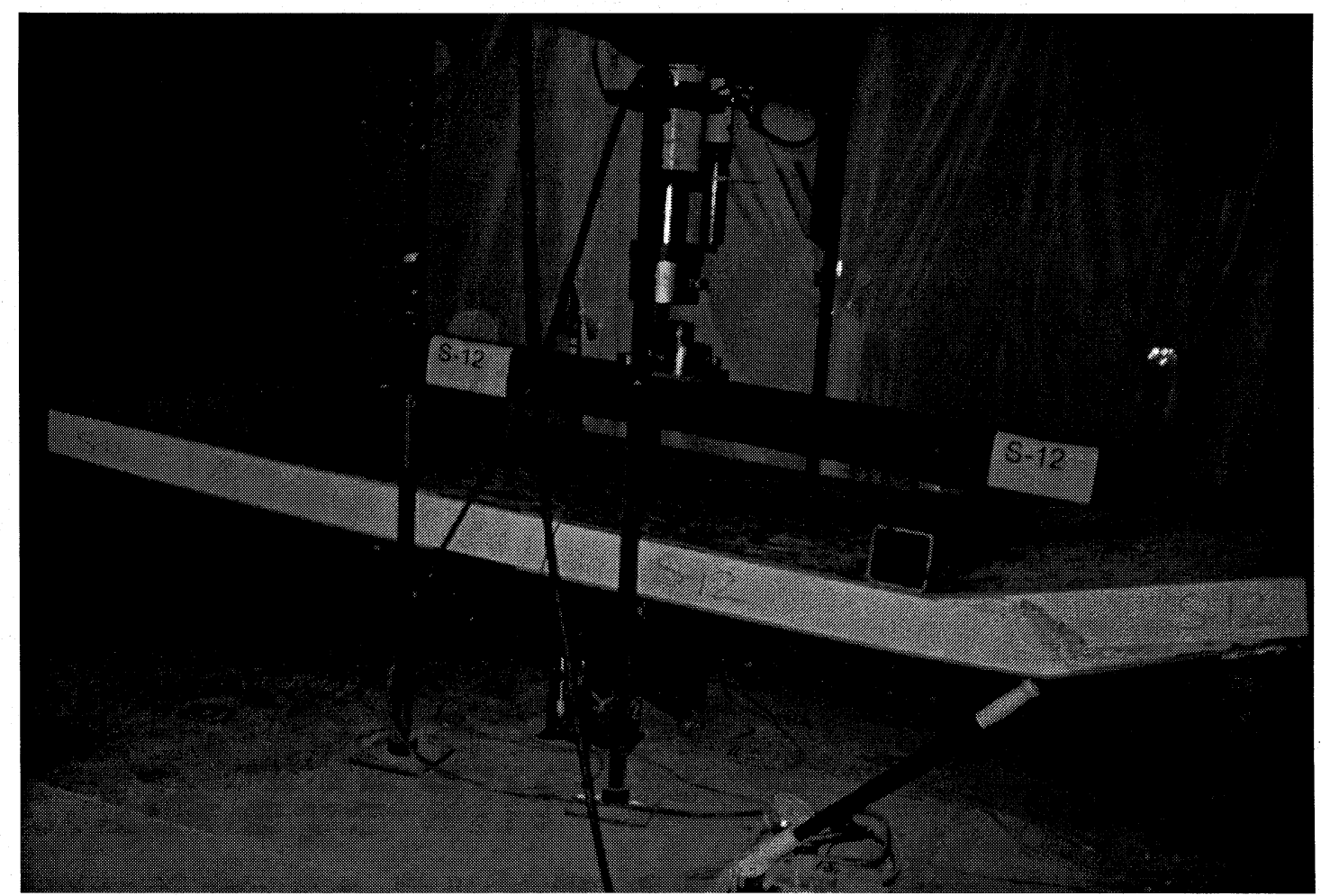

Figure AI-58. View of specimen S-12 after failure

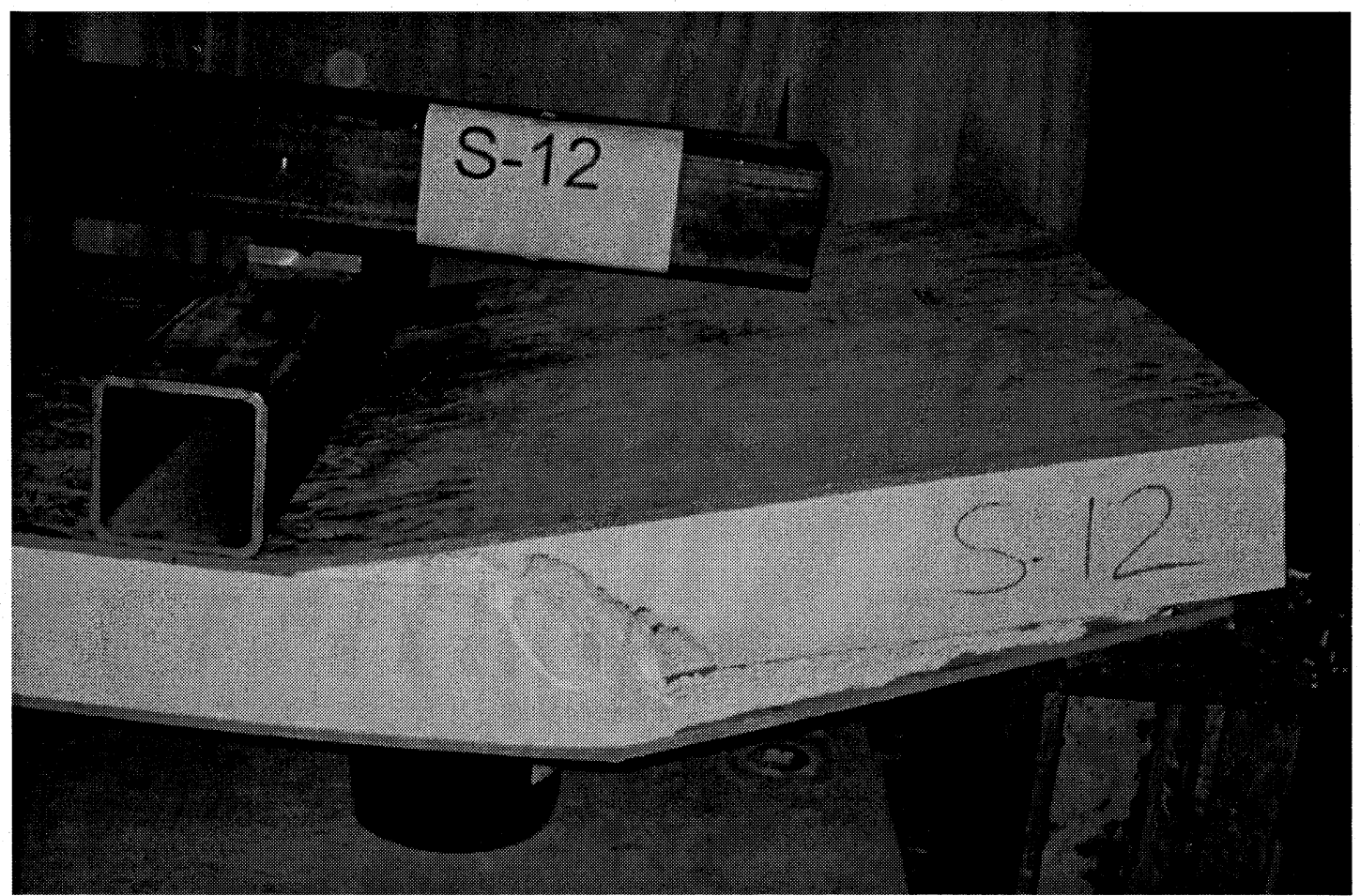

Figure AI-59. Close-up view of the failure pattern from one side of specimen S-12 


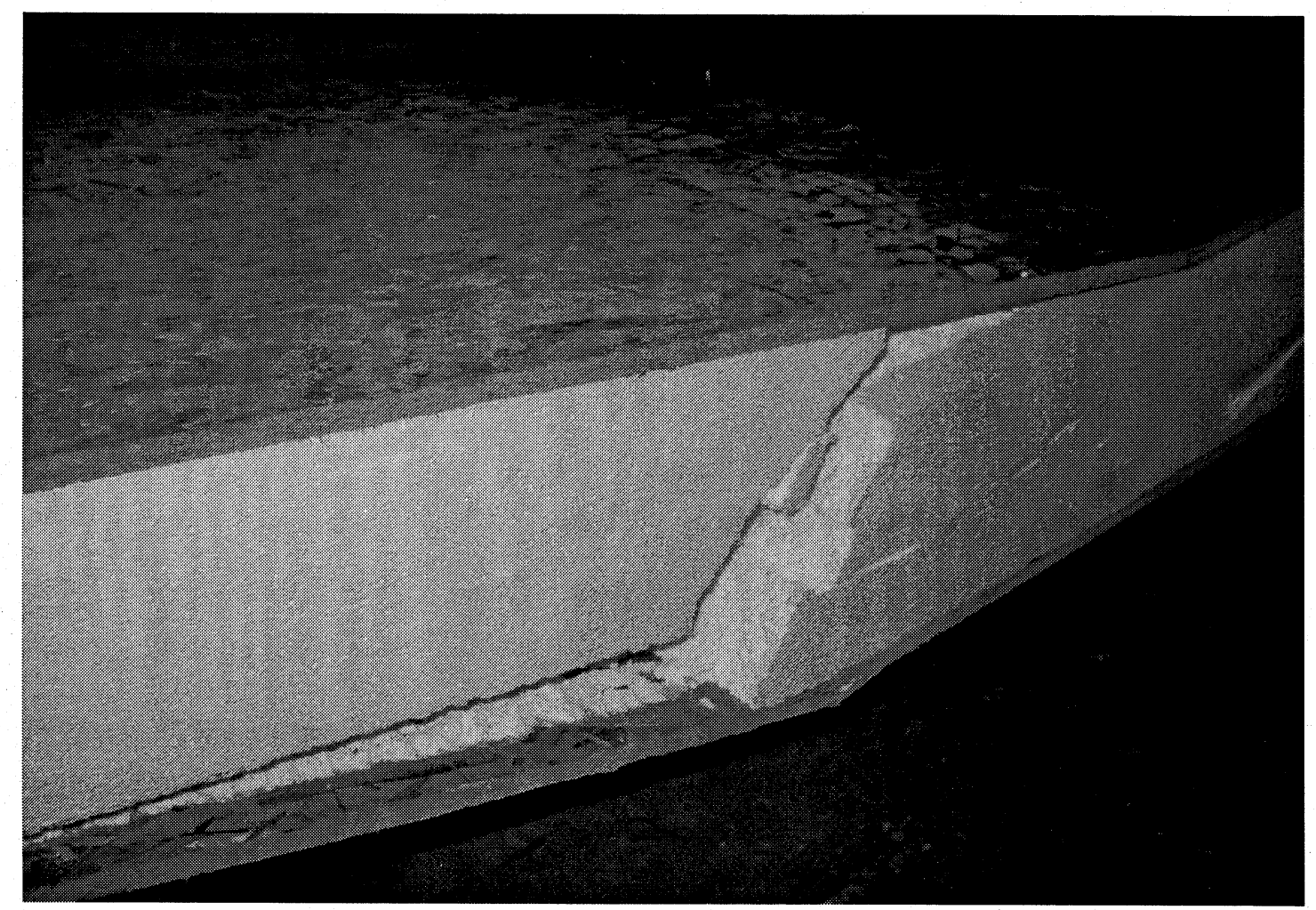

Figure AI-60. Close-up view of the failure pattern from the other free edge of specimen S-12 


\section{Specimen \# S-44}

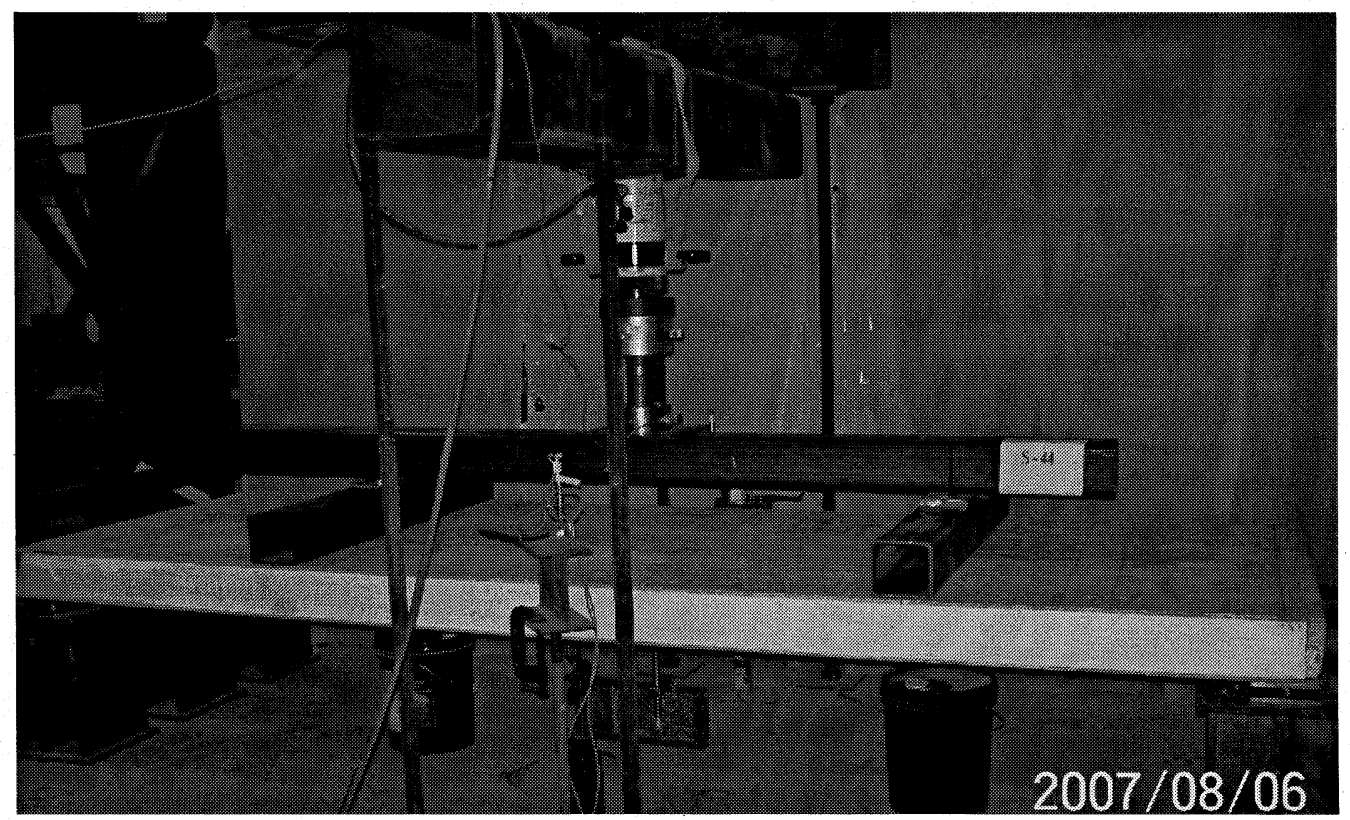

Figure AI-61. View of Specimen S-44 before testing

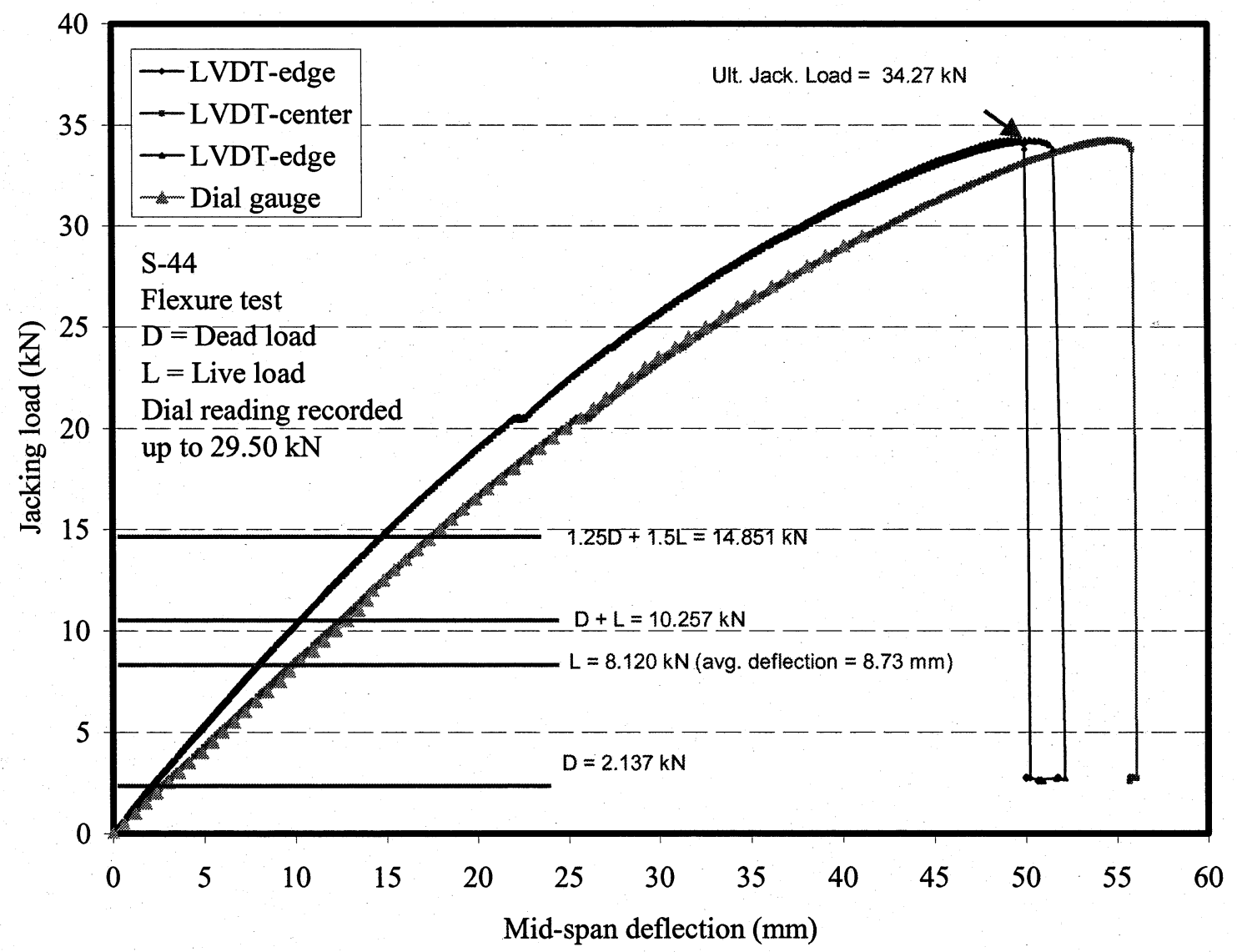

Figure AI-62. Load-deflection relationship for specimen S-44 


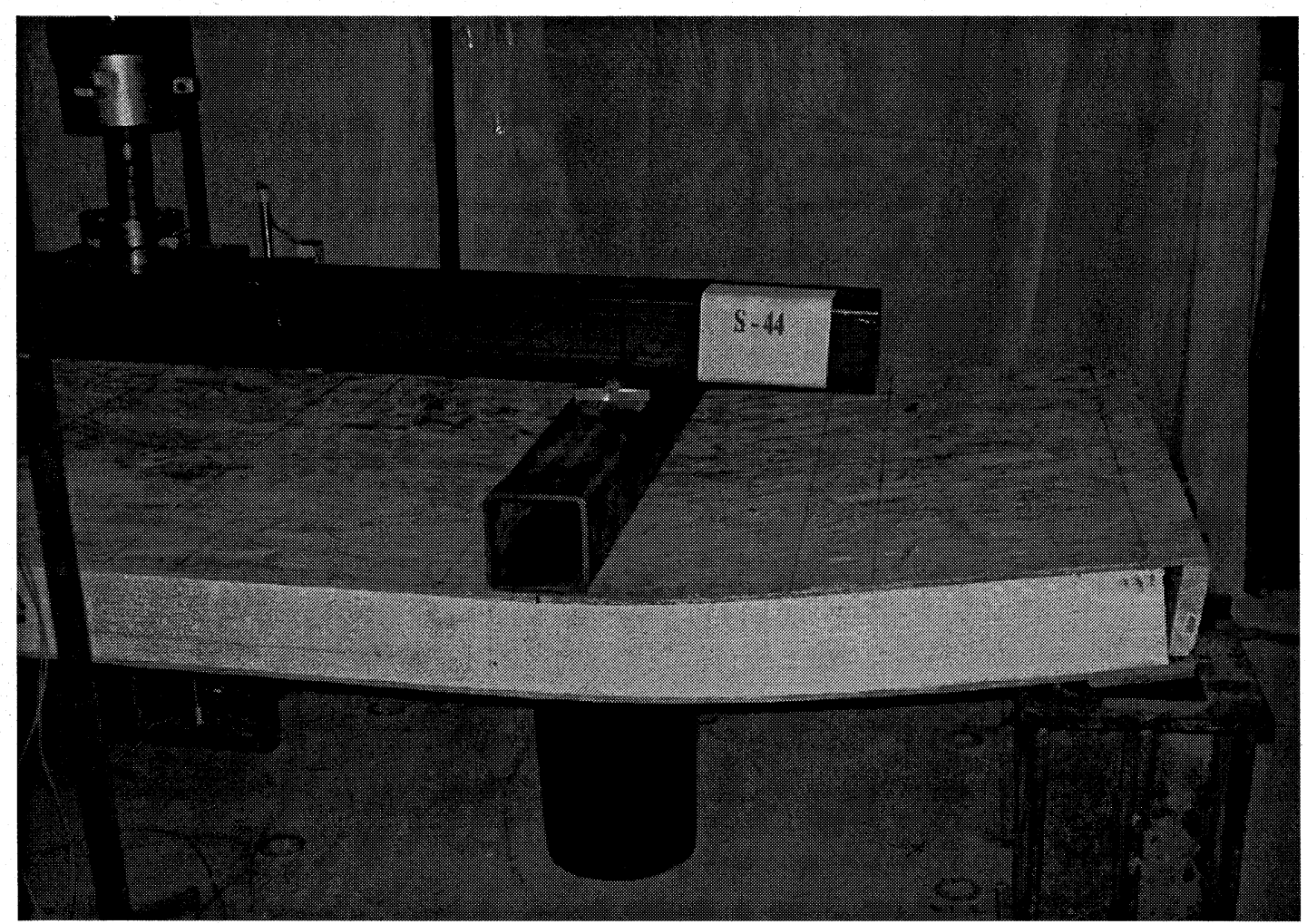

Figure AI-63. View of specimen S-44 after failure

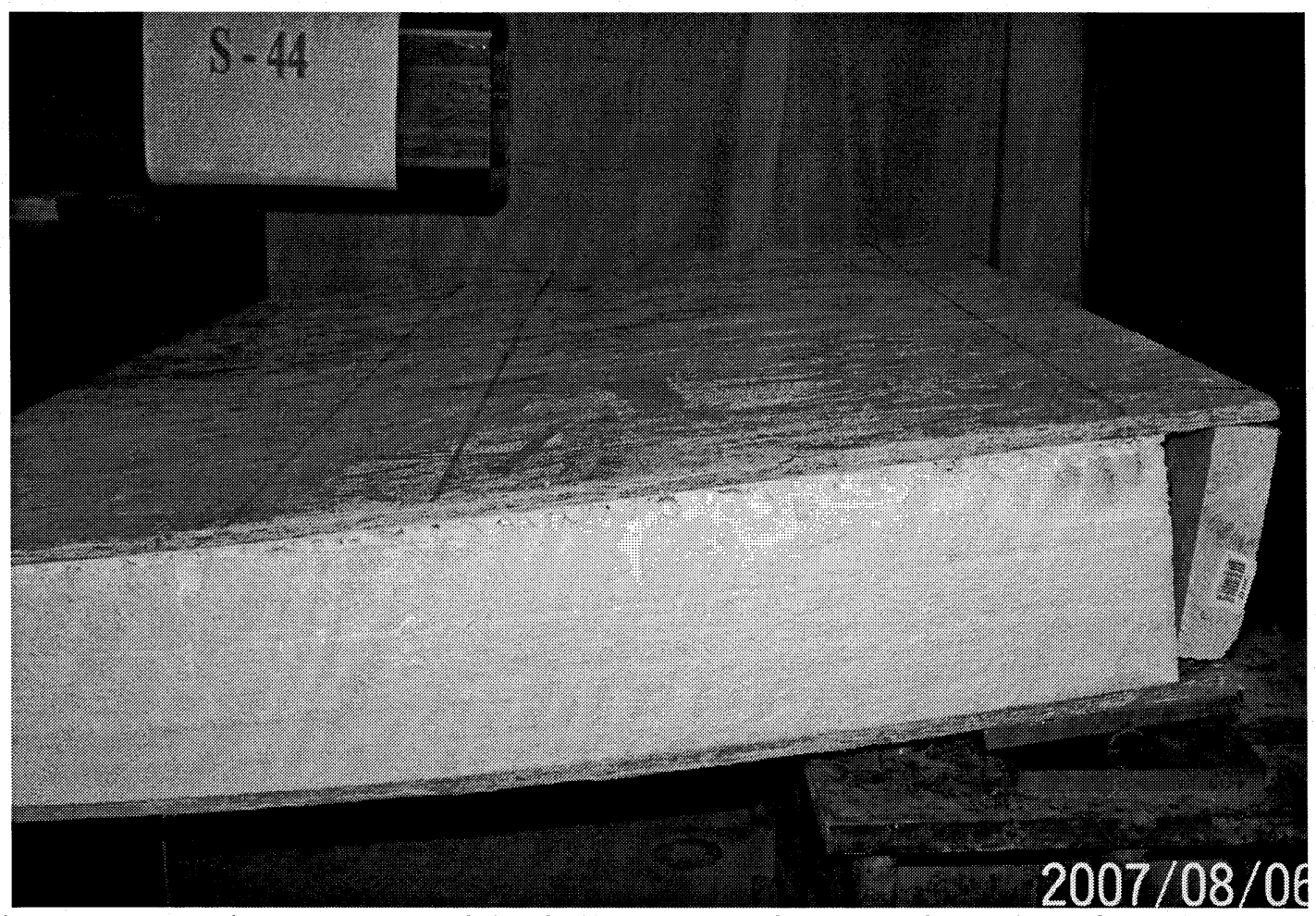

Figure AI-64. Close-up view of the failure pattern from one free edge of specimen S-44 


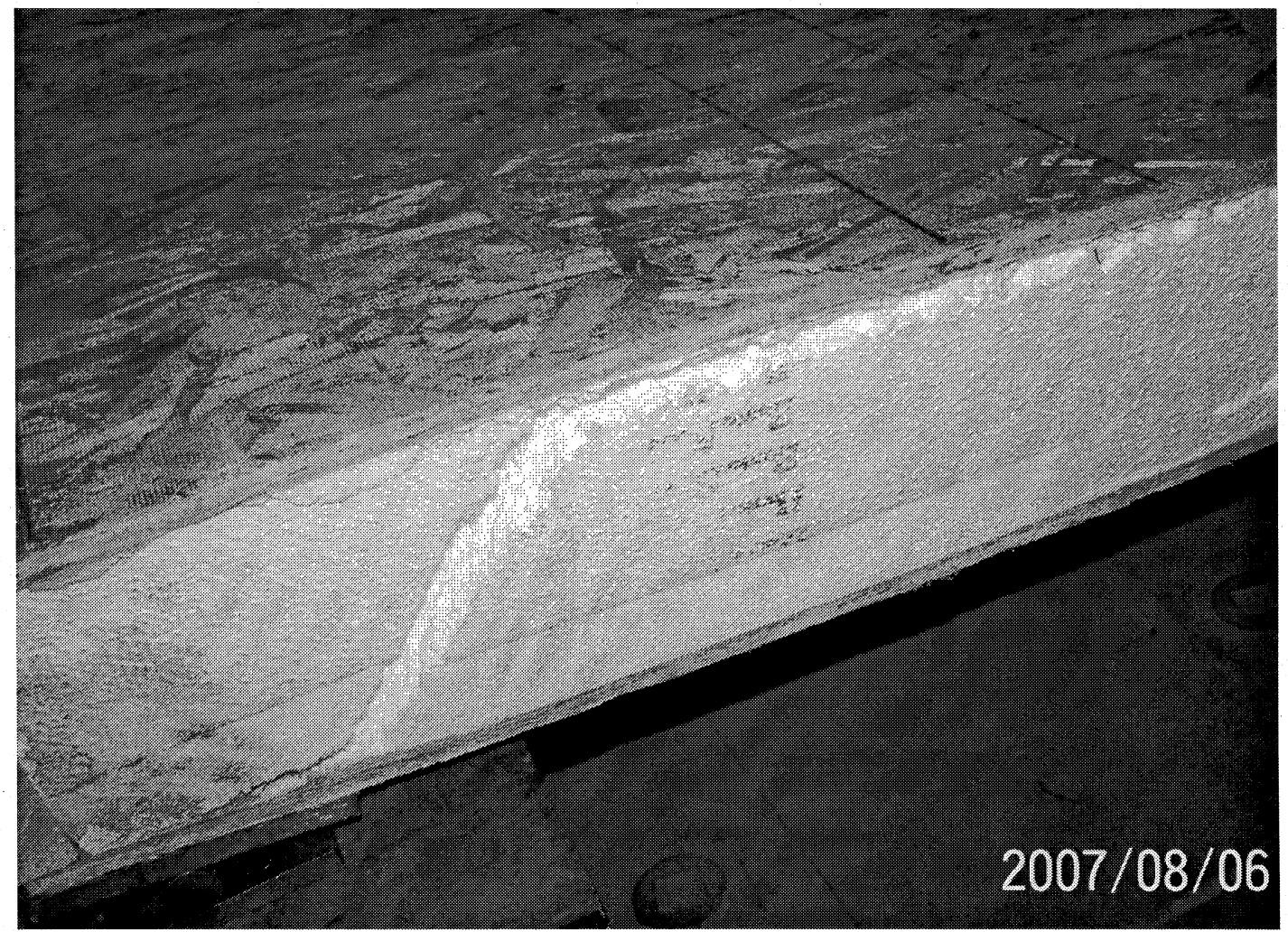

Figure AI-65. Close-up view of the failure pattern from the other free edge of specimen S-44 


\section{GROUP E}

\section{Specimen \# 13}

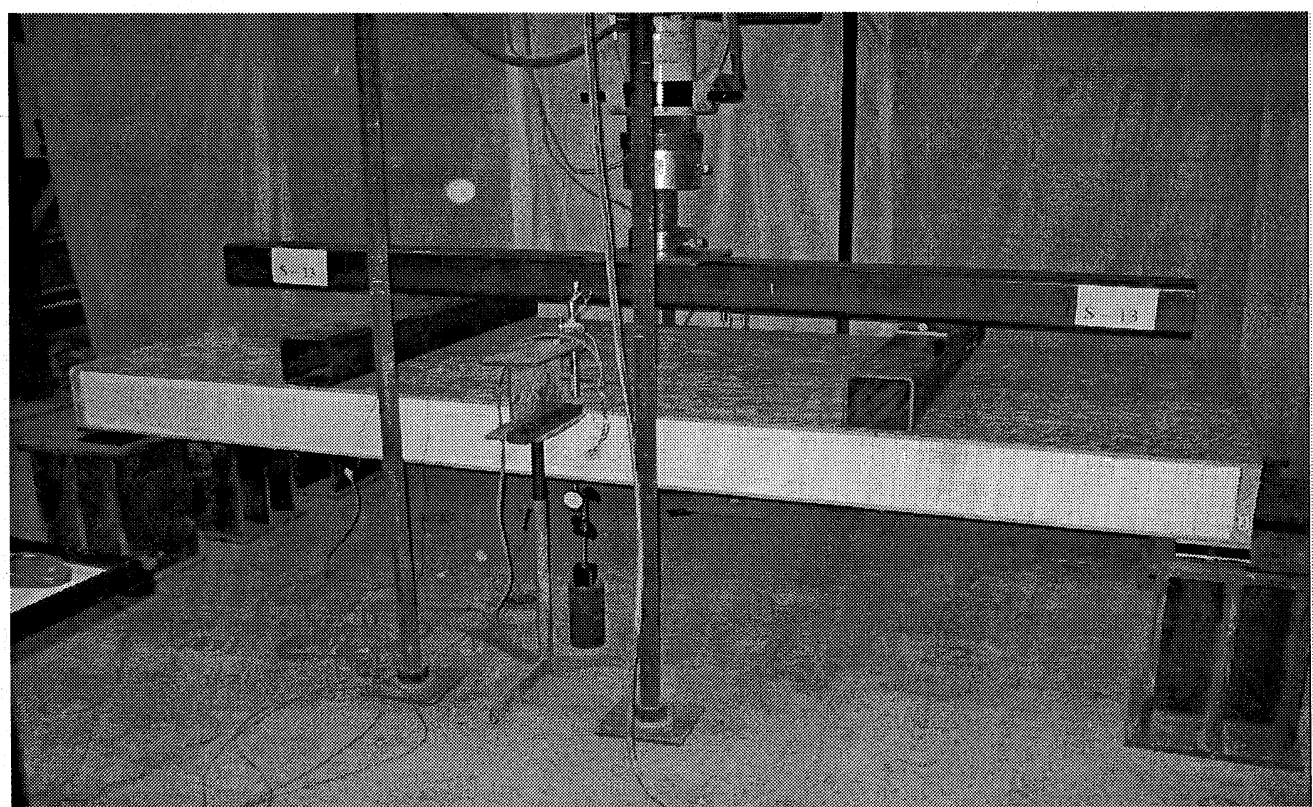

Figure AI-66. View of Specimen S-13 before testing

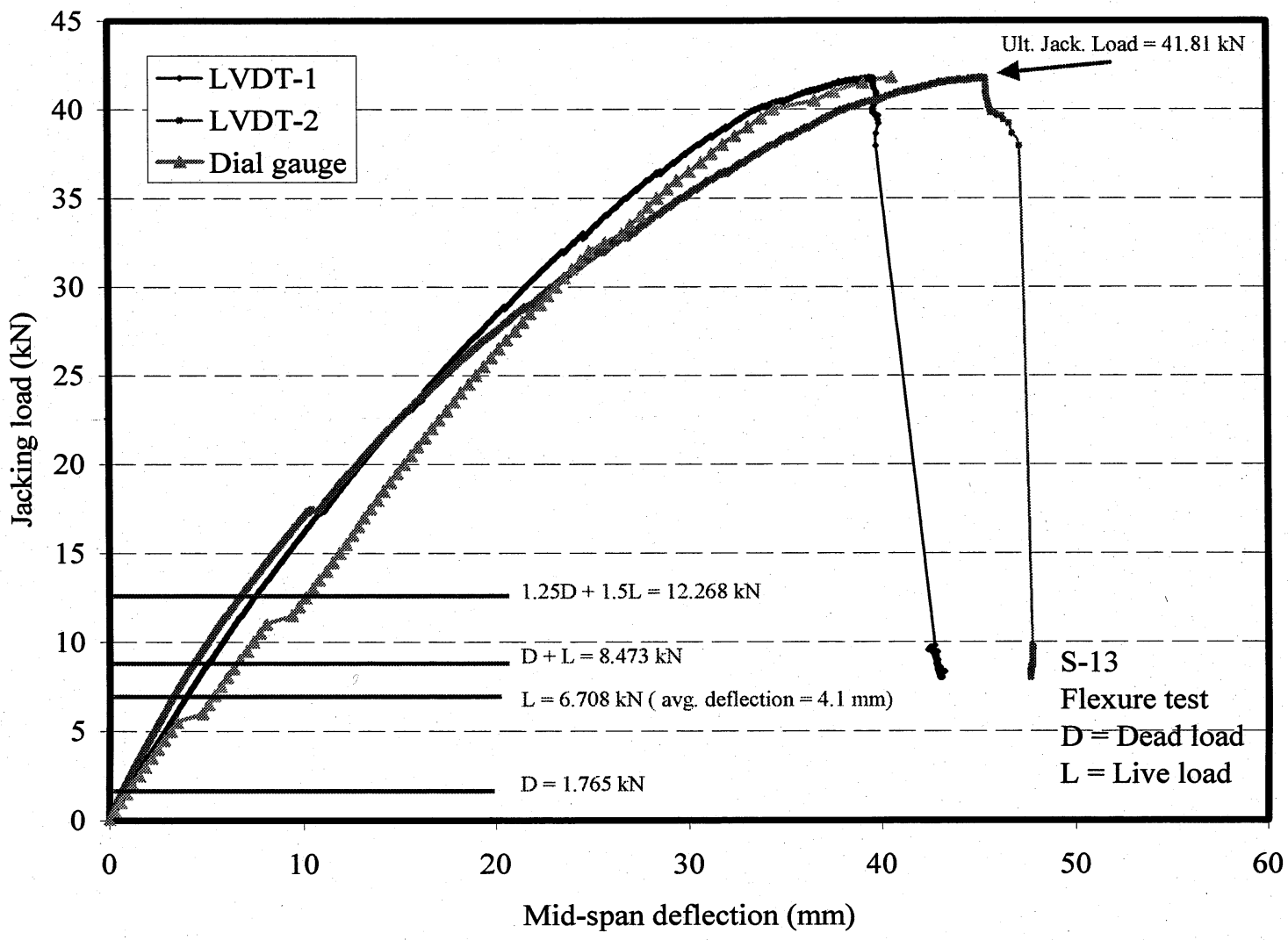

Figure AI-67. Load-deflection relationship for specimen S-13 


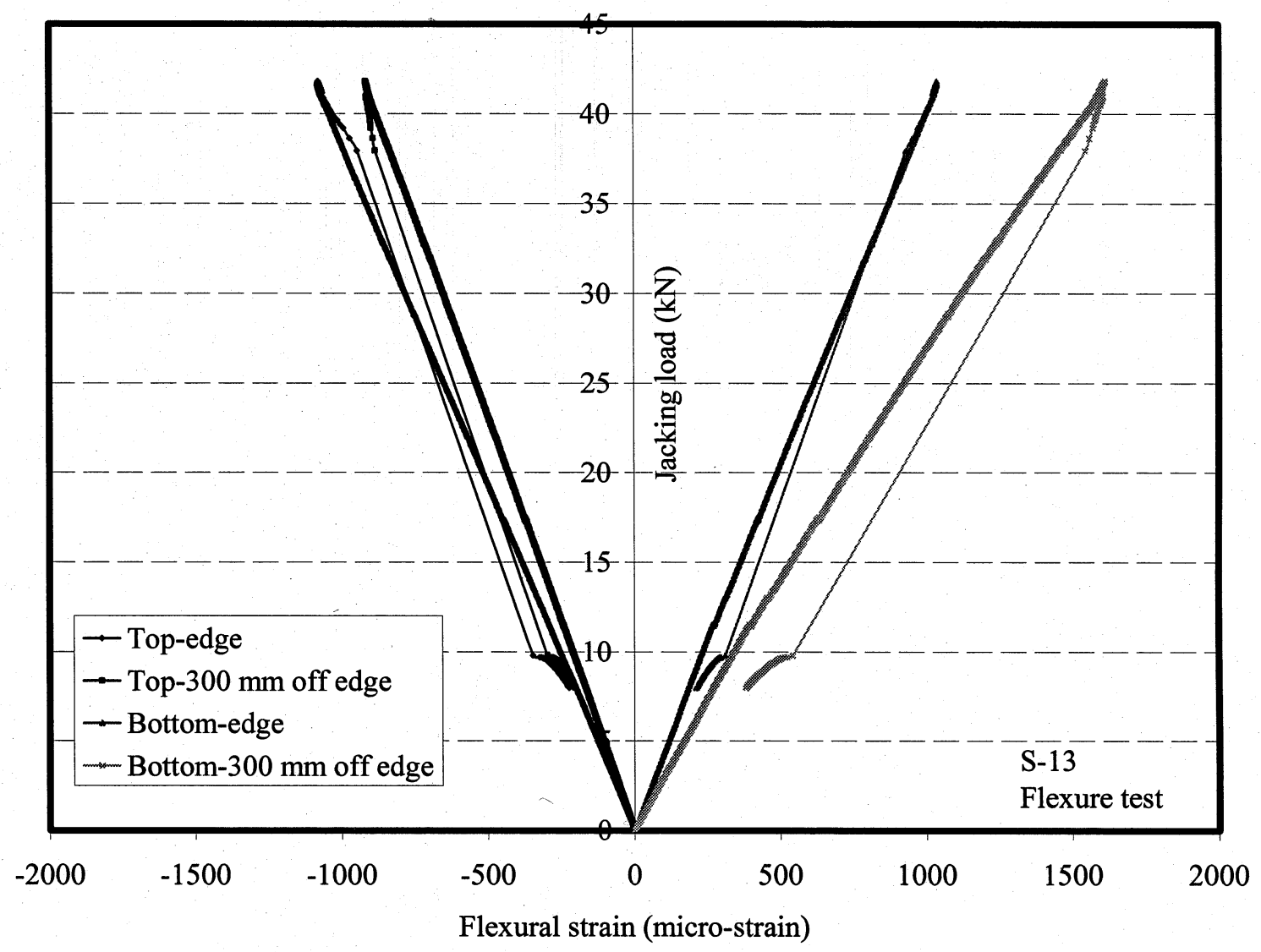

Figure AI-68. Load-strain relationship for specimen S-13

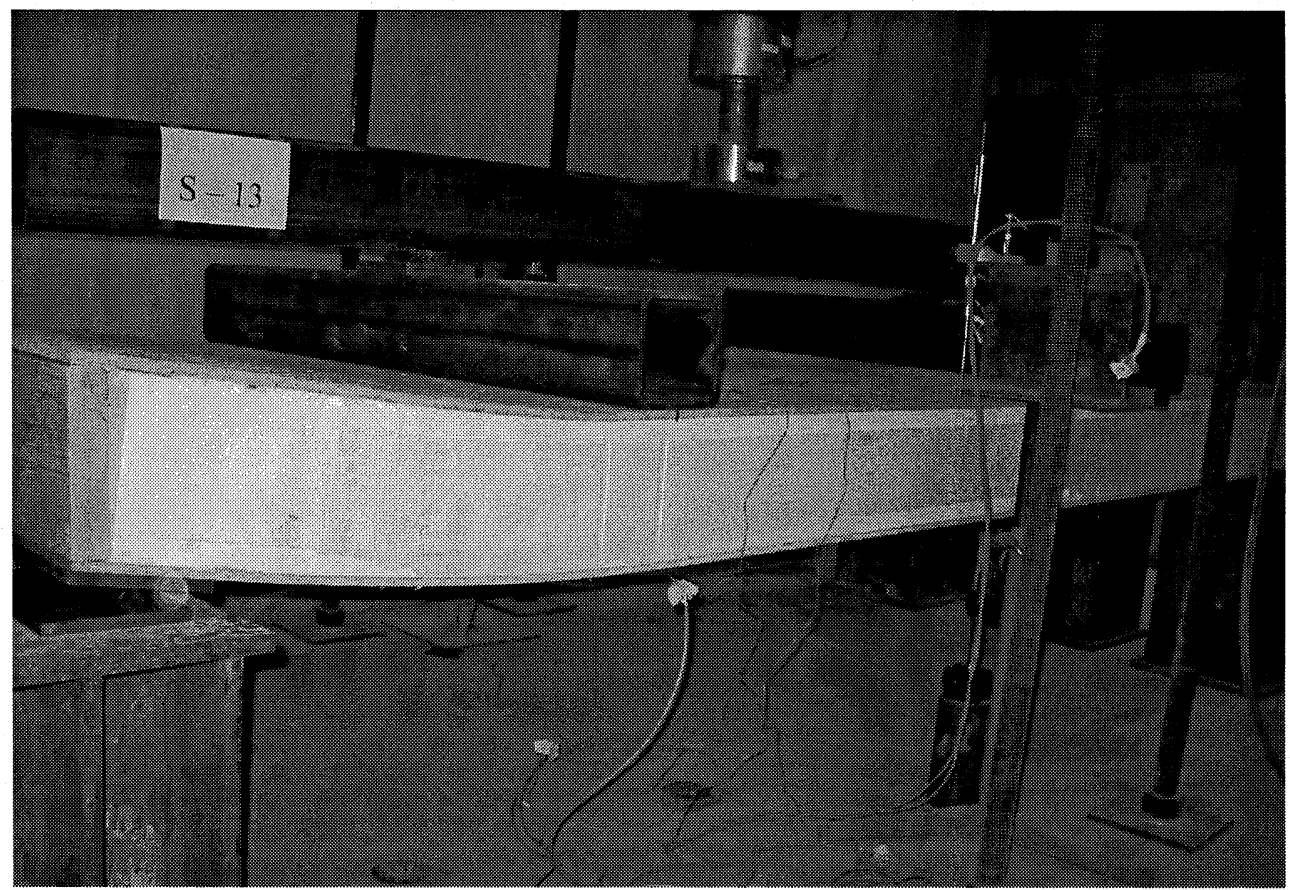

Figure AI-69. View of specimen S-13 after failure 


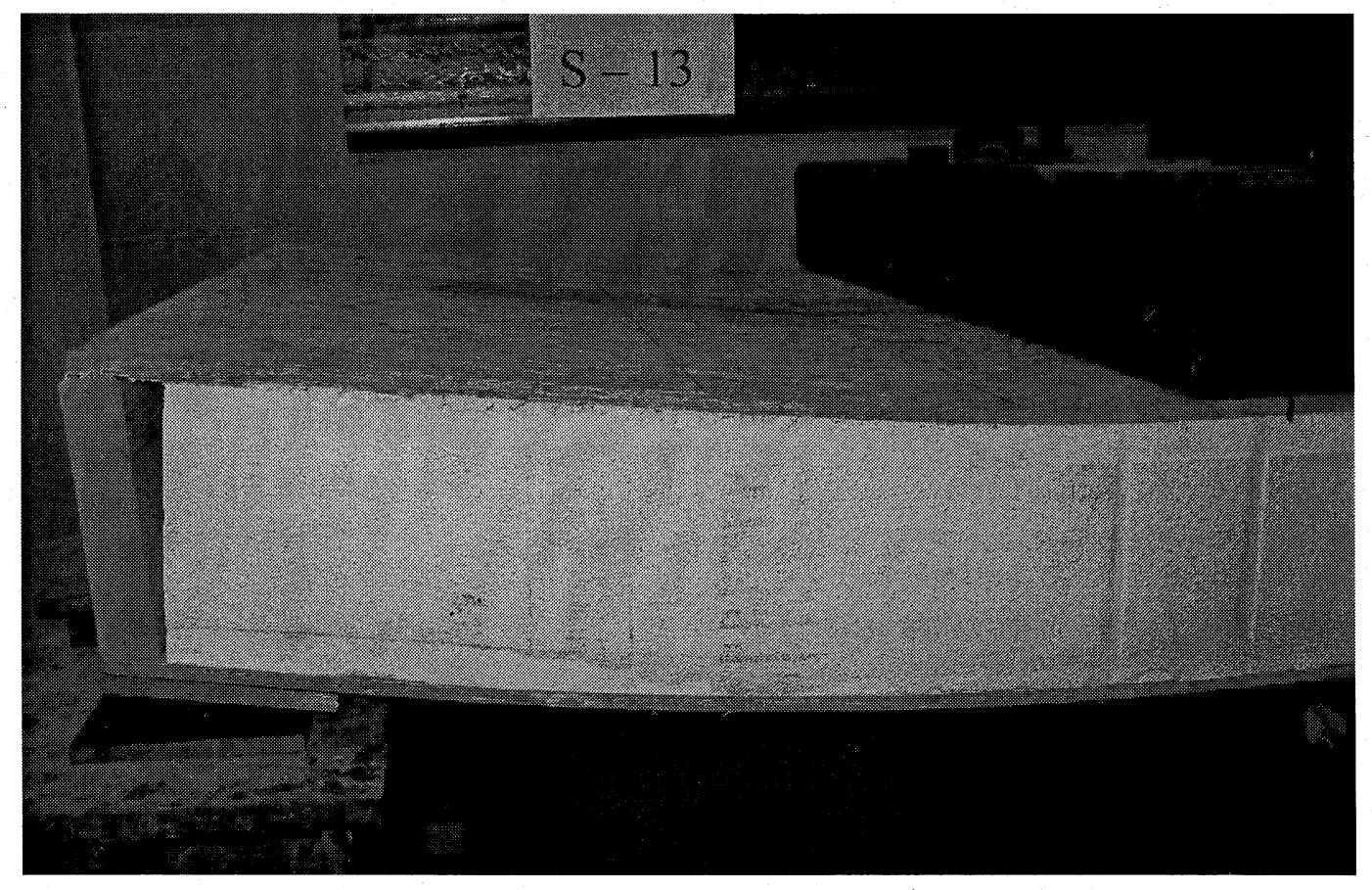

Figure AI-70. View of the horizontal shear failure of specimen S-13 at the interface of the foam and the top OSB board 


\section{Specimen \# S-14}

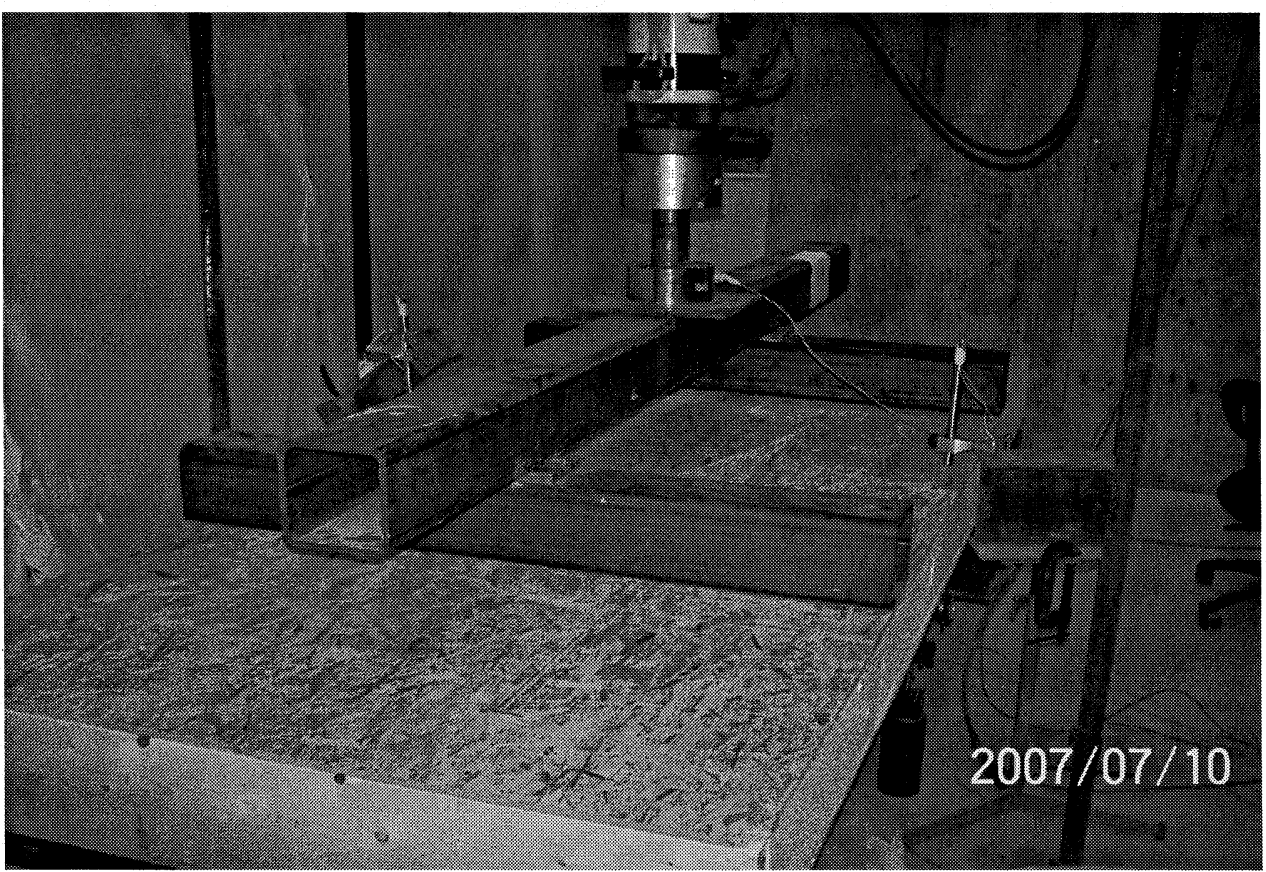

Figure AI-71. View of Specimen S-14 before testing

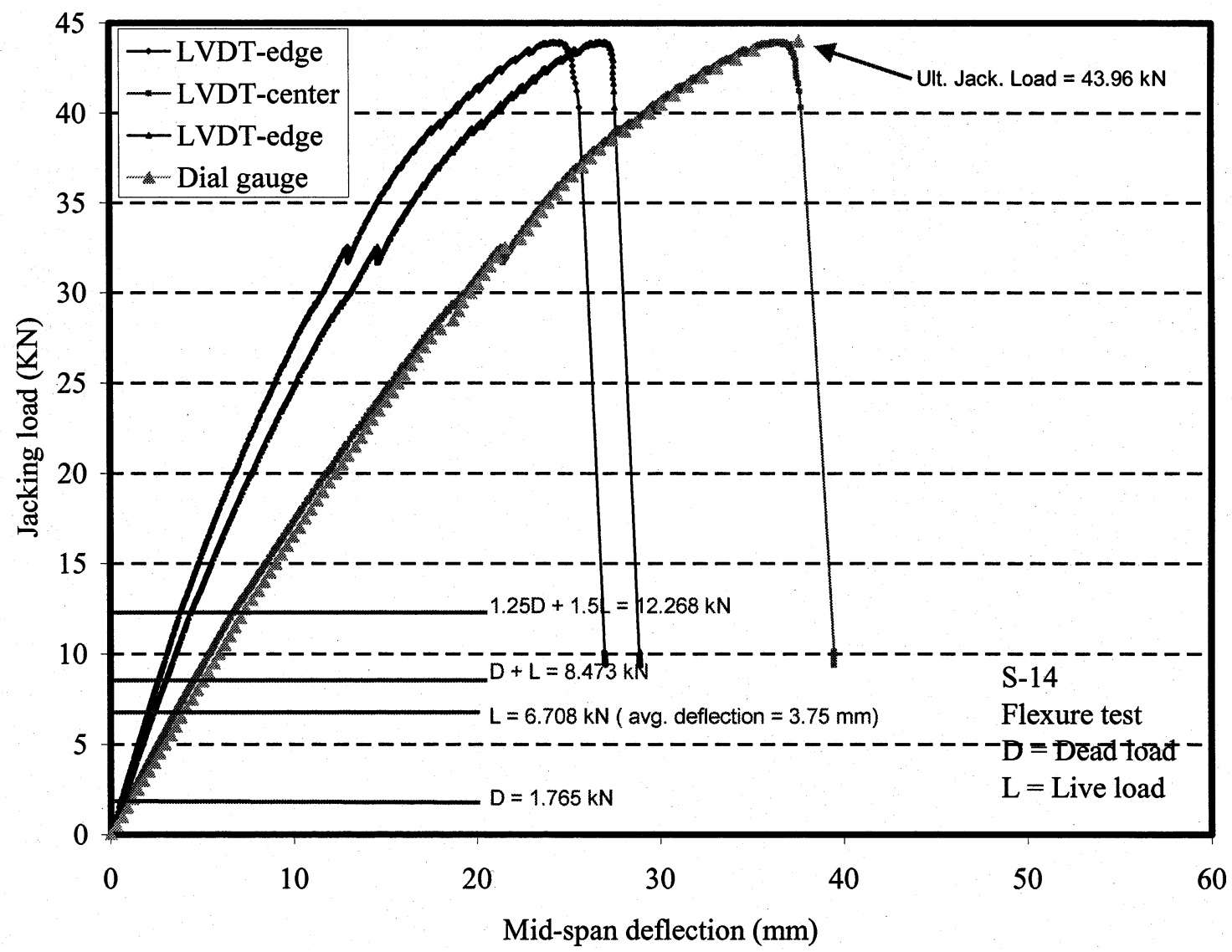

Figure AI-72. Load-deflection relationship for specimen S-14 


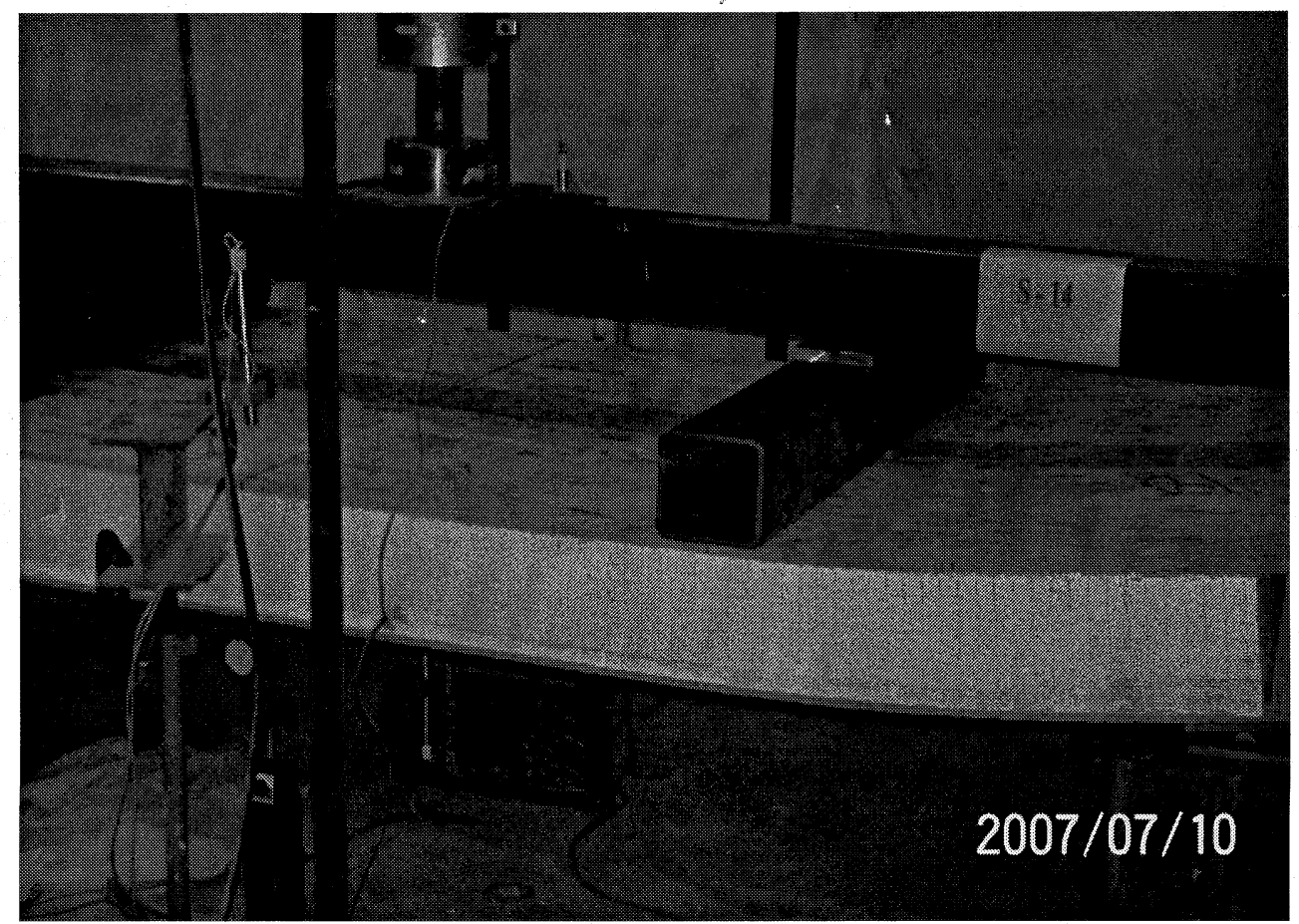

Figure AI-73. View of specimen S-14 after failure

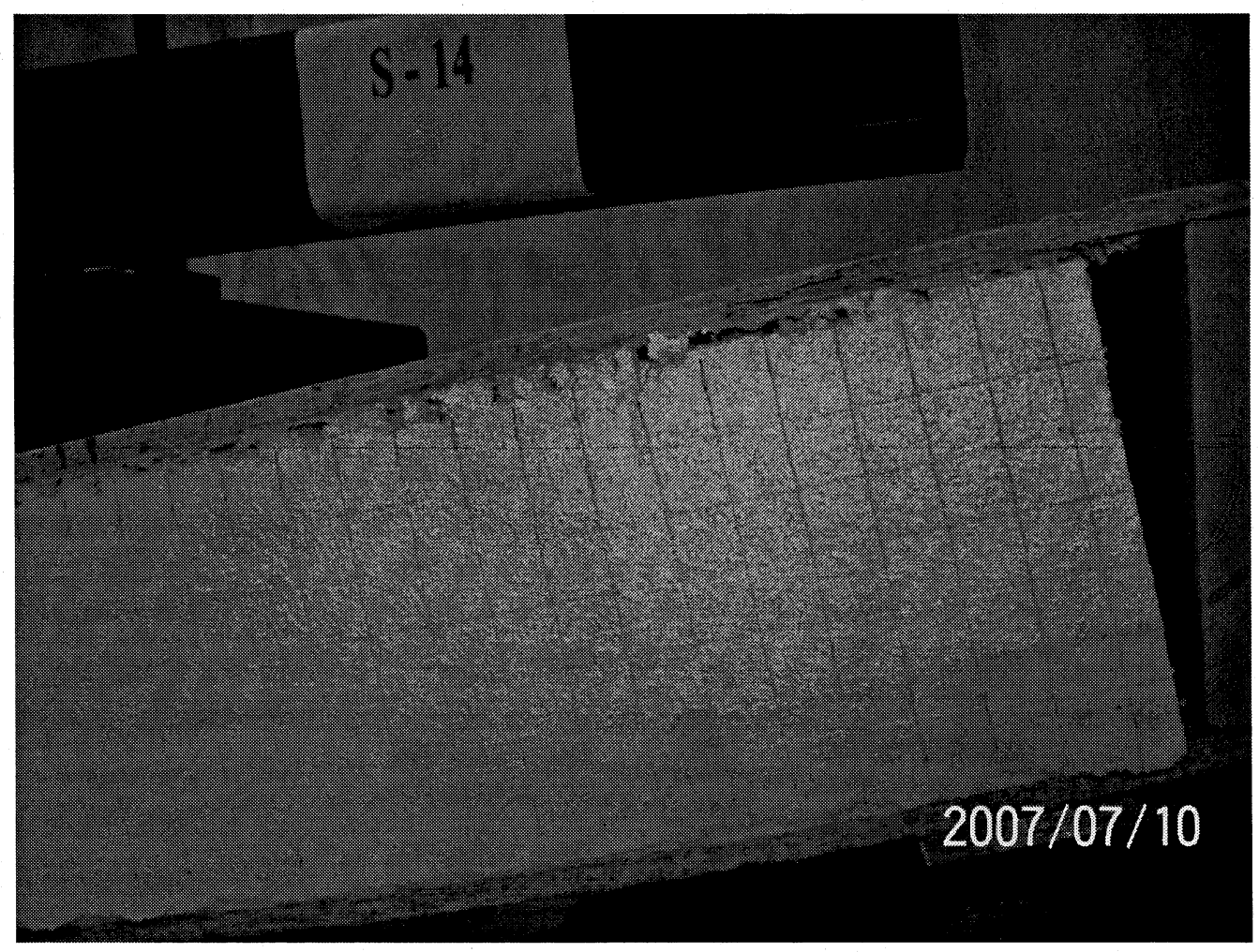

Figure AI-74. View of the horizontal shear failure of specimen S-14 at the interface of the foam and the top OSB board 


\section{Specimen \# S-15}

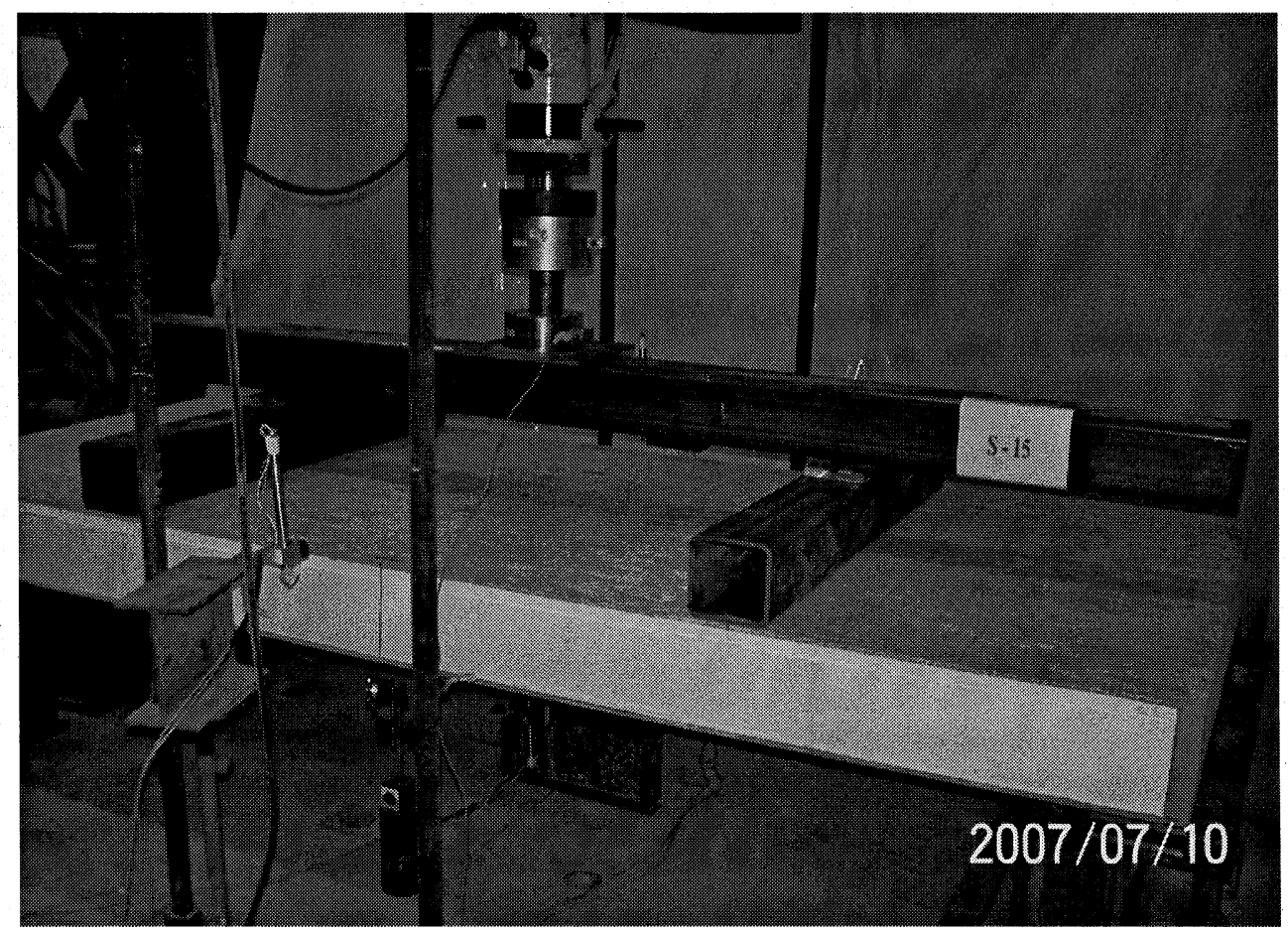

Figure AI-75 View of Specimen S-15 before testing

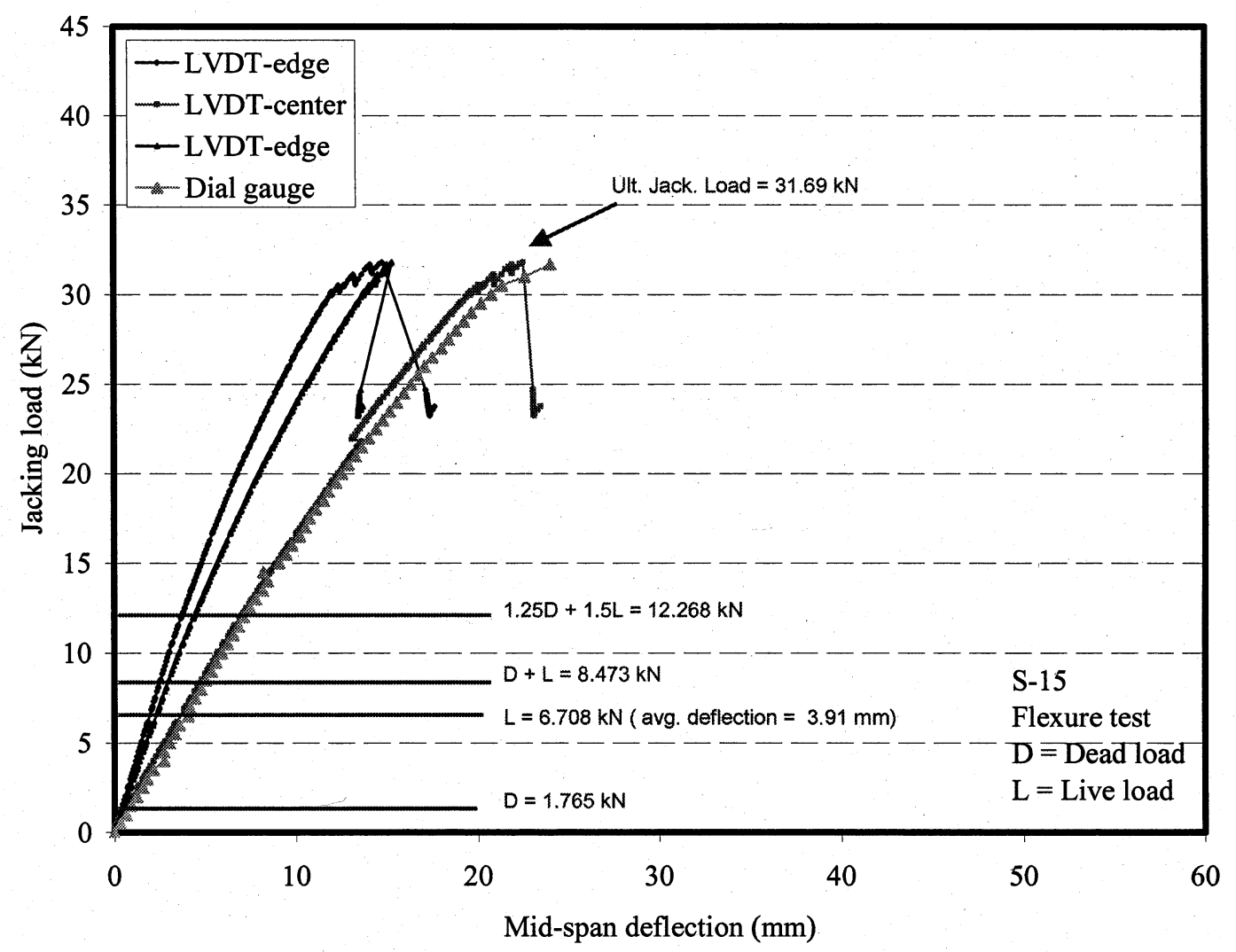

Figure AI-76. Load-deflection relationship for specimen S-15 


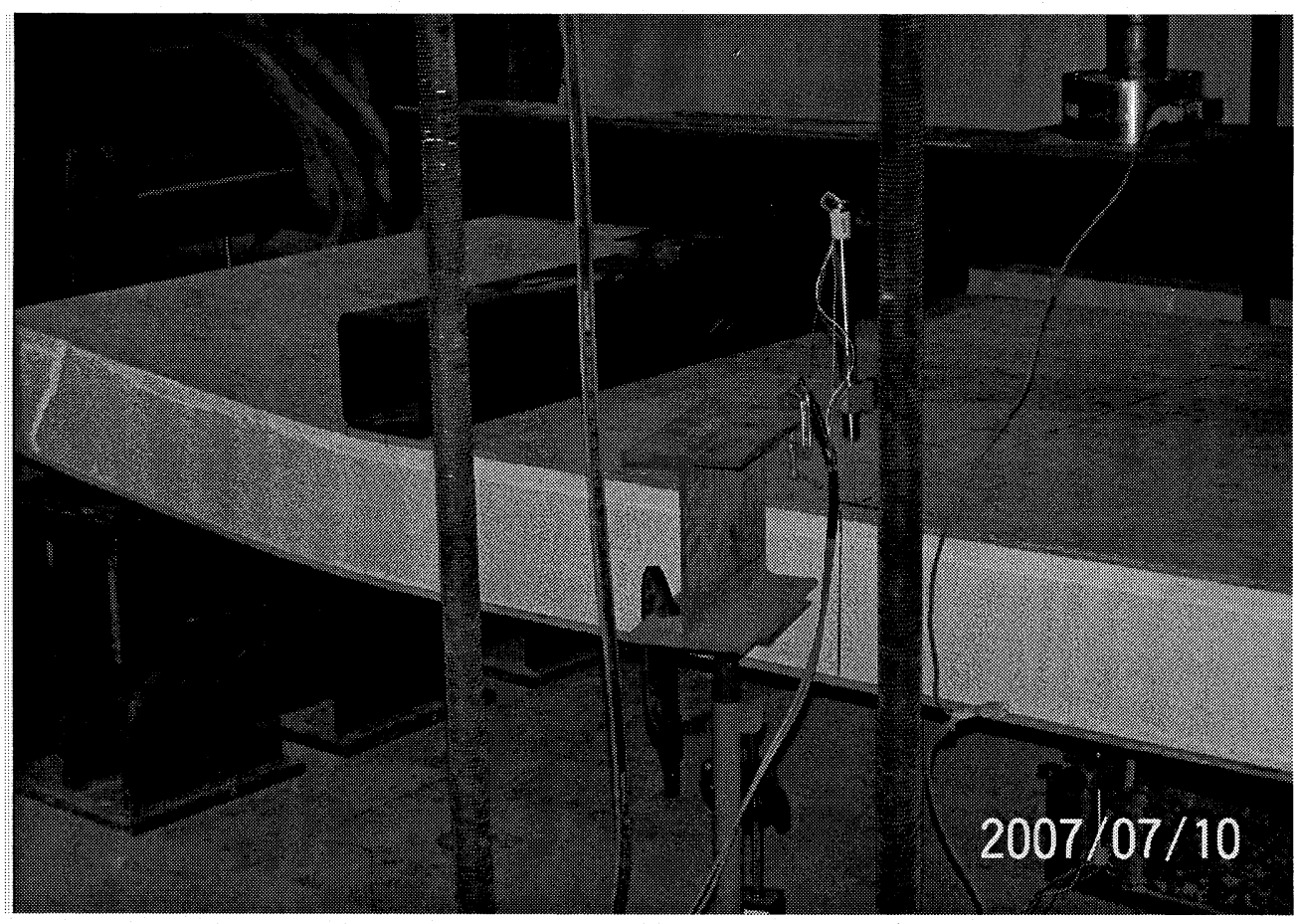

Figure AI-77. View of specimen S-15 after failure

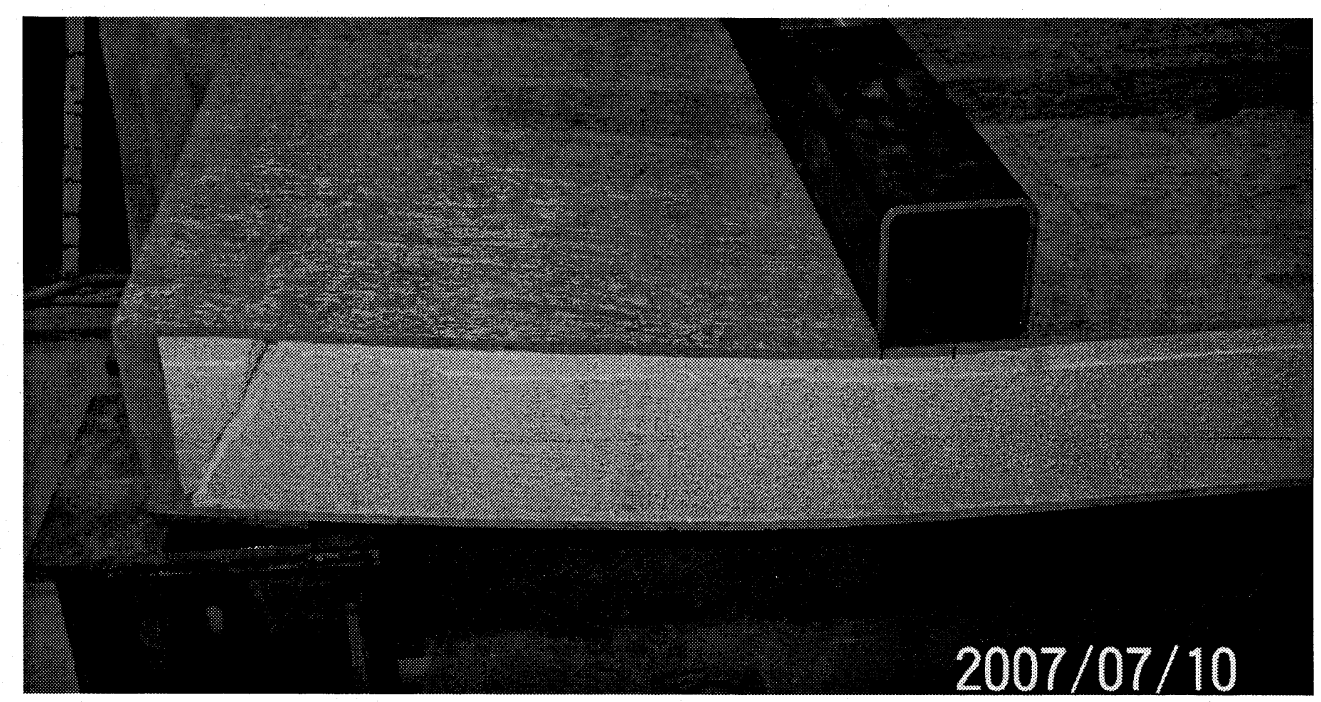

Figure AI-78-a. View of the diagonal shear failure of specimen S-15 at the support 


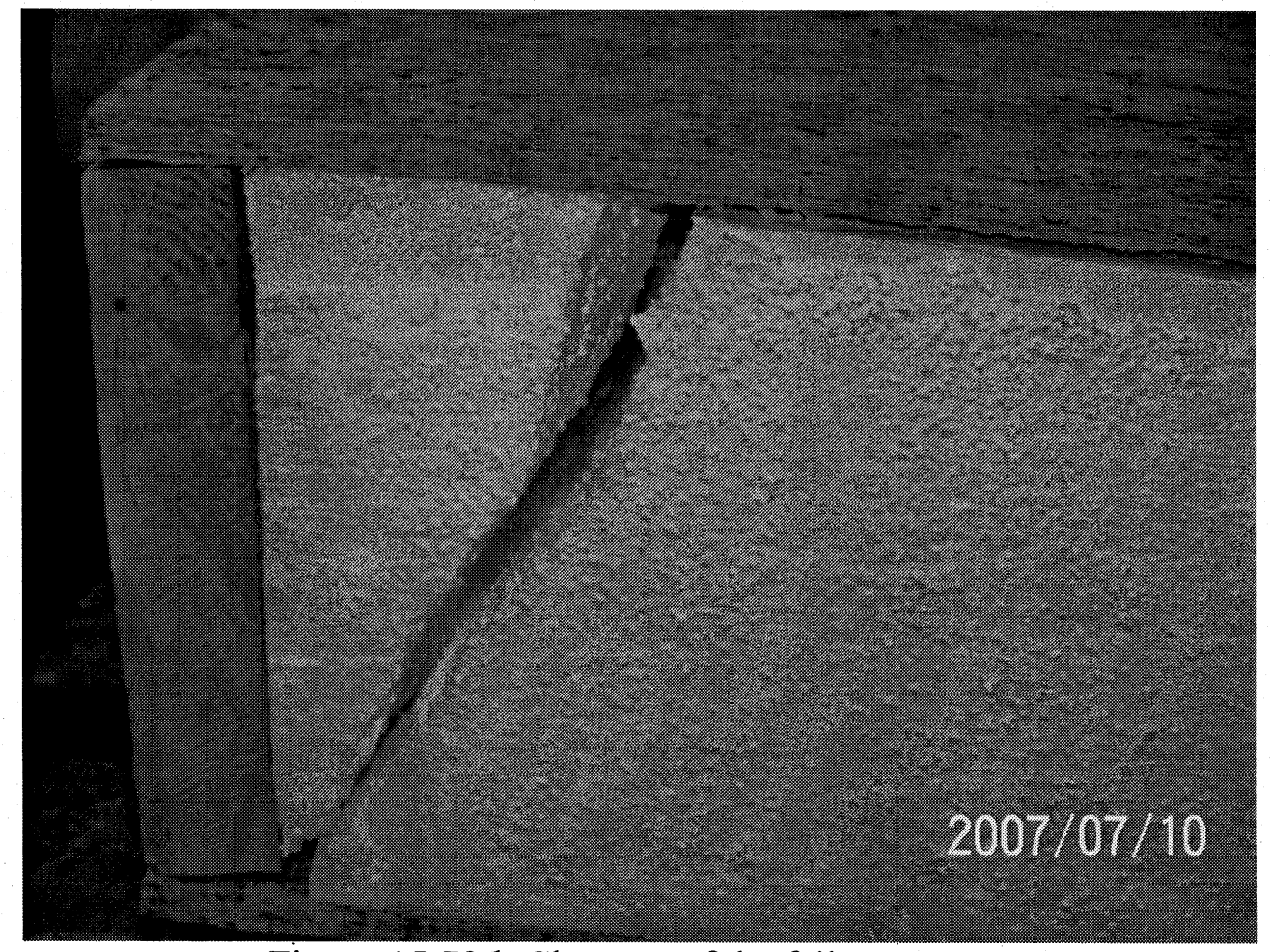

Figure AI-78-b Close-up of the failure pattern 


\section{Specimen \# S-15-1}

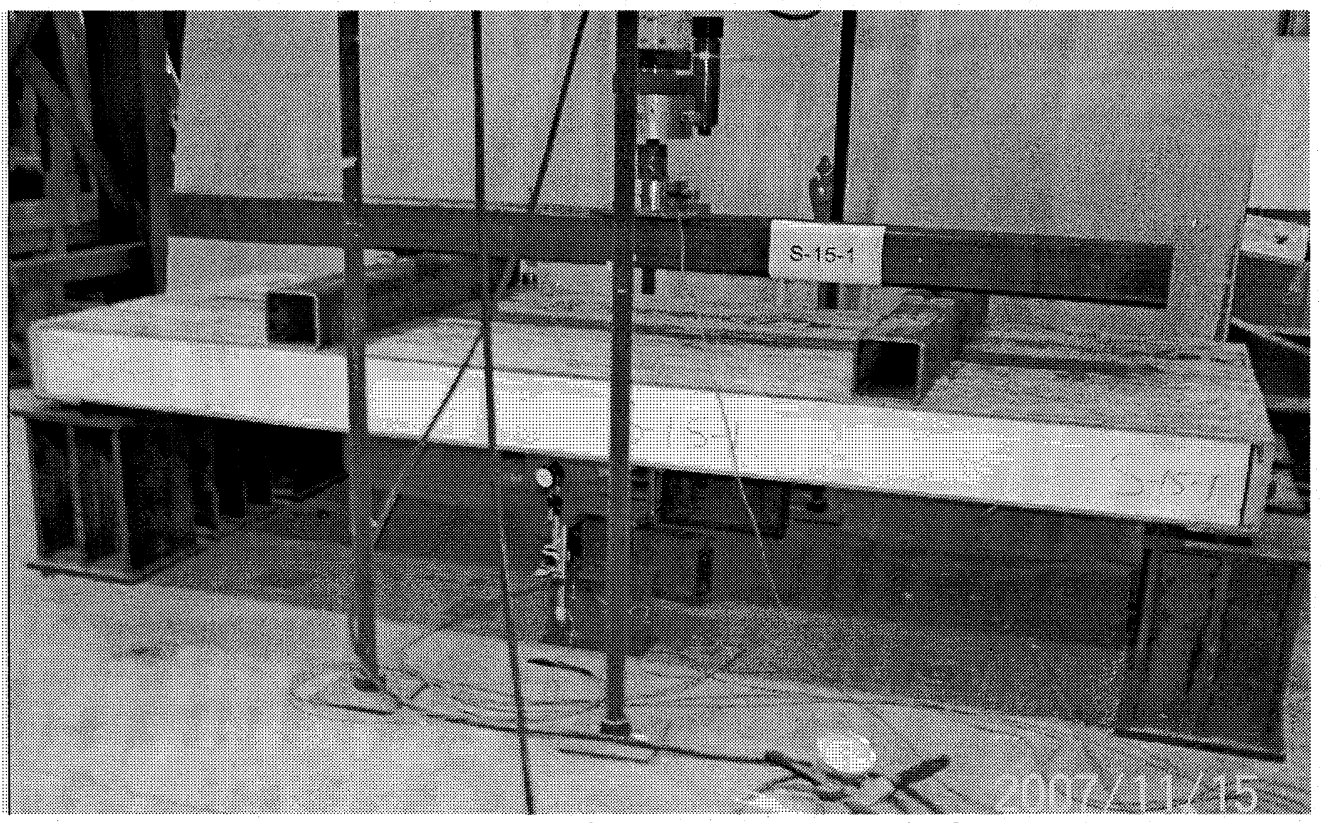

Figure AI-75-1. View of Specimen S-15-1 before testing

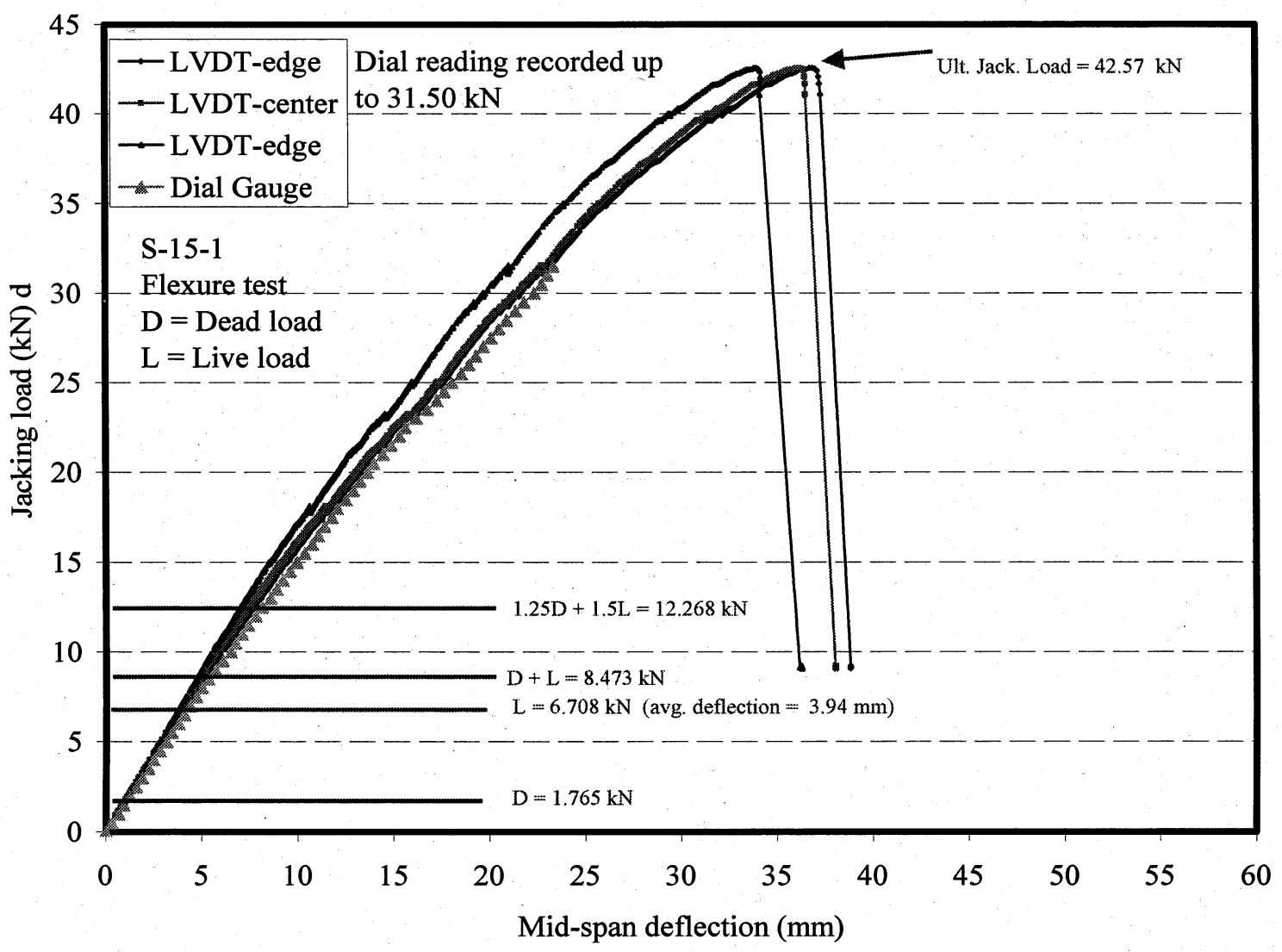

Figure AI-76-1. Load-deflection relationship for specimen S-15-1 


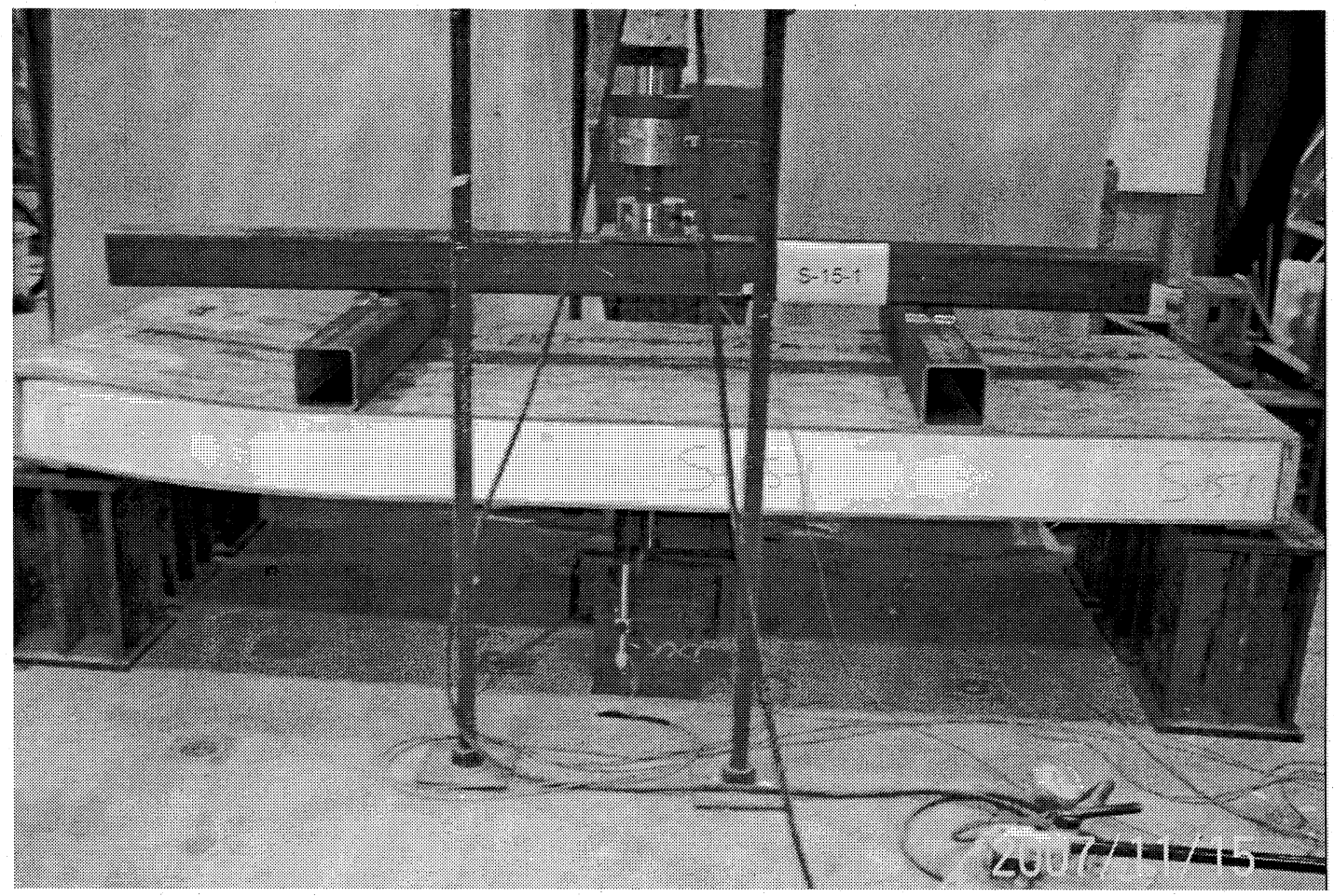

Figure AI-77-1. View of specimen S-15-1 after failure

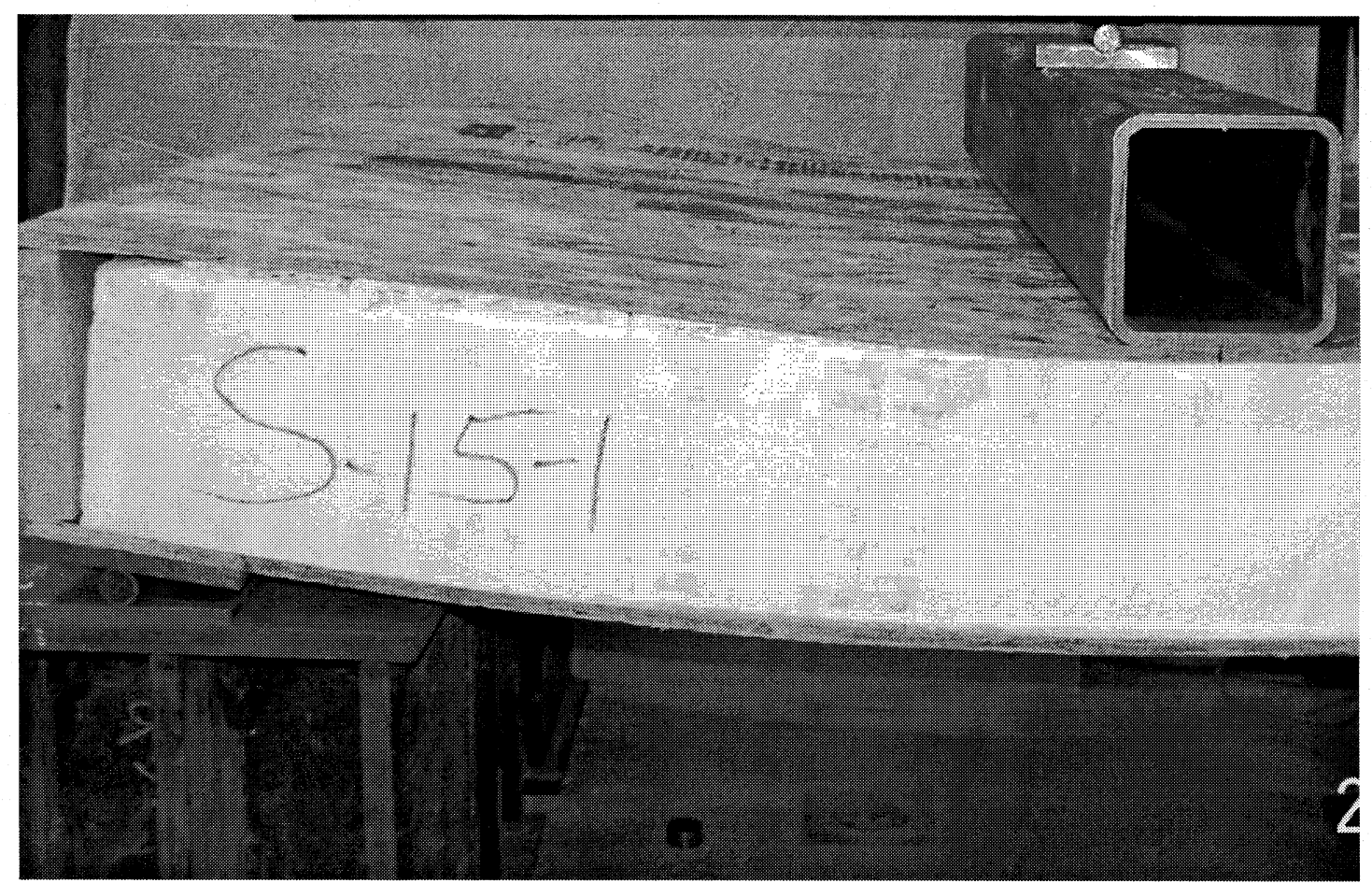

Figure AI-78-1. View of the horizontal shear failure of specimen S-15-1 at the interface of the foam and the top OSB board 


\section{GROUP F}

\section{Specimen \# S-16}

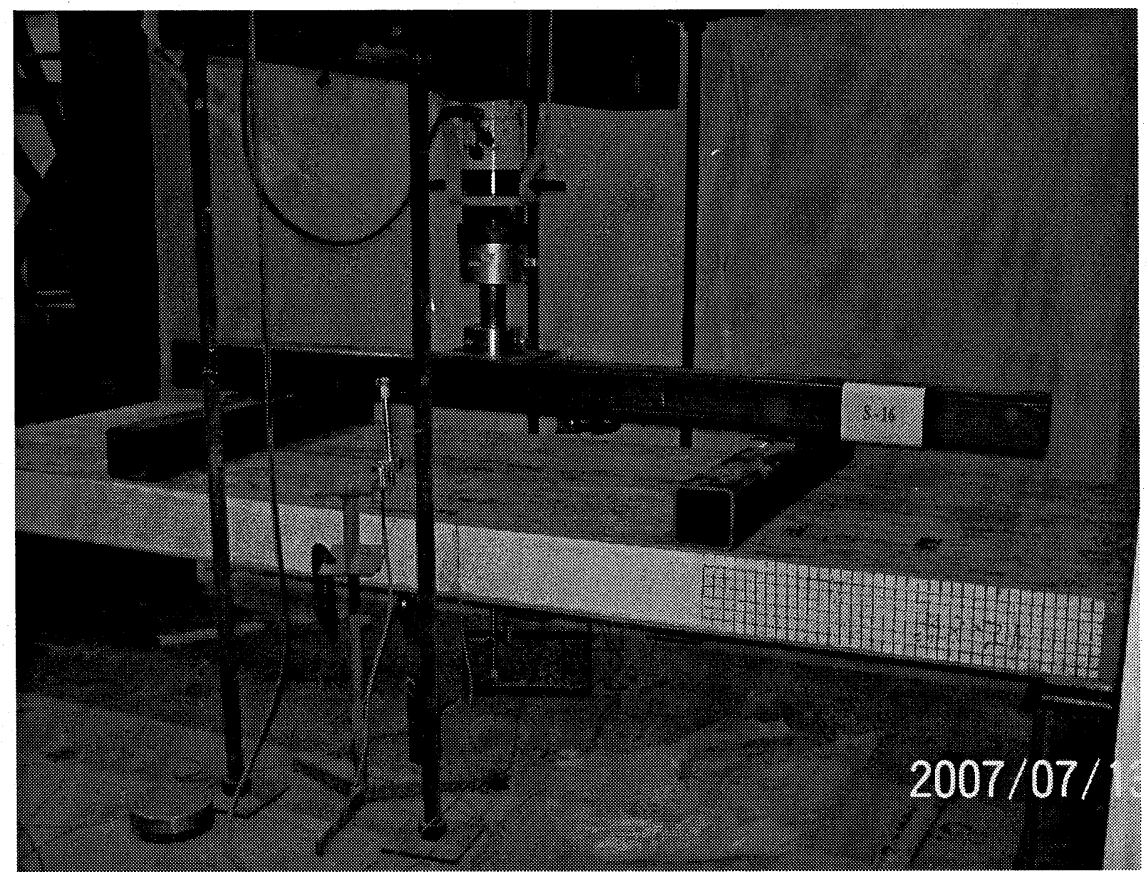

Figure AI-79. View of Specimen S-16 before testing

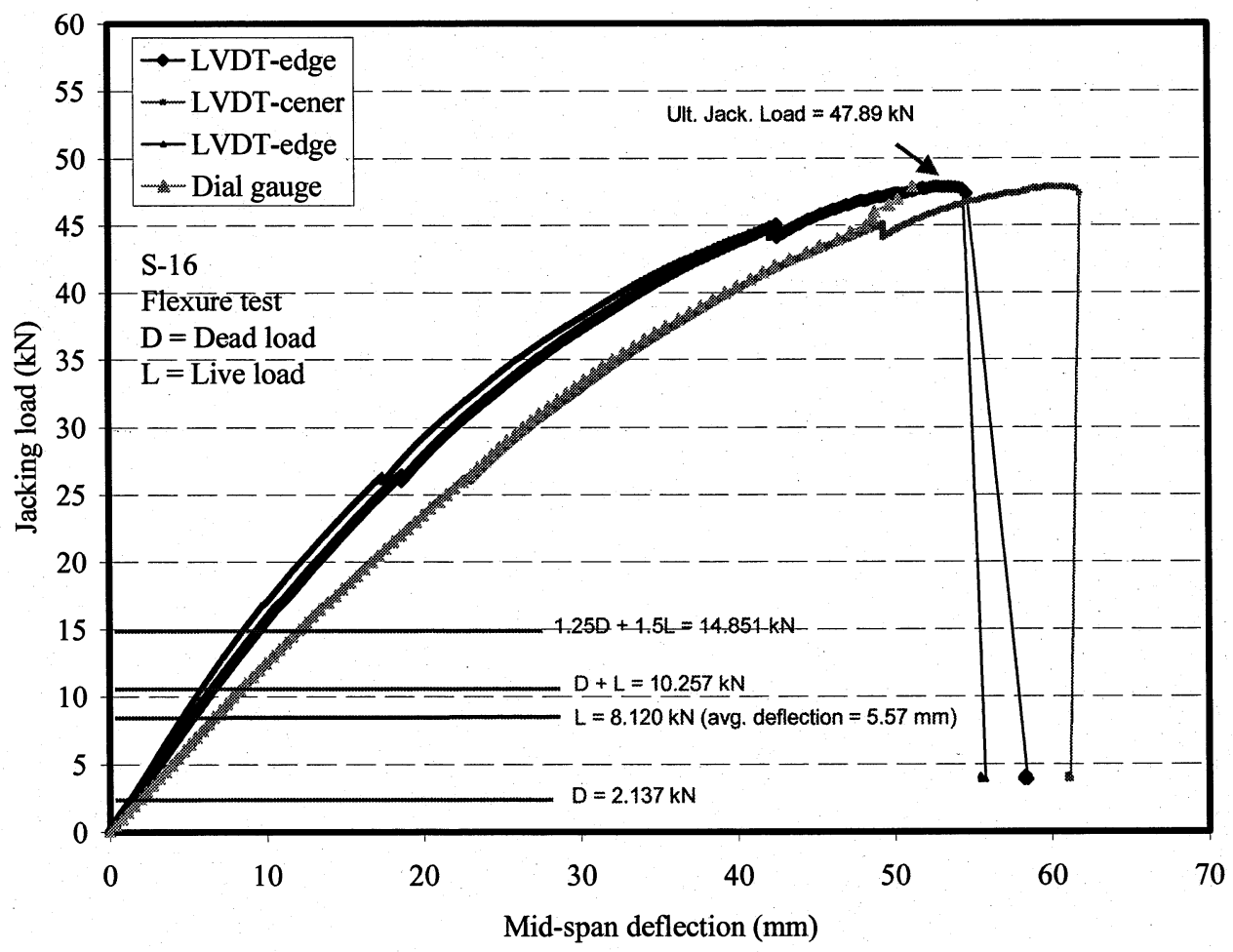

Figure AI-80. Load-deflection relationship for specimen S-16 


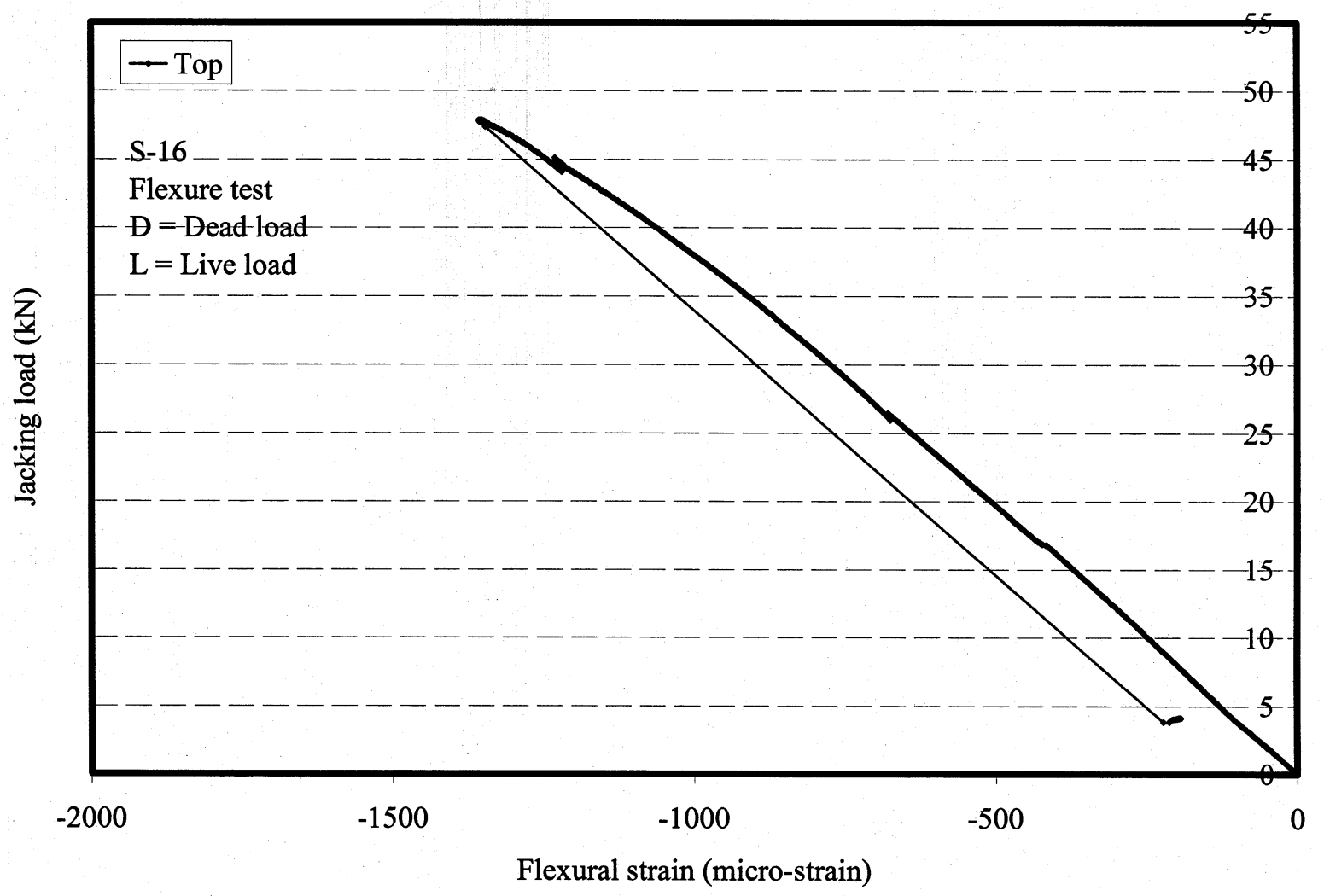

Figure AI-81. Load-strain relationship for specimen S-16

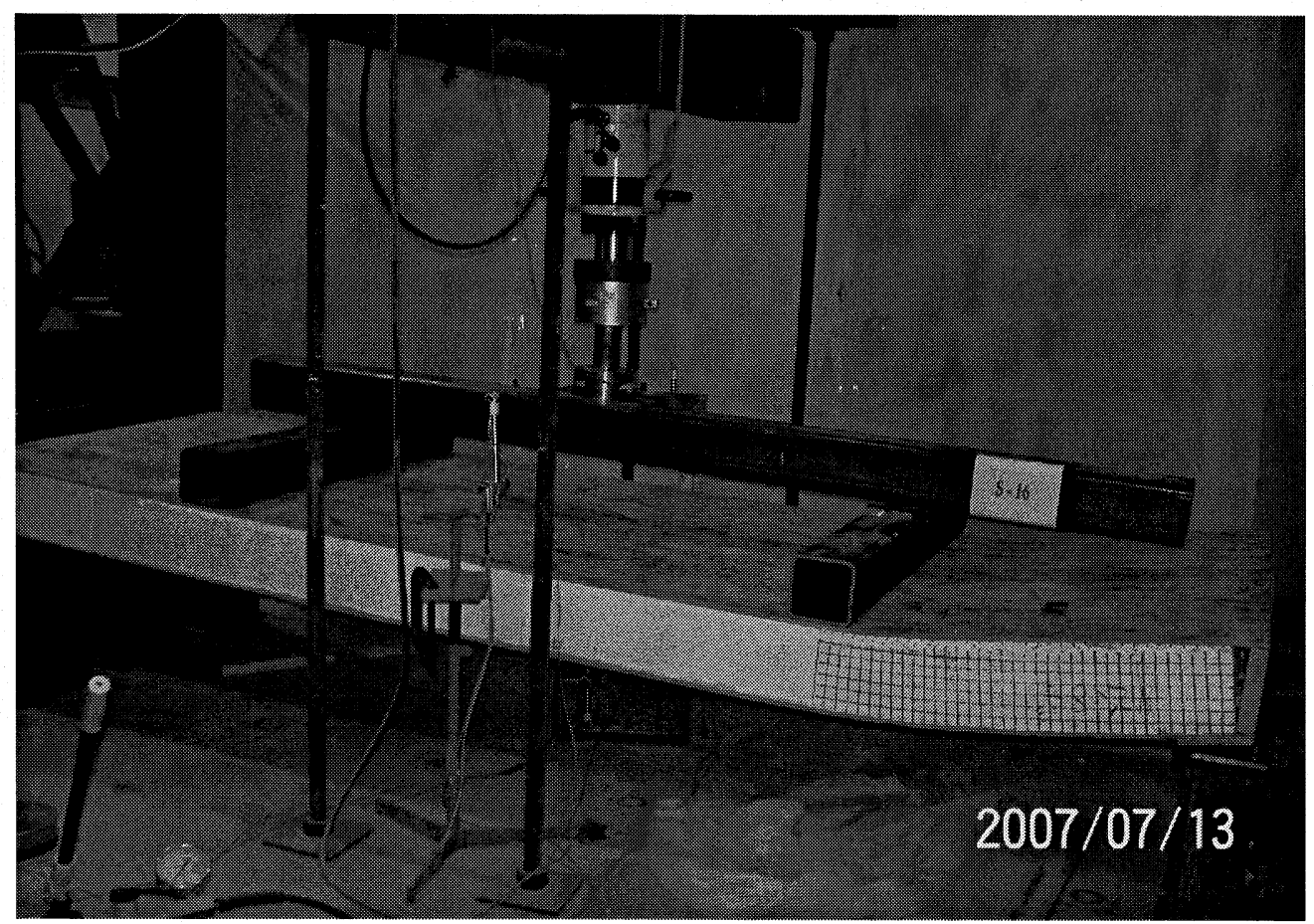

Figure AI-82. View of specimen S-16 after failure 


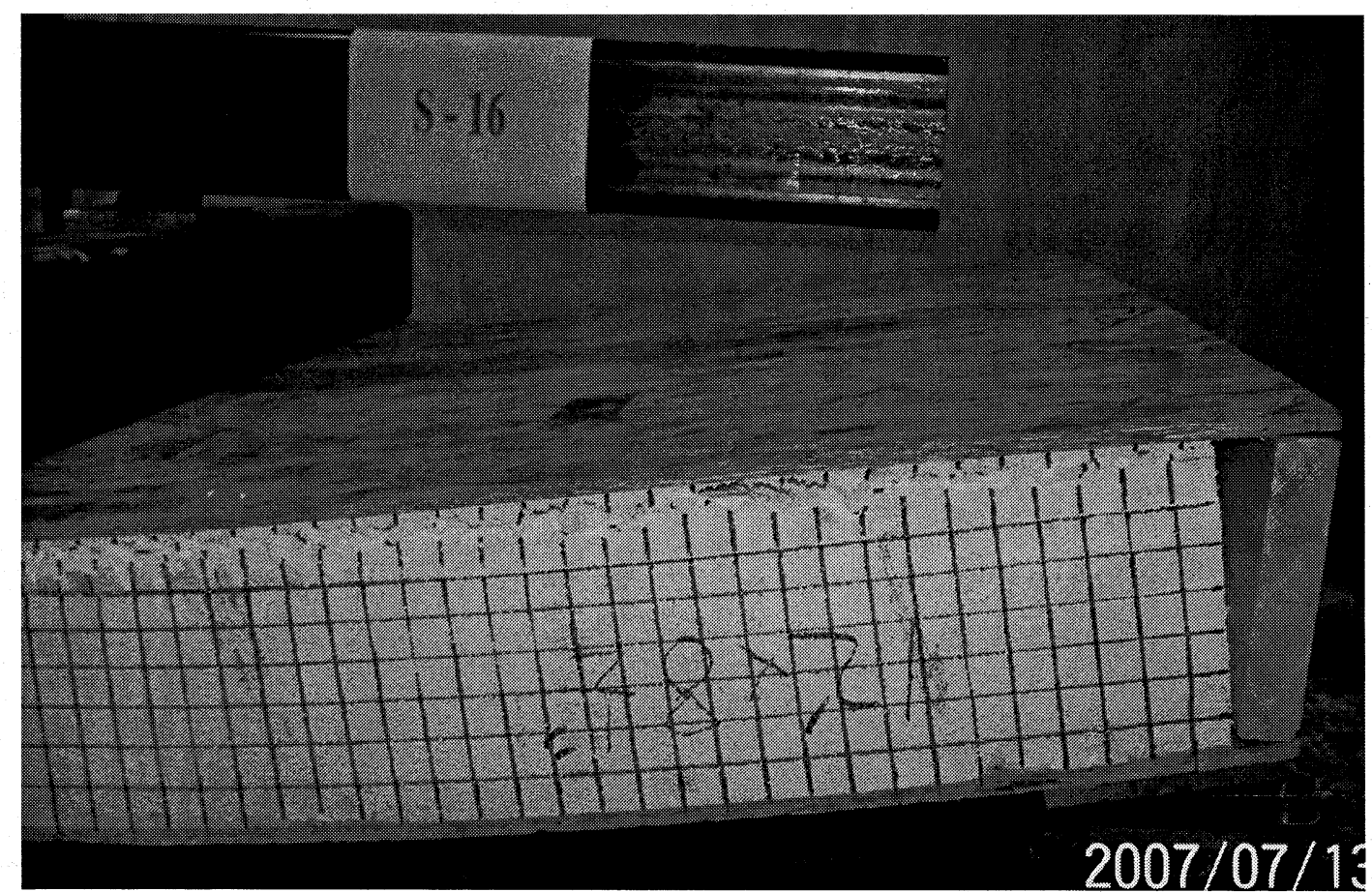

a) After failure on one side of the panel

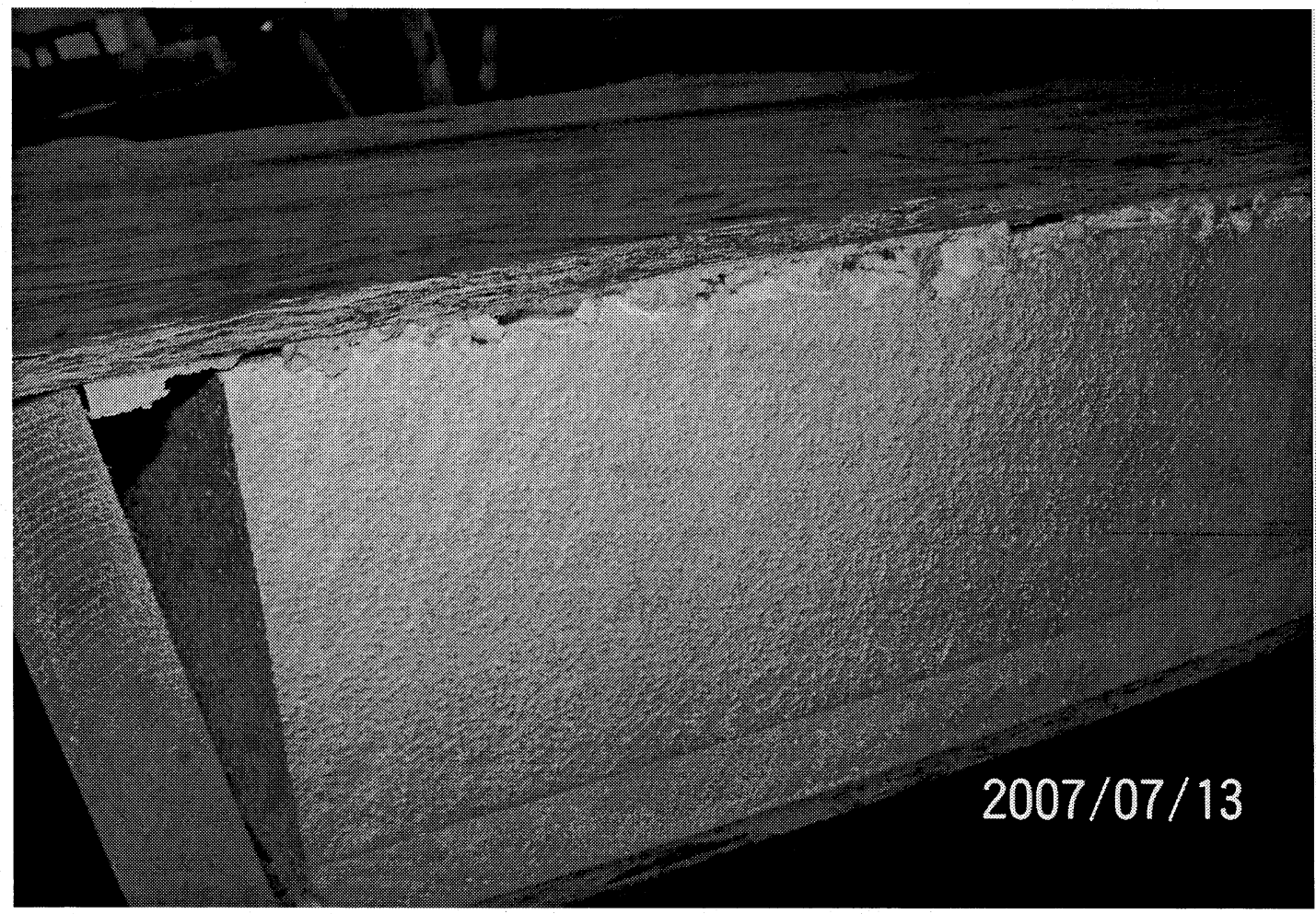

a) After failure on the other side of the panel

Figure AI-82. View of the horizontal shear failure of specimen S-16 at the interface of the foam and the top OSB board 

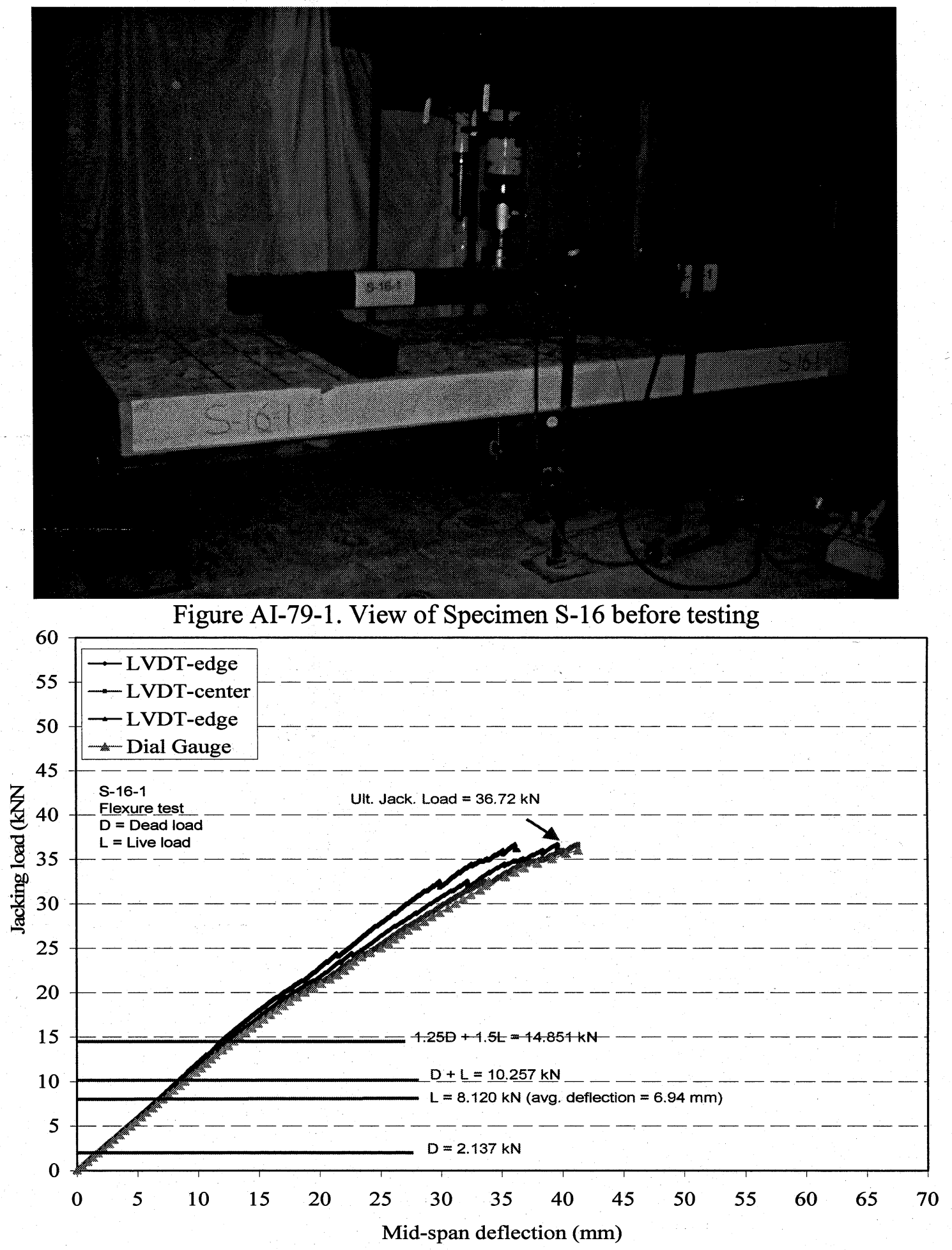

Figure AI-80-1. Load-deflection relationship for specimen S-16 


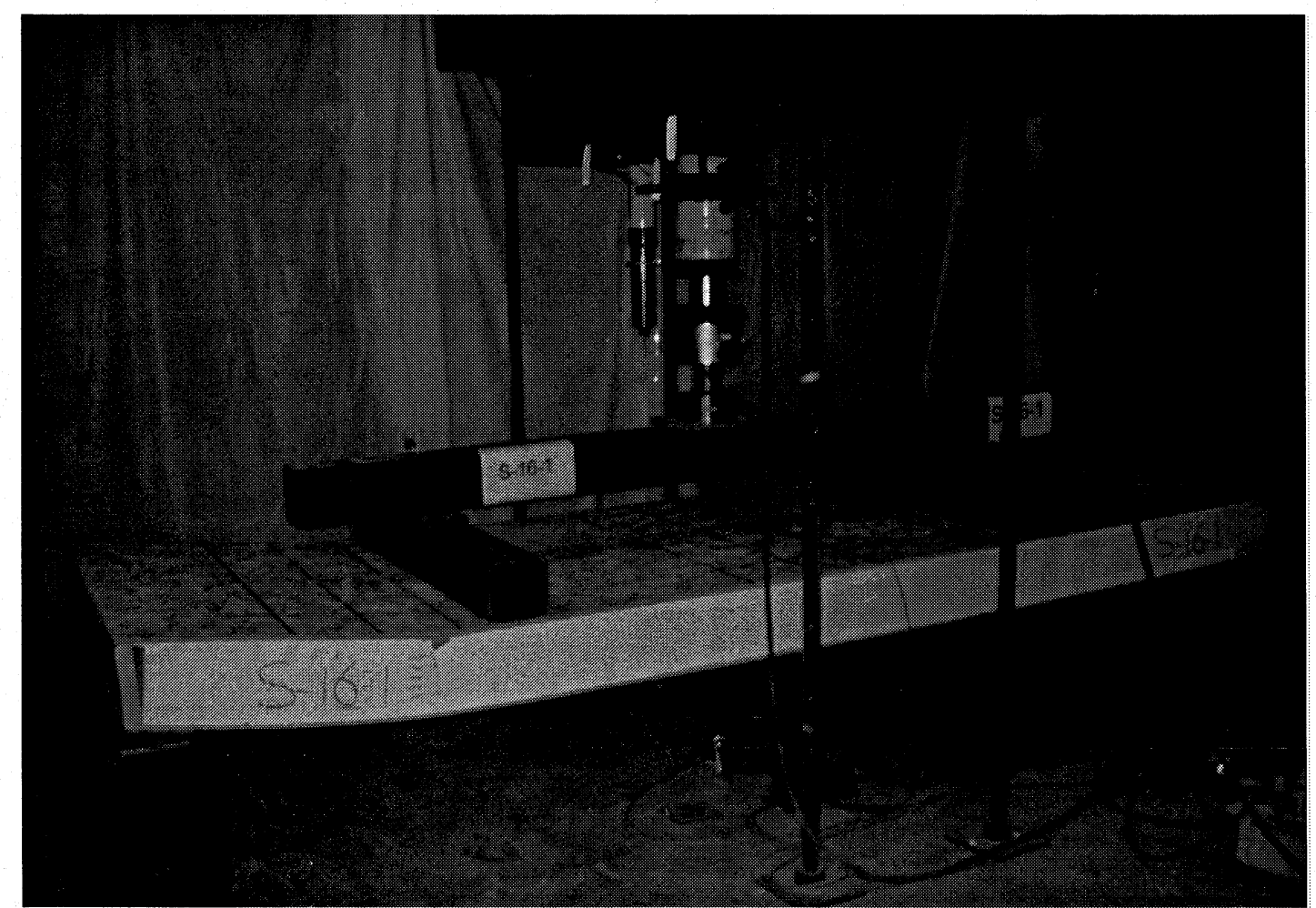

Figure AI-81-1. View of specimen S-16 after failure

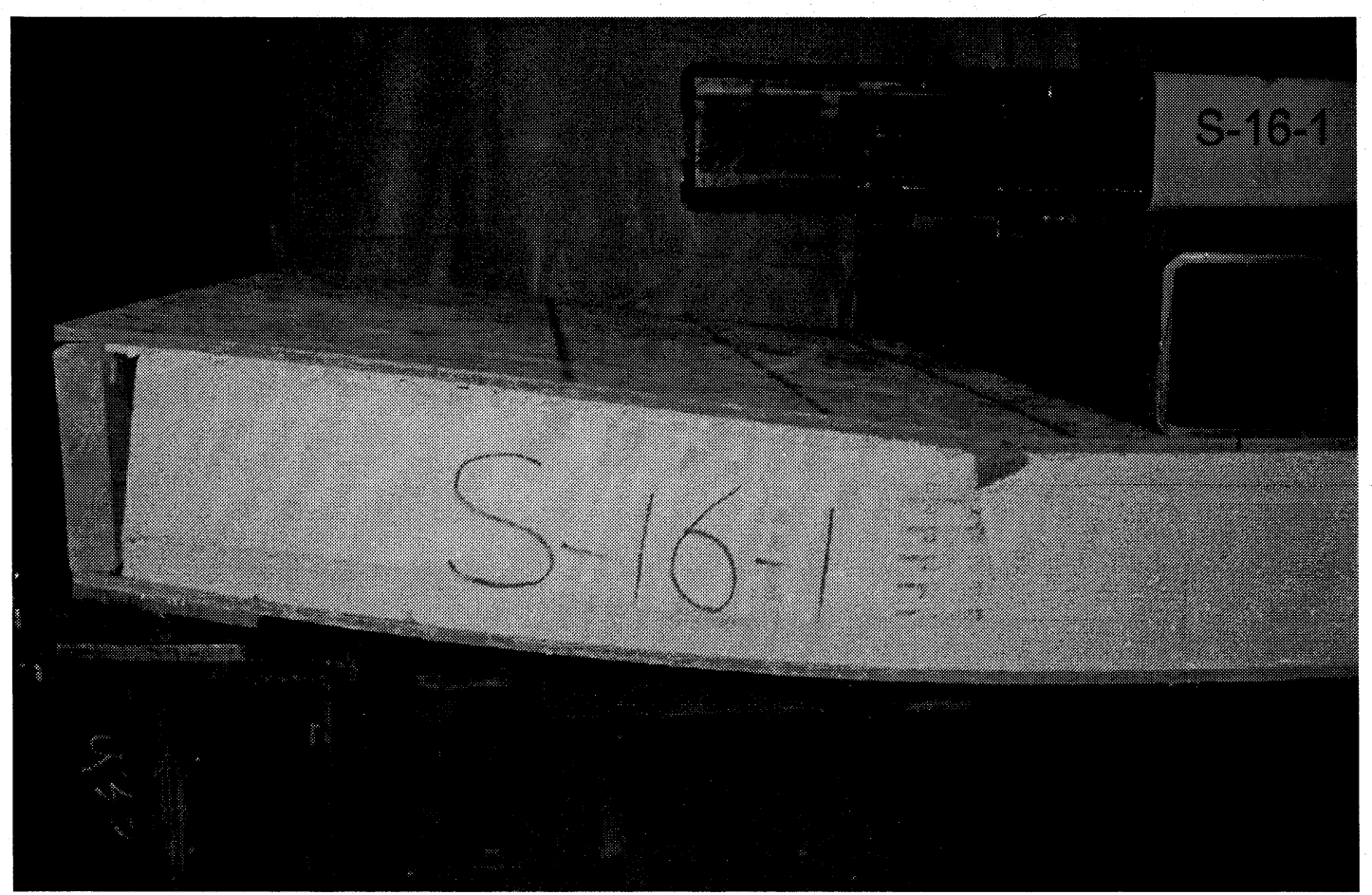

Figure AI-82-1. View of the horizontal shear failure of specimen S-16 at the interface of the foam and the top OSB board 


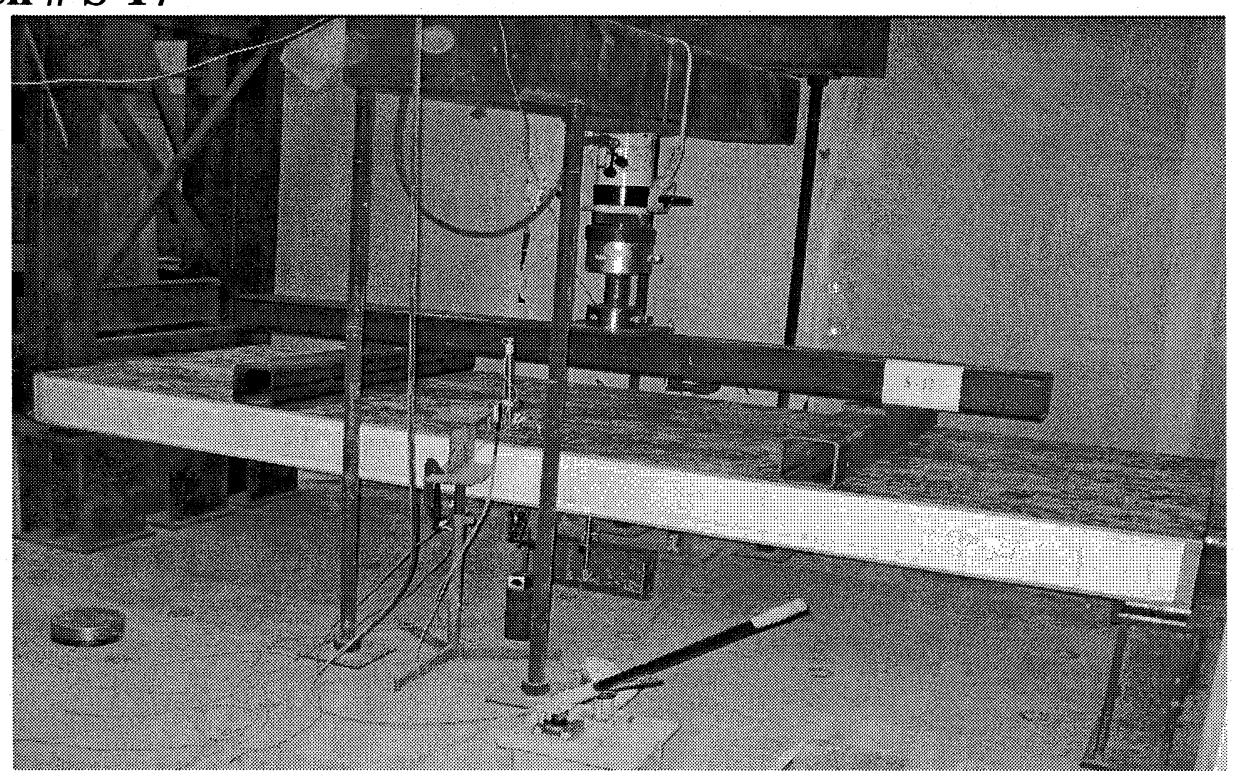

Figure AI-83. View of Specimen S-17 before testing

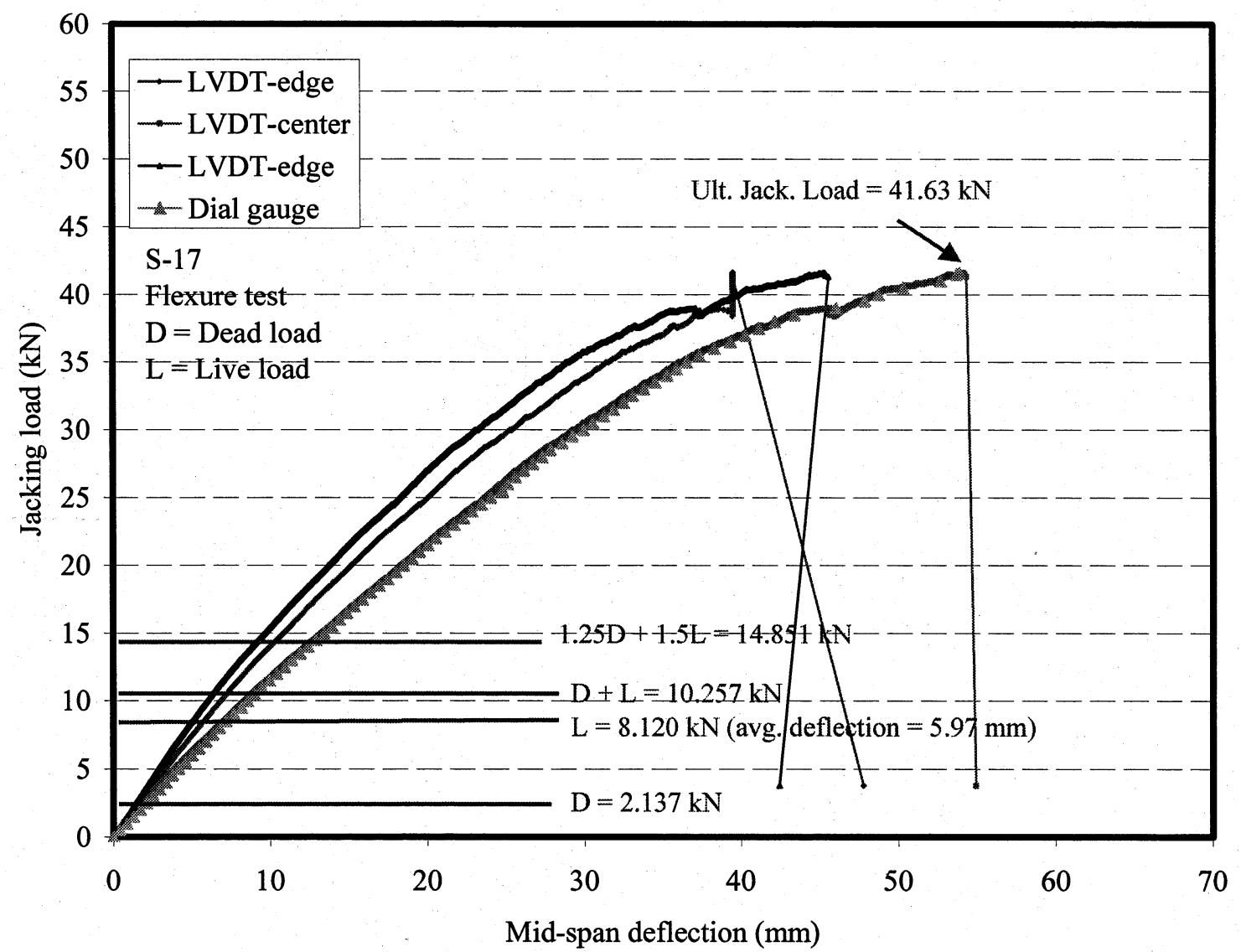

Figure AI-84. Load-deflection relationship for specimen S-17 


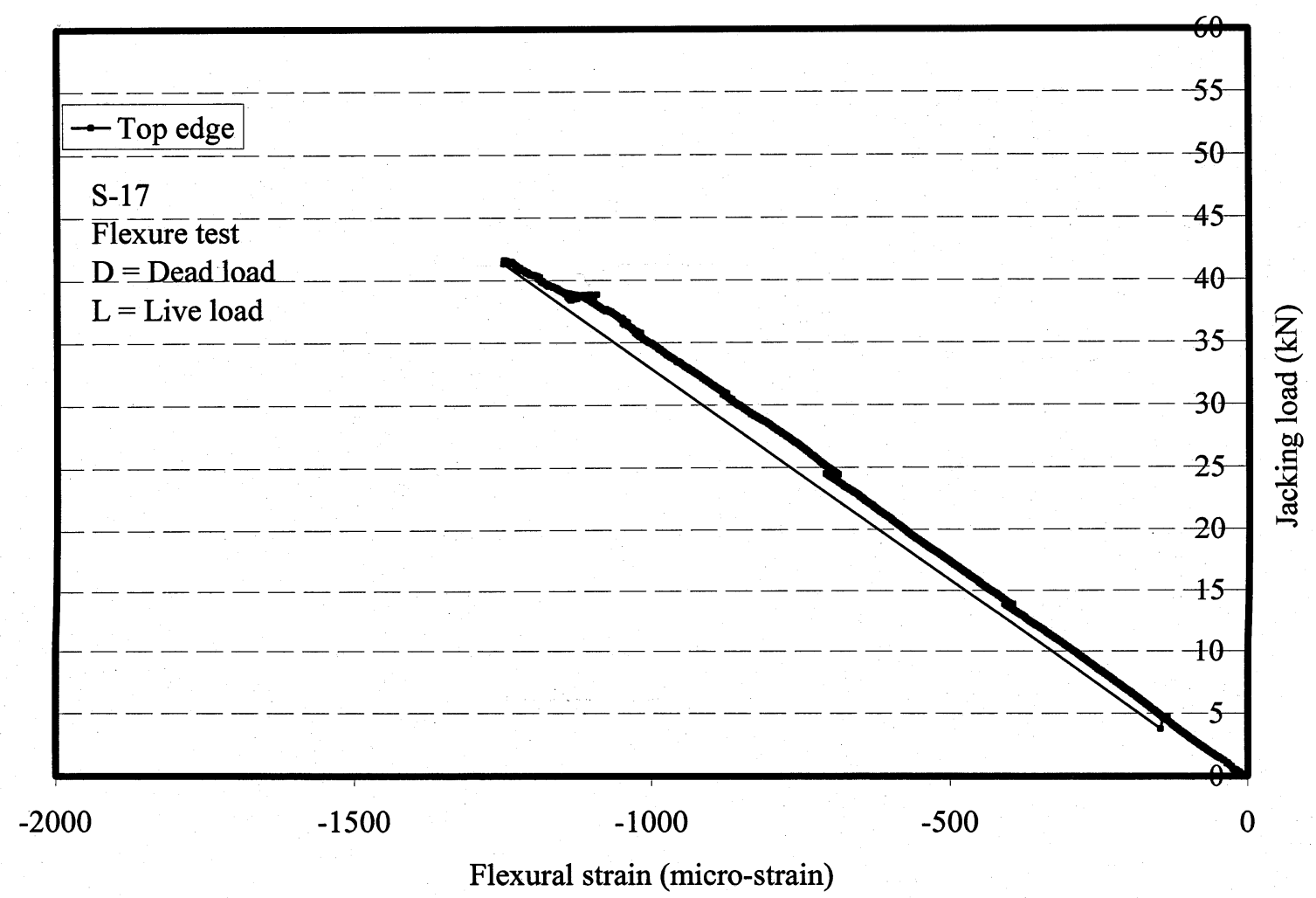

Figure AI-85. Load-strain relationship for specimen S-17

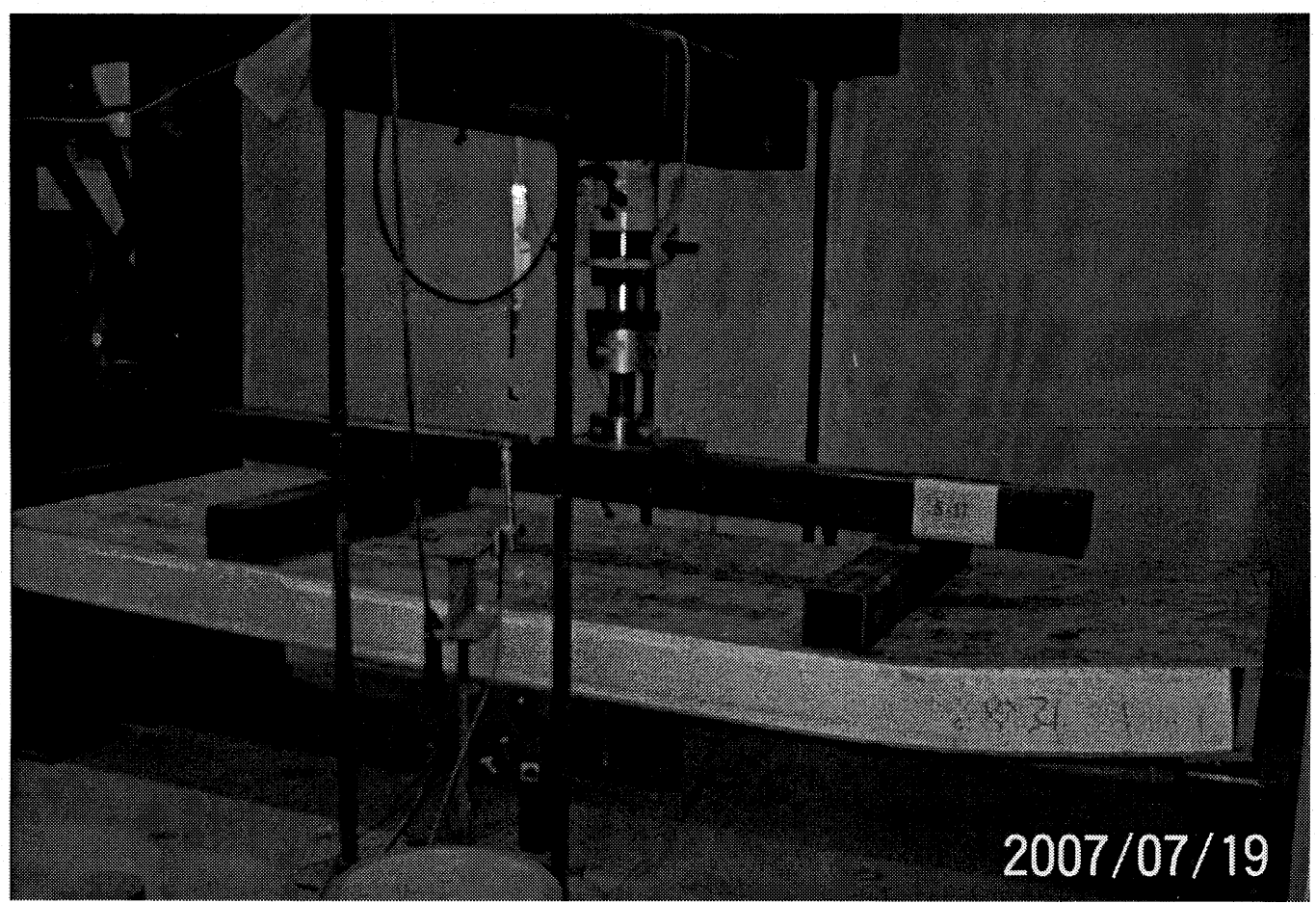

Figure AI-86. View of specimen S-17 after failure 


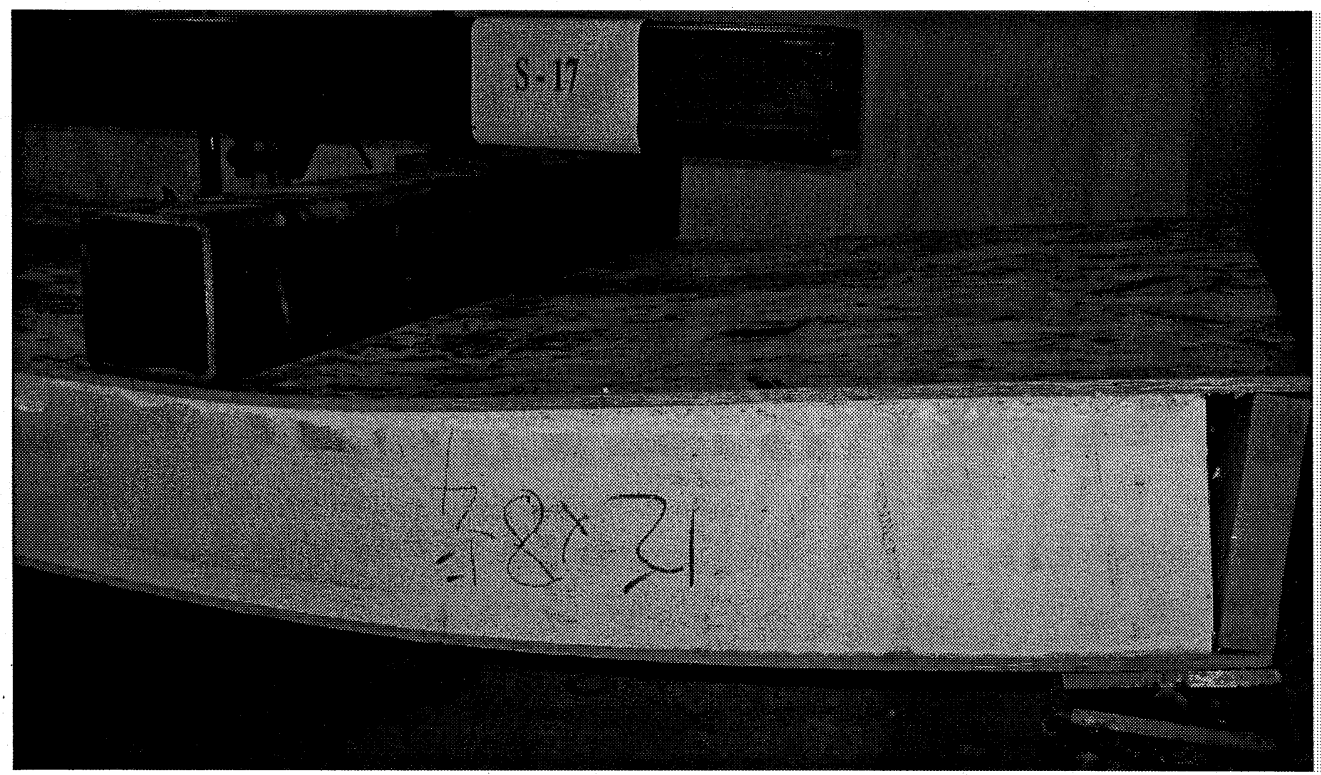

Figure AI-87. View of the horizontal shear failure of specimen S-17 at the interface of the foam and the top OSB board 


\section{Specimen \# S-18}

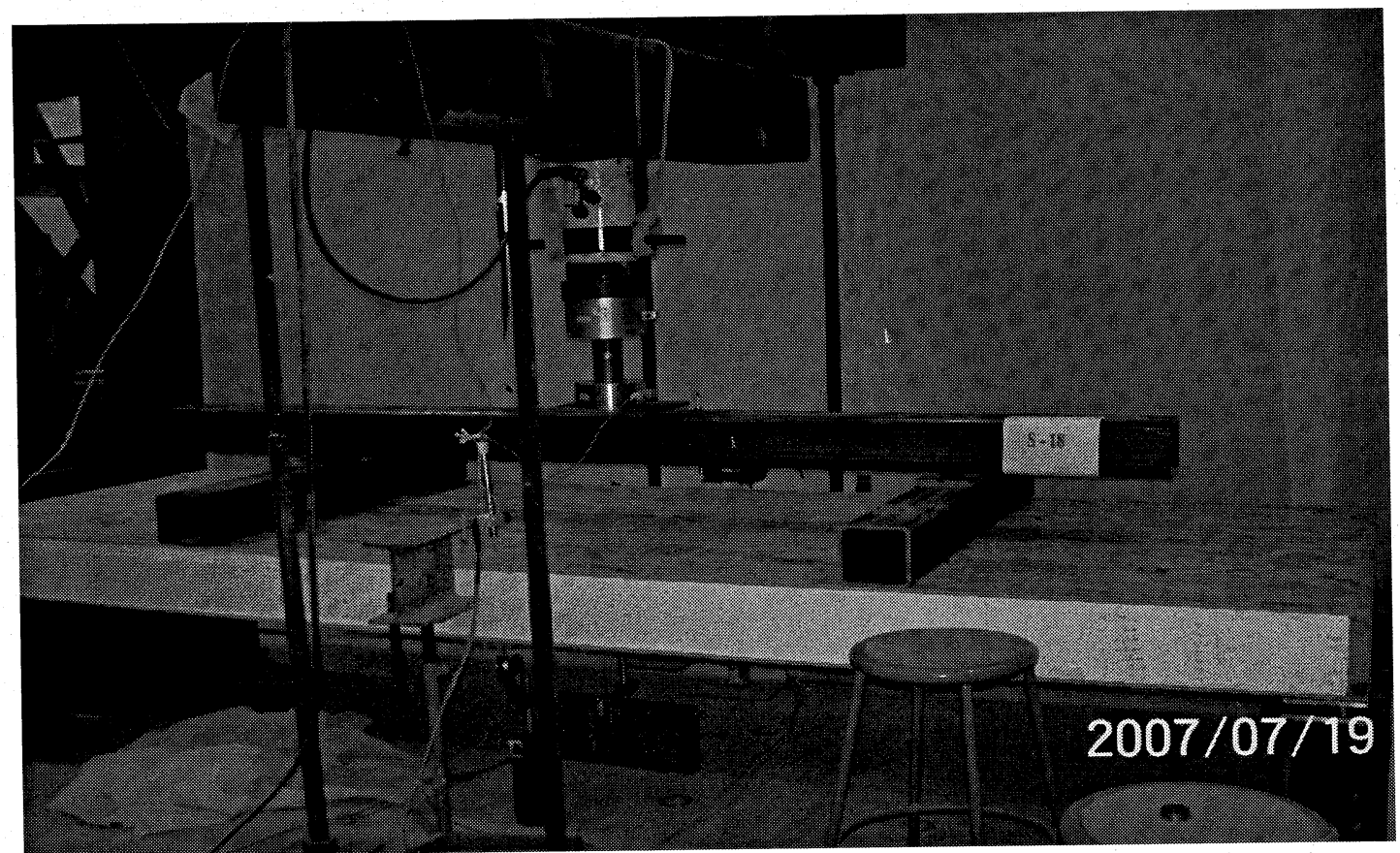

Figure AI-88. View of Specimen S-18 before testing

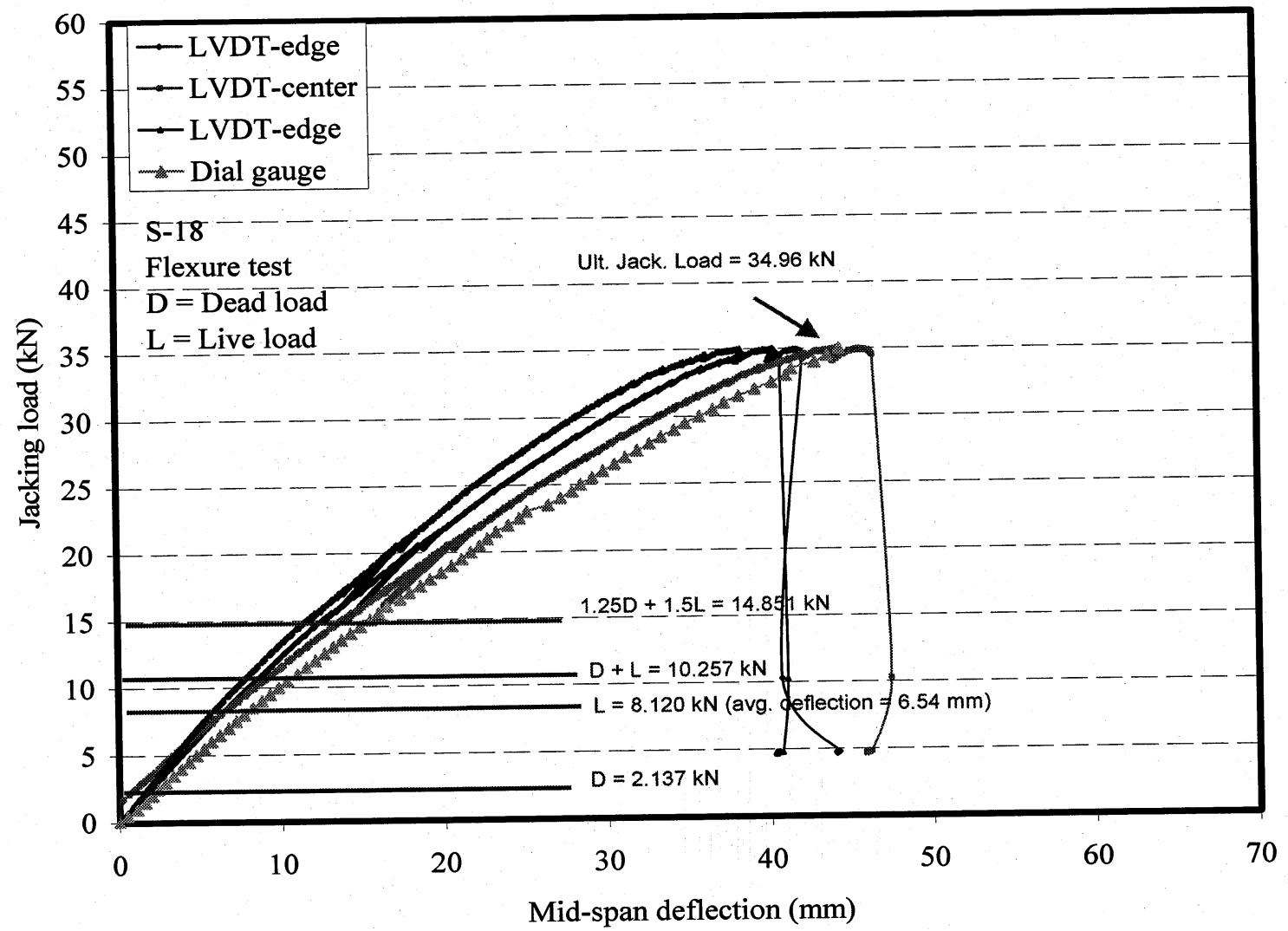

Figure AI-89. Load-deflection relationship for specimen S-18 


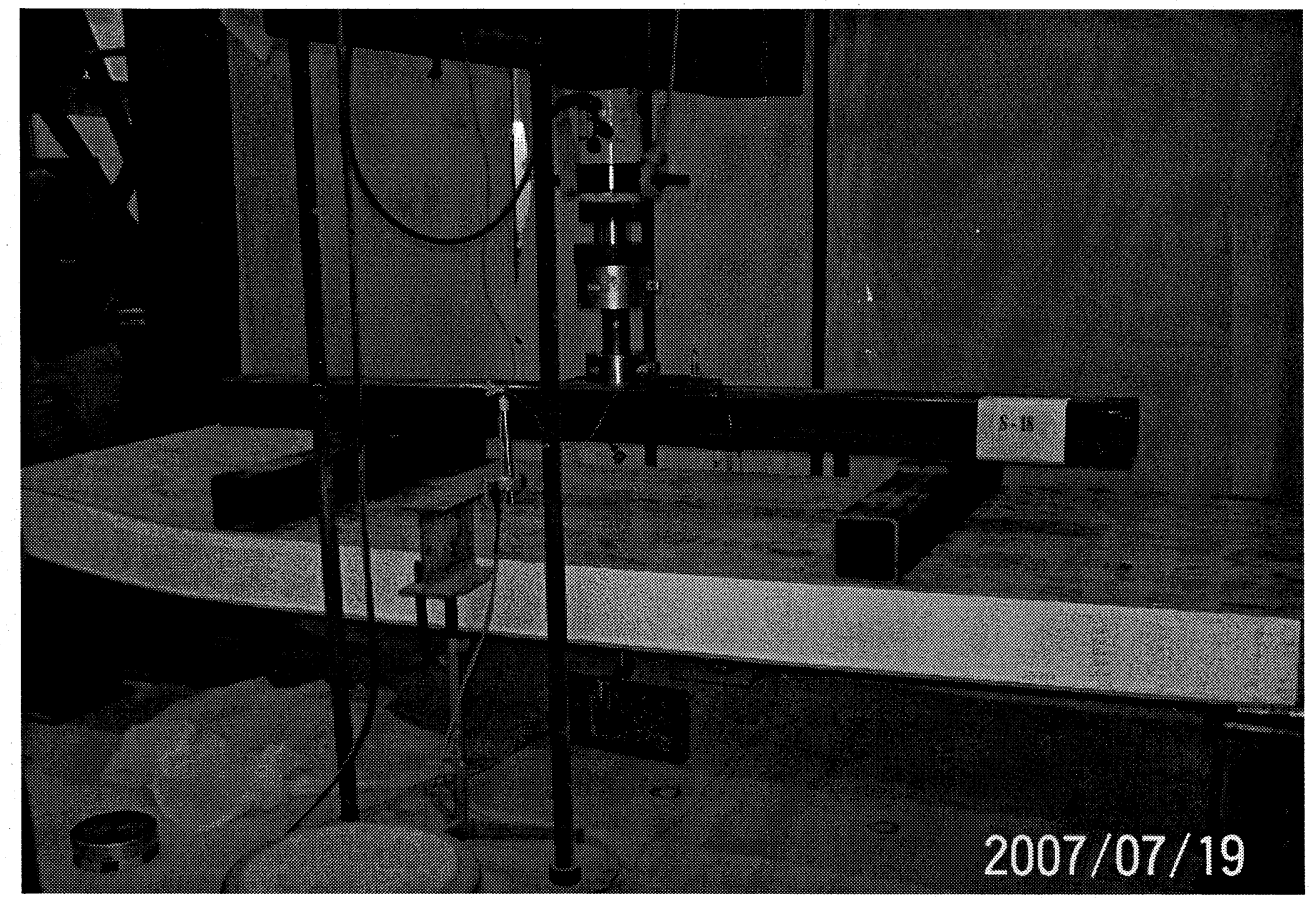

Figure AI-90. View of specimen S-18 after failure

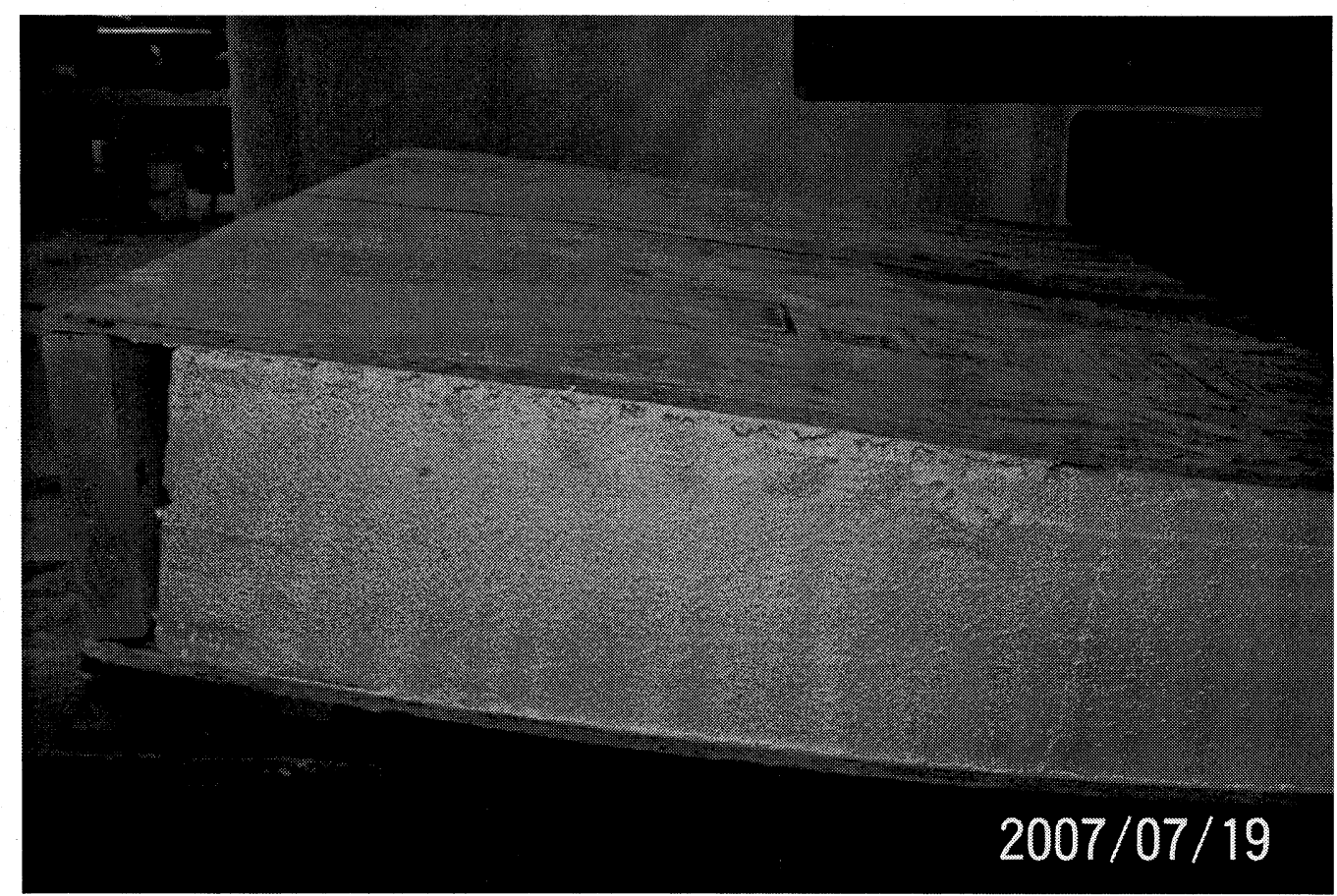

Figure AI-91. View of the horizontal shear failure of specimen S-18 at the interface of the foam and the top OSB board 


\section{Specimen \# 19}

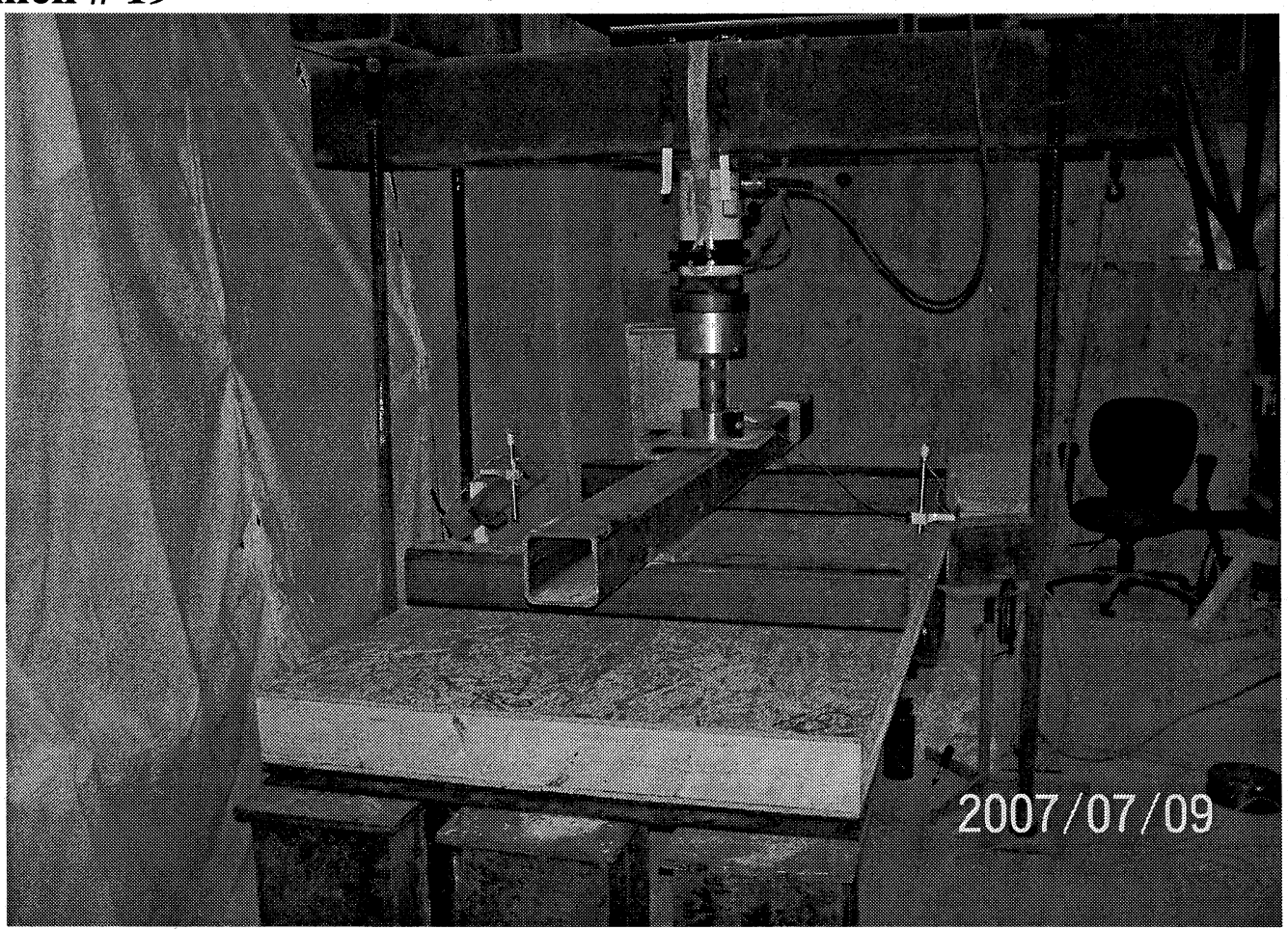

Figure AI-92 before testing

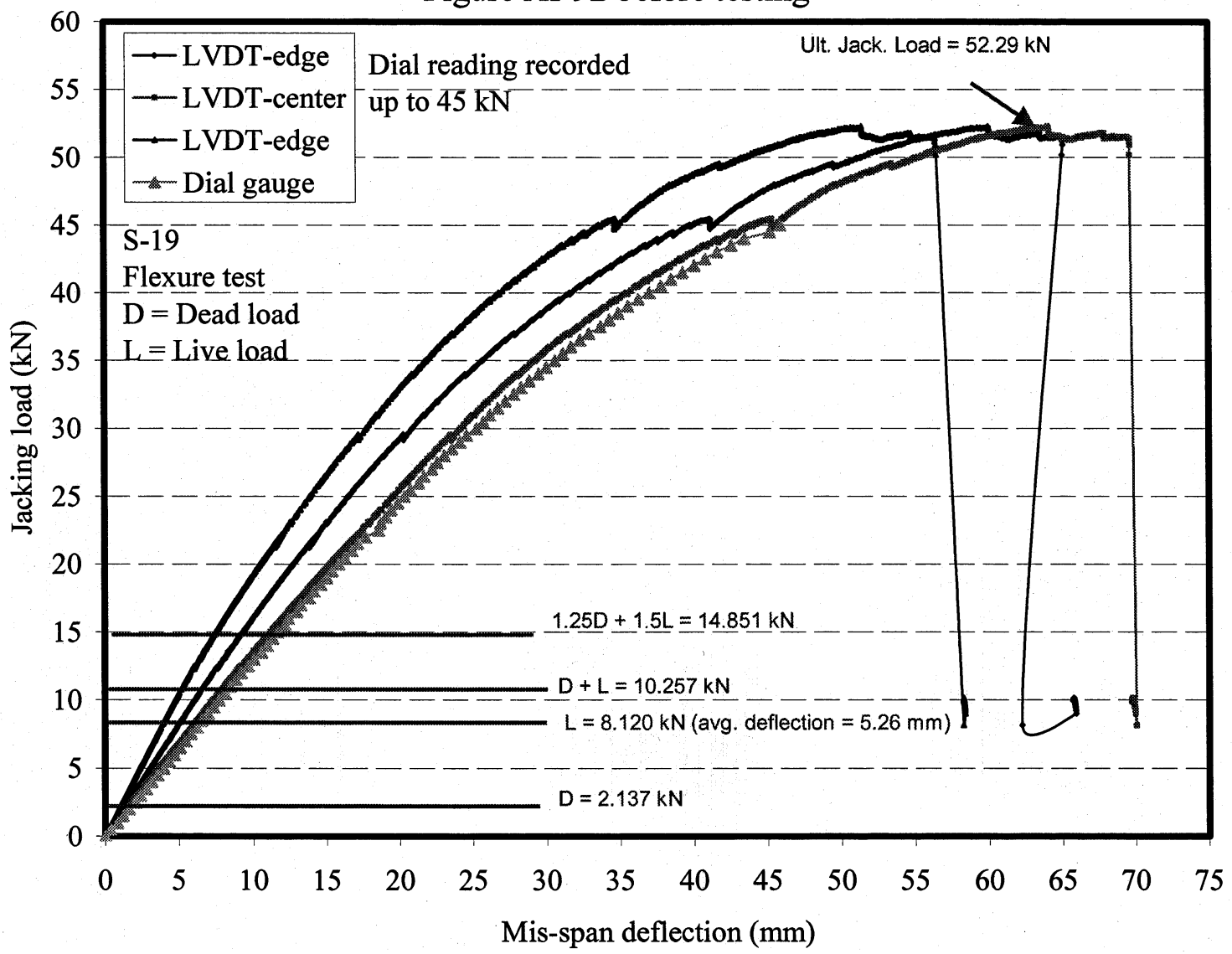

Figure AI-93. Load-deflection relationship for specimen S-19 


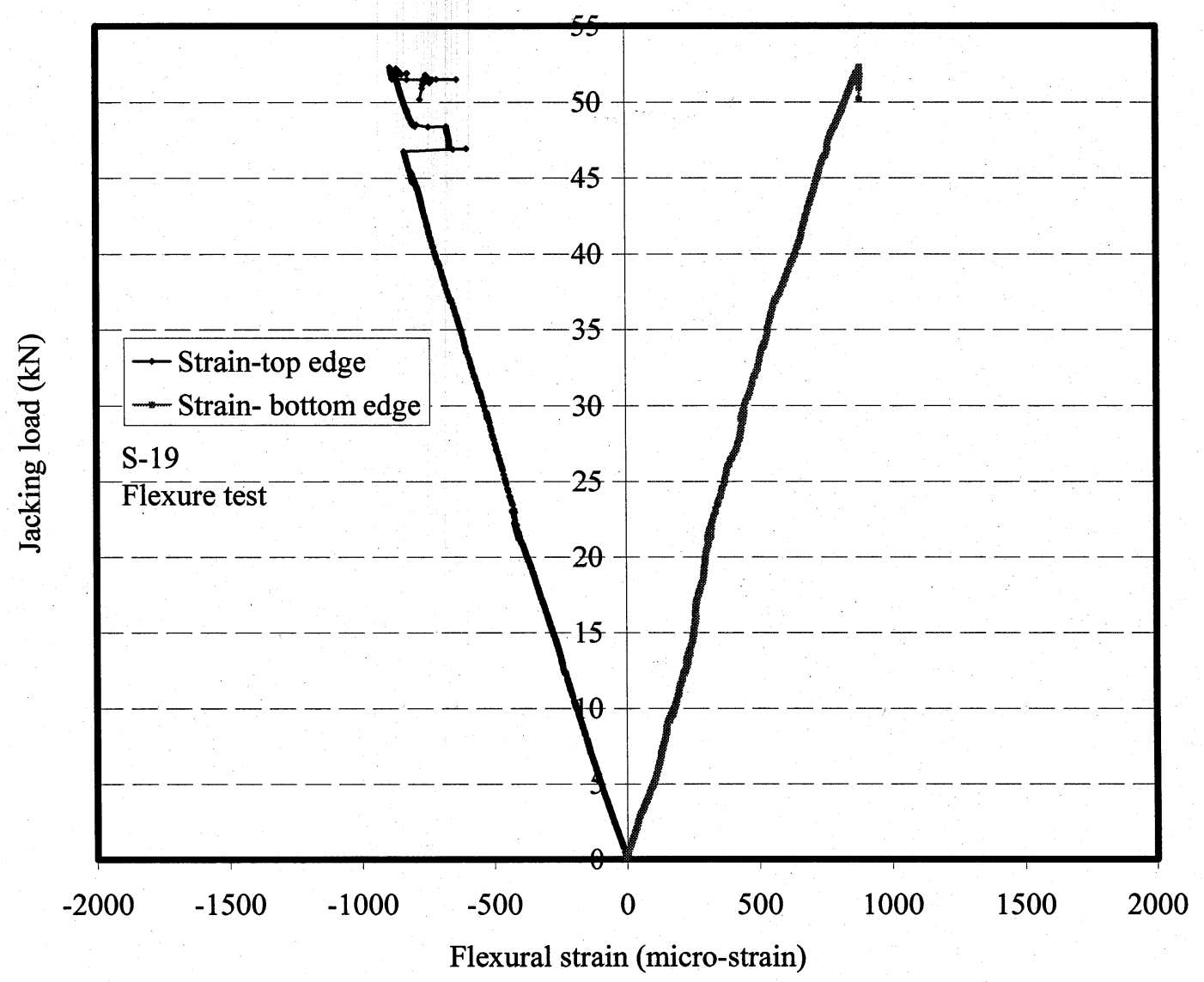

Figure AI-94. Load-strain relationship for specimen S-19

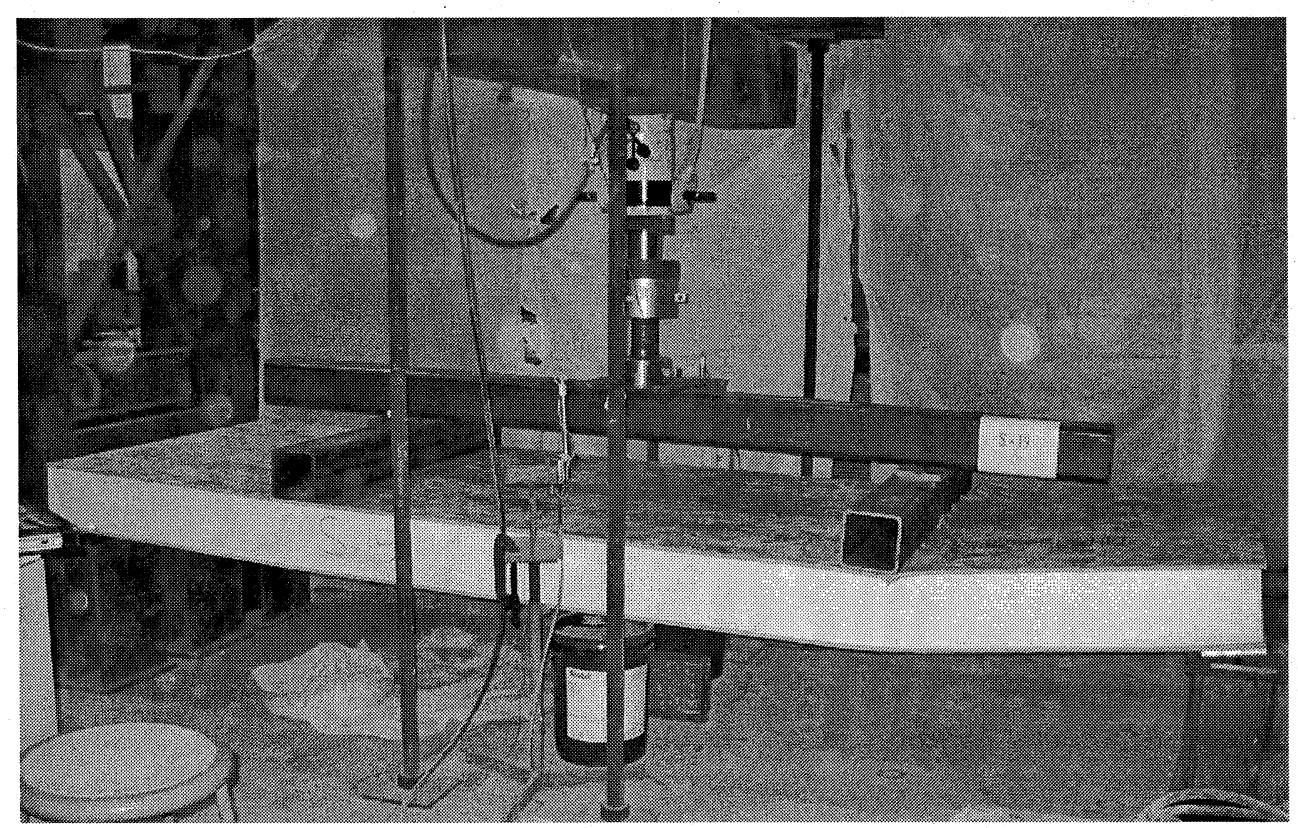

Figure AI-95. View of specimen S-19 after failure 

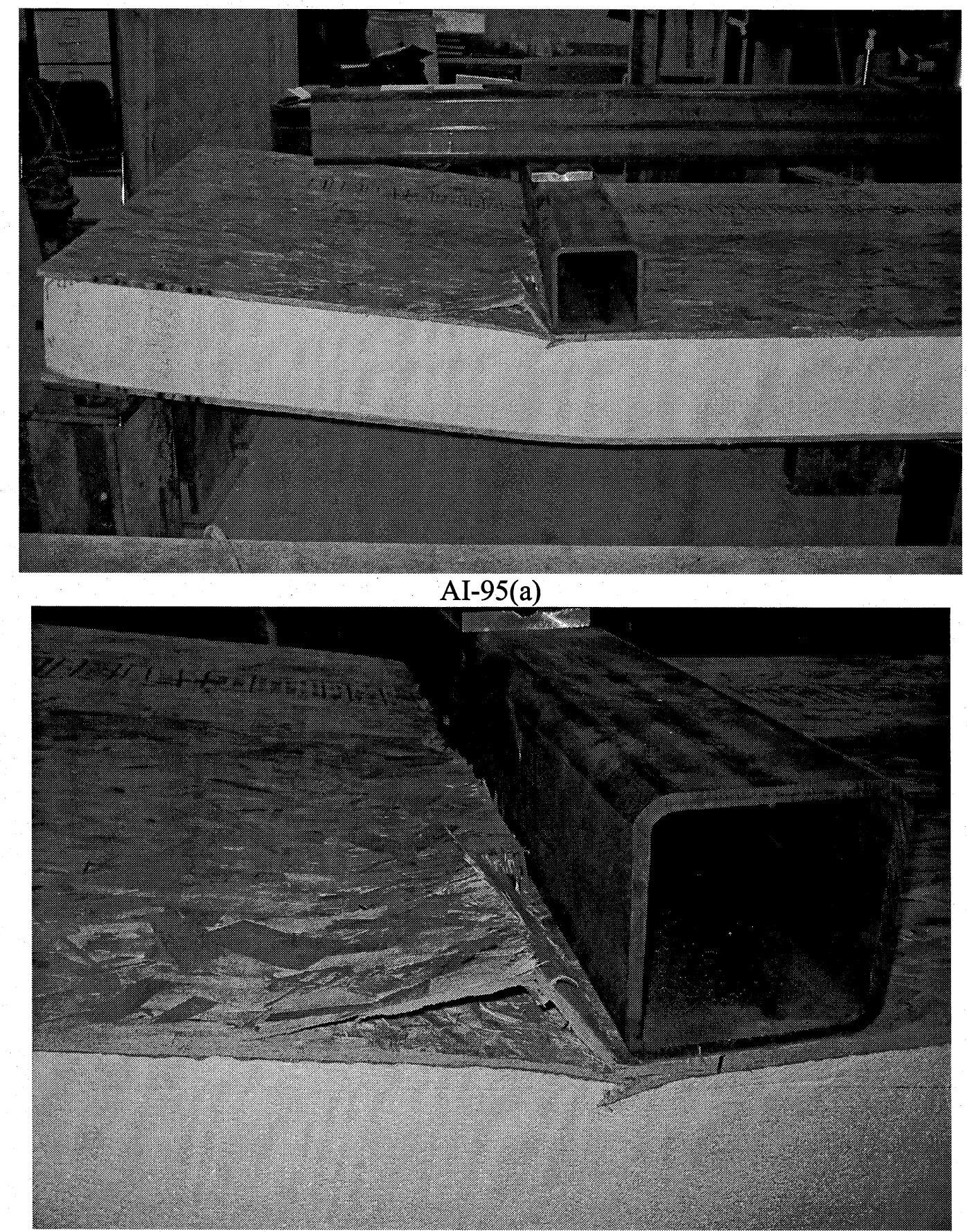

AI-95(b)

Figure A-95(b) View of outward crushing of OSB fibers in one side of specimen S-19 at the interface of the loading beam and the top of the panel 

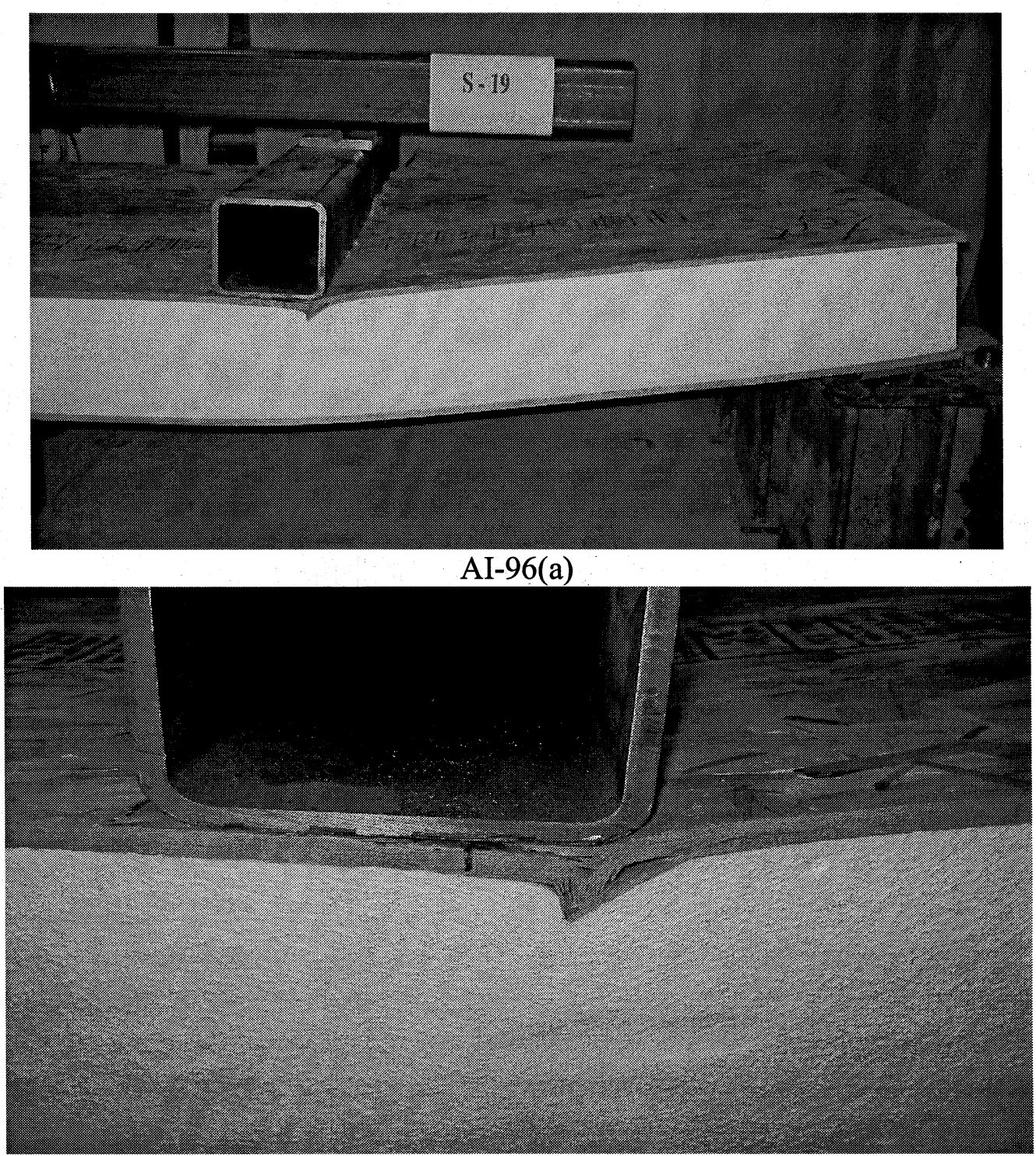

AI-96(b)

Figure A1-96(b) view of inward crushing of OSB fibers on the other free side of specimen S19 at the interface of the loading beam and the top of the panel 


\section{GROUP G}

\section{Specimen \# S-20}

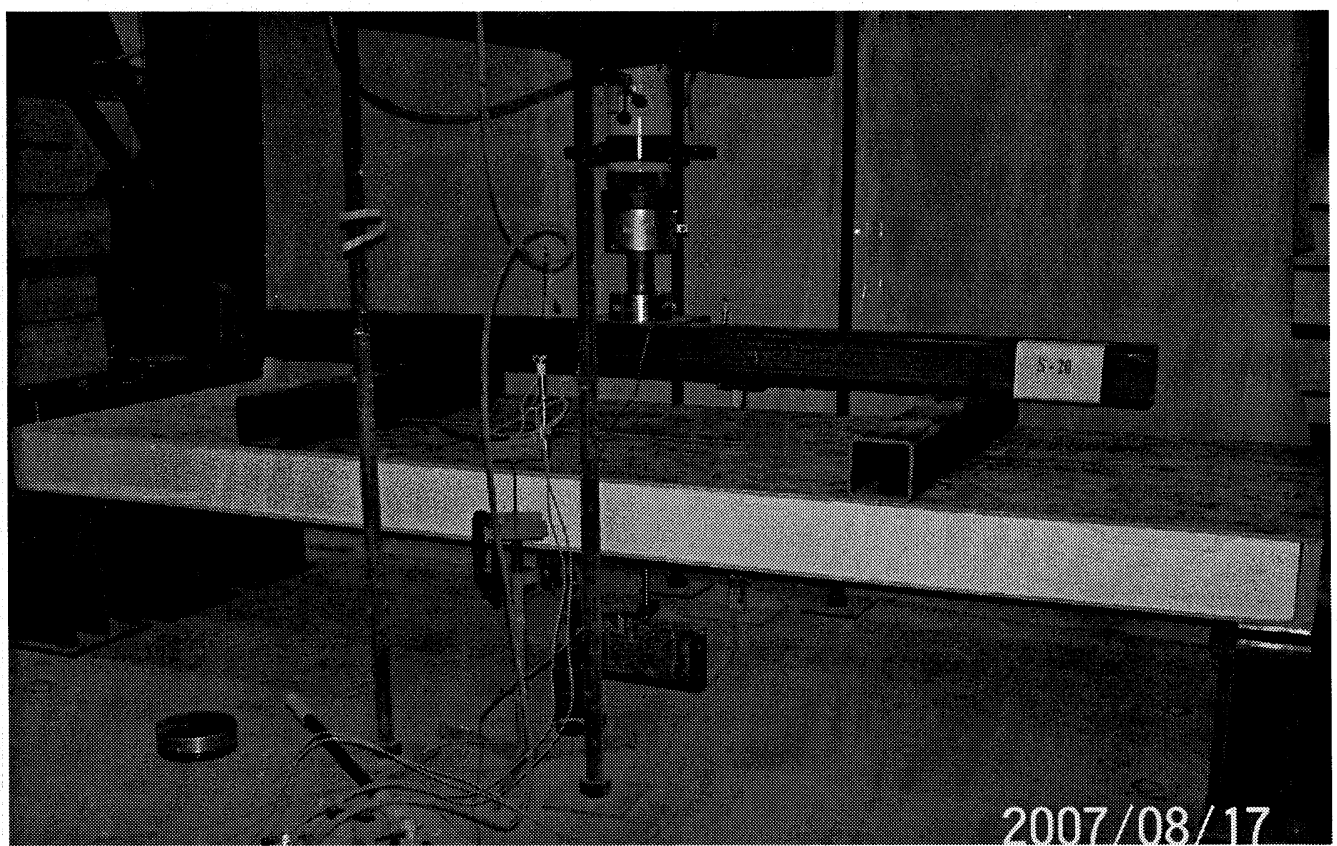

Figure AI-97 View of Specimen S-20 before testing

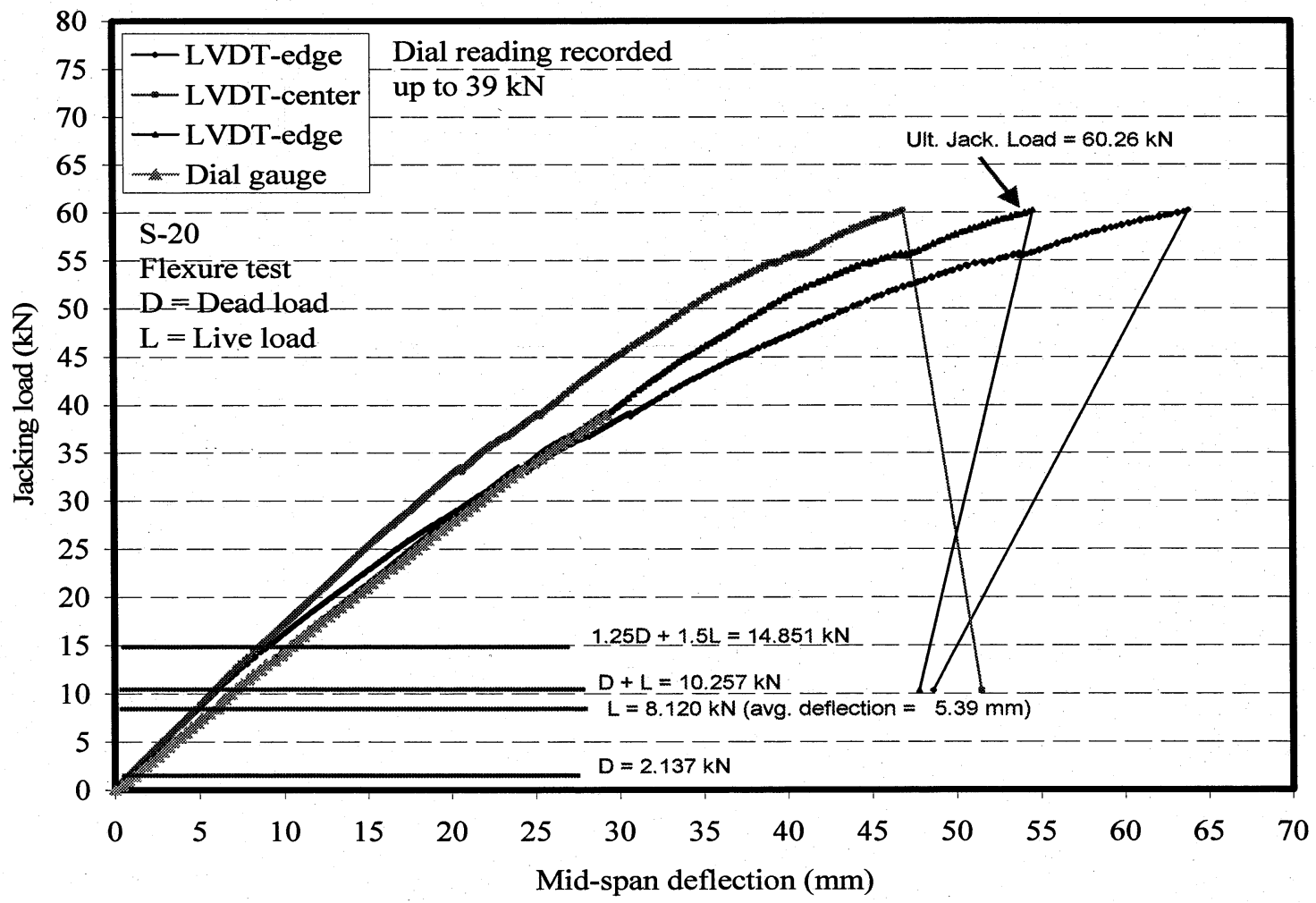

Figure AI-98 Load-deflection relationship for specimen S-20 


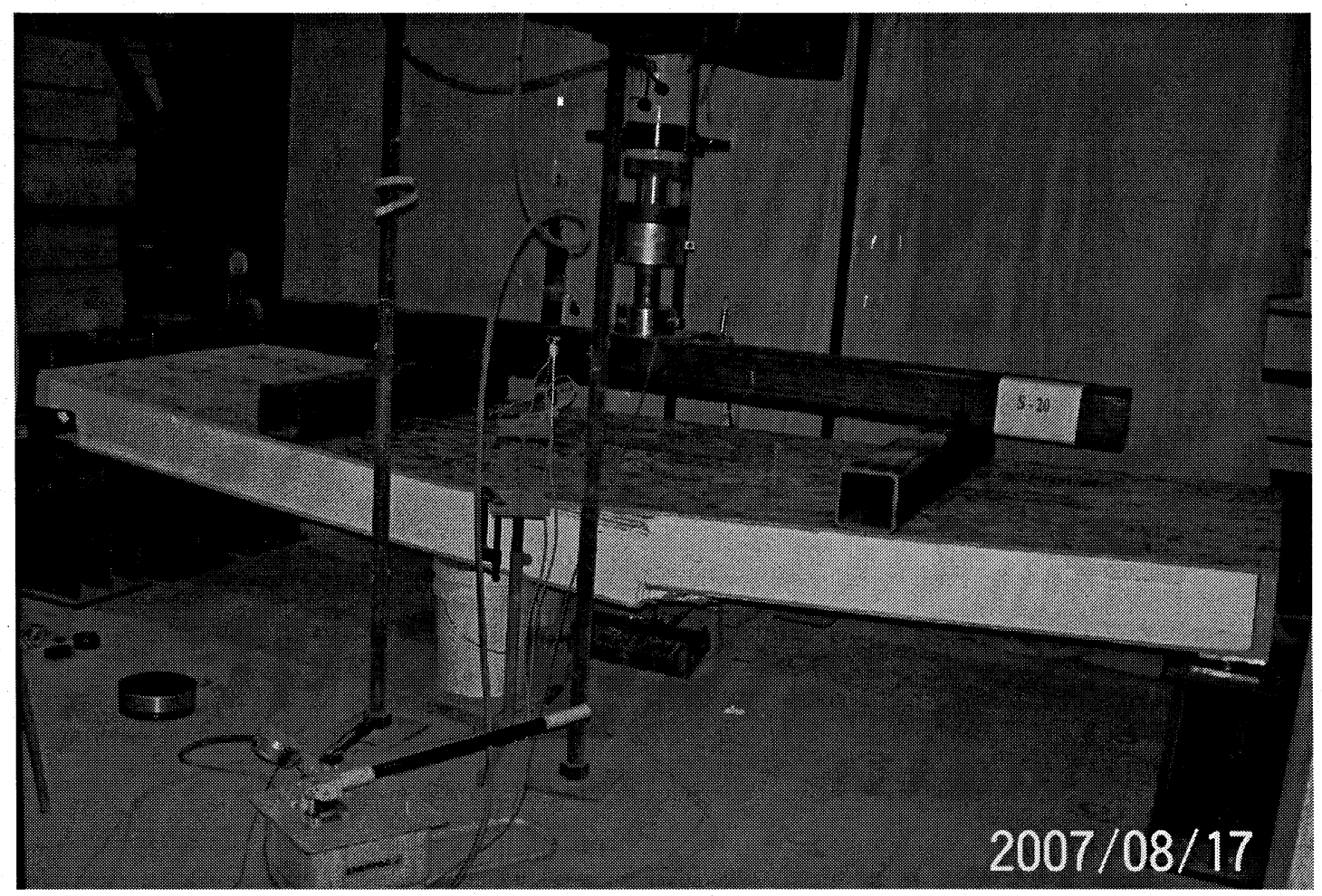

Figure AI-99View of specimen S-20 after failure

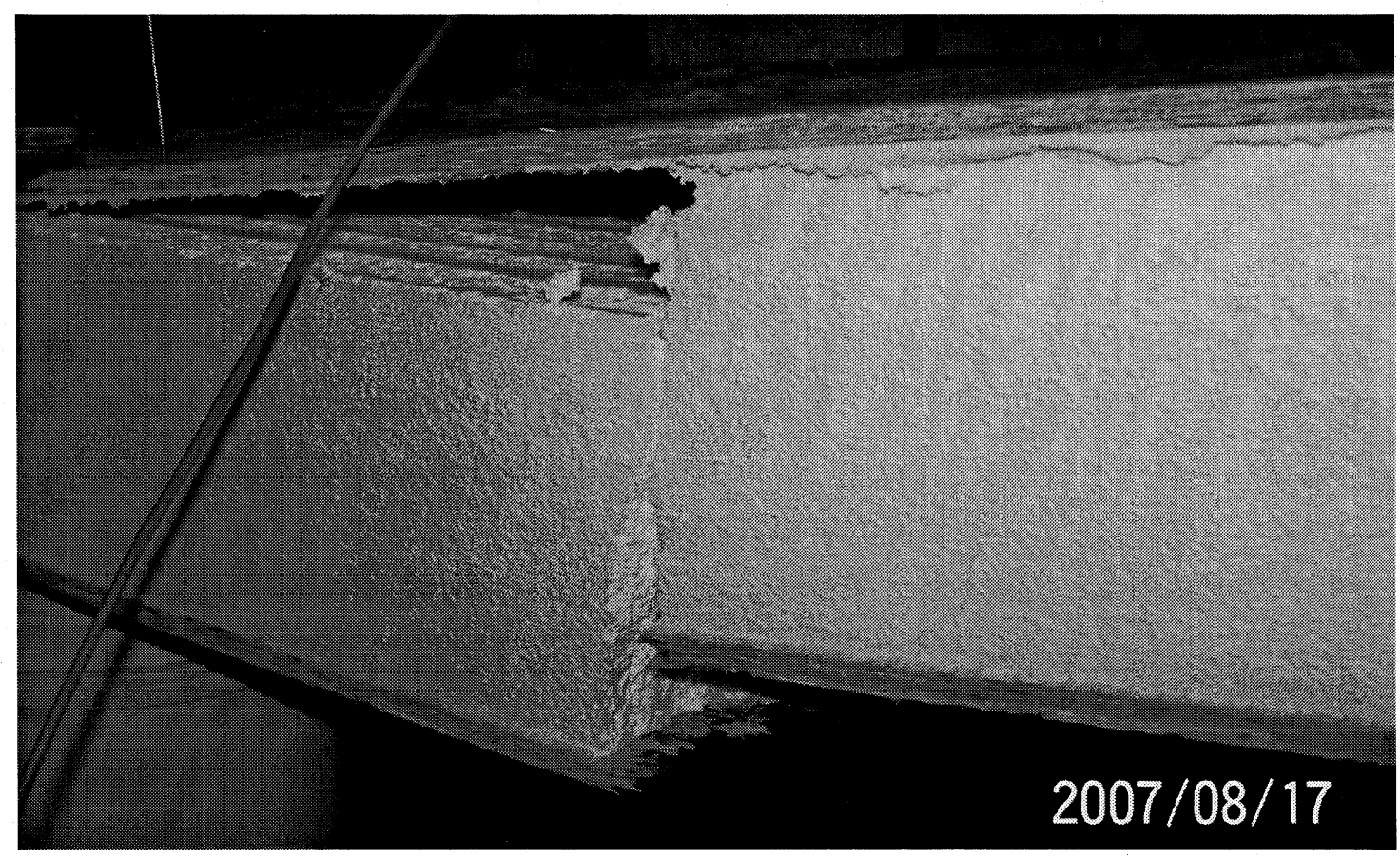

Figure AI-100View of the flexural failure of specimen S-20 


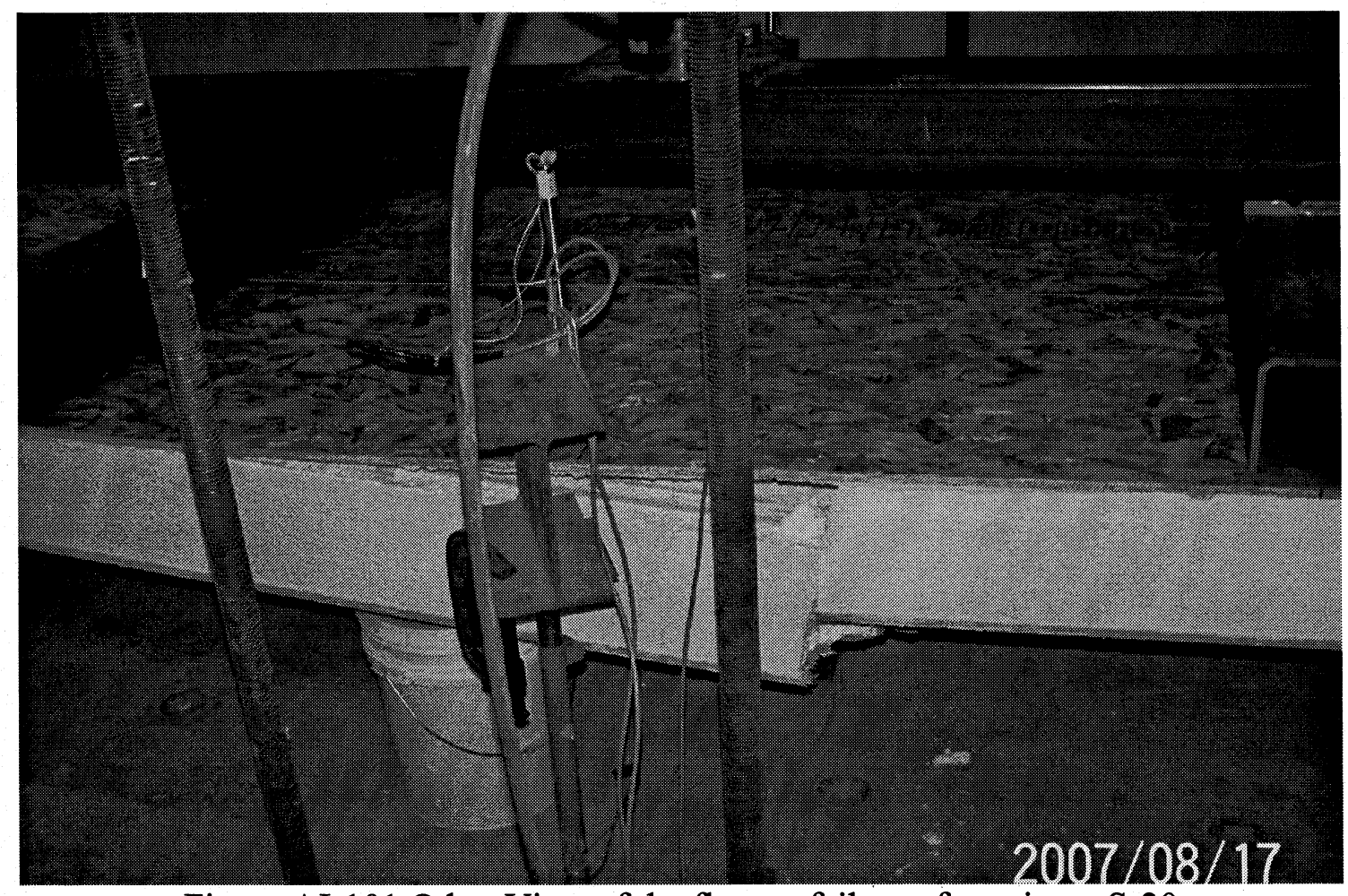

Figure AI-101 Other View of the flexure failure of specimen S-20 


\section{Specimen \# S-21}

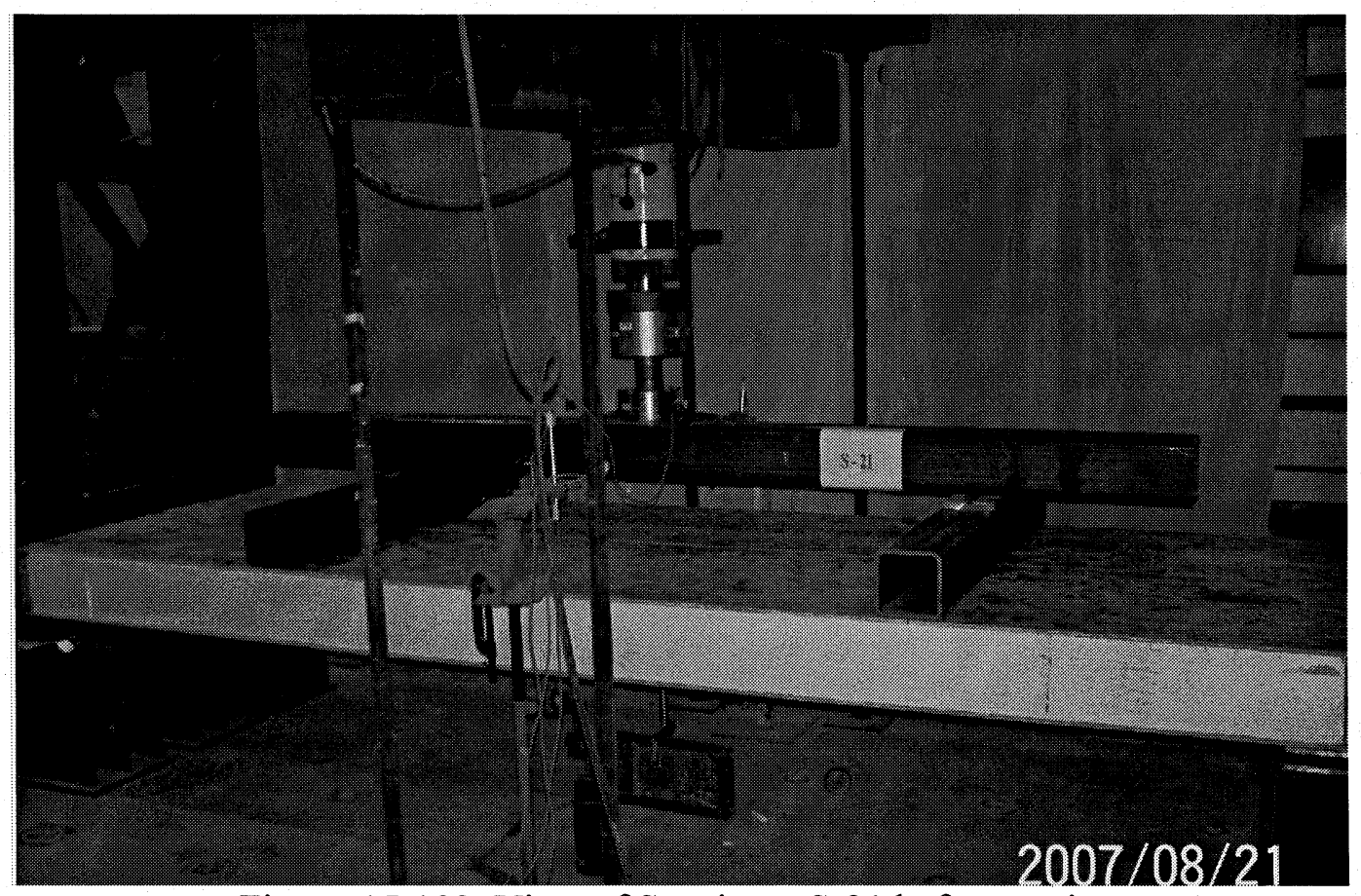

Figure AI-102. View of Specimen S-21 before testing

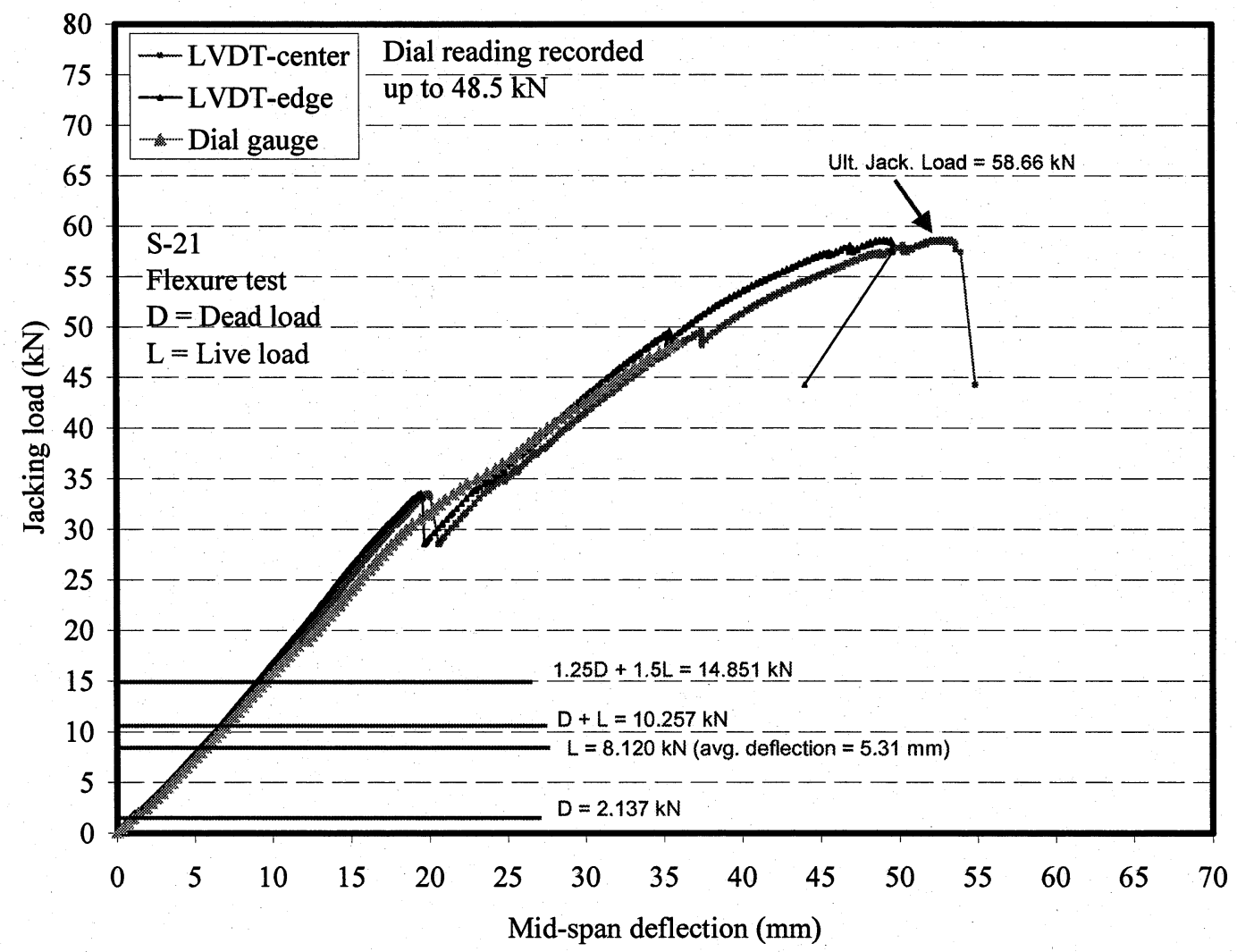

Figure AI-103. Load-deflection relationship for specimen S-21 


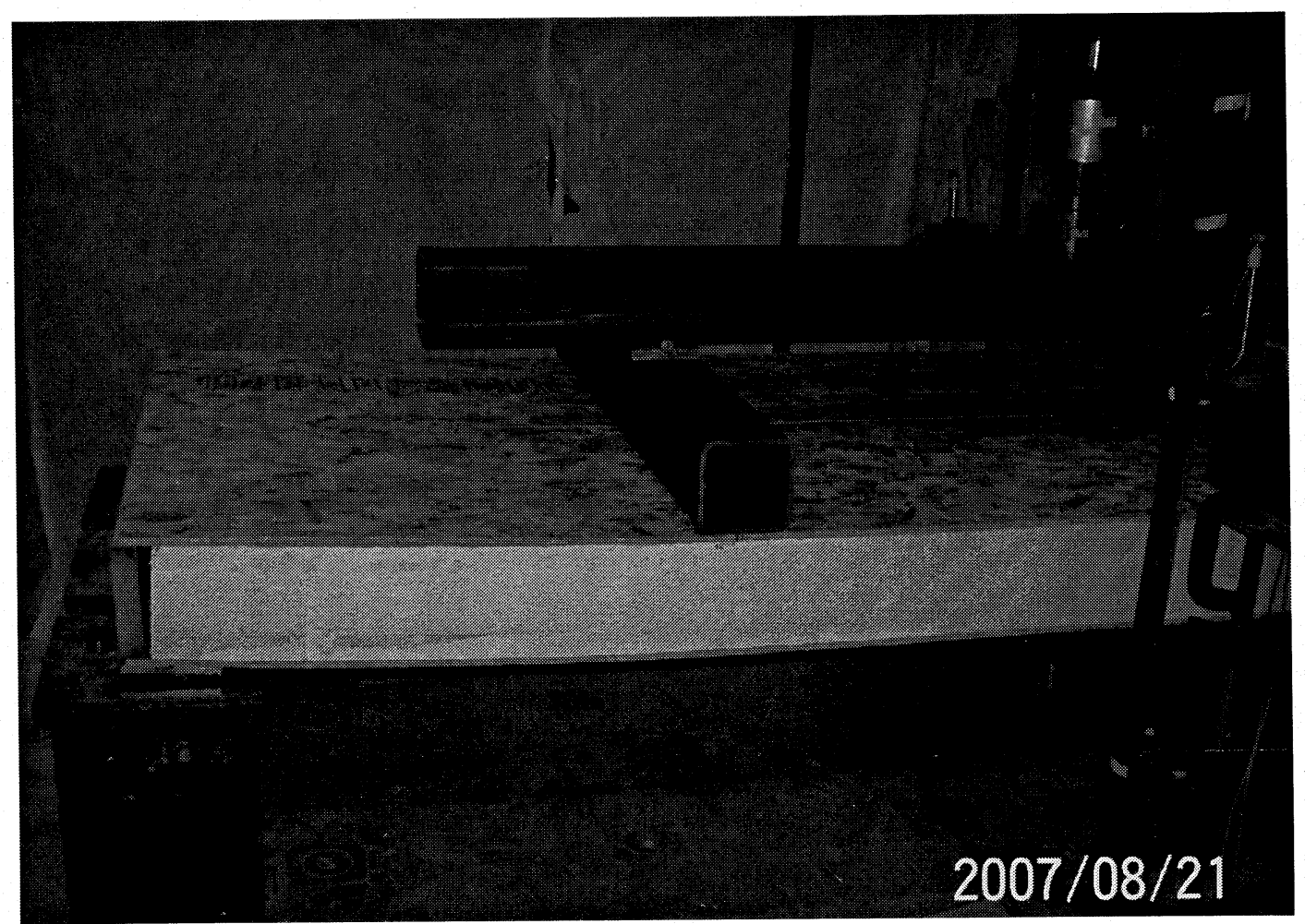

Figure AI-104. View of specimen S-21 after failure

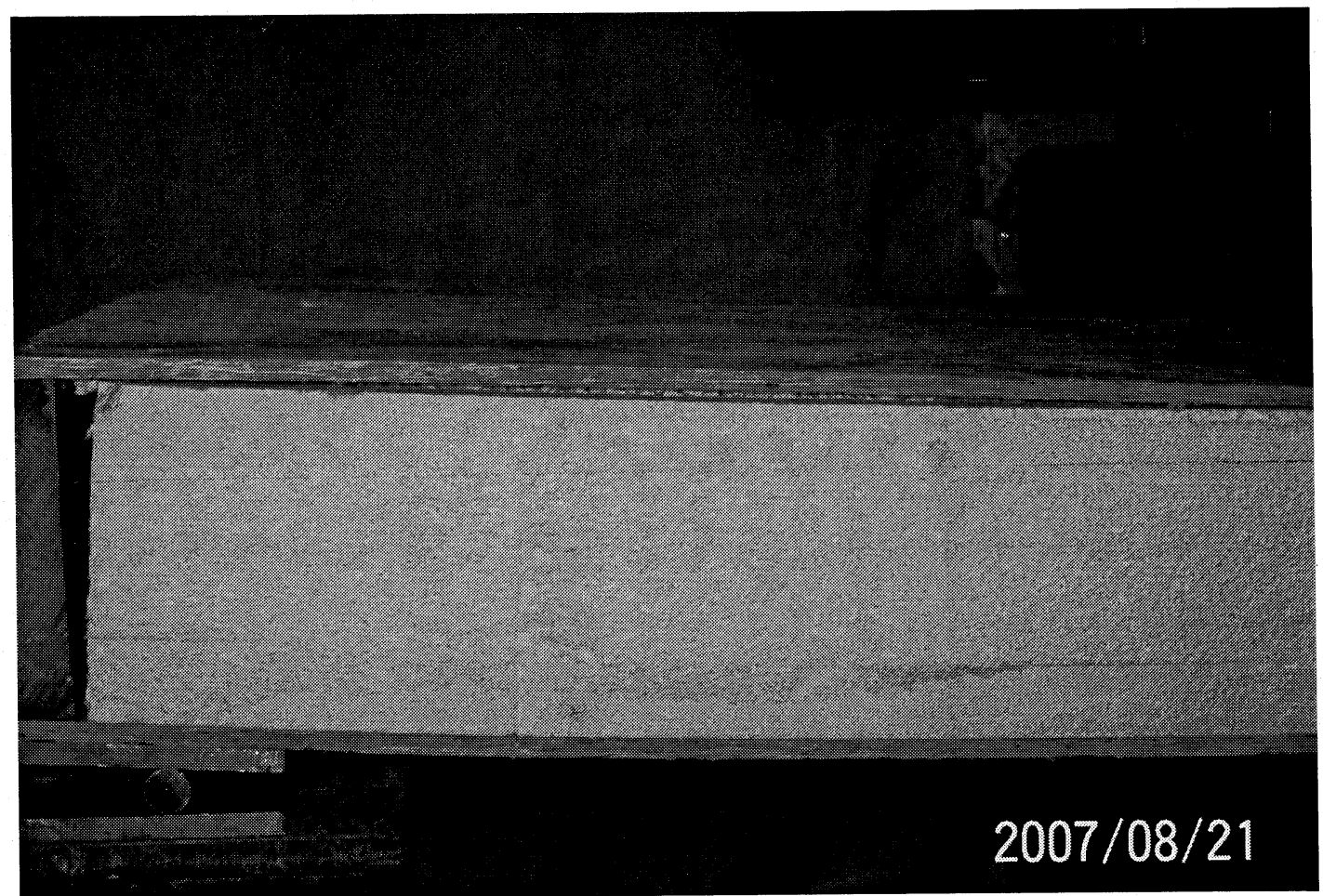

Figure AI-105. View of the horizontal shear failure of specimen S-21 


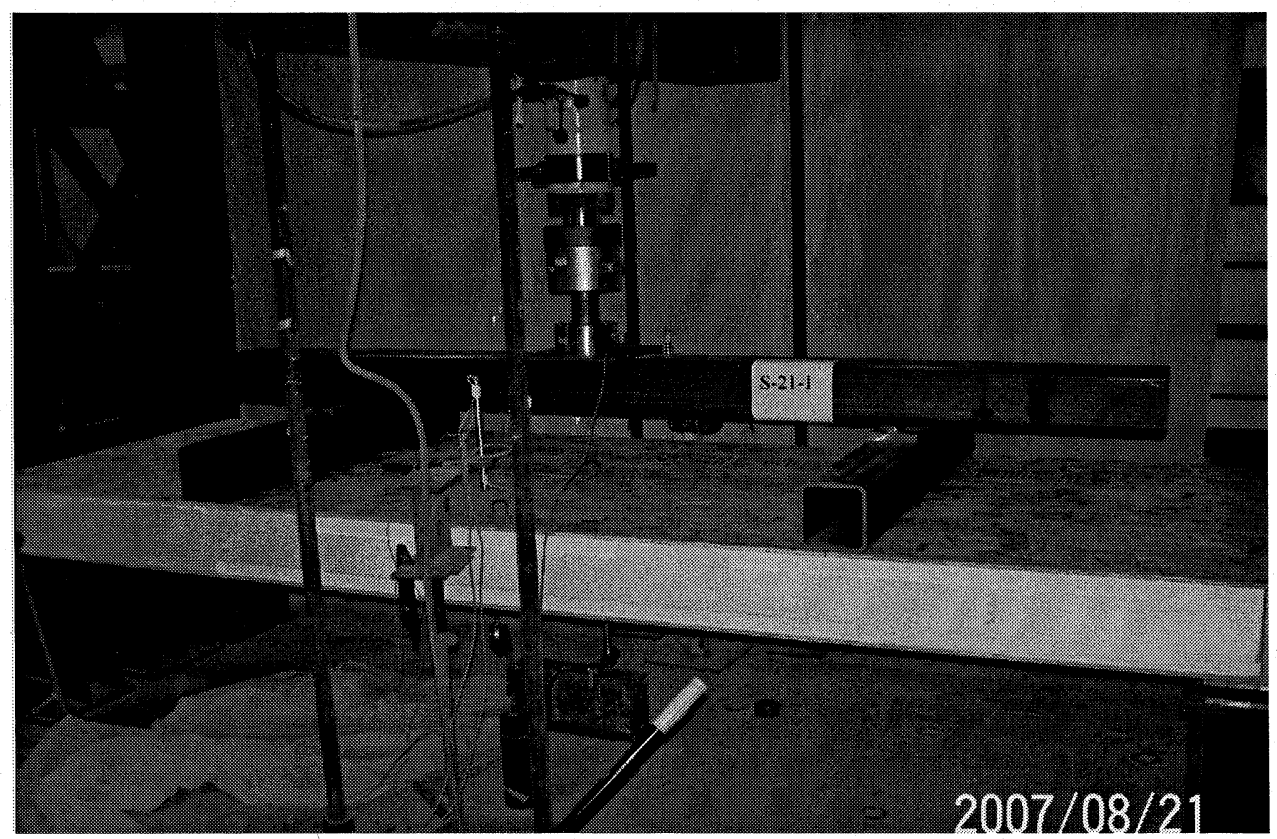

Figure AI-102-1. view of Specimen S-21 before testing

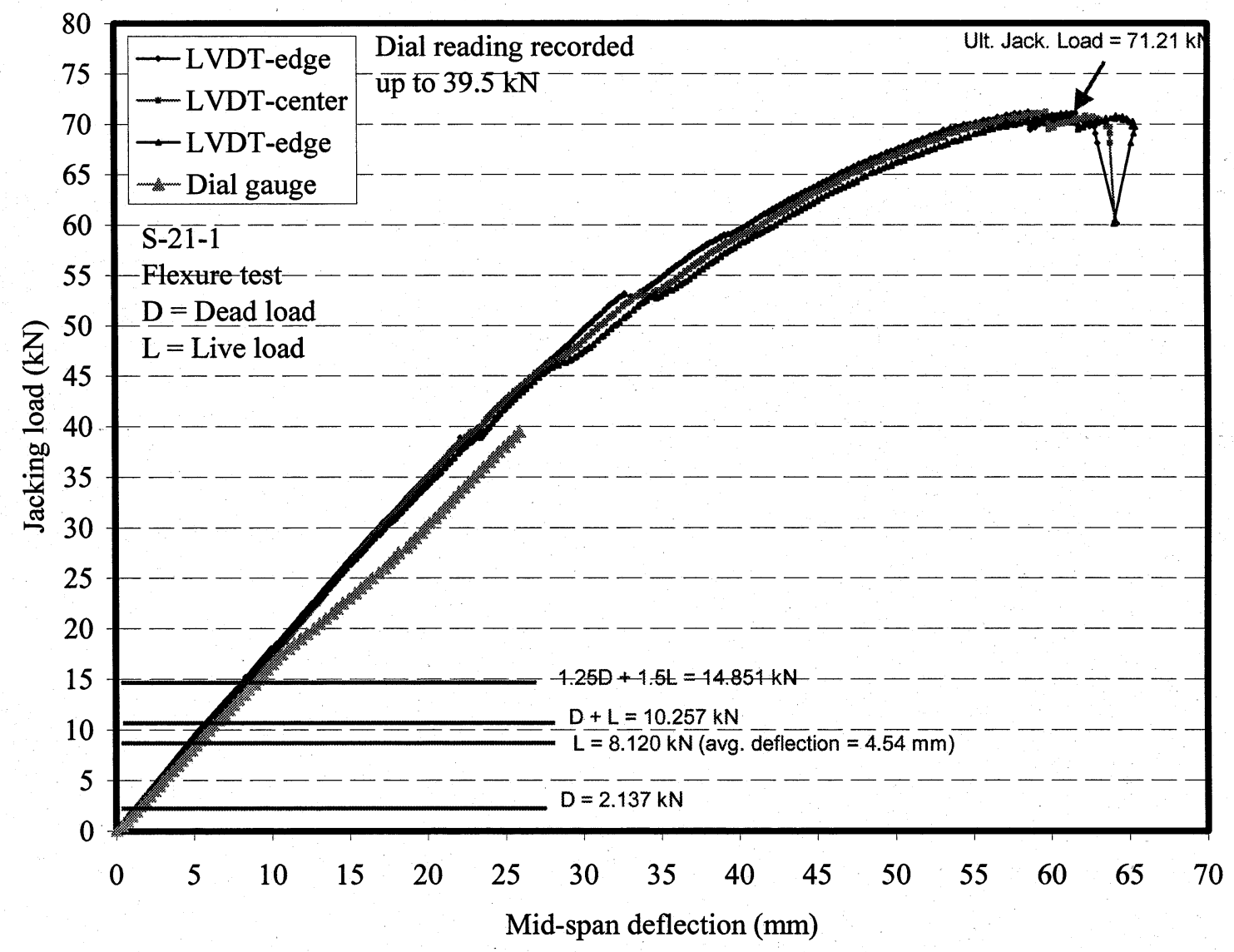

Figure AI-103-1 Load-deflection relationship for specimen S-21-1 


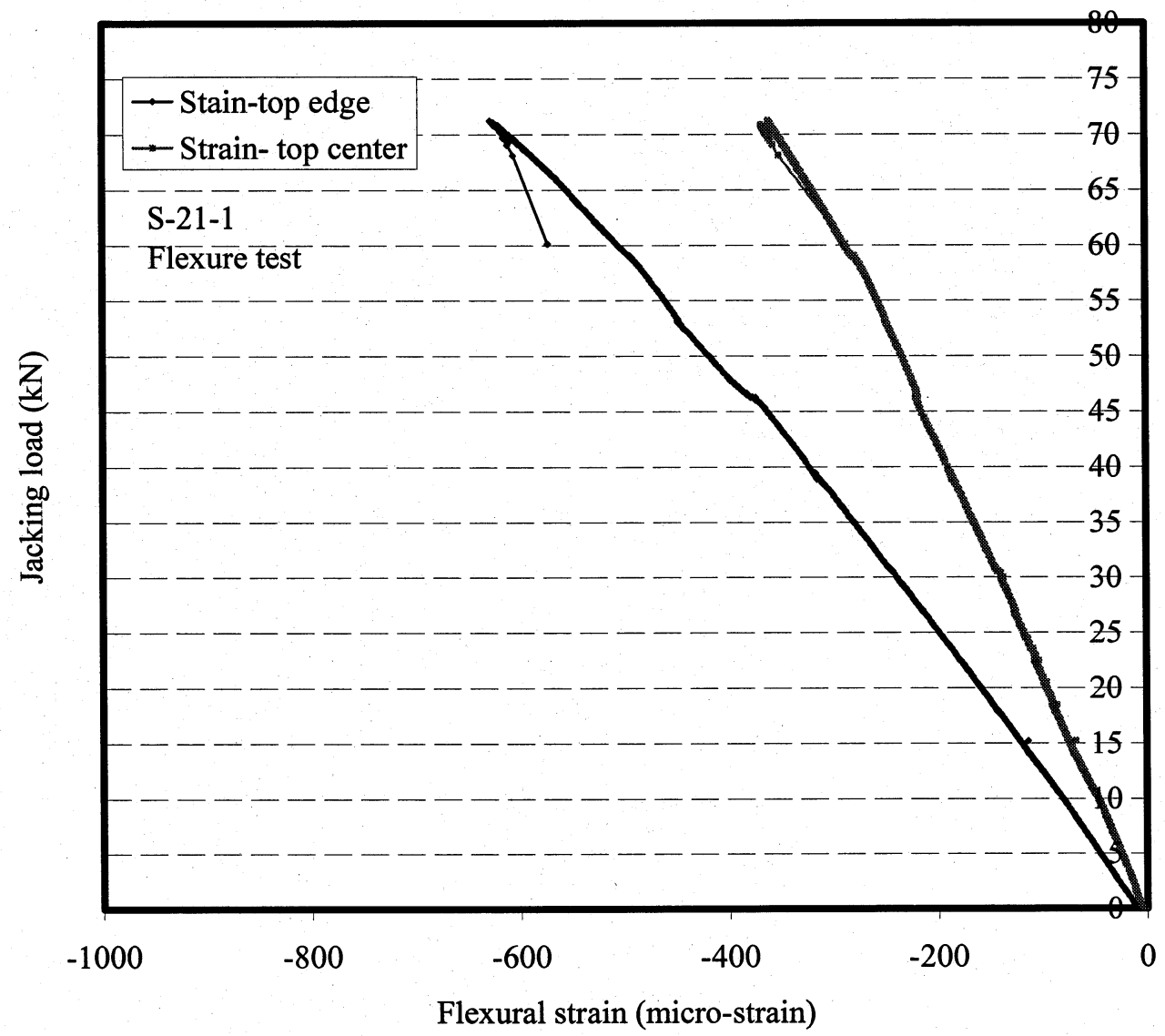

Figure AI-104-1 Load-strain relationship for specimen S-21

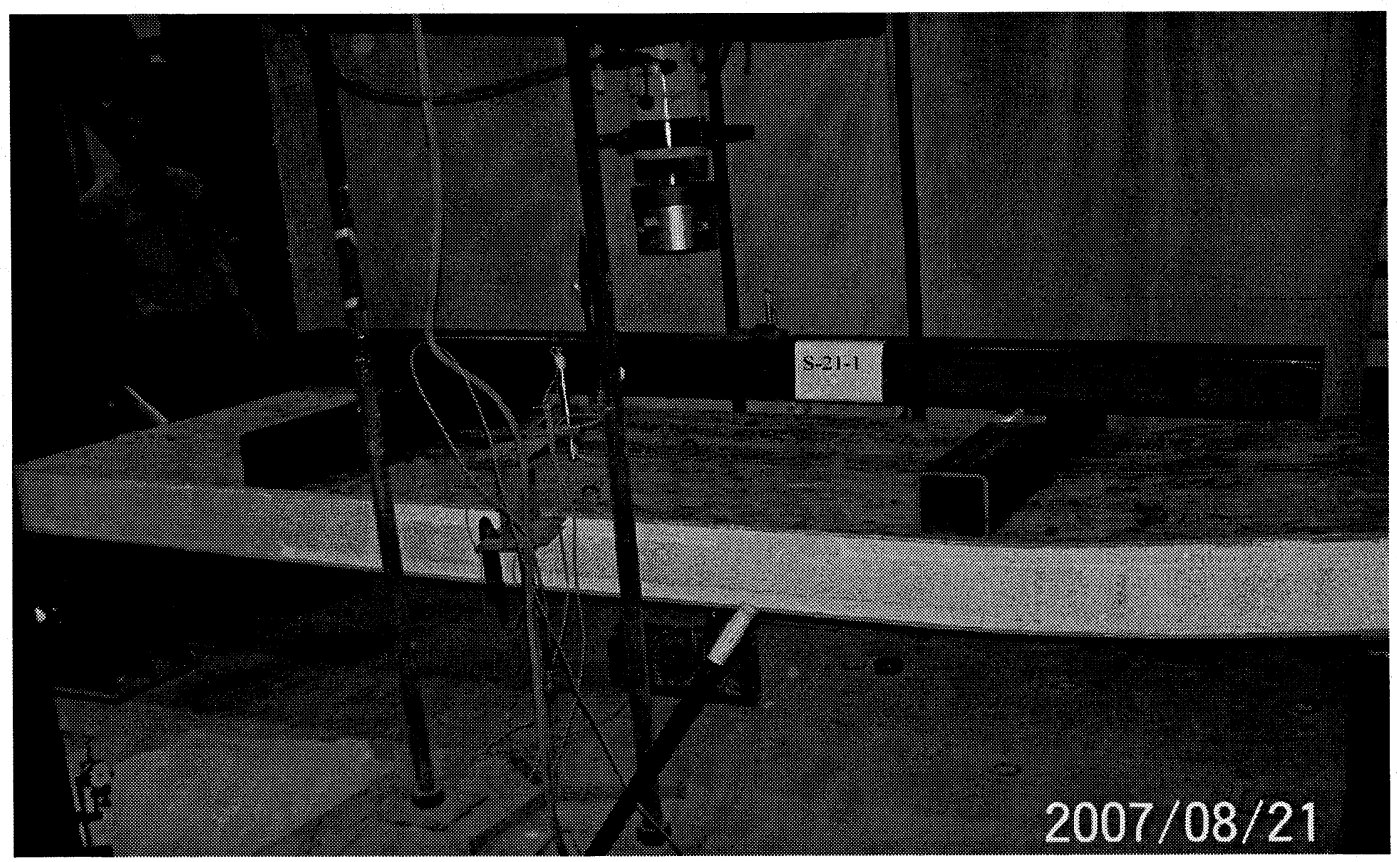

Figure AI-105-1 View of specimen S-21 after failure 


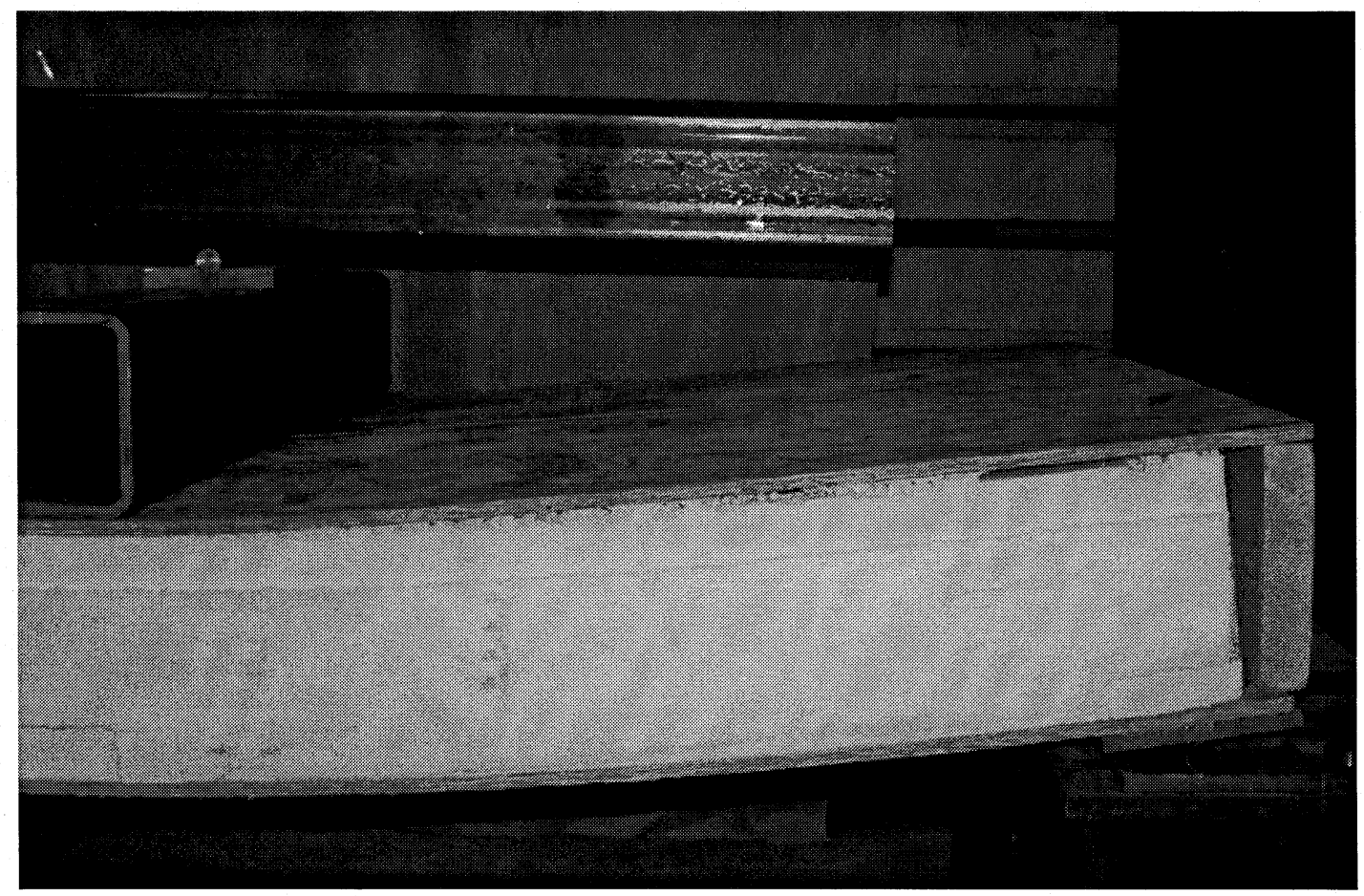

Figure AI-106-1 view of the horizontal shear failure of specimen S-21 


\section{GROUP H}

\section{Specimen \# S-22}

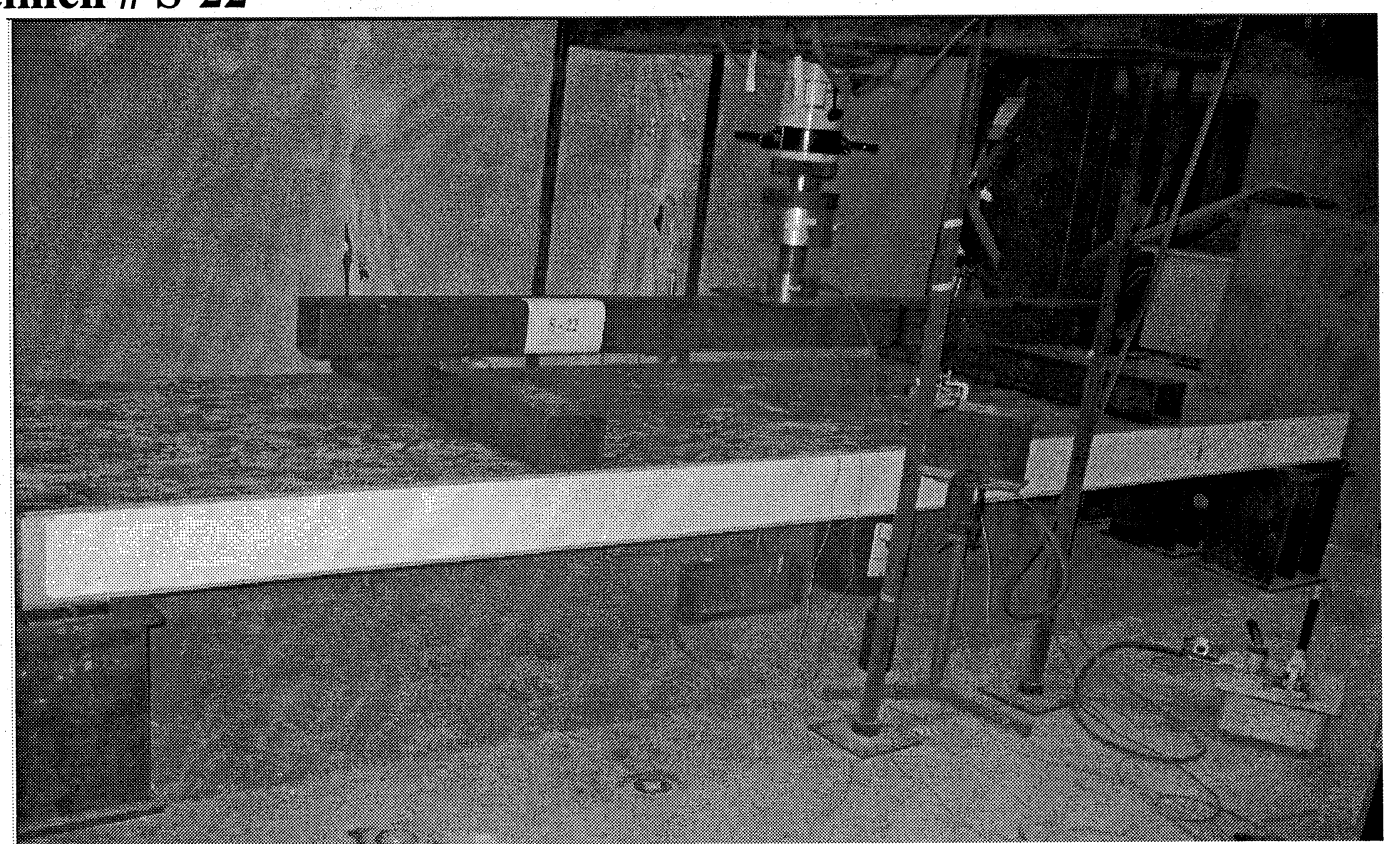

Figure A1-107. View of Specimen S-22 before testing

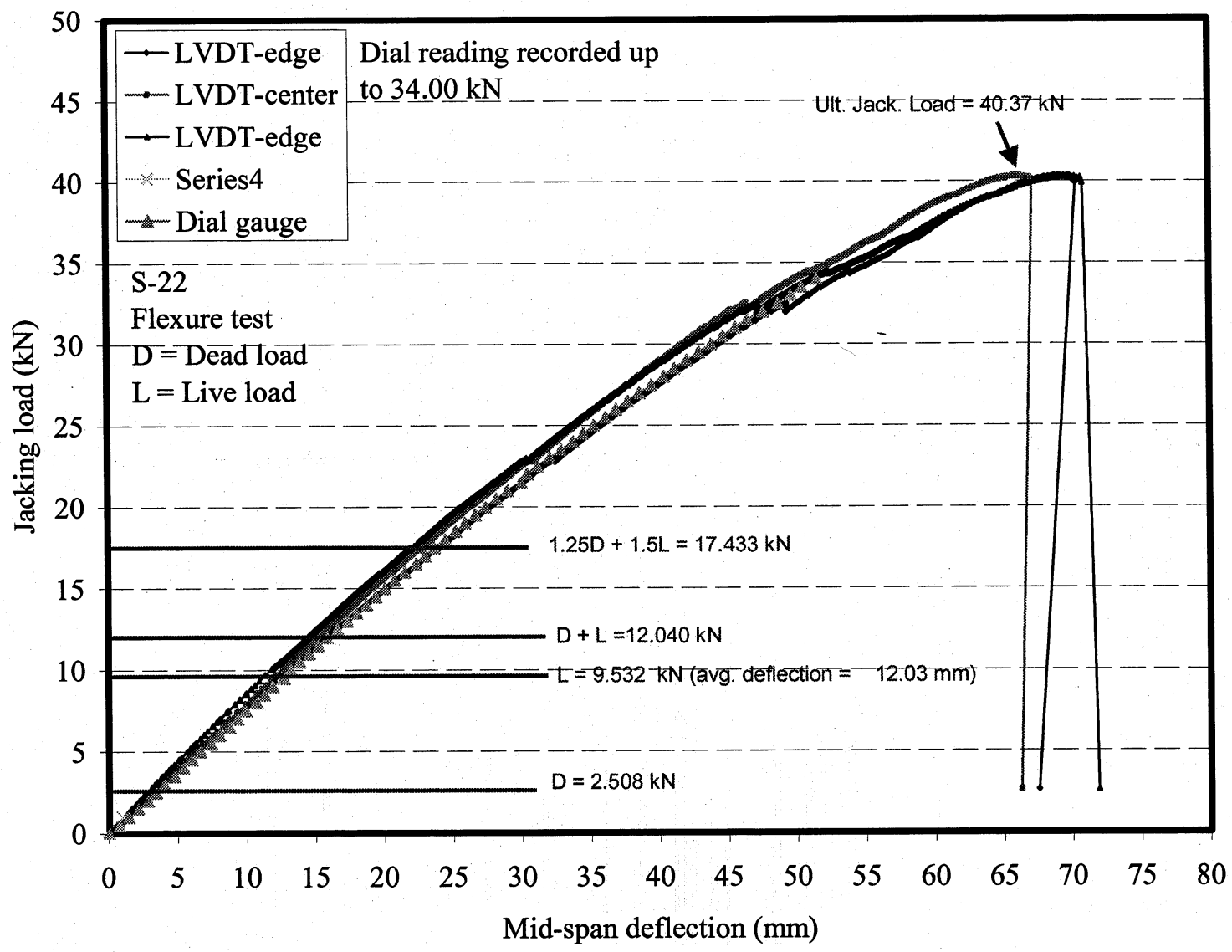

Figure AI-108. Load-deflection relationship for specimen S-22 


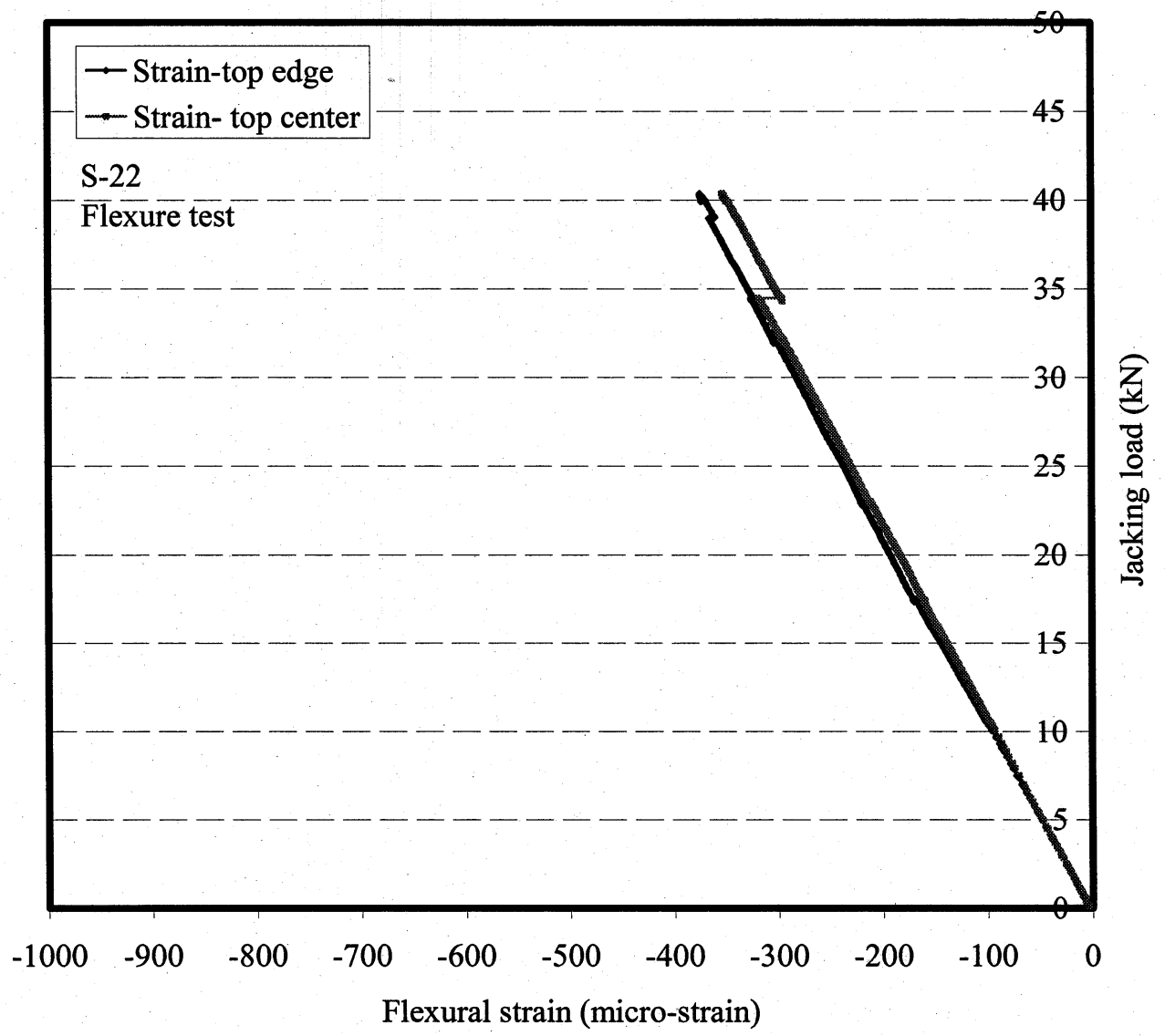

Figure AI-109. Load-strain relationship for specimen S-22

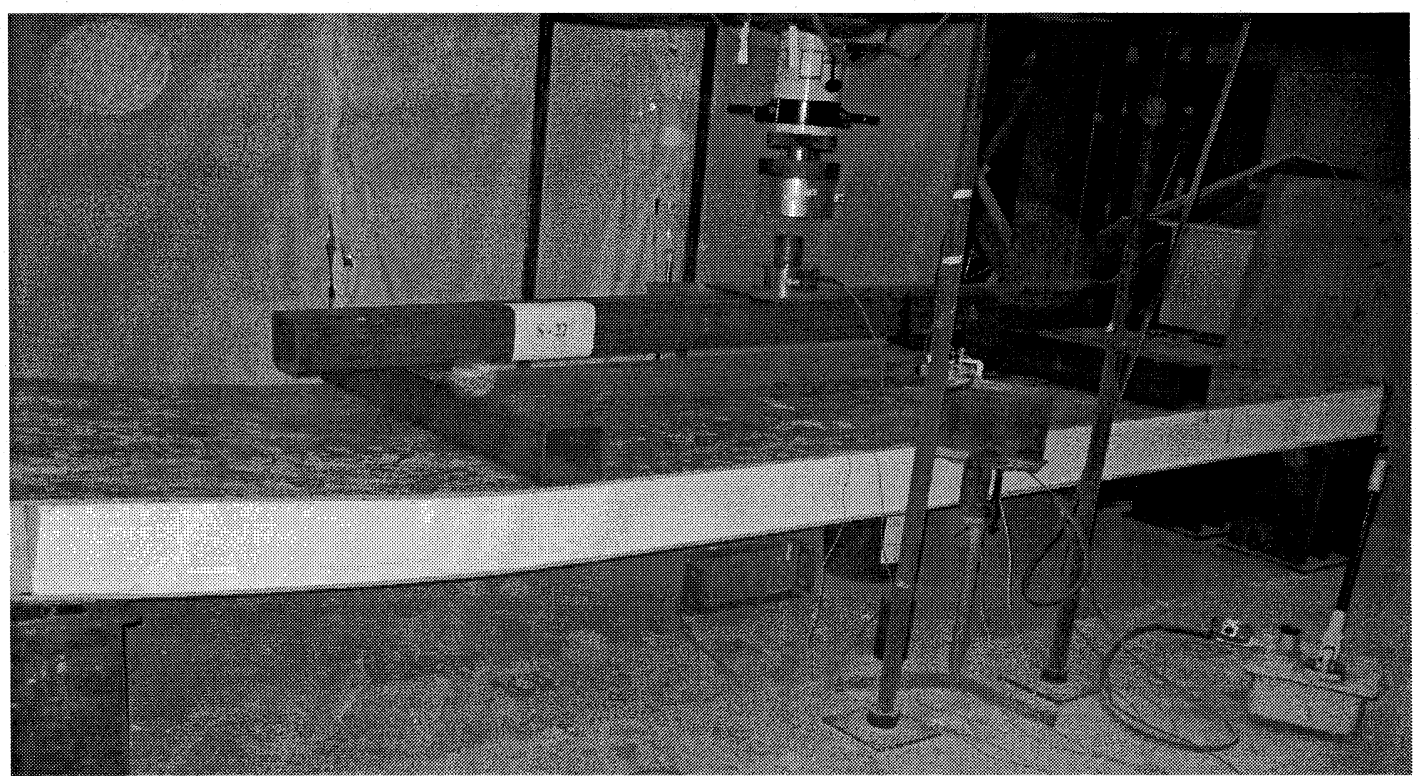

Figure AI-110. View of specimen S-22 after failure 


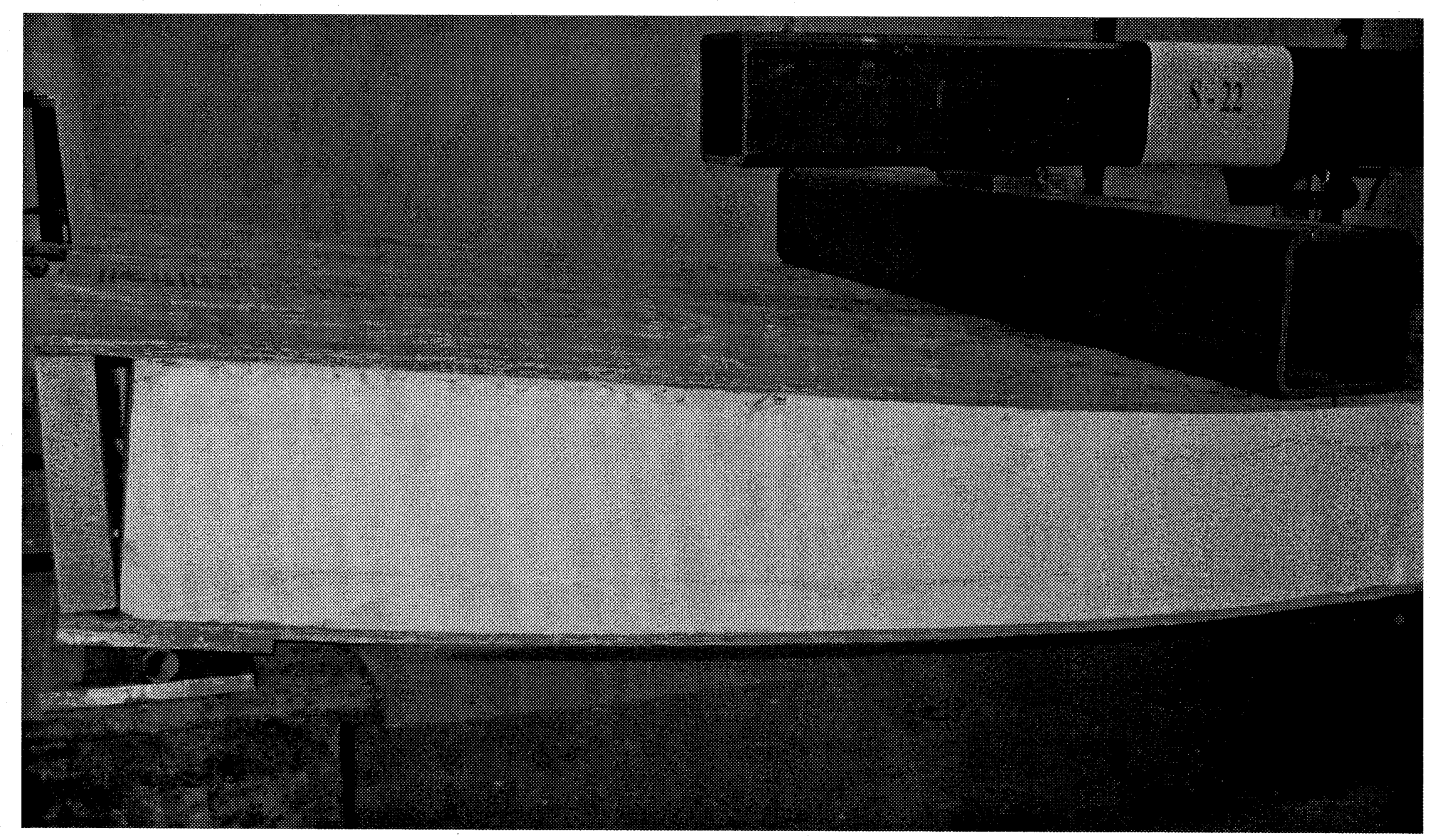

Figure AI-111. View of the horizontal shear failure of specimen S-22

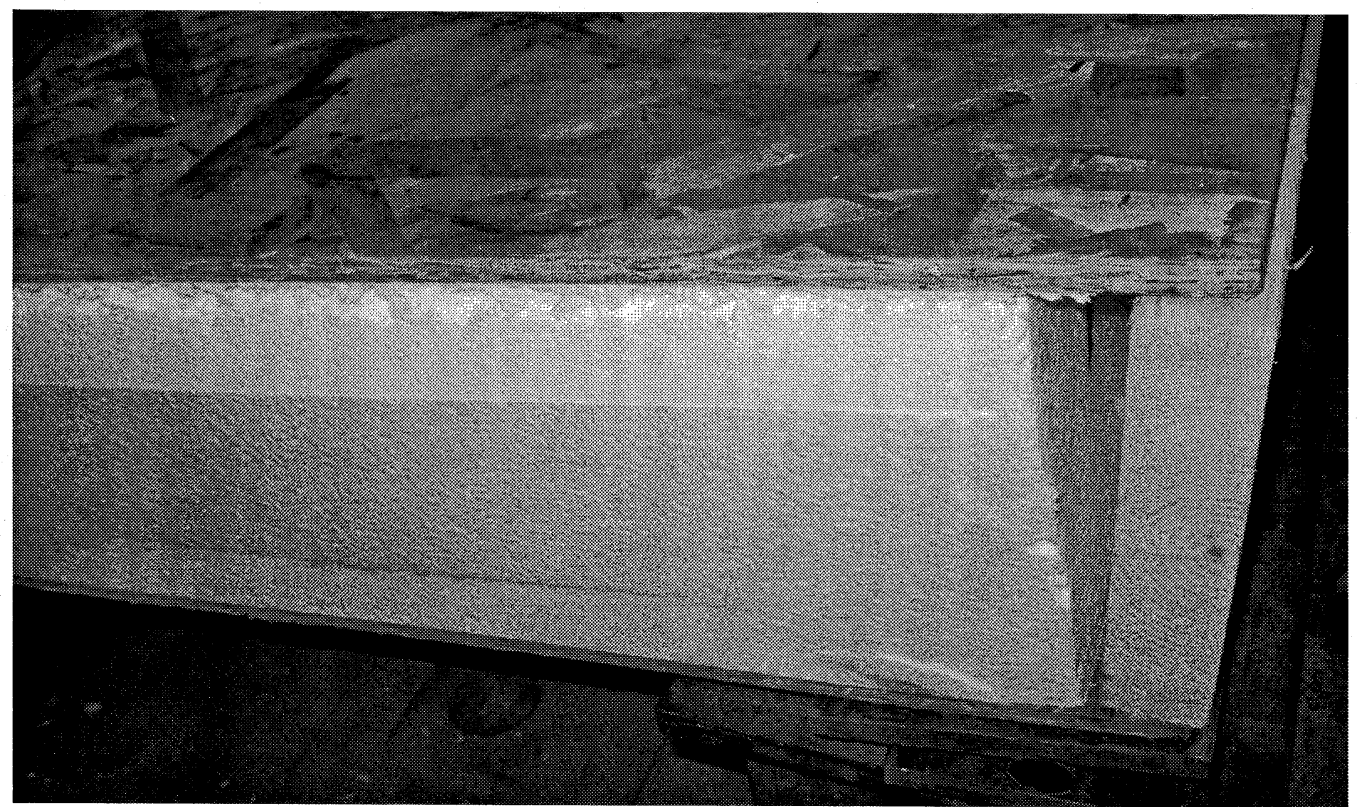

Figure AI-111. View of the horizontal shear failure on the other free edge of specimen S-22 


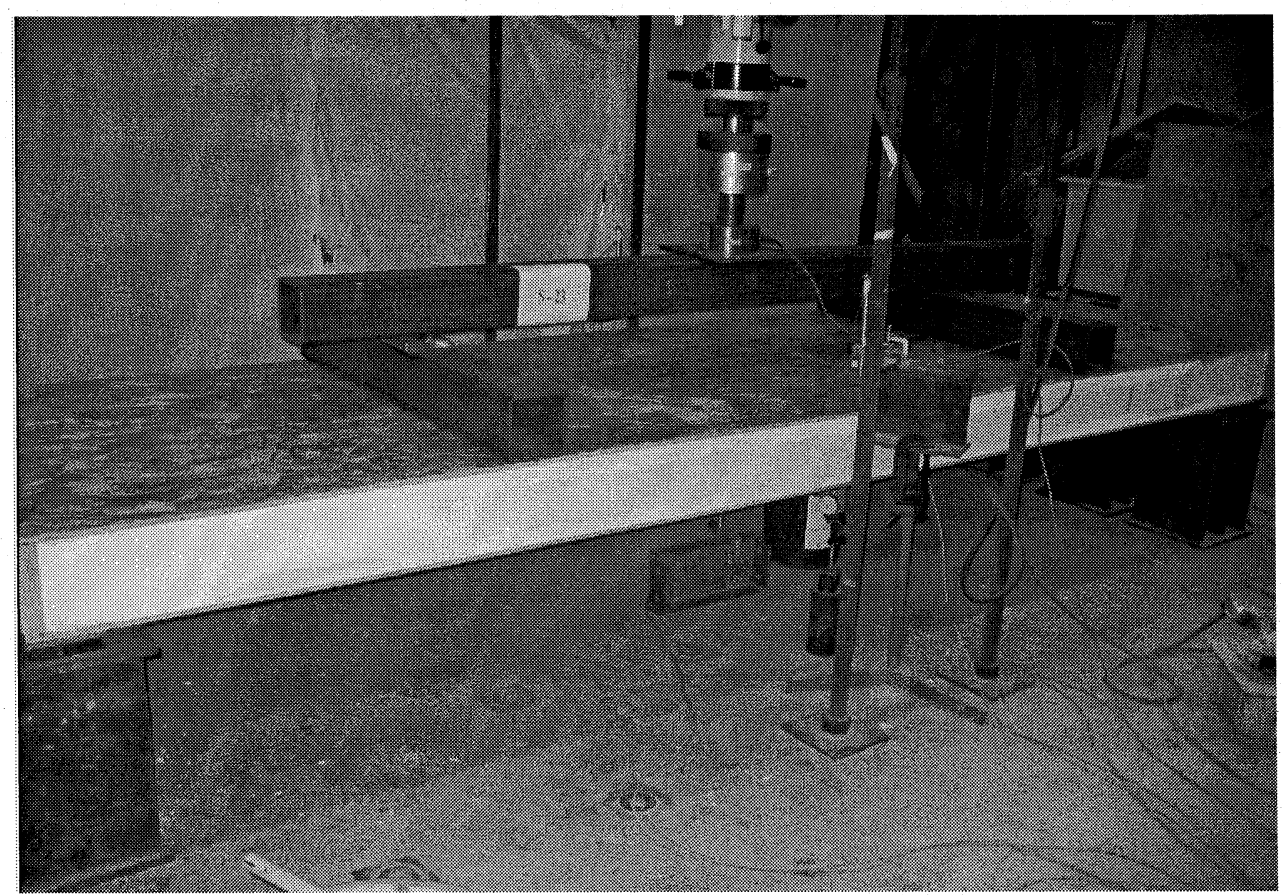

Figure AI-112 View of Specimen S-23 before testing

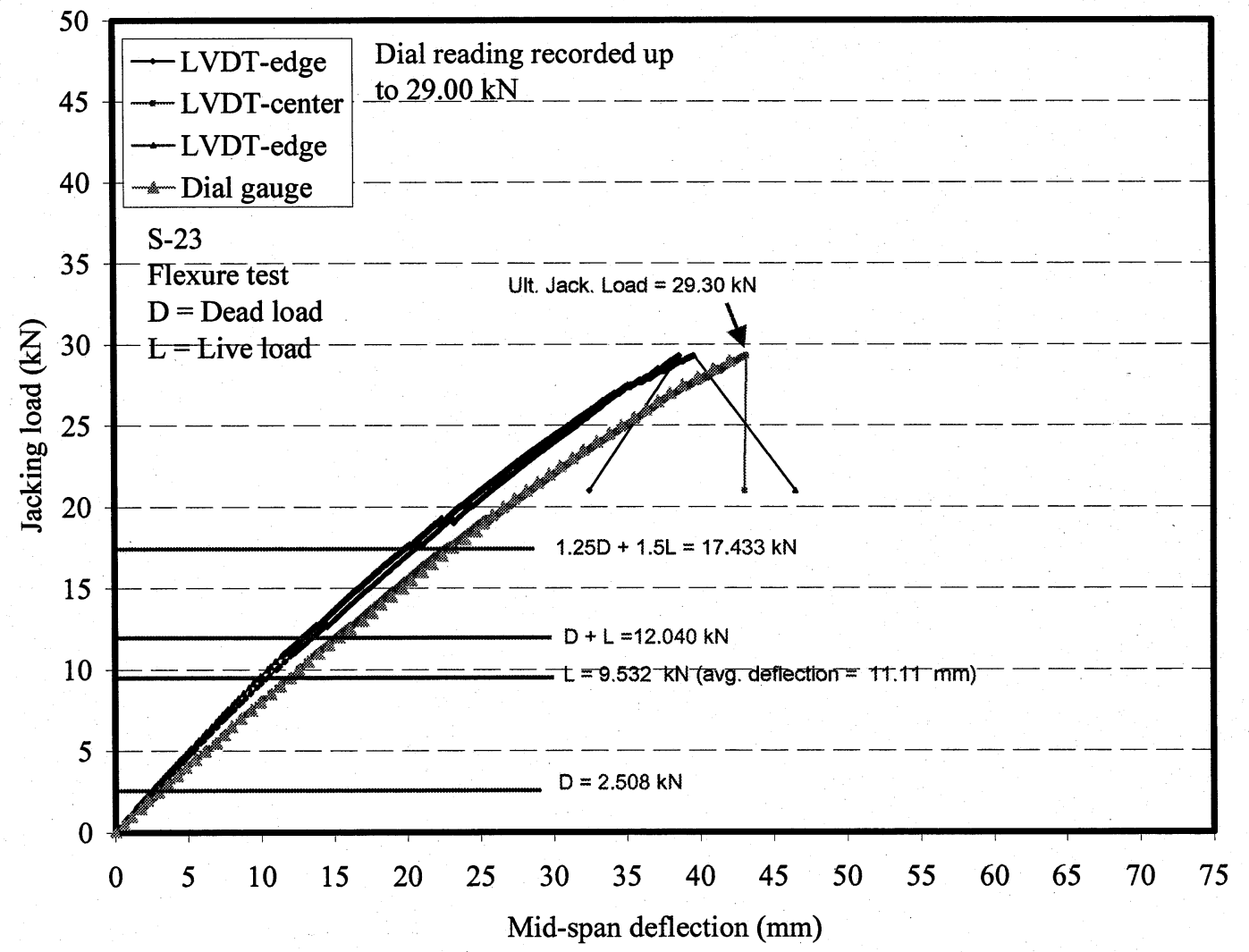

Figure AI-113 Load-deflection relationship for specimen S-23 


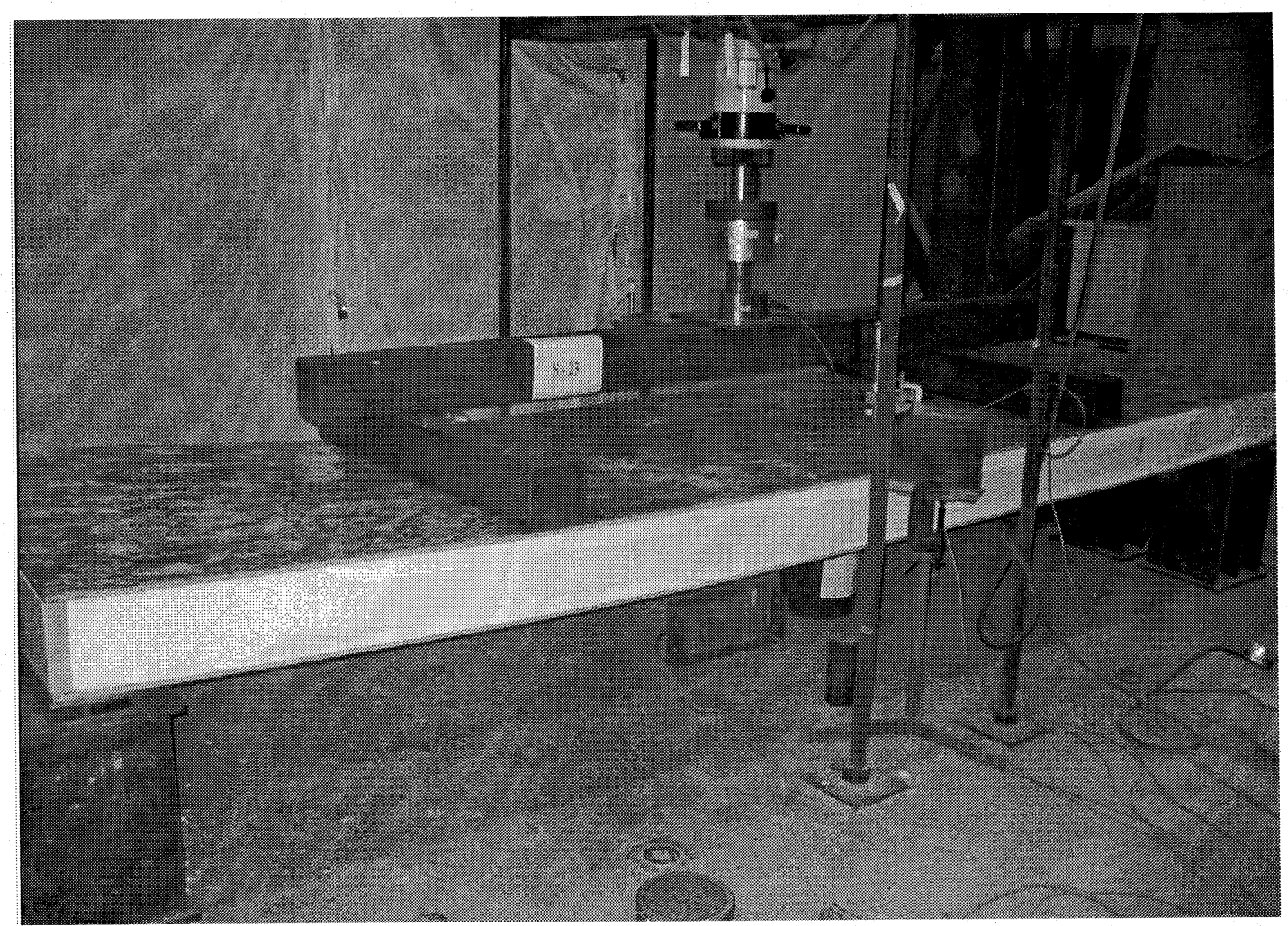

Figure AI-114 View of specimen S-23after failure

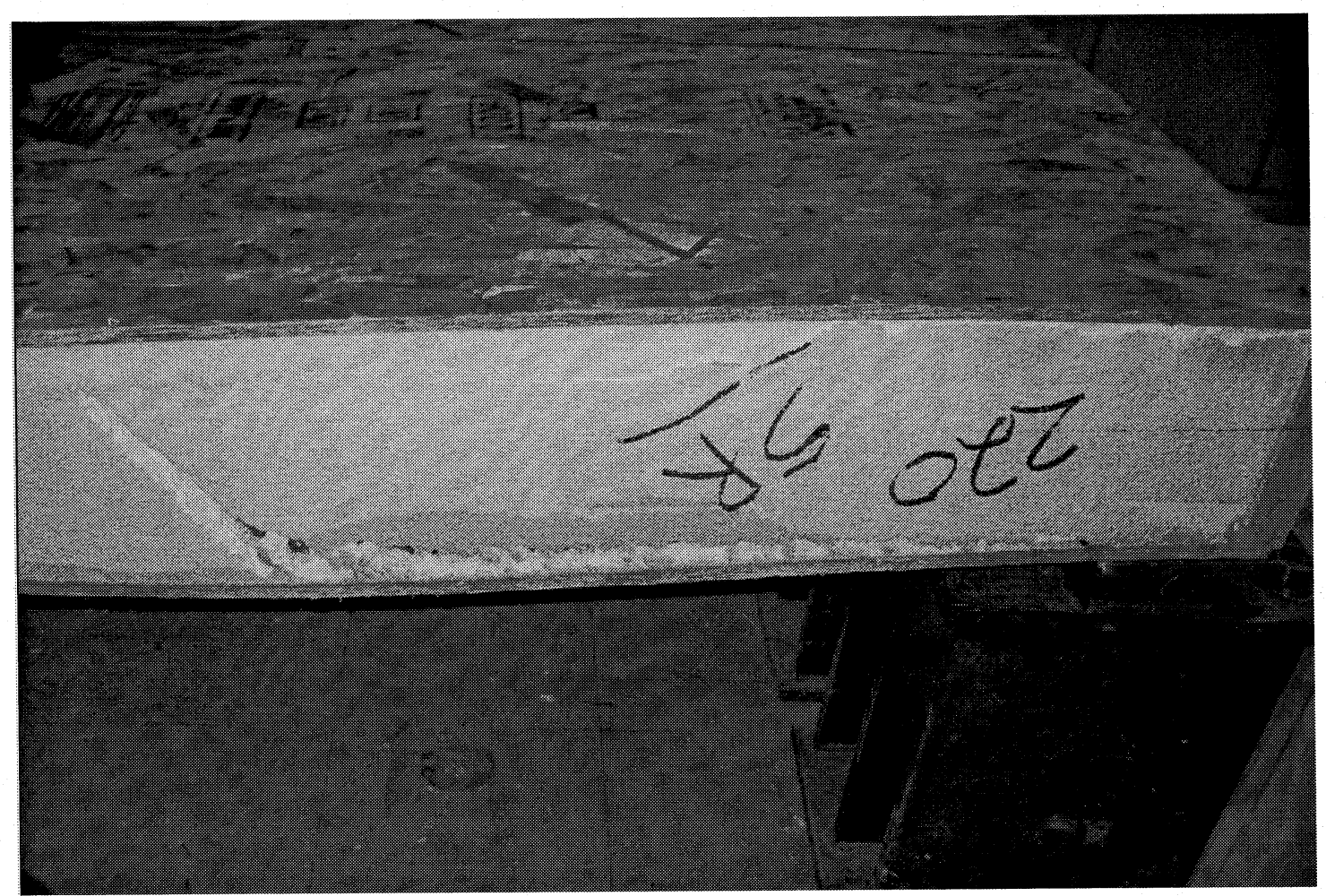

Figure AI-115 View of shear failure of specimen S-23 


\section{Specimen \# 23-1}

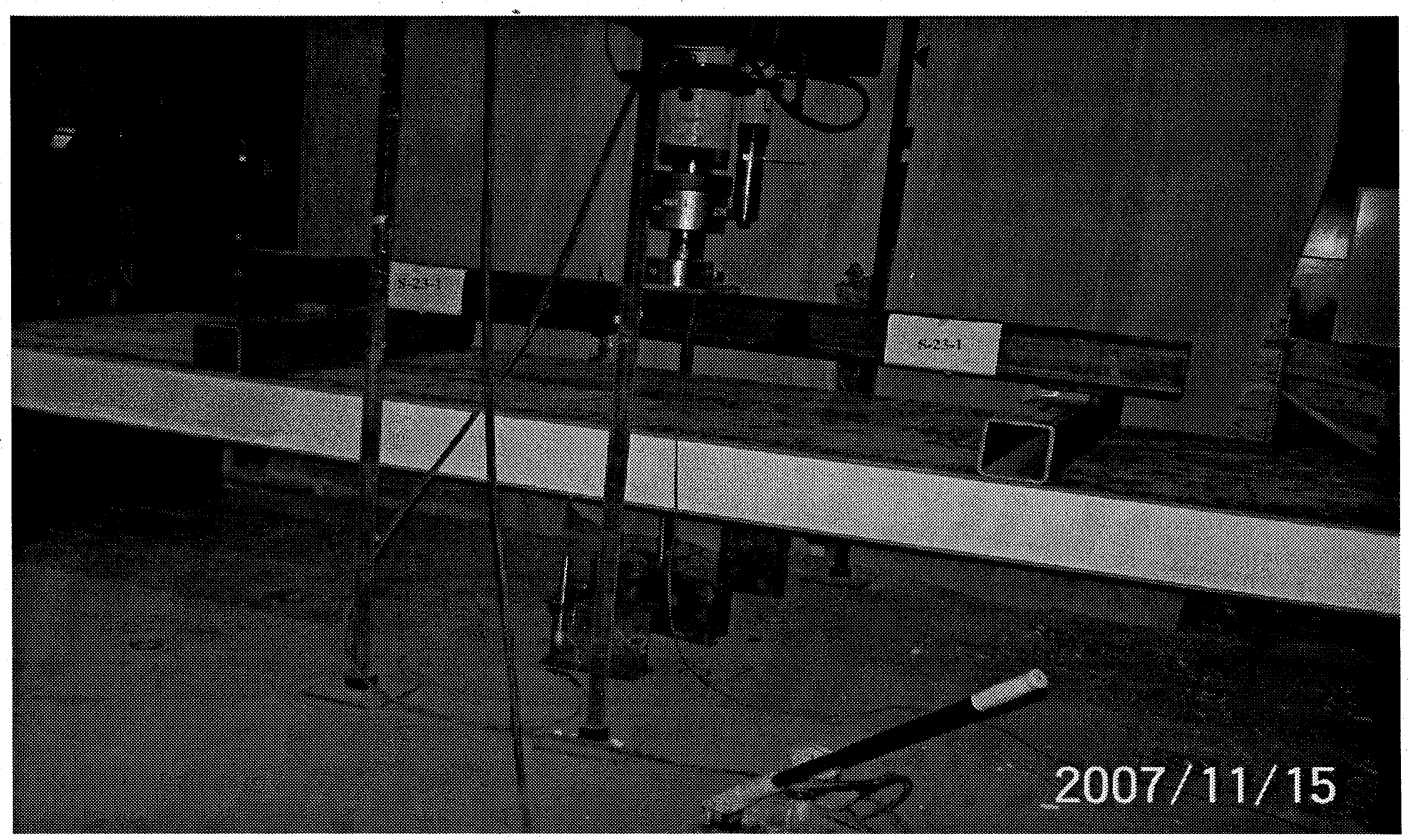

Figure AI-112-1. View of Specimen S-23 before testing

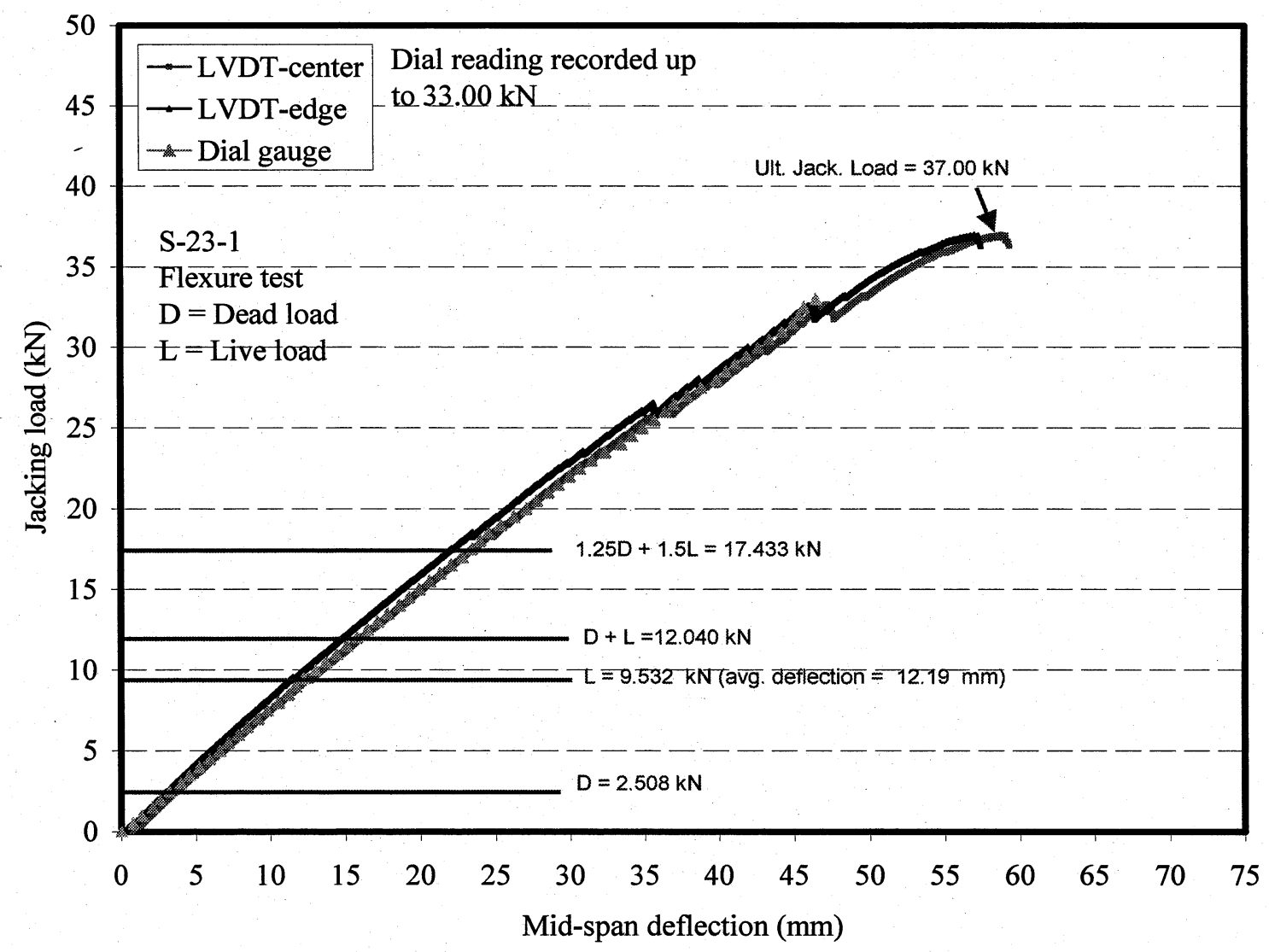

Figure AI-113-1. Load-deflection relationship for specimen S-23 


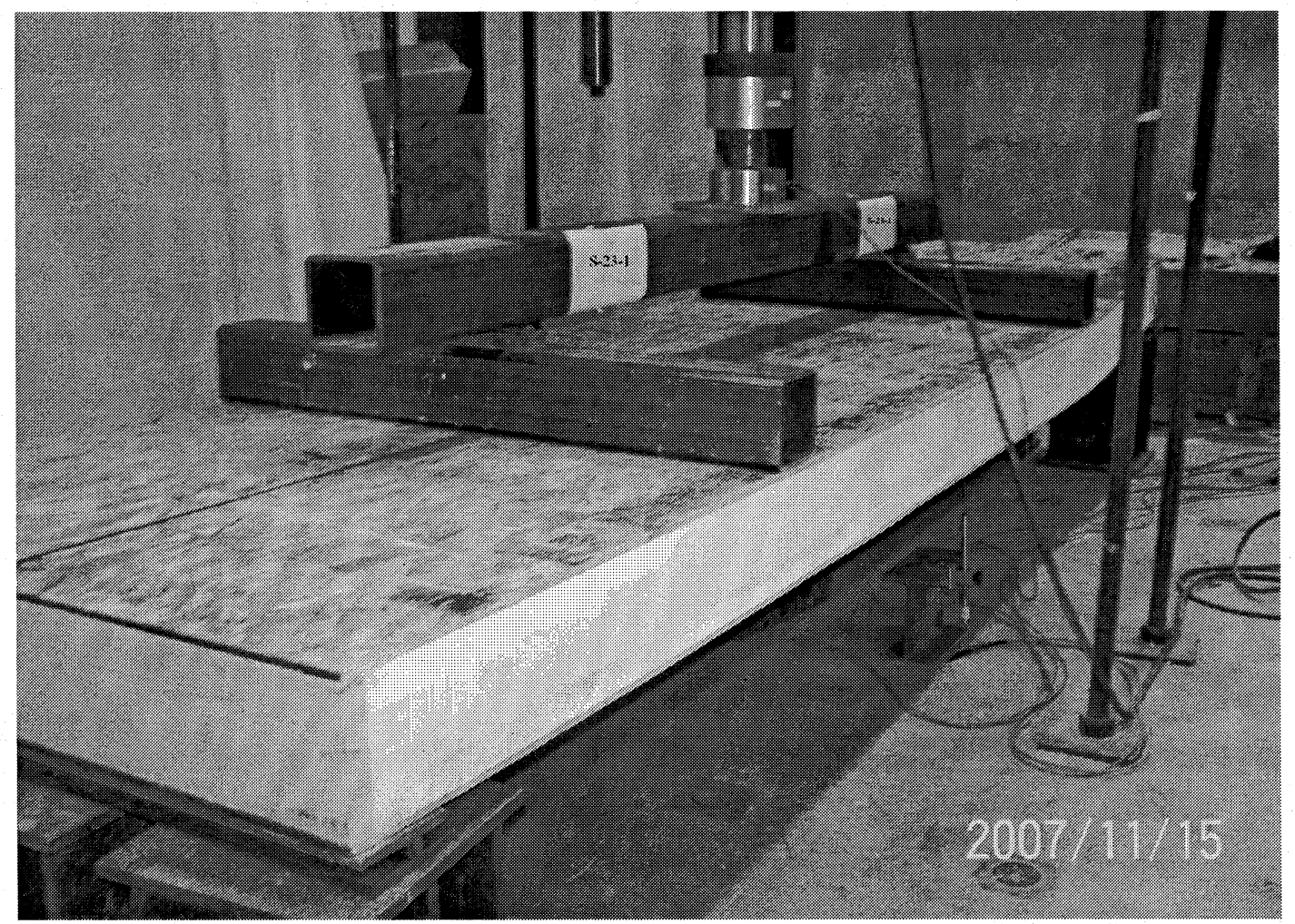

Figure AI-114-1. View of specimen S-23 after failure

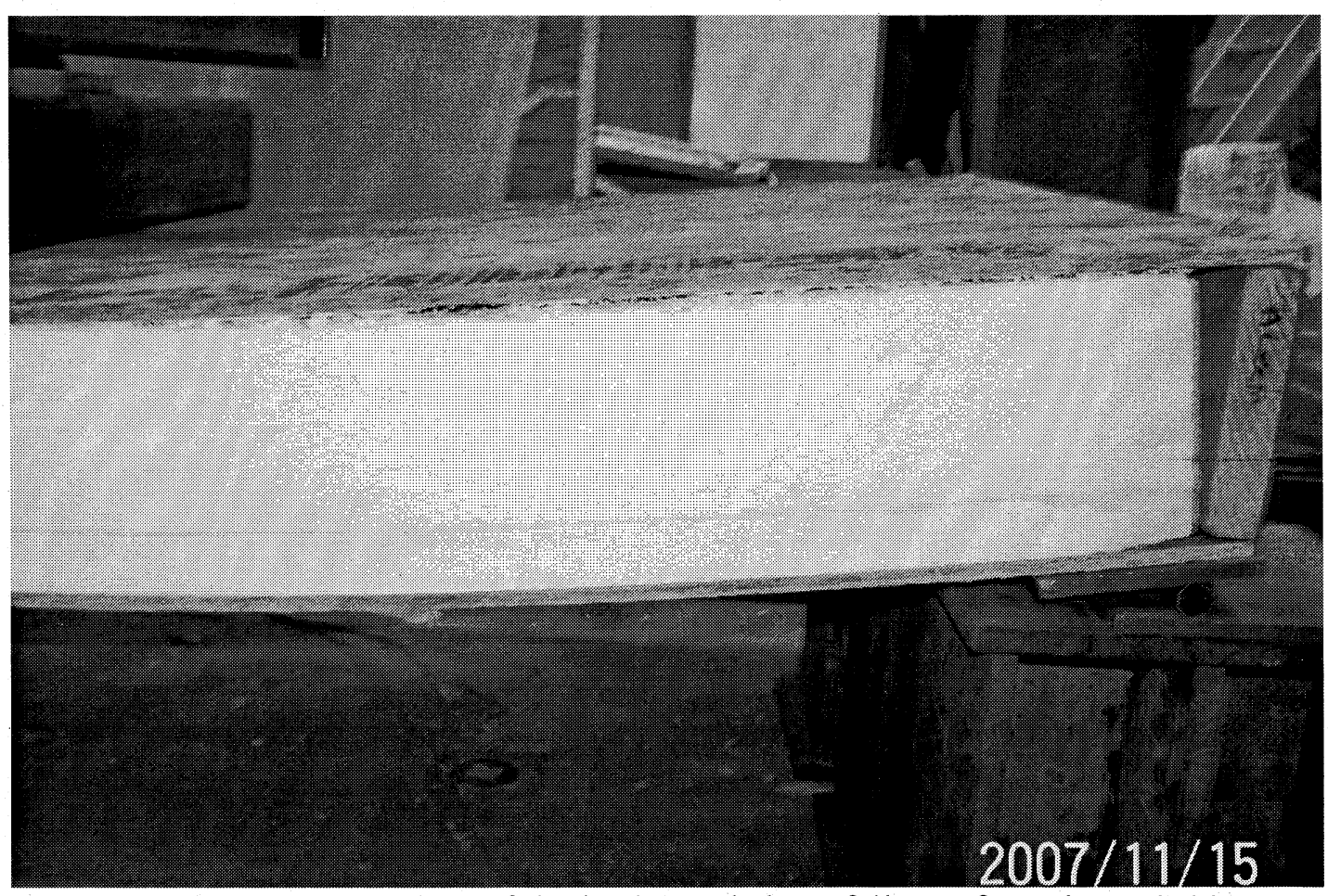

Figure AI-115-1. View of the horizontal shear failure of specimen S-23 


\section{Specimen \# S-24}

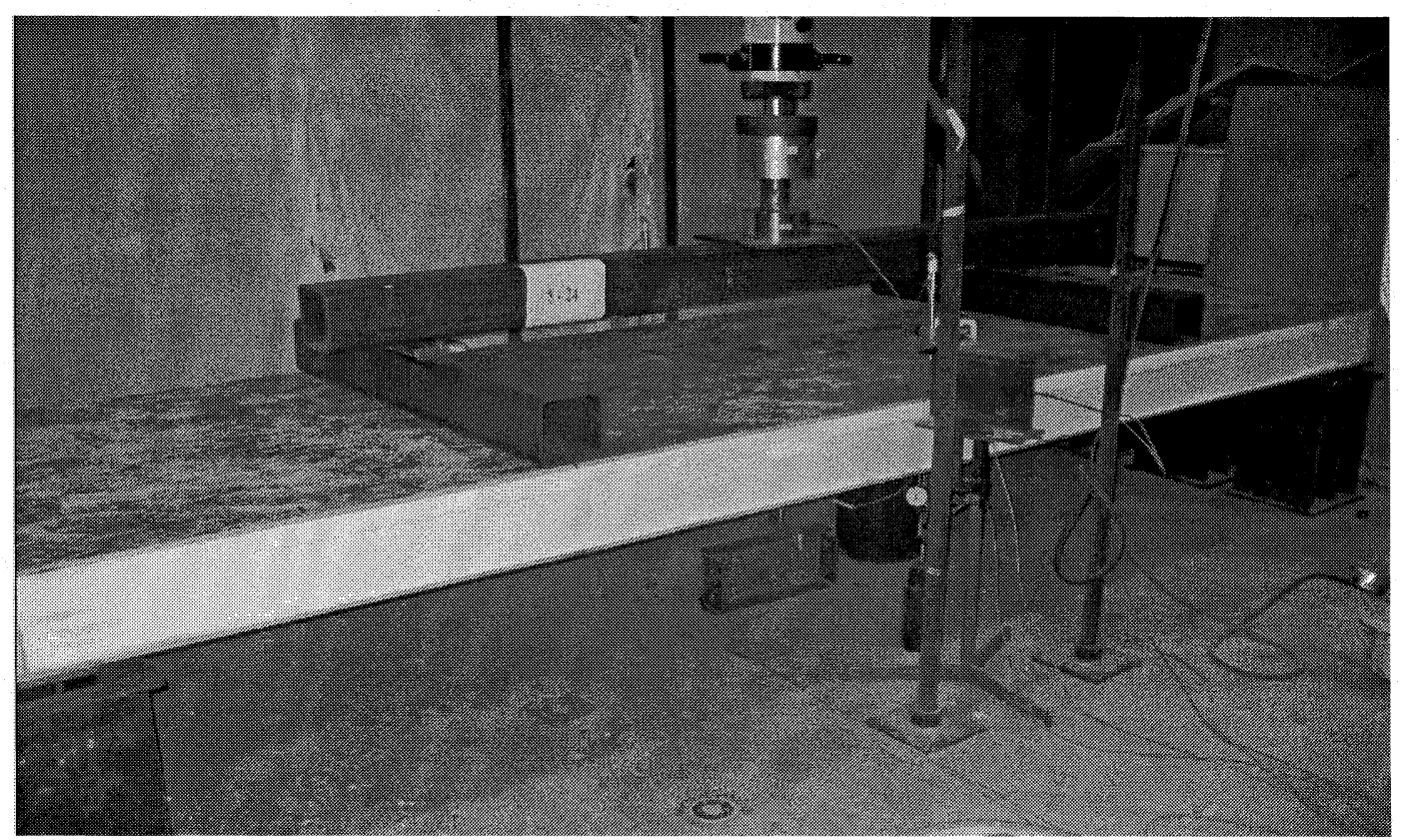

Figure AI-116. View of Specimen S-24 before testing

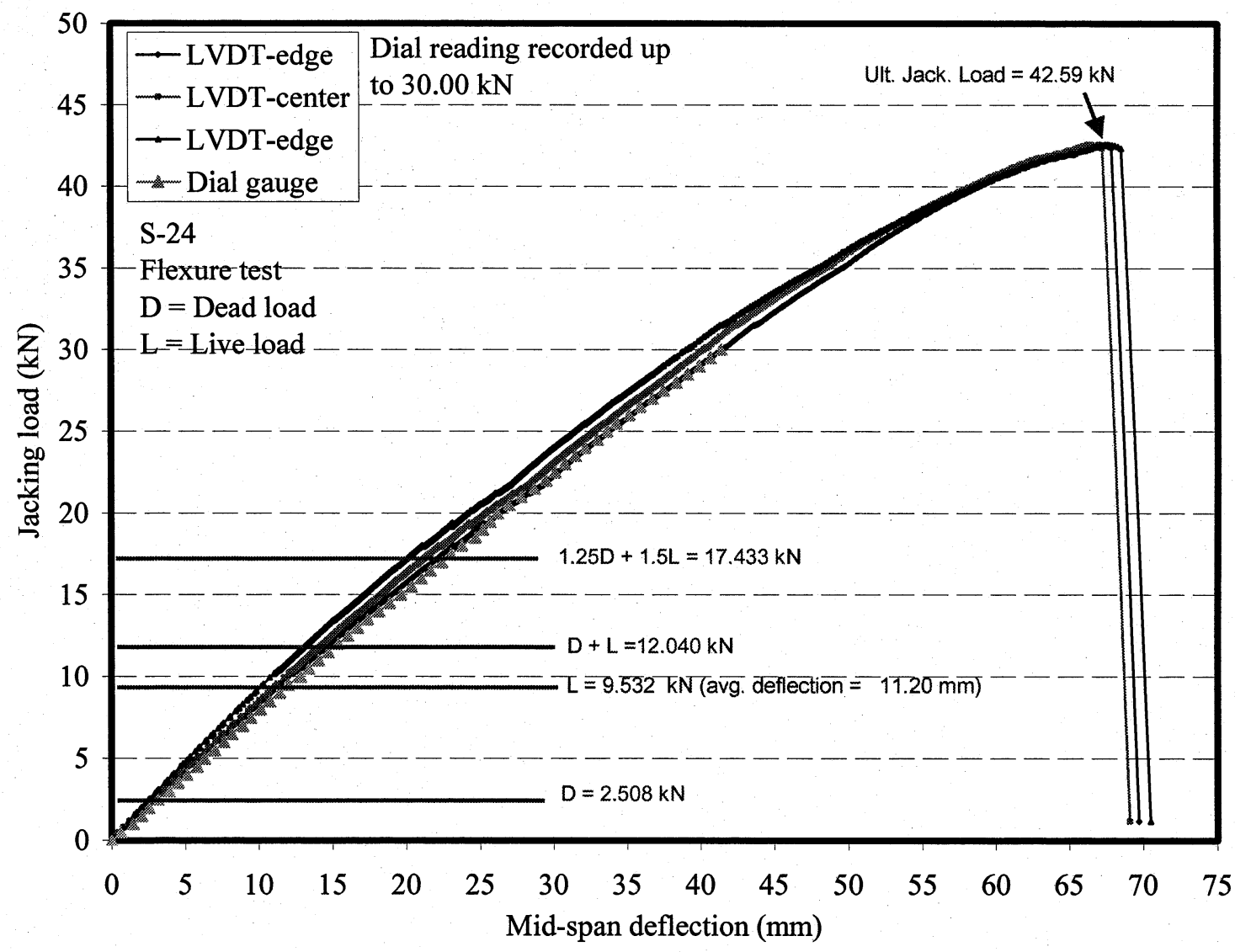

Figure AI-117. Load-deflection relationship for specimen S-24 


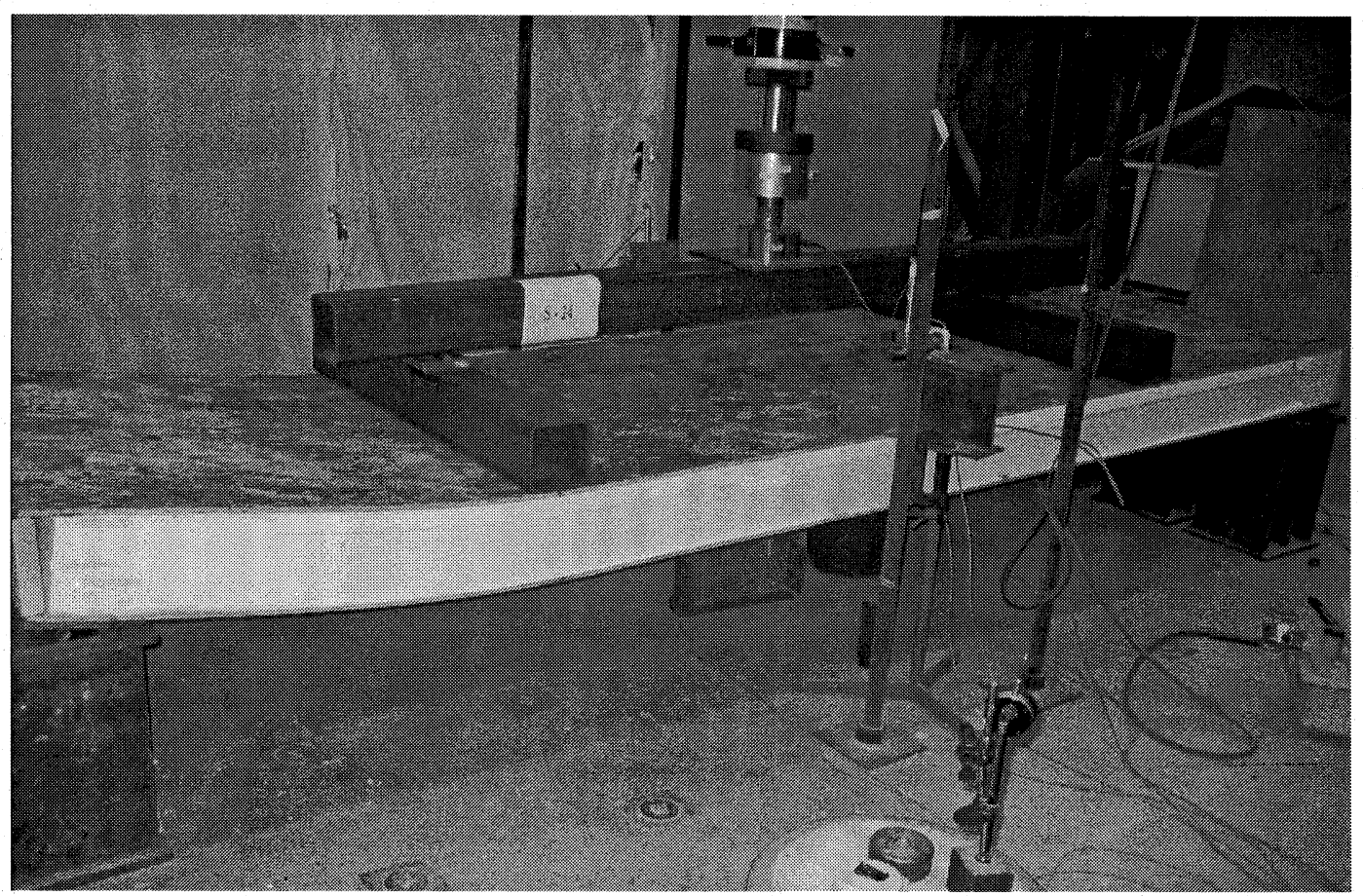

Figure AI-118. View of specimen S-24 after failure

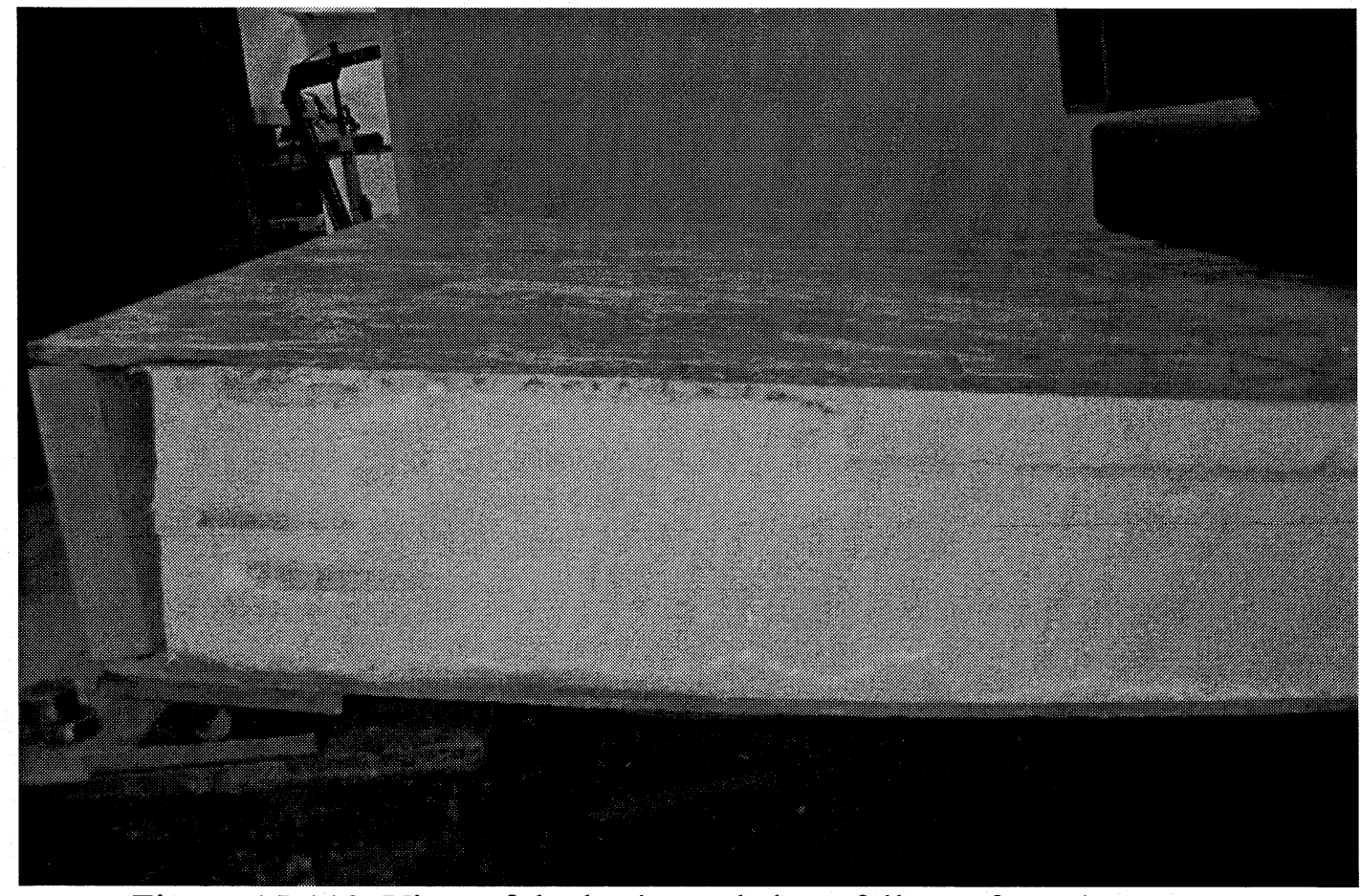

Figure AI-119. View of the horizontal shear failure of specimen S-24 


\section{GROUP-I}

\section{Specimen \# S-25}

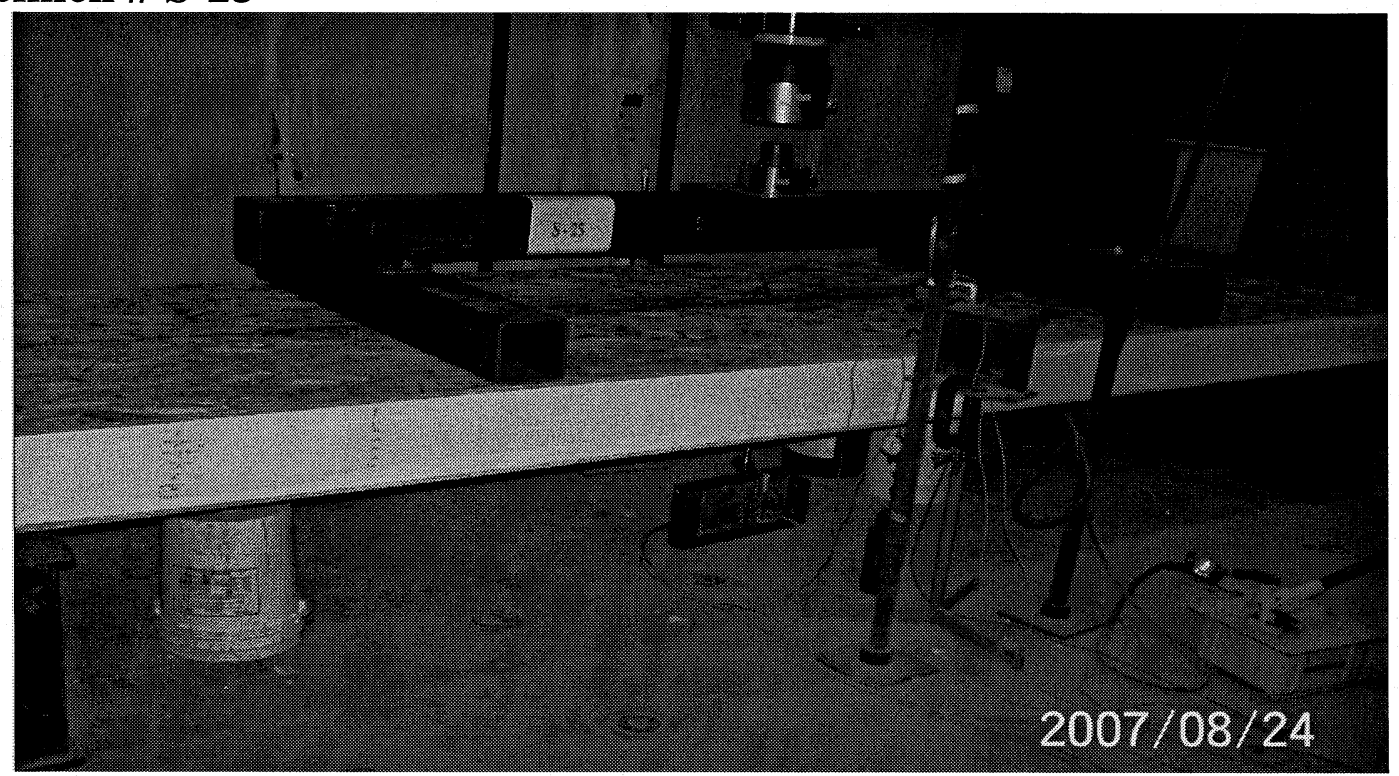

Figure AI-120. View of Specimen S-25 before testing

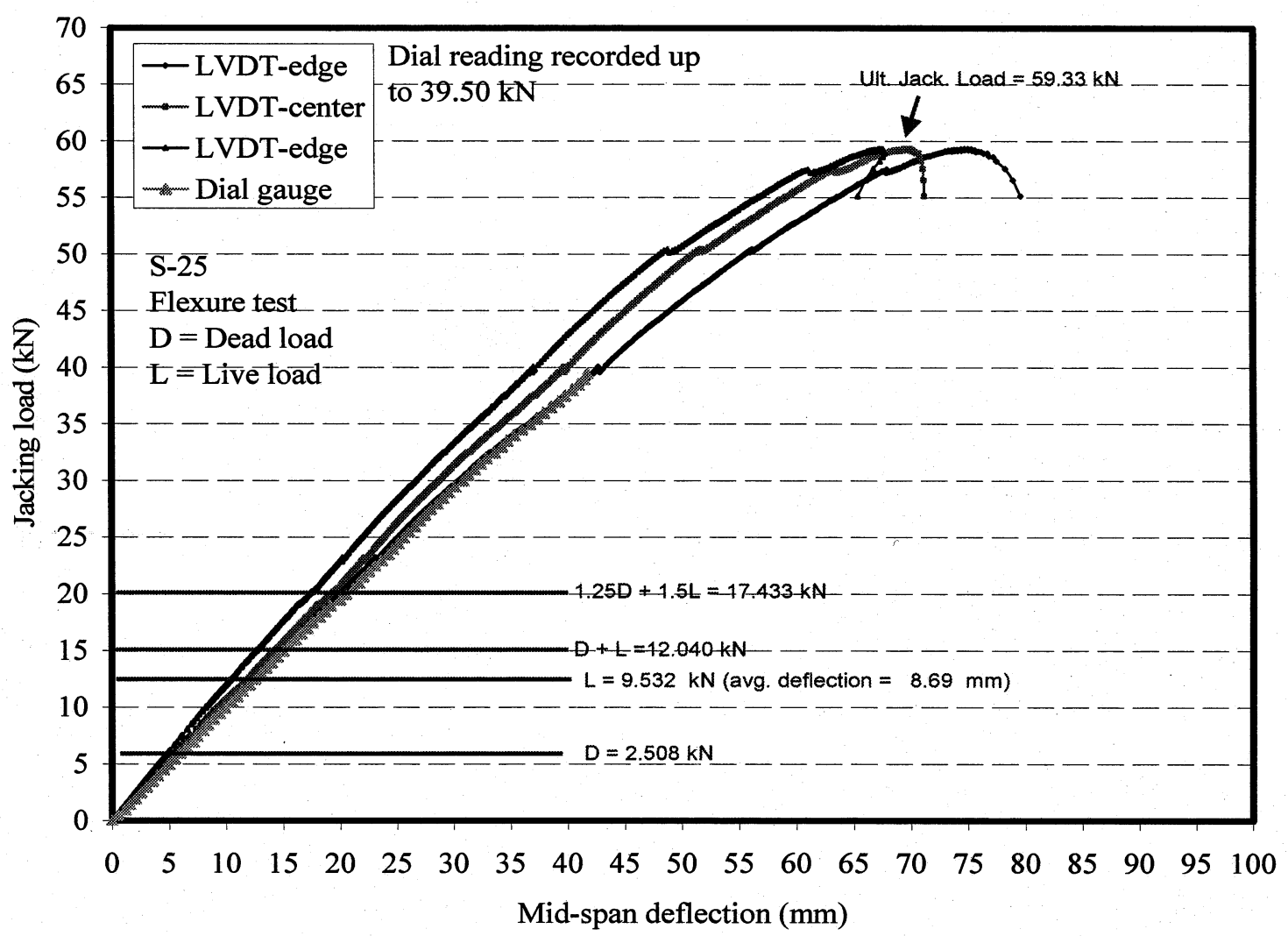

Figure AI-121. Load-deflection relationship for specimen S-25 


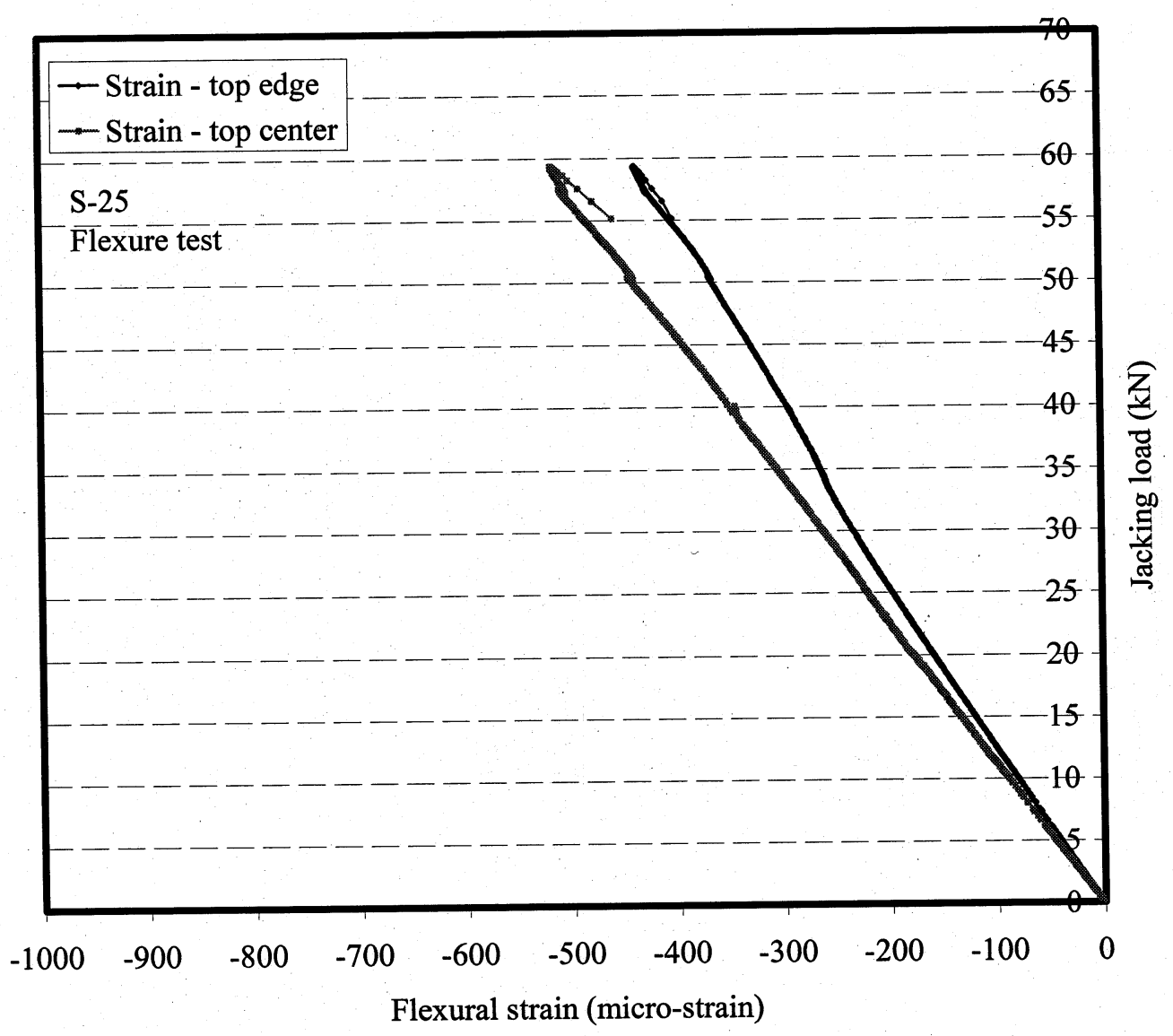

Figure AI-122. Load-strain relationship for specimen S-25

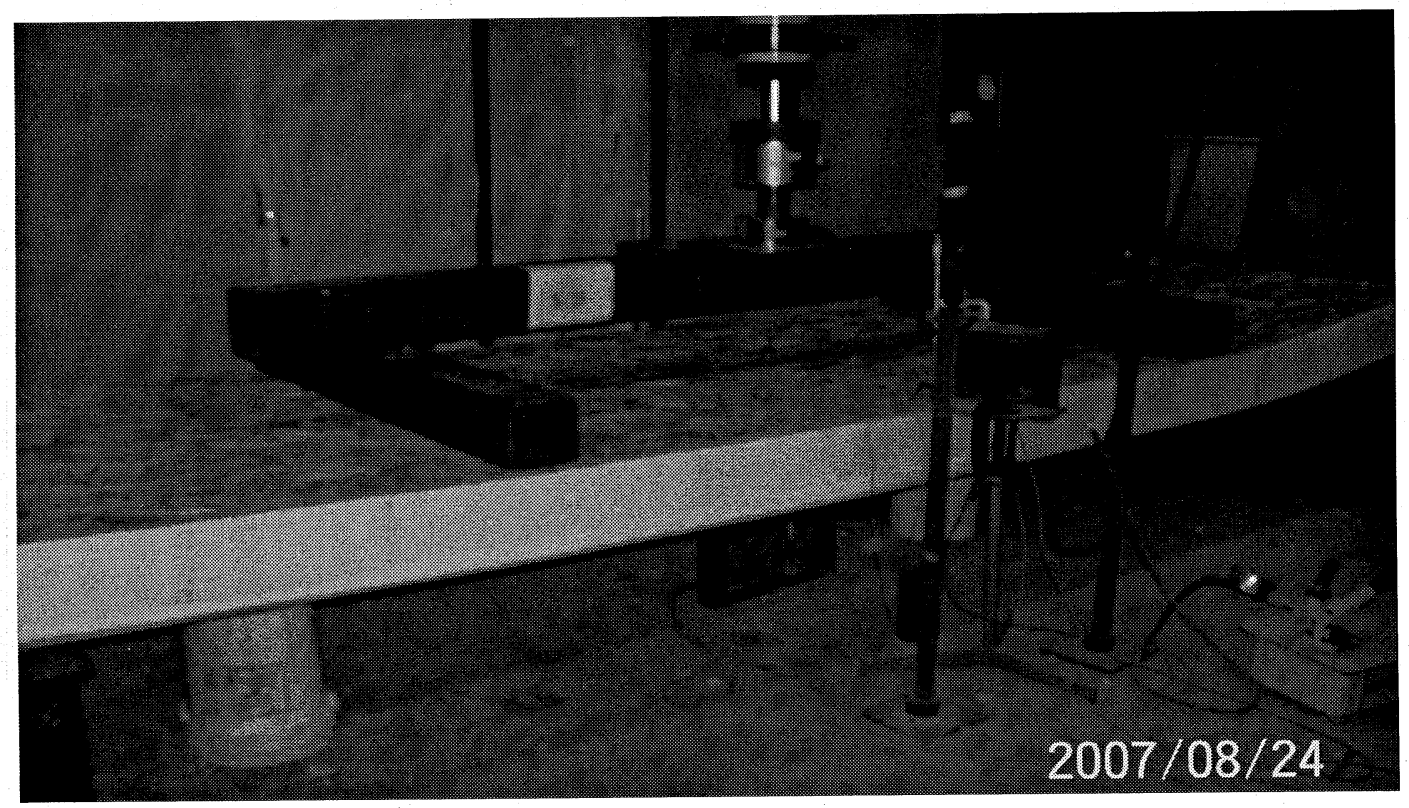

Figure AI-123. View of specimen S-25 after failure 


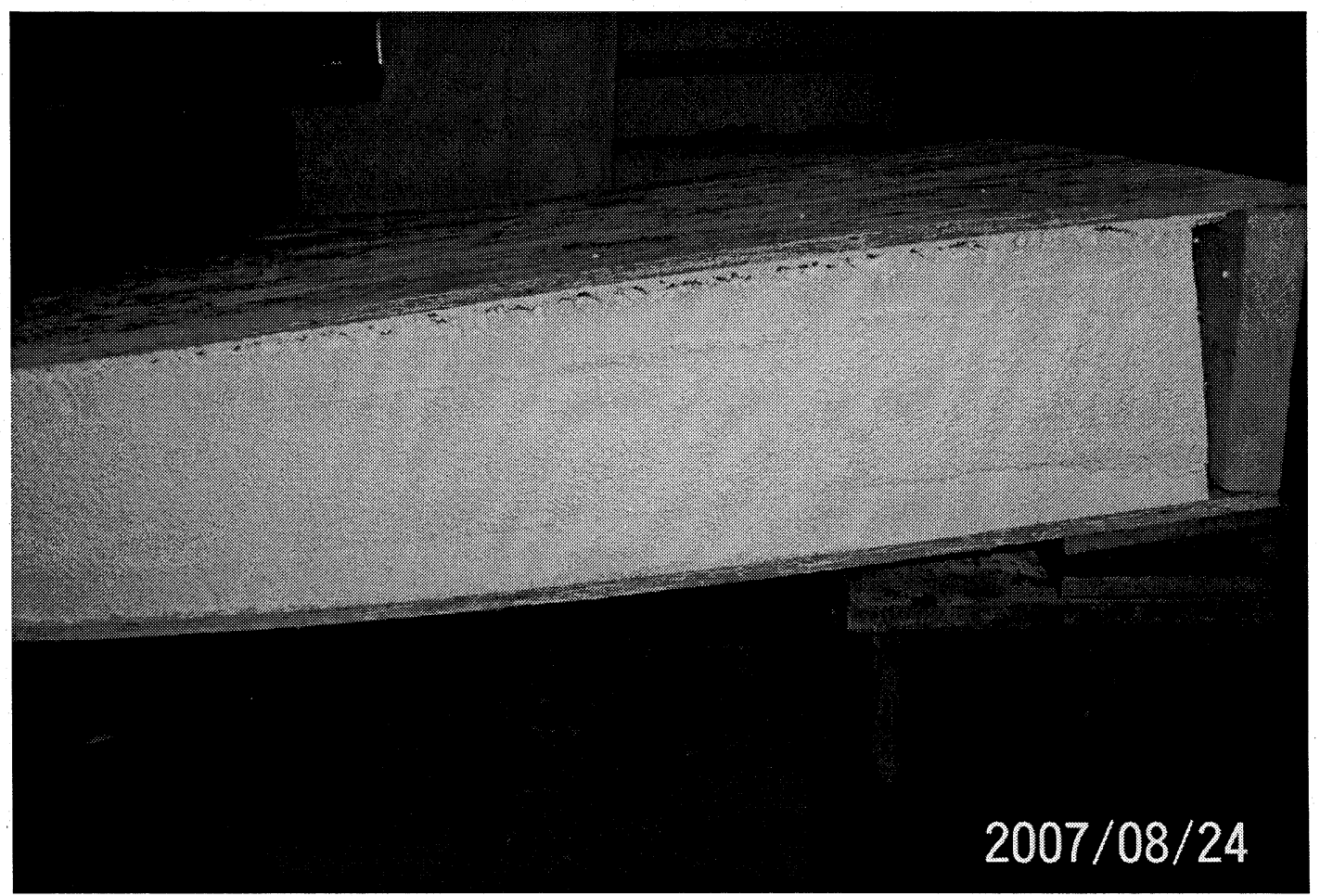

Figure AI-124. View of the horizontal shear failure of specimen S-25

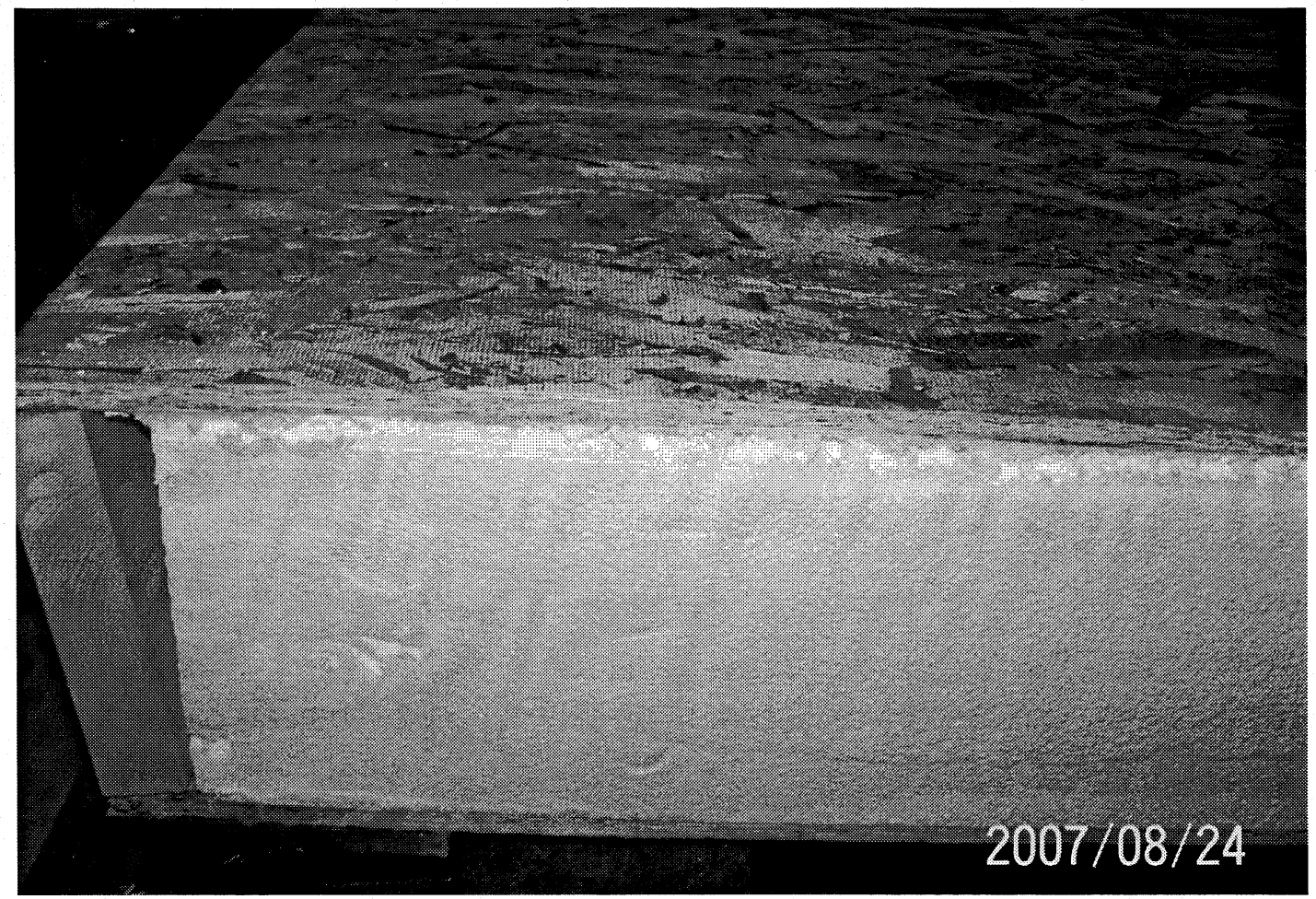

Figure AI-125 View of the horizontal shear failure on the other free edge of specimen S-25 


\section{Specimen S-26}

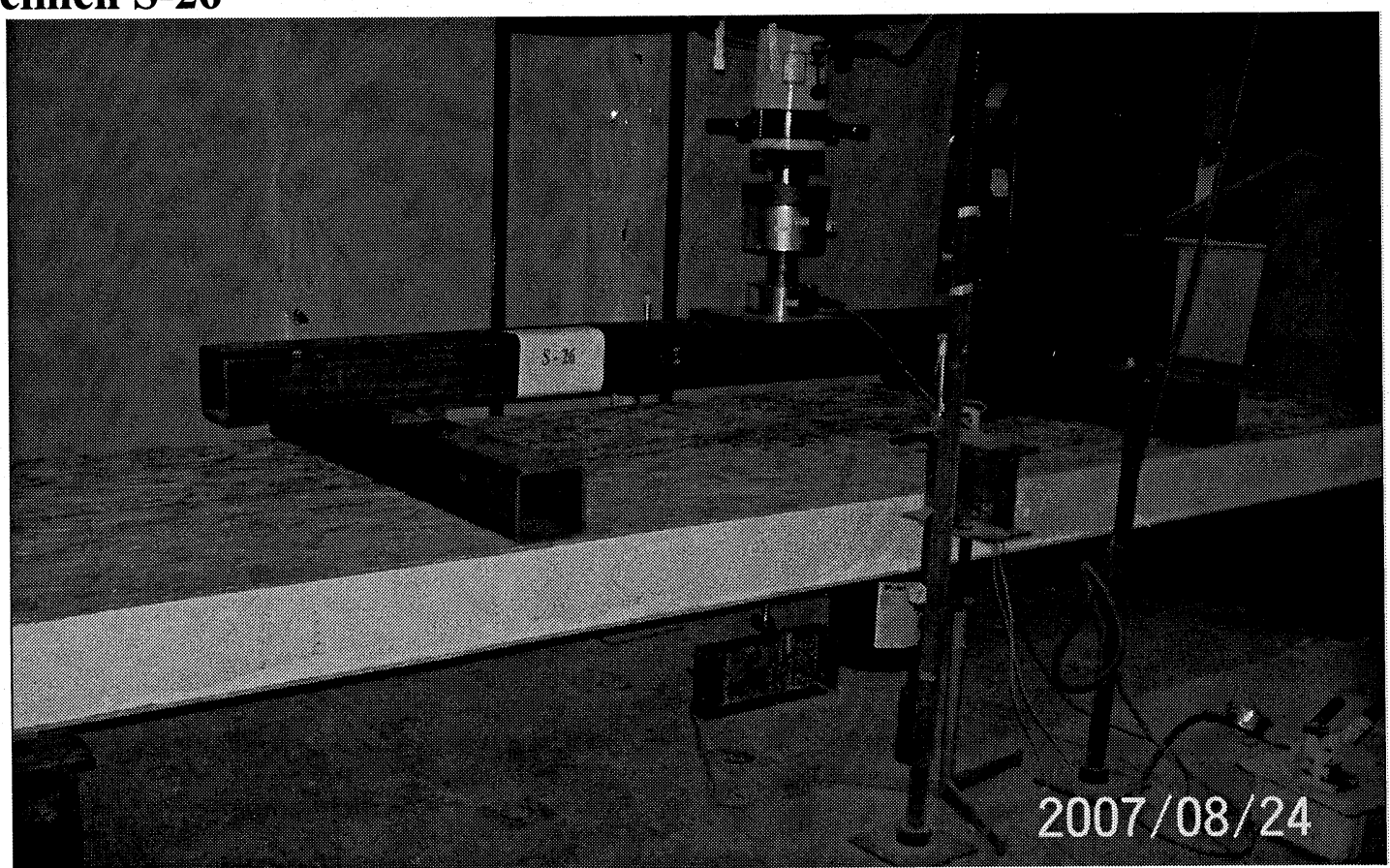

Figure AI-126. View of Specimen S-26 before testing

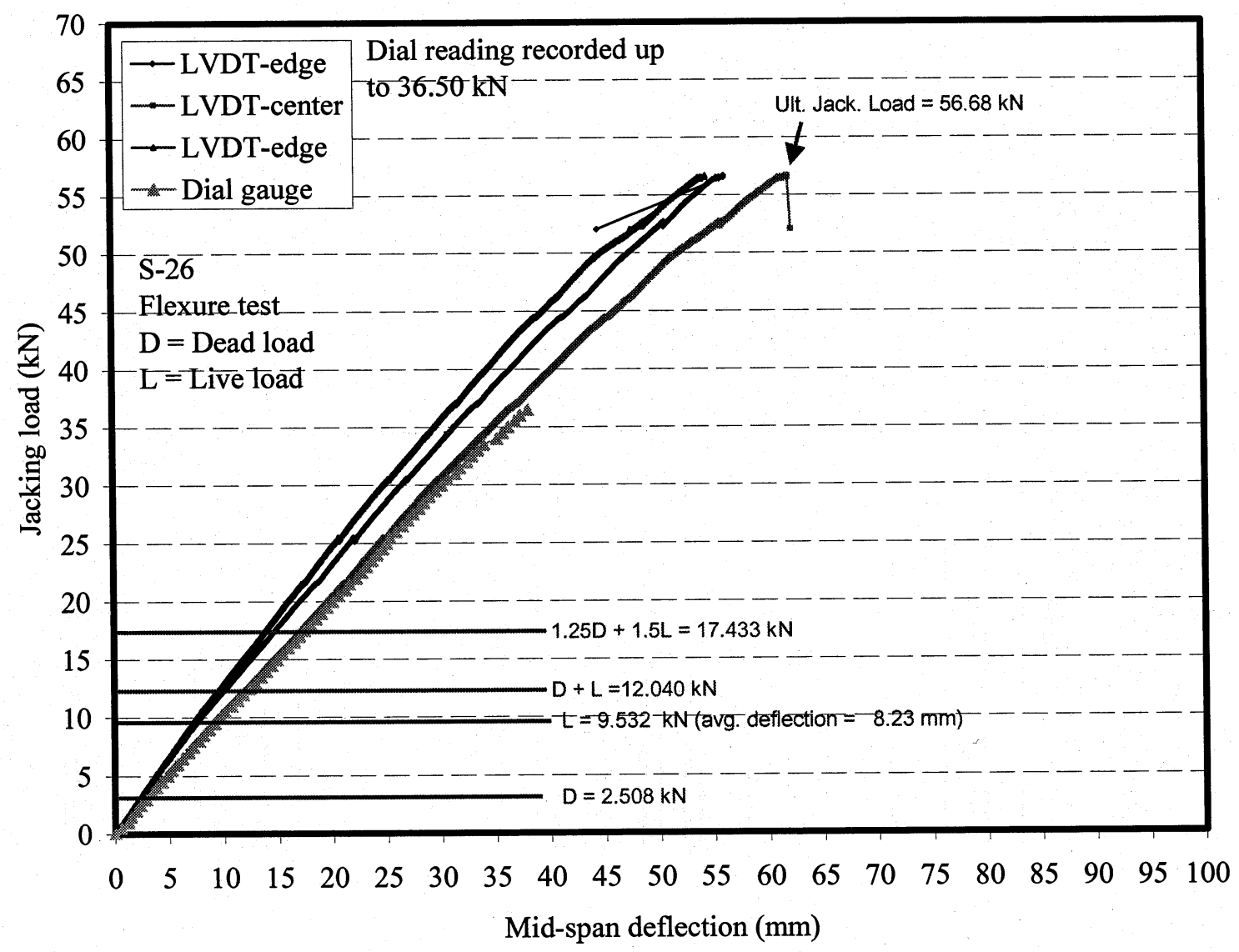

Figure AI-127. Load-deflection relationship for specimen S-26 


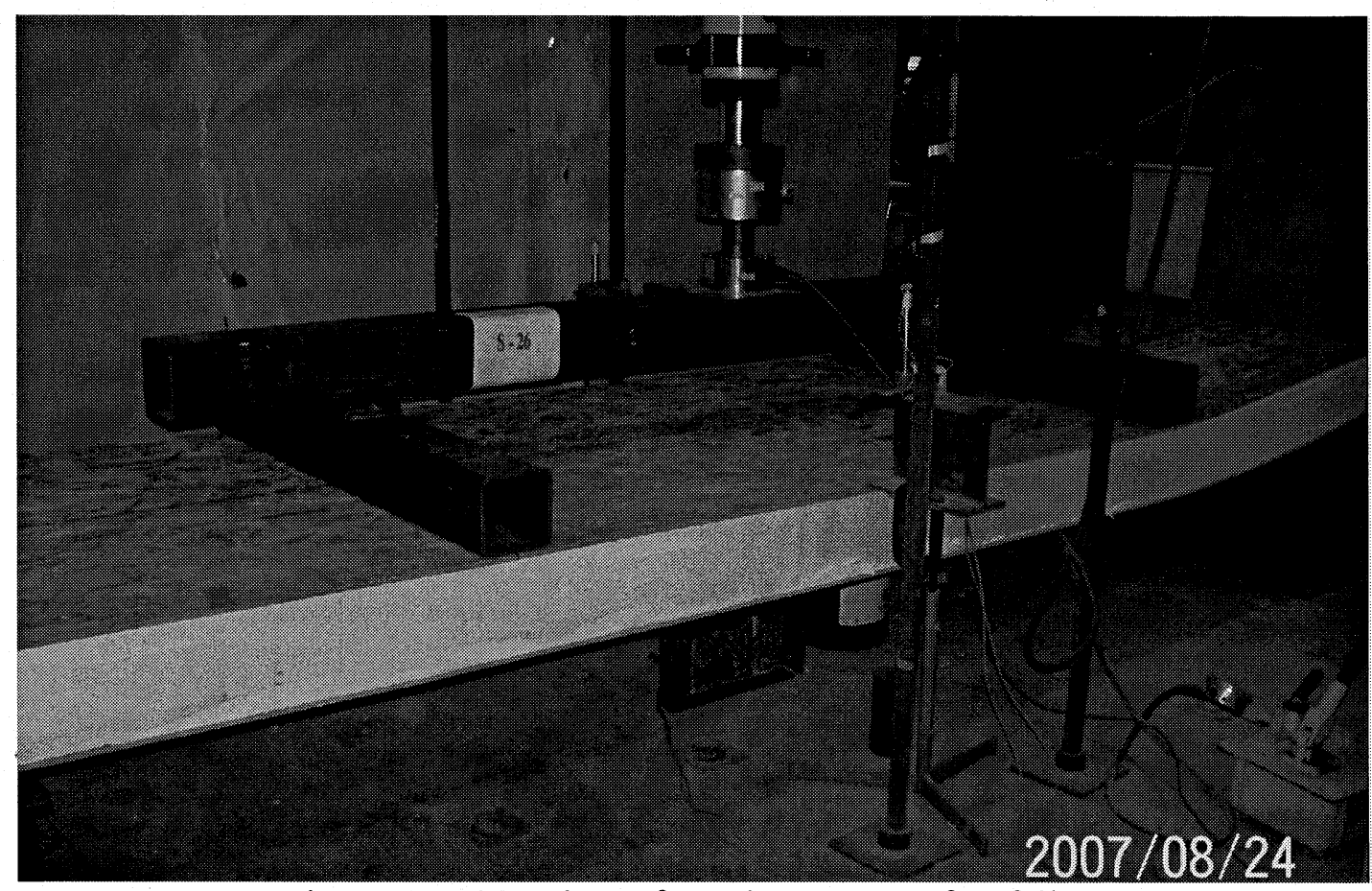

Figure AI-128. View of specimen S-26 after failure

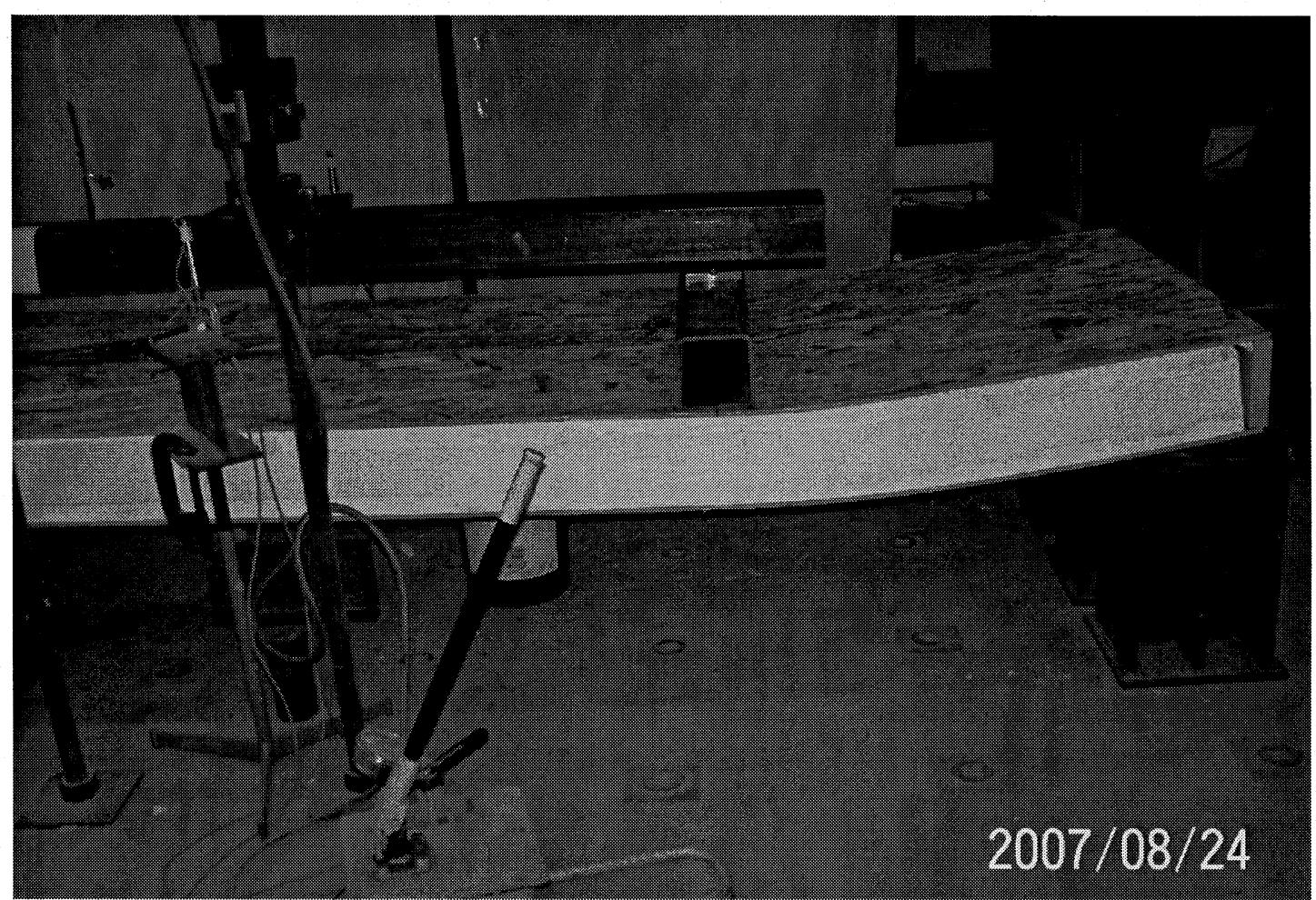

Figure AI-129. View of the horizontal shear failure of specimen S-26 


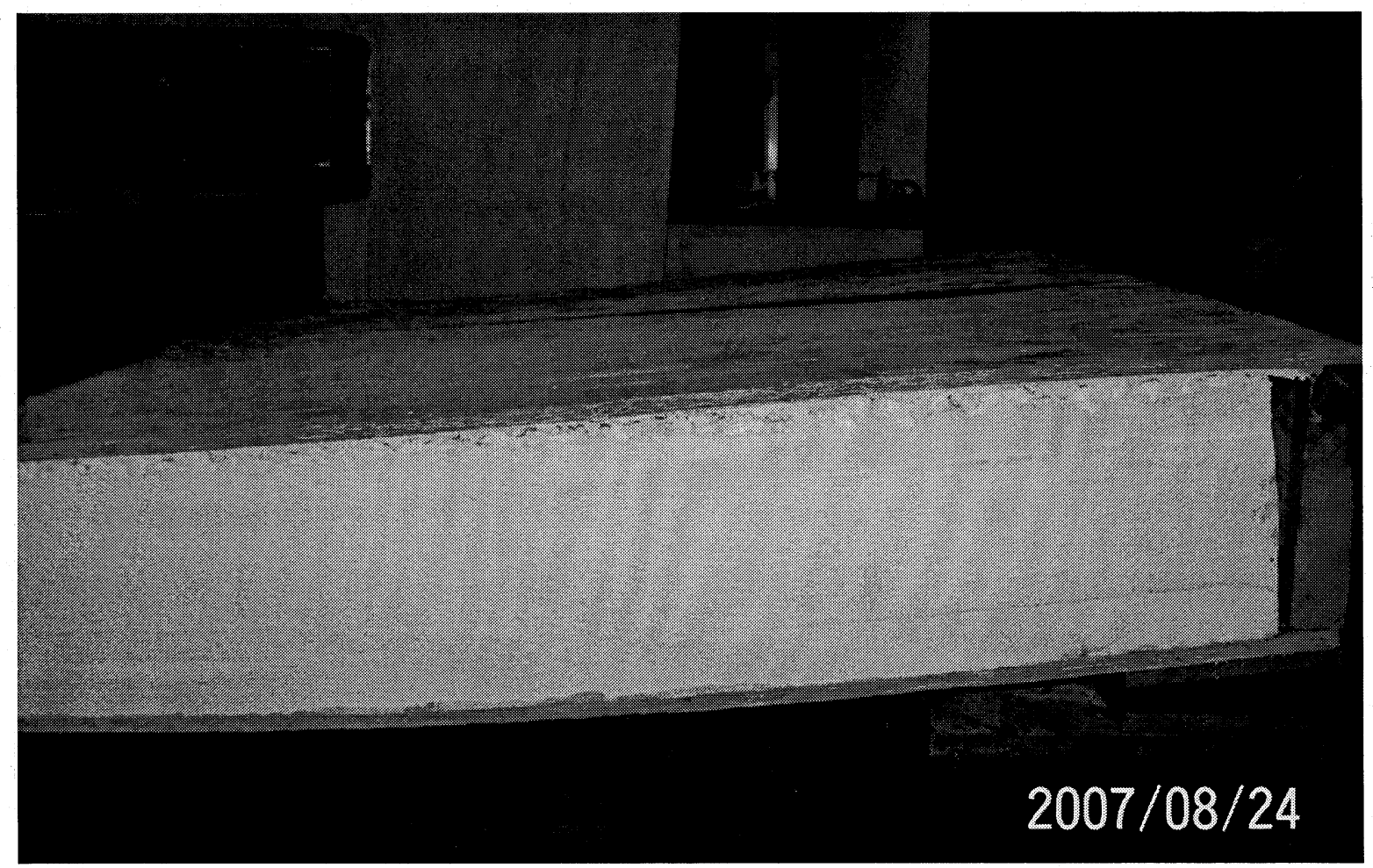

Figure AI-130. View of the horizontal shear failure of specimen S-26 


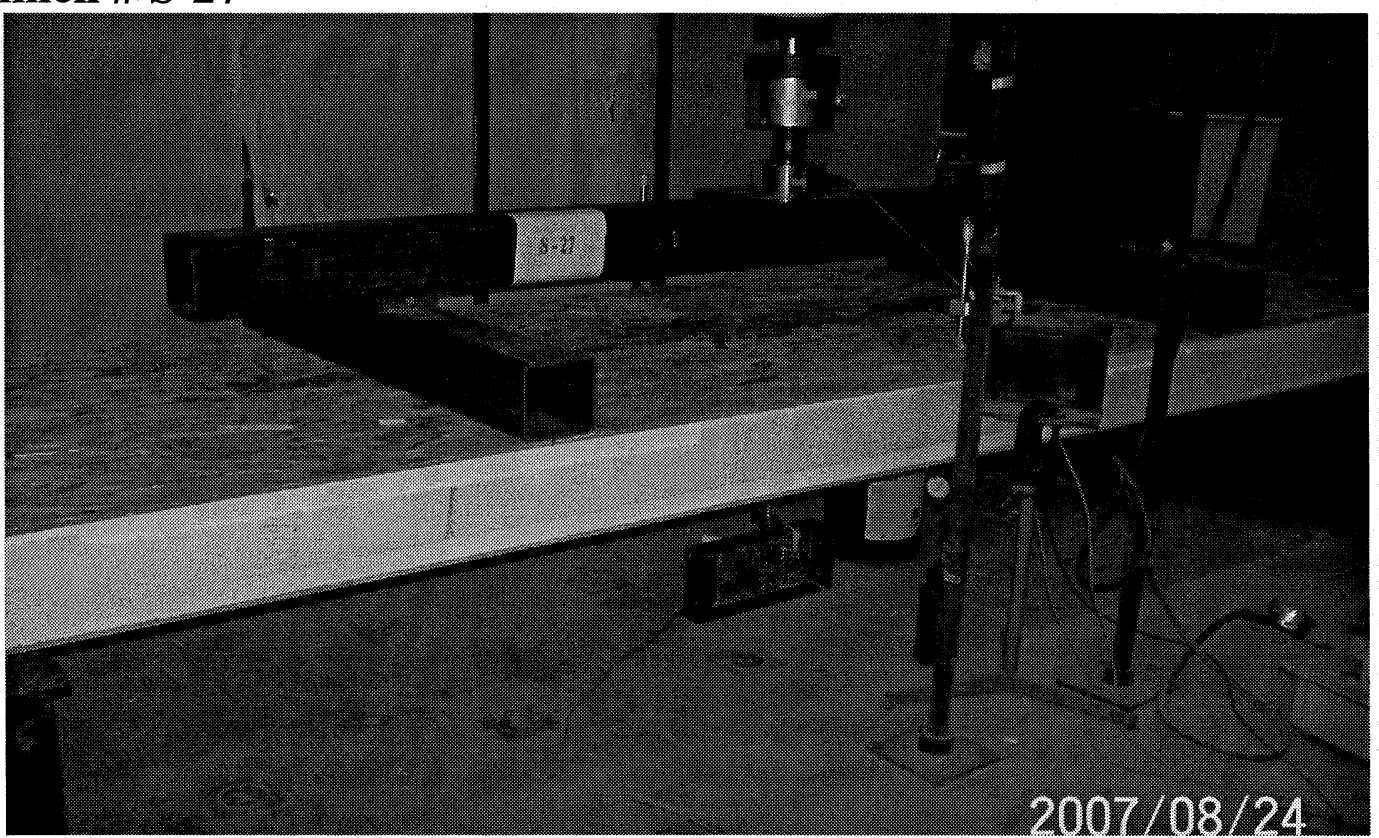

Figure AI-131. View of Specimen S-27 before testing

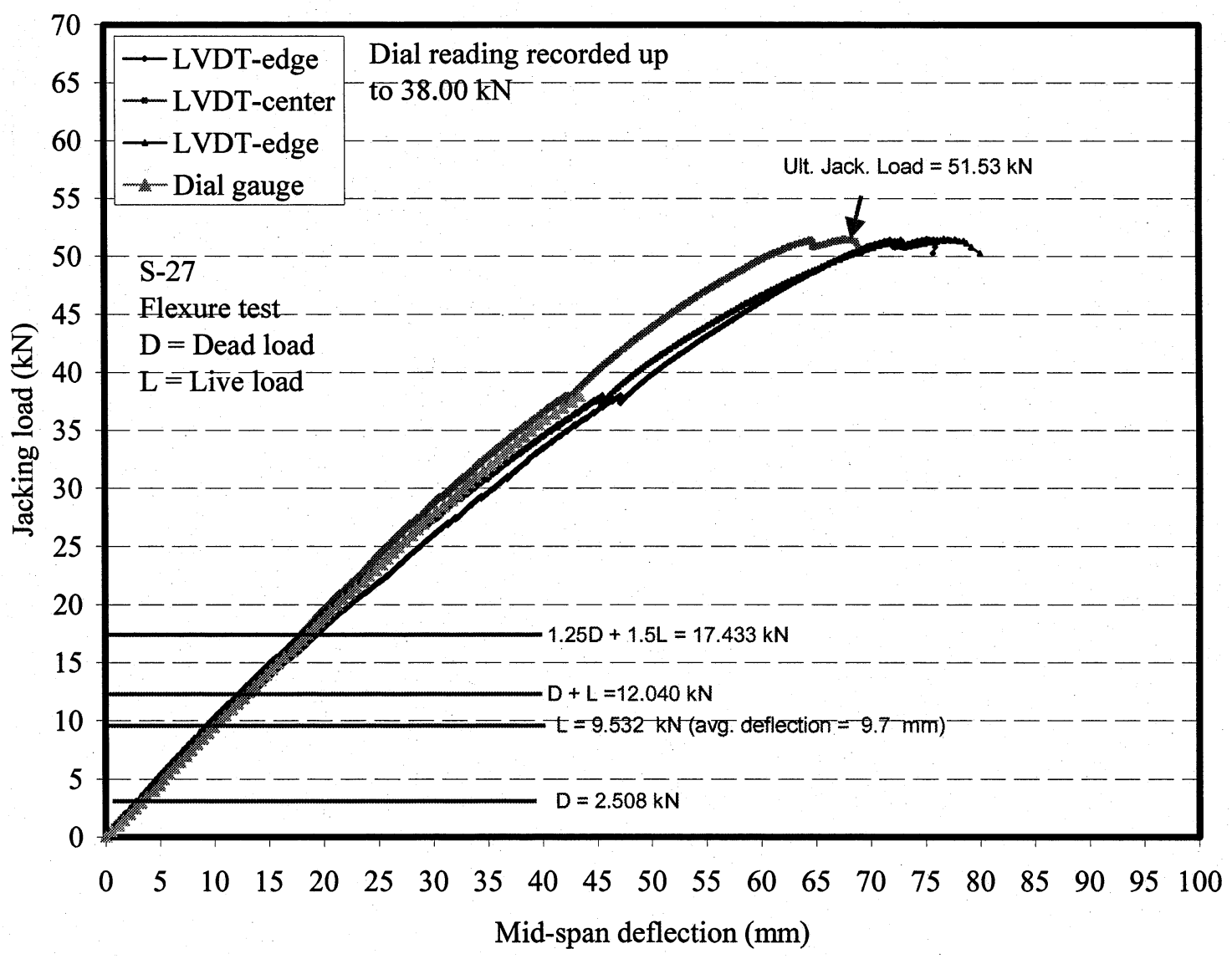

Figure AI-132. Load-deflection relationship for specimen S-27 


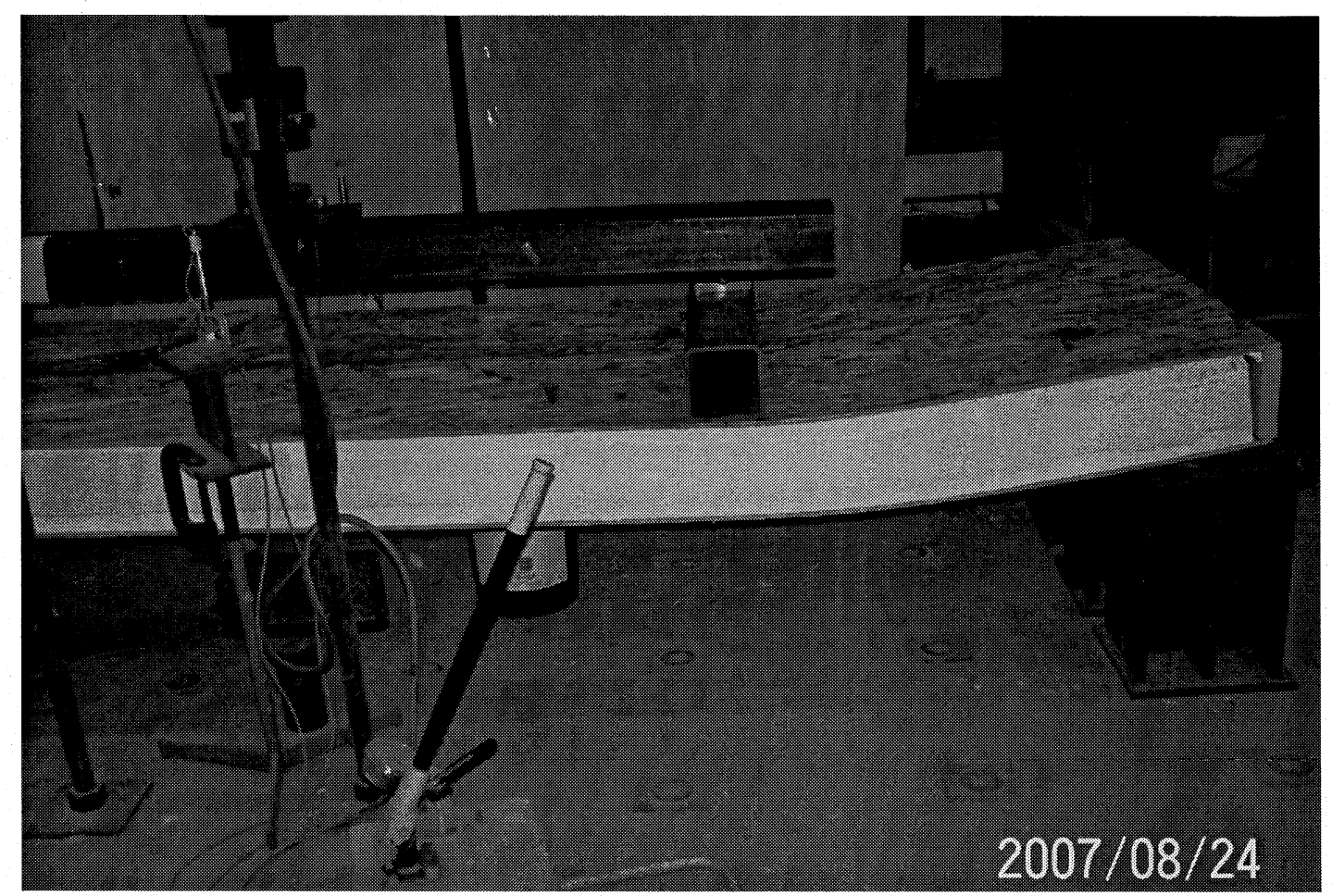

Figure AI-133. View of specimen S-27 after failure

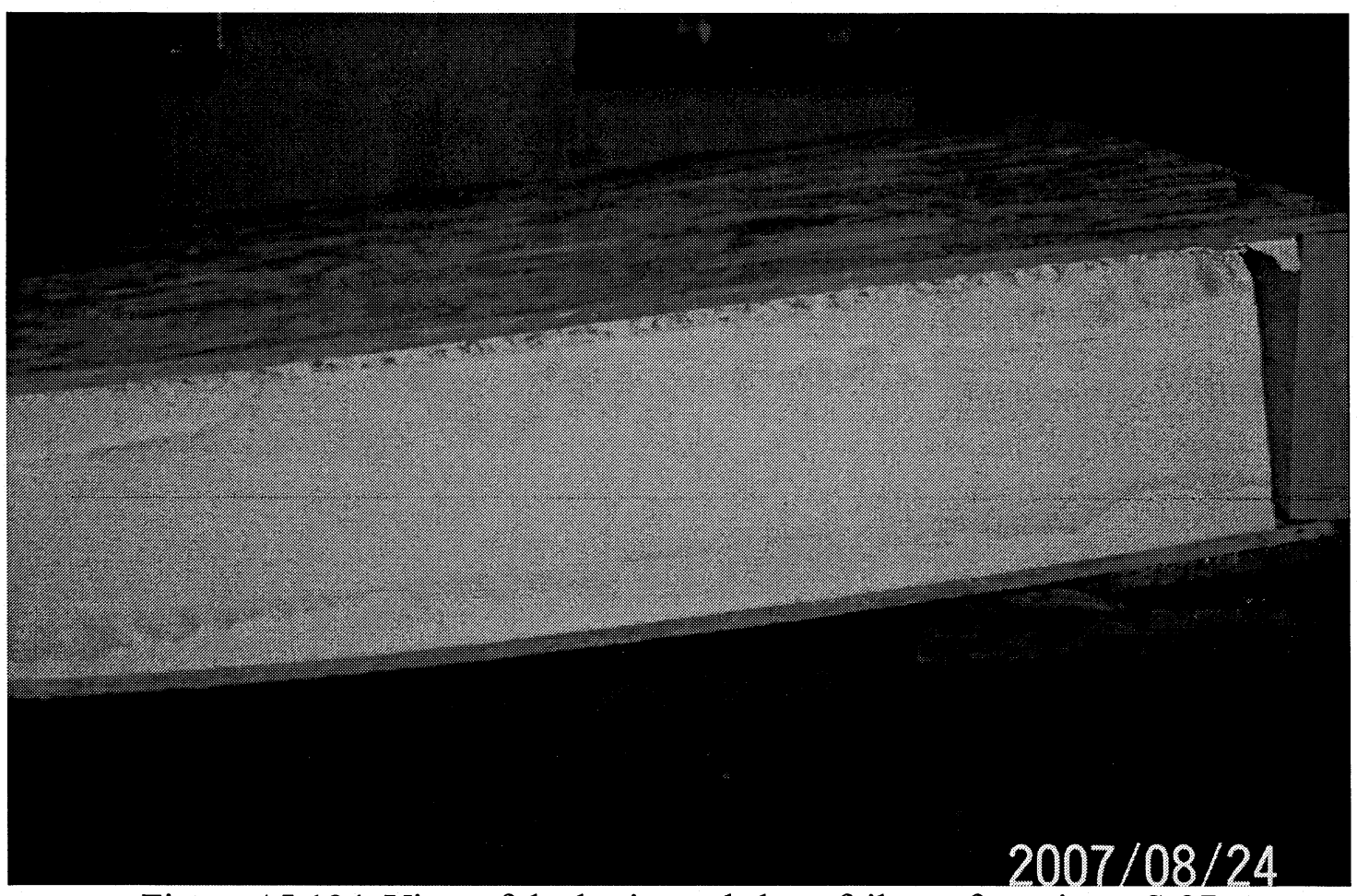

Figure AI-134. View of the horizontal shear failure of specimen S-27 


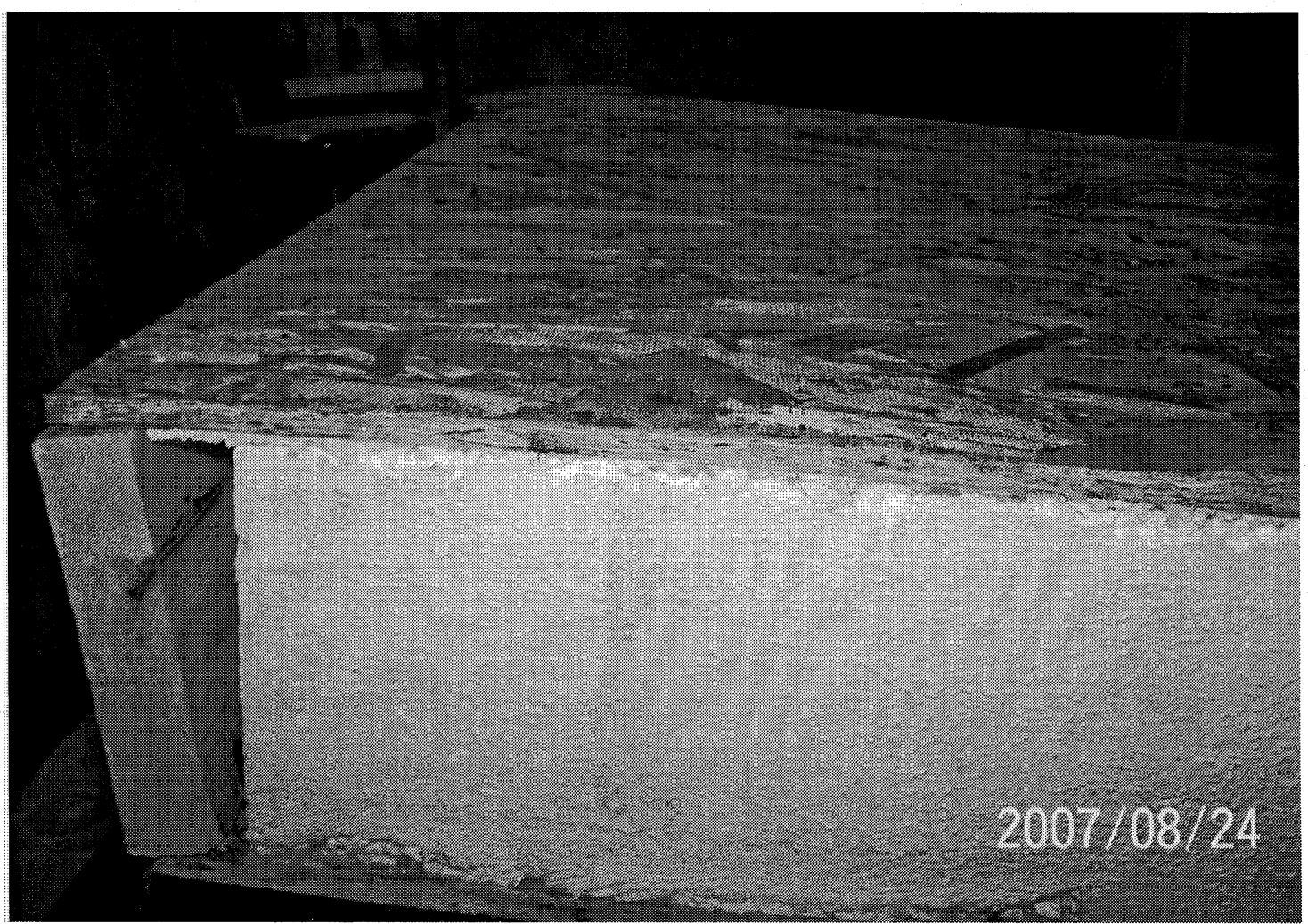

Figure AI-135. View of the horizontal shear failure a the other free edge of specimen S-27 


\section{GROUP J}

\section{Specimen \# S-28}

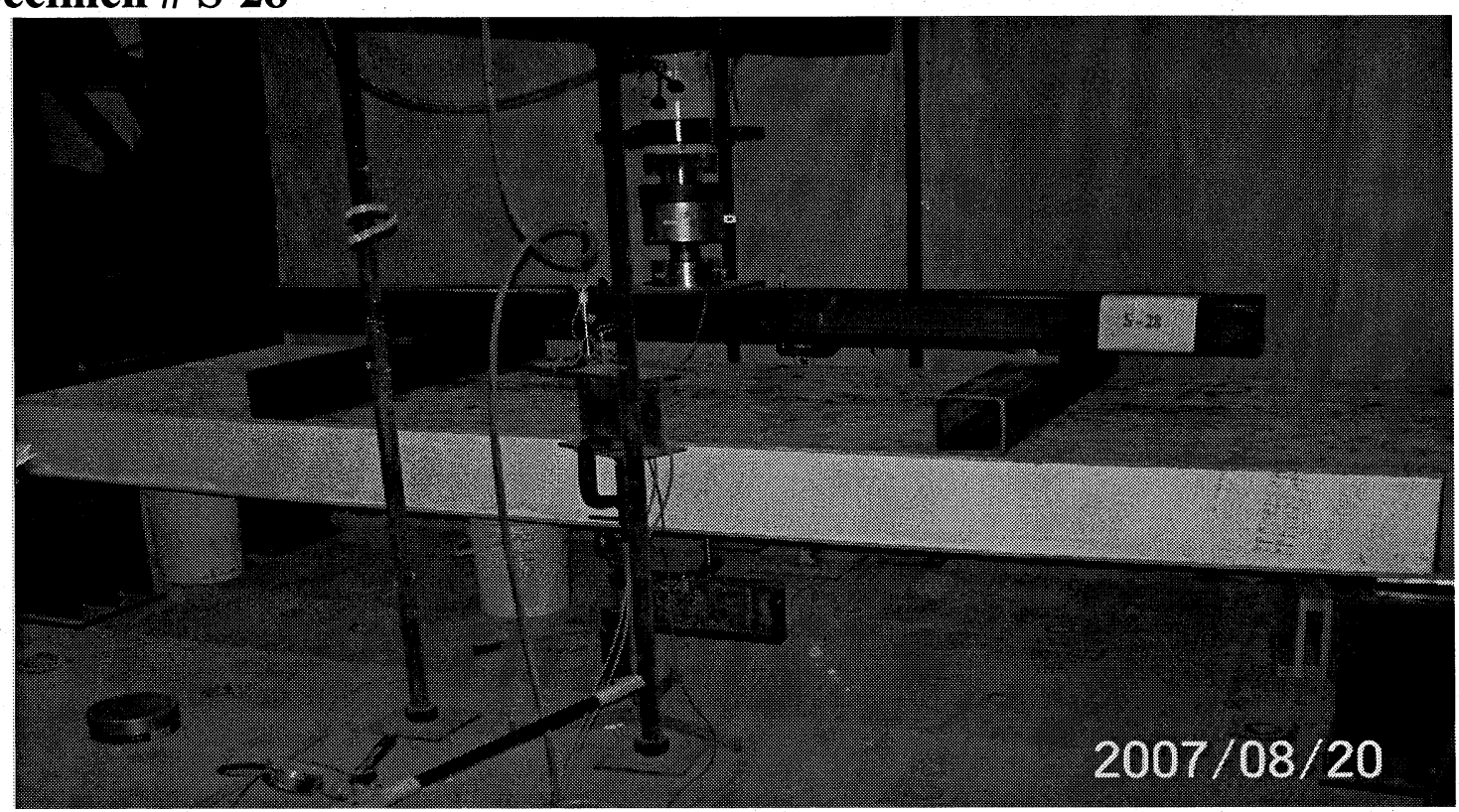

Figure AI-136. View of Specimen S-28 before testing

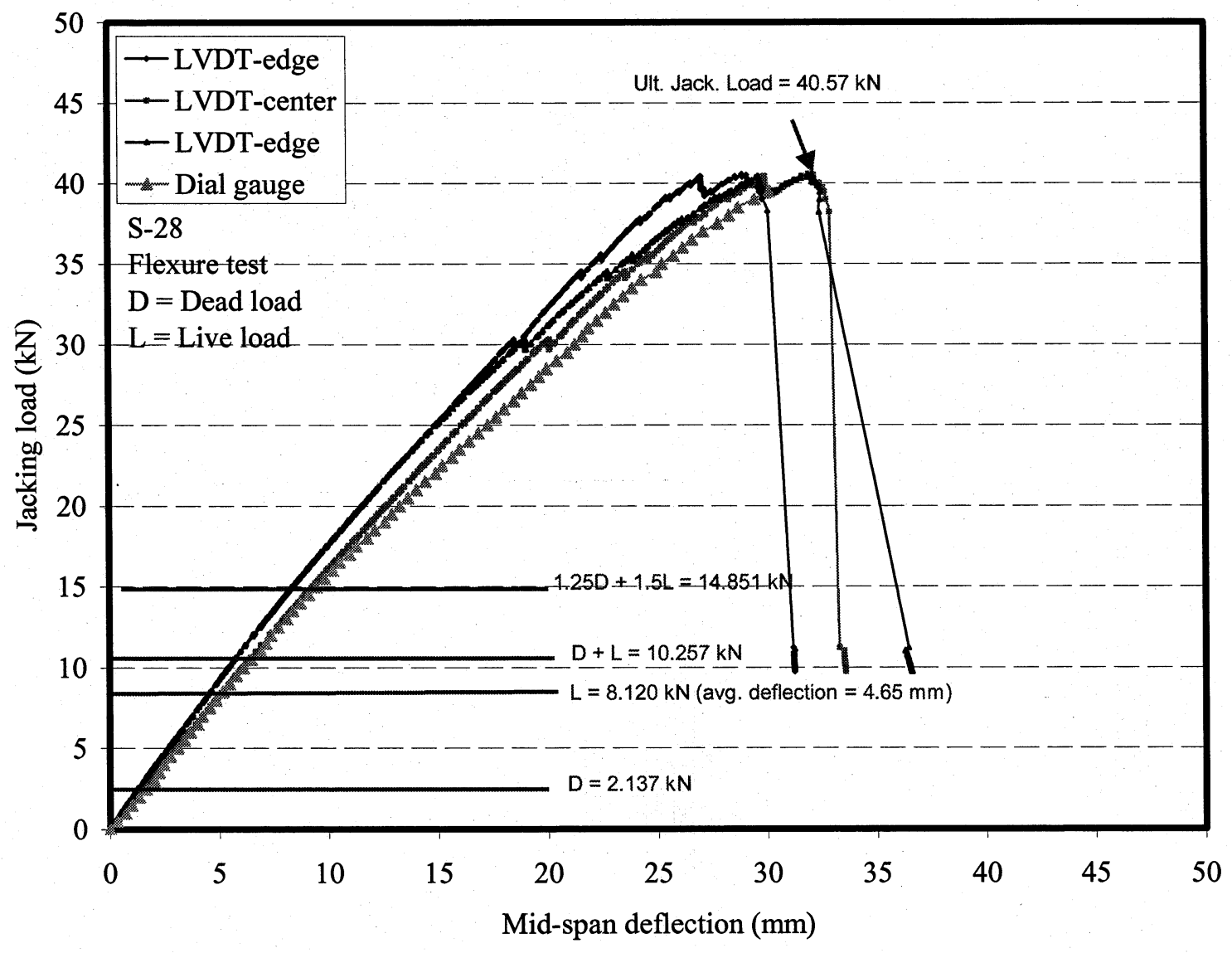

Figure AI-137. Load-deflection relationship for specimen S-28 


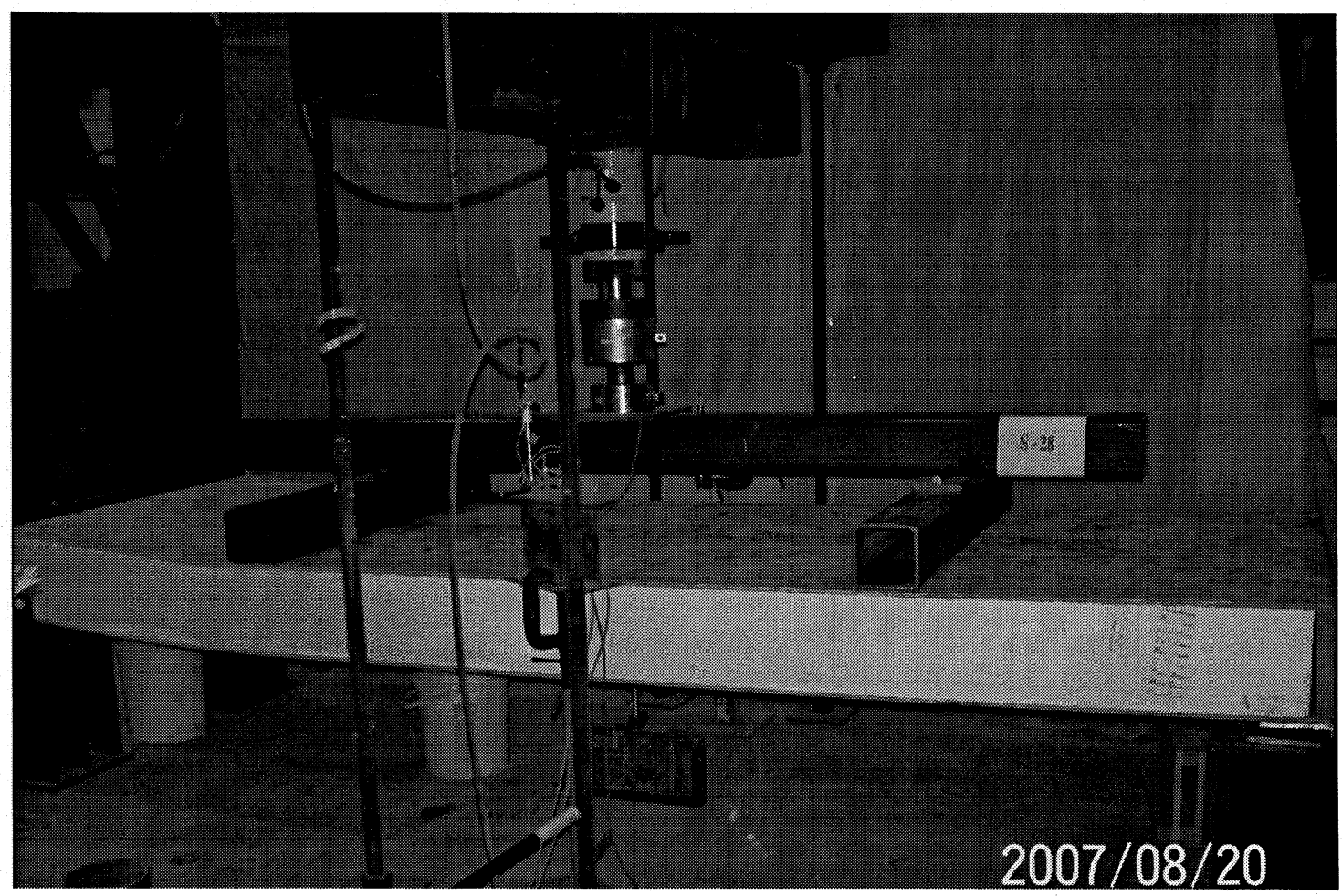

Figure AI-138. View of specimen S-28 after failure

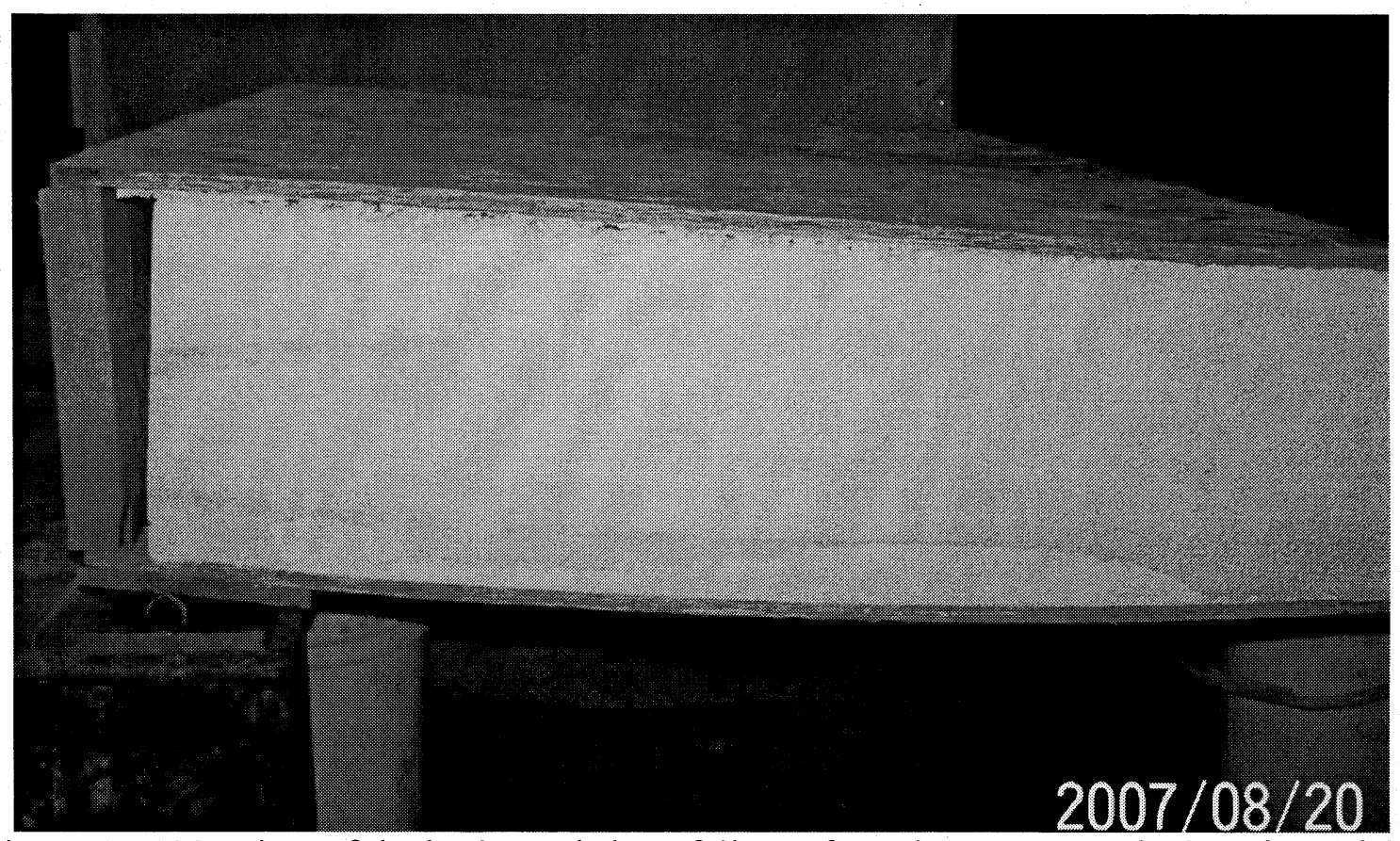

Figure AI-139. View of the horizontal shear failure of specimen S-28 at the interface of the foam And the top OSB board 


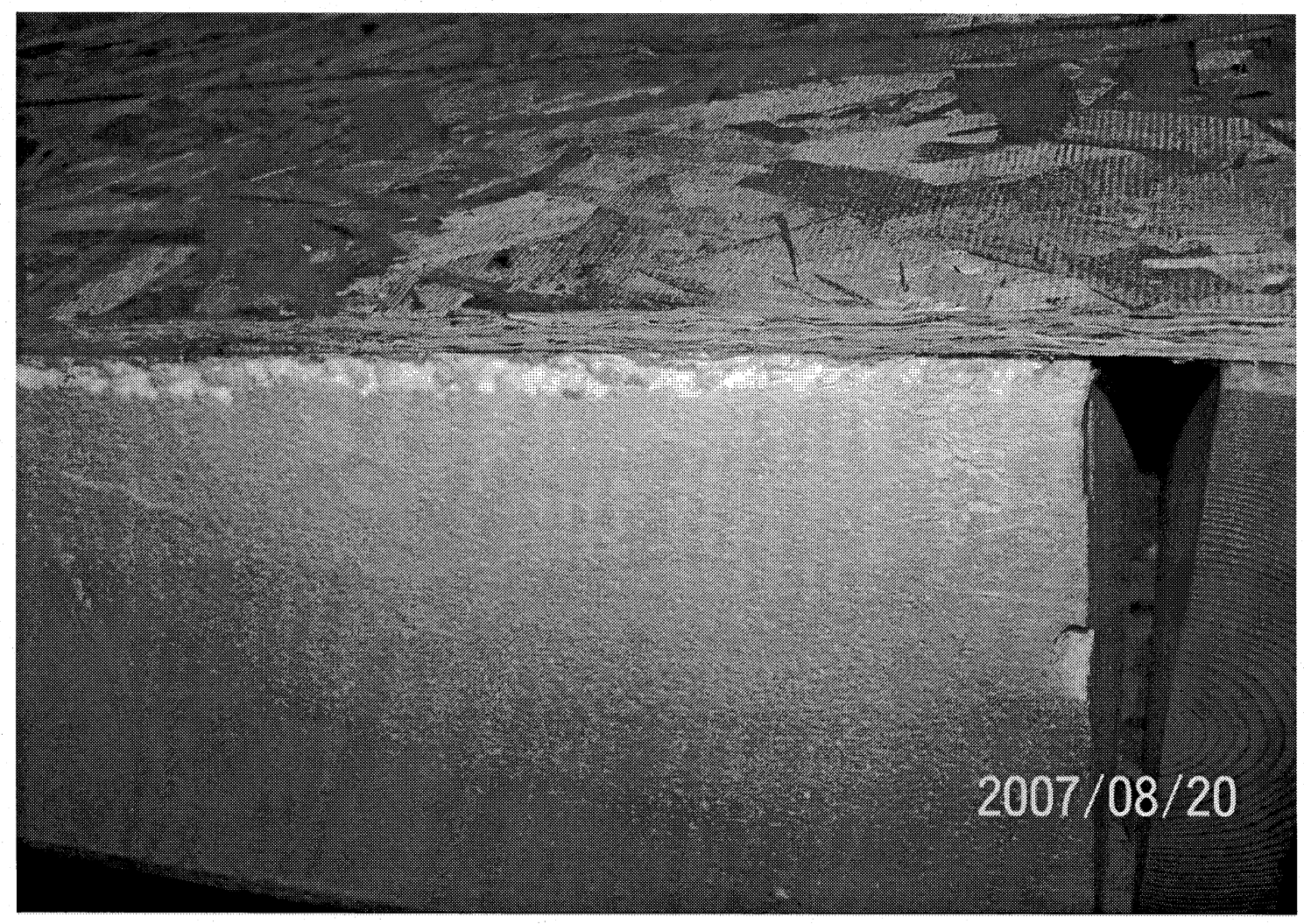

Figure AI-140. View of the horizontal shear failure at other free edge of specimen S-28 


\section{Specimen \# S-29}

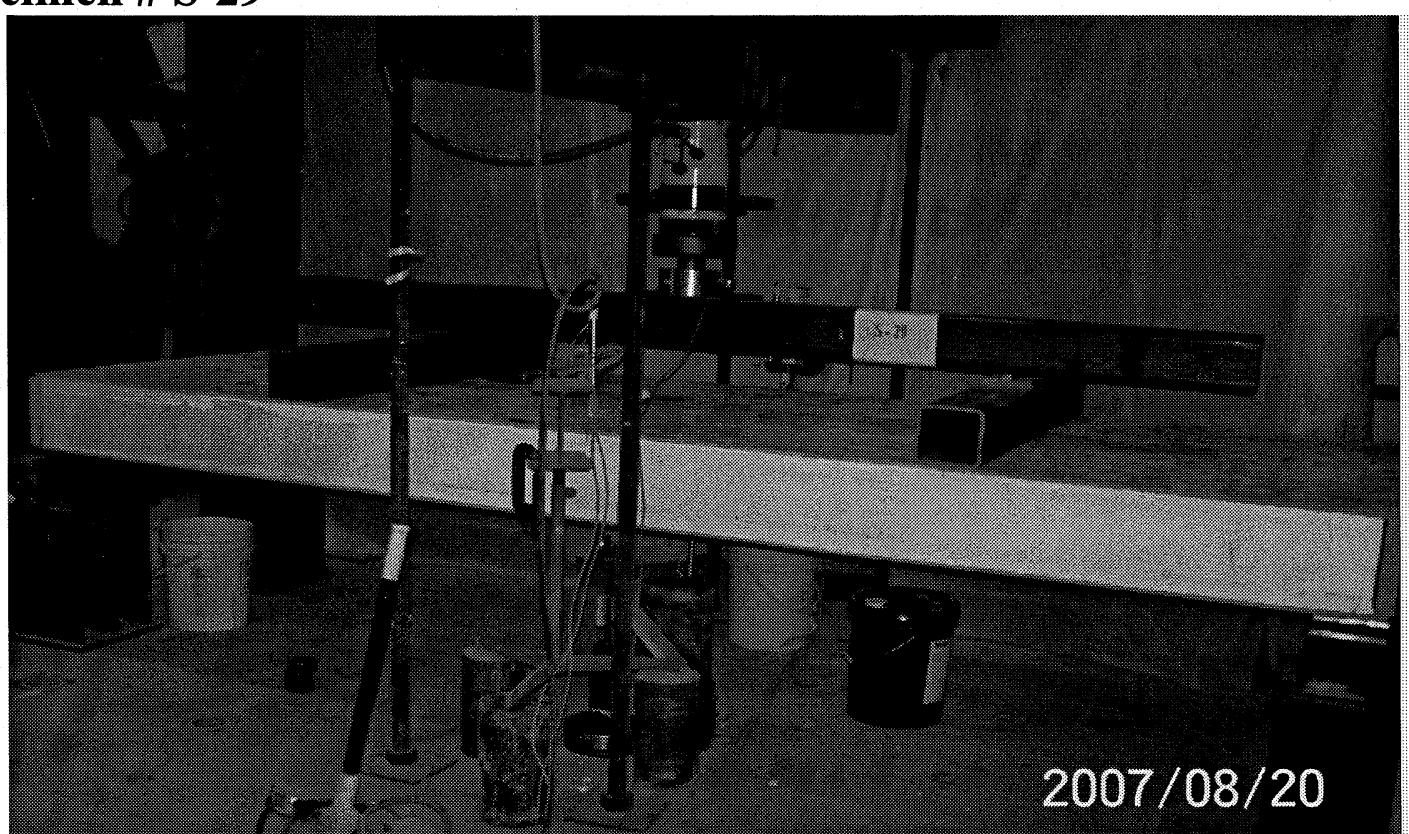

Figure AI-141. View of Specimen S-29 before testing

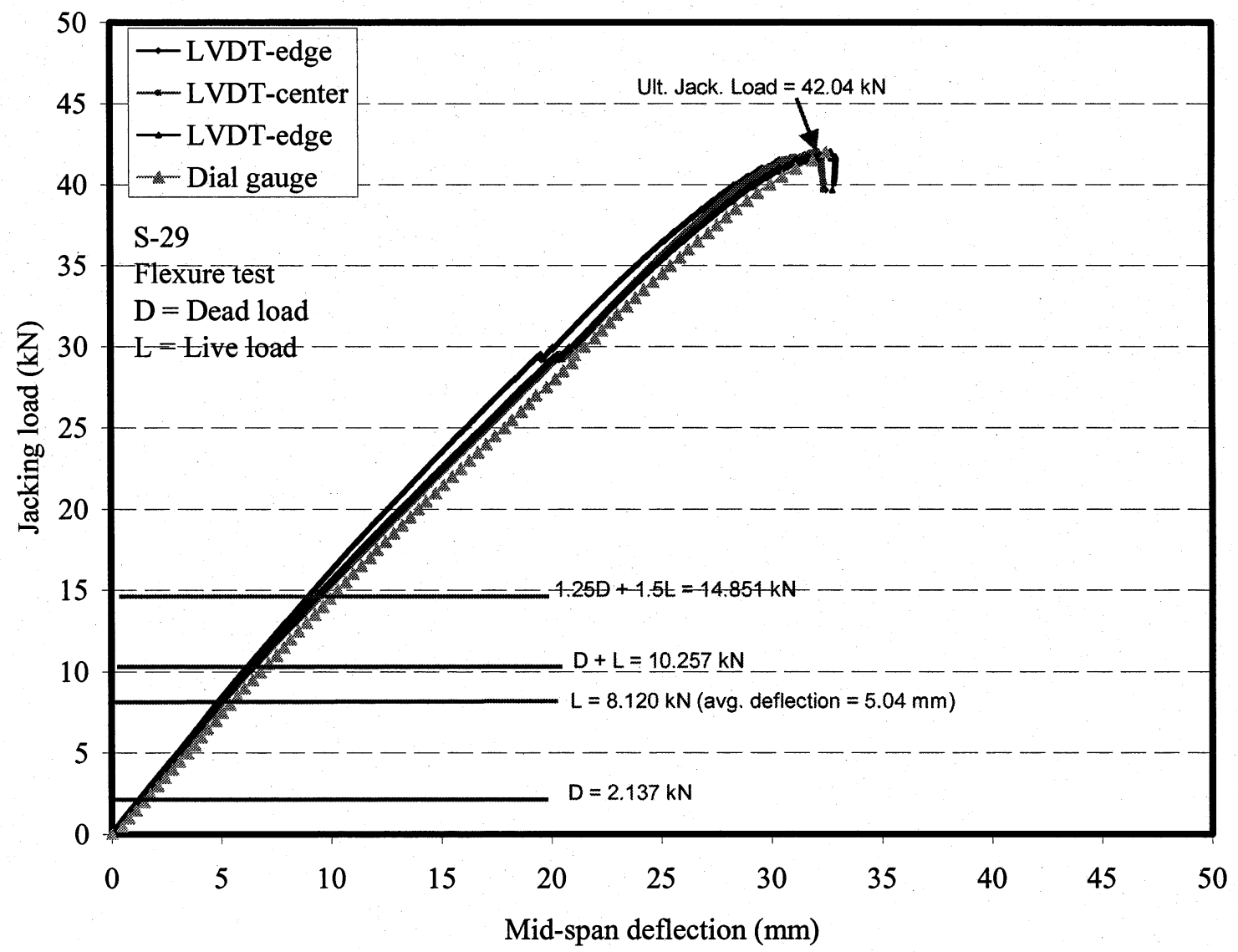

Figure AI-142. Load-deflection relationship for specimen S-29 


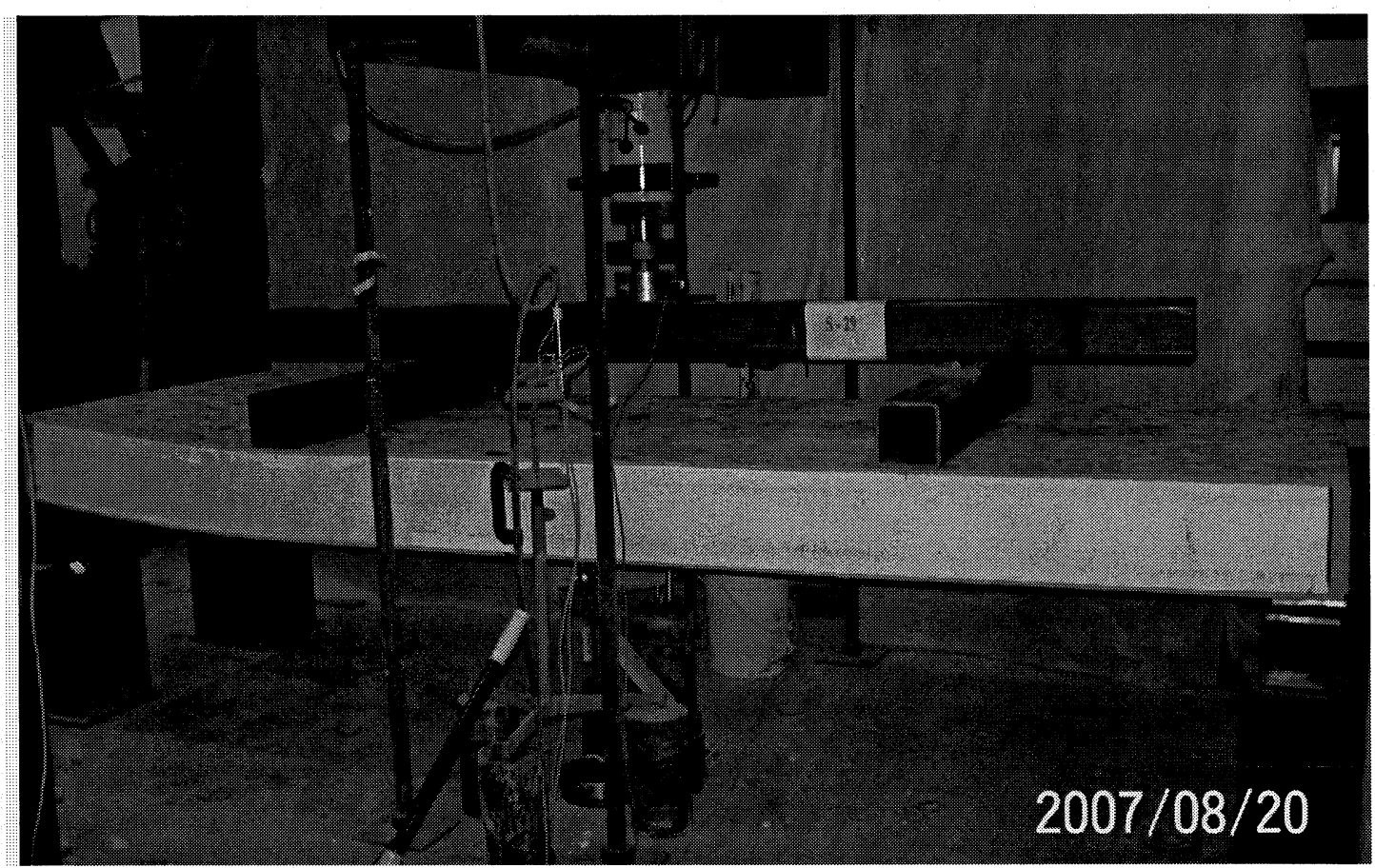

Figure AI-143. View of specimen S-29 after failure

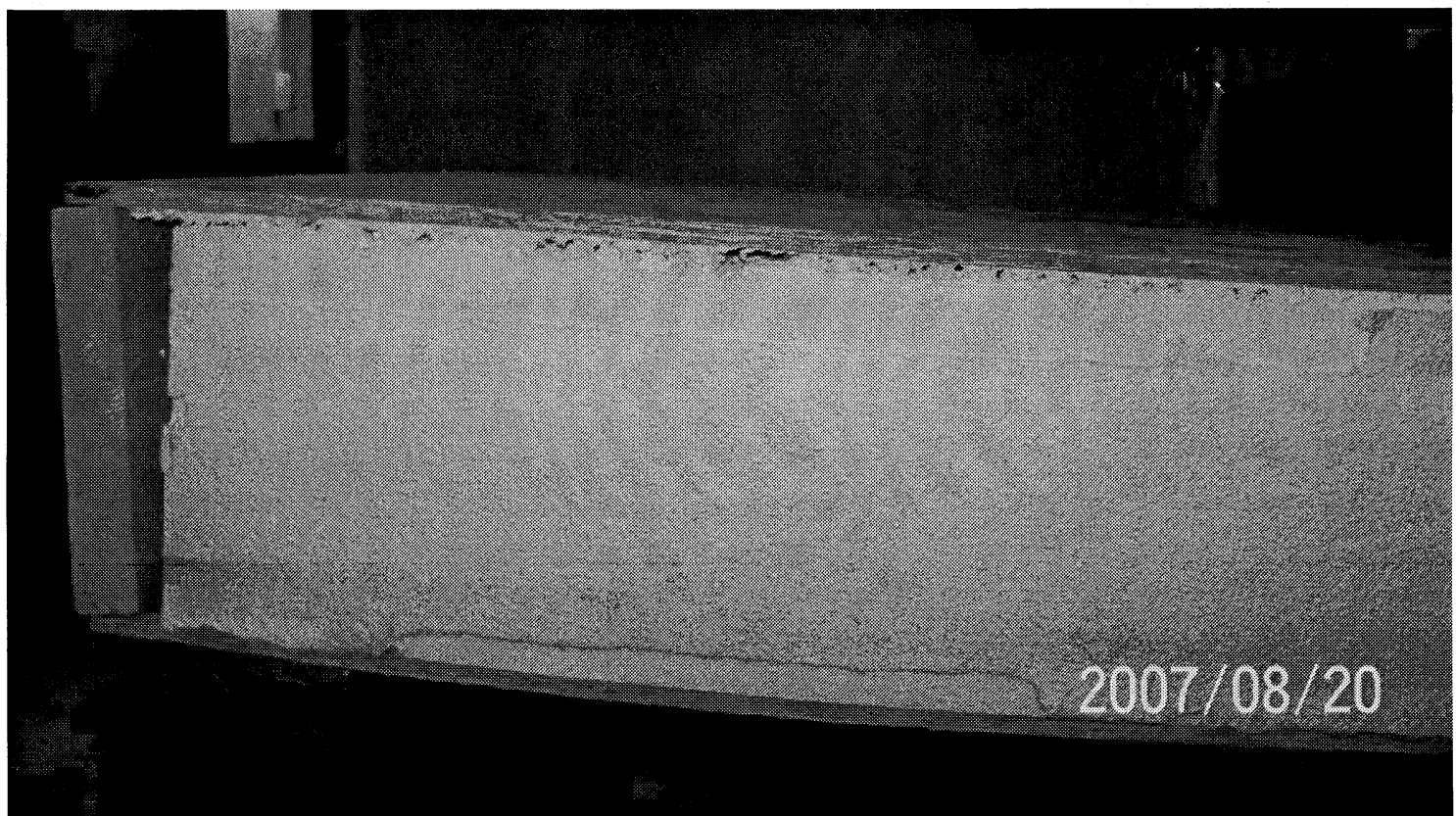

Figure AI-144. View of the horizontal shear failure of specimen S-29 at the interface of the foam and the top OSB board 


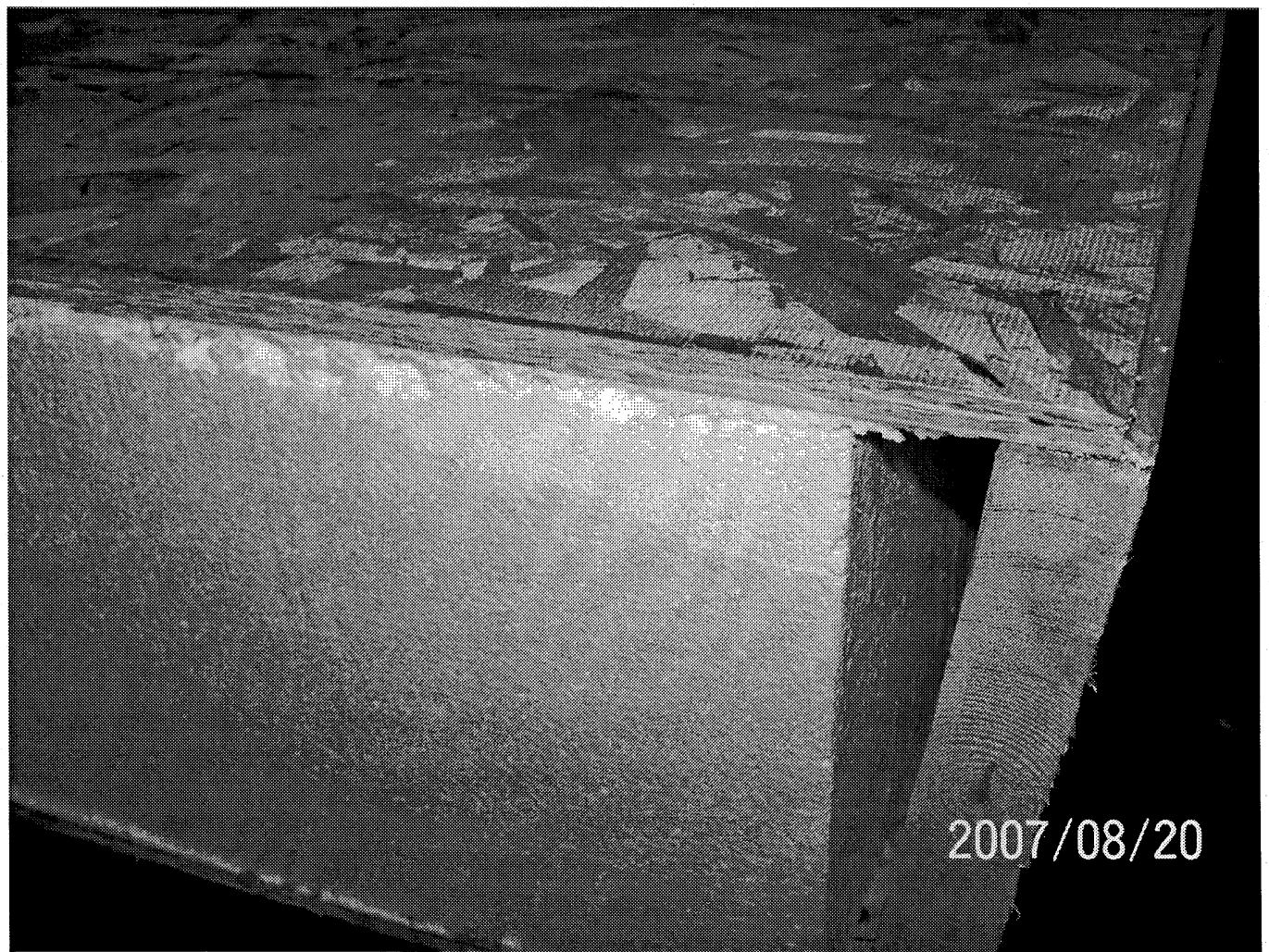

Figure AI-145. View of the horizontal shear failure at other free edge of specimen S-29 


\section{Specimen \# 30}

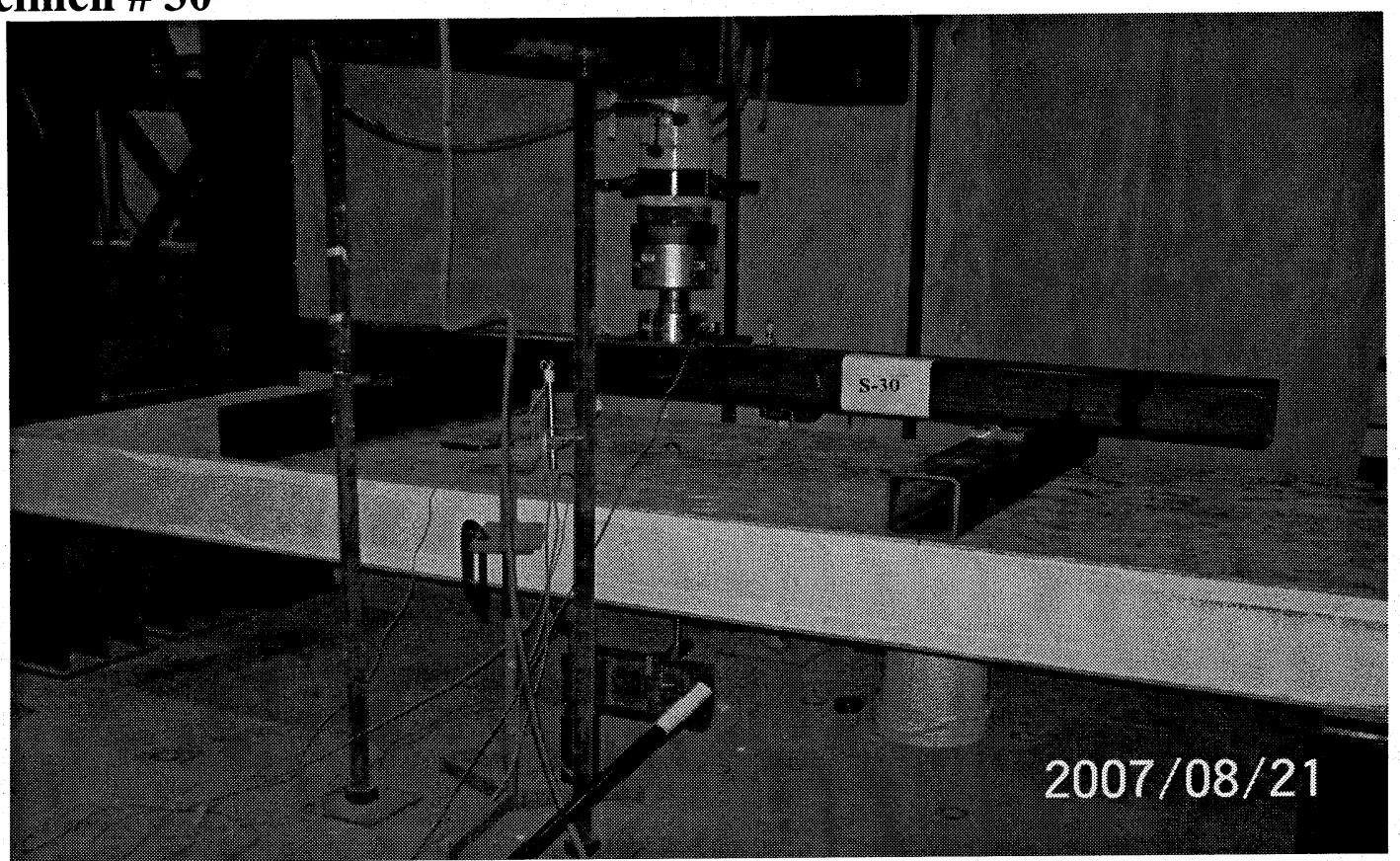

Figure 146. View of Specimen S-30 before testing

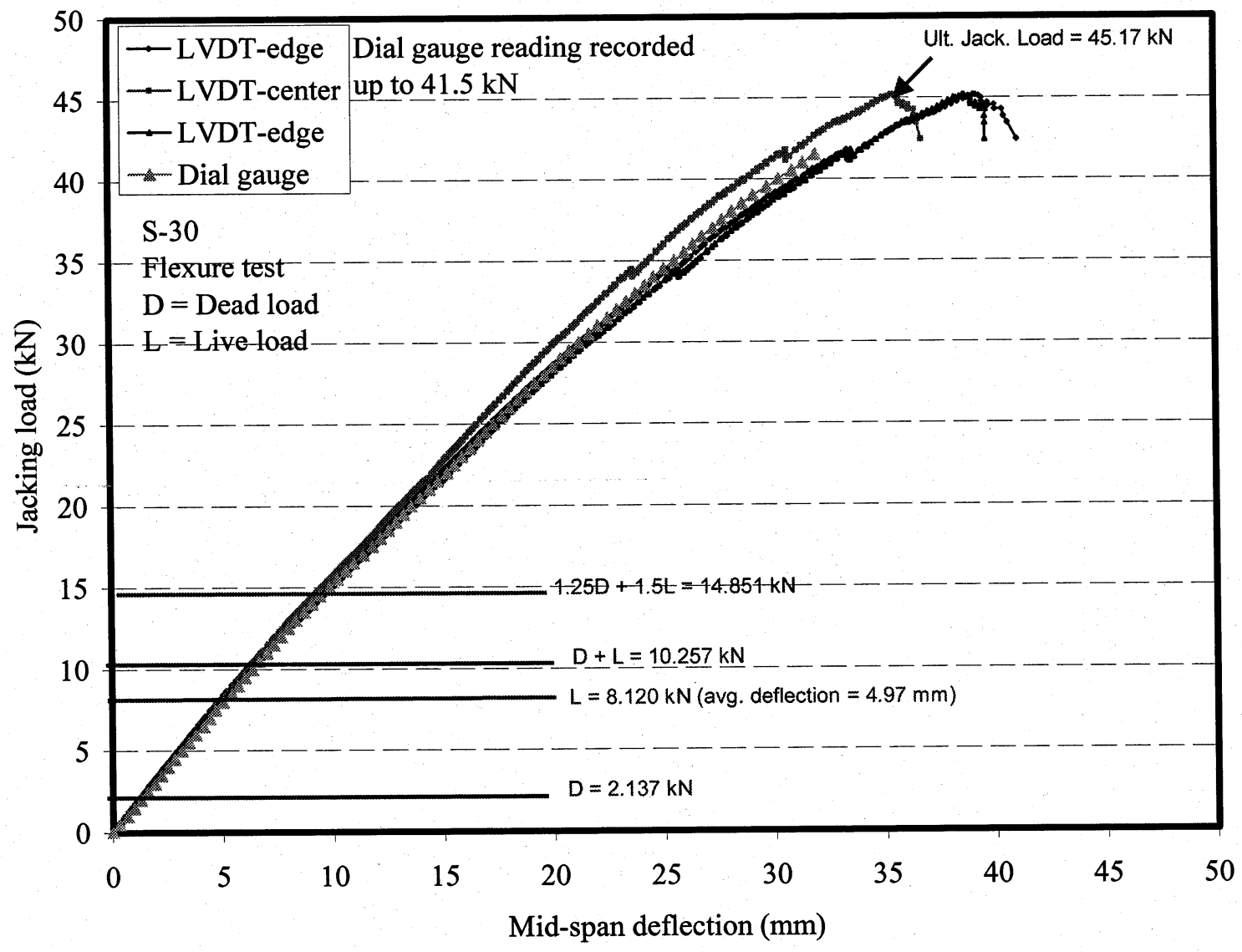

Figure AI-147. Load-deflection relationship for specimen S-30 


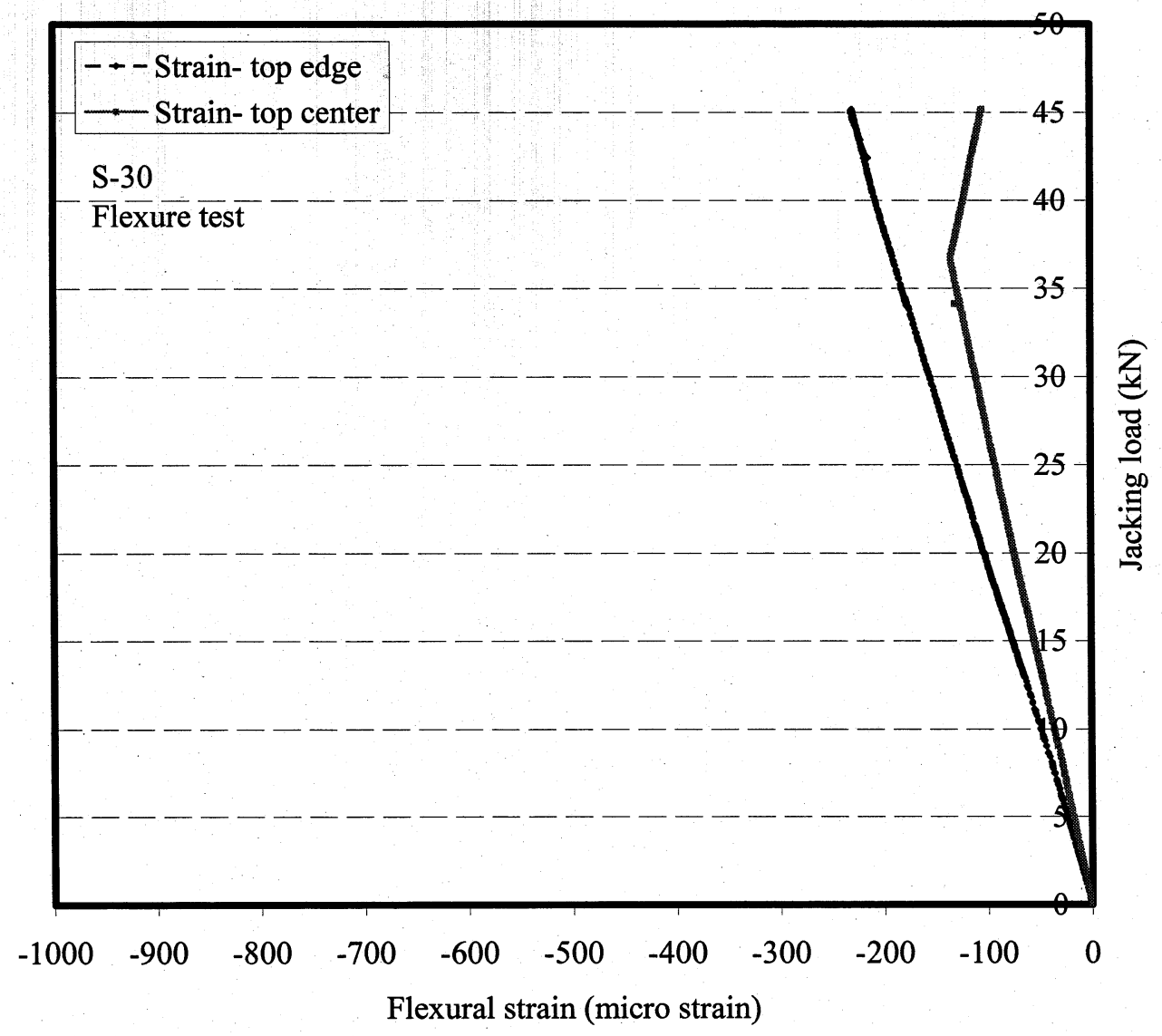

Figure AI-148. Load-strain relationship for specimen S-30

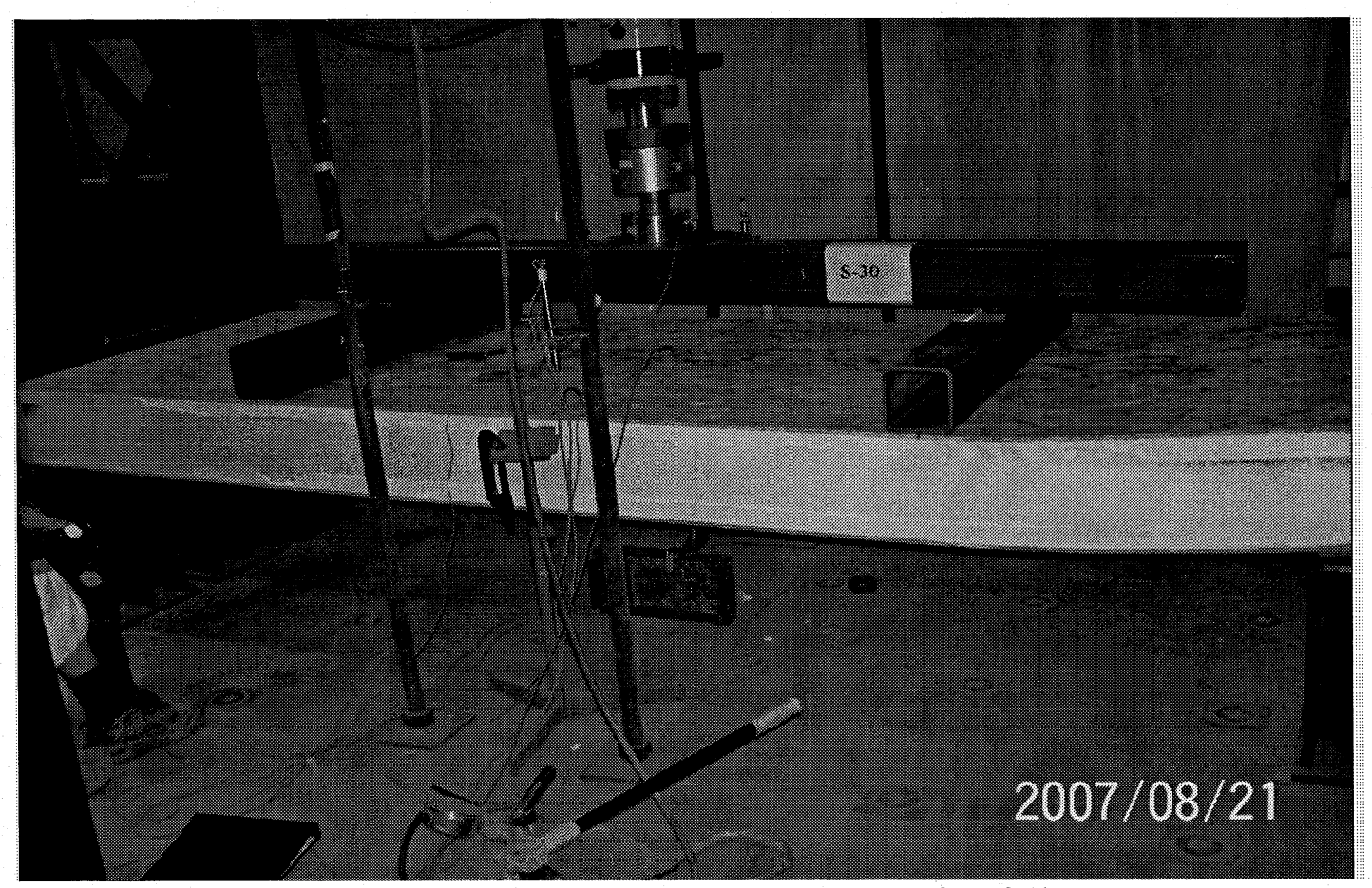

Figure AI-149. View of specimen S-30 after failure 


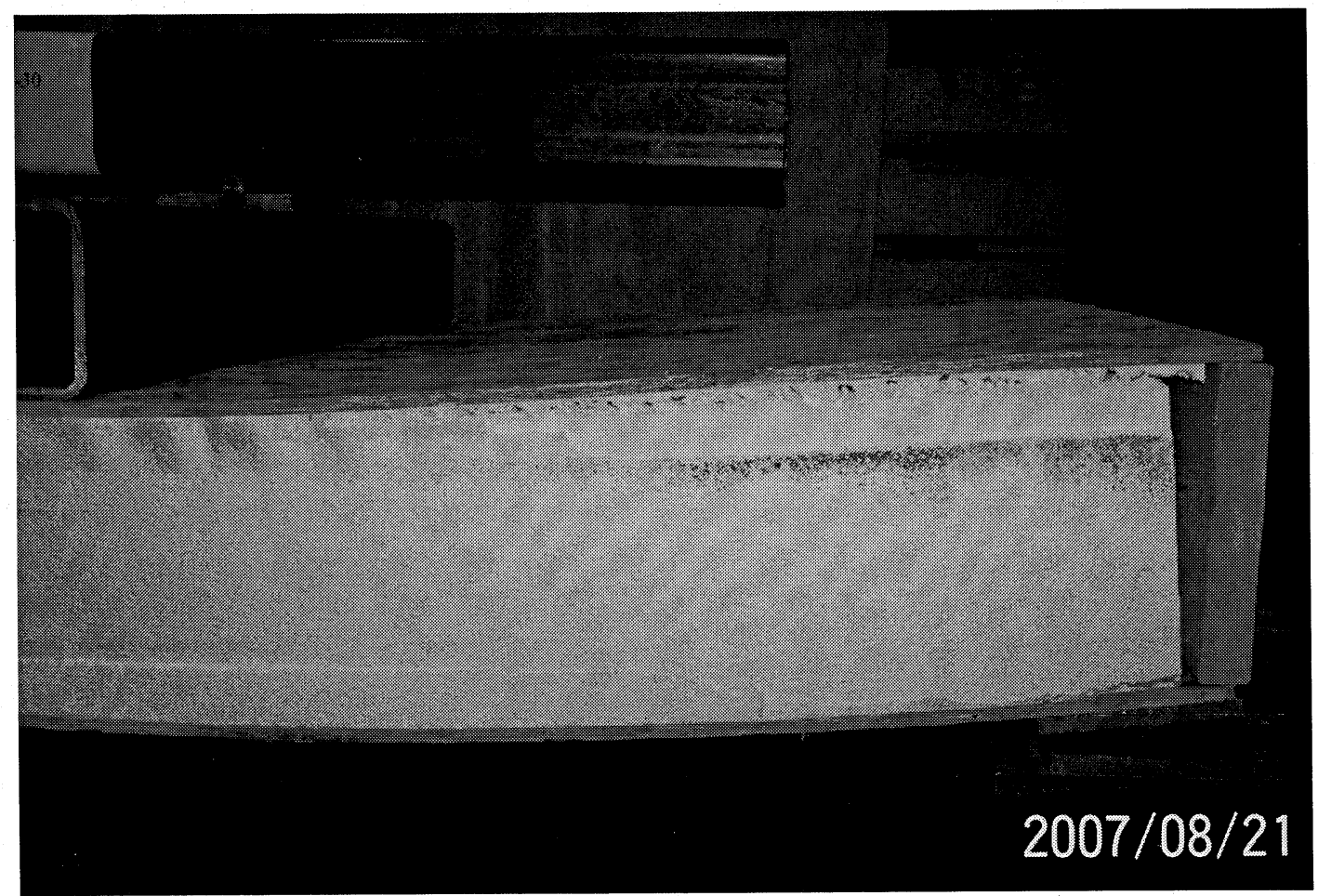

Figure AI-150. View of the horizontal shear failure of specimen S-30 at the interface of the foam and the top OSB board

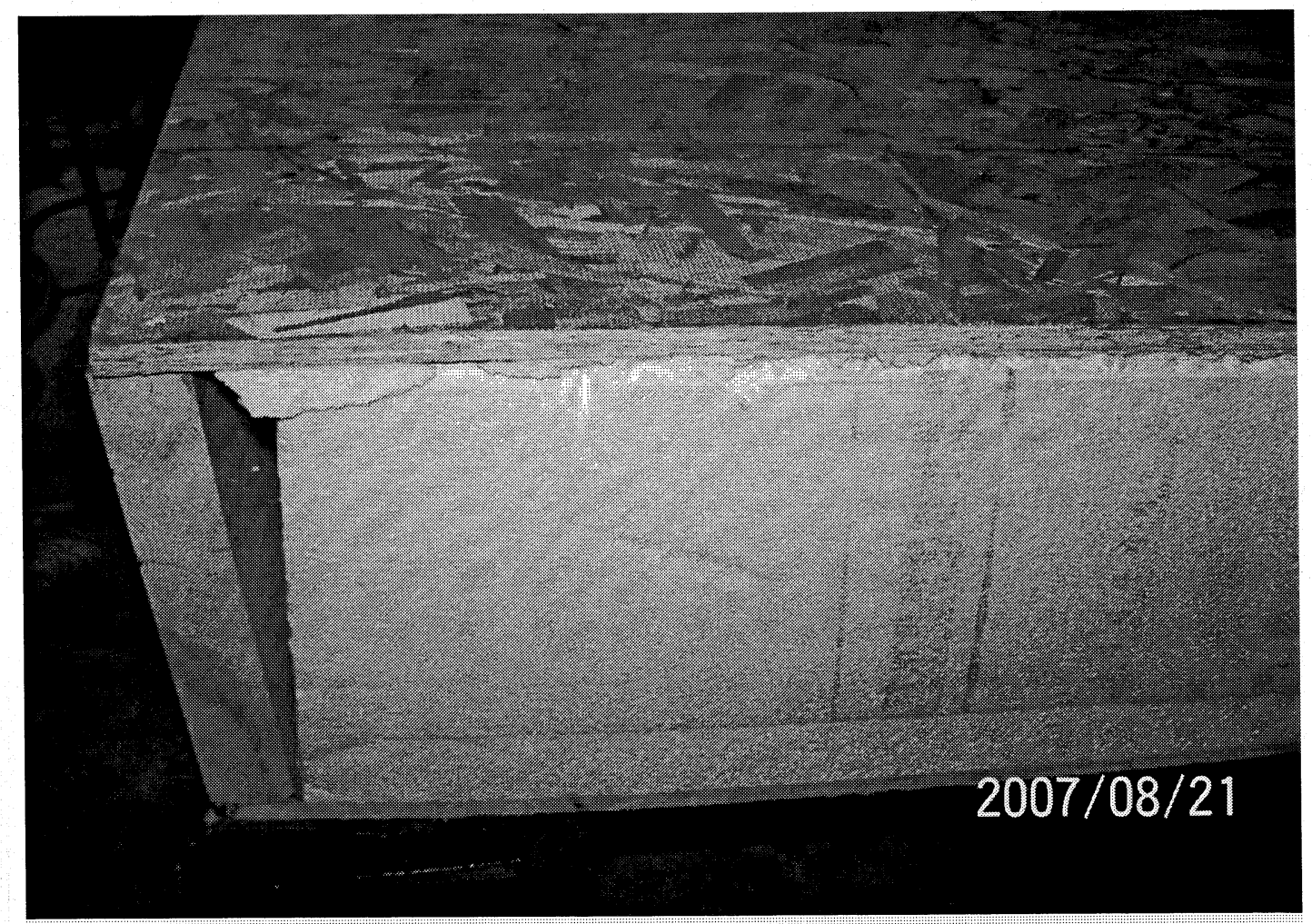

Figure AI-151. View of the horizontal shear failure at other free edge of specimen S-30 


\section{GROUP K}

\section{Specimen \# S-31}

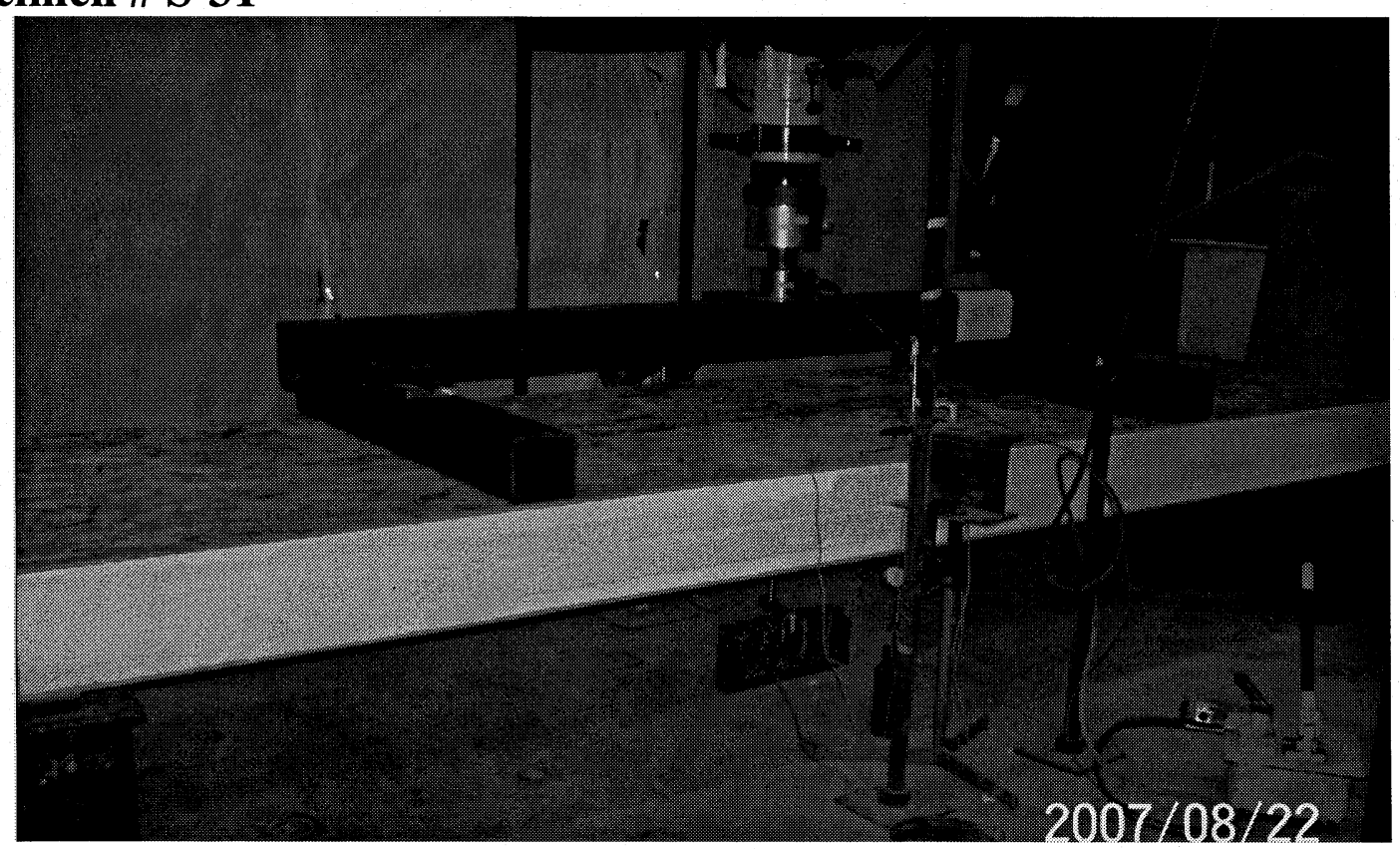

Figure AI-152. View of Specimen S-31before testing

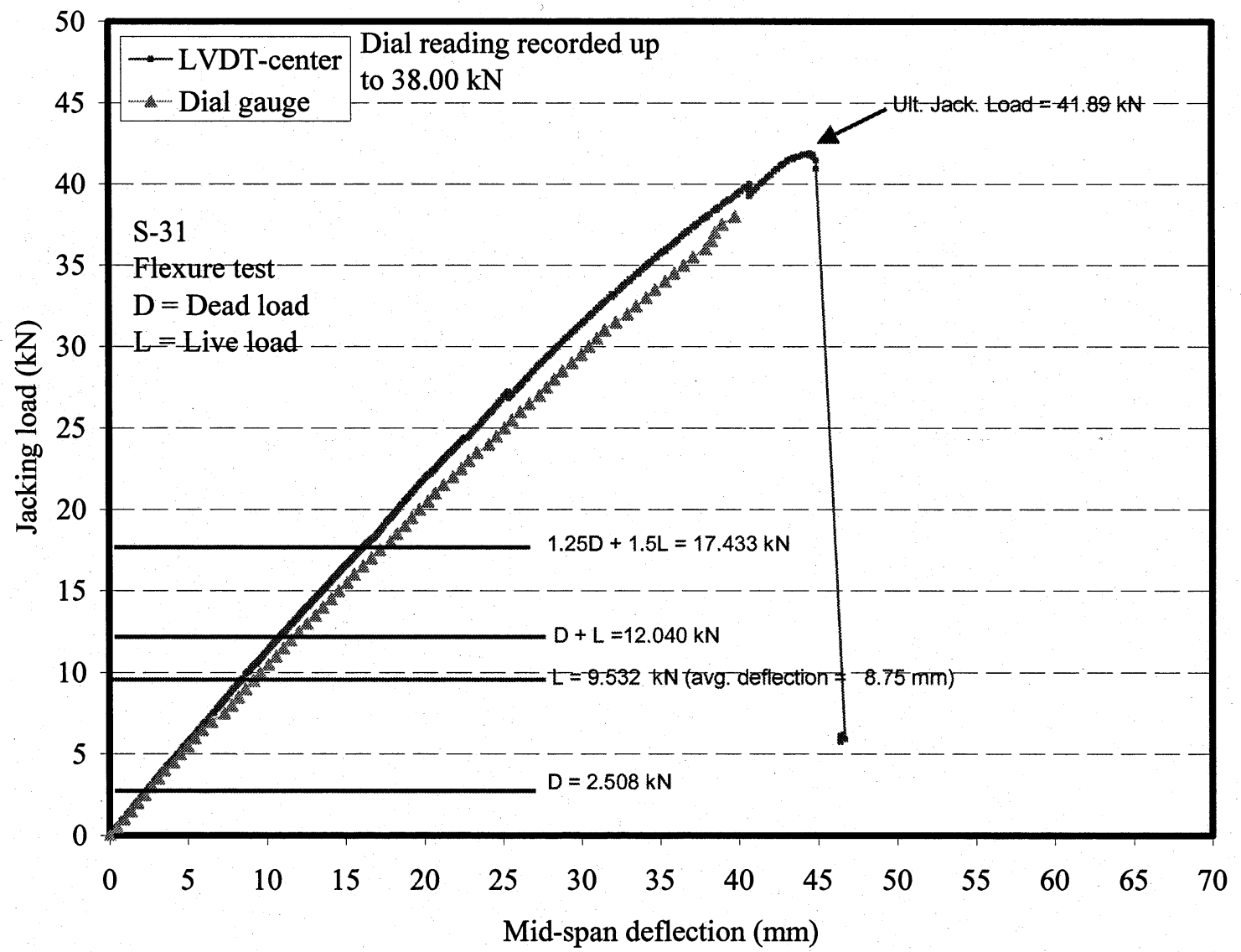

Figure AI-153. Load-deflection relationship for specimen S-31 


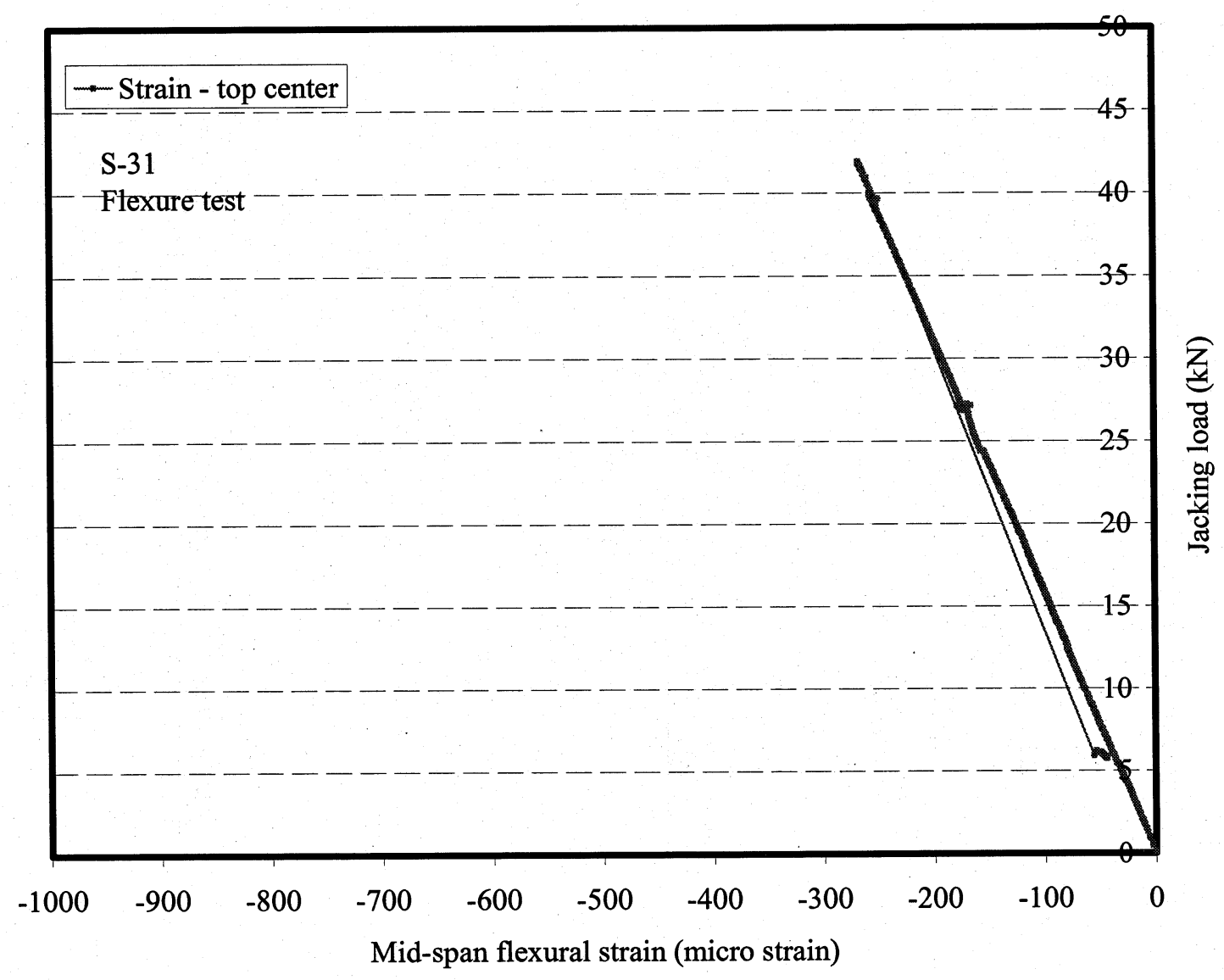

Figure AI-154. Load-flexural strain relationship for specimen S-31

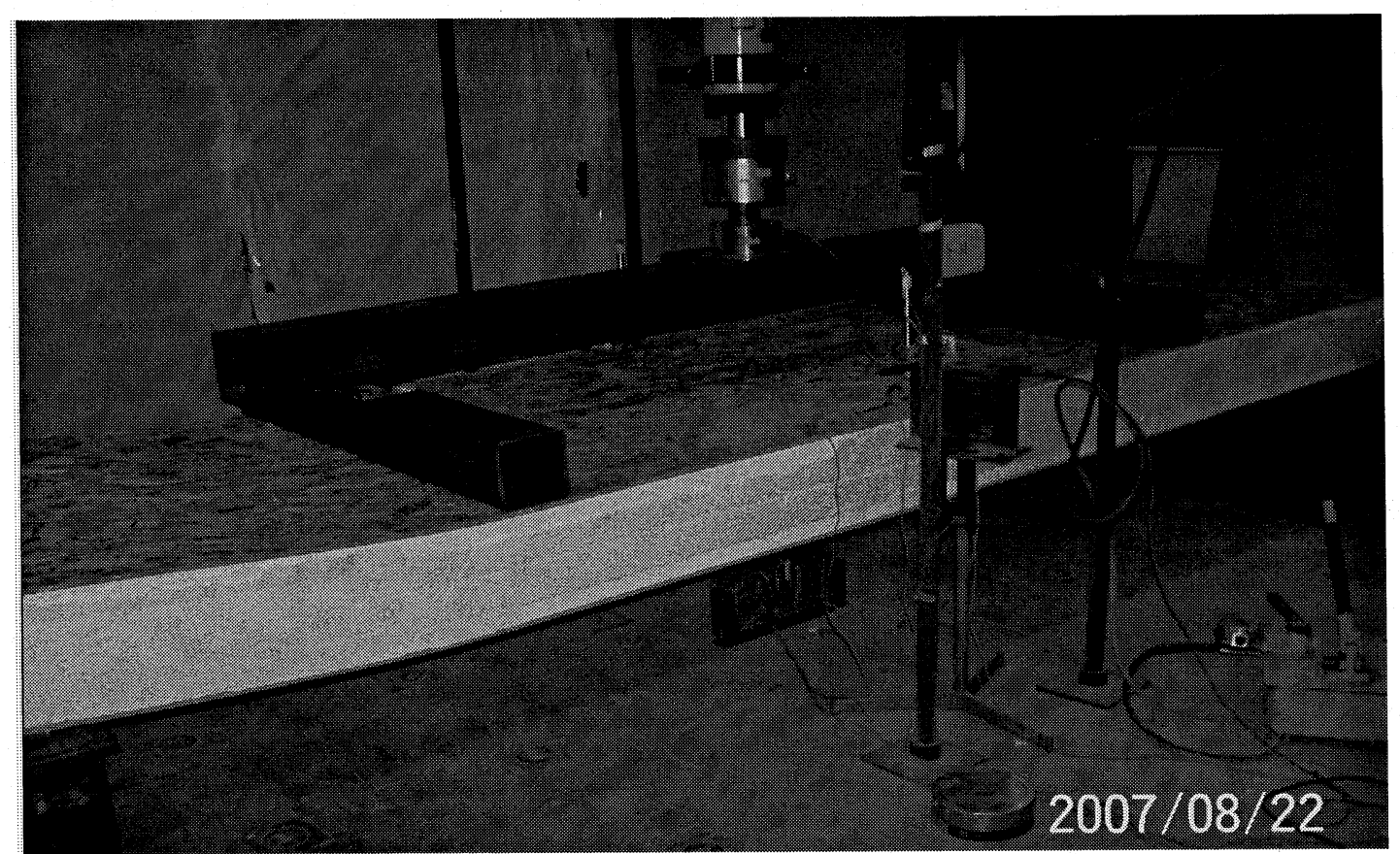

Figure AI-155. View of specimen S-31 after failure 
Figure AI-156. View of the horizontal shear failure of specimen S-31 at the interface of the foam and

the top OSB board

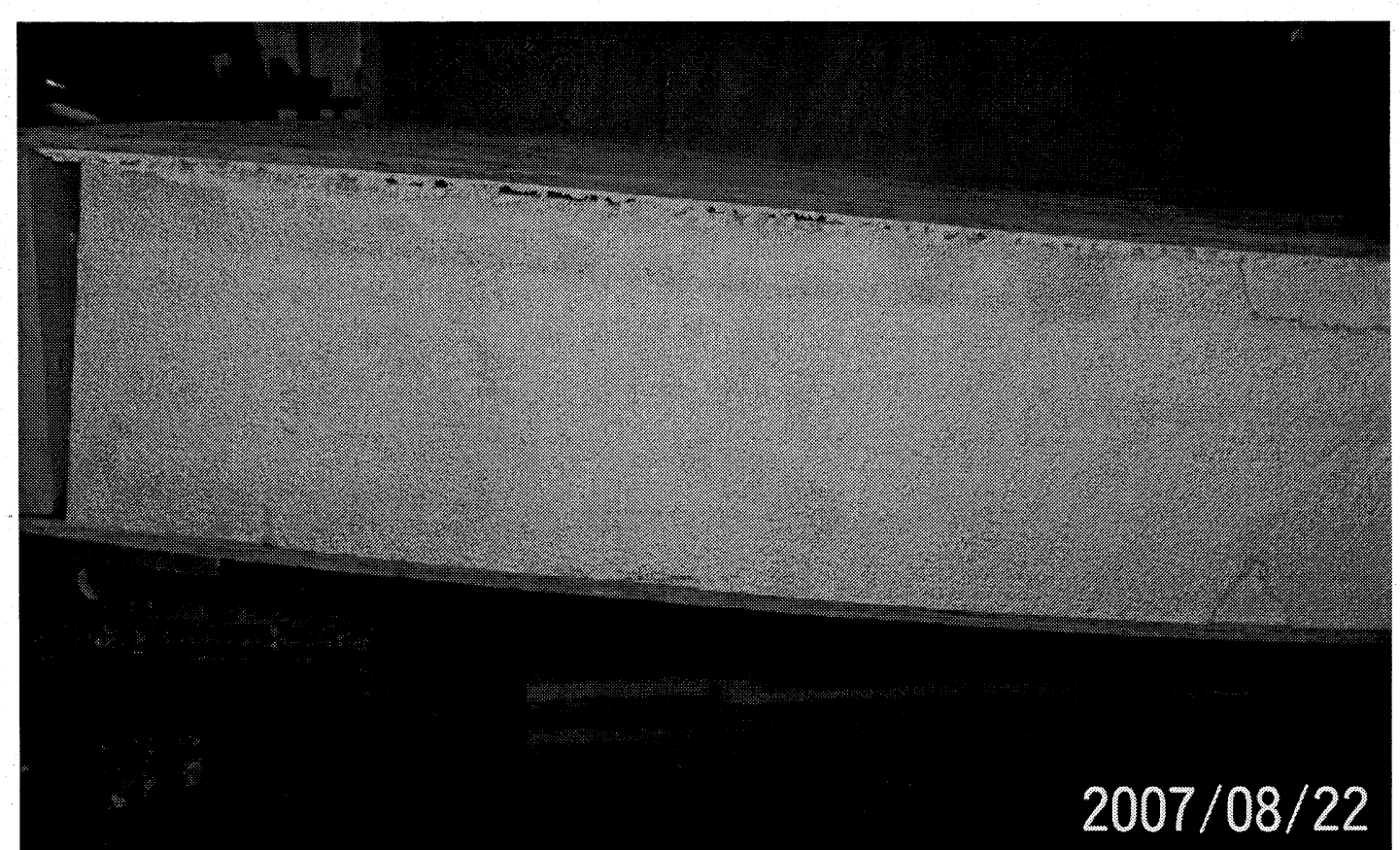

Figure AI-157. Close-up view of the horizontal shear failure of specimen S-31 


\section{Specimen \# S-32}

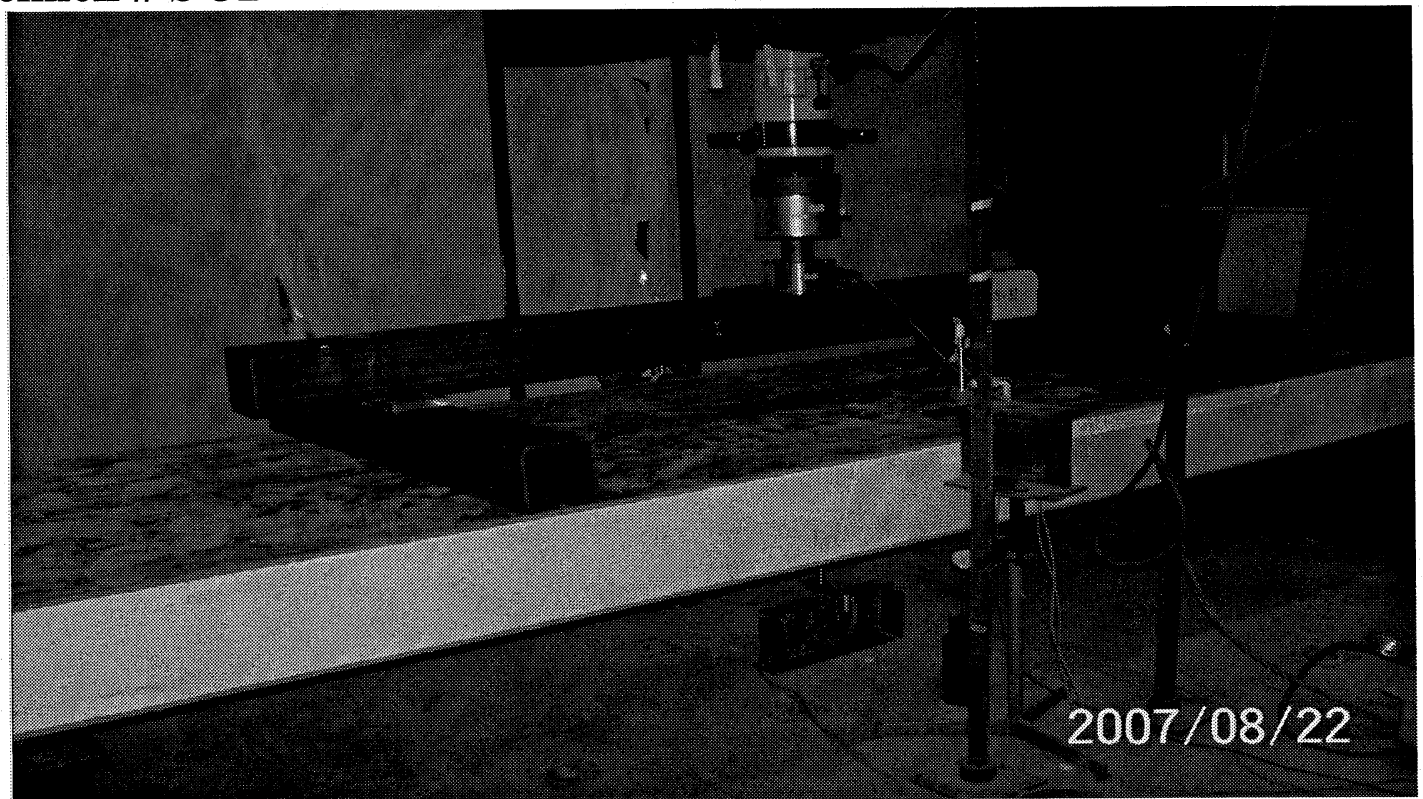

Figure AI-158. View of Specimen S-32 before testing

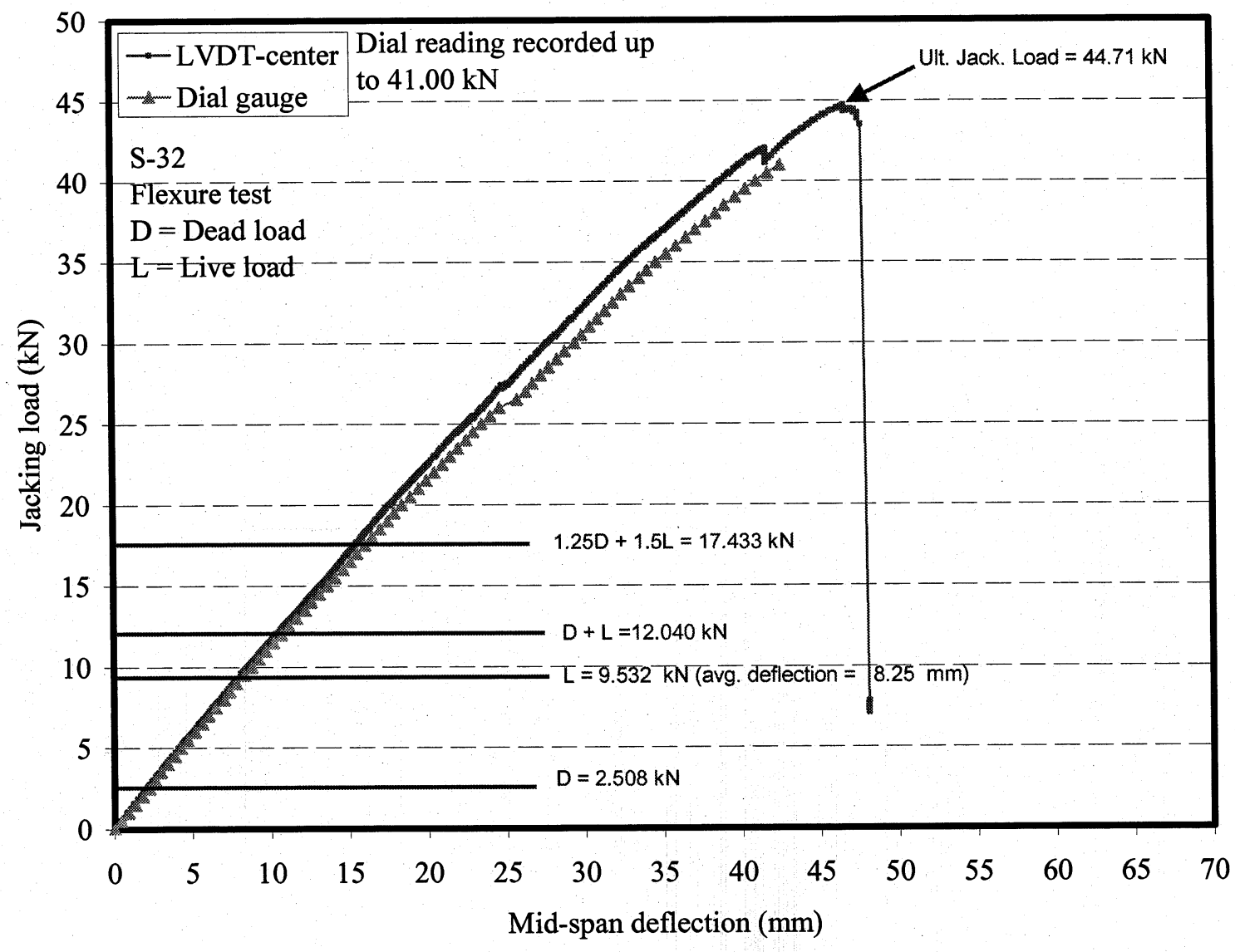

Figure AI-159. Load-deflection relationship for specimen S-32 


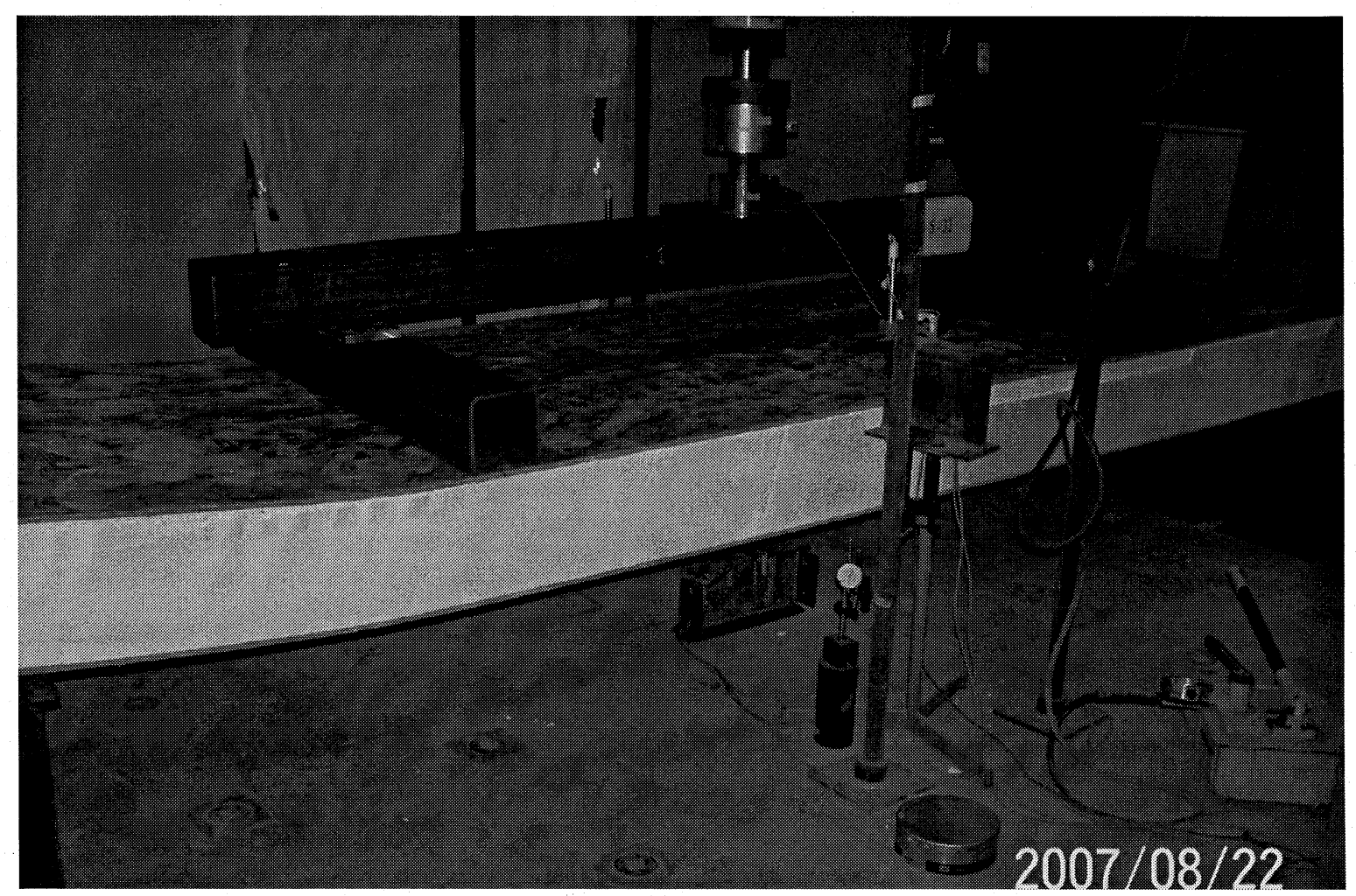

Figure AI-160. View of specimen S-32 after failure

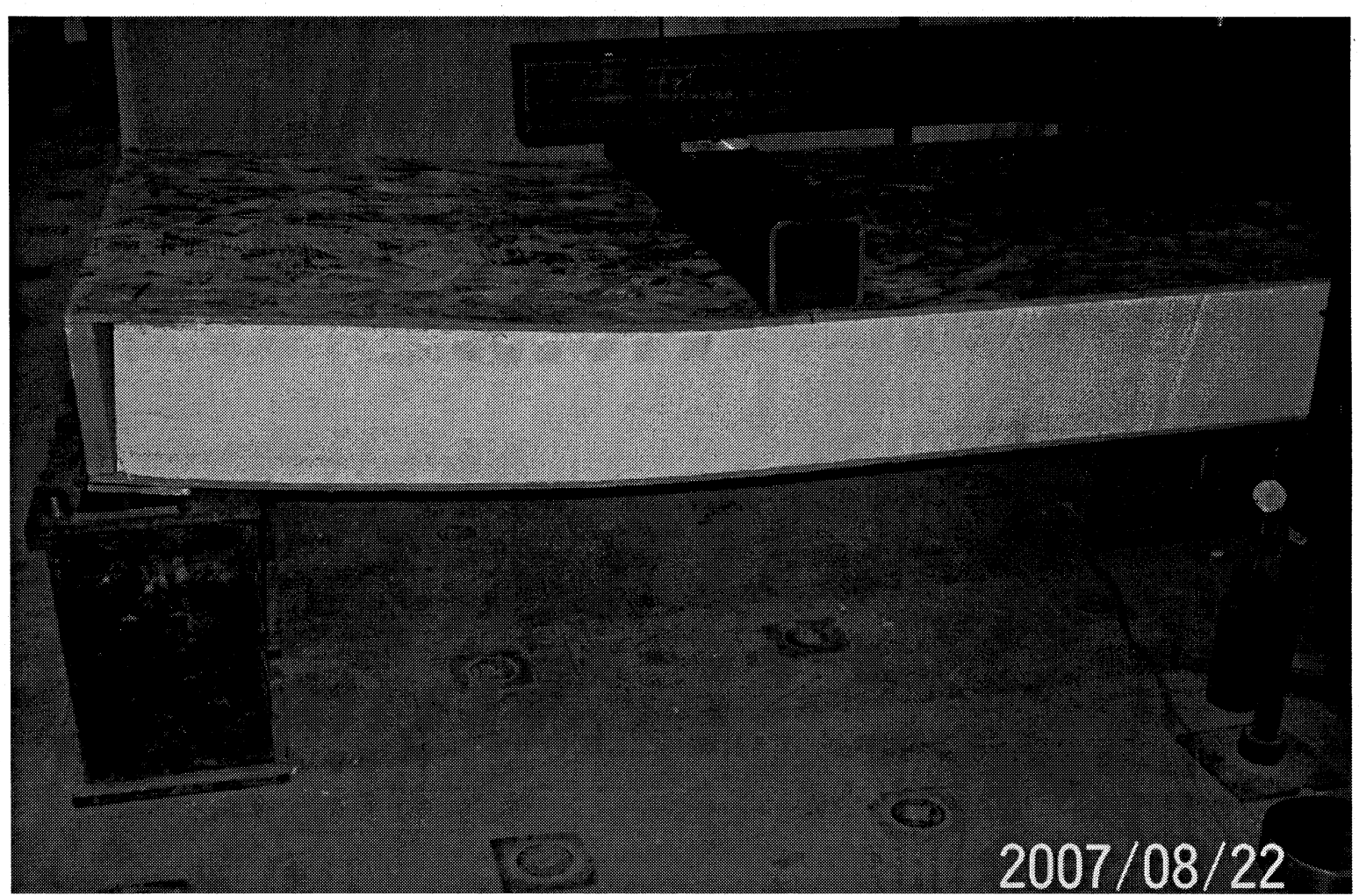

Figure AI-161. View of the horizontal shear failure of specimen S-32 at the interface of the foam and the top OSB board 


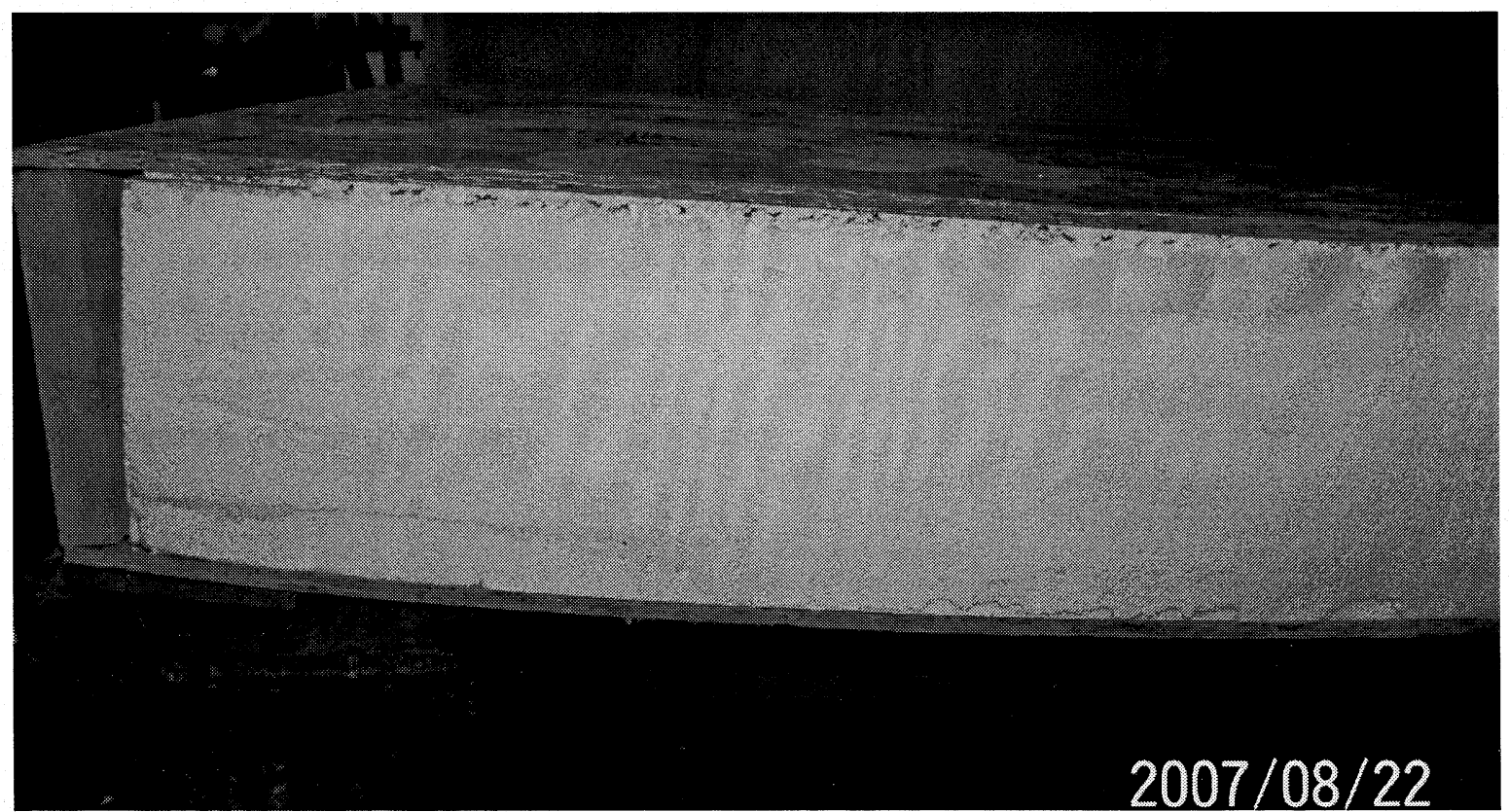

Figure AI-162. Close-up view of the horizontal shear failure of specimen S-32 


\section{Specimen \# S-33}

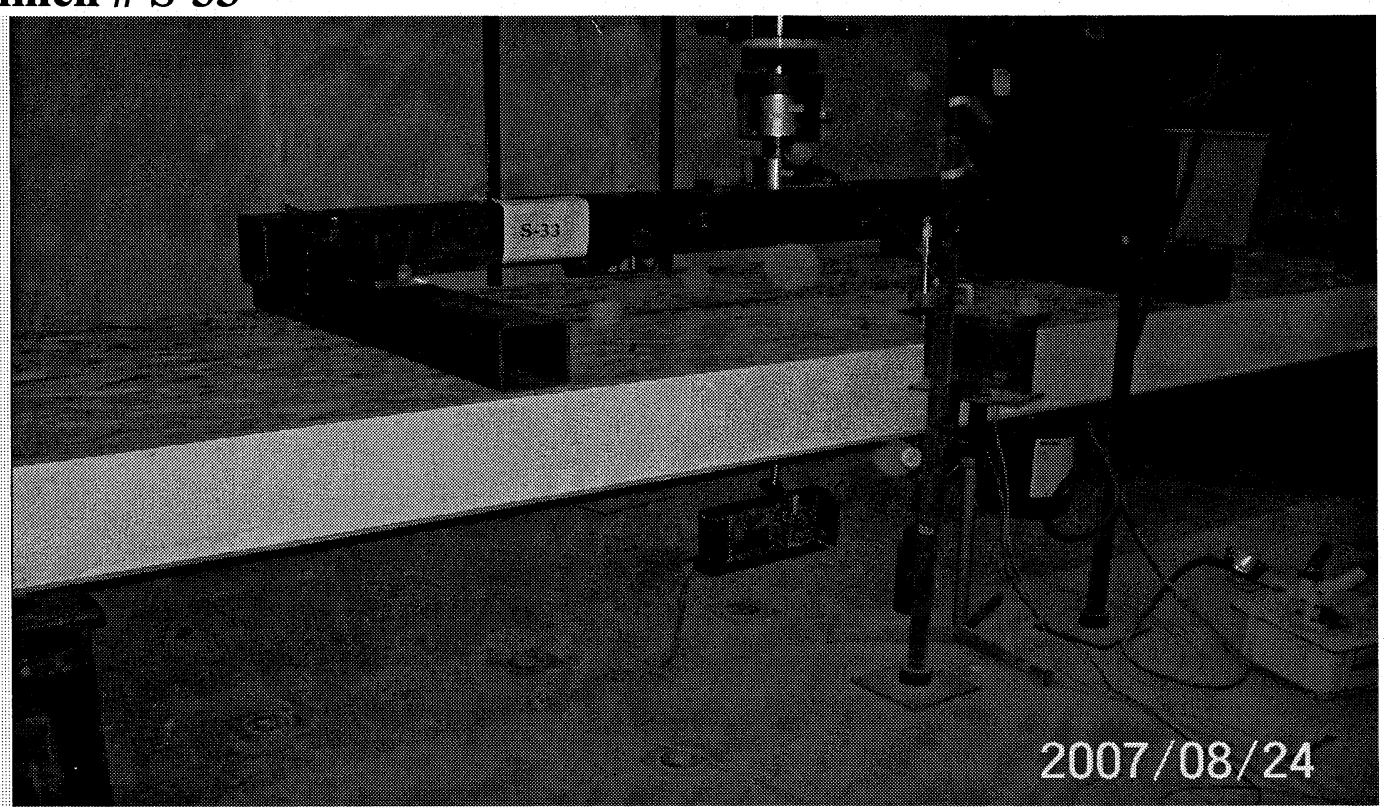

Figure AI-163. View of Specimen S-33 before testing

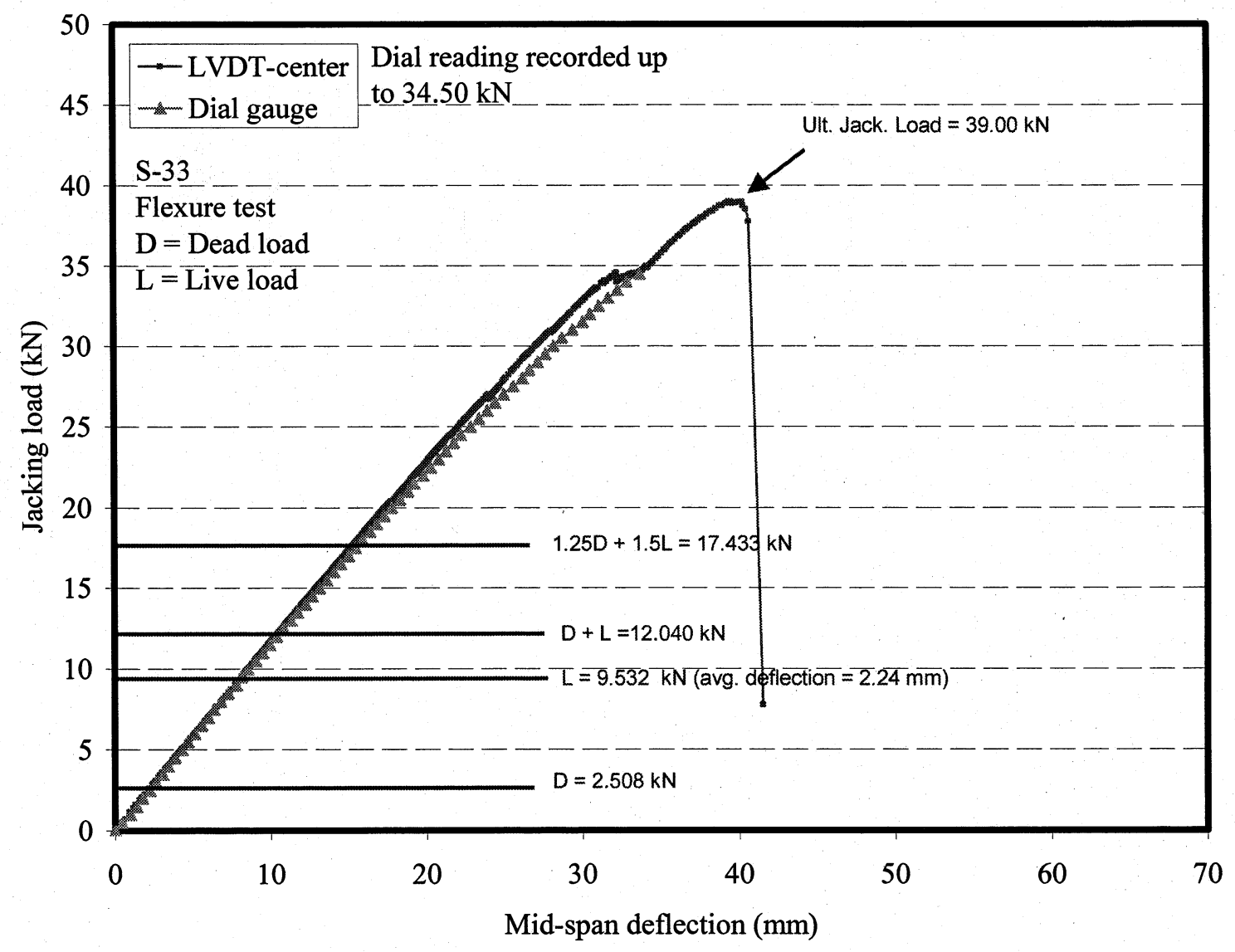

Figure AI-164. Load-deflection relationship for specimen S-33 


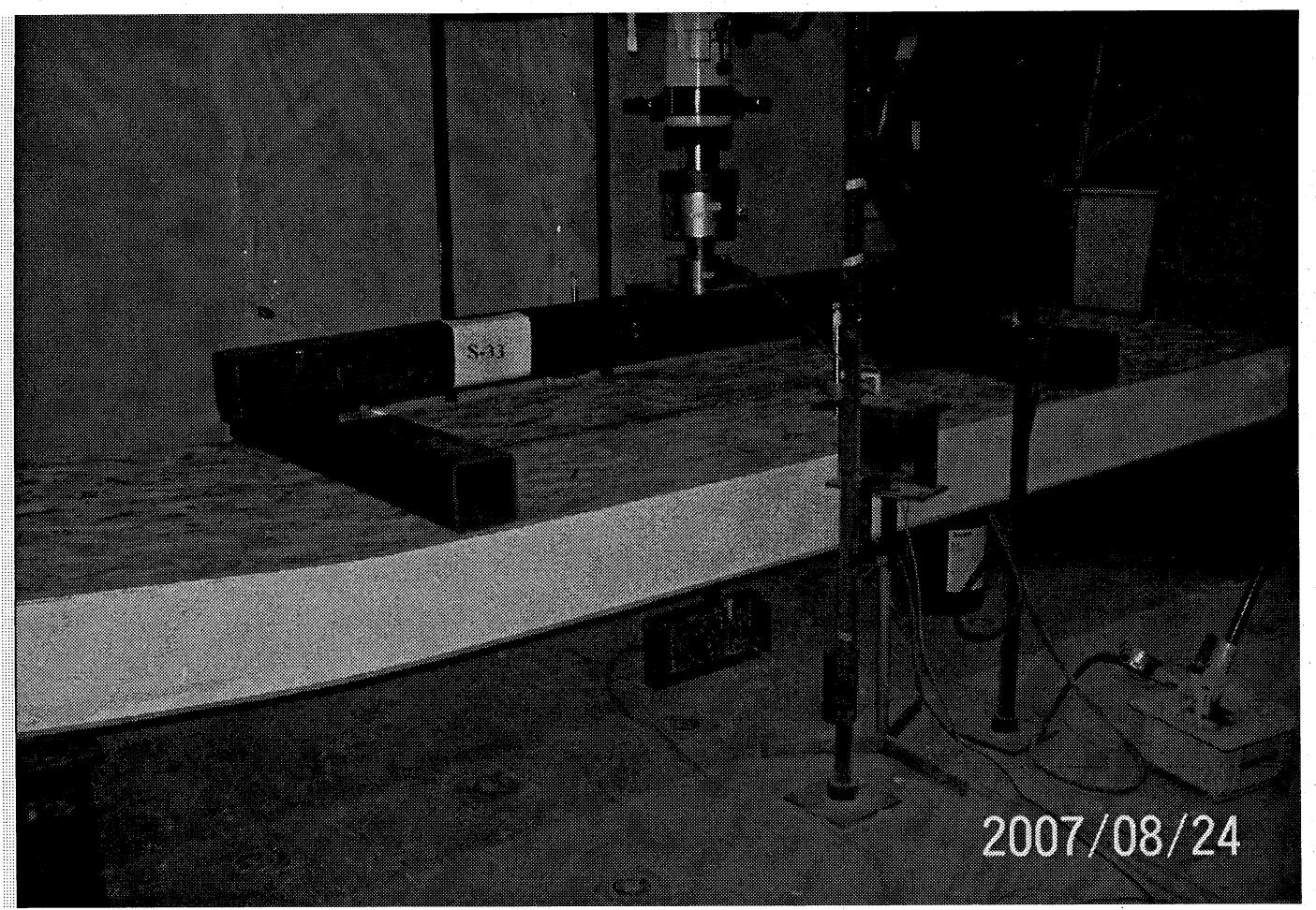

Figure AI-165. View of specimen S-33 after failure

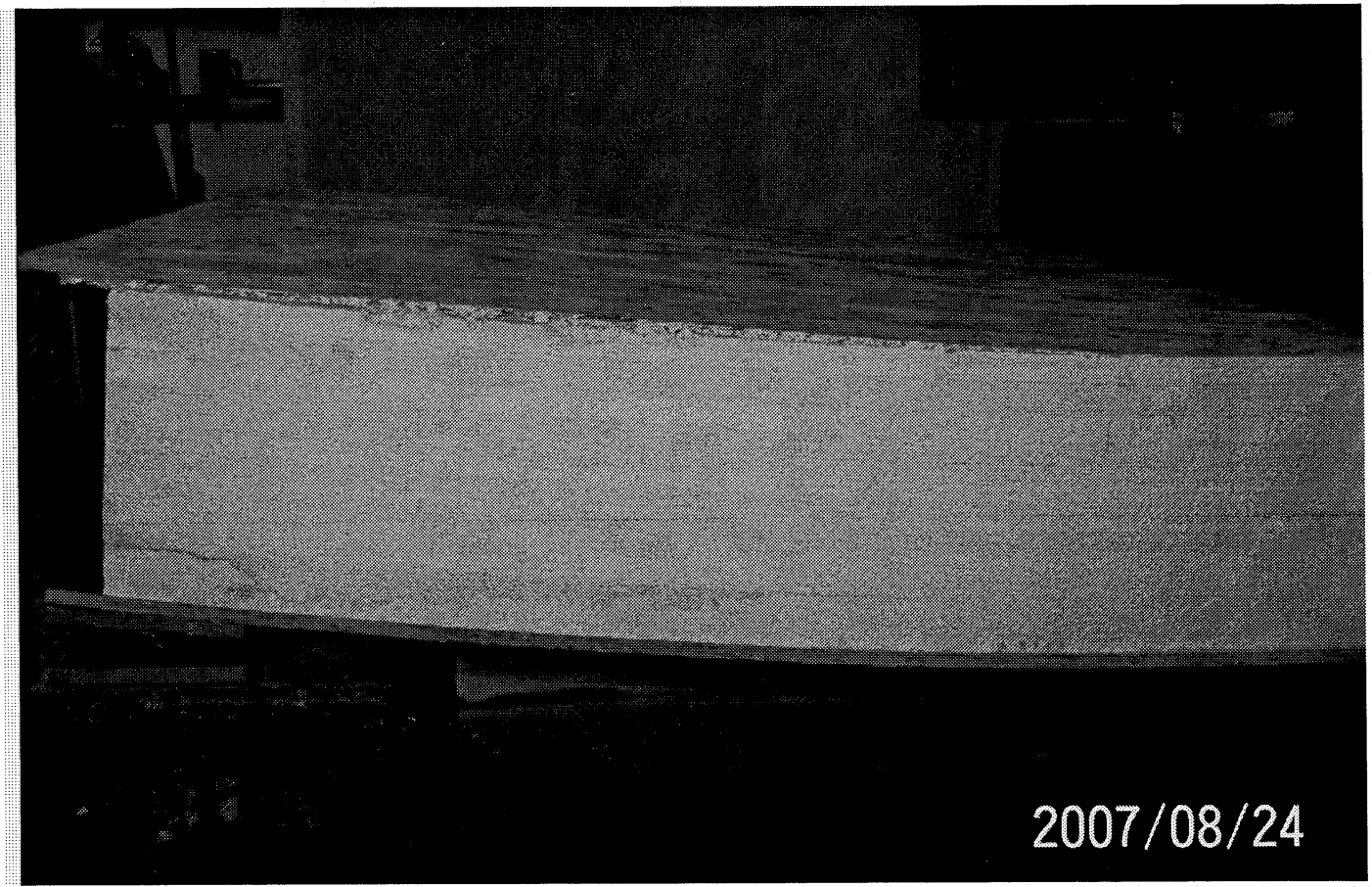

Figure AI-166. View of the horizontal shear failure of specimen S-33 at the interface of the foam and the top OSB board 


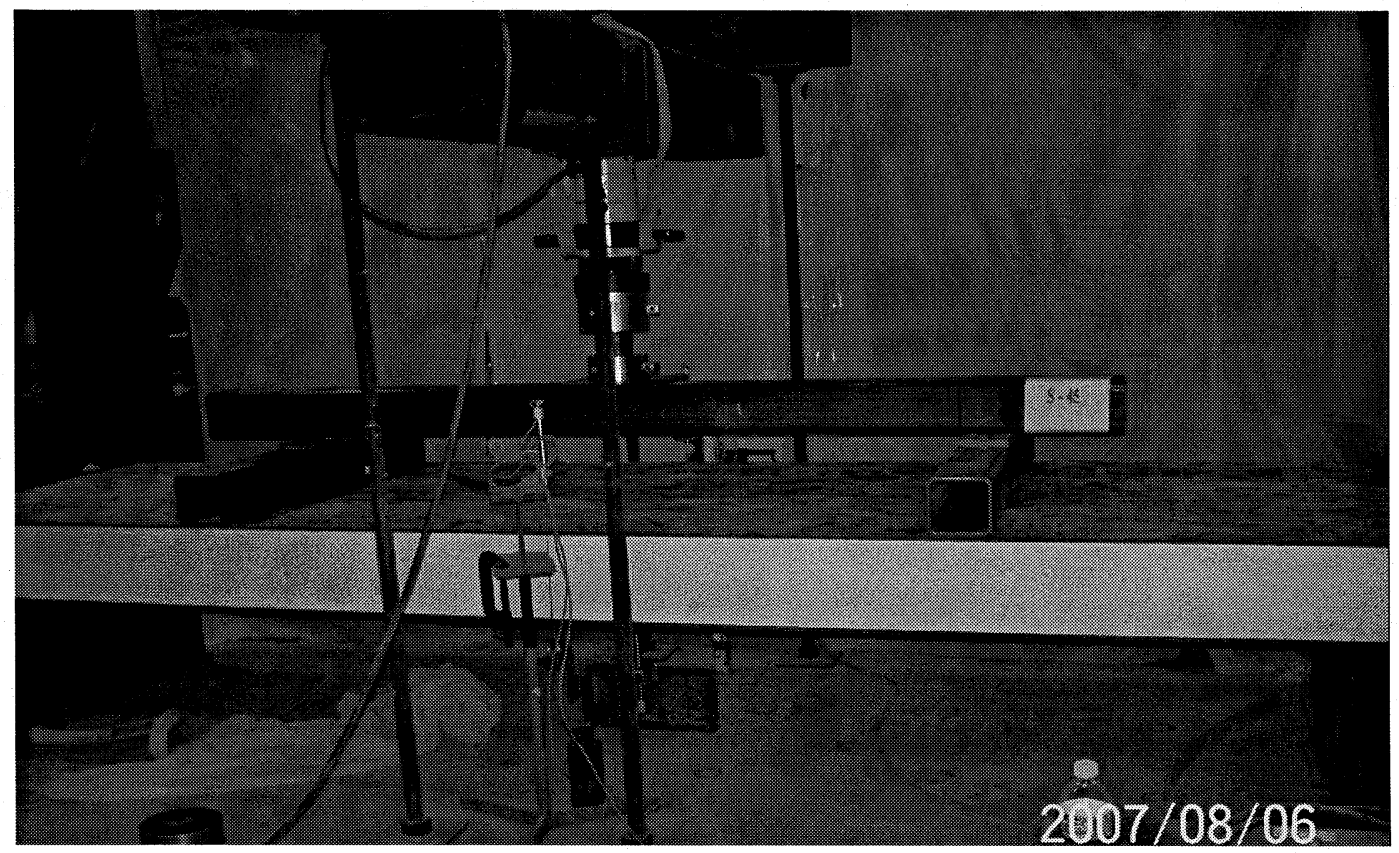

Figure AI-167. View of Specimen S-45 before testing

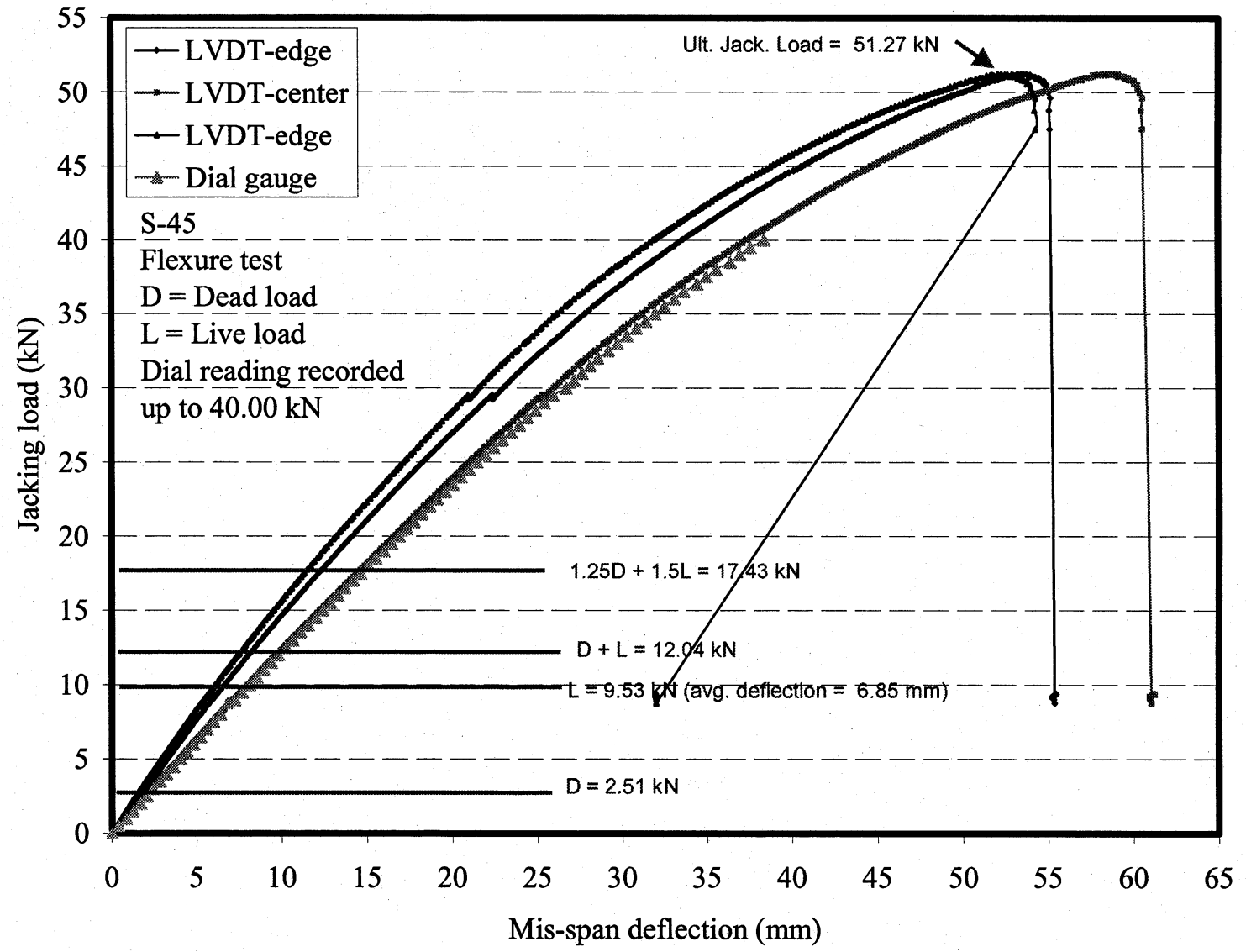

Figure AI-168 Load-deflection relationship for specimen S-45 


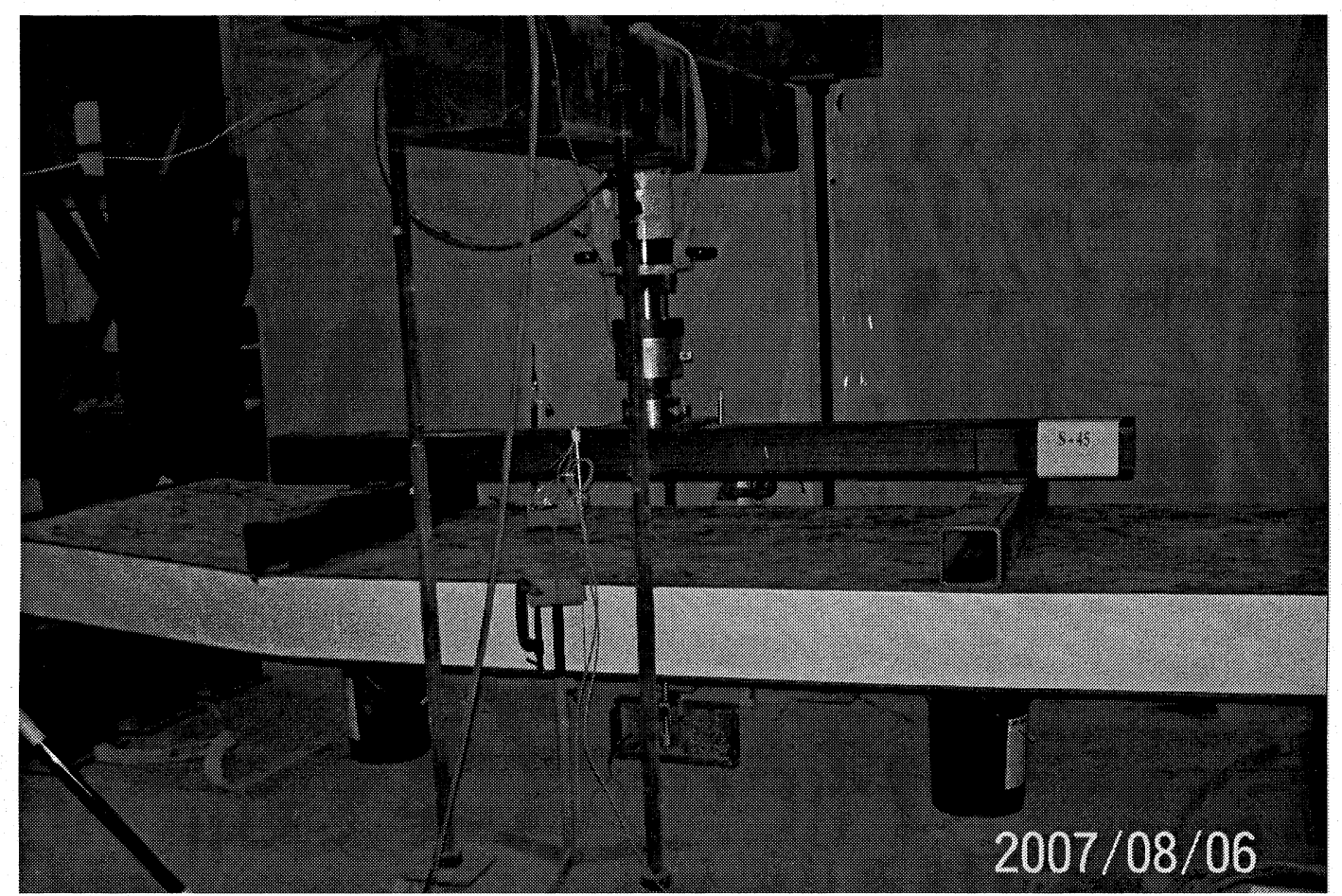

Figure AI-169. View of specimen S-45 after failure

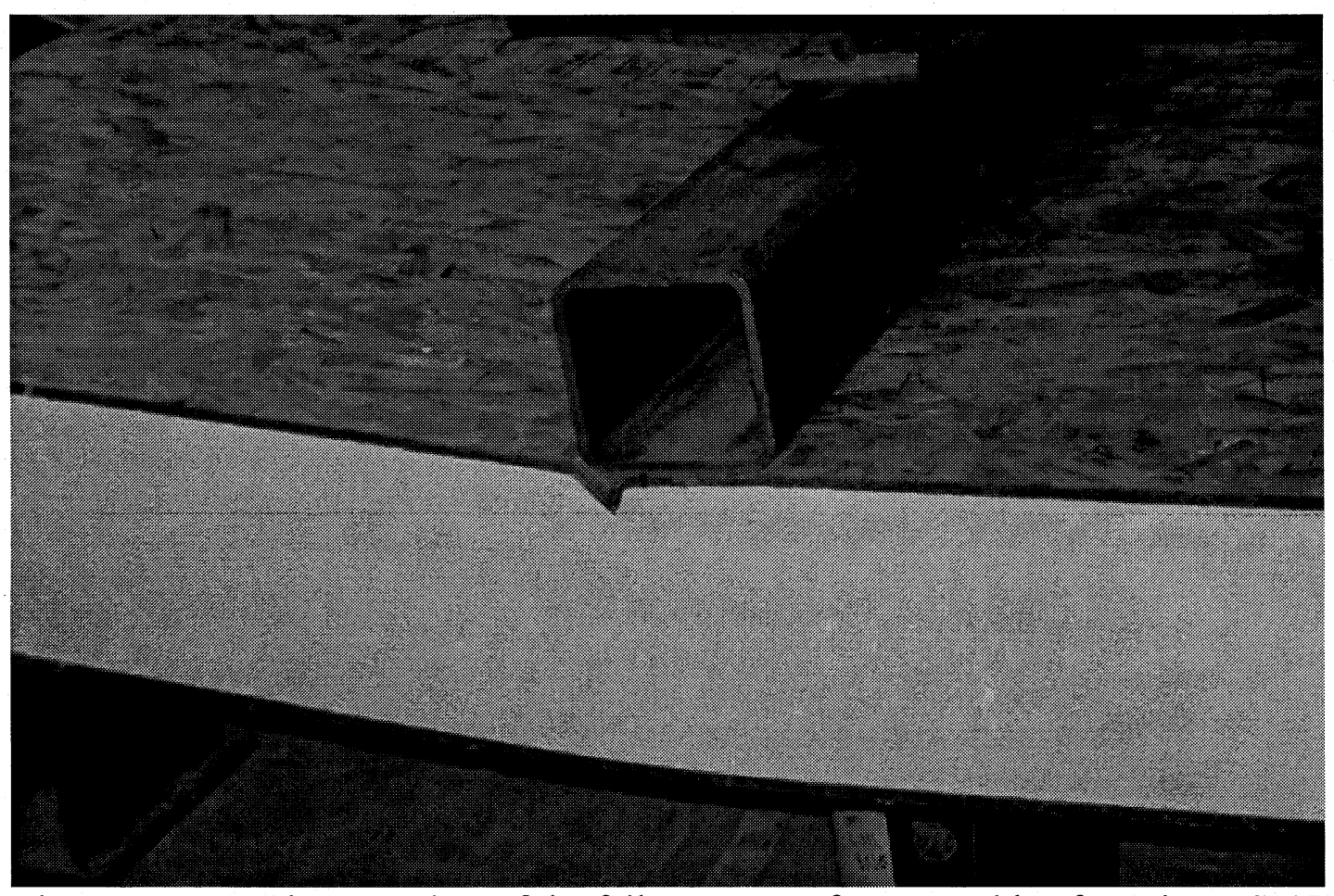

Figure AI-170. Close-up view of the failure pattern from one side of specimen S-45 


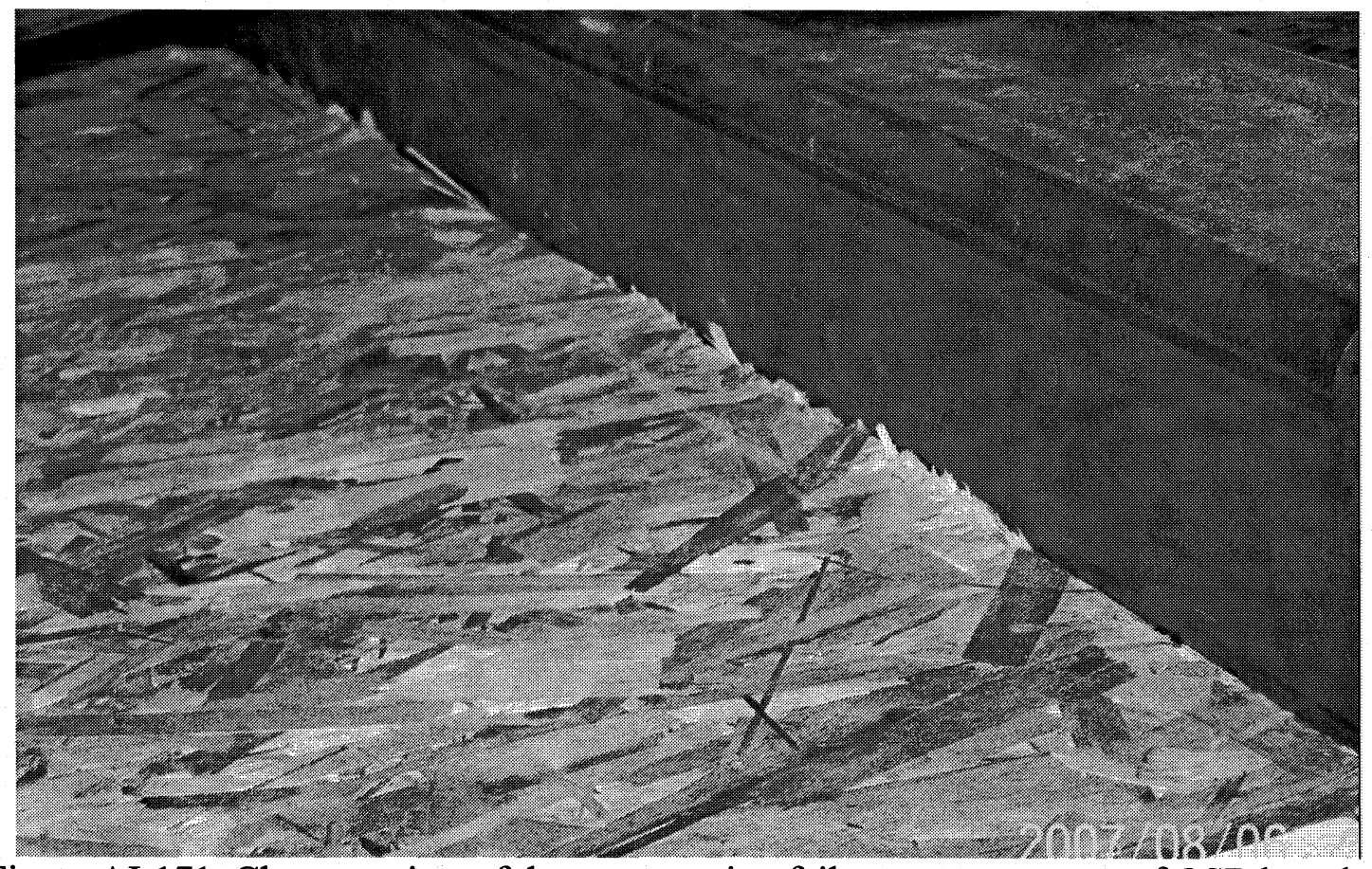

Figure AI-171. Close-up view of the compression failure pattern on top of OSB board of specimen $\mathrm{S}-45$ 


\section{GROUP L}

\section{Specimen \# S-34}

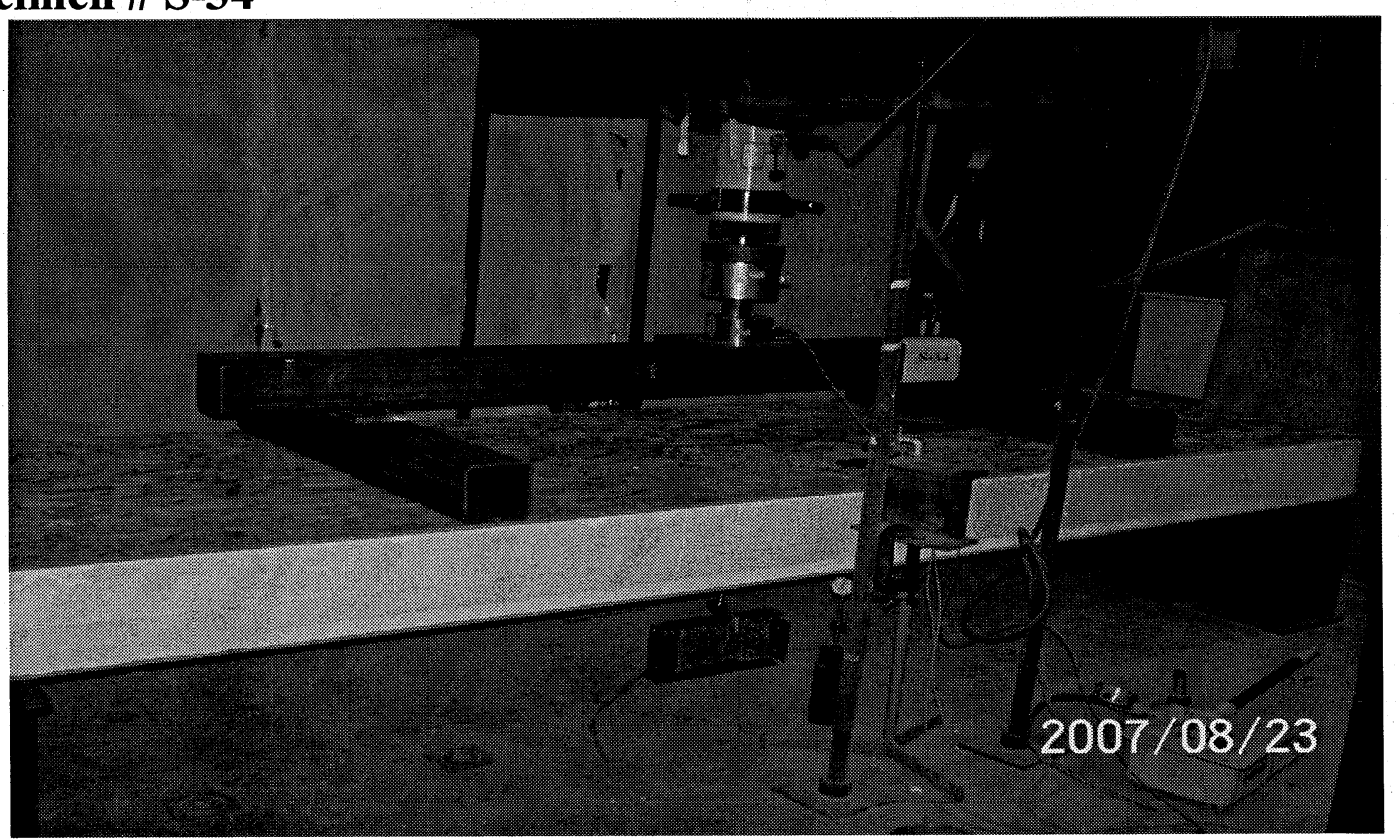

Figure A1-172. View of Specimen S-34 before testing

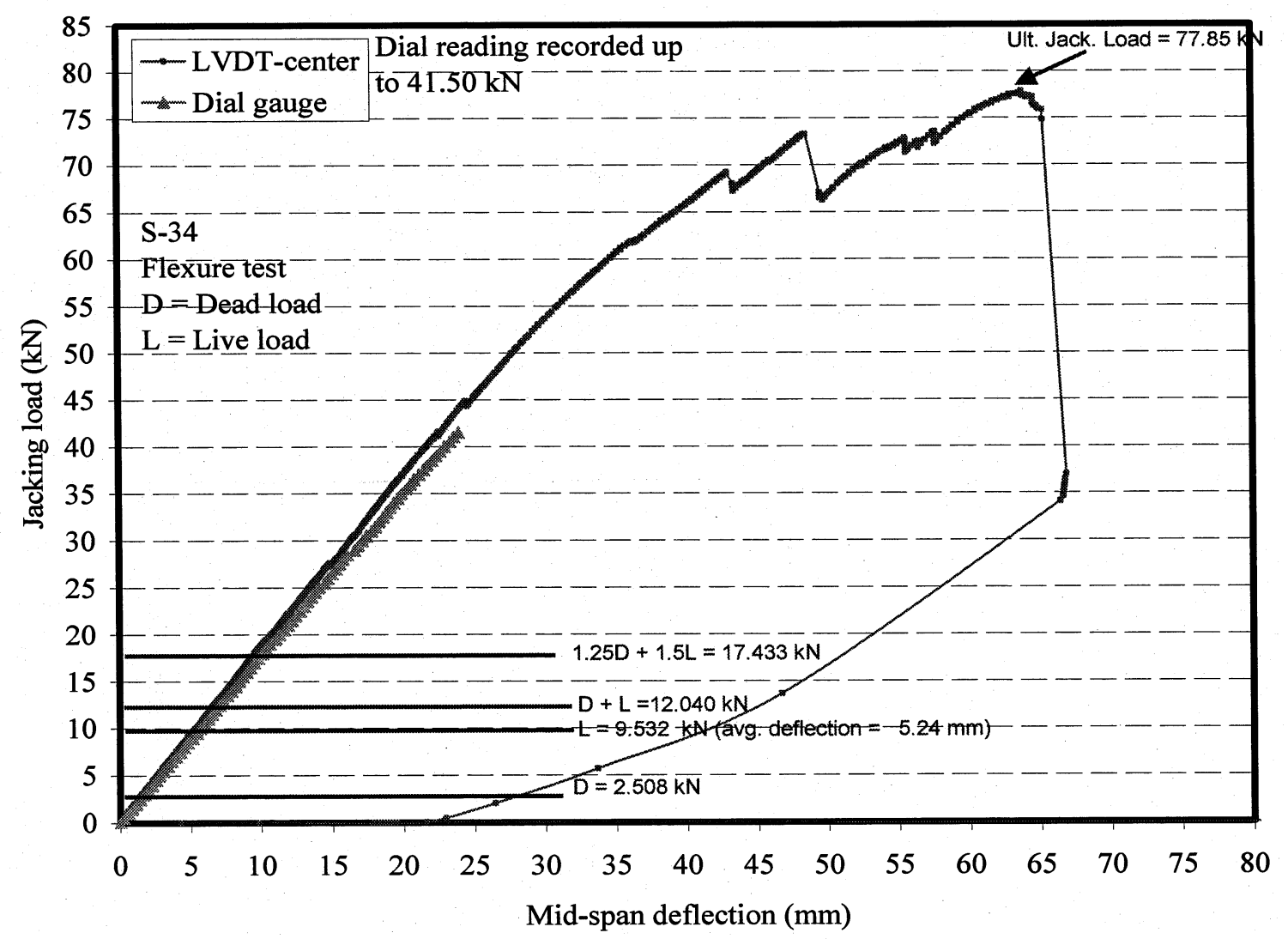

Figure AI-173. Load-deflection relationship for specimen S-34 


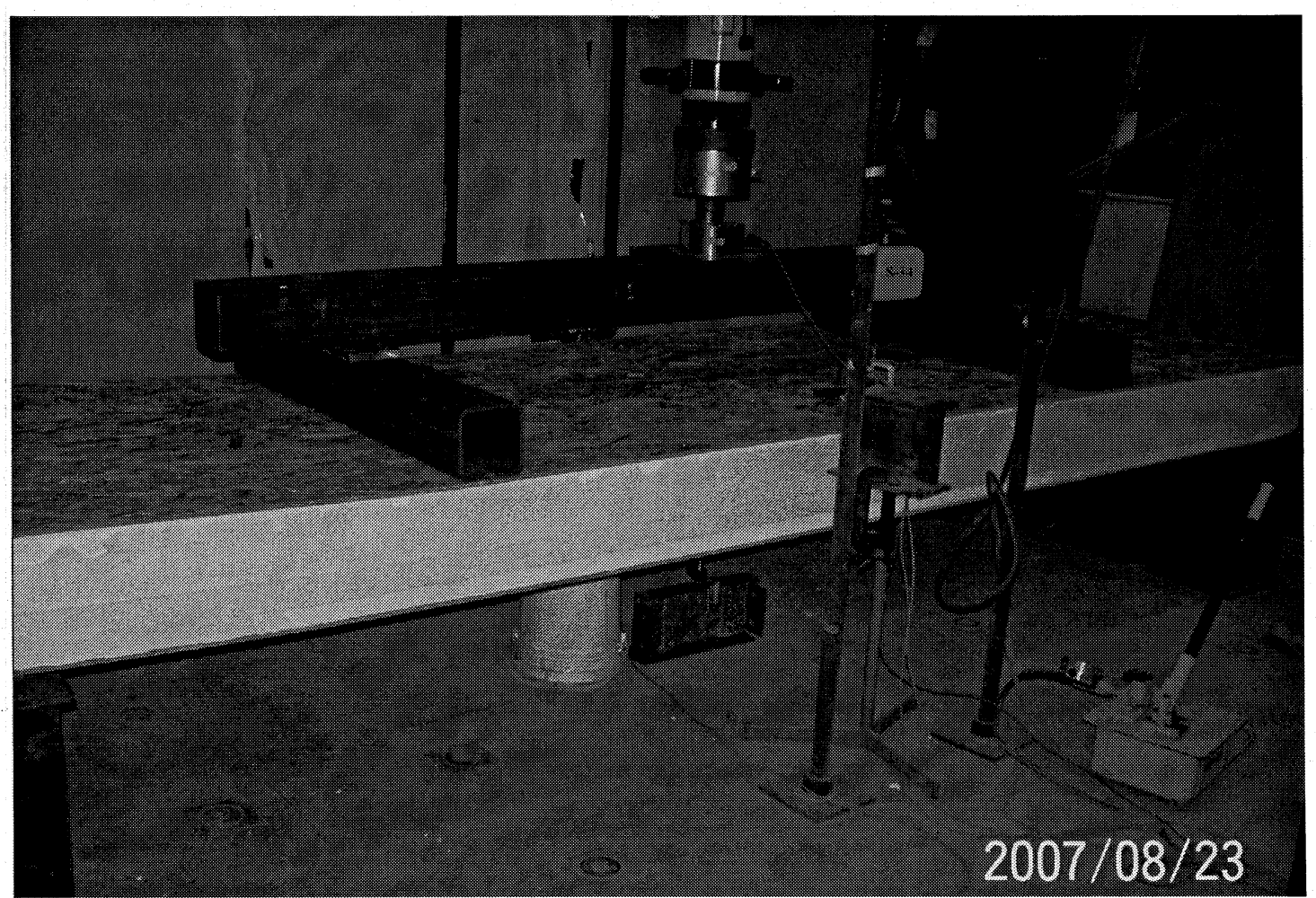

Figure AI-174. View of specimen S-34 after failure

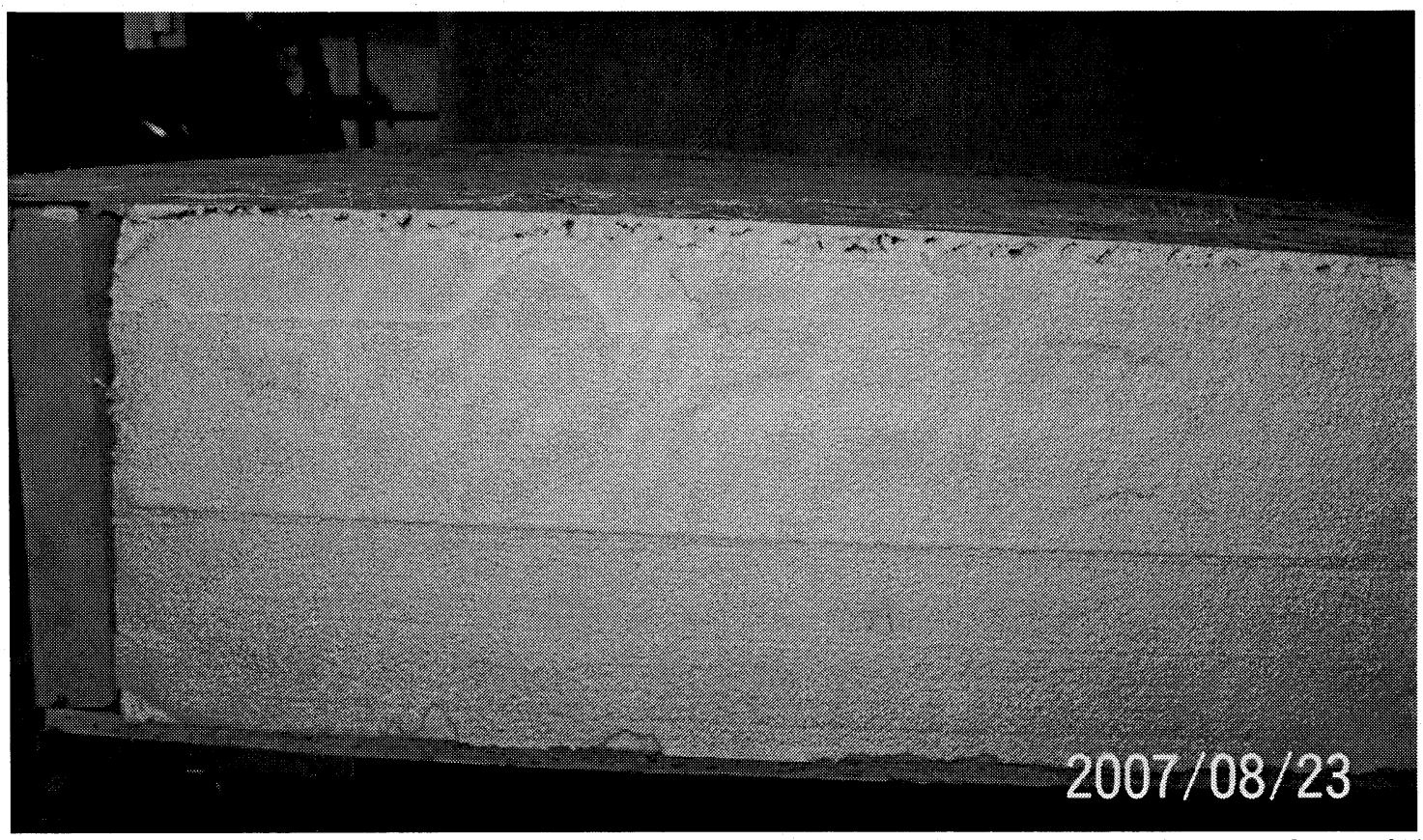

Figure AI-175. View of the horizontal shear failure of specimen S-34 at the interface of the foam and the top OSB board 


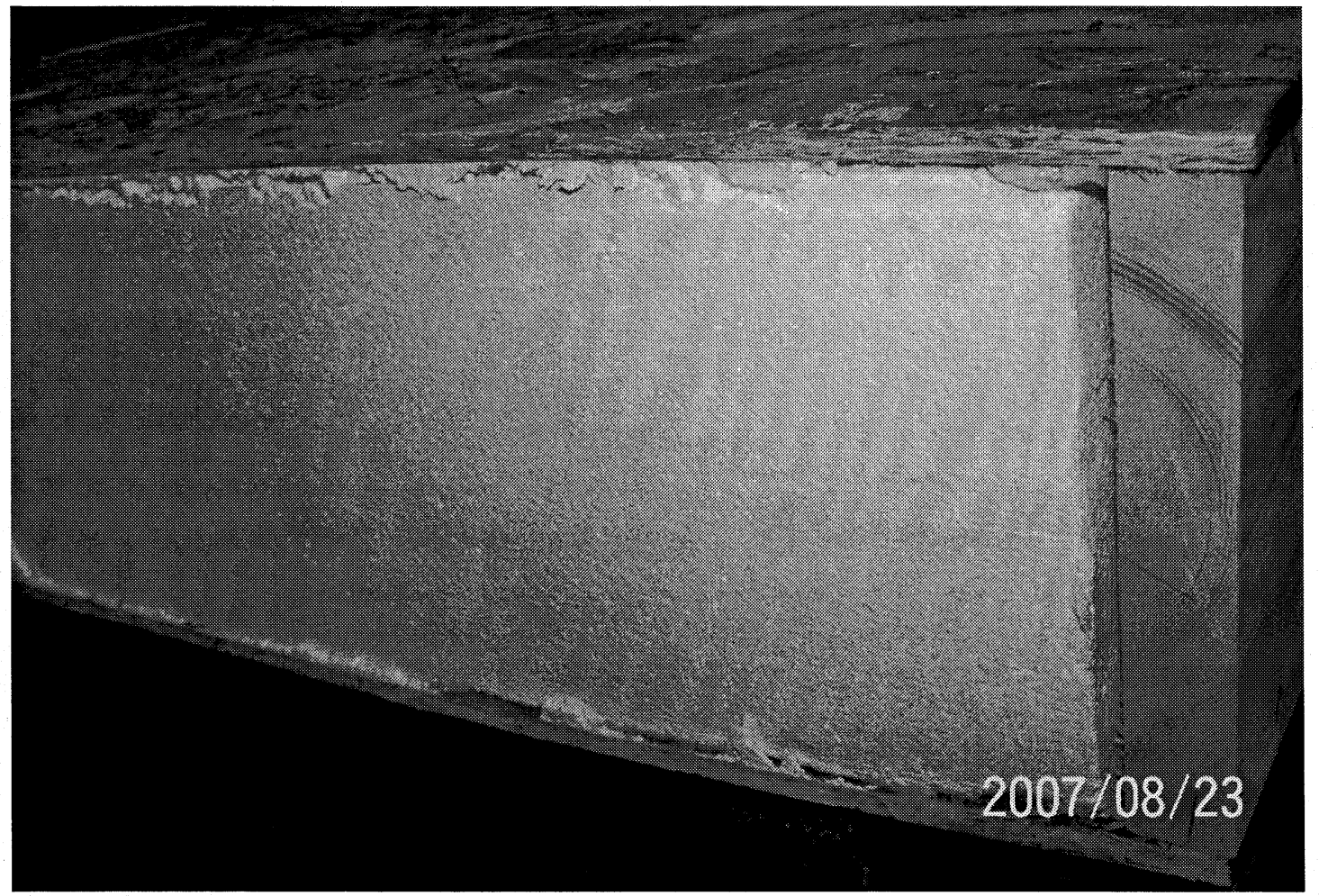

Figure AI-176. View of the horizontal shear failure at other free edge of specimen S-34 


\section{Specimen \# S-35}

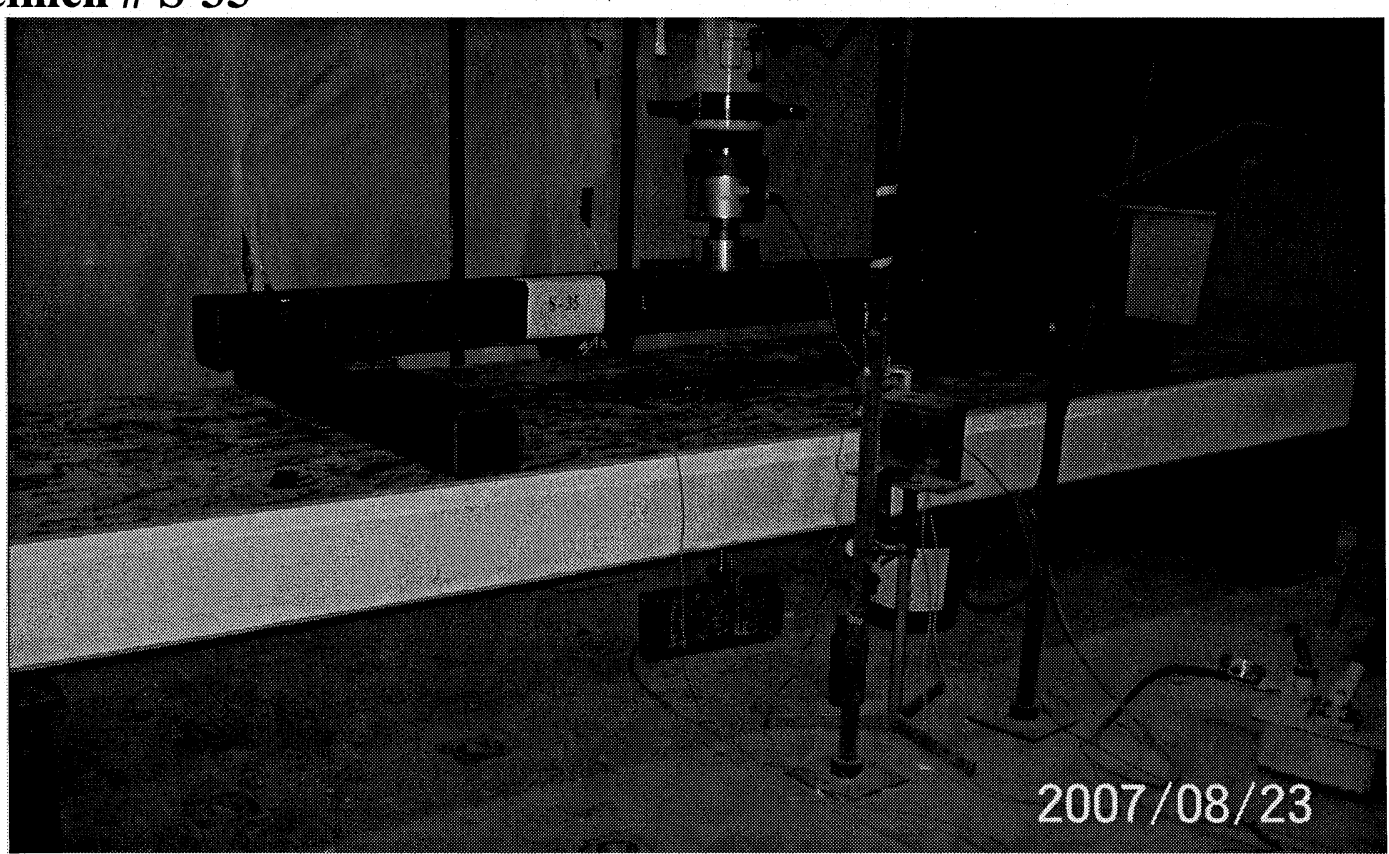

Figure AI-177. View of Specimen S-35 before testing

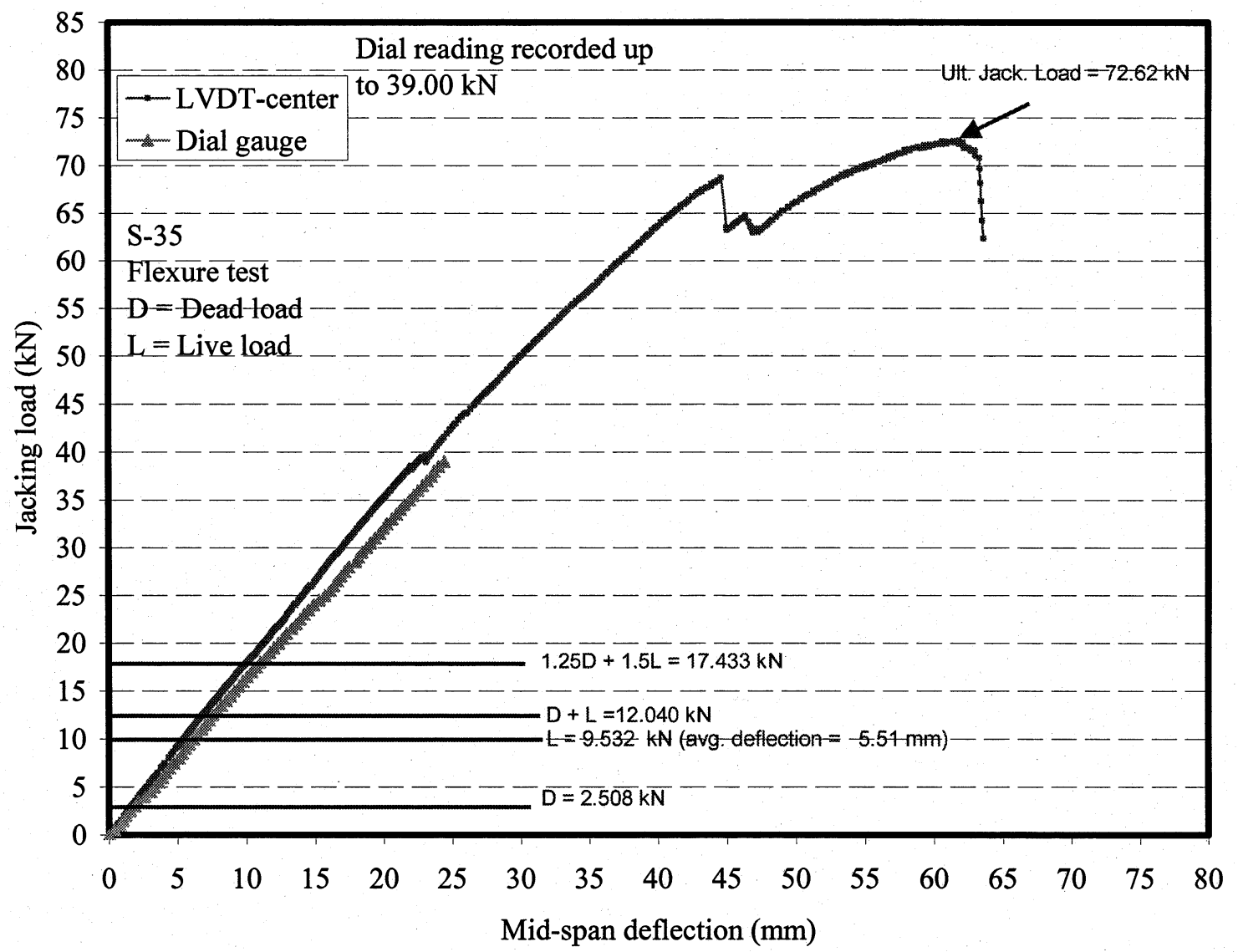

Figure AI-178. Load-deflection relationship for specimen S-35 


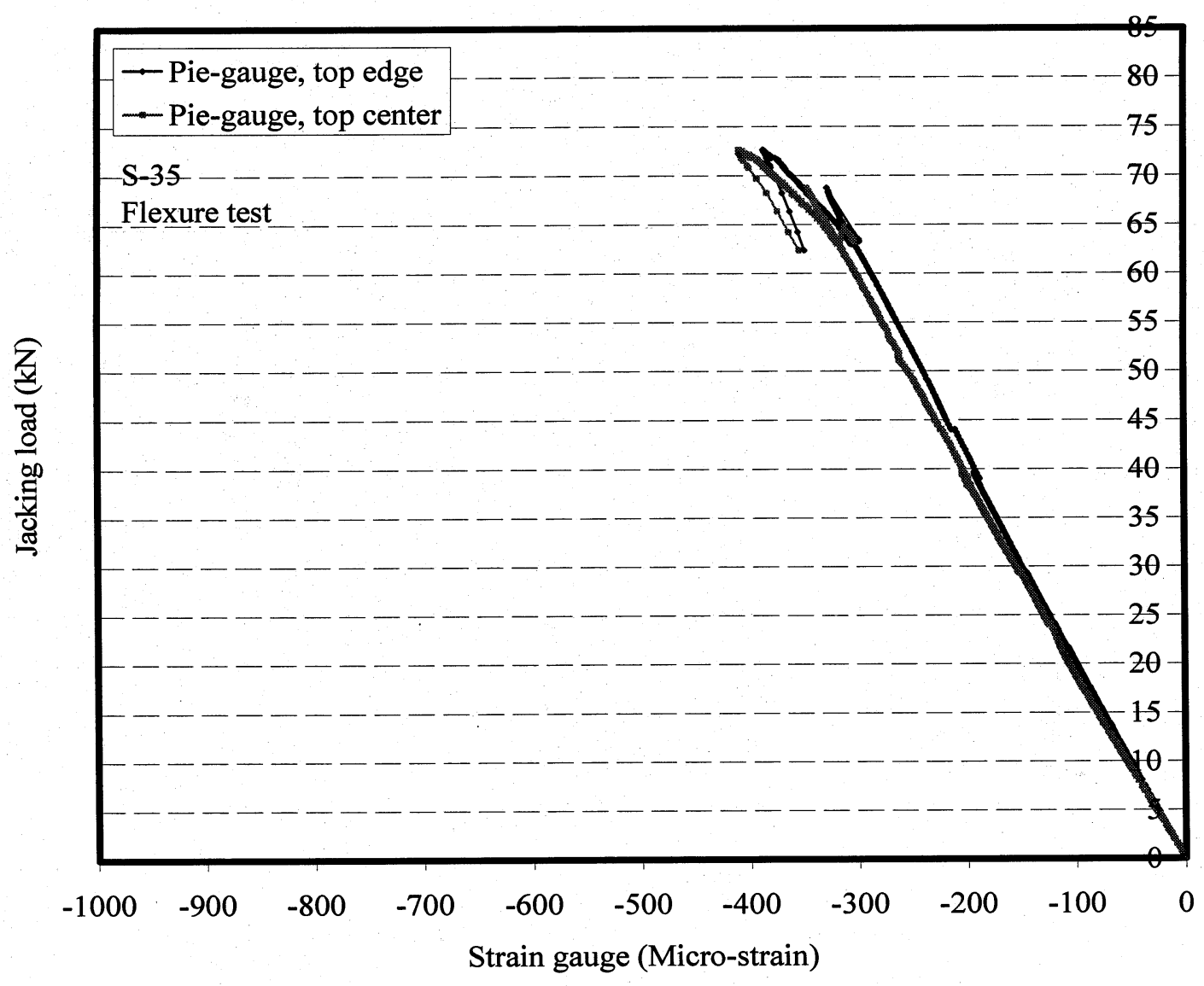

Figure AI-179. Load-strain relationship for specimen S-35

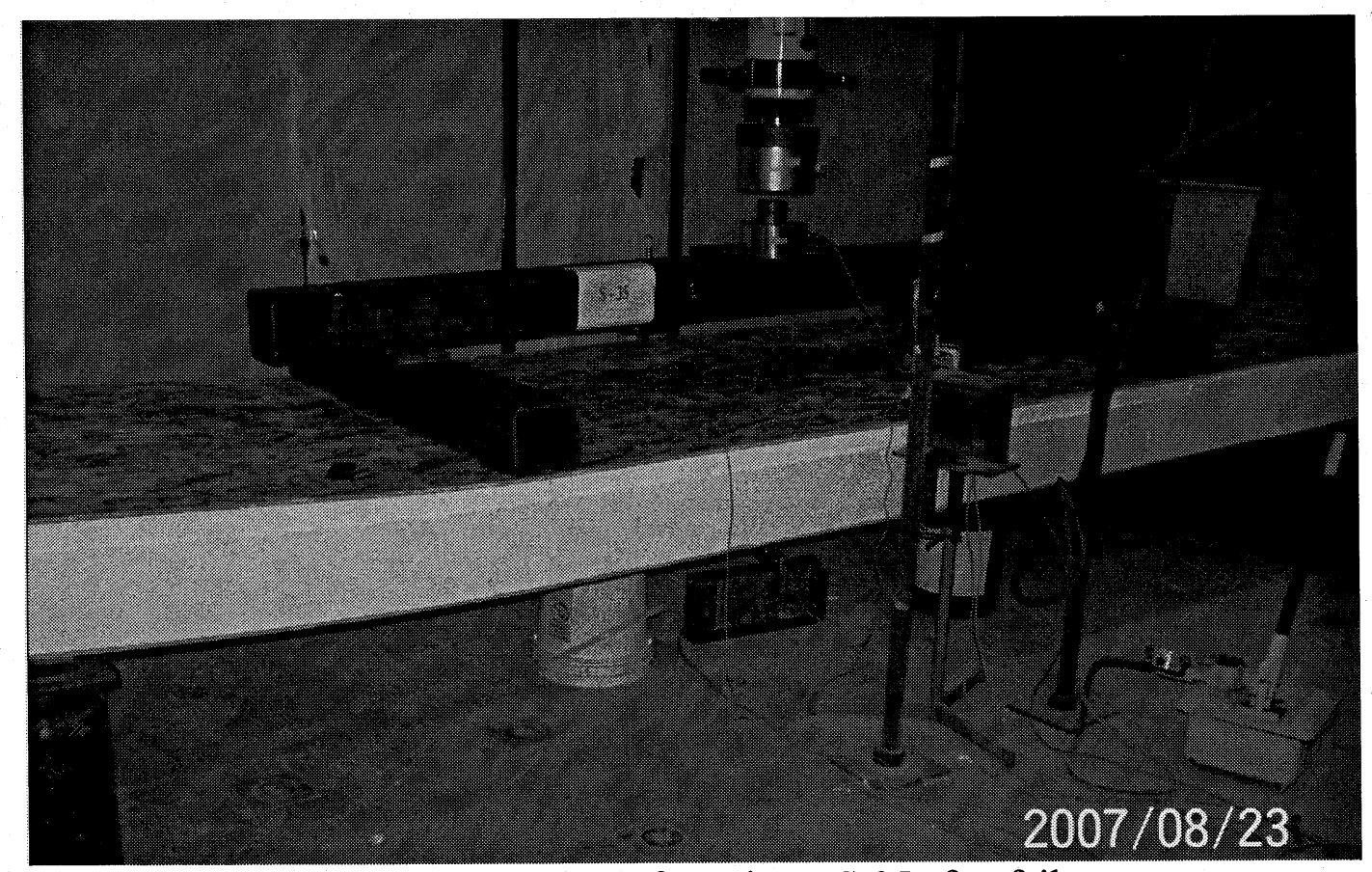

Figure AI-180. View of specimen S-35 after failure 


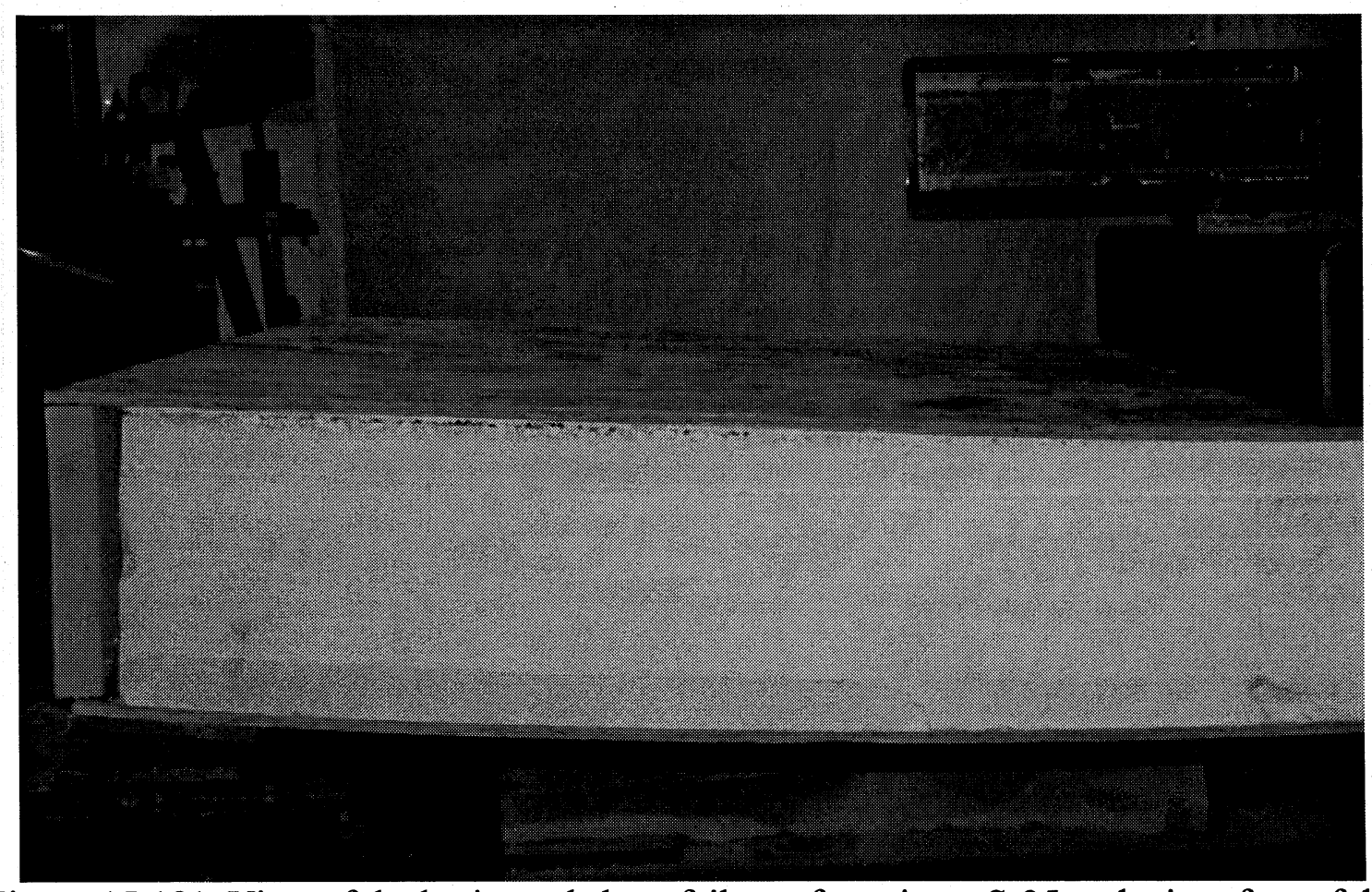

Figure AI-181. View of the horizontal shear failure of specimen S-35 at the interface of the foam and the top OSB board 


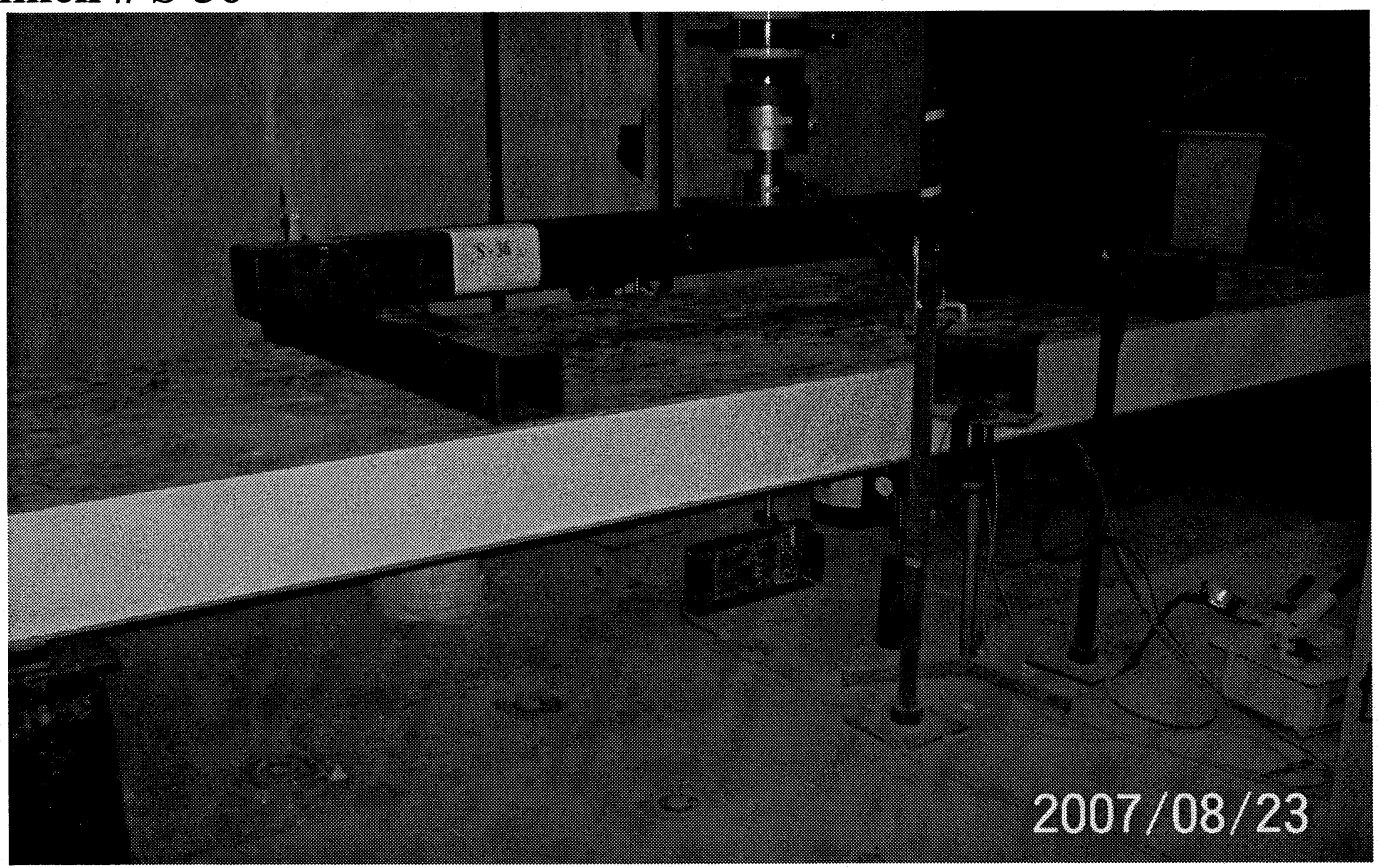

Figure AI-182. View of Specimen S-36 before testing

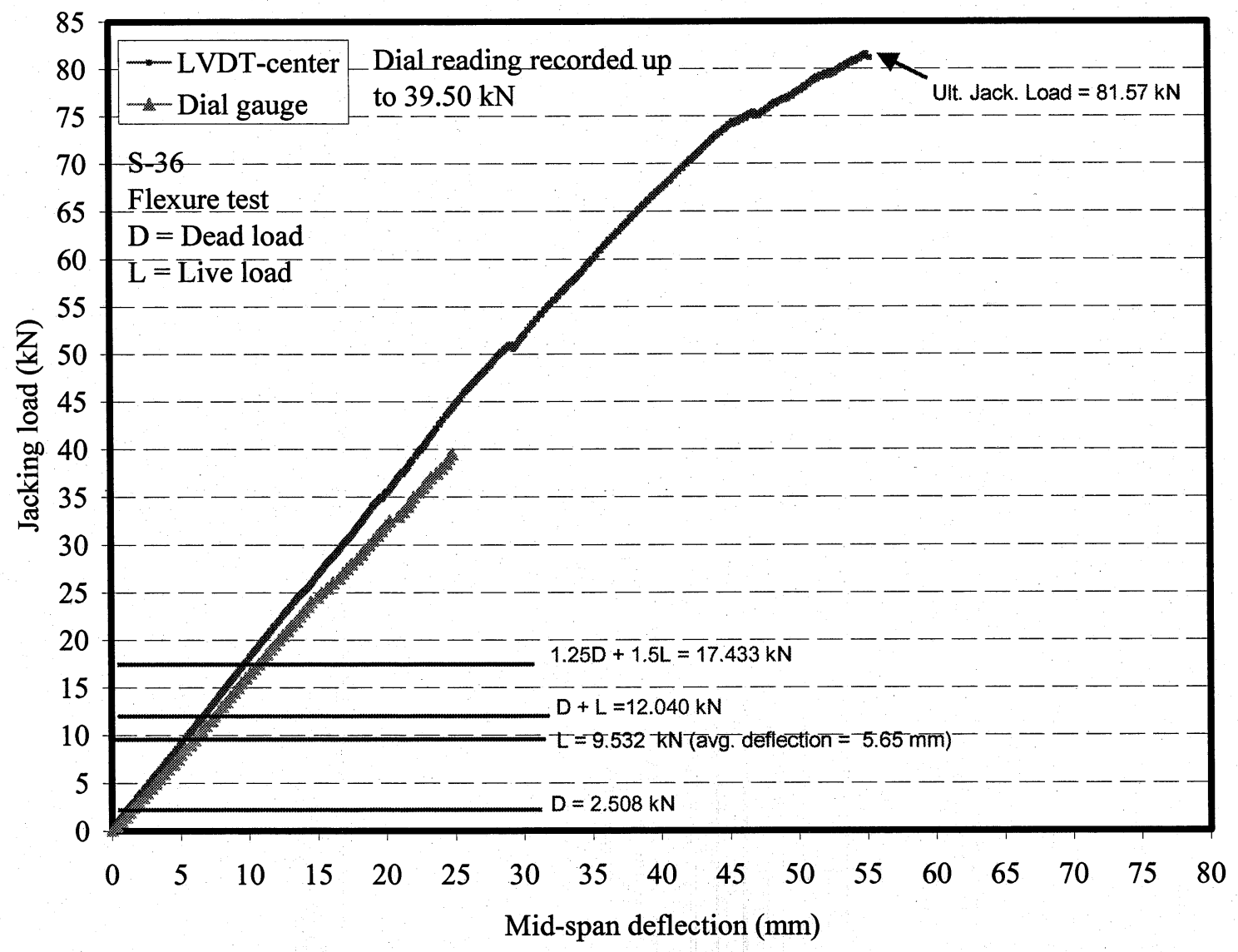

Figure AI-183. Load-deflection relationship for specimen S-36 


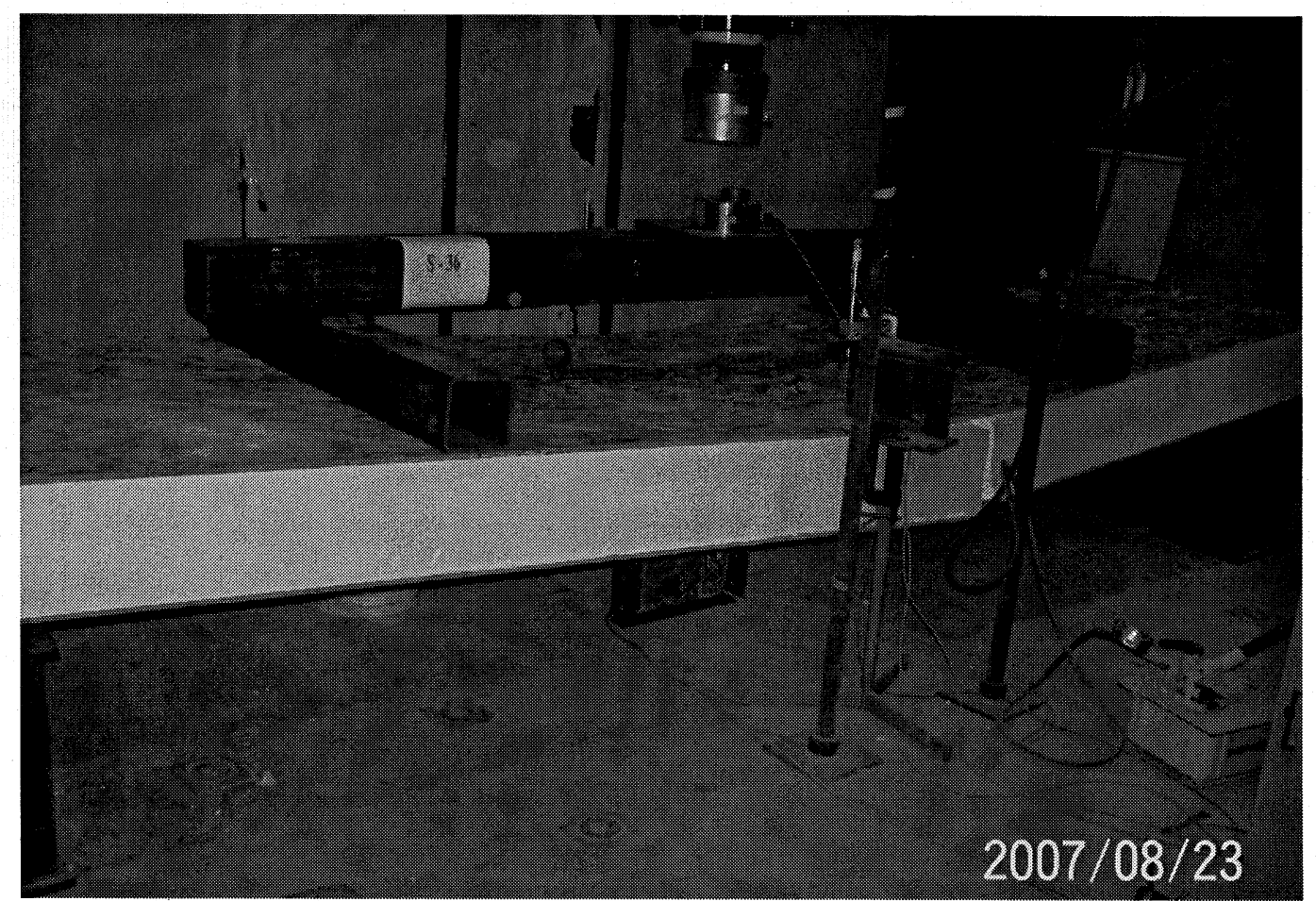

Figure AI-184. View of specimen S-36 after failure

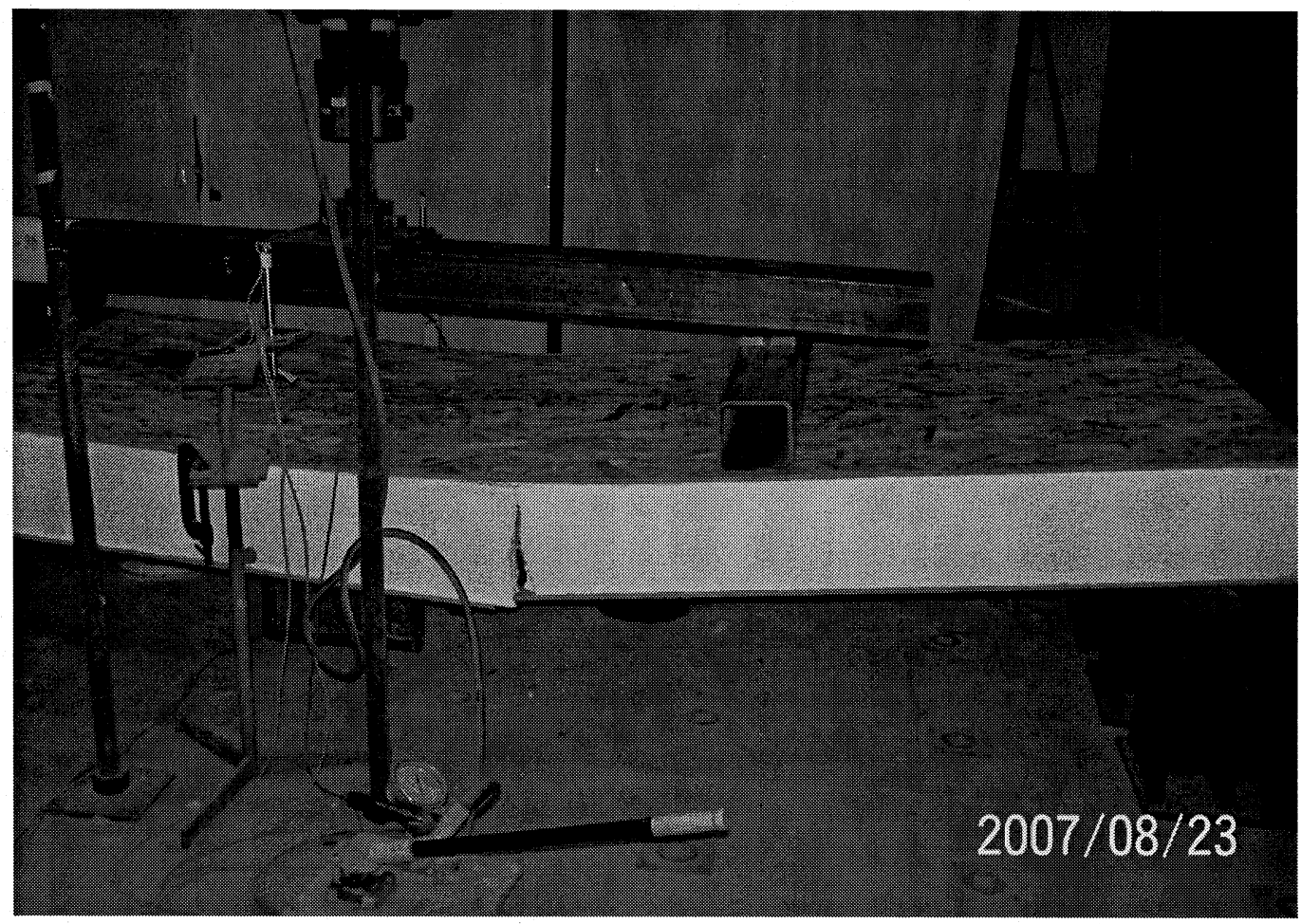

Figure AI-185. Other view of specimen S-36 after failure 


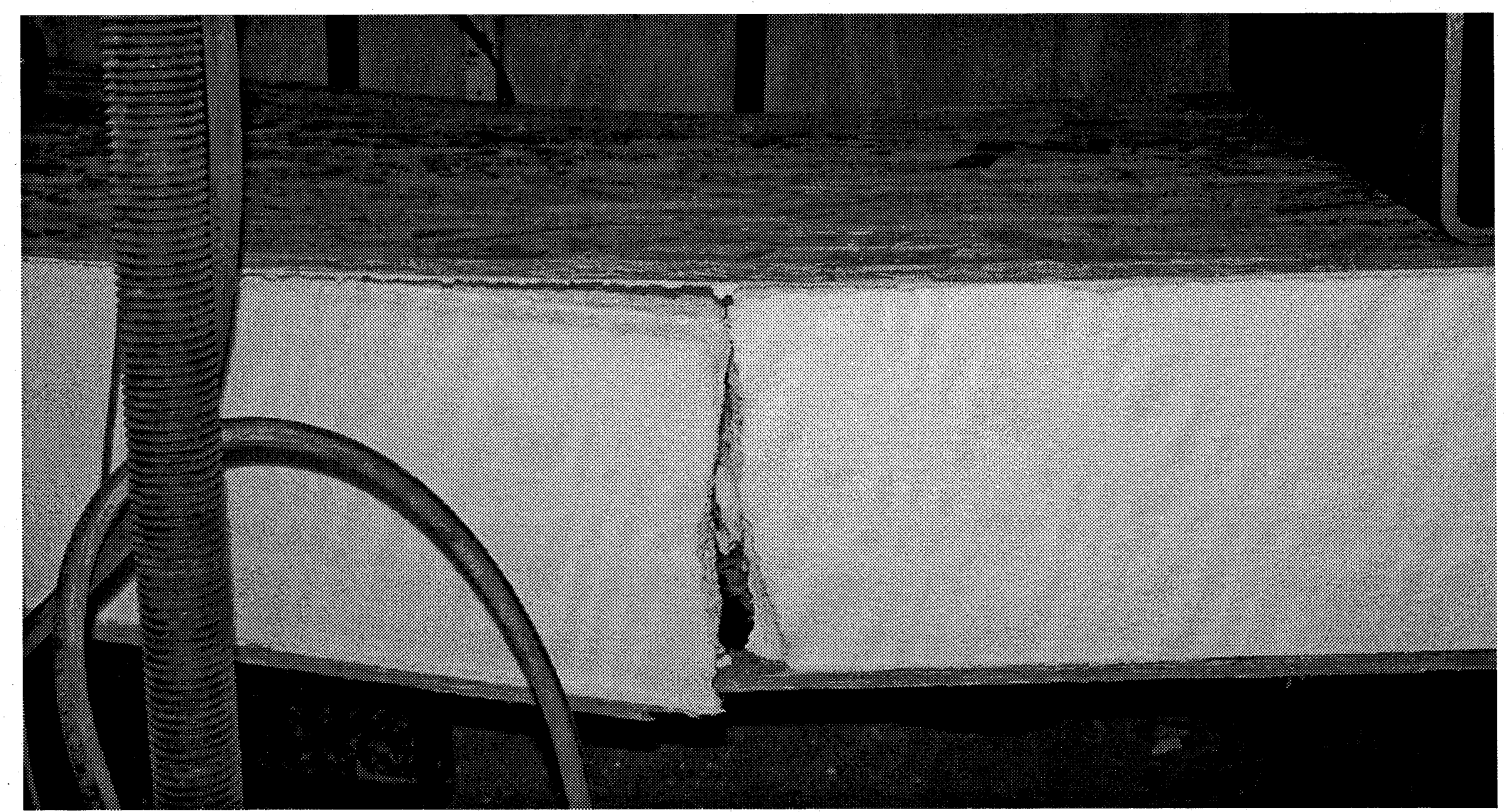

Figure AI-186.Close up of flexural failure on one free edge of specimen S-36

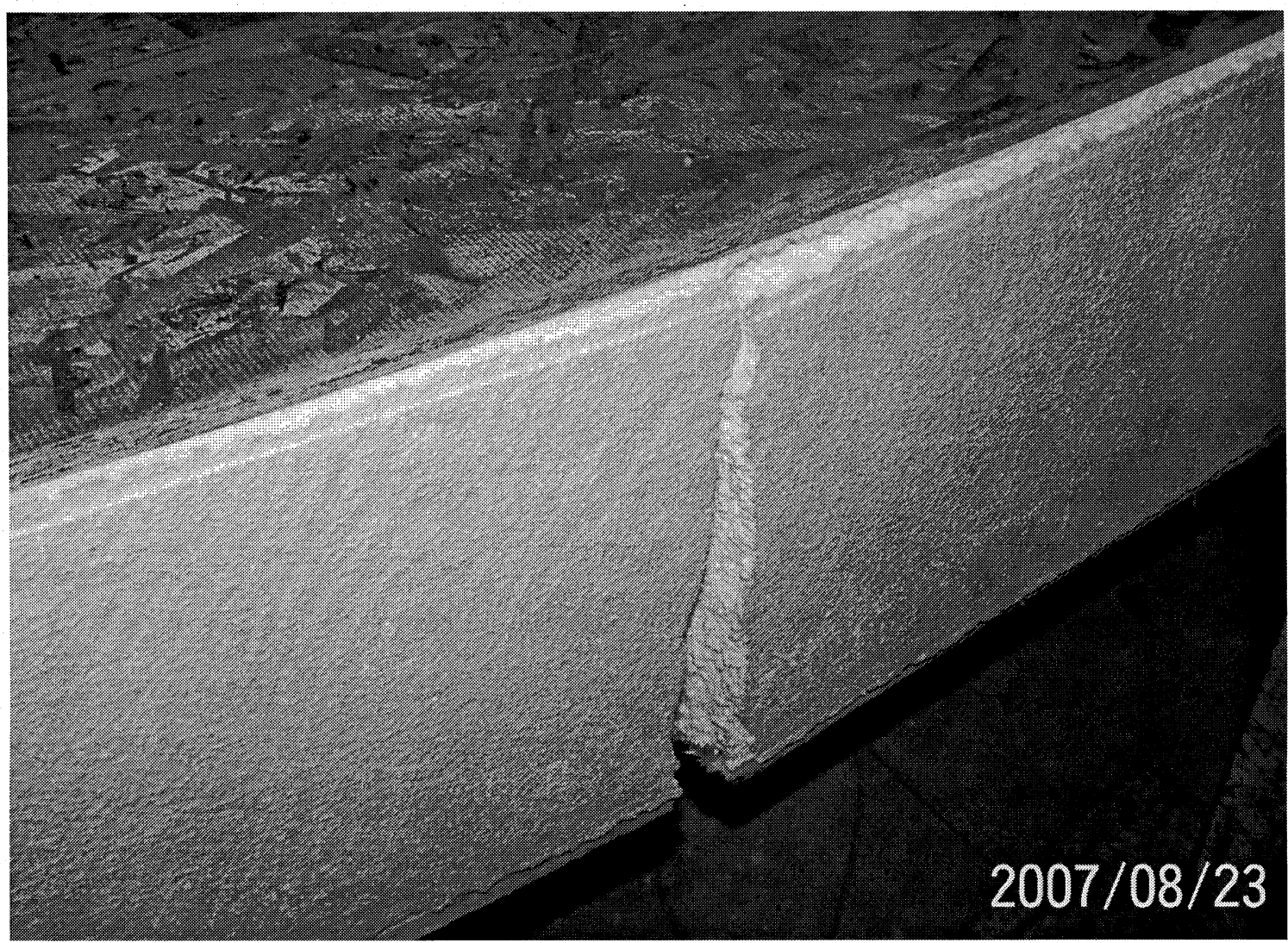

Figure AI-187.Close up of flexural failure on the other free edge of specimen S-36 


\section{GROUP M}

\section{Specimen \# S-37}

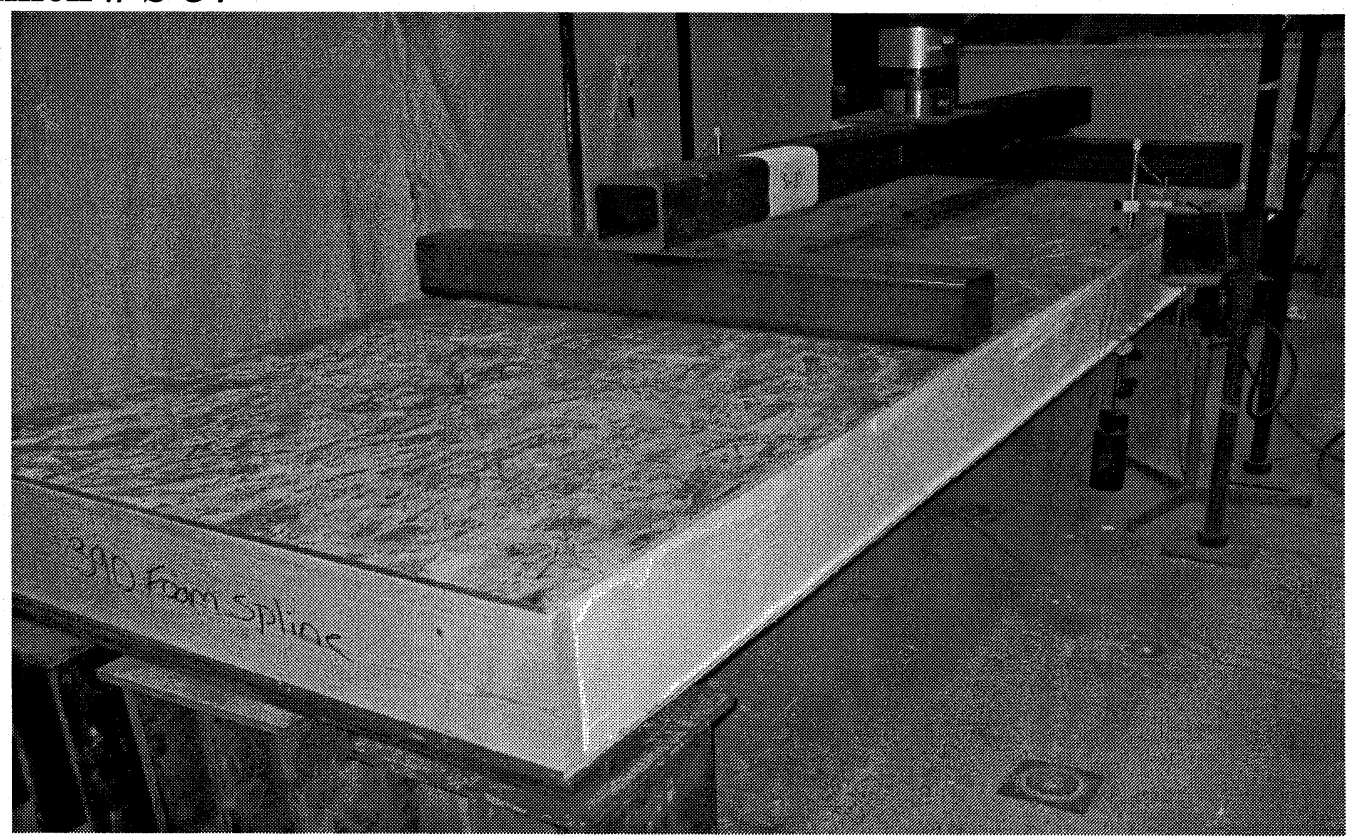

Figure AI-188. View of Specimen S-37 before testing

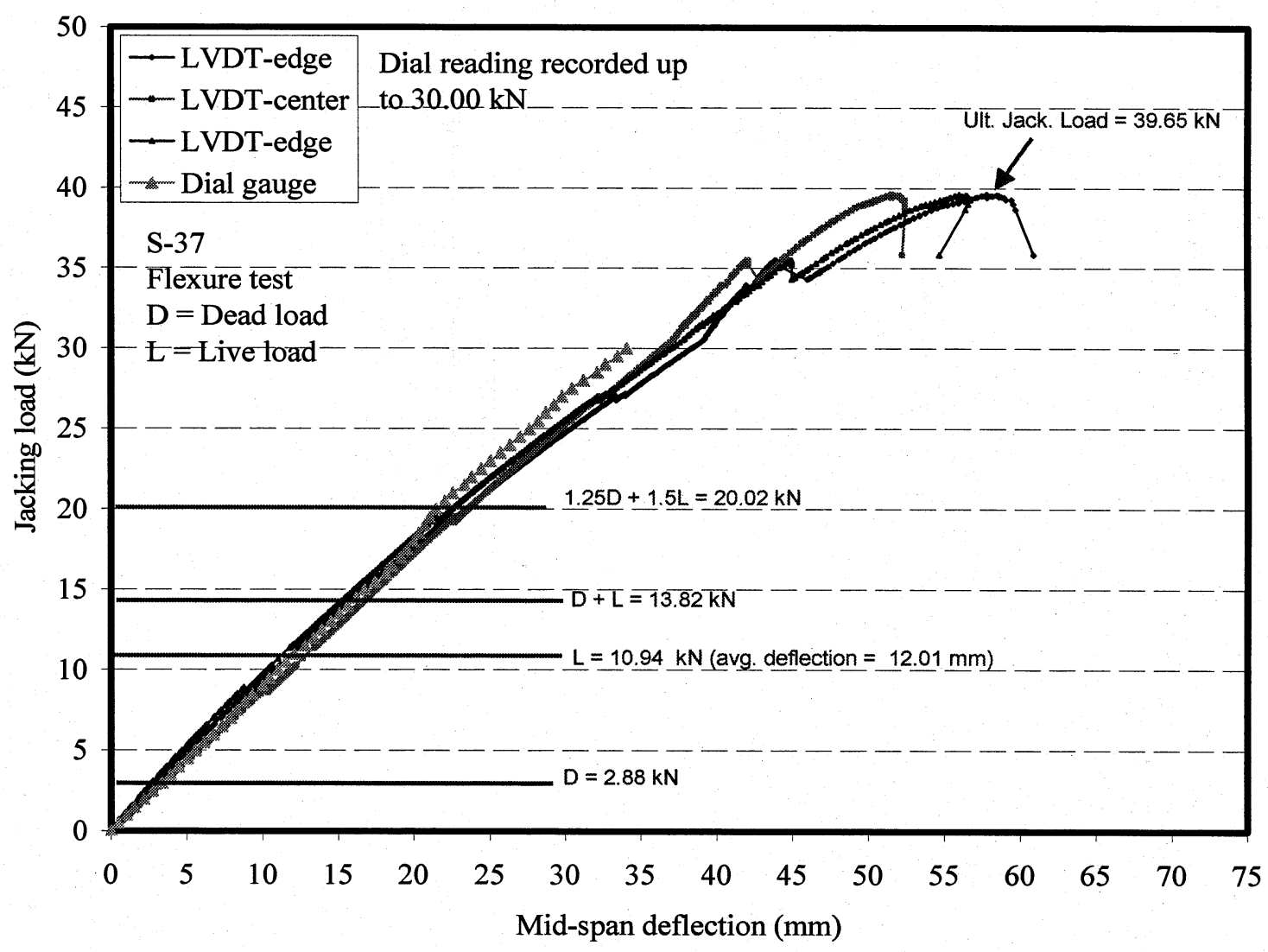

Figure AI-189. Load-deflection relationship for specimen S-37 


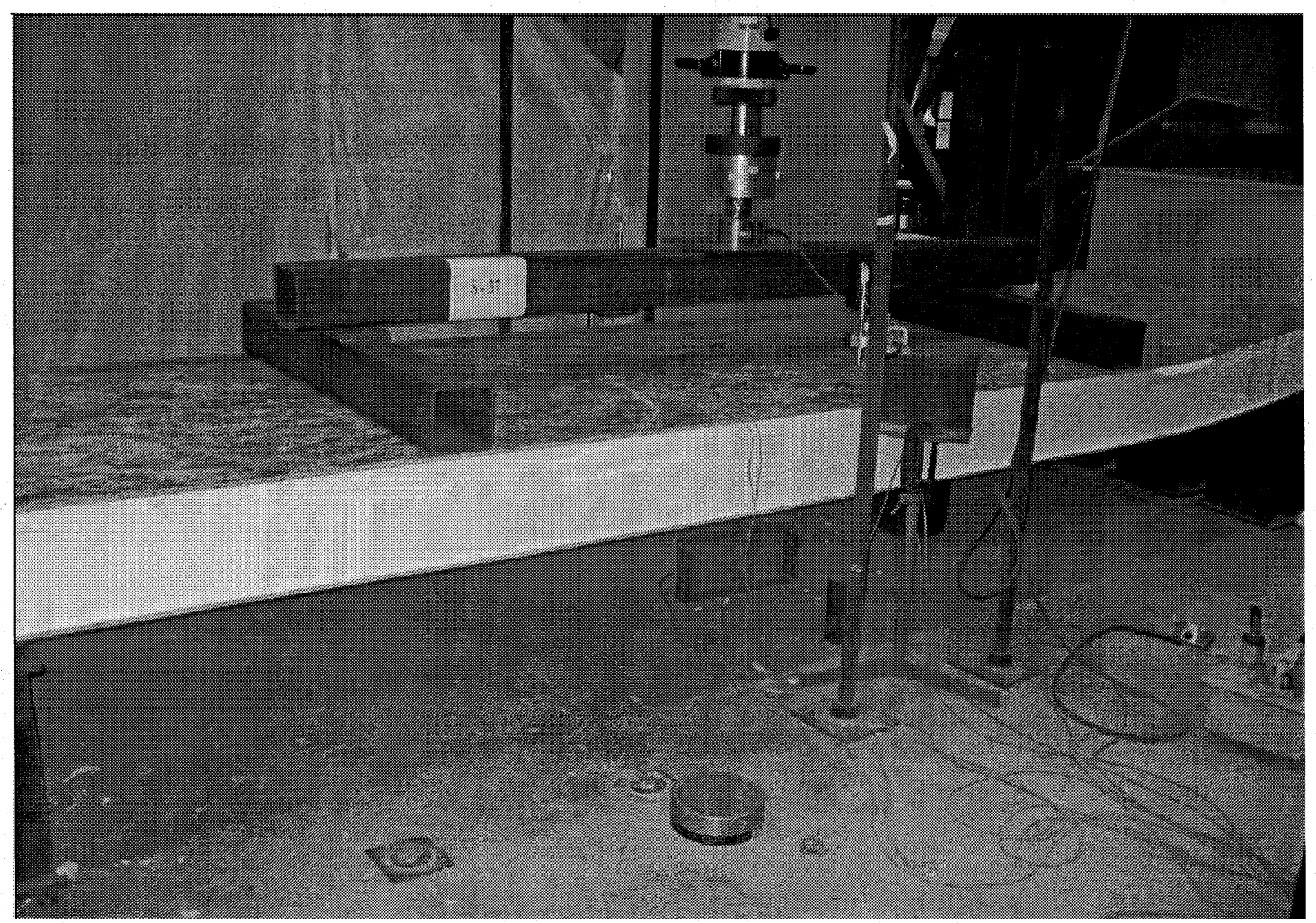

Figure AI-190. View of specimen S-37 after failure

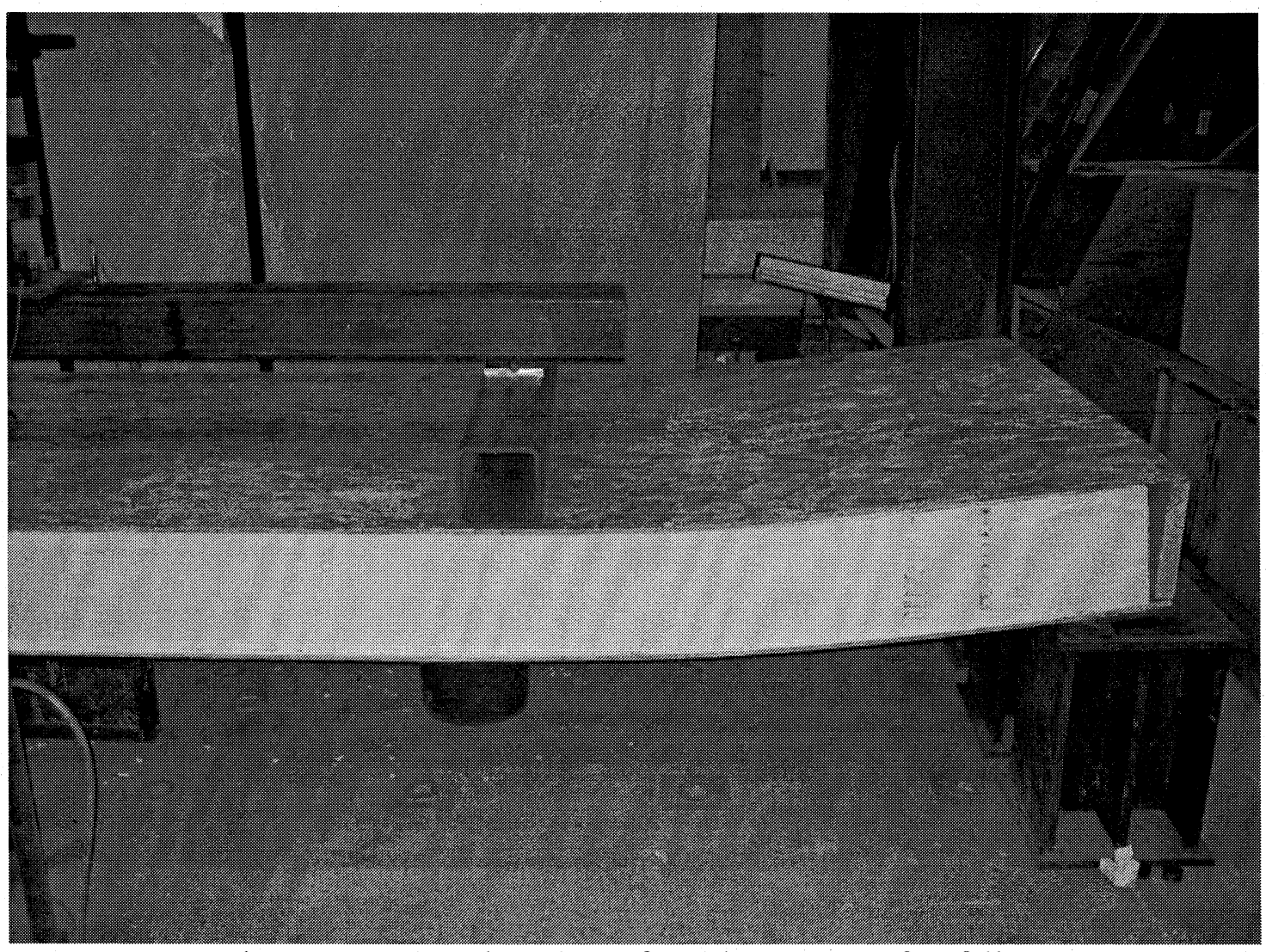

Figure AI-191. Other view of specimen S-37 after failure 


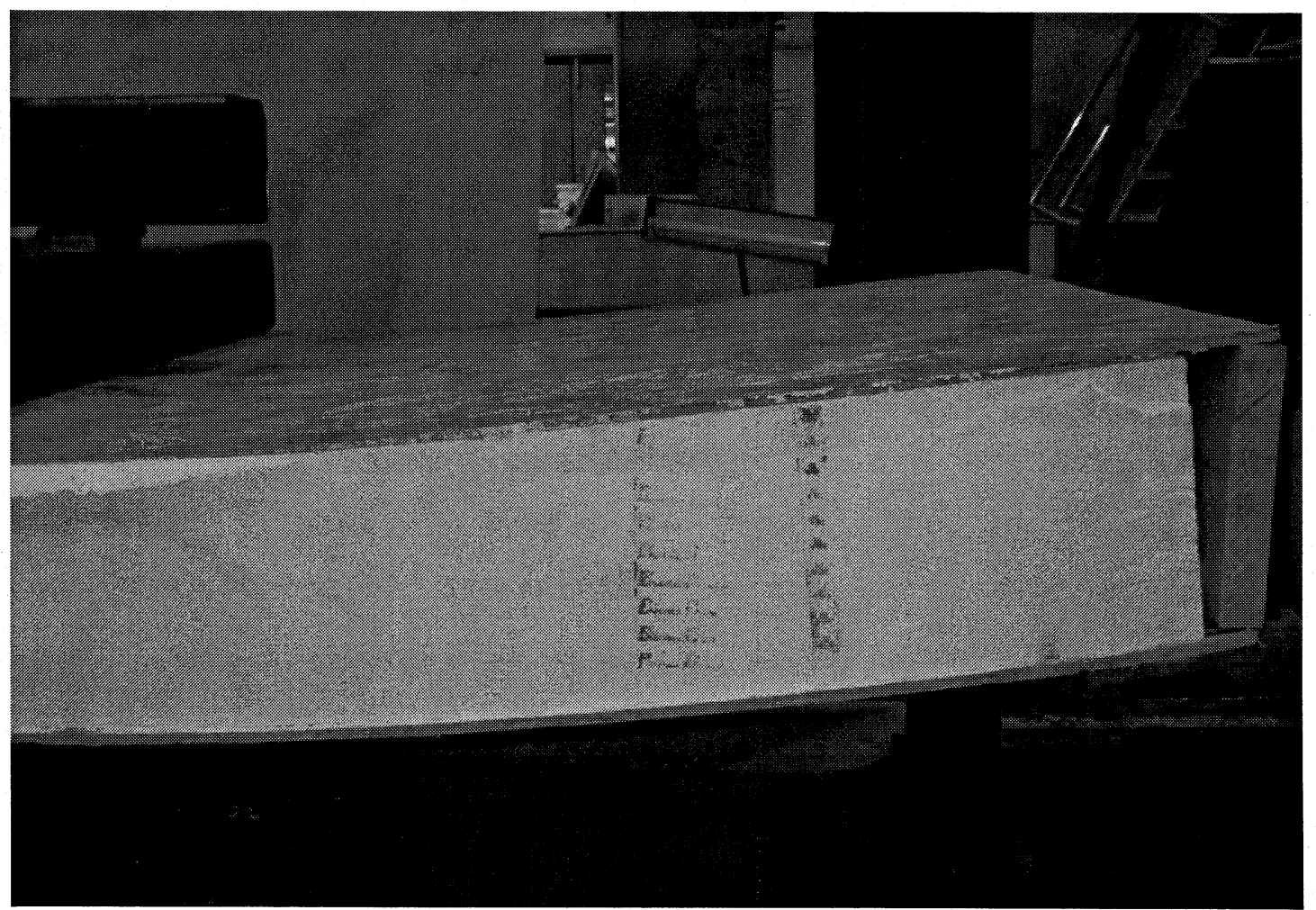

Figure AI-192.Close up of flexural failure on the free edge of specimen S-37 


\section{Specimen \# S-38}

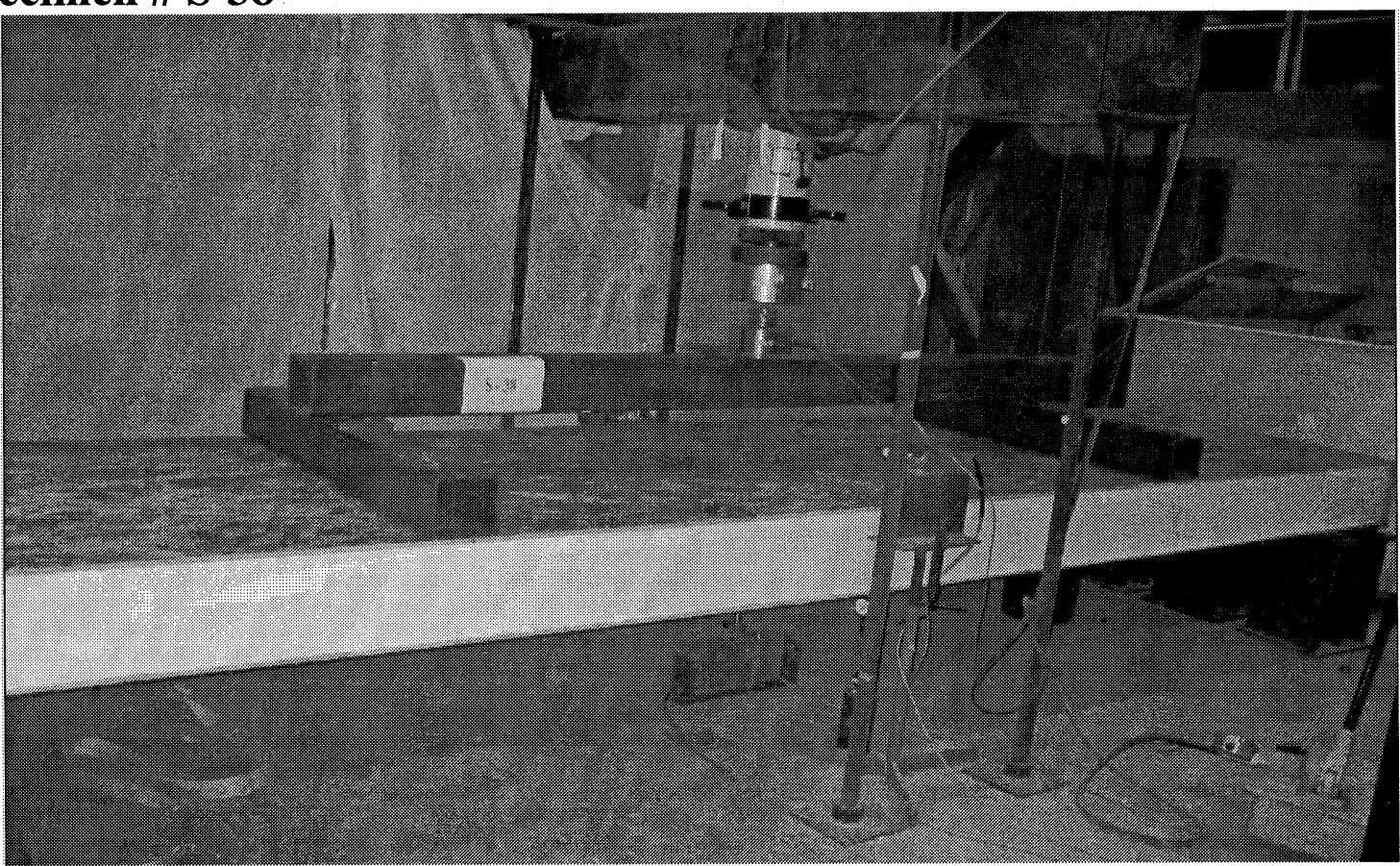

Figure AI-193. View of Specimen S-38 before testing

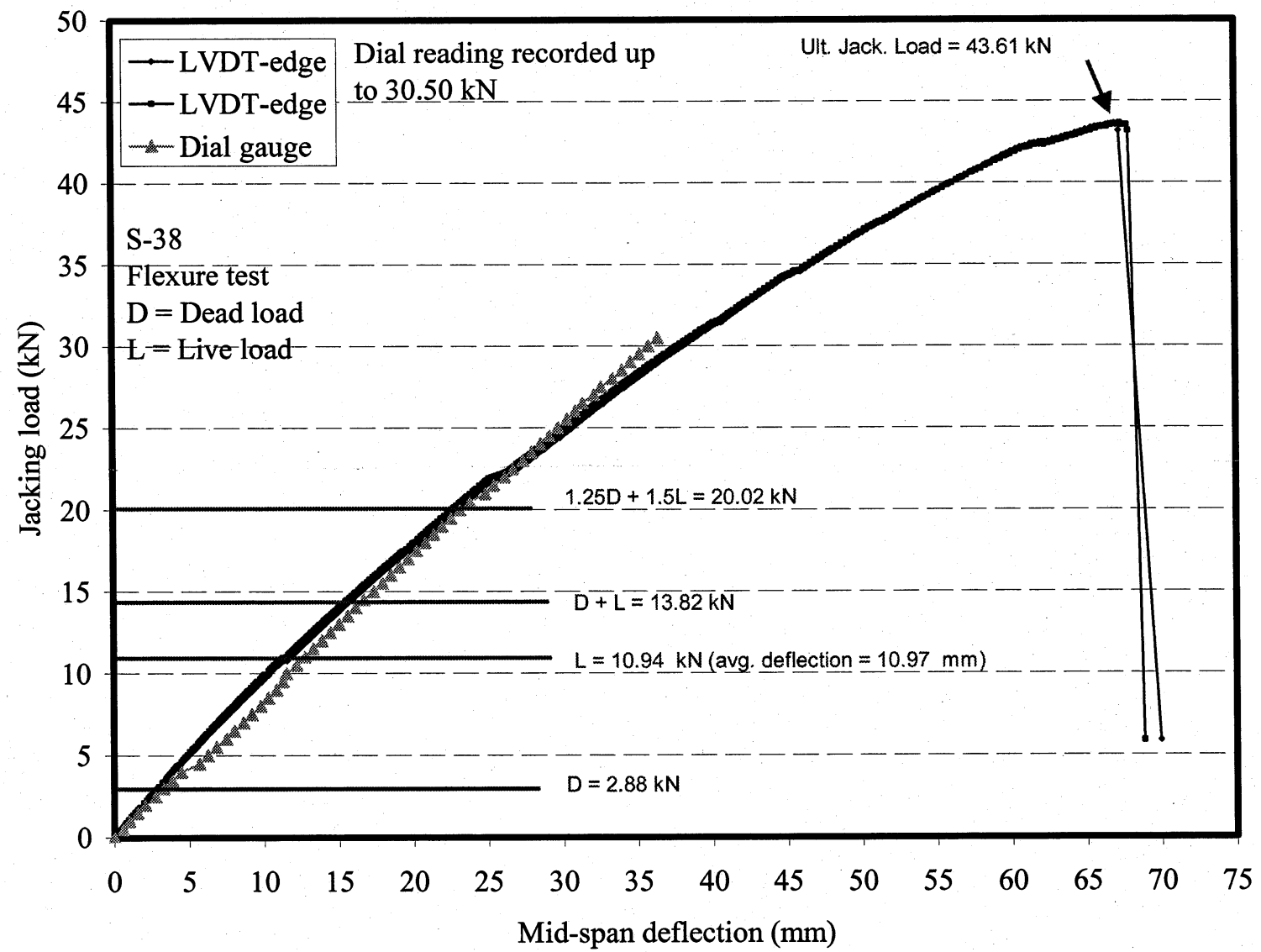

Figure AI-194. Load-deflection relationship for specimen S-38 


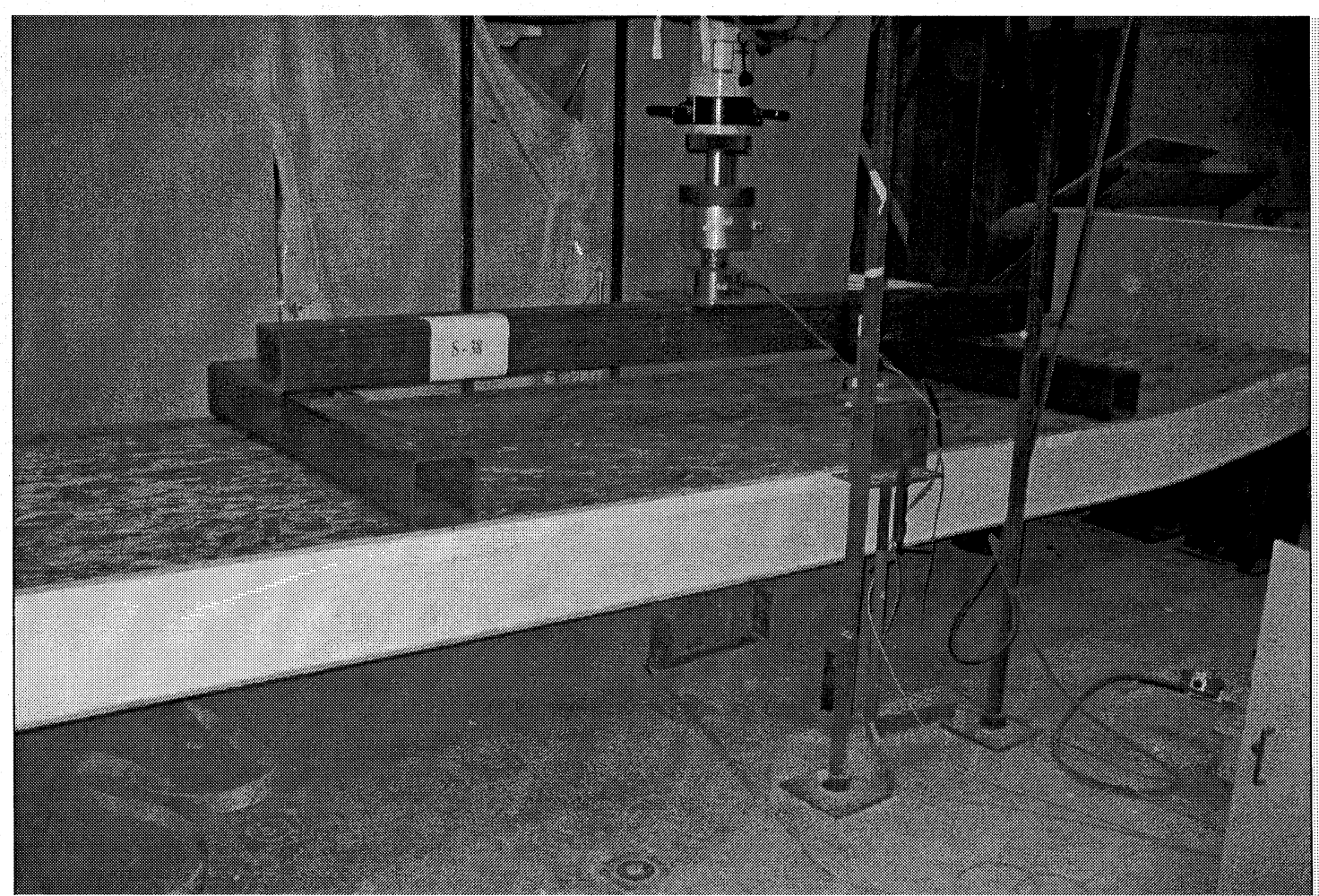

Figure AI-195. View of specimen S-38 after failure

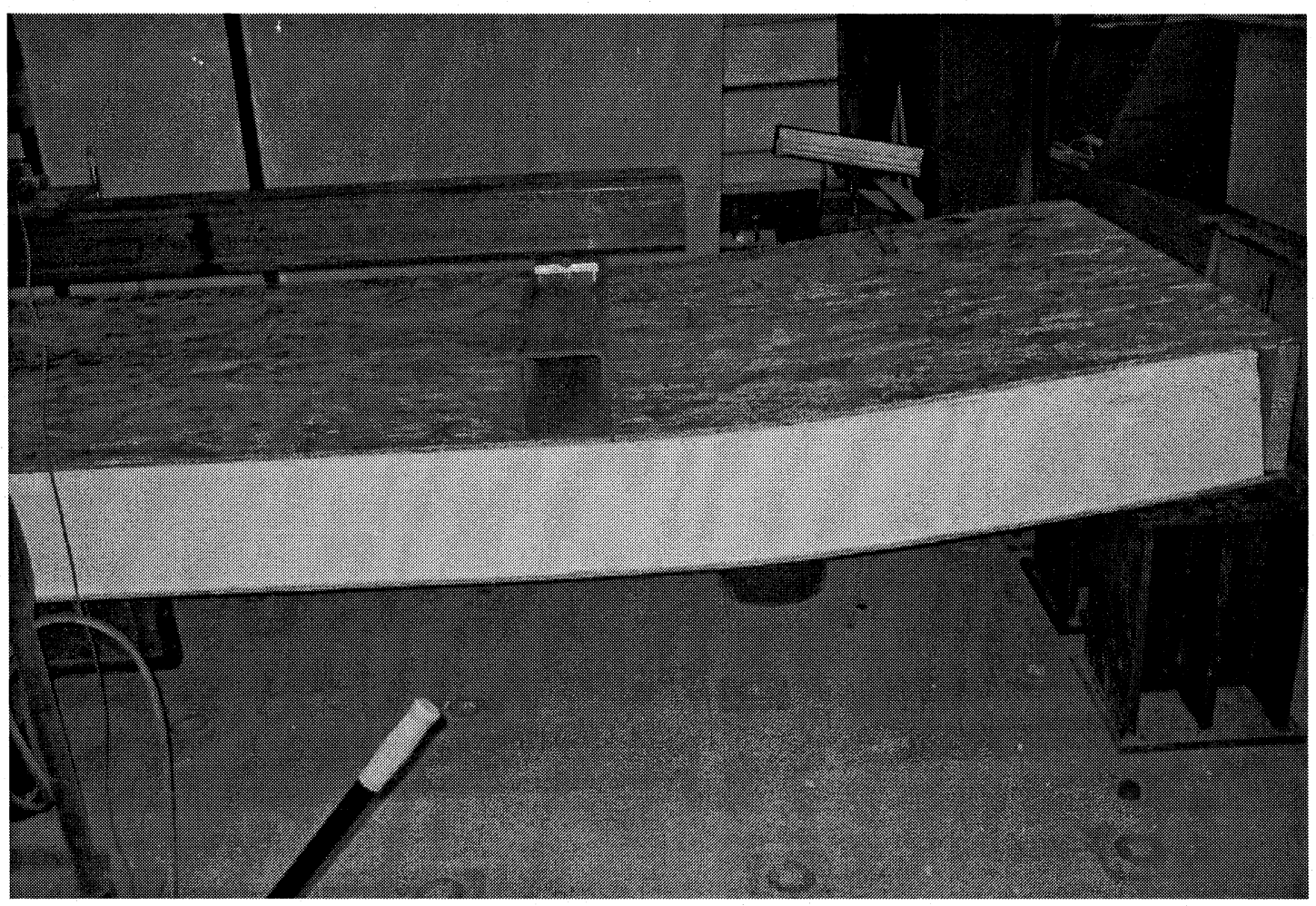

Figure AI-196. Other view of specimen S-38 after failure 


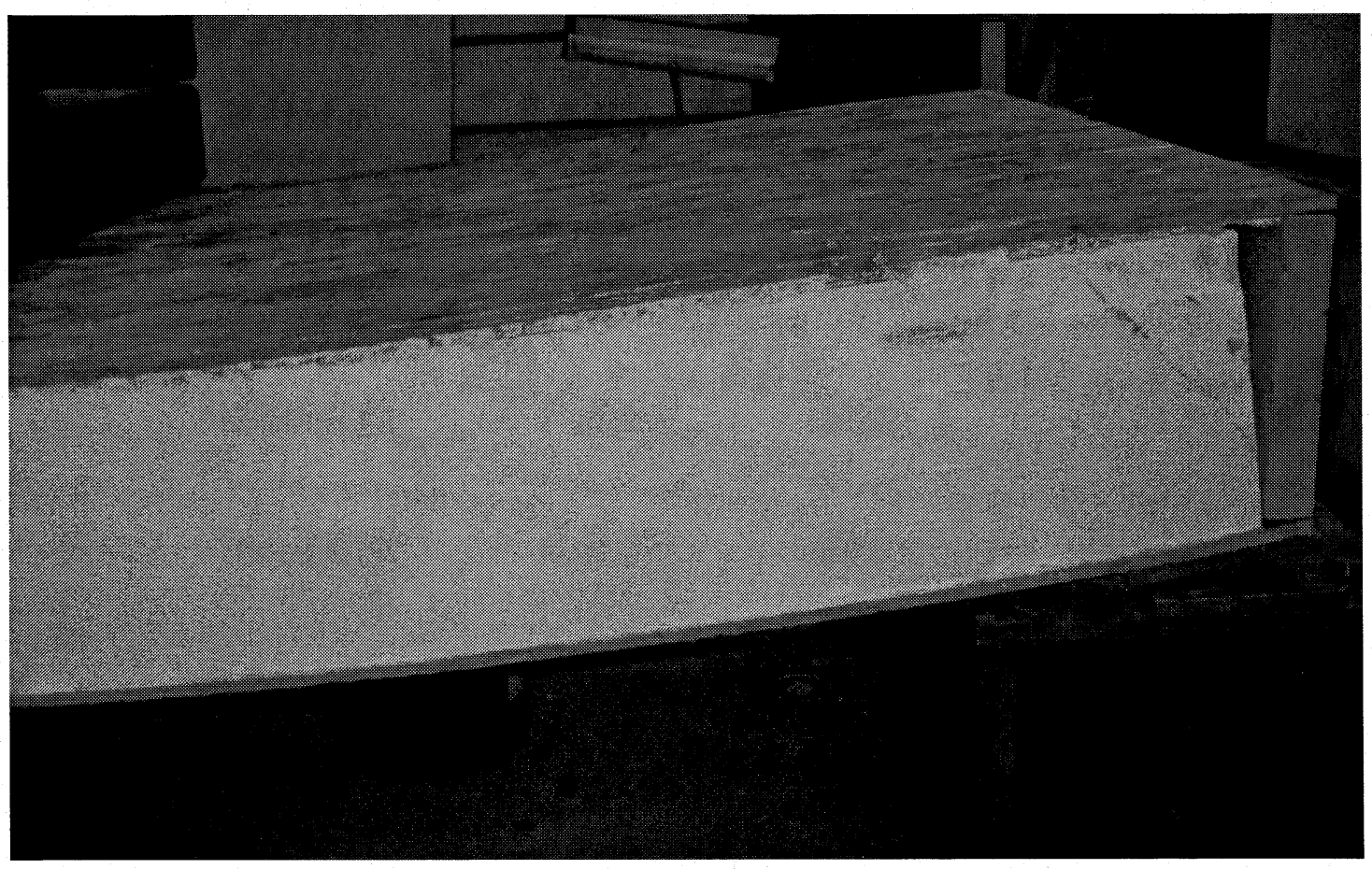

Figure AI-197.Close up of flexural failure on the free edge of specimen S-38 


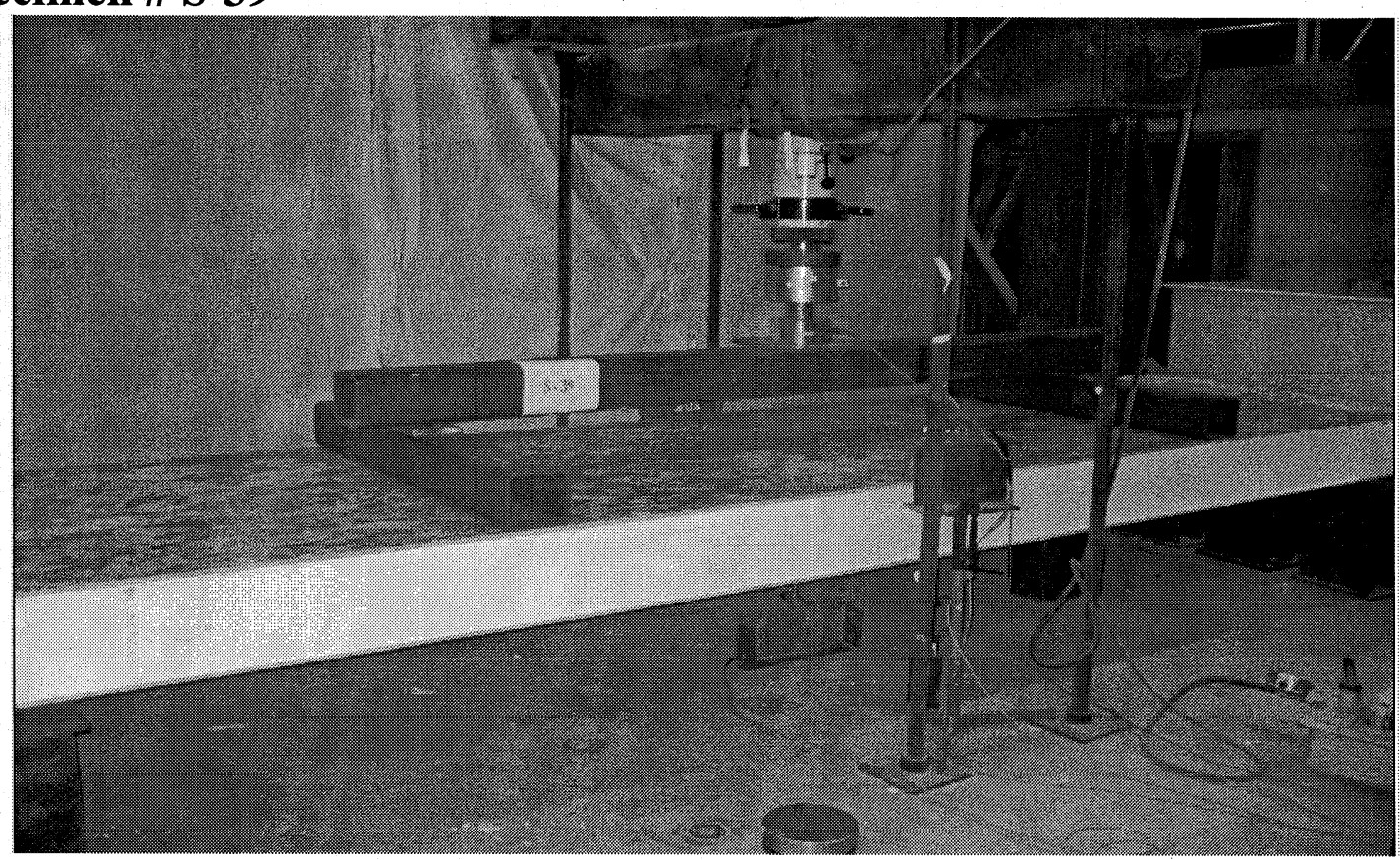

Figure AI-198. View of Specimen S-39 before testing

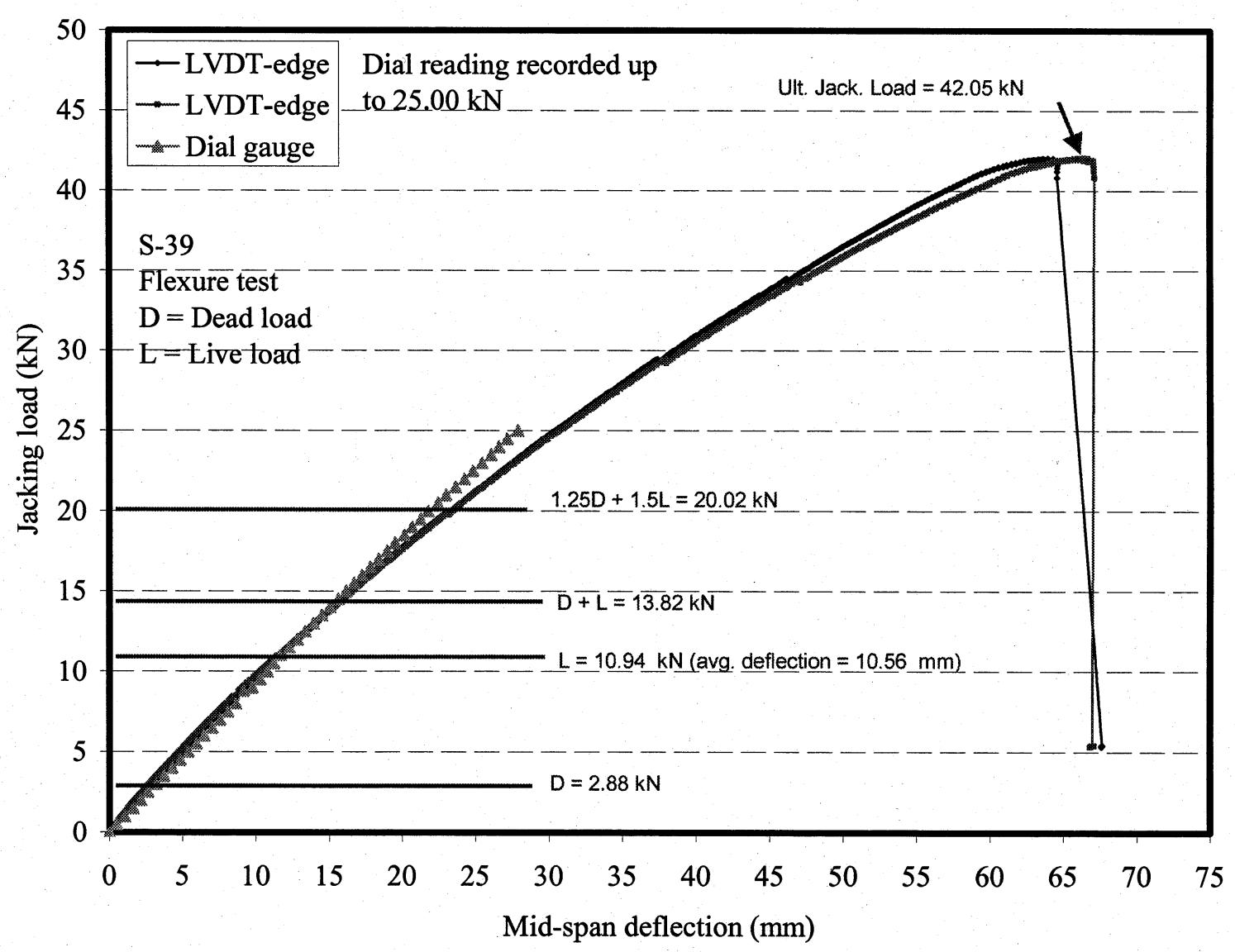

Figure AI-199. Load-deflection relationship for specimen S-39 


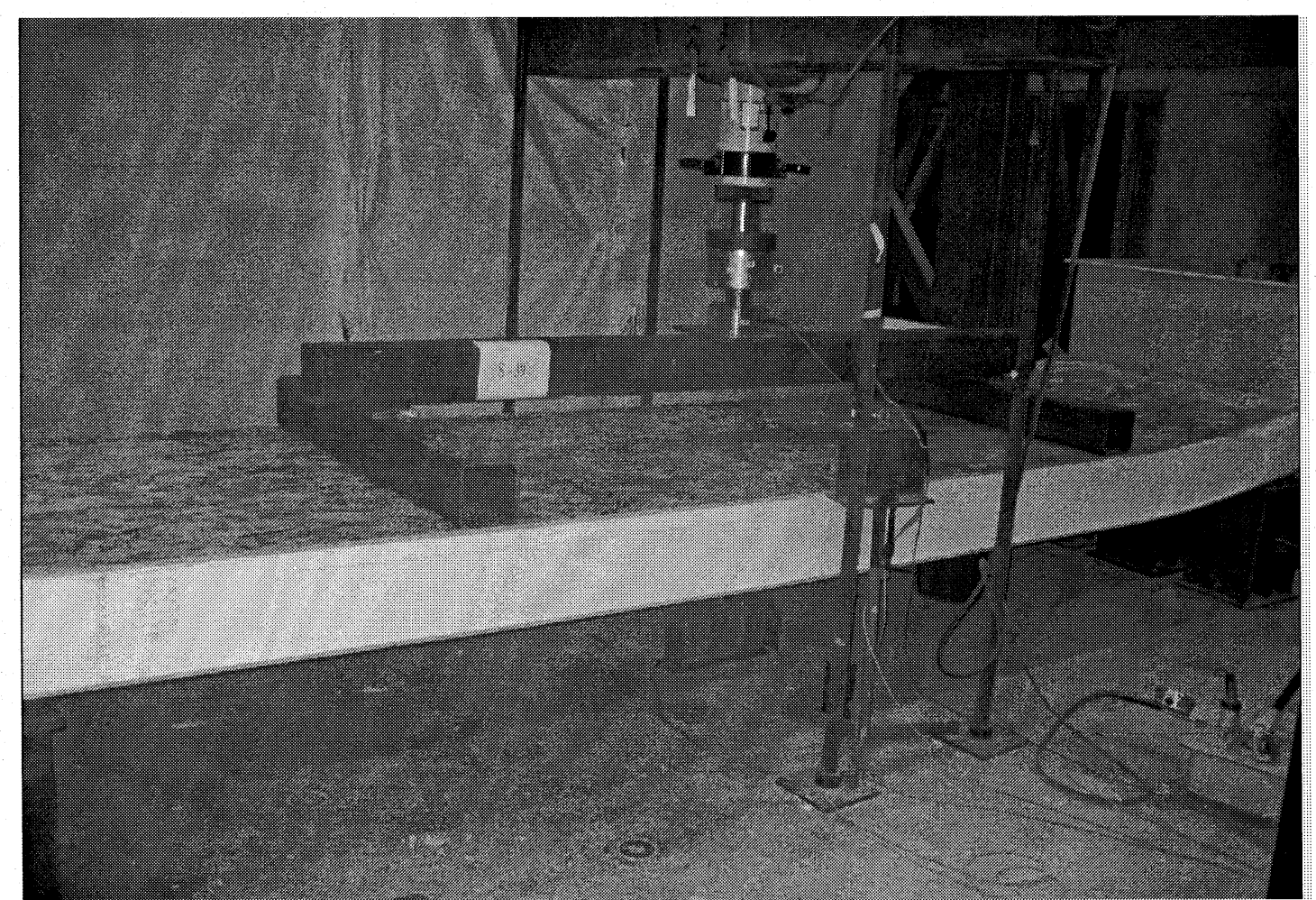

Figure AI-200. View of specimen S-39 after failure

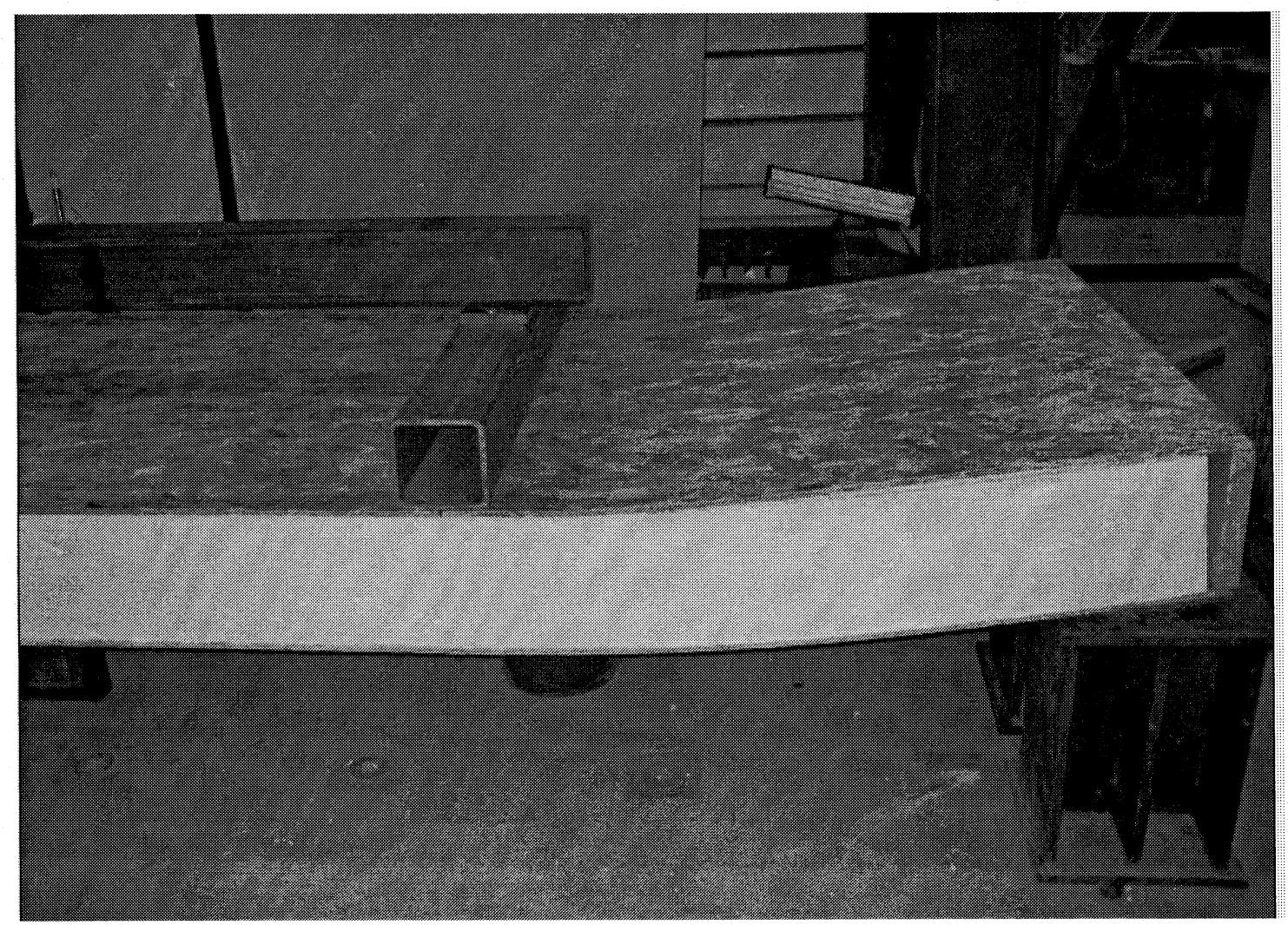

Figure AI-201. Other view of specimen S-39 after failure 


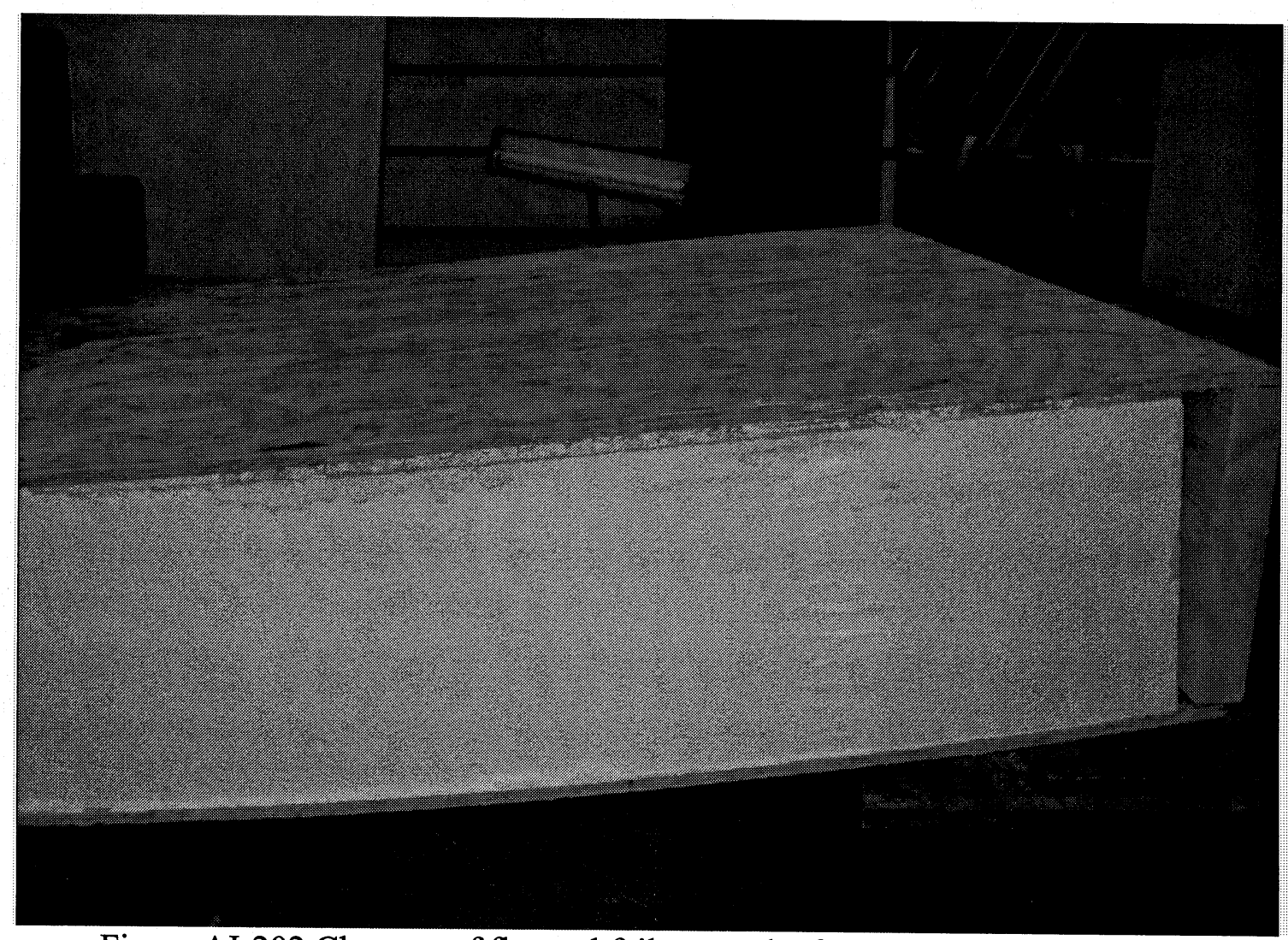

Figure AI-202.Close up of flexural failure on the free edge of specimen S-39 


\section{GROUP N}

\section{Specimen \# S-40}

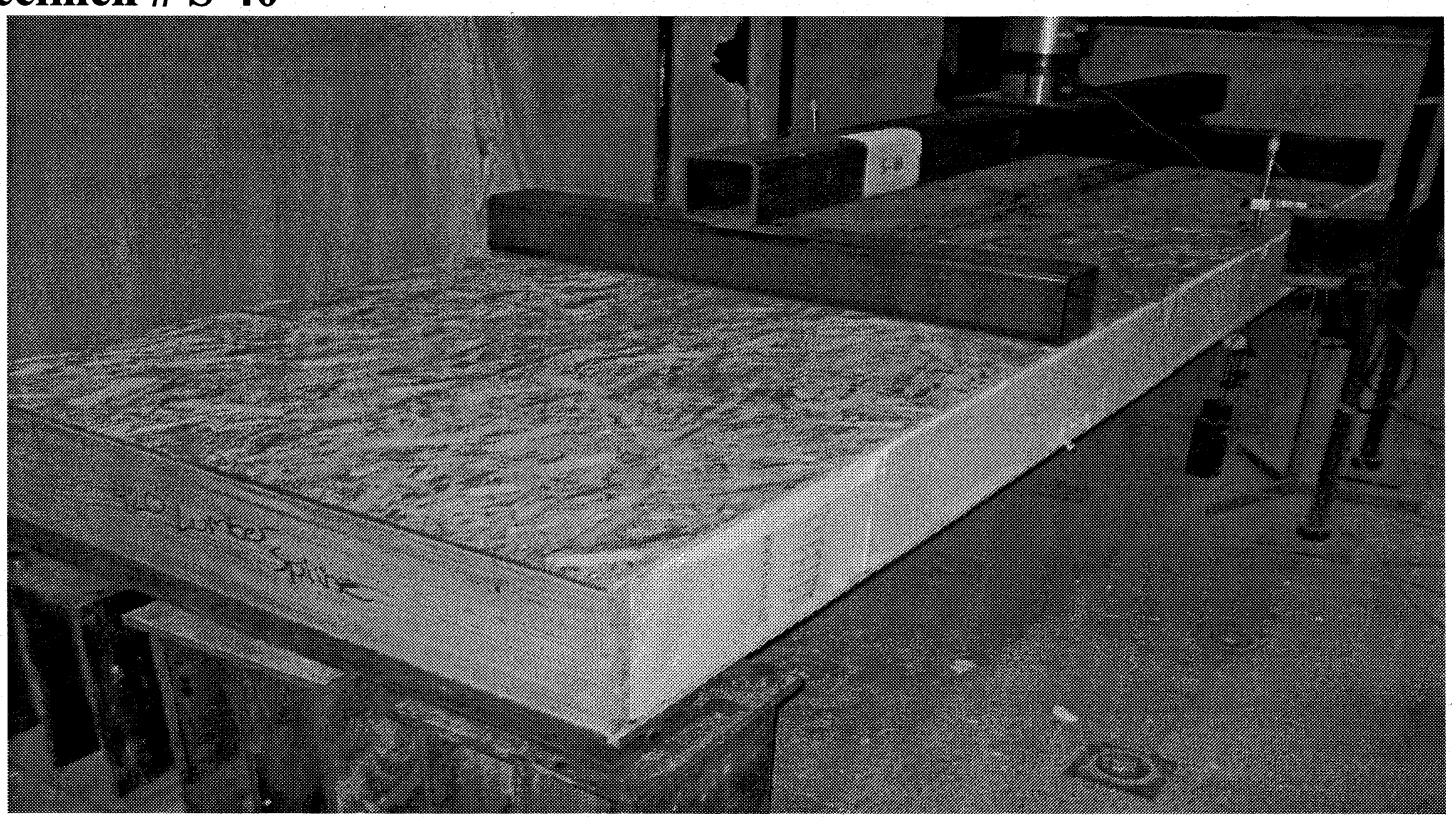

Figure 203. View of Specimen S-40 before testing

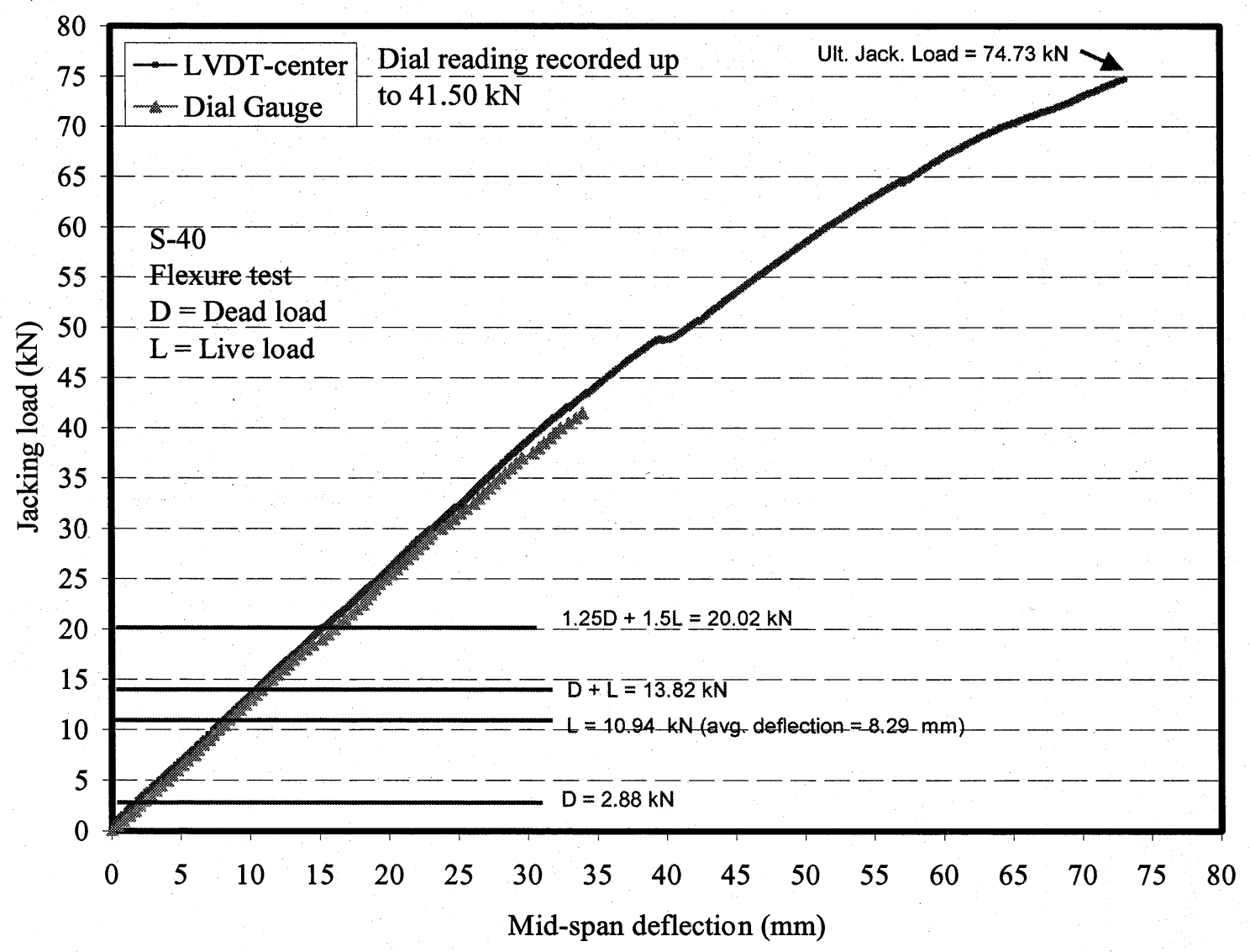

Figure AI-204. Load-deflection relationship for specimen S-40 


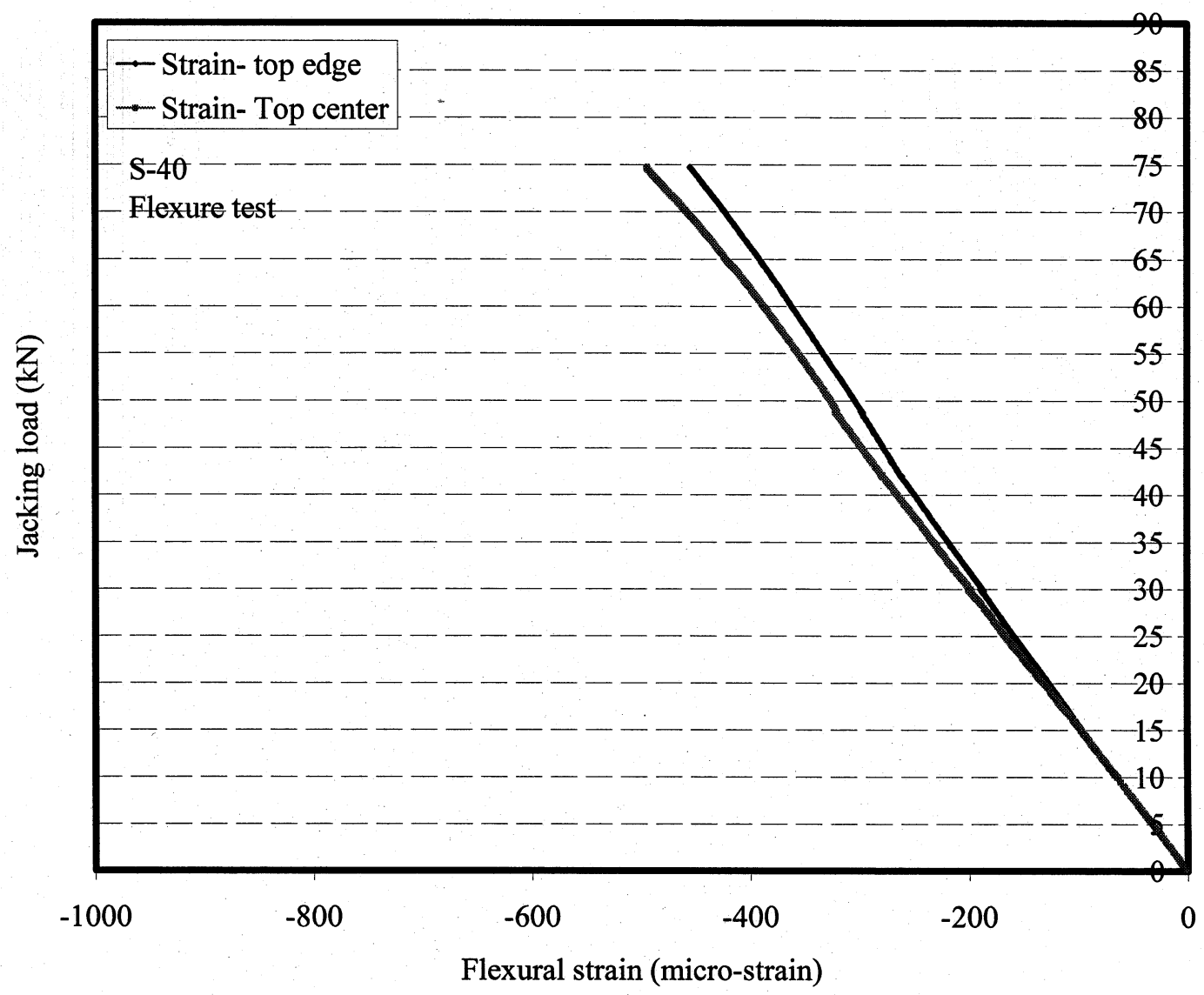

Figure AI-205. Load-strain relationship for specimen S-40

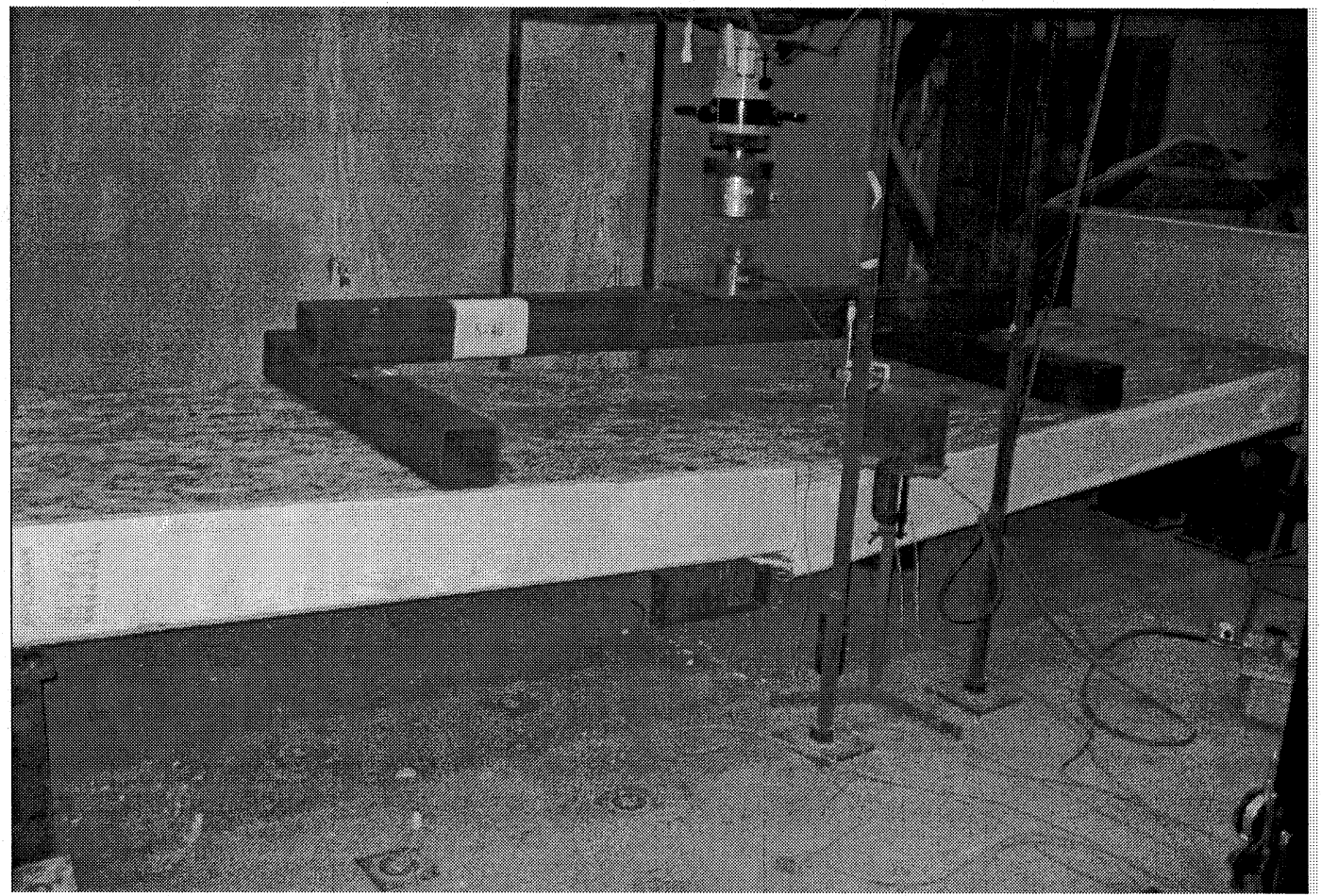

Figure AI-206. View of specimen S-40 after failure 


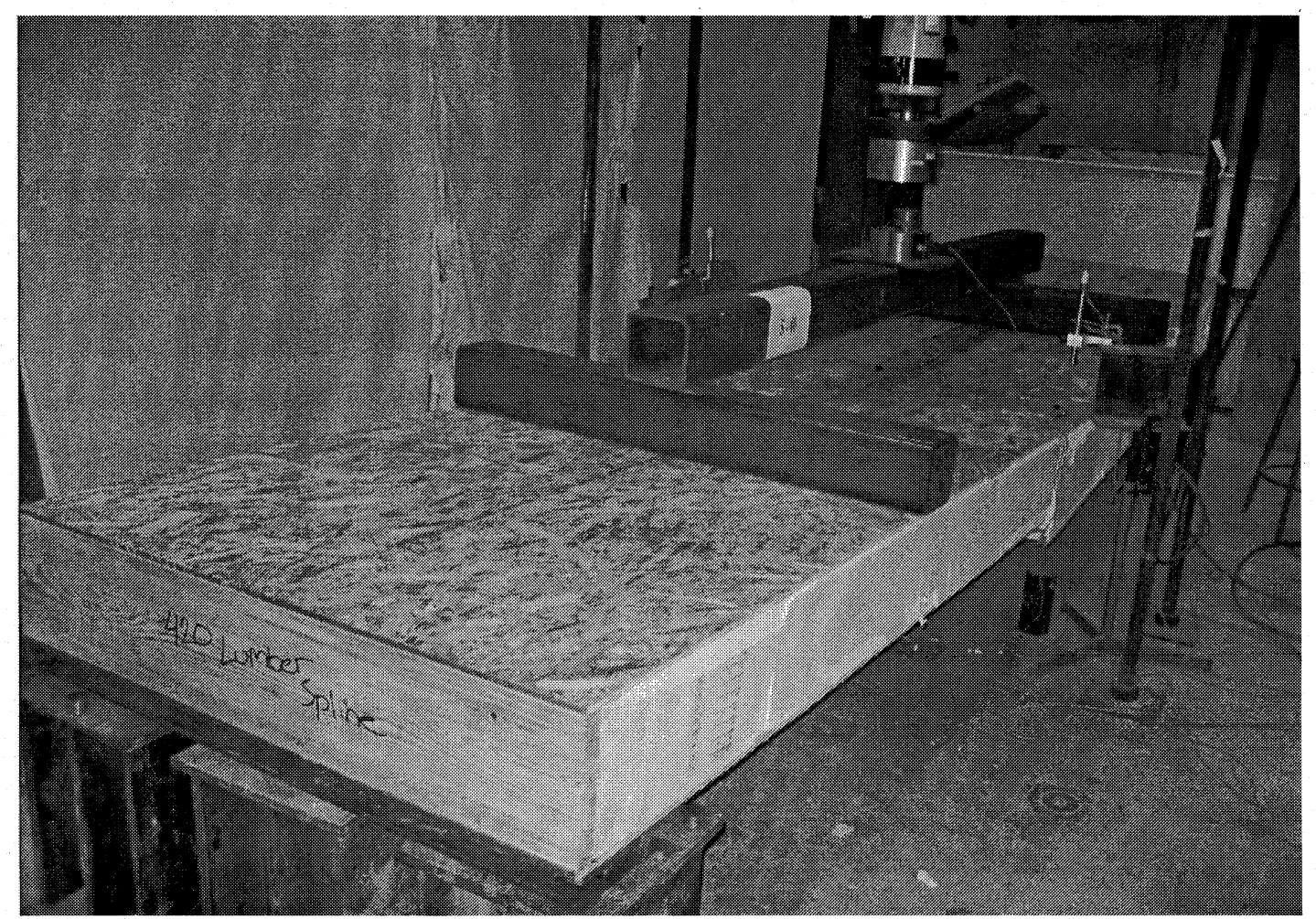

Figure AI-207. Other view of specimen S-40 after failure

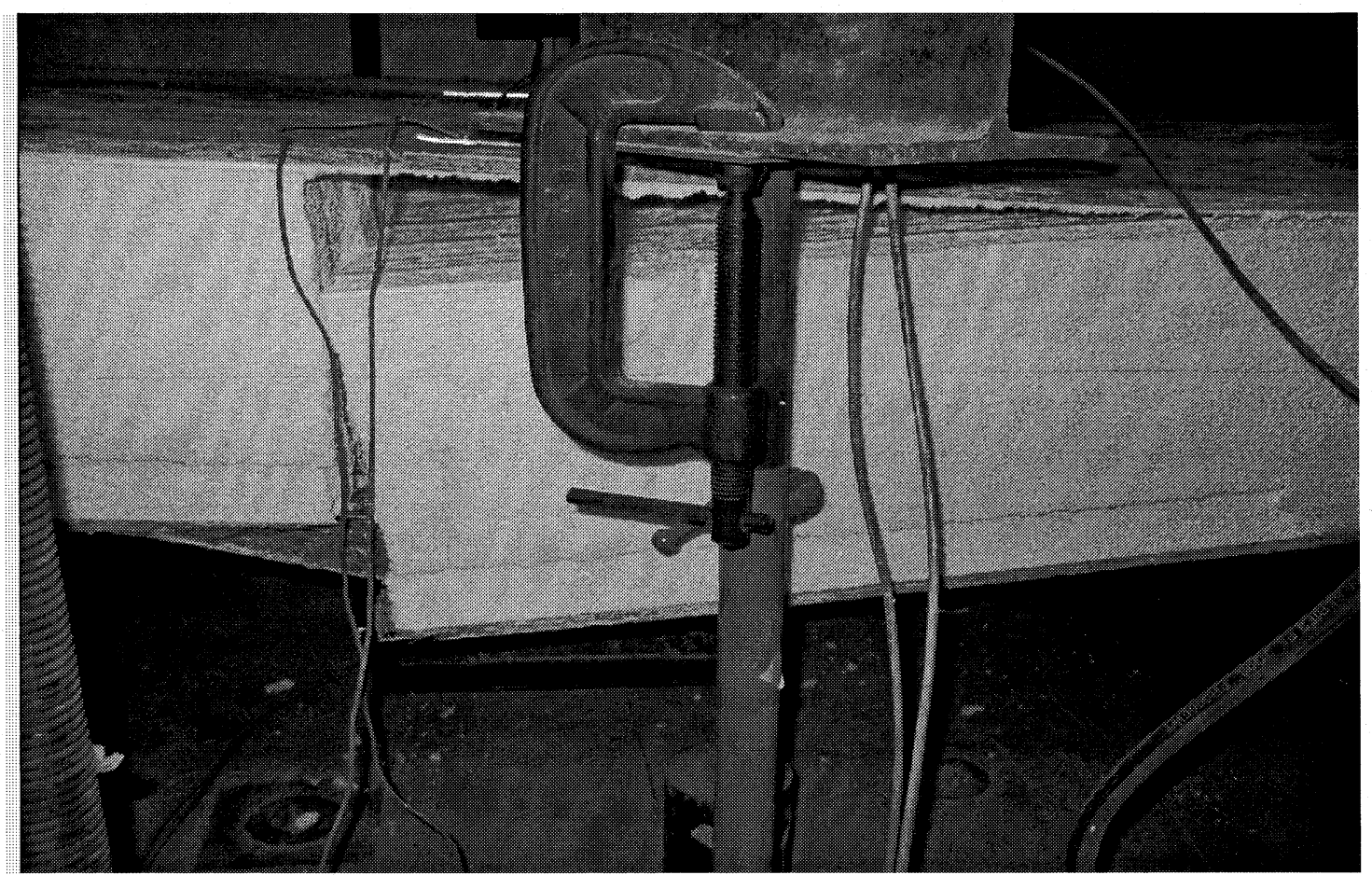

Figure AI-208. Close up of flexural failure on the free edge of specimen S-40 


\section{Specimen \# S-41}

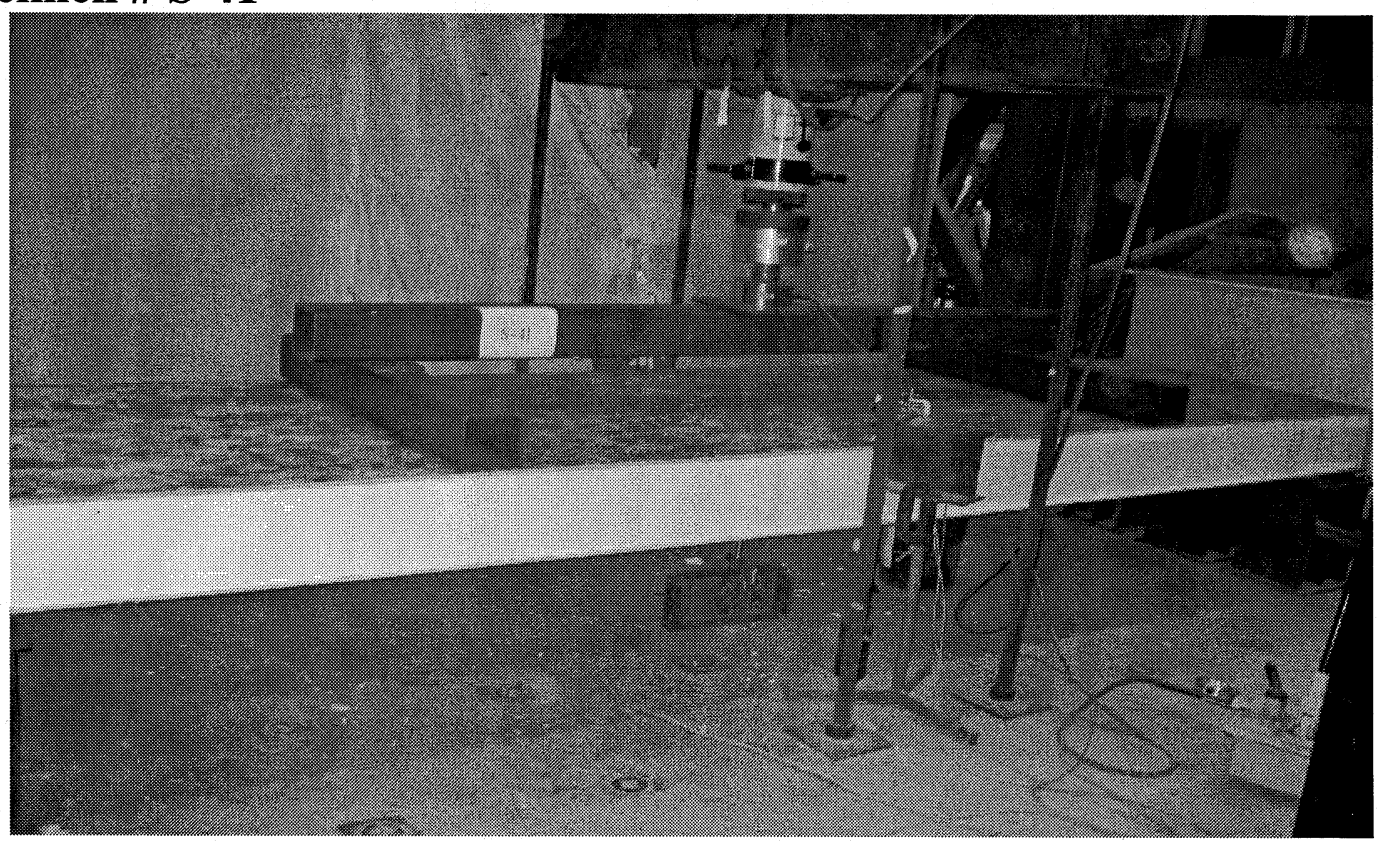

Figure AI-209. View of Specimen S-41 before testing

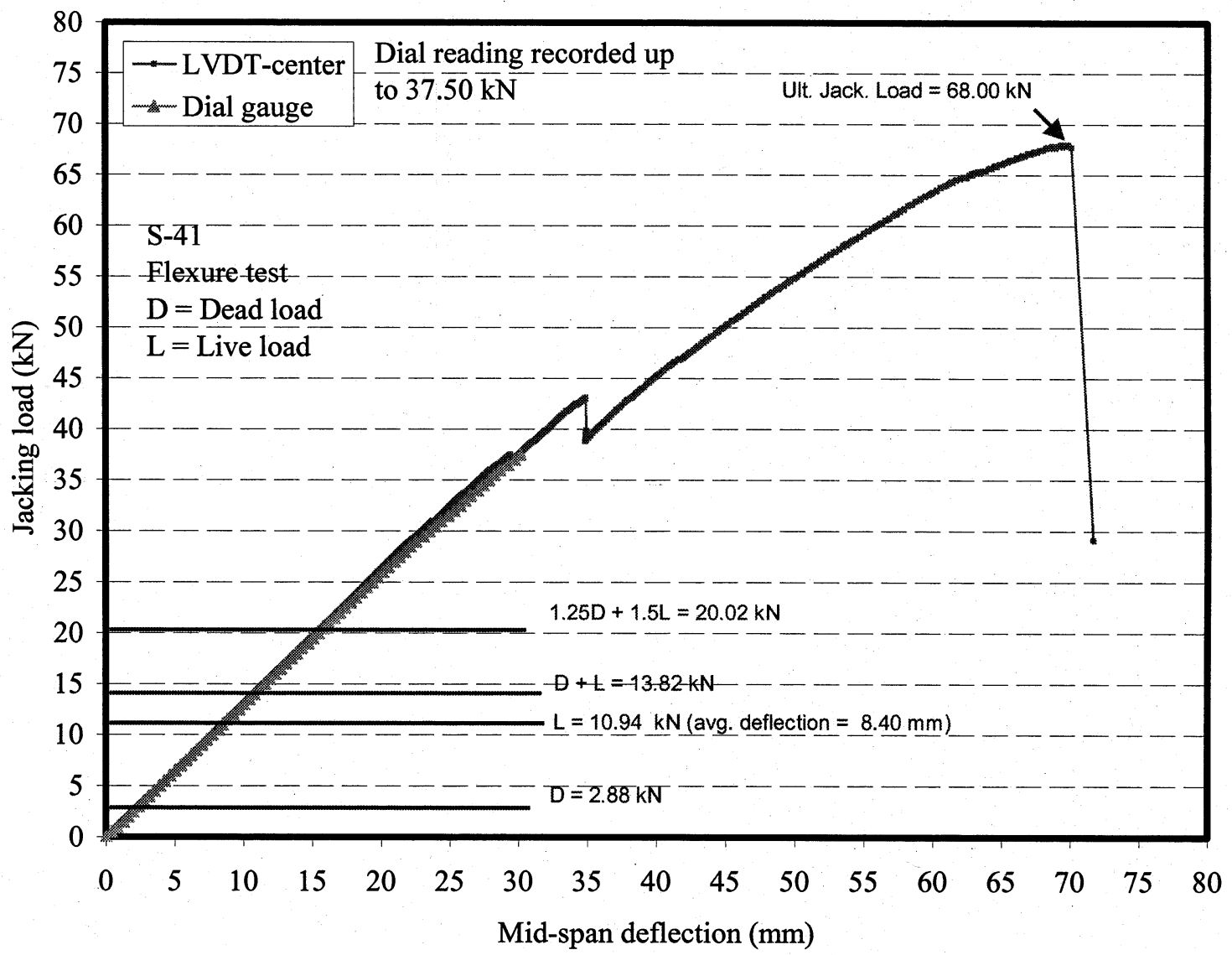

Figure AI-210. Load-deflection relationship for specimen S-41 


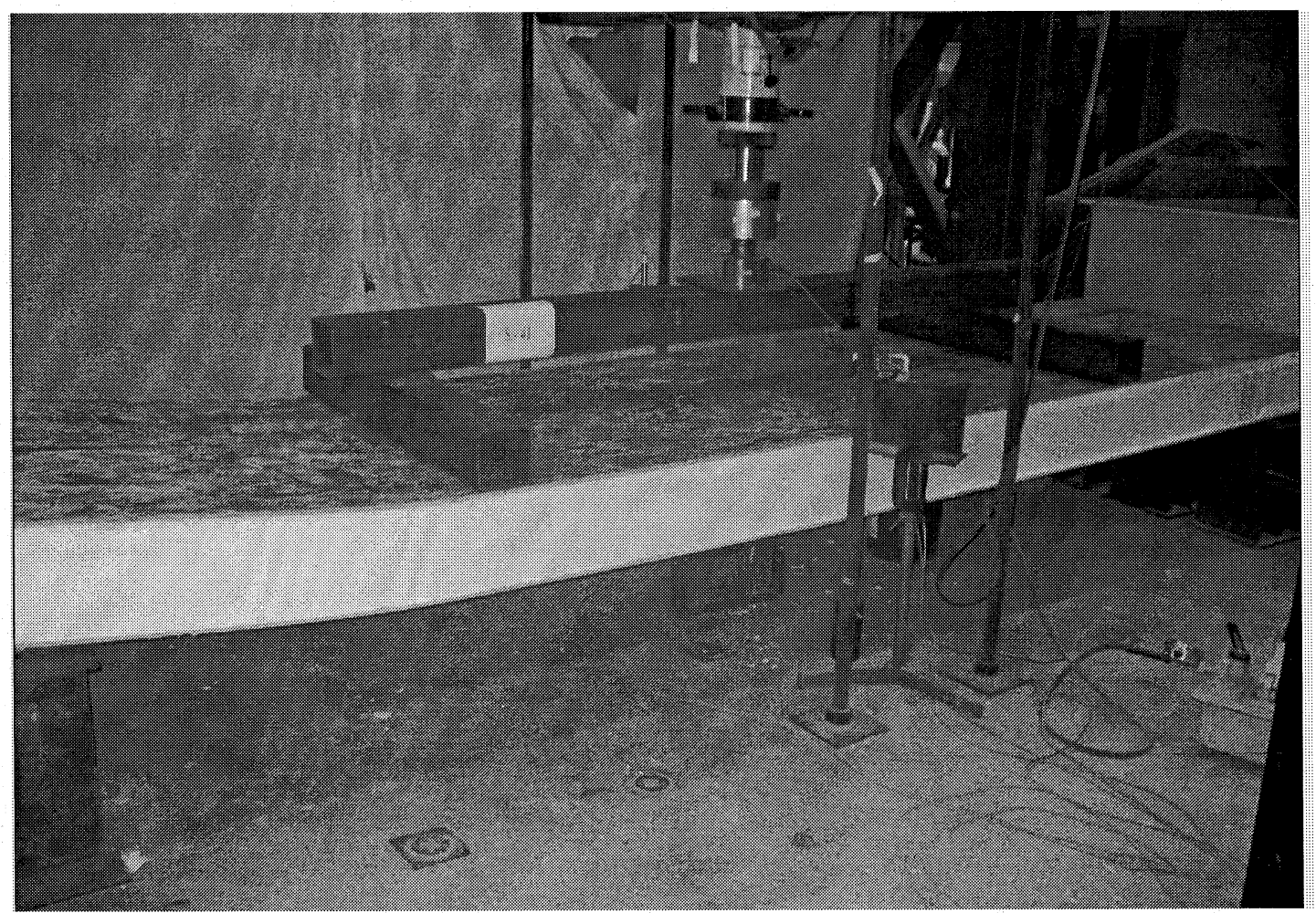

Figure AI-211. View of specimen S-41 after failure

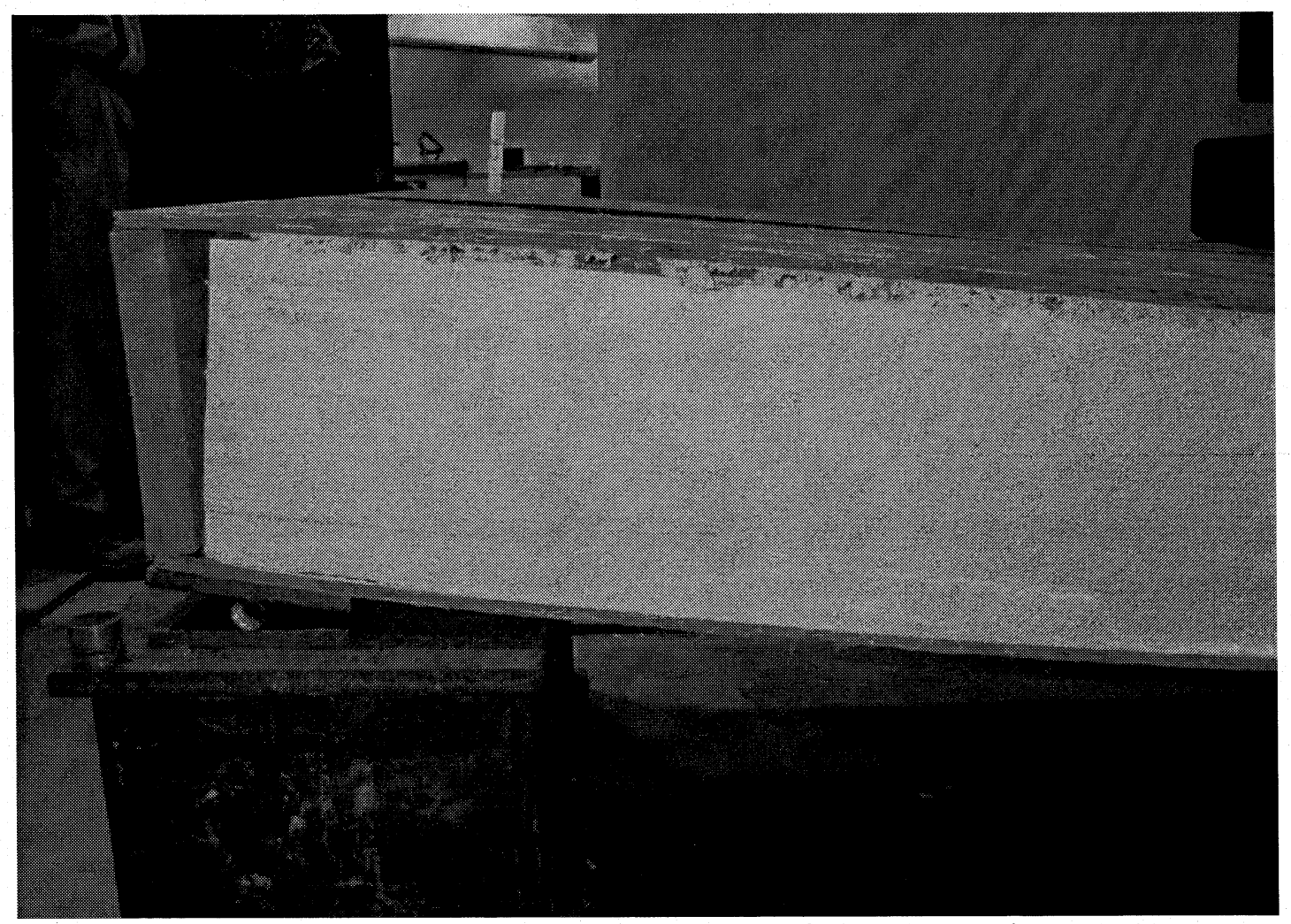

Figure AI-212. View of the horizontal shear failure in specimen S-41 


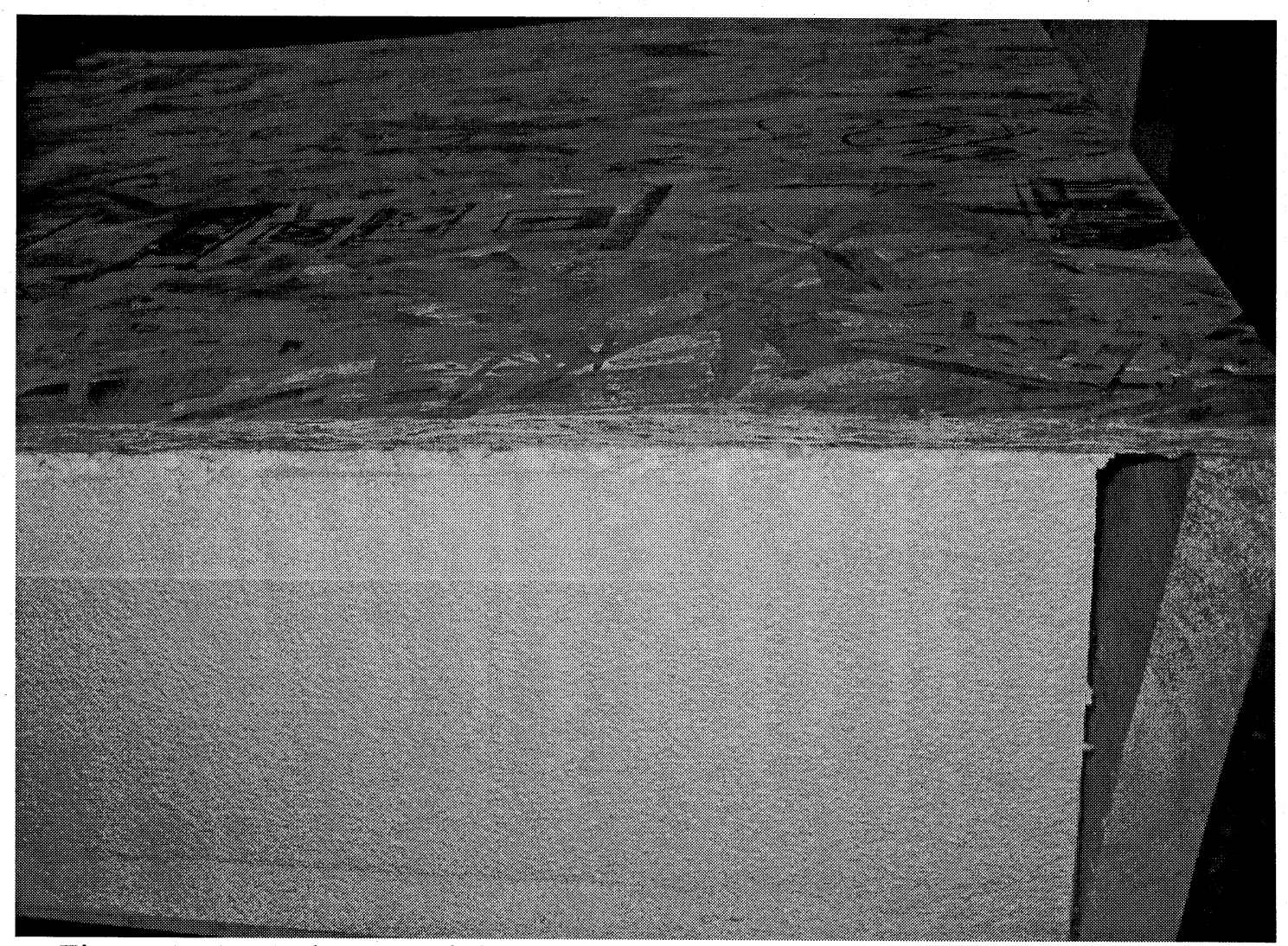

Figure AI-213. Close up of shear failure on the other free edge of specimen S-41 


\section{Specimen \# S-42}

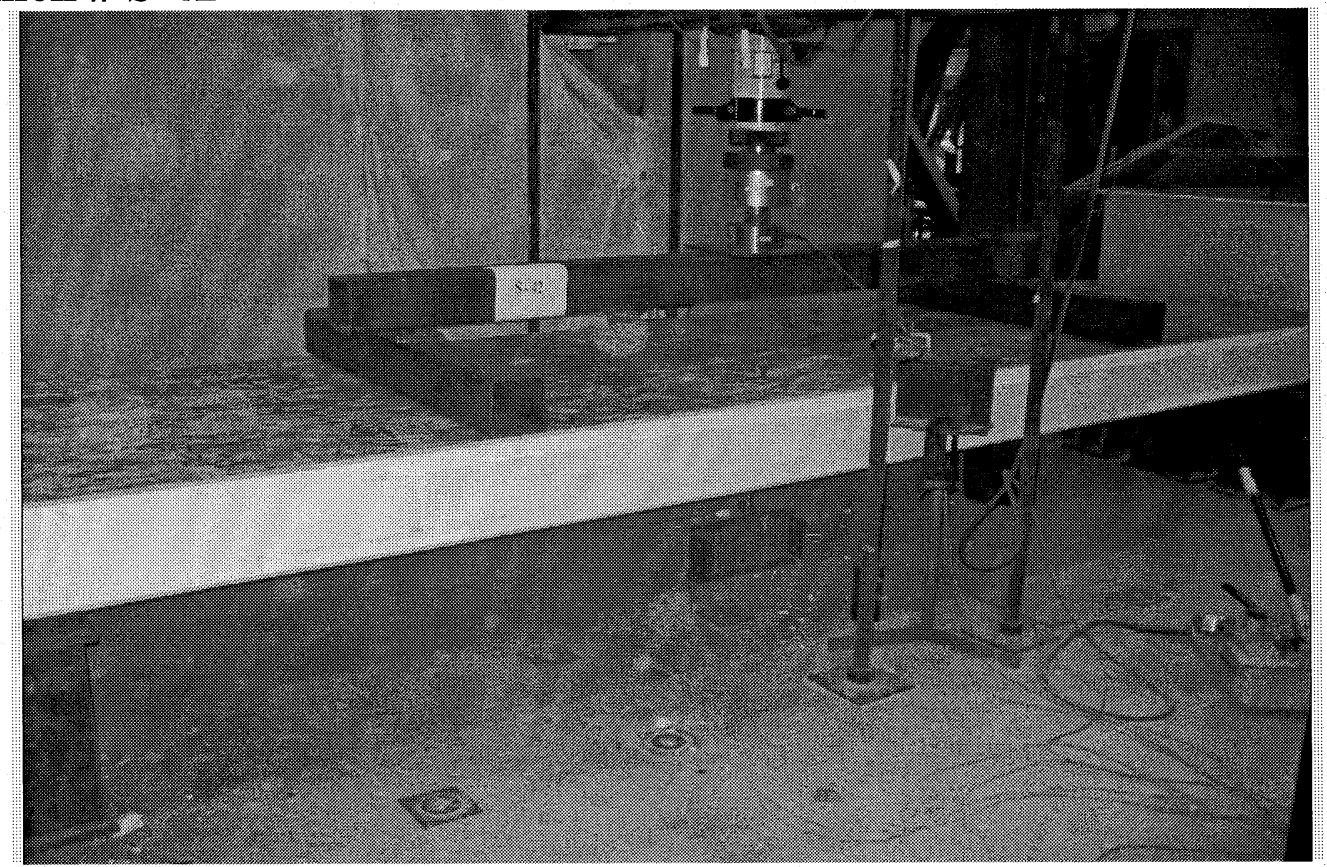

Figure AI-214. View of Specimen S-42 before testing

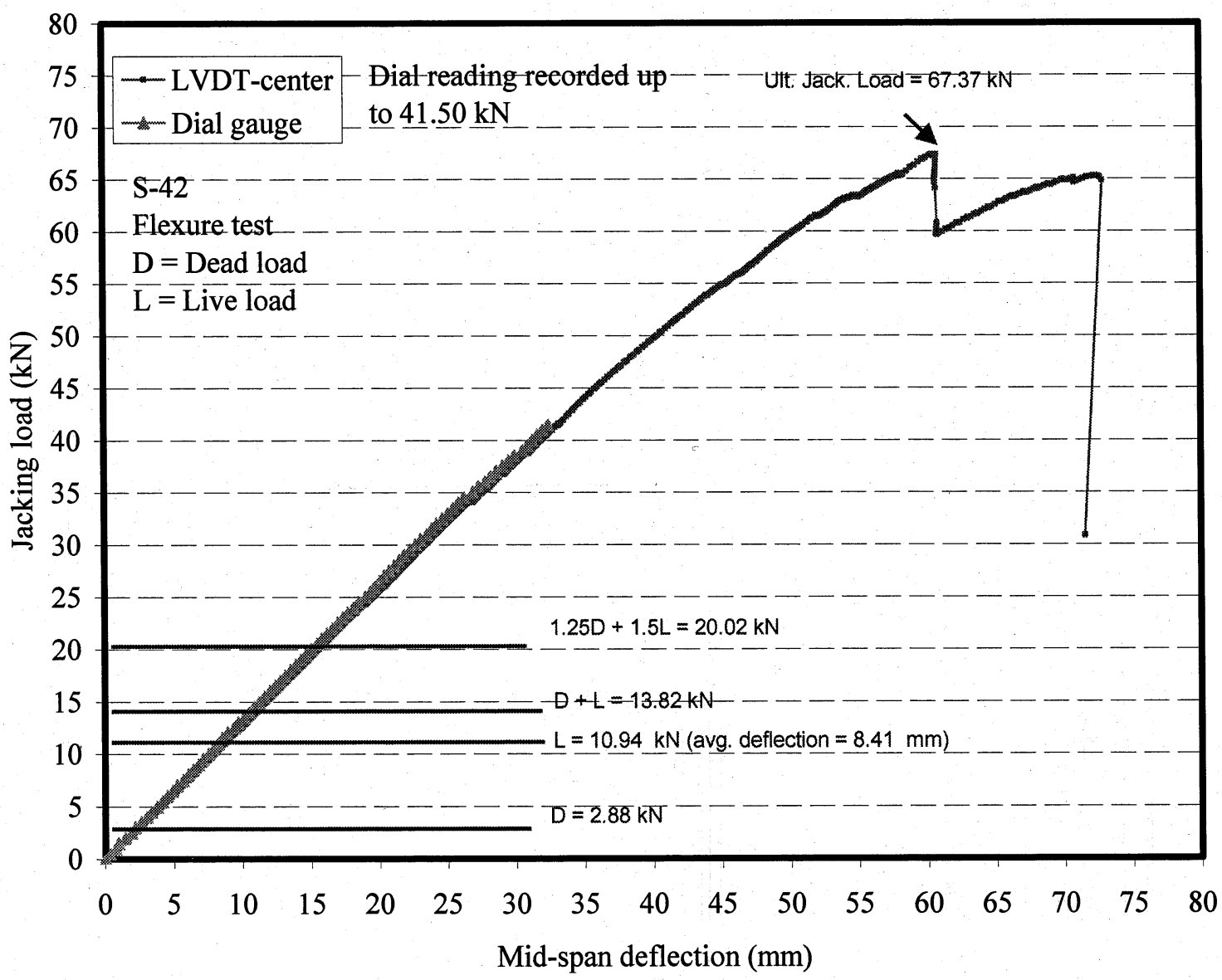

Figure AI-215. Load-deflection relationship for specimen S-42 


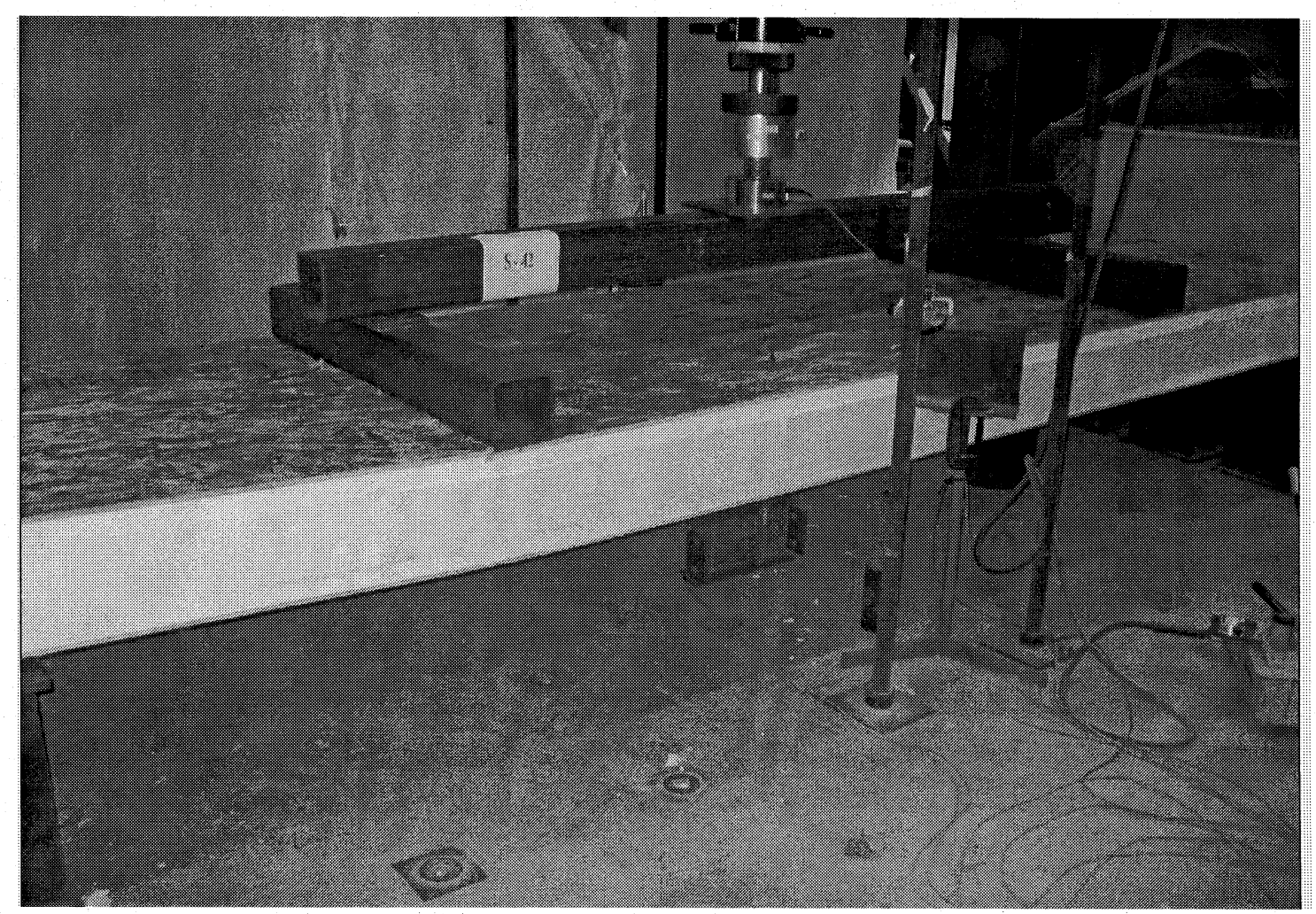

Figure AI-216. View of specimen S-42 after failure

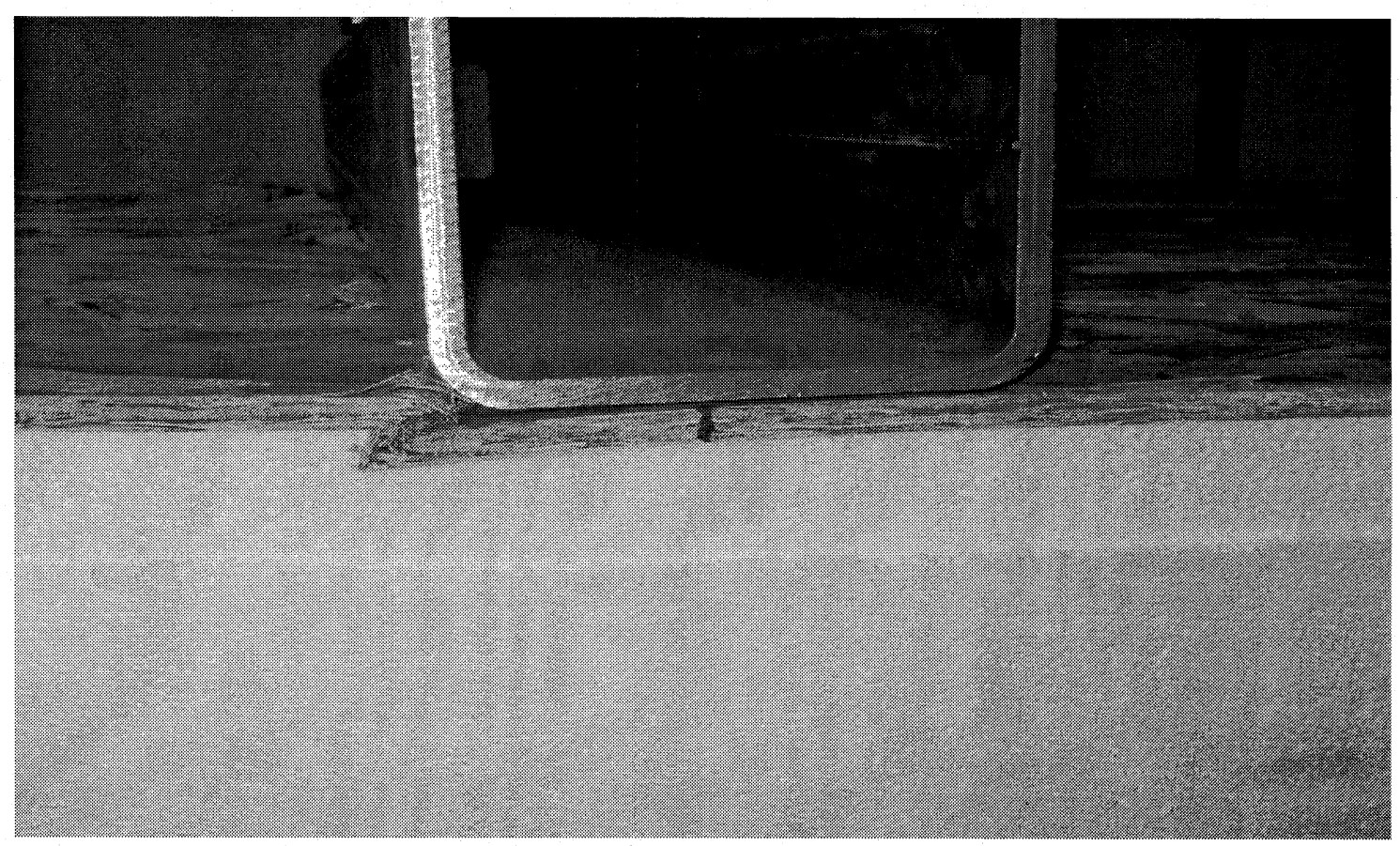

Figure AI-217. View of OSB crushing in specimen S-42 


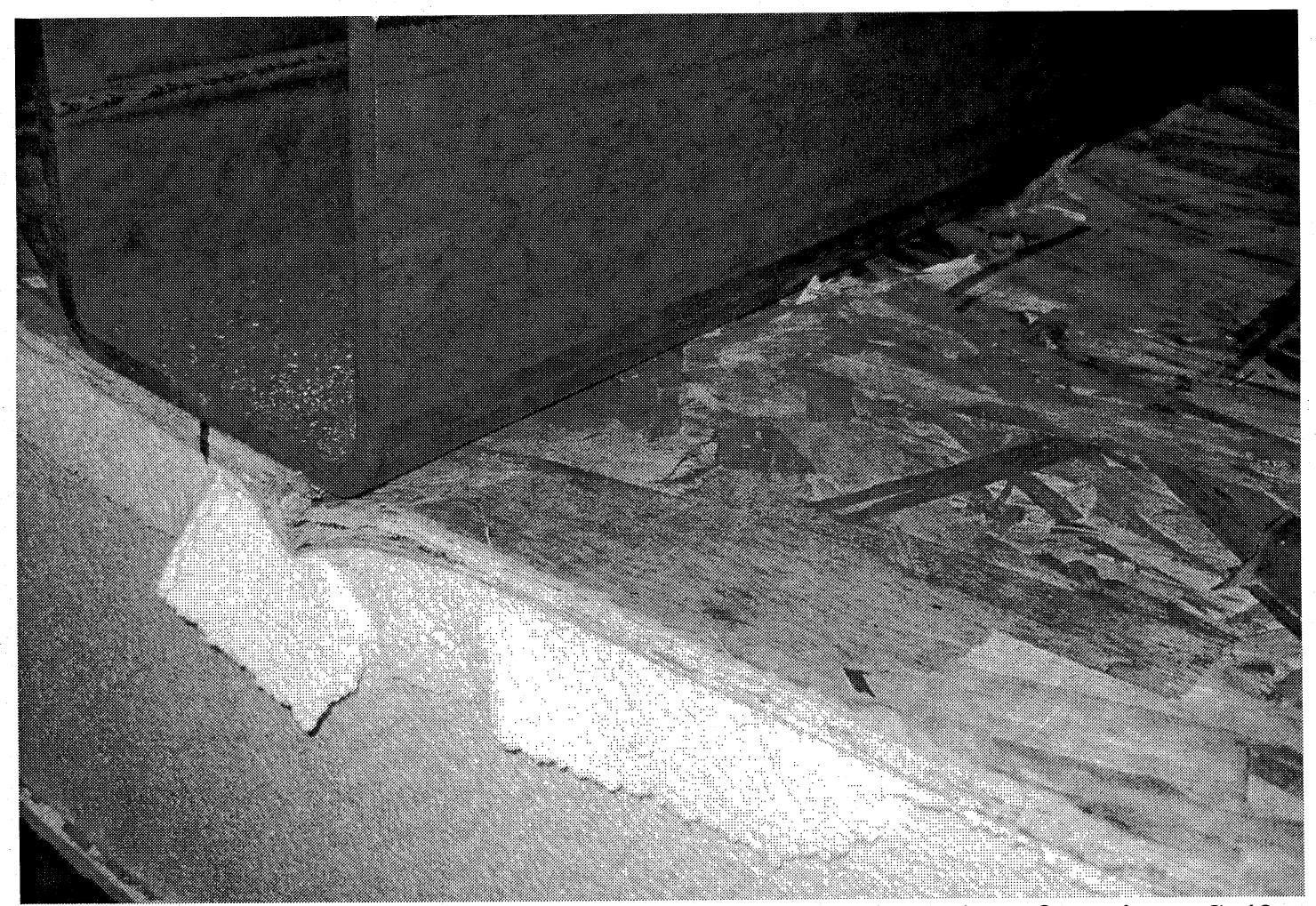

Figure AI-218. View of the OSB crushing at the other free edge of specimen S-42 


\section{GROUP O}

\section{Specimen \# S-46}

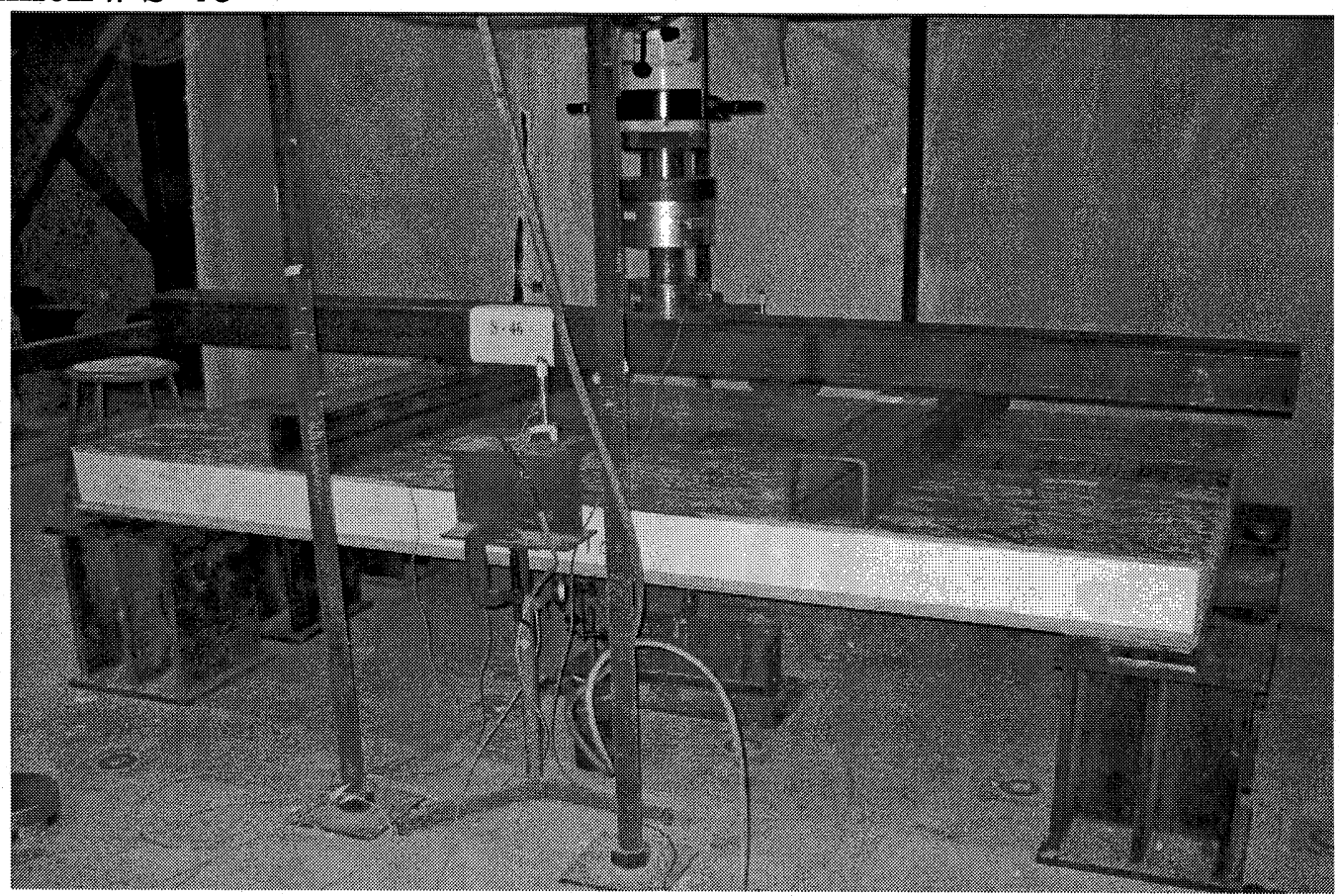

Figure AI-219. View of Specimen S-46 before testing

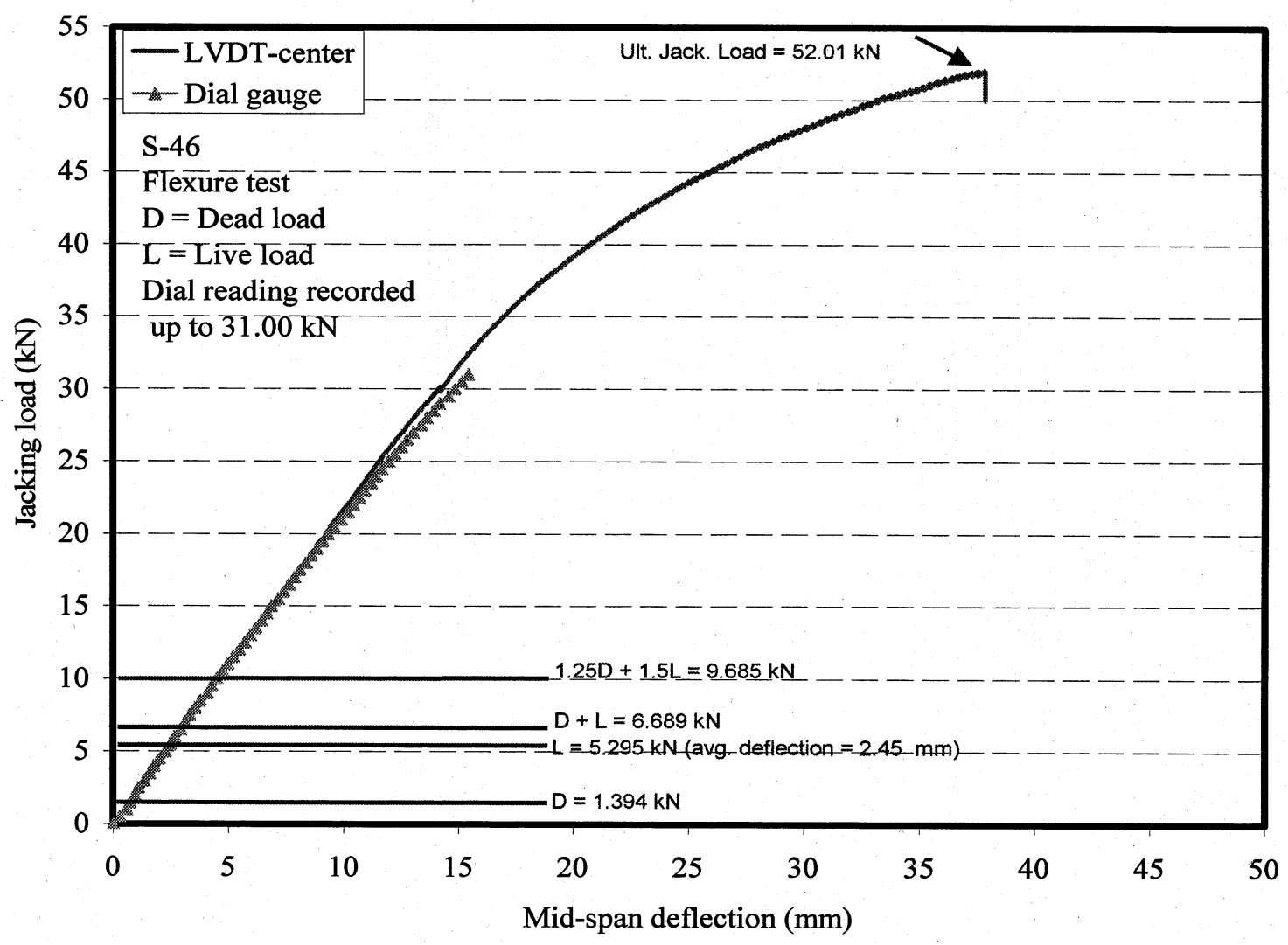

Figure AI-220. Load-deflection relationship for specimen S-46 


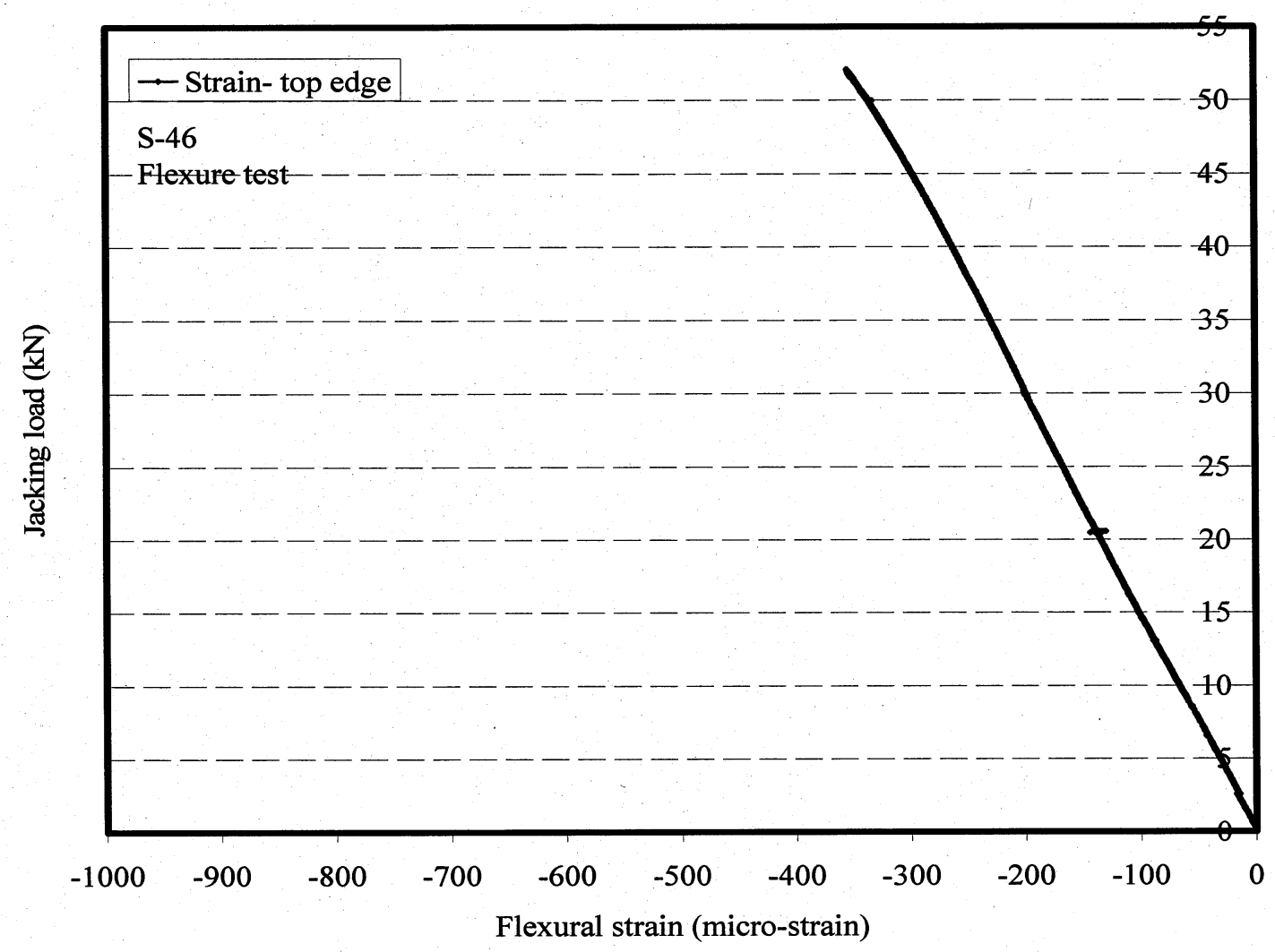

Figure AI-221. Load-strain relationship for specimen S-46

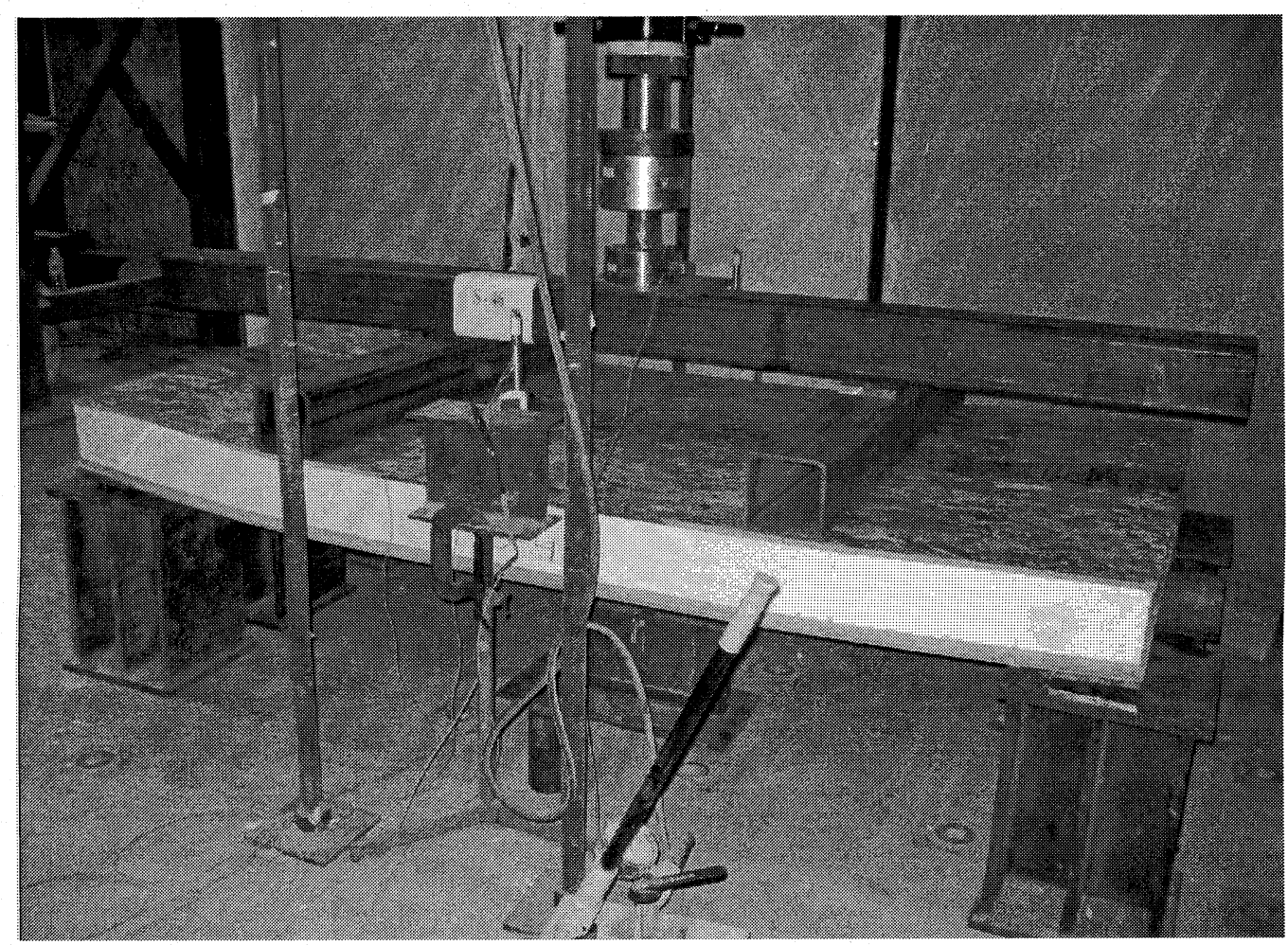

Figure AI-222. View of specimen S-46 after failure 


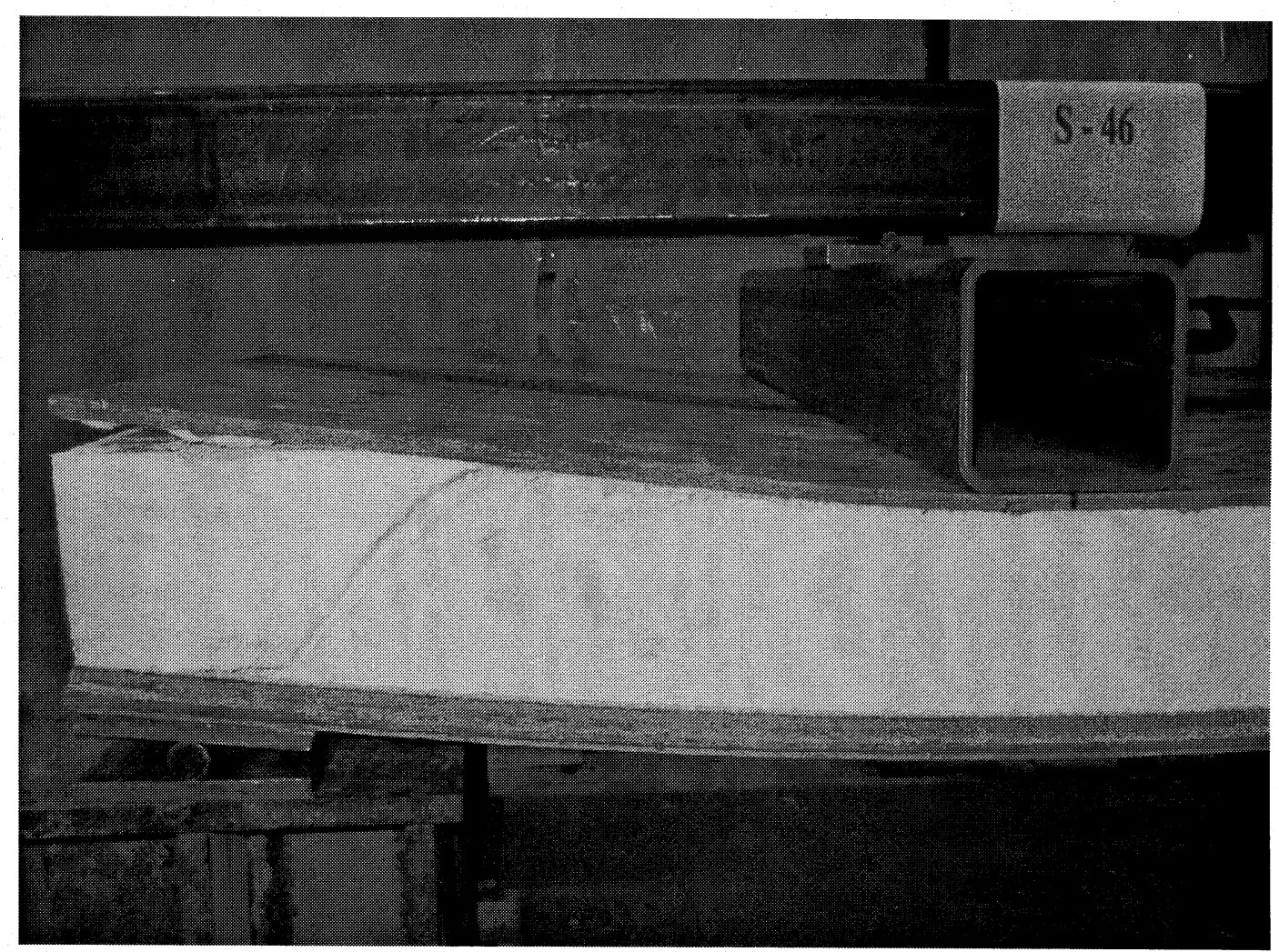

Figure AI-223. View of diagonal shear failure in specimen S-46

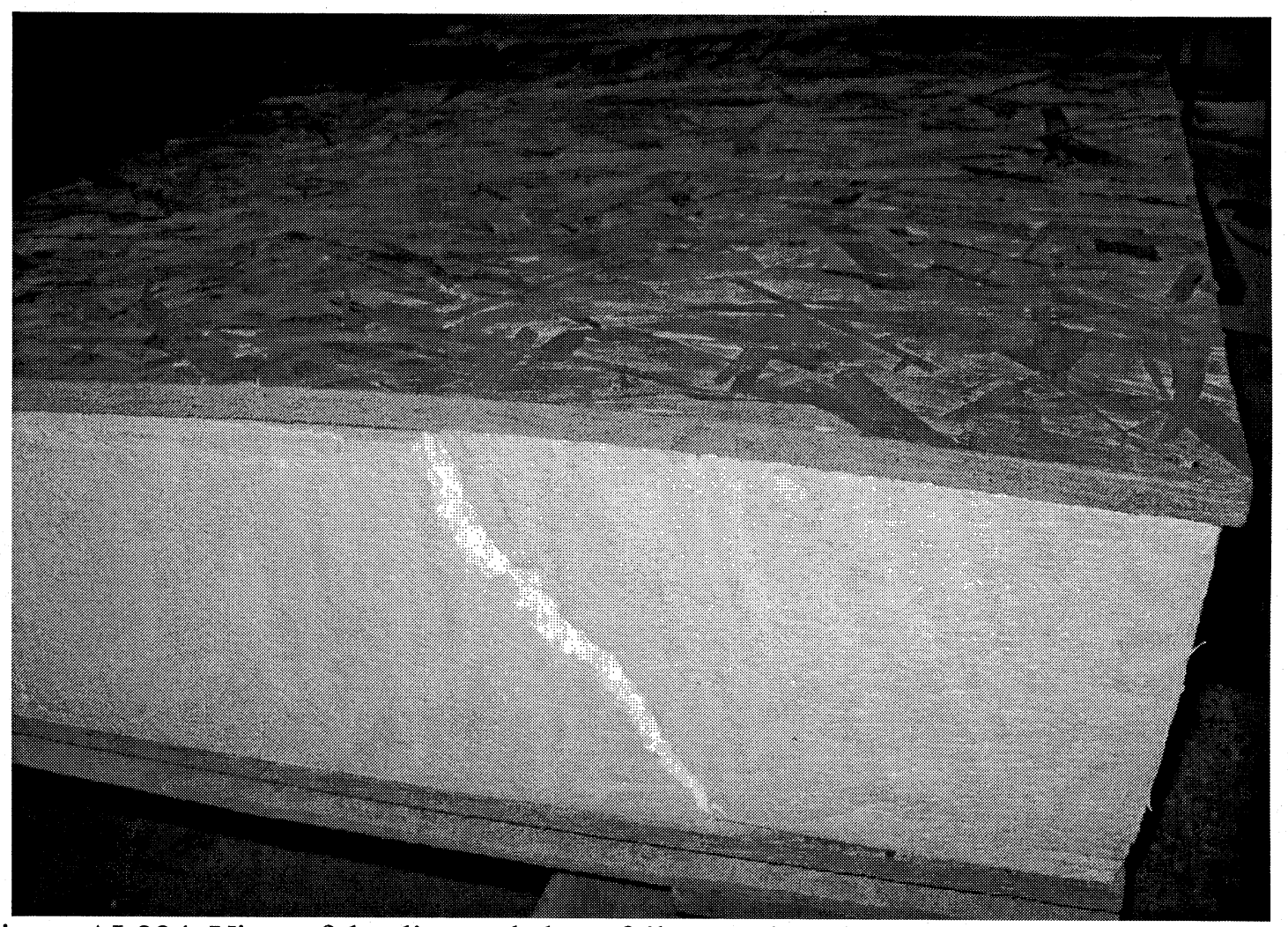

Figure AI-224. View of the diagonal shear failure at the other free edge of specimen S-46 


\section{GROUP P}

\section{Specimen \# S-47}

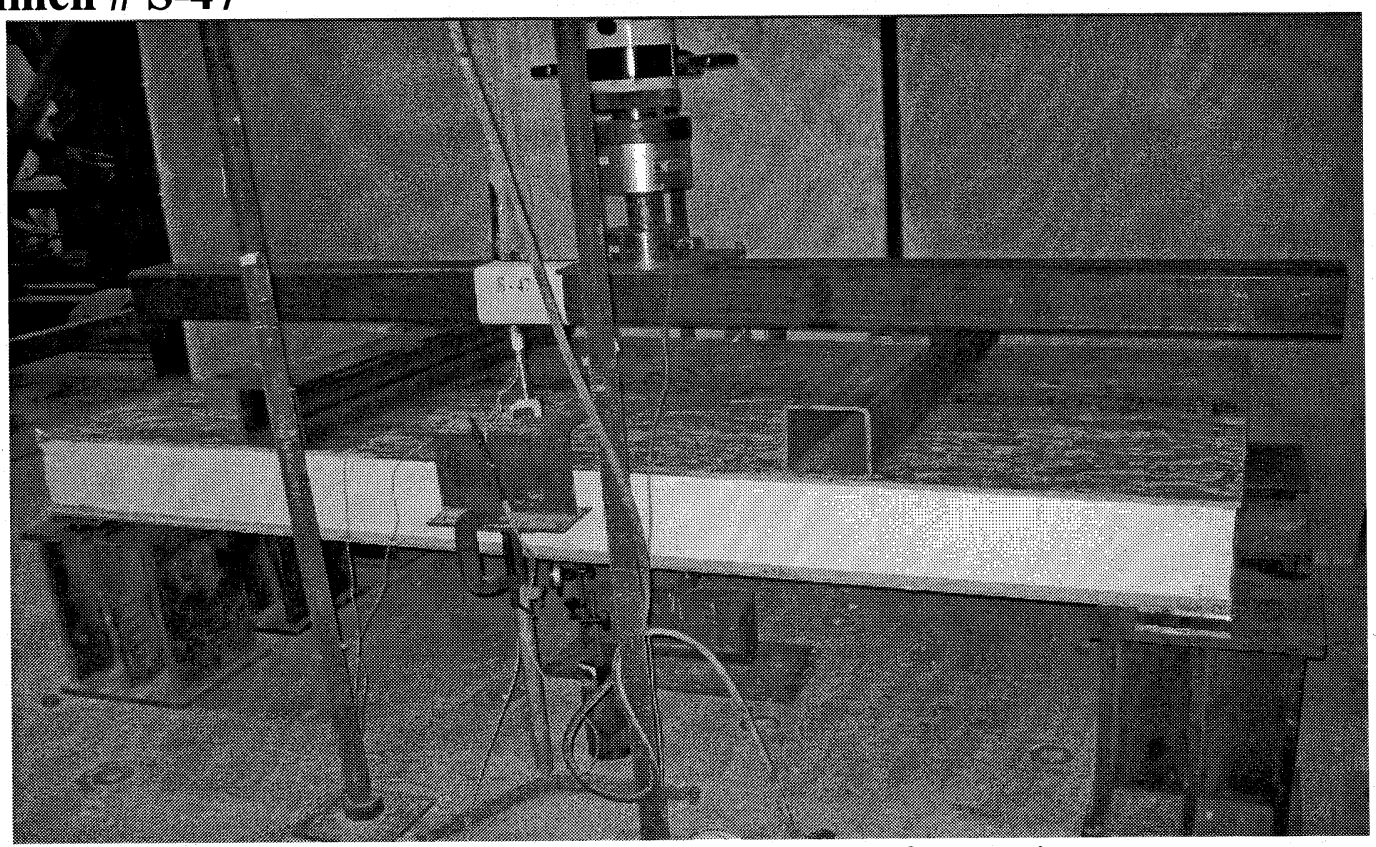

Figure AI-225 of Specimen S-47 before testing

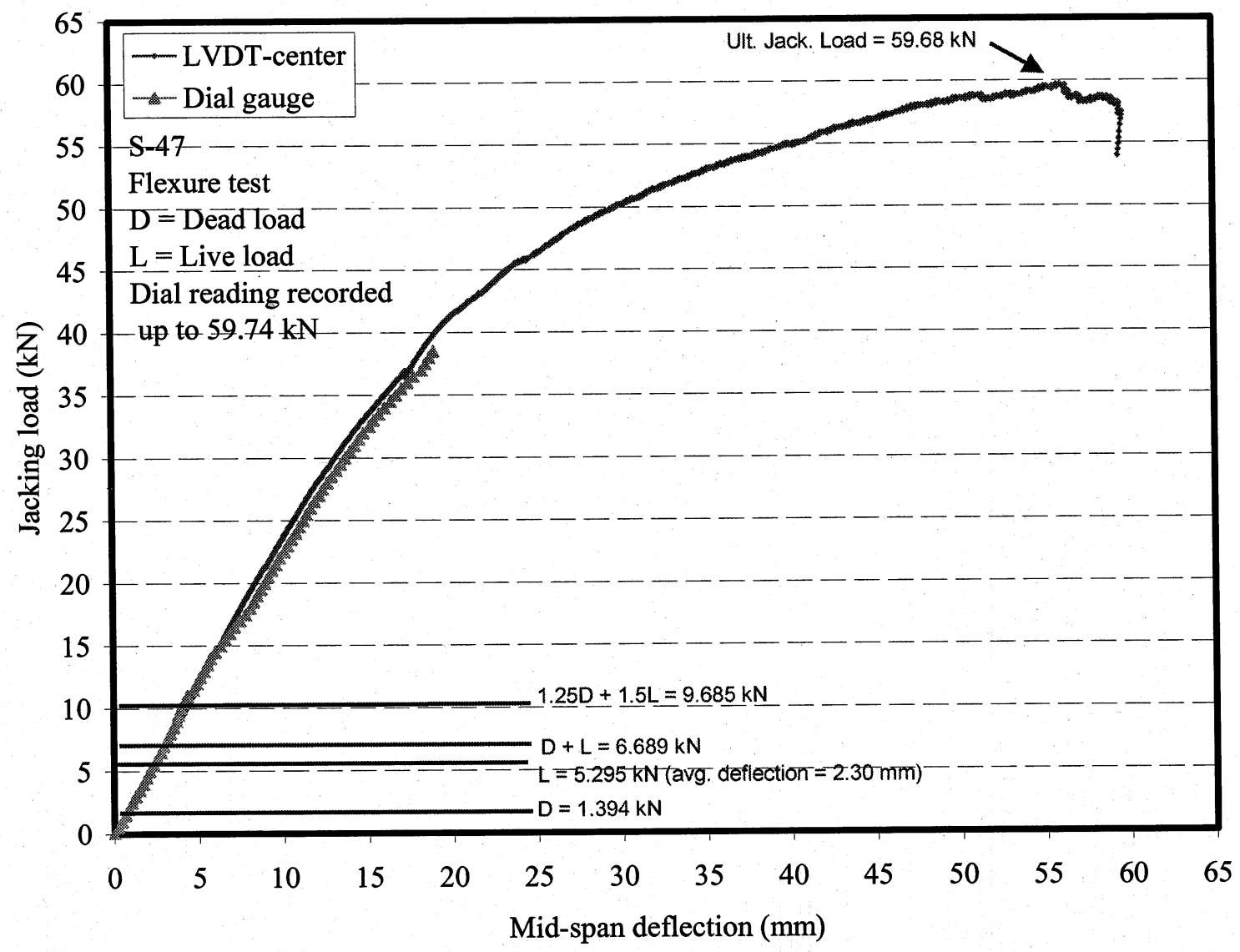

Figure AI-226 Load-deflection relationship for specimen S-47 


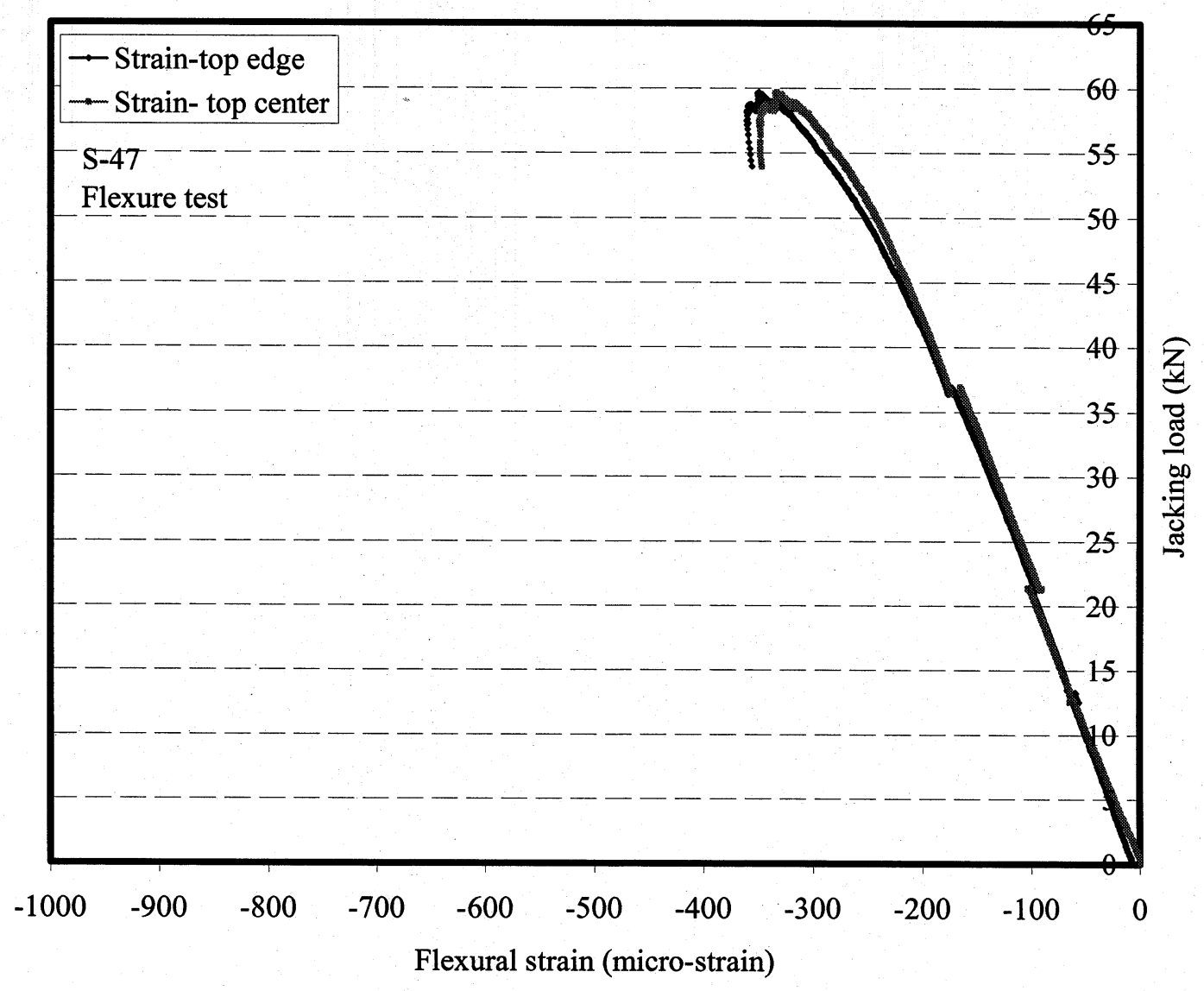

Figure AI-227. Load-strain relationship for specimen S-47

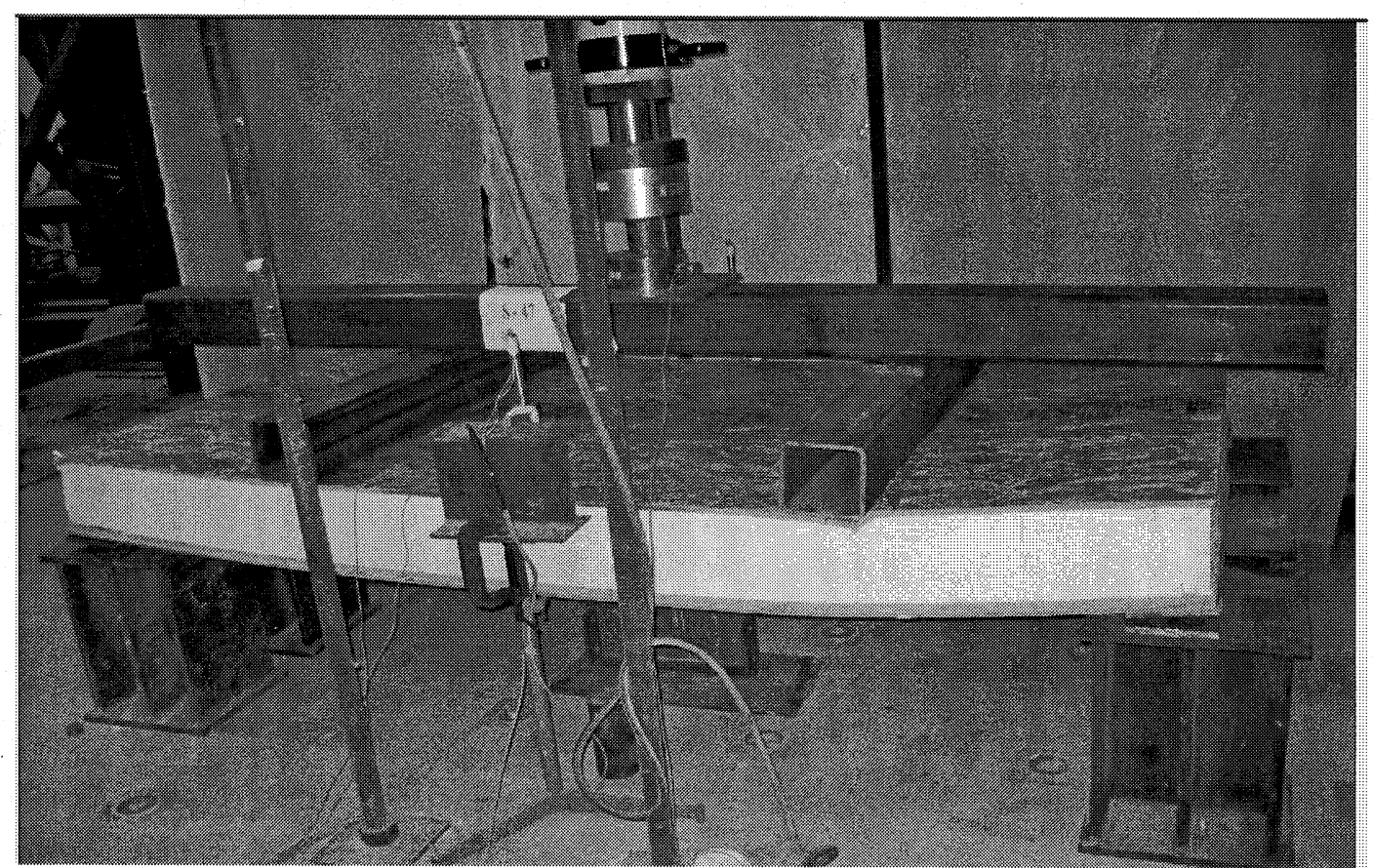

Figure AI-228. View of specimen S-47 after failure 


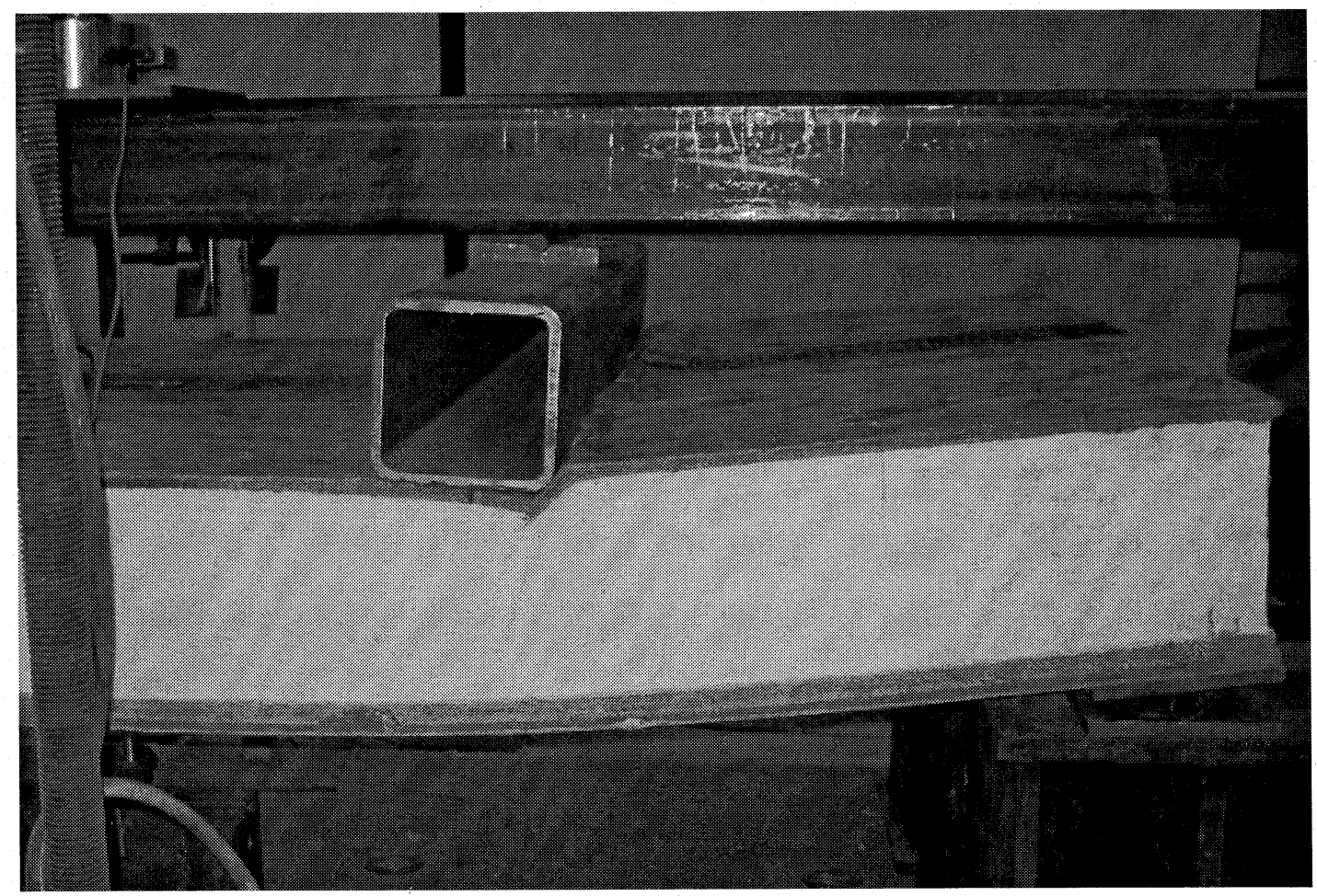

Figure AI-229. View of OSB crushing in specimen S-47

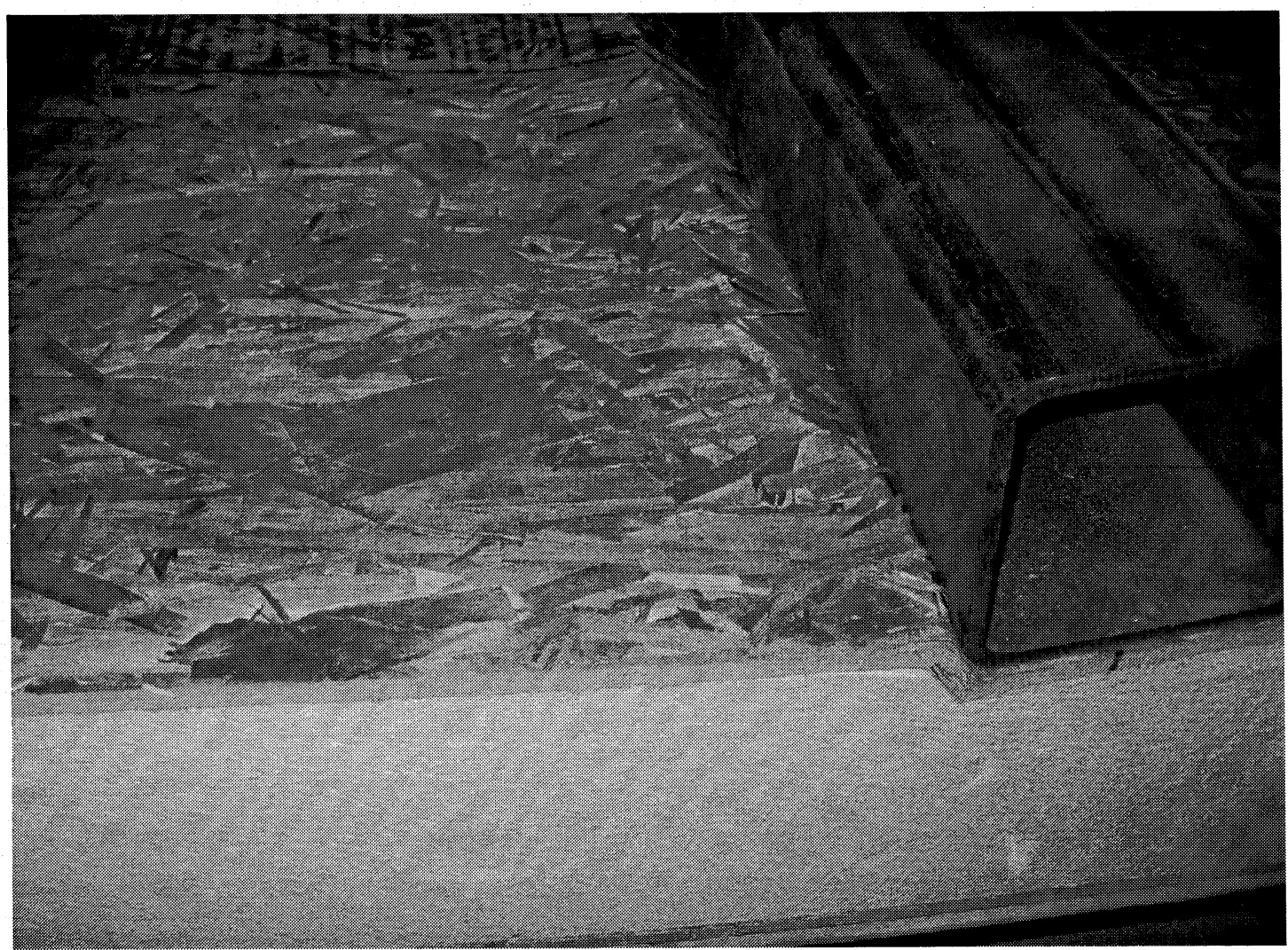

Figure AI-230. View of OSB crushing at the other free edge of specimen S-47 
